How

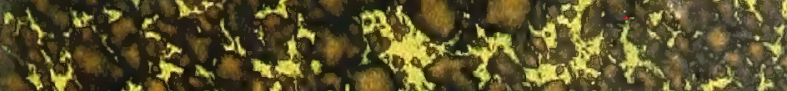

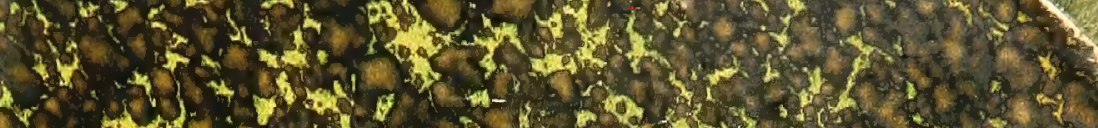

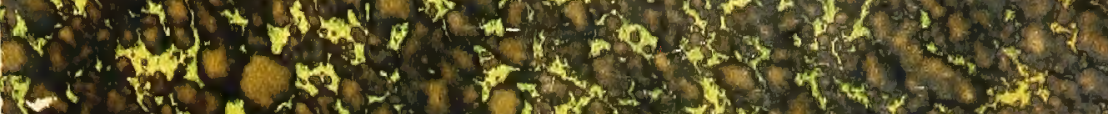

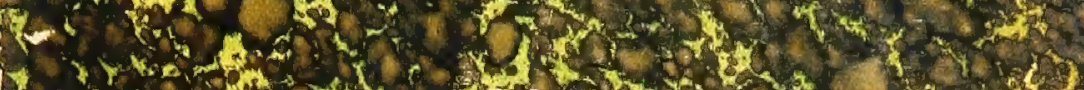

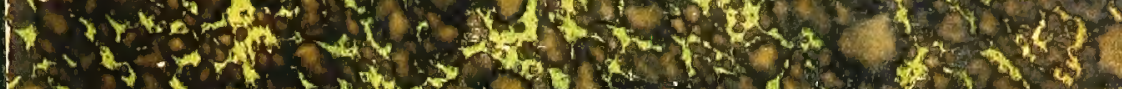

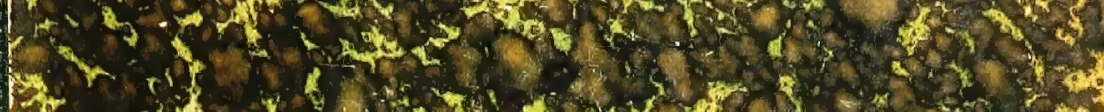

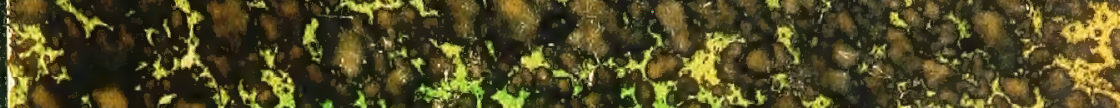

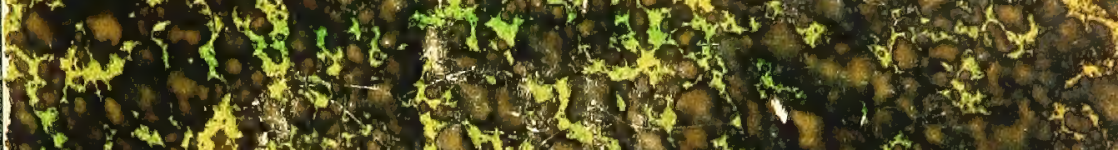

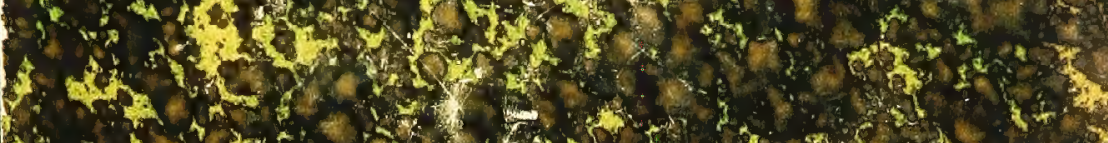

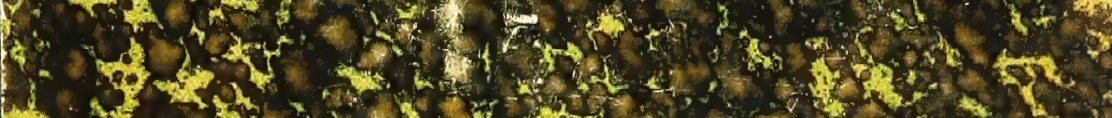

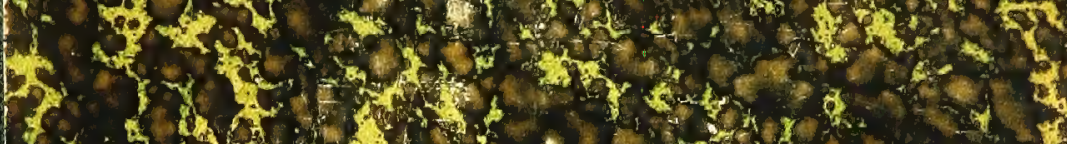

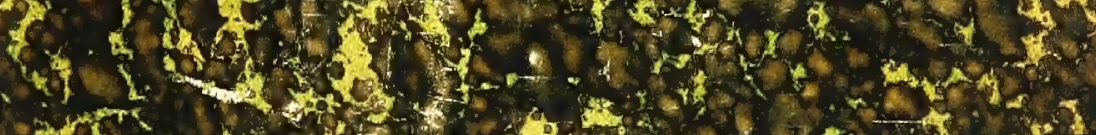

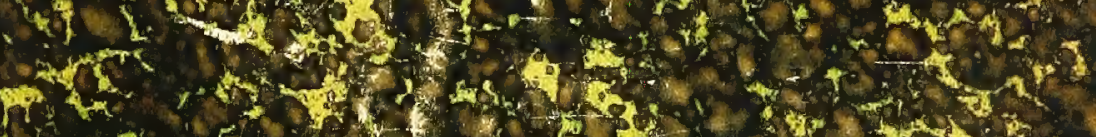

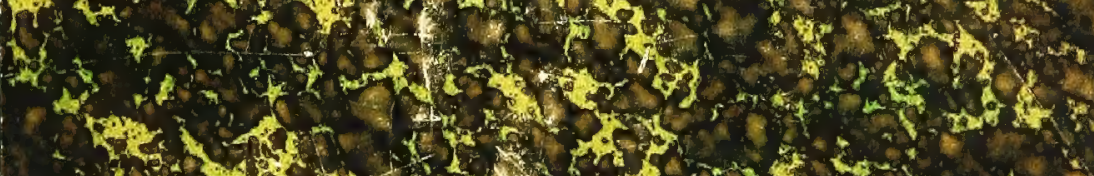

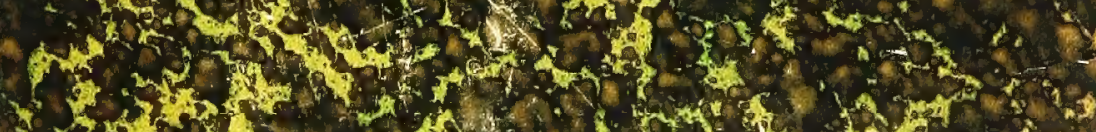

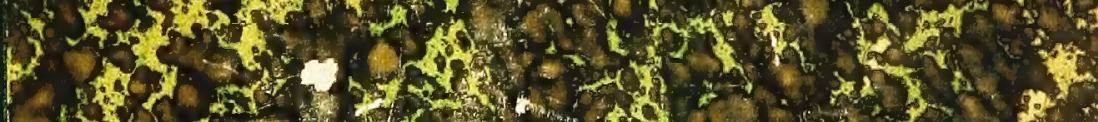

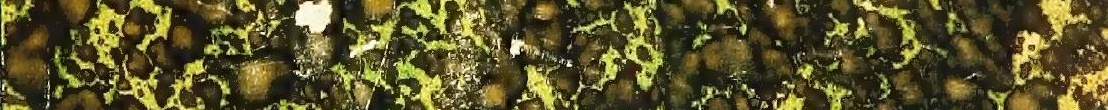

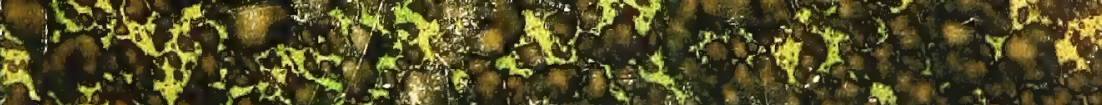

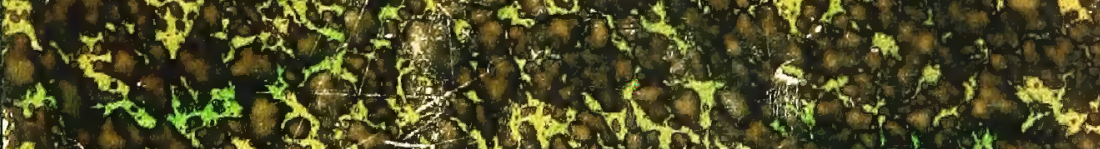

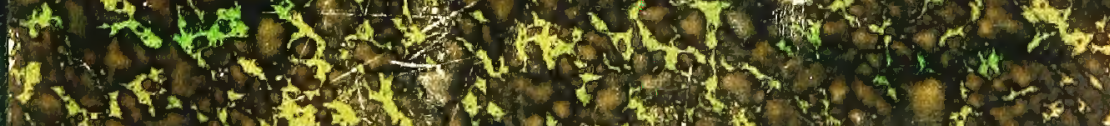

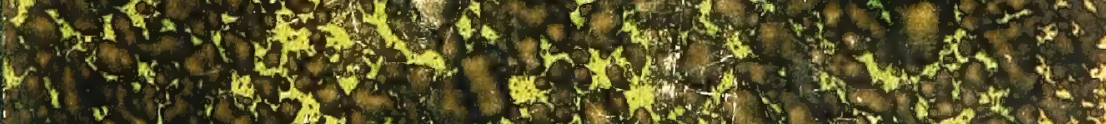
S.

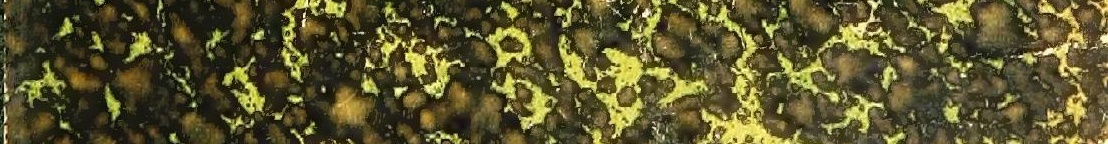

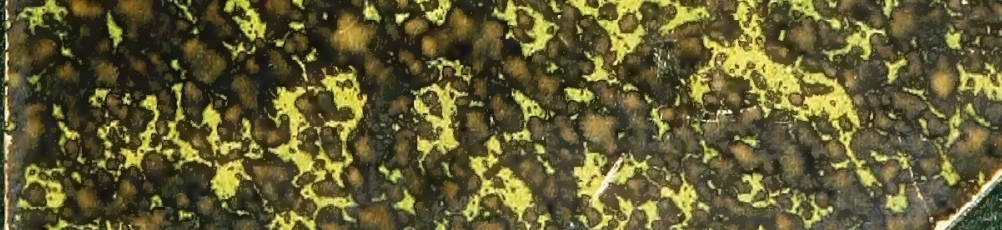
546 nes $^{2}-370$ 
$Q L$
$C 78$
$v_{0}$,

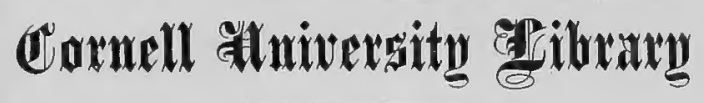

THE GIFT OF

Mrs \& Q C pe.

A. 170613

$\frac{11 / 9 / 13}{4553}$ 
The date shows when this volume was taken.

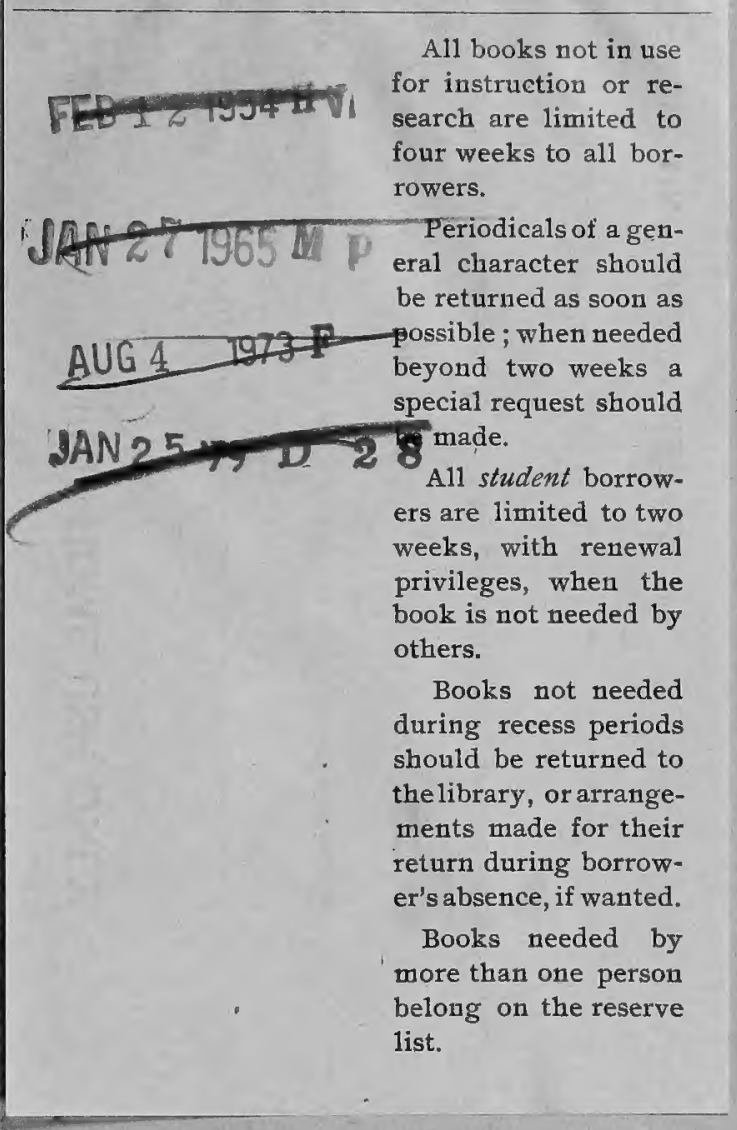

All books not in use search are limited to four weeks to all borrowers.

eral character should be returned as soon as beyond two weeks a special request should All student borrowers are limited to two weeks, with renewal privileges, when the book is not needed by thers.

Books not needed during recess periods should be returned to the library, or arrangements made for their return during borrows absence, if wanted.

Books needed by more than one person belong on the reserve list.

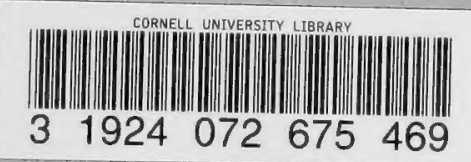





bontents:-

1. Extinct Batrachia and Reptilia of Touth America.

2. Iypes of Mammalia Educabilia.

3. Osterlogy of Japiroid Hugrachigus.

\$. Homologies of cranial bones of Reptilia.

5. Significance of Paleonantology.

6. barmivora of the Ercene of Rocky Mountaines.

7. Batrachia of the coal measures of Ohis.

8. Brain of Procamelus Dccidentalis.

9. Suessonian Fauna in Dorth America.

10. Paleontological Bulletin, No. 28.

11. Herpetology of Iropical America.

$\iota$

12. Brain of boupphodon.

13. Origin of the will.

14. Fresh water fiches of routh barolina.

15. Brain of Procamelus Occidentalis.

16. Barnivorous Dinvosaurian.

Schthyological fauna of Sreen River shales. Erisichthe.

17. Paleontological Bulletin, No. 30 .

18. Fishes of Peuvian Amazon.

19. Abstracts of proceedings of Reological socicty of London 

20. Extinct Ameriean rihinoceroses.

21. Modern inuseum.

22. Felidae and banidae.

23. Yertebrata of Permian formation of Jexas.

24. Foramina perforating squamosal bone of Xlammalia.

25. Northern Masatch Fauna.

26. Vertebrata of Permian formation of U, B.

21. Perissodactyla.

28. Miocene dogs.

29. Paleontological Bulletin, Do. 33 .

30. Mammalia of the lowest Eocene.

31. Gocene Plagiaulacidal.

32. Fauna of Nickajack bave.

33. Neur type of Perissodactyla. 


\section{Cornell University Library}

The original of this book is in the Cornell University Library.

There are no known copyright restrictions in the United States on the use of the text.

http://www.archive.org/details/cu31924072675469 


SopPlamen'T to the "Synopsis of the Extinct Batrachia and Reptilia of North America."

BY E. D. CoPE.

(Read before the American Philosophical Society, March 3, 1871.)

BATRACHIA.

Sauropleura remex, Cope.

Proc. Acad. Nat. Sci., Phila. 1868, p. 217. O. amphiunimus, Cope. Trans. Am. Phil. Soc. 1869,17 in parts.

A fine specimen of this species recently sent me by Prof. Newberry, from Linton, Ohio, includes the vertebral columan from the lind limbs to the end of the caudal series. One of the former is preserved and exhibits slender digits and other characters like those already described in the $S$. pectinata. Having ascertained that the Oestocephalus amphiuminus possesses no anterior limbs, I regard my reference of these species to that genus as premature, and will allow them to remain in Sauropleura, where I originally placed them.

Oestocephalus amphiminus, Cope.

Trans. Amer. Phil. Soc. 1869 , p. 17 ; 1. c. p. ii.

The bones formerly regarded by me as referable to a rudimental fore limb in this genus, appear to be rather branchihyals, and indicate the existence of external branchiæ.

Colosteus scutellatus, Newb.

Pygopterus scutellatus, Newberry, Proceed. Ac. Nat. Sci., Phil. 1856. Colosteus crassiscutatus, Trans. Amer. Phil. Soc. 1869, 23.

The original description of this species by Prof. Newberry was overlooked, in preparing my ascount of it above quoterl.

\section{MUSASAURID $巴$.}

Liodon sectorios, Cope, sp. nov.

Established on a large part of the under and upper jaw, and otlier parts of the cranium with a vertelbra, from the green sand of the upper bed of the Cretaceous of New Jersey.

The character which at once distinguishes this species from other Liodoris, and especially from all the species of Mosusaurus, is the very compressed form of the crowus of the teeth, which approach nearer in this respect to those of Diplotomodon, than any others that I liave seen. The vertebra, a lumbar, has also subround articular faces, thus removing the species from close relntionship to those with depressed vertebræ, of some of which the tecth are unknown.

In the presenc specimen crowns and pedestals of thirteen teeth are preserved. Those of the mandible are most numerous, and display the successional modification of form from before backwards visible in other species of the family. The anterior teeth are less compressed, and have

A. P. S. - VOL $X I I-F$ 
but one, an anterior, entting edge, the posterior fuce being regularly convex. The inner face is much more convex than the outer, and the flatuess of the latter is marked at the apex of the tooth by a short ridge which bounds it posteriorly. 'This is a trace of the bounding angle which extends to the basis of the crown in Moscisaurus. 'l'le anterior' cutting edge is in profile convex; the posterior oulline concave to near the tip. The cutting edge is acute, and beautifully ribbed on each side, but not properly denticulate. The surface of the tooth is not facetted, but the outer ficce exhibits the peculiarity of a longitudinal concavity, or shallow groove exteuding from the base to the middle of the crown. The enamel is polished, but under the microscope minutely and extensively striate ridged. This description is taken from the second or third from the anterior end of the maxillary bone. The third from the distal end of the dentary is very similar.

The crowns become rapidly more compressed as we pass backwards. From a broad oval section of two crown bases, we reach a flattened oval crown, with the cutting elge sharp behind as well as before, and minutely ribbed. The crown is not facetted, and is more convex interiorly than exteriorly. The exterior convexity is chiefly anterior; the posterior face is slightly concave from the open groove already described as present in the auterior teeth. In two posterior crowns, one still more elongate in section, the external concavity becomes flatter and includes a great part of the outer face. A tooth still more posterior presents the peculiarity of the species in the strongest light. The crown is still more compressed, directed Uackwards, and only .2j higher than wide antero-posteriorly at the base. The latter is a little over twice the transverse diameter just belind the middle. The surface presents the characters described in others. The outer concave surface is wide and shallow, and contributes to the attenuation of the posterior half of the tooth rather than the anterior, which is consequently thicker. The cutting edres are sharp, the anterior convex and retreating backwards to the rather obtuse apex; the posterior convex above, concave below.

The exposed parts of the dental pedestals are frustra of cones, neither swollen mor concave.

$$
\text { Weasupements. } \quad M \text {. }
$$

'Third superior maxillary length crown. ............. 0.083

" hoight crown and pedestal.................. .048

" longitudinal diancter base crown.............. 02

" transverne........................ 013

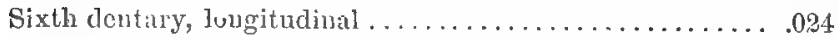

" " transverse....................... 014

Fleventh dentary height erown ................. 034

" height crown and pedestal..................50

“ longitudinal diancter busis crown.......... .020

“ transverse......................... 014

The articular bone is perliaps .60 the size of that of Mosasaurus dekayi 
and presents less powerful development of the interior ridge for the pterygoid muscle. The cotylus descends abruptiy behind it. The coronoid bone exlibits the usual anterior fissure. The rolled front margin of the ascending portion is thickened. The superior surface of the anterior part of the frontal bone, is lumpy and with some shallow pits ; the outer face of the articular is smooth. The vertebra preserved is a posterior lumbar, and is injured; the anterior articular face is nearly round. Its vertical diameter is M.0.j8. Length of centrum M.058.

The forms of the teeth distinguish the Liodon sectorius from the species of Mosasaurus, and that of the vertebra, from such species as liodon perlatus, Cope, and L. dyspolor, Cope. There remain to compare with it, L. proriger, Cope; L. mitchillii, Dekay; L. laevis, Owen; L. congrops, Cope ; L. iciericus, Cope; and $I$. mudgei, Cope. In size it will only compare with the first two species, being from twice to four times as large as any of the remaining four. The flattened teeth distinguish it at once from $L$. irtericus, and the abrupt rising superior margin of the articulur bonc, from the L. mudgei, where the upper and lower margins are for some distance parallel. The less compressed vertebral centrum distinguishes it from $L$. laevis. From the two large species, dental charneters separate it. Thus in $L$. proviger the teeth are less compressed, and are ficetted, especially the anterior ones, with concave grooves separated by obtuse ribs. In M. mitchillii the tecth present more similarity, but are abuudantly distinct. They are much less compressed, even where the posterior cutting edge is strongly developed, the external face is convex to the apex and withont concave or flat facet; it is narrower at the base as compred with the height, and has an incurvature not seen in this Liodon. The enamel is smooth, and not striate under the glass.

This' and the $L$. mitchilli are the largest Liodons of the Eastern cretaceous. I have recently obtained thrce anteriol dorsal vertebræ and a tooth of the latter, from the lower bcd of cretaceous green sand near Freehold, N. J. The vertebrre rival in size those of Hosasaurus dekayi, but are of a more clongate form. The articular extremities are cordiform and nearly round, the posterior with the smooth neck band just in front of its margin. In front of this, the surface is sharply striate, especially on the inferior aspect; the same appears on the bascs of the diapoplyssis. The tooth is like one of those described by Leidy. (Cret. Rept. Pl. XI.)

The Liodon sectorius was obtained by Judson C. Gaskill, from the marl pits of the Penberton Marl Co., at Birmingham, N. J., and liberally placed at my disposal by him.

\section{ADOCID $\mathrm{E}$.}

The species of this family display considerable differences in the nature of the sutures of the bones of the plastron. In the thickest species the sutures are fine and the processes very small. This is especially the case with Adocus pectoralis. In A. beatus nhich is thinner, the sutures are coarser, but without gomphosis; that between the hyo- and hyposternal elements looking as though a slight mobility existed in life, as I have 
observed in a former article. In $A$. synthetious the sutures are a little coarser, and in $A$. ayilis a further increase is seen, but with but little gomphosis. In A. pravus, according to Leidy, there is a little gomphosis. but how much is not ascertainable from his figure and description. ' In Homorophus insuetus, a stouter turtle, the gomphosis is very strongr. especially in the longitudinal sutures, where the teeth are long and stout. In Zygoramma this coarseness of gomphosis reaches a maximum, being. strong in all the sutures of the two species, except the anterior mesosternal of

\section{Zygorama miroglypila, Cope, sp. nov.}

This large species is represented by the greater part of plastron and half of carapace, with four marginal bones, of an individual from the New Jersey cretaceous, of two and a half feet in length. Its cliscovery is interesting as enabling me to refer this genus to the Adocida without doubt, a point which the specimens of the original species, $Z$. striatula, Cope, left uncertain.* The episternal bone displays beautifully the wide intergular scutum separating the lateral reduced gulars. The postabdominal bone displays the swellings corresponding to the pubis and ischium. The pectoral dermal scuta advance medially on the posterior part of the mesosternal bone. These characters are those of Adocus. On the other band there is not satisfactory indication of the intermarginal scuta, though they may exist, and the free marginal bones anterior to the bridge display the double articulation, by suture and gomplosis characteristic of Zygoramma. It might be liere observed that it is possible that this structure will be found tu exist in "pecies at present referred to Adocus, A. agilis,. for example, where the marginal bones are unknown.

This species is one of those in which the mesosternal is received in the very open emargination of the lyyosternals, a character indicating the breadth of the former, and seen in $A$. agilis and $A$. syntheticus. The bones are relatively thin, the marginals light and gently recurved. The anterior lobe of the plastron is truncate, the straight anterior margin grooved lengthwise. The posterior lobe is regularly contracted, and rounded, and with thin edge. The xiphisternal and hyosterual of the right side hine each an oblique sutural union with the hypostemal of the left. The mesosternal is broader than long. the posterior margin broadly. truncate, the latero-posterior eurved sigmoidally, the anterior regularly convex. The episternal is but moderately thickened. The parts of the hyposternals on the bridge are nearly in the plane of the rest of the plastron. The marginal bones near those of the bridge have a thickened shoulder above within, into which the slender costal processes are received: they thin out rapidly and are gently everted distally. More distal marginals are lighter and more everted.

The bones of the carapace include three vertebrals and numerous costals. The latter display very weak capitular processes, but in none are they entirely abscnt. Neither they nor the vertebrals are thickened. The 
vertebrals are short coffin-shaped, concave or emarginate in front; a stont laminar neural spine supports the vertebra below.

The sculpture of all the bones is a delicate impressed punctation, the impressions forming lines or delicate grooves in some places. These run obliquely across some of the costals and marginals, and sublongitudinally on the posterior lobe of the plastron. The corneous scuta have left distinct impressions. The marginals extended on to the costal bones at the place of the fiee marginal bones. The vertebrals were a little longer than wide, witb bracket shaped lateral sutures, and openly emarginate below. The intergular plate was pentagonal, with straight sides, and broader than long. The gulars are short and not prolonged very far on the outer margin of the plastron. The pectorals are narrowed laterally, and present a convex median outline on the mesosternum. The abdominofemoral suture crosses a little behind the iniddle of the hyposternal bone. The median longitudinal suture winds from side to side on the posterior lobe in the most erratic fashion, abnormally no doubt, and the suture for the anals is anterior, convex in front, sigmoid at the sides.

Measurements. $\mathrm{M}$.

Length of plastron (restored) ..................... 0.45

" from front to postabdominal suture............34

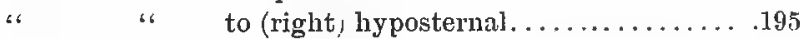

" " " to hyosternal........,..........104

" " $\quad$ to mesosternal................... 038

Width at mesosternal..........................194

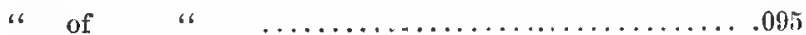

" at postabdominal suture..................22

Thickness of mesosternal behind................ .0116

" of hyposternal medially................ 0158

Width of average costal at vert. scute suture $\ldots \ldots \ldots \ldots . .055$

Thickness of same......................... 011

'Total length adjacent vertebral. ................. 066

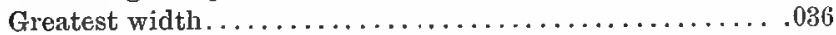

Width do. at end........................... . 22

Length of first free marginal from bridge...........065

Width of do. .............................. 10

Thickness proximally...................... 0175

" of a free marginal proximally............ 01

Width "6 " $6 \ldots \ldots \ldots \ldots .0 \%$.

Length " " "

The type specimen of this species is about twice the size of that of $Z$. striatula. It also differs in some respects which might be attributed to age, as the greater recurvature of the marginal bones and the greater extent or prolongation of the thickening on the inside of the marginals next the bridge. But there are others wbich appear to be specific. Thus there is very little evidence of cross-union of sternal elements in the $Z$. striatula, and the sculpture is twice as coarse and so much more marked. 
The pegs of the costal gomphosis are absolutely twice as linrge, and relatively still larger. I therefore believe this specimen to represent another species. Besides the sutural characters, thuse of the intergrular scuta separate this species from 1 docus beatus. In the litter that scute is urceolate, and the gular's sickle-shaped, being ploduced backwards on the margins of the elisternal or clavicular bones. In A. synthetieus the intergular is narrower. and convex behind, the mesosternum is angulate posteriorly, and the plastron mueh thicker. In $A$. agrzis the plastron is nearly similar in thickness, but the mesosternum is angulate behind, and is narrower, and the sculpture very much coarser.

The Z. microghypho was found by my friend, Judson Caskill, in the marl excavations under $h_{\text {is }}$ directim, at Birmingham, N. .J.

\section{AGOMPIIL', Cope.}

This name is proposed for a genus of Testrdincta heretofore not recognized. It appears to belong to the Emydida so far as kwown, but to differ from them in lacking the articulation of costal and marginal bones by gomphosis, characteristic of the existing genera of the fimnily. It does not appear to differ in any other point so far as known. The type species is Agomphus turgidus, Cope (Emys Trans. Amer. Phila, 1870, 127) ; others from the eretaceous of New Jersey are A. firmus, Leidy (1. c. 126) and 4. petrosus, Cope, (1. c. 126).

\section{(?) PROPLEURID $A$, Cope.}

Siblim. Amer. Journ. Sci. Arts, 1870, (L) $13 \%$ i.

Catapleura ponderosa, Cope, spec. nov.

This turtle is represented by two posterior marginal bones, six costals, a hyposterual, scapula and procoracoid, and femur and humerus, all more or less firactured.

The margiuals are the candal, and adjoining one of the right side. They botlı present a suture for the pygal vertebral, and the lateral presents also a pit for articulation by gomphosis with the last costal bone. They are of heavier form than those of any other species of the group. The hyposterual has lad no sutural union with the hyosternal unless exteriorly; this, if existing, has been slight. The shaft of the humerus is contracted and mearly cylindrical ; the great trochanter of the femur is little elevated, and not continuous in the plane of the lead, but separated. from it by a depression.

The above characters express the generic relationslups of this type. The gompliosis with the last lateral marginal, as weil as the lack of union of the liateral elements of the sternum separates it from Osteopygis; their union is more extensive than in Propleur:a sopita. This would not prevent the generic unity of the two, were it not for the additional characters of a slender shafted humerus, and probably broad short mandible with long: symphysis. In P. sopita the rami are slender, and the sympysis short. The characters are much like those of Catapleura repanda, and I arrange it with that species until better information compels a ehange. 
The caudal marginal is strongly conenve below, convex above, the margin littlo recurved. The anterior outline is convex medially, with straight continuations at right angles to each lateral suture. A portion of the elge is broken off. Lateral marginal strongly and openly emarginate, surface not convex as in the median. Both are massive as in Agomphus firmus and allies. The union with the pygal ceases behind the costal pit.

The costals are thick and considerably curvel transversely to the vertebral axis, the rib heads are unusually large and prominent and subcylindric in section. The rib-ridge is more elevated and rounted in section than in any other species.

The hyposternal is from the left side. It exlibits the free articulation for the xiphistemals; the posterior margin is thinned out, while the anterior is more abruptly rounded, and without trace of hyosterual suture. The external fice is distally myed with narrow ridges. The common peduncle of the scrpula and procoracoid is short and wide, the sutural face for the coracoid, subtriangular.

The bicipital ridgo of the humerus is as usual at right angles to the head, and is thin and llat. The plane of the inner crest makes an open angle with the outer; its base is less distant from the shaft than that of the onter. The great trochanter diverges somewhat from the plane of the axis of the liead of the femur. The latter overhangs the shaft belind; the latter is curved, and beyond the middle subruadrate. In this as in the humerus, oce of the two crests is continued as a ridge along the shaft.

Measupements.

Length caurlal marginal. ...................... 06

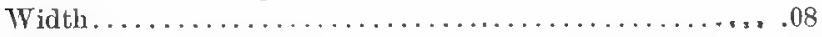

Thickness............................... .0017

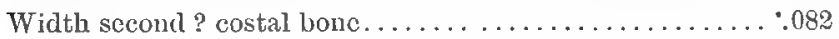

Thickness do. at centre.........................

Width hyposternal at middle.................... 064

Thickness do. near anterior margin............. .012

Length free portion of a rib................... 018

Diameter (loug) hear humerus.................. 037

" " " shaft "

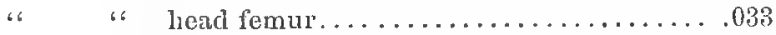

" $"$ shaft "

Width mandible at symplyysis at right angles to margin . .034

Thickness mandible at symphysis posteriorly ............ 011

Accompanying the above remains were those of a small clielydrine turtle, and of a Taphrosphys, and a portion of the mandible of a species allied to Lytoloma augusta and other species. Its size relates well to the other bones of the Catapleura ponderosa, and I suspect that it belongs to that species. It has the expanded form with slightly recurved alveolar margin, of this group; the masseter fossa is strongly marked; the dental 
foramen opens almost superiorly; the posterior margin of the jaw is deeply grooved.

The C. ponderosa differs from $C$. repanda in its rounded instead of flattened rib-ridges on the inferior surface of the costal bone, and in the different proportions of the crests of the femur. The lesser trochanter in the latter is more robust, and less narrowed and prolonged as a ridge on the shaft. The proximal half of the shaft is straight; in $C$. ponderosa curved.

This species was discovered by John G. Miers, a gentleman who has already enriched palæontology with many interesting forms. From the upper bed of Cretaceous green sand at Hornerstown, New Jersey.

In the nomenclature of the elements of the plastron of the Testudinata, I will in future adopt in part that proposed by Parker (on the shoulder girdle Roy. Society, 1869), who has shown after Rathke that the posterior pieces do not belong to the sternum. The bones from front backwards should then be named, clavicle ("episternal"), mesosternal, hyosternal, hyposternal, and postabdominal ("xiphisternal").

\section{CROCODILIA.}

Botrosaurus macrorHynchus, IIarlan.

\section{C. harlani, Meyer. Bottosaurus harlani, Agass., Leidy, Cope.}

The present state of knowledge of this rare species and genus involve some confusion, and I propose here to set it to rights in a brief manner. This is rendered easy by the discovery of the almost complete skeleton of a nearly grown individual, in the upper bed of cretaceous green sand.

Following my predecessors, I regarded the Crocodilus basitruncatus of Owen as this species, in the synopsis Batr. Rept. N. Am., 1869, p. 65, but with expression of considerable doubt. At page 231 of the same work, I distinguished the species of Owen as a true Ilolops. As I had supposed the cervical vertebræ to present the characters of Holops, the assignation of the specimens on which this opinion was founded to a species of that genus, left an entire uncertainty as to their character in Botfosaurus. The discovery of a series of vertebræ as above mentioned, settles that their structure is not that of the other cretaceous genera, but that of the Tertiary and recent forms, $i$. e., that the hypapophysis of the cervicals are produced and undivided to the axis. Deducting the erroneously supposed character, there remains oue curious feature to distinguish this form from the recent Alligator. The fangs of the teeth posterior to the eleventh are not enclosed by the dentary bone, but are exposed to the inner face of the splenial. How far the latter protects them the nature of the specimen does not allow me to decide.

It remains to correct the specific relations of this crocodile. At page 230 of the above work, I described a new species of Bottosaurus, under the name of $B$. $t u b$ erculatus, establishing it on remains of cranium of one individual and those of the posterior parts of a skeleton of another. The anterior part, with jaws of the latter having fortunately been recovered 
as above mentioned, and placed in my hands, I find that the animal belougs to the original $B$. macrorhynchus, and that the first jaw and teeth represent an individual of another species, which will bear the name of $B$. tuberculatus. It differs from the first named in the acute or conic form of the crowns of some of the teeth, and probably in the much smaller size.

In addition to the generic peculiarities already mentioned, this species exhibits a disparity between the lengths of the centra of the lumbar and cervical vertebre, which is unusual; compare the measurements below with those given for the remainder of the same animal as above cited.

The hypapophysis of the dorsal vertebra are long, with parallel sides, and oval in section. In that one where the capitular articular face is near the suture of the neural arch, the articular cup is entirely round, and its margin flared out regularly to the capitular surface. The neurapophyses are narrow, and the anterior zygapophyses directed very obliquely downwards.

The cervicals are not only shortened, but diminish very much in diameter anteriorly, and the cup continues round. The hypapophysis is very stout on the anterior, more compressed on the posterior vertebra. The neurapophysial articular faces have the nsual rugose anterior and radiate crested posterior areas, but are short and wide, and the anterior area has an oblique concavity extending across it outwards and anteriorly.

The posterior area is, however, the more deeply grooved, especially on the lumbar vertebra.

The rami of the mandible are preserved nearly entire. The large external foramen between the dentary, angular, and articular bones, exists as also the smaller one on the inner face of the ramus. The rami are hollow and thin walled, though of very stout form. The anterior teeth extend along the outer margin of the dentary and then cross to the inner side, the teeth from the twelfth to the eighteenth or last being separated, the first by rudimental septa the latter by mere low ridges. Six of these teeth are exposed without osseous wall on the inner face, and that for the anterior tooth is probably incomplete. The whole length of the ramus is about twenty-eight and a half inches. It is elevated at the position of the tooth usually called the inferior canine; this nay be made to appear like an external expansion by. rotating the ramus outwards (see Leidy Cretaceous Rept. U.S., Tab. IV. fig. 20). There is another elevation at the seventh tooth behind this point, aud a concave curve to the elevation of the articular bone. The angle of the jaw is prominent. The cutting edgo is rather obtuse and delicately ridged transversely; the rest of the crown is rugose-striate.

\section{Mensurements. $\quad M$.}

Length ramus mandible.................... 0.780

Length series of last seven teeth ..................160

Deptli ramus at twelfth tooth (from front) ............ 084

" at external foramen.................145 
Measurements. $\quad 1 \%$.

Length centrum anterior lumbar................. 055

Diameter cup do. . ....................... 042

" neurapophysis do................... .043

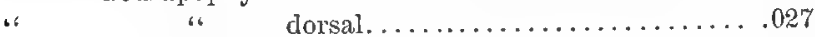

" cup of centrum " . . ................ 035

I.ength base hypapophysis.................... 03

Iength centrum median cervical .................. .051

Width cup " " " $\quad$ "

Depth " " " " 6 " $6 \ldots \ldots \ldots \ldots \ldots \ldots \ldots . .035$

" " $"$ anterior $"$ "

Wirth " " " 6 " $6 \ldots \ldots \ldots \ldots \ldots \ldots \ldots .032$

" between post. marg. parapophyses............ .045

Depth of centrum to lower edge..................04

Bottosaurus macrorhynchus, Harl, was then a crocodilian with a body of the proportions of our alligator, but with larger legs, and relatively considerably larger head. The cranial bones, however, are much less massive, as though to reduce the weight which wonld prove inconvenient to a body of no larger size. The bowes of the mandible are thin and enclose large pneumatic cavities; the teeth are hollow and with thin walls.

I am indebted to Judson C. Gaskill for the opportunity of examining this interesting fossil.

\section{DINOSAURIA.}

Hadrosaurus cavatus, Cope, sp. nov.

This species is indicated by remains derived from the upper green sand bed of the upper Cretaceous of New Jersey. They belong to an individual of the gigantic proportions characteristic of the four known species of the genus. It is smaller than $H$. tripos or H. occidentalis, and in a less degree smaller than the $H$. foulkei. The remains consist of four caudal vertebre from the median part of the series, three of them exhibiting l'udiments of the diapophyses. In two of them the neural arch remains, one with the spine, and the articular prominences for the clievron bones are nearly complete.

The first character which is olserved in these vertebræ is their opistho coelian articulation. The posterior concave face is marked by a more or less prominent elevated band descendiug from the end of the floor of the neural canal, and which is sometimes grooved medially. The convex extremity is swollen in the middle, most especially so at three points, and a groove or clepressed band which has less than one fourth the wirlth of the centrum, extends round the margin outside of it. The general form of the extremities is rounded hexagonal, the anterior a little depressed, the posterior a little compressed. The sides of the centra are quite concave. The cherron articuląr projections are quite prominent, terminating ante- 
riorly in a low ridge which extends to near the anterior face. At the latter position chevron articuar faces are either wanting or very little marked. 'The centra exhibit no lateral angulation; the third from the anterior has a trace in a longitudinal fulness above the middle of the side; the last, the same, below the middle of the side. The margins of the extrenities are well flared. The neural canal is a little compressed and deeply excavated in the centrum. The surface of the centrum is only rugose at the base of the diapophysis. The general form viewed laterally is subquadrate, the anterior vertebra a little deeper than long, the posterior a little longer than deep.

Measurements. $M$.

Iength centrum of anterior $\ldots \ldots \ldots \ldots \ldots \ldots \ldots \ldots \ldots .6 \ldots$

Depth posterior face......................... :071

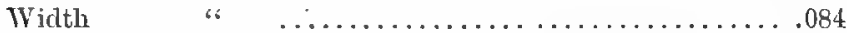

" of both chevrou processes.................. $0 \mathrm{j}$

“ of netral caval.......................... .023

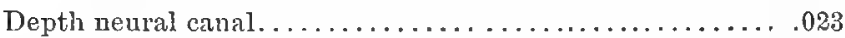

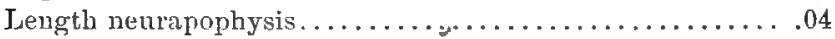

Third vertebra, depth posteriorly......................

“ depth posteriorly with chevron process........... .078

Fourth vertebrn, width centrum behind............. 075 " depth " $\quad \ldots \ldots \ldots \ldots \ldots \ldots .066$

" " with chevron process............. .

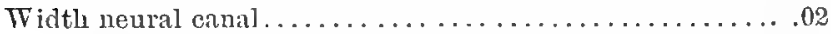

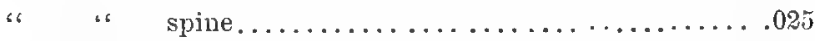

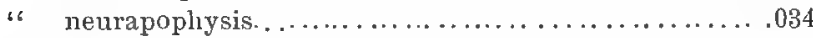

The measurements of depth of centrum are made from the floor of the neural canal, not from the upper margin of the superior lateral projections of the articnlar faces.

As in $I I$. forlliei, the neural spines have a small antero-posterior diameter, and the zygopoplyyses are little developed. The anterior are subacuminate and more or less joined together. As the neural spine is very oblique, the posterior zygapophyses are above a point behind the articular extremity of the centrum.

This species differs at once from the $H$. tripos, $H$. foulkei and $H$. minor in the opisthocoelian vertebræ, resembling in this respect the $H$. occidentalis (Thespesius, Leidy). The latter differs from $I I$. cavatus in the development of the chevron articulation equally on both adjacent centra, instead of on the posterior extremity only. In $H$. foulkei and H. tripas this double junction of chevrons extends to the extremity of the caudal series, adding another important ground of difference between them and the $H$. cavatus. The single caudal vertebra of $H$. occidentalis known, is like that of the former species in this respect, but there is no certainty that the structure continues the same throughout the caudal series, and that the distal vertebræ may not be like those of $F$. cavatus in this re- 
spect. It, however, further differs in the relatively more compressed or oval centrum, and much greater size. From $H$. minor the present reptile differs in the opisthocoelian vertebra, the known caudals of the former having plane articular surfaces, and in the much larger size. It is not possible to compare similar parts of this species and the Ornithotarsus immanis, Cope, but the larger size and much lower stratigraplic horizon of the latter renders their ilentity very doubtful.

Should the genus Thespesins of Leidy turn out to be well eatablished, the present species will enter it. I am not, however, entirely satisfied that the difference in the form of the articular faces of the caudal vertebrio is such as indicates generic difference. It was on this ground that I referred this form to Irudrosaurus (in Symopsis Extinet Batr. Rept. N. Amer., p. 98), and not from misapprehension of Leidy's definirion of it, as the latter supposes (Proceed. Aca. Nat. Sci., 1870, p. 67).

The rather slight material above described is fortunately so characteristic as to enable us to establish satisfactorily the existence of another monster of the remarkable group of the Dinosiuria; beings, whose appearance and structure have rivalled the strangest creations of the imagrination, and slown again what every other page of the book of nature teaches, that reality is stranger than fiction.

On Two extinct forms of Physostomi of the Nentropical Region.

By E. D. CoPE, A. M.

(Read before the American Philosophical Society, March 3, 1871.)

Fam. ELOPID $\mathbb{E}$.

Primates, Cope.

Dorsal fin above the anal with short basis and very elongate rays; the posterior ray free and longer than the others. Ventrals posterior. Vertebræ with deep lateril grooves, disproportionally numerous in the abdominal region, viz.: Abr. 49, caudal 18. Tail deeply bifurcated, its exterior or supporting rays, like those of the dorsal, ventral and pectoral, very stout and obliquely segmented. Head short, month (in the specimen) inferior; teeth simple, small. Scnles with many concentric grooves and a few radii on the proximal portion. No lateral line discoverible.

The pertinence of this genus to the Elopidx is inclicated in various ways. The general form is that of Elops and Megulops, and the normal and supernumerary ribs are quite as in the former. The interneural spines extending from the liead to the dorsal fin, are quite like those of the same genus. It differs from both in the posterior position of dorsal fin, and relatively numerous abdominal vertebræ. From Elops it differs especially in the long posterior lash-like ray of the clorsal, and the deeply grooved vertebræ.

Prymnetes longiventer, Cope, sp. nov.

Established on a very fine and noarly perfect specimen, preserved on a 
block of lime slate from Chiapas, Mexico. The body is seen in profile, but the head has been pressed from above, and the view is therefore oblique.

The general form is elongate. The pectoral fins are inserted at the pectoral plane, and are of moderate lengtl. The ventrals are short and small. It is uncertain whether they reach the anal, as the anterior part of that fin is destroyed. From the small number of interhemal spines, the anal has probably had a short basis. Caudal lobes narrow. A strong liorizontal interneural spine. The anterior interneurals are like those of Megalops, slender, gently curved rods, apparently, but not really continuous with the neural spines in some places. 'T'he dorsal fin laid backwards extends to the emargination of the caudal. The vertebre near the lead are not altered. There appears to have been a laminiform crest on the head, but the bones thus described may be those of the opposite side of the cranium. The muzzle appears to be contracted and projecting beyond the mouth. Three narrow obtuse teeth appear on the edge of the premaxillary bone. Dentary bone, stont. Orbit, round, large; entering 4.66 times the head to the posterior margin of the operculum, and 1.83 times the length of the muzzle. Operculum rounded.

Radii ; D. 2. 13. 1, C. ?. ?. 6, 6, A.? V.? I. 7. P., apparently not numerous, but very numerously divided. There are about twenty-five longitudinal series of scales at a point a short distance anterior to the ventral fins.

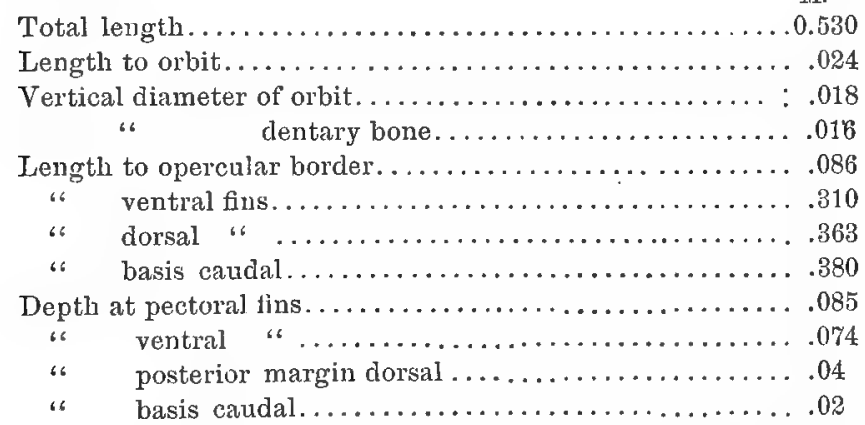

This species was found near Tuxtla Chiapas, Mexico, by Dr. J. Berendt, and by him sent to the Smithsonian Institution. Mus. No. 9819-20.

\section{Fam. (?) CHARACINID $\nexists$.}

\section{Anedopogon, Cope.}

Mouth opening almost vertically upwards. Dentition weak, consisting of lancet shaped teeth on the dentary and premaxillary bones; maxillary without or with minute teeth. Post-temporal bone large. Scales with few radii, no concentric grooves or cclls. 
'The pertinence of this genus to the Characinida cannot be considered as entirely established, as the specimen described does not display any of the fins. The appearance is not unlike that of Osteoglossum, but the structure of the scales distinguishes it. The great development of the $8 u b$ and postorbital bones, and small size of the preorbital, distinguish it as allied to the Characins. Its dentition and general form approach the genus Anacyrtus Müll. but it is at the same time distinguished by the lack of maxillary teeth. In addition, it appears to lack the anterior interneural spines found in so many Characin and Clupeoid genera, and in families allied to them. They are at least not apparent on the faces of two fractures across the vertebral column. Three vertebru are exposed throughout their length. They are longer than deep, and exhibit the two lateral grooves common to so many Teleosts. The only scales preserved are those above the pectoral fins, with but few above the vertebral column. None of these present traces of the lateral line. The clavicle makes a right angle with its inferior limb, and with the coracoid, and is produced backwards at the base of the pectoral fin. The epiclavicle and post-temporal are wide bones. The operculum is developed upwards to the epiotic, and the interoperculum is present. A fragment represents the suboperculum, which was probaly a narrow bone. 'The coracoid was a broad vertical lamina, extending horizontally forwards to below the preoperculum.

\section{Axedopogon tenutidens, Cope.}

Orbit round, its diameter entering the length of the head five times, and a little exceeding that of the muzzle and closed uuder jaw. The profile is gently descending and perbaps slightly concave; the symphysis mandibuli is very stout and presents an angle outwards; the iuferior marrin of the dentary is slightly convex. The maxillary bone is slender. The suborbital bones togetber form a shield deeper than wide; with the postorbitals they reach the preoperculum. The head increases rapidly in depth. The scales are large, and extended below the operculum on the sides of the coracoid region. They have smooth margins, and are everywhere quite thin. The surface is glistening, and in some seales exhibits under the microscope delicate parallel lines which separate short concave lines. The middle of the scale is marked with obtuse tubercular radii, or small or minute tubercles.

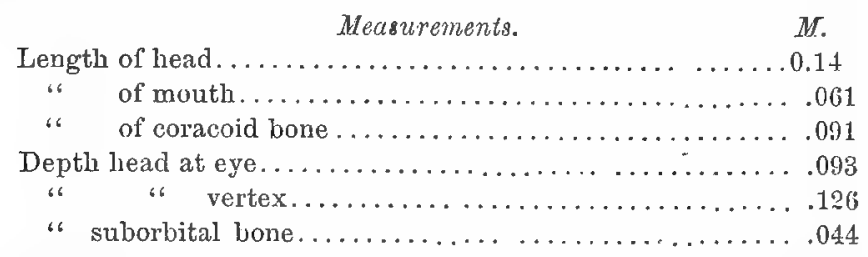

Six series of scales between basis of pectoral fin and vertebral column. A mandibular tooth is lancet shaped, and with minately striate enamel. A premaxillary is more conic; botl are rather small. 
This species may have more affinities with Amia than with the Characinida. A single specimen was obtained in a clay nodule by the naturalists of the U. S. Paraguay Expedition under Capt. Page, from the neighborhood of Para. It was accomnanied by several specimens of a fish from other nodules, which closely resembles an Aspidorfuynchus. Museum of the Snithsonian Institution.

\section{On the occurrence of fossit Cobitidice in Idaho.}

\section{By E. D. Cope.}

\section{(Read before the American Philosophical Society, March 3, 1871.)}

Of the five genera of extinct Cyprinidæ and allied forms discovered by Capt. Clarence King* in the fresh water deposit of Catharine's Creek, etc., Idaho, the writer has been able to indicate the affinities of three. Thus Semotilus, Anchybopsis and Irylocyprinus, were regarded as representations of existing types of both carnivorous and herbivorous habits. Oligobelus and Diastichus were not assigned to any definite position in relation to known types of the same great group, and I am still compelled to leave the former in the same uncertain position. Diastichus I find, on the other hand, presents the peculiar direction of the pharyngeal teeth which is characteristic of the Cobitido, and I suspect that it.represents a form of that family. I am entirely confirmed in this conclusion by the discovery, amoug the specimens submitted to me by the Smithonitn Institution, of the inferior element of the three modified anterior vertebri, which are so characteristic of certain families of the Physostonous fishes. This portion, moreover, is that which occupies this position among the Cobitidos only among them. It consists of a longitudinal plate terminating posteriorly in a bladder-like chamber on each sicle, each of which is closed below by a transverse process of the inferior plate : an angular fissure extends round the ends of these, and at the angle sends a short continuation upwards. This is quite similar to what is observed in Cobitis. The specimen described is apparently adult, and indicates a considerably smaller species than either the Diastichus macrodon or $D$. parvidens.

The occurrence of Cobitidæe is perhaps the most interesting fact brought to light by the examination of these extinct fishes. All of the numerous existing species are found in the Eastern Hemispliere, and the great majority in tropical Asia, a few only occurring in Europe and South Africa. Extinct species are found in the Miocene of Oeningen. We have, then, in the genus Diastichus another example of the occurrence of Asiatic types in North America prior to the glacial epoch, and as in a freshwater fish, strongly suggestive of continuity of territory of the two continents. 


[Read before the American Association for the Advancement of Science, Portland Meeting, August 20, 1873.]

On some Extinct Types of Horned Perissodactyles. By Edward D. Cope, of Philadelphia, Penn.

IT is well known that the type of Mammalia of the present period, which is preëminently characterized by the presence of osseous borns, is that of the Artiodactyla ruminantia. At the meeting of the Association of last year, held at Dubuque. I announced that the horned mammals of our Eocene period were most nearly allied to the Proboscidians. I now wish to record the fact, as I believe for the first time, that the Perissodactyles of the intermediate formation of the Miocene embraced several genera and species of horned giants, not very unlike the Eobasileus and Uintatherium in their armature.

While exploring in connection with the United States Geological Survey of the Territories, I discovered a deposit of the remains of numerons individuals of the above character, which included among other portions crania in a good state of preservation. Most of these skulls are nearly or quite three feet in length, and mostly deprived of their mandibular portions; these are quite abuudant in a separated condition. The crania represent at least six species, while the mandible represents a condition distinct from that of Titanotherium or any allied genus, viz. : I., $0 ;$ C., 1 ; P. M., 3; M., 3. The teeth diminish rapidly in size anteriorly, and there is no diastema behind the canines, whose conic crowns do not exceed those of the premolars in length. To the genus and species thus characterized I have elsewhere given the name of Symborodon torvus.

One of the crania, referred to under the name of Miobasileus ophryas, is characterized by its strong and convex nasal bones (108) 
and concave superior outline posteriorly, and by the presence of a massive horn core on each side of the front, whose outer face is continuous with the inner wall of the orbit, as in the Loxolophodon comutus. It stood above the eye in life, and diverged from its fellow so as to overhang it. In the specimen, which was fully adult, they were worn obtuse by use - length, about eight inches; thickness, three inches. The molar teeth differ from those of Titanotherium Proutii in having cross crests extending inward from the apices of the outer chevrons, each of which dilates into a Tshape near the cones.

The third species is referred to the new genus Symborodon under the name of $S$. acer. It has overhanging eyebrows and the vertex little concave; but the nasal bones are greatly strengthened, and support on each side near the apex a large curved horn-core of ten inches in length with sharply compressed apex. These horns diverge with an outward and backward curve, and when covered with their sheaths must have considerably exceeded a foot in length. This was a truly formidable monster, considerably exceeding the Indian rhinoceros in size.

The fourth species is allied to the last, and has well developed superciliary crests without horns. 'The latter are situated well anteriorly, anr are short tubercles not more than three inches in height. 'They are directed outward and have a truncate extremity. The type individual is of rather larger size than those of the other species. There are several crania referrible to the three now named. The present one has been named Symborodon helocerus.

Other species based upon crania without mandibles were referred to the genus Symborodon.

These animals show true characters of the Perissodactyla in their deeply excavated palate, solid odontoid process, third trochanter of femur, which has also a pit for the round ligament, in the divided superior ginglymus of the astragalus, etc. 



\section{ON THE}

\section{PRIMITIVE TYPES}

OF THE

\section{Orders of Mammalia Educabilia.}

BY

PROF. F. D. COPF. 



\title{
ON THE PRIMITIVE TYPES OF THE ORDERS OF MAMMALIA EDUCABILIA.
}

\author{
Br Proy. E. D. Cope.
}

(Read before the American Philosophical Society, April 18, 1873.)

In the Proceedings of the American Philosophical Society, 1872, p. 554, the writer described a species of Quadrumanous Mammal under the name of Anaptomorphus cemulus, comparing its dental and other characters with Simia and Homo.* In the American Journal of Science and Arts for November, $\nmid 1872$, Prof. O. C. Marsh announced that he believed that three genera previously described by him, viz., Thinolestes, Limnotherium and Telmatolestes, $\ddagger$ were referable to the Quadrumana, saying that they "have the principal parts of the skeleton much as in some of the lemurs." Prior to either of these determinations, the author de-

* Published October 12th, 1872 † Published October 8th, 1872 . 
scribed a new genus and species as allied to Notharctus, Leidy, under the name of Tomitherium, * but made no suggestion as to its ordinal position.

On a re-examination of the last-named genus, I am satisfied that it also should be referred to the Quadrumana, and describe it as follows:

\section{TOMITHERIUM. Cope.}

Dental formula $\stackrel{? ? ? ?}{2}$, in an uninterrupted series. Last molars with five tubercles, others with four; all low and slightly alternating, the outer wearing into crescents. Canines quite small. Incisors very prominent, the median pair with transverse cutting edges. Symphysis coössified, projecting in front. In the molars, the adjacent horns of the two outer crescents unite with the auterior outer tubercle; the posterior outer is insignificant. There is a projection but no tubercle in front of the outer anterior tubercle. The premolars present but a single compressed conic crown; the posterior, however, widened behind, and with a low tubercle. The first and second premolars are one-rooted (not entirely a generic character).

I base the distinction between this genus and Notharctus on the small canine, and the sub-horizontal position of the incisors; belicving that when other portions of the skeleton are studied, other differences will appear.

The portions of the skeleton of the type species preserved are: the entire dentition of the lower jaw minus the crowns of the outer incisor, canine and first premolar; the left ramus nearly complete, the extreme angle being wanting: the right humerus complete, witli right ulna and radius, the latter lacking the distal extremity; a large part of the left ilium; the right femur nearly entire; part of the left humerus, metatarsals, etc.

The mandibular rami are quite stout, but not very deep; the symphyseal portion long and oblique, and the coronoid and condylar portions elevated, with axis at right angles to that of the horizonal portion. The condyle is well elevated, and the coronoid process small; the dental foramen is half way between the margins of the ascending ramus, and opposite the bases of the crowns of the molars. The inferior margin of the jaw shows no tendency to inflection at a point immediately below this foramen, where it is broken off. The mental foramen is divided, the exits being at points opposite those between the premolars 1-2 and 2-3.

The humerus has a round head directed backwards and a little outwards. The tuberosities are rather small, of about equal size, and obtuse; they enclose a short bicipital groove. The bicipital crests are very largely developed, and extend to the middle of the shaft enclosing an open groove between them. The external is narrow and most 
elevated, the internal more obtuse and directed inwards. The shaft is thus sub-triangular in section. The distal extremity is nearly at right angles to the axis of the proximal and is much expanded transversely. A large part of this expansion is caused by the truncate internal tuberosity, and by the less prominent external one. The latter is continued in a thin ala which only sinks into the shaft at its middle. The condyles are small, the external the most prominent. There is a shallow olecranar fossa, and no coronoid, and hence no supercondylar foramen. There is an arterial foramen above the internal tuberosity.

The ulna is compressed, and contracts rapidly to the extremity. The olecranon is broad and obtuse and the humeral cotylus oblique to the long axis. The coronoid process is low. The shaft is remarkably curved from right to left (inwards). The radius has a discoidal bead with central depression, and it was evidently capable of complete rotation. It exhibits a tuberosity and slight flexure below the head. The distal extremity has a horizontal triangular section with the apex internal and truncate; the shaft near it is quite flat.

The left ilium is obspatulate and flat, widest at the convex crest, and slightly concave on the outer side. It is rather thin, and the impression for the sacral diapophyses is elongate. The inferior border thickens gradually to the acetabulum; the superior is excised so as to form an open concavity.

The right femur is remarkable for its length. Its shaft is flattened from before backwards, and without flexure. The great trochanter is large, and embraces a deep in-looking fossa. There is a flat tuberosity looking outwards just below, and the little trochanter is a little below opposite to it. The condyles are sub-similar in size, the trochlear surface wide, but not flat, and the inner border thickened and considerably elevated. The femur is $\mathbf{1 . 7 5}$ times as long as the humerus; it was scarcely longer, though a small piece is wanting from the shaft of our specimen.

Remarks. Having described the more important parts of the skeleton preserved, I now proceed to consider its systematic position, and the order to which it should be referred.

The first impression derived from the appearance of the lower jaw and dentition, and from the humerus, is that of an ally of the coati (Nasua). The humerus indeed is almost a fac-simile of that of Nasua, the only difference being a slight outward direction of the axis of the head. The same bone resembles also that of many marsupials, but the flat ilium, elevated position of dental foramen, and absence of much inflection of the angle of the lower jaw, etc., render affinity with that group highly improbable. The length of the femur indicates that the knee was entirely free from the body as in the quadrumana, constituting a marked distinction from anything known in the Carnivora, including 
Nasua. The round head of the radius indicates a complete power of supination of the fore foot, and is different in form from that of Camivora, including Nasua; and finally, the distal end of the radius is still more different from that of Nasua, and resembles closely that of Semnopithecus.

We have, then, an animal with a long thigh free from the body, a foot capable of complete pronation and supination, and a form of lower jaw and teeth quite similar to that of the lower monkeys. The form of the humerus and its relative length to the femur are quite as marked as in some of the lemurs. The most marked difference is seen in the increased number of teeth; but in this point it relates itself to thelother Quadrumana, as the most ancient types of Carnivora and Ungulates do to the more modern; e.g., Bycenodon to the former and Palcosyops to the latter. In its special dental characters it shows a close resemblance to small types of the Eocene, which have been regarded as low Perissodactyles, as Hyopsoctus, etc.

\section{Tomitheridu. rostratour. Cope.}

Proceedings of the American Philosophical Society, 1872, p. 470.

This species was about the size of the prehensile tailed-monkey, so frequently seen in shows. The first and second premolar have but one root, the base of the second being about the size of the base of the canine. The latter are cylindric at base. The incisors form a parabolic outline, and have entire edges, the middle pair transverse ones. Enamel generally smooth, premolars somewhat striate; an indistinct inner cingulum.

M.

Length of entire dental series (straight)......... 0.044

. "6 symphysis mandibuli................... . .020

Depth ramus at second molar................ . .010

Length crown of $"$ " $"$.

Width " " " " $"$ " $6 \ldots \ldots \ldots \ldots \ldots \ldots \ldots . .6045$

" between two " " " .................. .014

" " canines.................... .005

" of ascending ramus above dent. foramen.... . .016

Length of humerus...................... .083

Diameter of head........................ .013

Diameter of shaft at middle................ 0.0085

" " distal end, transverse............. .023

" " " " antero-posterior.......... .0078

Depth of olecranon..................... .009

" " ulna at coronoid ................... .010

Diameter extremity of radius, proximally........ .009

" " " $"$ distally............ . .010

Length of ilium from acetabulum ............. . .042

Width near crest....................... .017

Length of femur preserved................ .137 
M.

Width just below neck.................... .017

" at middle....................... .011

" " extremity......................... .019

" of trochlea........................ .009

Longest chord of condyles and trochlea......... $\quad .019$

The remains of this species were found together by the writer in the Bridger beds on Black's Frork, Wyoming.

\section{ANAPTOMORPHUS. Cope.}

Proceedings of the American Philosophical Society, 1S72, p. 554.

This genus is represented by the left ramus mandibuli of a single species. The posterior portion is broken away, and the teeth remaining perfect are the P. M. 2, and M. 1 and 2. The ramus, though small, is stout, and deeper at the symphysis than at the last molar. What appears to be the dental foramen is nearly opposite the bases of the crowns of the molars. The mental foramen issues beneath the first premolar.

Dentition of the ramus mandibuli, In. 2, C. 1, P.M. 2, M. 3, total, 16. It differs in many respects from these; there is no interruption in the series near the canine, and the symphysis, though massive, is not coosssified. Further details are, the last molar is three-lobed and elongated behind. The composition of the crowns of the preceding molars consists of four opposed lobes, which are very stout, and connected transversely by a thin ridge behind, or in close contact in front. The premolar tooth which is best preserved, is a perfect second, which, while having two roots, possesses a crown which stands almost entirely on the anterior, presenting a curved sectorial crest forwards and upwards.

The dentition is more decidedly quadrumanous in this genus than in the last, and it might be referred decidedly to Lemuride were it not for the unossified symphysis. It no doubt represents a distinct group or family from Tomitherium, and one more nearly related to the existing types of Madagascar and South Africa.

\section{Anaptomorphus amulus. Cope, loc. cit.}

This species was about as large as a marmoset or a red squirrel. The enamel of the teeth is entirely smooth.

Measurements.

Length dental line....................... 0.0148

" of last molar..................... .0030

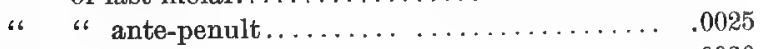

Width " " $"$ " $\ldots \ldots \ldots \ldots \ldots \ldots \ldots \ldots \ldots . . . \ldots 20$

Length of three molars preserved............ .0070

From the Bridger Beds of the upper valley of Green River. 
On the Phylogeny of the Mammalian Orders. So much liglut is thrown on this subject by the researches into the structure of the fossil mammalia of the Eocene formation, that it seems opportune to call attention to. the subject. I deem it demonstrated to a certainty, that the case with the mammals of this formation is the same as witl the reptiles of the T'rias, i.e., that the family types are all more generalized, and the orders not nearly so widely distinguished as in later periods of the world's history.

The succession of forms which lias terminated in the horse, bas been clearly pointed out by Prof. Huxley, as well as the line which has given the world the beantiful order of the Artiodactyla; but the approximate lineal predecessors of the Proboscidia, of the Ungulate animals as a whole, of the Quadrumana (including man), and of the Carnivora, have not been clearly pointed out.

The genus Elobasileus has been shown* to be a Proboscidian which combines some important features of the Perissodactyla with those of its own order, thus standing in antecedent relation to the elephants, etc., of the present day. The number of such characters was shown to be somewhat increased in Bathmodon, which therefore stands still nearer to the common point of departure of the two orders. This point is to be found in types nearer the clawed orders (Unguiculata), in the number of their digits (4-5), aud in which the transverse and longitudinal crests of the molar teeth are broken up into tubercles more or less connected, either type of dentition being derived according as such tubercles are expanded transversely or longitudinally. We have several genera which answer this description so far as the teeth are concerned, but unfortunately the digits are unknown; such are Oligotomus, Orotherium, etc.

The type of Tomitherium already described, evidently stands between Lemurine monkeys and such small allies of Palaotheriida, with conictubercular teeth, and which abound in the Eocenes of Wyoming and France. The dentition of the two types is indeed but little different in the Quadrumanous and Ungulate types respectively, being a continuous series of I. 2 or 3 ; C. 1, P.M. $3-4$; MI. 3 ; the canines but moderately developed.

A comparison with Nasua reveals no distant affinity. As above remarked, the fore-limb presented a great similarity in this genus and To:nitherium. The teeth, though less numerous, in the molar series have the cutting type anterior and tubercular posterior, in both genera. Notharctus, Leidy, resembles Nasua still more than does Tomitherium, and occurs in the same Eocene strata. Prof. Leidy originally regarded it as a Carnivore, and subsequently (Hayden's Survey Montana, 1871) placed it among Ungulates. He was probably nearly correct on both occasions, and that only a techuical line will ultimately decide whether it be not a monkey. $\dagger$

\footnotetext{
* On the Short-footed Ungulata of Wyoming, page 3.
}

+ Dr. Lockwood, of Rutger"s College, in a recent number of the Popular Science Monthly, expressed serious suspicions of the Quadrumanous relationships of the Coati, little thinking at the time that the specimens to confirm his view were at that moment in the hands of palmontologists. 
But the genus which associates more definitely the orders Carnivora and Quadrumana, is the Cercoleptes, which F. Cuvier* placed between the two. Its two cutting premolars and three true molars, with the coössified rami of the mandible are truly Quadrumanous features, although it should on other grounds be regarded as a plantigrade carnivore. Several of the extinct genera of the Wyoming Eocene will prove to be allied to this form.

Cercoleptes does not, however, present us with the ultimate original type of the Carnivora. Such a type must also generalize the seals, with their longitudinal, cone-bearing molars, and flat, fissured claws. Some of the seals also unite the scaphoid and lunar bones later in life than other Carnivora, hence we would reasonably look for the division of these bones in their predecessors. The flat-clawed genera of Wyomingt answer these demands. The genera Mesonyx and Synoplotherium presents us with a series of molar teeth which repeat each other in form, are compressed below, and bear conical cusps. The jaws in the latter genus are slender, and the canines teud to the great development seen in many seals; but principally, the scaphoid and lunar bones are distinct, and the claws flat and widely fissured. The tympanic bone is more like that of the bear, and some seals, than that of the digitigrade Carnivora. These genera, though probably good swimmers, were well removed from the seals in the structure of the long bones of the limbs, and were probably remote in their ancestry.

In Oligotomus, Orotherintm, Hyopsodus and similar forms, the conic tubercles of the lower molars have a slight alternation, and the posterior, which has a crescentoid section in wearing, inclines to connection with both the inner conic tubercles by low ridges. These ridges are fully developed in Palceosyops so that we have a dental crest of two $\mathrm{Vs}$, in the inferior molars. This in wearing produces the two crescents of Pabceotherium. The addition of two tubercles on the inner side takes place in the higher forms, which terminates in the four crescent-bearing molars of the Ruminants. How this is done is proven later by examples from the maxillary teeth. In Orotherium vasaceiense there is a tendency for the conic tubercles to be connected in pairs by low cross ridges. These ridges fully developed produce the two cross-crests of Hyrachyus and Tapirus. In Rhinocerus the outer portion retains a crescentoid form, giving rise to an L-shaped crest. In Bathmodon diagonal ridges appear which would result in two Vs, as in Palcossyops, were it not that both transverse and oblique elements of the posterior $V$ disappear, leaving but one such in the middle and posterior part of the maudibular series. In Uintatherium the diag onal from the posterior crest never appears, leaving a transverse crest and a $\mathrm{V}$ on the true molars.

In the superior molar series the flattening of the outer tubercles may

- Dentes des Mammifers, p. 31.

t See the Flat-clawed Carnivora of Wyoming, by E. D. Cope, April, 1873. 
proceed so far as to produce on wearing a confluence of the crescentoid surfaces. This is the case in Orotherium sylvaticum in the mandibular series. In both Palcosyops and Hyrachyus those, tubercles of the upper molars are confluent into two Vs (more or less open, when unworn). In the former the inner tubercles retain their primitive conic tubercular form, but in Palcotherium, Rhinocerus, Lophiodon, Hyrachyus and Tapirus they elongate transvcrsely so as to meet the corresponding outer tubercles (now crests) forming the familiar cross-crests of those genera. If the tubercles are alternate, they produce the oblique crest of Palcotherium, if opposite, the cross-crest of Tapirus.

If on the other hand the inner tubercles flatten like the outer, on wearing; we have the quadricrescentoid type of Anoplotherium and the Ruminants.

But it is important to observe, that the lower types of Quadrumana and Carnivora present the quadrituberculate crown with tendency to flattening of the outer tubercles, as seen in these lowest Ungulatu. In the Carvivora the sectorial tooth is produced by the greater flattening and partial confluence of the outer tubercles, and the.entire loss of the inner, the "heel" being in the dogs and cats, e.g. their only representative. In the Quadrumanous families, including man, the primitive quadrituberculate type of molars is preserved, the flattening of the outer tubercles being finally lost.

It is to be observed that the lines of Ungulata, Quadrumana, and Carnivora, origiuate in plantigrade types, a state of things quite predominant among the lower series, or Lissencephala. It is universal in Edentata and very usual in Rodentia and Insectivora. The lower forms of Morsupialia and all of the Monotremes present it. In the Marsupials, Rodents, Ungulates, and Carnivores we have series whose highest expression is in the most highly digitigrade gemera.

The accompanying diagram is designed to express to the eye more clearly the propositions made above. By comparing it with a similar table published by Prof. Gill (Proceedings of the American Association for the Advancement of Science for 18\%1, p. 295), a close resemblance between the two may be observed, as well as certain differences.

I wish to be understood that the genera named in it as ancestors, are to be regarded in the light of types of groups. There is no other mode of explaining the facts, than that in accordance with the law of "homologous groups," $i . e$. that several genera of one group have undergone similar modfication into corresponding ones of a second group.*

* See Origin of Genera, page 79, Prop. V.

Published, May 6th, 1873. 


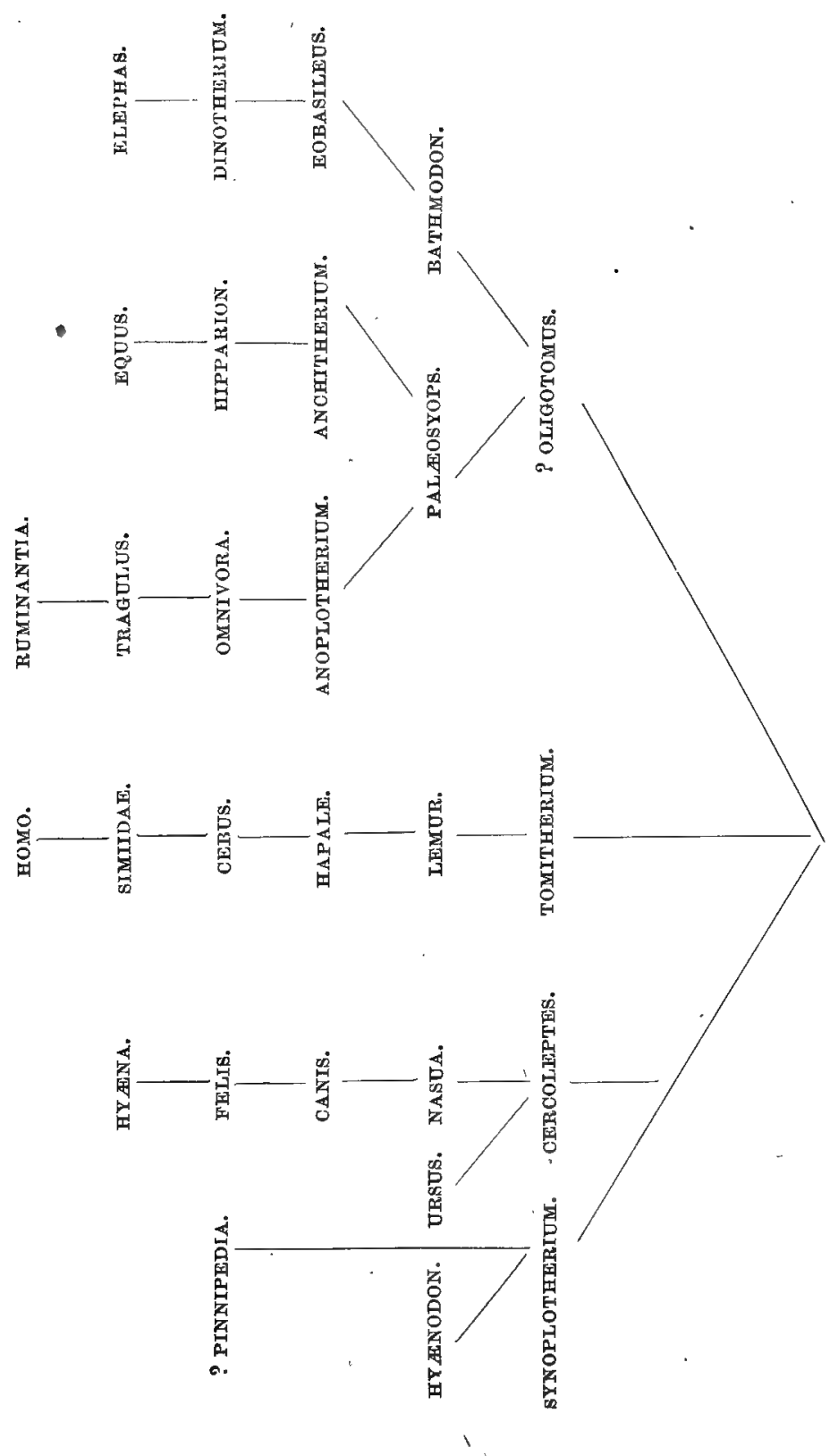







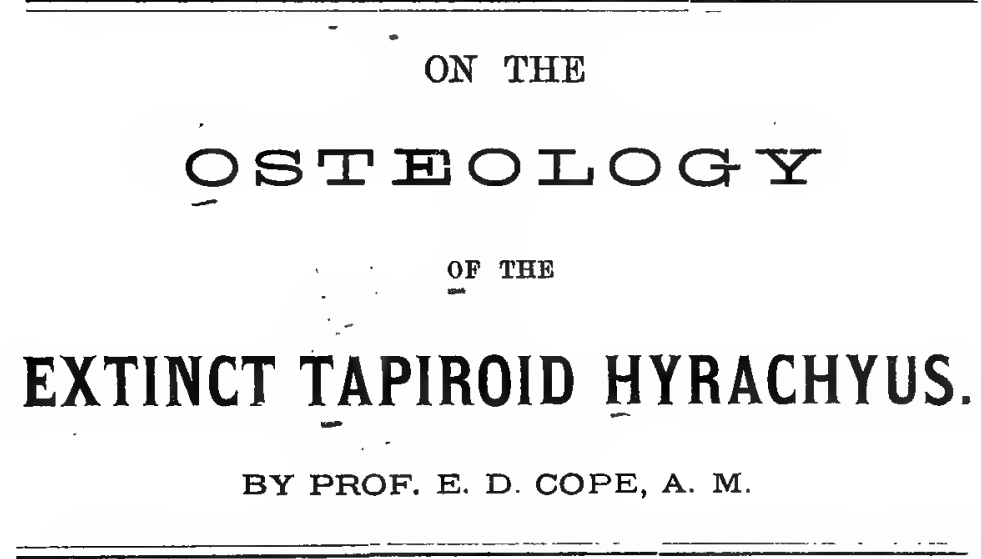





\title{
ON T THE OSTEOLOGY OF THE EXTINCT TAPIROID HYRACHYUS.
}

\author{
By Prof. E. D. Cope, A. M. \\ (Read before the American Philosophieal Society, April 18, 1873.)
}

This genus was originally described by Leidy* from portions of skelctons of individuals from the Eocene tertiary of Wroming. He recognized it as related to the Lophiodon of Cuvier in dentition, and as sharing with characters of that Eocene genus, peculiarities which belong to the existing genus Tapirus.

Having obtained a large series of remains of this genus, including more or less numerous portions of six species with nearly complete skeleton of $H$. eximius, Leidy, I propose to give such an account of its osteology as will place its relations on a certain basis.

The characters which distinguish its dentition from those of the allied genera are as follows:

Tapirus, Briss. Lower jaw : third molar two-crested ; three premolars, the third and fourth with two transverse crests. Upper jaro: seven molars, first with an inner heel tubercle; other premolars with two transverse crests.

Hyrachyus, Leidy. Lower jaw : third molar with two crests ; four premolars, third and fourth with one transverse and one longitudinal crest. Upper jan: seven molars, first without interior heel; premolars with two transverse crests.

Lophiodon, Cuvier. Lower jaw : third molar with three cross-crests; premolars three, Nos. 2 and 3 with lorgitudinal crests. Upper jaro: premolars with longitudinal crest only; No. 4 witl two transverse crests. Upper jaw: premolars with only one transverse crest.

In Hyrachyus the nasal bones are elongate, and unite with the maxillaries anterior to the orbit; in $H$. eximins above the foramen infra-orbitale exterius; in Tapirus those bones are much shortened, and either do not unite with the maxillaries or join them and the frontals above the orbit at different points from the anterior to the posterior borders. The temporal fossæ are so extended as to produce an elevated sagittal crest, which is bifurcate behind, each projectiou continuing along the outer margin of the occipital region as a lateral crest. The tympanic bone is unossified beneath the meatus auditorius externus, which is bounded in front by a strong postglenoid process. Posteriorly it is bounded by a long descending mastoid process of the squamosal bone, nearly closing it below. This is bounded posteriorly by a long and stout paramastoid process, which is compressed from before backwards and curves backwards and inwards. The foramen magnum has prominent supero-lateral margins which àre nearly straight, and unite at a right angle above.

The dentition is thus : I. $\frac{3}{3}$; C. $\frac{1}{1}$; P.M. $\frac{4}{4}$ M. $\frac{3}{5}$; a considerable diastema separates the premolars and the canine.

In the species studied, the vertebræ are divided as follows: C. 7 ; D.

* Hayden's U. S. Gieological Survey of Montana, 1871, p. 361. 
18 ; L. 7 ; S. 5 ; C. ? ; Of the cervicals the seventh only is not pierced by the arterial canal. The atlas has a broad flat "transverse" process.

The digits are $4-3$; the third with a symmetrical hoof, those of the exterior digits halved; the former have two reverted proximal processes, the latter, one. The astragalus exhibits a deeply-grooved and extensive trochlear arc, with rather long neck, which has a greater facet for the astragalus, a lesser for the cuboid bone.

From the above it is evident that this genus is nearly allied to Tapirus and cannot be removed to another family. Professor Leidy states that the premolar's differ from those of Tapirus in having "but one inner lobe connected with the external crest by two transverse crests." The appearance of one lobe is produced by the posterior curvature of the anterior transverse crest round the inner extremity of the posterior crest.

I now proceed to describe the skeleton more exactly.

\section{Hrrachyos eximids. Leidy.}

Hayden's Geol. Survey, Montana, 1871, p. 361.

Cranium. In the specimen to be described, the anterior portion from the glenoid cavities is wanting. The sagittal crest is quite elevated, and the lateral occipital quite prominent, and continuous below with the superior margin of the squamosal portion of the zygoma. Four nutritious foramina pierce the parietal bone near its middle and above the paramastoid process, and two enter the squamosal above the postglenoid process. The paramastoid process approaches near the occipital condyle by its posterior border. I cannot discover the sutural boundaries of the mastoid bone, but that separating the paramastoid process from the process in front of it is distinct. The condyle of the mandible is massive and the posterior border of the latter extends backwards with a slight obliquity.

$$
\text { Measurements. } \quad \text { M. }
$$

Elevation of sagittal crest above foramen magnum. . . 0.045

Width of bifurcation of crest behind.............. 038

" occiput behind meatus auditorius.......... .070

Width between, inclusive of occipital condyles....... .046

is temporal fossa at meatus.................. 050

" meatus auditorius...................... .012

" condyle of mandible.................... .032

Depth of ramus behind.................... 095

In further illustration of the species I add measurements of teeth, etc. from another specimen :

Length of last two superior molars............... 041

" last molar.......................... .019

Width of last "6 $\ldots \ldots \ldots \ldots \ldots \ldots \ldots \ldots \ldots \ldots . .022$

Length of inferior molar series...............095

" " " premolars......................... .040

" " last molar. ...................... 021 
Measurements. $\quad$ M.

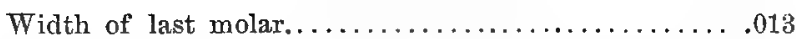

Depth ramus at first true molar.............. .040

Vertebrce. The atlas is deeply incised anteriorly above. It is rather short and its transverse processes are flat, thin; about as long as broad and with regular convex distal margin. The arterial foramen issues some distance above and within the notch which marks the anterior base of the transverse process. It enters at the notch at the posterior base. The neural arch is quite convex and its anterior margin is obtusely rounded. The axis is near the same length and bears a prominent and elongate laminate neural spine. Its diaparapophysis is narrow and overlaps the parapophysis behind it three-quarters of an inch; it is pierced for the cervical artery. The centra of the third and fourth cervicals are about equal in length to that of the axis, but the remaining ones shorten successively to the seventh which maintains a length somewhat greater than its width. The parapophyses of these, except the seventh, are flattened and have cousiderable antero-posterior extent, their extremities overlapping. A short and rather narrow and stout diapophysis is present on the sixth cervical; on the seventh it is larger, especially expanded antero-posteriorly at the base, and truncate. There is no parapophysis. The fourth, fifth, sixth and seventh have strongly opisthocolian centra; that of the third is injured.

Measurements. M.

Length of the cervical series................ 0.175

" atlas, between articular faces.............. .046

" base transverse process................. .035

" of " "

Diameter neural canal in front................. .021

" of anterior expanse...................050

" "total "

Length axis along basis neural arch............ .021

Elevation crest (rectangular) from posterior zygapo-

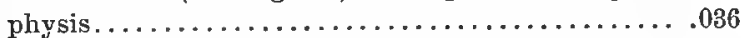

Length parapophysis of fifth cervical on margin...... .051

Extent zygapophyses " " " "

Expanse "6 " " " "

Elevation neural spine of C. $6 . \ldots \ldots \ldots \ldots \ldots \ldots \ldots . .056$

" " " $6.7 \ldots \ldots \ldots \ldots \ldots \ldots \ldots .075$

Length centrum below " " ................. 028

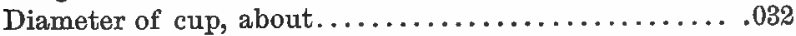

The measurements indicate that the neural spines of the sixth and seventh are quite elevated, the latter nearly equal to that of the first dorsal.

The spines of the dorsal vertebræ are elevated in the front of the series rising some distance above the scapulæ. They shorten and widen rapidly 
from the middle of the series backwards. The extremities of all from the scapula posteriorly are turned forwards. The metapophyses are conspicuously elevated above the diapophysis on the eleventh dorsal, and on the eighteenth, their elevation is about .4 that of the neural spine. The diapophysis is extended beyond the tubercular articulation, on the 18th dorsal; the extension and expansion increases rapidly on the lumbars. On the fourth they are as wide at the base as .66 the length of the centrum and maintain their width, being directed anteriorly. On the sixth and seventh they are still wider and longer, and very thin. They present a projecting transverse surface backwards one fourth the length from the base for articulation with the seventh lumbar and first sacral respectively. The centra of the lumbars are depressed and slightly opisthocœlian, except the last, which is flat. They are contracted and keeled below.

The sacrum is long and narrow, and thoroughly coössified in the specimen. The diapophysis of the first and part of that of the second gives attachment to the ilium. The intervertebral foramina are rather small.

Measurements.

M.

Length of dorsal vertebræ along middles of neural spines..........................420

" of lumbars do. . ...................298

" of sacrum along centra.................170

Diameter centrum first dorsal (transverse) . . . . . . . . . . .019

" " " " 6 (vertical)............. 019

" " " fifth lumbar "

" " " " 6 (transverse) ...........

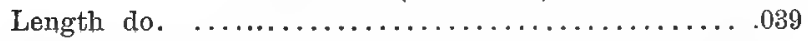

" diapophysis sixth do. .....................

Greatest transverse width of diapophysis sixth lumbar. .030

Length centrum seventh lumbar................034

Transverse diameter centrum first sacral............ 036

" expanse diapophyses do. .......................

" diameter end of last sacral............ .020

" " diapophyses do. ............ 043

Elevation neural spine second dorsal............ 095

" " seventh " above scapula.... .035

" " eighteenth " (from arch behind) .037

The ribs are long and slender, the first but little expanded distally and united with the manubrium sterni a little behind its middle. They number eighteen, but as the last is quite long, there may have been another pair of shorter ones not yet exposed in the matrix.

Measurements. M.

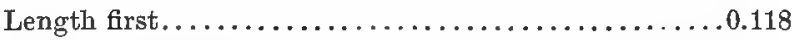

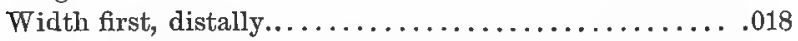

Length eighteenth............. $\}$ from tubercle. $\{\ldots .180$ 
There are four sternal segments preserved, with a fragment of another. They are distinct, and the first is the largest. It is a longitudinal plate, placed on edge, with the anterior border strongly excavated. The inferior margins of the succeeding segments are thickened, but the compressed form remains, the section being triangular.

The scapula is large for the size of the animal. It has an approximately triangular form, the base being superior. The posterior angle is right, but the anterior regularly rounded. The apex supports the glenoid cavity on a neck which is contracted by a shallow excavation of the anterior margin. The latter is bounded next the glenoid cavity by the short obtuse coracoid, which stands a short distance above the articulation. The spine is long, rather elevated, with a regular convex border curved backwards.

Measurements. $\mathbf{M}$.

Length of three sternal segments.............. 0.147

\begin{tabular}{|c|c|c|c|c|}
\hline “ & first & “ & 6 & .084 \\
\hline Depth of & " & “ & “" & in front....... \\
\hline Width of & "6 & "6 & $"$ & below .... \\
\hline "6 & third & "4 & 6 & 015 \\
\hline
\end{tabular}

Length of scapula (median) ..................215

Width above (greatest) ....................130

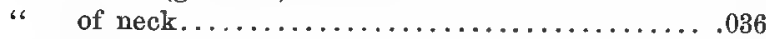

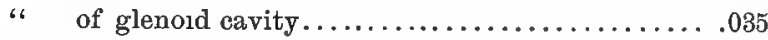

Humerus. The head is directed a little inside of directly backwards. The bicipital groove is very deep and the inner tuberosity large and directed forwards. The external tuberosity is much larger, as usual in this group of ungulates, and rises in a hook-like apex above the level of the head. The external bicipital ridge is lateral, and not very prominent, extending on one-third the length of the shaft. The shaft is moderately compressed at the middle, but transversely flattened below. It is nearly straight. The condyles are narrow, and the inner and outer tuberosities almost wanting; their position marked by shallow concavities. The external continues in a lateral crest which turns into the shaft below the lower third. The inner condyle is both the widest and most prominent; the external has its carina at its middle, and its external trochlear face oblique and narrow; narrowest behind. The olecranar and coronoid fossæ are deep and produce a small supra-condylar foramen.

The ulna exhibits a large and obtuse olecranon, concave on the external face. Its glenoid cavity is narrowed and elevated behind; in front it widens, and there the ulna receives the transverse proximal end of the radius, which overhangs it on both sides, leaving the little elevations of the right and left coronoid processes about equal. The vertical diameters of the shaft of the ulna are about equal throughout. Its section is triangular, the base being next the radius for the proximal third. This is followed by an edge next the ulna, and the base of the section is on the outer inferior aspect, an account of the direction of an angle from a short 
distance beyond the outer coronoid process to the base of the nlnar epiphysis, where it disappears. Distally there are two other very obtuse ridges above this one. The extremity bears two facets, the larger for the cuneiform, the smaller for the pisiform bone.

The radius is throughout its length a stouter bone than the ulna and bears much the greater part of the carpal articulation, viz. : with the scaphoid, lunar and part of the cuneiform bones. This articulation is transverse to that of the ulna, which is thus at one side of and behind it. The head is a transverse oval in section, the narrower end outwards. The articular face consists of one-and-a-half trochlex, the latter wider and internal. The shal't is a transverse oval in section, with an angular ridge along the middle externally, and the distal part proximally. A broad groove marks the upper face of the epiphysis, where the shaft has a vertical inner face.

Measurements. M.

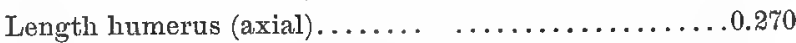

Diameter head to bicipital groove................ 037

Length along crest outer tuberosity (about)........ .052

Transverse diameter, distally................. 046

Antero-posterior do. inner condyle............ .042

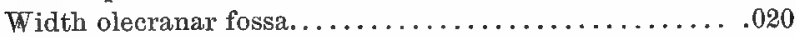

Length ulna..........................260

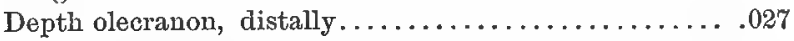

" at coronoid process..................... 025

" of distal end......................... .019

" at middle shaft......................... . 019

Length radius..........................200

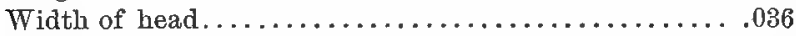

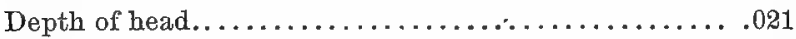

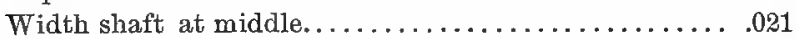

" near distal end (greatest)............... .037

" distal articulation.................... 030

The elements of the carpus are distinguished for length, and for reduction of width. The anterior faces of all are considerably longer than broad, but the longest faces of the cuneiform, scaphoid, and trapezoides are antero-posterior. The facets are as usual in the carpus; scaphoid $\frac{1}{3}$; lunar $\frac{1}{2}$; cuneiform $\frac{3}{1}$; trapezium $\frac{1}{1}$; trapezoides $\frac{1}{1}$; magnum $\frac{2}{2}$; unciform $\frac{2}{1}$. The cuneiform has a rather L-shaped external face. The pisiform has two proximal facets and is enlarged and thickened distally ; pressed inwards it reaches the scaphoid. The trapezium is a small subdiscoid bone with convex outer face. The magnum is as broad as deep in front, where its surface is swollen; it is produced behind into a spatulate decurved hook. The unciform has a narrow sub-acute hook behind, with wide base.

Measurements. M.

Width of carpals of first row together............ 0.044

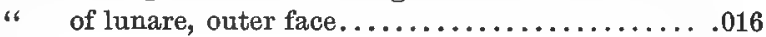

Depth " " $"$ " $6 \ldots \ldots \ldots \ldots \ldots \ldots \ldots .020$ 
Measurements. M.

Depth cuneiform outer face. . ................ .020

Width " "

Length pisiform $\quad$ " $\quad \ldots \ldots \ldots \ldots \ldots \ldots \ldots \ldots \ldots . .630$

Depth distally " " $\quad \ldots \ldots \ldots \ldots \ldots \ldots \ldots \ldots . . \ldots 14$

Width three carpals of second row.....................

" magnum outer face.................... .015

Depth
"6
Width
unciform

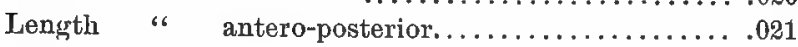

" magnum "6 $\ldots \ldots \ldots \ldots \ldots \ldots \ldots . . \ldots 29$

Total length of carpals..................... 040

The metacarpals are quite slender. The first only is wanting; the third is rather stouter than the others, while the fourth is considerably the most slender. Its distal extremity is oblique with prominent median keel, which is wanting on the superior aspect. The proximal facets of these bones are respectively (2d) $2,(3 \mathrm{~d}) 2$, (4th) 1 , (5th) 1 . There is a short shallow groove near the proximal front of No. 3. The phalanges corresponding are lost in the specimen.

Measurements. M.'

Length of fifth metacarpal.................. 0.070

Estimated length of foot...................187

Distal diameter of 5 th metacarpal............... .012

Proximal " "

$"$ " $"$ th " $"$ th

" " 6 " 6 d

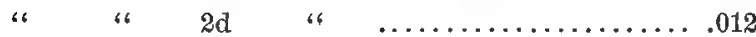

The above are taken on the articular faces transversely.

The pelvis is perfectly preserved. The ischium is but little over half as long as the ilium measuring from the middle of the acetabulum. The ilium is a triradiate bone, the superior or sacral plate rather shorter and wider than that forming the "crest," which is subsimilar to the peduncular portion. The crest expands very slightly distally forwards and downwards. The ischio-pubic suture is a long one, and the obturator foramen a long oval; the inferior pelvic elements do not form a transverse, but meet at an open angle.

Measurements. $\mathbf{M}$.

Length ilium to sacral border................ 0.130

" " " crest...........................180

" crest................................. .060

Width peduncle........................ .030

Length ischium from middle of acetabnlum......... .110

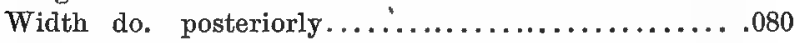

Length obturator foramen................... . 041

Width " " $"$ " . . ............... 034

Expanse of ischia above at middle..............076 
Femur. The head projects inwards on a well-marked neck. The great trochanter is strongly recurved and presents an anterior tuberosity as well. It rises to an incurved apex much elevated above the head. The prominence of the front of the femur is continued into the front of the trochanter. The outer margin of the shaft is thin, and at a point two-fifths the length from the proximal end is produced into a low thin trochanter, which is curved forwards and thickened on the margin. The trochlea is well elevated, the inner margin a little the most so, and is narrow. It is continuous with the surface of the inner condyle, which is the shorter and more vertical; the external is longer and divergent; its terminal face is marked by two fossæ, one in front of the other just outside the distal end of the ridge bordering the trochlea. Little trochanter moderate.

Measurements.

M.

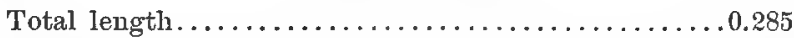

Proximal width of head and trochanter........... 075

Width from front to edge third trochanter......... 050

" just above condyles.................. ${ }^{\circ} .035$

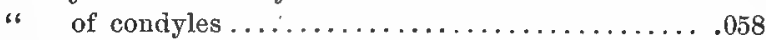

Chord of outer condyle and trochlea........... 060

The tibia has a broad prominent crest, which is remarkable in being deeply fissured longitudinally at its superior portion. The tendinous notch separates the outer portion of the crest from the spreading margin of the outer cotyloid face. The crest disappears at the proximal third, and the shaft becomes flattened in front and on the inner side. The distal articular extremity is impressed by $1 . \frac{2}{3}$ trochleæ, the outer being completed by the fibula. The posterior tuberosity is more nearly median than usual, hence the inner margin of the inner trochlea is low posteriorly, and the inner malleolus has a considerable beveled inferior margin. The fibula has a slender shaft, but little compressed. The head is expanded fore and aft, and the malleolus is quite stout.

Mẹsurements. $\mathrm{M}$.

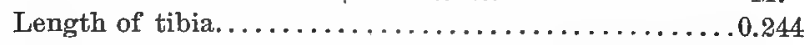

Diameter from outer angle of head to inner angle of

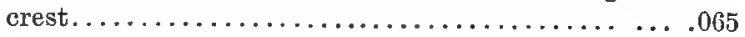

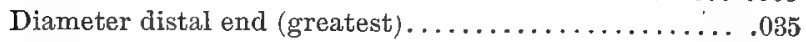

Diameter articular face; transverse............... 027

" " " fore and aft............. 026

Both hind feet are perfectly preserved. The calcanerim is rather elongate and compressed; the lower face truncate with two longitudinal bounding ridges; the outer of which is discontinued before reaching the heel. The surfaee between them is ștriate grooved. The outer face is slightly concave. The astragaline facets are much expanded inwards; the outer is transverse and strongly convex, and separated by a groove from the inner; which is longitudinal and nearly plane. The posterior 
edge of this, and convexity of the outer facets are received into a transverse groove of the posterior part of the lower face of the astragalus. The cuboid facet is diagonal and is bounded within by a third narrow facet for the astragalus. The astragalus has a strongly convex deeply grooved trochlea; the convexity extends over $158^{\circ}$. The trochlea is nearly in the vertical, a little oblique to the longitudinal axis of the foot. The exterior malleolar facet is well marked and bounds a lateral fossa above. The neck of the astragalus is broad and not contracted, but not wider than the trochlea. Its navicular facet is wide and concave, the cuboid narrow, with a long angle behind. The cuboid is quite elongate and with a narrow anterior face; it has a large posterior tuberosity not projecting much posteriorly. The navicular is flat with a sigmoid proximal face, convex on the inner side, concave on the outer. It has the three cuneiform facets below, the inner antero-posterior. The inner is a flat bone with antero-posterior plane, and apex directed backwards, and considerable oblique facet for the second metatarsal. The mesocuneiform is much the smaller and brings the third metatarsus a short distance proximal to the fourth. The ectocuneiform is a little wider than deep. The metatarsals are three, and are rather slender. The two outer are equal in length, and the median but little wider proximally, the increased width being more obvious distally. They have no proximal grooves, and the outer has a low outer tuberosity. The facets of the second row of tarsals are $\frac{1}{1} \frac{1}{1} \frac{1}{1}$. The phalanges, including ungueal, are 3, 3, 3. The proximal ones are longer than wide and contracted at the ends; the penultimate are still stouter in form. The ungues of the middle line are symmetrical and broad, with the margin a segment of an ovoid, and slight contraction at the neck. The proximal articulation is bounded by a fossa on each side, which is in its turn, isolated by the elongate process found in the tapir and in the horse. The margin is marked by radiating striæ separated by grooves, of which the median is the most marked. The lateral ungues are contracted on the inner side, and only possess the proximal fossa and hook on the outer side. The median distal groove is well marked.

Measurements.

M.

Length of hind foot from heel............... 0.286

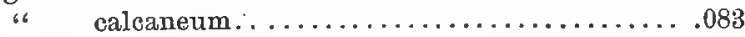

" cuboid facet of do. $\ldots \ldots \ldots \ldots \ldots \ldots \ldots .024$

Depth calcaneum behind.................... .025

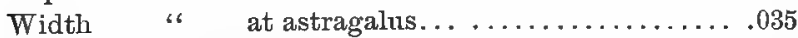

Greatest axial length of $6 \quad \ldots \ldots \ldots \ldots \ldots \ldots \ldots .045$

Width between trochlear crests do. ............ .022

Length neck do. outer side.................. 014

Width head do. ....................... 030

“ navicular......................... .081

Length "6 at middle.................. 010

" cuboid............................ 022

Depth " outside.................... 025 
Measurements. M.

Length ectocuneiform in front................. 013

Width " "

" mesocuneiform "

Length " " "

" entocuneiform at side................... .021

Depth " " "

Length of metatarsus I[ ...................102

" $" \quad$ III. . . . . . . . . . . . . . 107

Width $\quad$ II. proximally............. 016

" $"$ " III. " $"$. $\ldots \ldots \ldots \ldots \ldots .020$

". $"$ II. distally... $\}$ within $\{\ldots \ldots .016$

" " III. ". ... $\}_{\text {fossa. }}\{\ldots .025$

Length median phalanges $I \ldots \ldots \ldots \ldots \ldots \ldots \ldots \ldots .025$

Width " " " distally...........................

Depth " " " " " 6 ".

Length " "

" " " " unguis................ 029

Width of articular facet do..................... .014

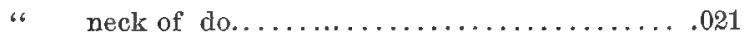

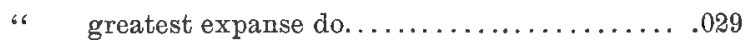

Length phalanges of metatarsal II ..............060

" unguis " " $6 \ldots \ldots \ldots \ldots \ldots \ldots .028$

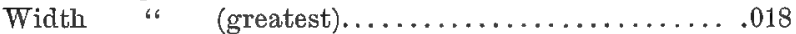

Length metarsus and phalanges IV.............. .158

Restoration. The following dimensions may be relied on as a basis for a restoration of this species :

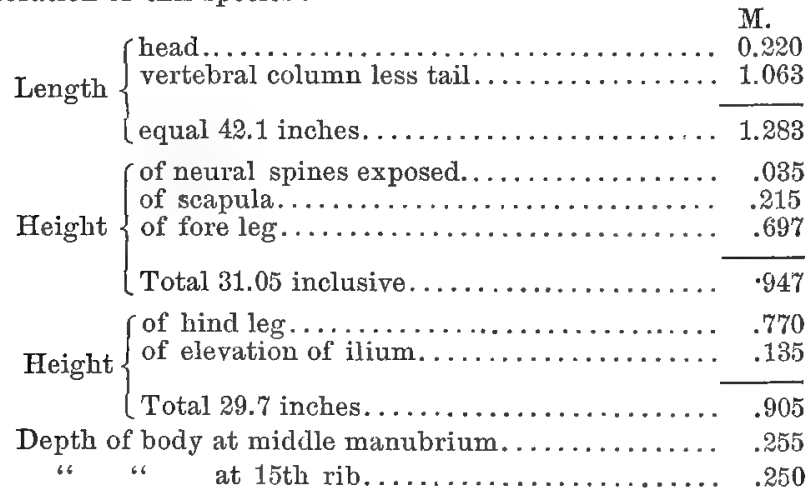

Allowance being made for the obliquity of the humerus, scapula, femur and ilium, the elevation in life was,

M.

At the withers $(26.6$ inch) $\ldots \ldots \ldots \ldots \ldots \ldots \ldots \ldots . .872$

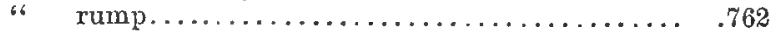

The size of this species was then that of a large sheep.

Comparison of the skeleton with that of Tapirus routini. For the opportunity of making this comparison I am indebted to the Smithsonian 
Institution, which possesses a skeleton of the above species of tapir from Equador, presented by President Moreno.

Cranium. In addition to the generic characters mentioned at the commencement of this description, the $H$. eximius and $T$. roulini, differ as follows : in $H$. eximius there is (1) a high sagittal crest which is wanting in $T$. roulini, T. malayanus, and approximated in $T$. terrestris. (2) The crest of the squamosal part of the zygoma is continuous with the lateral occipital crest, which is not the case in existing tapirs.

Vertebre. (1) The arterial canal of the atlas is not isolated in front $\mathrm{as}$ in $T$. roulini, but notches the basis of transverse process. (2) The axis is longer than in T. routini. (3) The neural spines and especially the metapuphyses of the posterior dorsal vertebræ are more elevated. (4) The ends of the centra of the lumbars are flatter, and more depressed. (5) The diapophyses are wider and longer and thinner and the penultimate articuates with the last by an angular process, which is not the case in $T$. roulini.

Scapula. (1) This bone is equal in size to that of a $T$. roulini of considerably greater general dimeusions, and is hence relatively larger. (2) The spine is not angulate as in that species, has a longer base, and longer elevated margin. (3) The neck is more contracted and (4) the coracoid is not recurved as in $T$. roulini. (5) The sinus bounded below by the latter is much shallower, and not bordered above by a recurved hook of the margin.

Humerus. (1) It is relatively smaller in $H$. eximius. (2) The internal bicipital ridge of $T$. roulini is wanting. (3) The external condyle is much shorter, whence its border is nearer its trochlear rib. The radius has a narrower head (1), the external articular plane being shortened. (2) The shaft is wider with a more acute longitudinal lateral ridge medially, and more rouncled distal end. The ulna is (1) absolutely nearly as long as in T. roulini, being thus relatively longer. (2) It has three weak, longitudinal ridges on a convex outer face; in T. roubini the external face is divided by a very prominent longitudinal angle from the radial cotylus, which spreads distally, sending one angle to the upper and another to the lower base of the distal epiphysis.

Carpus. This part is (1) absolutely and relatively smaller than in $T$. roulini. (2) The pisiform is more cylindroid distally. (3) The scaphoid is more produced backwards on the inner side; the excavation of the inner side is more continued as a concavity of the outer side of the front. (3) The unciform has an acute tuberosity behind; in T. roulini it is short, vertical and obtuse. (4) The trapezoides has a shorter, wider, and more swollen external face. (5) The pisiform is small and convex instead of being larger and flat.

The metacarpals (1) are absolutely and relatively smaller. (2) The inner (II) has a more oblique phalangeal articulation, which is short above and with the keel prolonged upwards instead of being as in $T$. routini, distal only.

The pelvis is distinguished by the much longer plate of the ilium, whose extremity constitutes the crest. (1) The crest is also shorter, and more 
anterior. In $T$. roulini, this plate does not so much exceed the sacral plate. (2) The pubes and ilia are not so horizontal, but meet at nearly a right angle, and (3) the ischiopubic common suture is considerably longer. (4) The obturator foramen is a more elongate oval.

The femur is very similar to that of $T$. roulini, being no smaller in relative size. (1) The great trochanter is wider fure and aft, and with margin more continued on the anterior aspect of the extremity of the shaft. (2) The great trochanter is nearer the middle of the length. (3) The condyle surfaces are continuous with the rotular, not isolated as in T. roulini. The latter also (4) lacks the two fossa on the outer margin of the external seen in $H$. eximius. (5) The rotular groove is also narrower in the latter and not so deeply excavated as in $T$. roulini.

The tibia is (1) reduced in size, and esptcially contracted distally; the relative widths of the ends are $6 \mathrm{~cm}: 3.5$; in $T$. roulini $7.5 \mathrm{~cm}$ to 5 . (2) The crest is more prominent and is deeply fissured by a groove, which is repsesented by a shallow concavity in T. roulini. The groove (3) external to this is deeper. (4) The posterior inner tuberosity of the distal end, is more median, hence, the inner trocllear groove is further removed from the anterior inner malleolus, which has, therefore, a greater inner )not outer) extent.

The tarsus (1) is generally longer and narrower, except in the case of the cuboid bone (2) which is shorter than in T. roulini. (3) The astragalus has a narrower neck which therefore appears more on the inner side. (4) The facet for the cuboid is smaller. (5) The inner tuberosity of the head is more prominent. (6) The calcaneum is more slender, with larger cuboid facet, especially posteriorly. The metatarsus is absolutely nearly as long as in $T$. roulini, and therefore relatively longer and more slender. (2) The median (III) is nearly similar to the others in width; in the $T$. roulini, much larger than the lateral.

The phalanges of the first cross series are more contracted distally.

The more important differences between the skeletons of the two species in addition to those pointed out under the head of the genus, are those of the ulna, the scapula, the lumbar vertebre, the ilium and the crest of the tibia. The scapula is more like that of Tapirus terrestris, while the ilium is approximated by that of $T$. malayanus among living species; its form leans tuwards the Equine series, and not to the Palcetheroid.

Conclusion. From the preceding it is evident that there lived in North America during thé Eocene period, a type of Tapirida only differing generically from that now existing in South America. Thus one form of the many peculiar and primitive ones of that time still persists in the Tropics and Soulhern hemisplere, which claims more ancient character than the Rhinocerus, Elephants, and other remains of Miocene time.

The affinities of Cercoleptes and Nasua to the types of the same period have been already indicated,* and with the present case may be regarded as confirmatory of the proposition stating the early geologic state of the existing Fauna Neotropica.

* See on the Primitive types of the Mammalian Orders, 1873. See Origin of Genera, p. 99 and preced. 


with the table-lands of Guiana and Brazil; * that the subsequent upheaval of the Andes left estuary friths now marked by the three river systems; $\dagger$ that the Andes did not reach their present altitude until after the deposition of the Amazon formation, though it was a slow movement in mass, for the beds are nowhere unequally tilted or dislocated; $\ddagger$ that the archipelago on the north was formerly united to the southern continent, and that it has since been an area of subsidence; $\S$ and that simultaneously with this subsidence was created the low watershed which now separates the Amazon and Caribbean waters.

* Bates has shown that the geographical distribution of insects indicates that Guiana was formerly an island.

$\dagger$ 'The sediments from these straits near the ocean would have a purely marine character; and Hartt observes that the clays and sandstones on the coast tie in with those of the Amazon.

$\ddagger$ This certainly follows, if the Pebas and Pichaua shells prove to be early tertiary. The clay beds ascend the eastern slope beyond the village of Napo, which stands 1,400 feet above Para, and in long. $77^{\circ}$. The red clay was not prominent on the Rio Napo till we reached long. $74^{\circ}$, and altitude of 550 feet, where there is a very high bank called Puca-urcu, or monte colorado, containing lignite, - una mina de carbon de piedra, says Villavicencio. This interstratified lignite is traceable eastward as far as Tabatinga. Darwin says that the Pampean formation was accompanied by an elevatory movement.

$\S$ This is suggested by the South American character of the West Indian mammals and mollusks. There are palæontological reasons for believing (Proceedings of the Academy of Natural Science, Phila., 1868, p. 313) that the Caribbean continent was not submerged before the close of the Post Pliocene.

A. A. A. S. VOL. XIX. 


\section{ZOÖLOGY.}

1. ON the Homologies of some of the Crantal Bones of the Rertilia, and on the Systematic Arrangenent of tae Čass. By Edward D. Cope, of Philadelphia, Penn.

THE great group of Reptilia may be considered as well circumscribed by the characters presented by their skeletal strutcure. They may be defined as vertebrates, with mandibular arch suspended fiom the cranium by the intervention of an os quadratum, or extra-auricular malleus; with the basis of the cranium formed of the cartilage bones, basisphenoid, sphenoid, and usually presphenoid; with a coracoid bone; and with metatarsals, metacarpals, second row (and usually first row) of tarsal and carpal bones distinct, and not coösified.

Within these limits there exists perhaps a greater variety of structure, in other respects, than in any other vertebrate class. The homologizing of the elements which present this variety is therefore a point not attainable without much study, while the homologizing of the same with their representatives in other classes is still more difficult. In the present essay a few points of this nature are, it is hoped, elucidated, especially with reference to the structures of the crania in the orders Ichthyopterygia and Anomodontia. Finally, the bearing of these and other points on the systematic arrangement of the class are alluded to.

\section{Homologies and Composition of the Cranial Arches.}

The bony arches which connect the facial part of the cranium with the posterior part of the brain-case, in nearly all Vertebrates, are primarily only two in number; viz., the zygomatic and the quadratojugal. They, however, form connections with each other and adjoining portions of the cranium, so as to complicate their determination, which is increased when one or other of their usual connections is, under these circumstances, atrophied or omitted.

The zygomatic arch takes its name from the only one which is present in the Mammalia; and that arch which is homologous with it throughout lower vertebrata must retain the name. It is then the arch connecting the maxillary with the squamosal (or squamosal part of the temporal) bone, and is therefore composed in large part of the malar. 
The quadratojugal arch, as its name implies, is that which connects the maxillary with the quadrate bone. As the quadrate bone only exists as the malleus within the ear-chamber in the Mammalia, it is obvious that it cannot exist in that class. It can only be found in the vertebrata, from and including the birds, downwards. As the quadratum is projected below the squamosal, the position of this arch is always inferior to that of the zygomatic. It is composed normally of the malar (or jugal) and quadratojugal.

A third arch, which is especially characteristic of the Reptilia, connects the parietal bone with the superior extremity of the quadrate. The connection is accomplished by the intervention of the opisthotic or squamosal, or both.

The character of the arches existing in the different types of the vertebrata, above the Dipnoi, may be expressed schematically by the following table:-

I. Neither zygomatic nor quadratojugal arches.

a. Without parieto-quadrate arch.

Batrachia Urodela except Pleurodelidæ; Ophidia.

Lacertilia Ophiosauri and Typhlophthalmi.

Testudinata Chelydidæ.

Mammalia Edentata (part).

$a \alpha$. With parieto-quadrate arch.

Lacertilia Nyctisaura.

Testudinata (Hydromedusa Platemys Rhinemys).

II. Quadratojugal only.

a. Without parieto-quadrate arch.

$\beta$. With quadratojugal bone.

Aves.

$\beta \beta$. Without quadratojugal bone.

Batrachia Anura in general.

III. Quadratojugal and zygomatic arches present.

1. No postorbital arch.

Batrachia Anura (Discoglossus).

2. A postorbital arch.

a. Withoùt postorbital bone.

Crocodilia.

$a a$. With postorbital bone.

Batrachia Stegocephali (Apateon).

Ichthyopterygia.

Rhynchocephalia (Sphenodon).

? Sauropterygia.

Ornithosauria:

IV. Zygomatic arch only.

1. With postorbital arch.

a. With postorbital bune. 
* Malar portion of zygomatic arch absent.

Lacertilia Varanidæ.

* Malar portion present.

Lacertilia in general.

Anomodontia.

Sauropterygia (? all).

Testudinata in general.**

$a$ a. Without postorbital bone.

* Malar portion wanting.

Batrachia Urodela Pleurodelidæ.

Py thonomorpha.

* Malar portion present.

Batrachia Gymnophiona.

Mammalia Quadrumana, Artiodactyla, Perissodactyla (part).

2. Without postorbital arch.

Mammalia Carnivora Proboscidia Perissodactyla (part), Cetacea, Rodentia,

Edentata (part), Monotremata.

From the above table, it will be observed that each class, and sometimes single orders, present many or several of the various types of structure of the arches. These arches are more or less protective or fixative in their use; that is, they protect the orbit, the temporal muscle, or the oral cavity, or fix the quadrate and prevent its motion. As adaptive characters, they are thus those which define very subordinate representatives of all the orders.

From want of analysis, the proper determination of the arches has not always been made, and the identification of the component and adjacent bones vitiated. This is no doubt owing to the fact, that in many Reptilia, where the orbits are large, and the temporal fossa small, - e.g., Ichthyopterygia, Crocodilia, etc., - the zygomatic arch makes a strong sigmoid flexure, leaving the quadratojugal to take the more direct course to its terminus. Thus Owen (Palæontology) homologizes the quadratojugal arch of Ichthyosaurus with the zygomatic of Mammals, and the true zygomatic with the temporal fascia of the same. In the same way $\left(l_{0} c_{.}, p\right.$. 210), he homologizes the quadratojugal arch of Nothosaurus with the zygomatic, thus: "The lower one (i.e., arch) is formed by the malar (27) and squamosal (28), the latter answering to the true zygomatic arch in Mammals." The figures obviously refer, in the cut, to the malar and quadratojugal bones; while the "mastoid"

* The postorbital is prolonged so far downwards in Chelone and Chelydra, as to look like a quadratojugal. 
in this, as in other determinations of the same author, is the squamosal.*

In the same way Günther, in describing Sphenodon (Philos. Trans., 1867), calls the quadratojugal arch the zygomatic, and the zygomatic the "temporal arch," employing a new name to designate it. Stannius (Zootomie der Amphibien) appears to have correctly identified the zygomatic arch in Lacertilia, but erroneously in the Crocodilia.

Before proceeding to determine more exactly the homologies of the posterior cranial bones, I will describe the cranial structures of Ichthyosaurus and Lystrosaurus, as our literature appears as yet to be deficient in these points.

\section{On the Cranium of the Ichthyopterygia.}

Commencing with the foramen magnum and occipital condyle, as fixed points, the connections of the bones, as they succeed each other forwards, may be safely considered.

All four of the occipital elements contribute to the margin of the foramen magnum, the supraoccipital not being excluded as in Crocodilia, Anomodontia, etc. The external or lateral margin of both exoccipitals and basioccipital are excavated by a large foramen. The continuous margin of both between these points is united to a bone which extends outwards and upwards, and which contributes by its superior and inferior margins to the outlines of the foramina just mentioned. Exterior to these, from the basioccipital to near the apex of the supraoccipital, there are no bones suturally united, and there is a vacuity in this position not seen in any other Reptilian cranium.

From the exterior margin of the inferior foramen, a subcylindric bone extends outwards. It is contracted medially, and is not in sutural connection with any other. Immediately exterior to it is a flat subvertical bone, which, as it bears the articular condyle for the mandible on its lower extremity, is no doubt the quadrate. That it is such is also proven by the fact that it is anteriorly connected to the malar bone by a quadratojugal.

If we now turn to the lateral view of the skull, we observe the zygomatic arch, as determined above; $i_{\text {. }}$., the superior of the two extending from the malar, and that which supports the postorbital arch. The bone which forms its posterior half must be the squa-

* This description, by the way, differs from Von Meyer's figures of Nothosaurus, where but one arch is represented. 
mosal, not only on this account, but because, as in other Reptilia, it is articulated with the summit of the quadrate.

Turning again to the posterior face of the cranium, we may be in a position to determine the two bones described above as lying outside of the occipitals, and between them and the quadrate and the squamosals. The superior (Op. O, fig. 2) occupies the position of the "external occipital" of Cuvier, in the tortoise, both by its articulation with the exoccipital (Ex. O) and its direction towards the squamosal $(\mathbf{S q})$. Its separation from the supraoccipital, and contact with the basioccipital, are against this determination, yet

Fig. 1.*

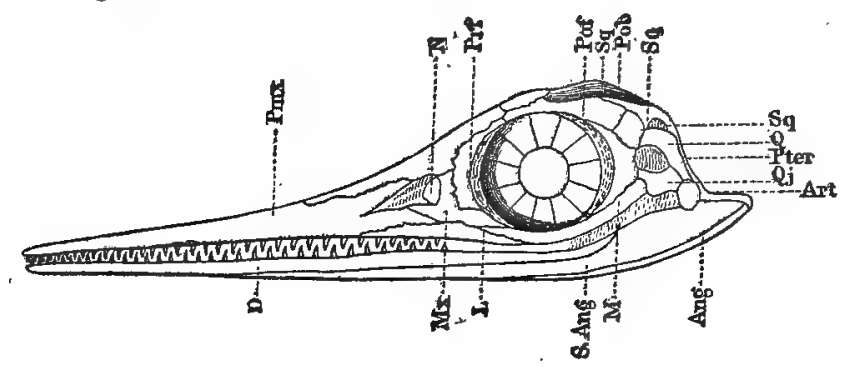

the weight of these arguments is much less than that of those for it; and therefore I suppose it to represent that bone, which is the opisthotic of modern nomenclature.

The large foramen below the last, and exterior to the basioccipital, is in the position of the opening of the internal ear in the Lacertilia, as regards its relation to the latter bone, the opisthotic being separated from it by the extension outwards of the exoccipital. Its relation to the opisthotic is the same as that in the Cheloniidæ, where it is separated from the basioccipital by an inferior process of the exoccipital. It is probably the fenestra ovale; and, if so, the second bone in question (stap) becomes the stapes.

It is a question, however, to what extent this element is really

*. Fig. 1. -Ichthyosaurus; lateral view (from specimen from Barrow, Leicestershire).

Pmx. . Premaxillary bone.

Mx. . Maxillary.

N. ... . Nasal.

Fr.... Frontal.

Prf. . . Prefrontal.

Qj.... Quadratojugal.

Q.... Quadrate.

Pob. . . Postorbital.

Pof. . Postfrontal.

Sq. . . Squamosal.

Pa. . Parietal.

D. .... . Dentary.

L. . . Lachrymal.

An. ... Angular.

Ar. ... Articular.

S. Ar. . Subarticular.

Pter. . Pterygoid. 
stapes. In existing reptiles, it is only proximally expanded, and distally a slender rod terminating in the cartilaginous expansions called by Huxley* suprastapedial and extrastapedial; the latter being, as the same author shows, the support of the stylohyoid and other elements of the hyoidean arch, and with the suprastapedial the homologue. of the incus. The expanded distal end of the bone marked stap, in Ichthyosaurus, looks as though it were the homologue of the cartilaginous expansions mentioned, in which case that bone becomes stapes and incus combined. This seems to us very probable. $\dagger$

As a whole, this bone is in that case homologous with the hyomandibular of the Sharks and Teleostei. This has been pointed out by Huxley on embryological grounds to be the case with the incus. If the element (stap) in Ichthyosaurus represent both stapes and incus, the same is probably true of the hyomandibular.

Turning again to the squamosal, we find it appears to possess an extraordinary development. Besides forming the posterior portion of the zygomatic arch, as in other vertebrata, and forming part of the combination which supports the quadrate, as in Reptiles and Batrachia generally, it sends down behind the quadrate a plate for more than one-third the length of the latter to the superior margin of the stapes. Instead of joining the parietal or opisthotic at its posterior margin, it is continued inwards to near the apex of the supraoccipital, and bending forwards continues, in company with its fellow of the opposite side on

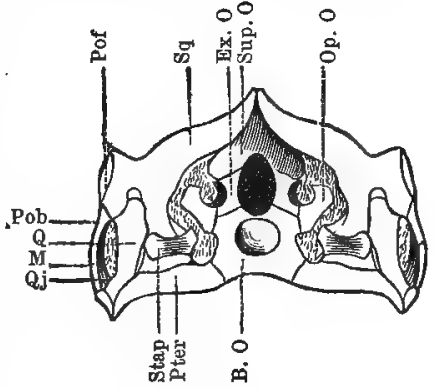

Fig. 2. $\ddagger$ the inner face of the temporal fossa, to a point above the middle of the orbit, where it unites suturally with what may be called the pari-

* In a most valuable essay on "The Representatives of the Malleus and the Incus of the Mammalia" (Proceed. Zoöl. Soc., 1869, p. 391).

$\dagger$ In the serpent Xenopeltis unicolor, a superior process of the stapes (suprastapedial) is ossified, and a separate element at the end of the bone (extrastapedial v. stylohyal ?) is also ossified. (See fig. 2.)

$\ddagger$ Fig. 2. -Ichthyosaurus; cranium; posterior view. Lettering the same as in fig. 1, with the following additions : -

B. O. . Basioccipital.

Ex. O. . Exoccipital.

Sup. O. Supraoccipital.
Op. O. . Opisthotic.

Stap. . . Suprastapedial, or hyomandibular. 
etal. (See figs. 2, 3, Sq.) Though it cannot yet be asserted that this is one primary element, yet in the adult Ichthyosaurus there is

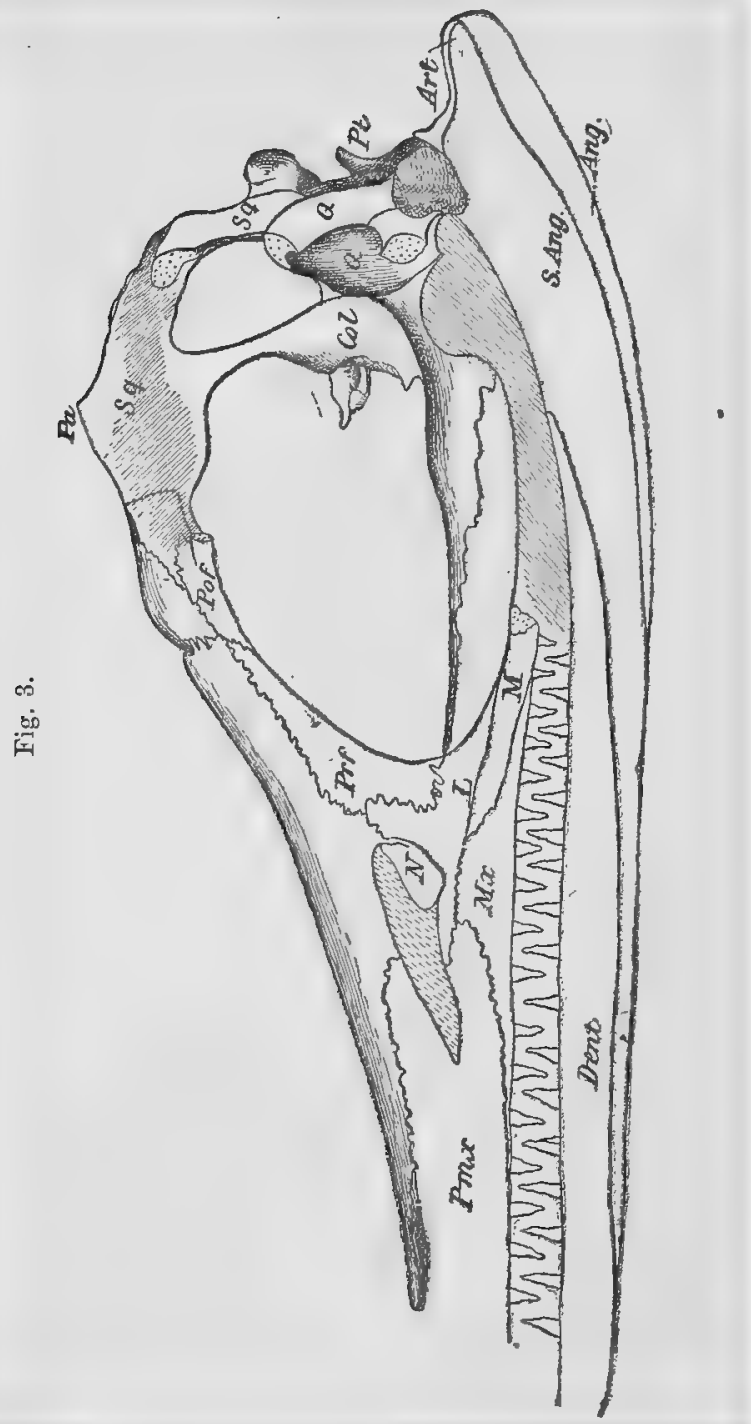

Cranium of Ichthyosaurus without arches.

Col, Columella. Pt, Pterygoid.

(The anterior extremity of the sphenoid is imperfect.) 
no line of division to be discovered.* It will be seen later that the same structure exists in the Anomodontia and Sphenodon. It is not impossible that its anterior portion will be found to represent the element in Teleostei, called by Huxley, perhaps by error, Squamosal.

Returning to the external arches, we find the zygomatic is partially vertical, owing to the large size of the orbit and the shortness of the posterior region of the cranium, and that it is extended by a supernumerary bone not found in the Mammalia, for which I adopt the name given by Owen in this genus, of postorbital. (Figs. $2,4,13, \mathrm{Pob}$.) It is the temporat of the Testudinata of Cuvier, and one of the postfrontals of the Lacertilia of the same author. It is most erroneously called quadratojugal by Stannius, and by Guinther, who follows him, in Sphenodon.

Anteriorly it articulates with the malar, here a long slender bone on account of the size of the orbit, and which, as usual, articulates anteriorly with the maxillary. Posteriorly the extent of the postorbital separates it from the squamosal, as is the case with some Lacertilia; while a short quadratojugal connects it with the quadratum, precisely as in the Crocodilia. This latter bone is the squamosal of Owen, who, on account of this erroneous determination, was compelled to apply a new name to the true squamosal, calling it "supratemporal." (See Palæontology, p. 198.)

Posterior to the postfrontal and postorbital, is an ovate bone connecting them with the squamosal. This is also peculiar to this order, and is the supersquamosal of Owen.

The postorbital arch is quite horizontal, and is composed of the postfrontal exclusively.

Turning to the superior aspect of the cranium, if we assume that the two posterior elements bounding the temporal fossæ are continuous with the squamosal, as has been above shown, there is no difficulty in determining the elements in front of them. Thus the undivided bone with large fontanelle near the posterior margin, bounding the squamosals anteriorly, would be the parietal. The posterior half of each of these bones is concealed by the anterior portion of the laminar squamosal as in Sphenodon: they descend. beneath the latter to a point a little before the line of the middle of the temporal fossa. It scarcely touches its fellow on the median line behind the fontanelle. The general shape of the bone is

* I have since found a suture in two of our Ichthyosaurus crania, and Dr. Seeley states that that is the normal structure.

A. A. A. S. VOL. XIX. 
square. Each half is united to the bone behind it, except at the median suture, by a double squamosal suture, the squamosal bone sending a plate below as well as above it. Medially the suture is single and serrate. Suspecting that the bone here determined to be parietal might possibly be fiontal, I searched for a bone posterior to it, beneath the prolongation of the squamosal, but without success. That the squamosal should contribute to the brain-case is apparently anomalous among Reptiles, though not among warmblooded Vertebrates; but if we suppose the anterior plate to be the epiotic the difficulty is much lessened.

It might be objected that the position of the fontanelle was rather in favor of the determination of this bone as frontal, since it is, as in the Lacertilia, pierced in its posterior margin, and therefore probably, as in that order, included between the frontal and parietal. But in reply it may be asserted that the position of the fontanelle in the two orders most nearly allied to the Ichthyopterygia - i.e., the Anomodontia and Rhynchocephalia - justifies the interpretation I have placed on this bone. Thus, in the former, it is pierced in the middle of the parietal with a suture extending from it to the occipital suture. In the latter it lies near the posterior margin of the parietal, so far as visible; for the latter bone is doubtless overlaid by the squamosals, as in Ichthyosaurus. Günther is probably correct in describing this median bone as parietal in Sphenodon.

The long paired bones, immediately anterior, which extend to near the middle of the muzzle, are the frontals. They extend to the premaxillaries, a junction only found in Reptiles with posterior nostrils, as Pythonomorpha, Varanidæ, etc., but common among Fishes. In Sphenodon the frontals are unusually produced in front.

Articulating with them on each side, and bounding the anterior and post and superior margins of the orbit, are the pre and postfrontals in their usual positions. The former almost excludes the latter from contact with the frontals, and leaves its connection with the parietal more extensive. Anterior to the frontals comes the elongate premaxillary. This of course bounds the nares in front; and as the latter are far removed posteriorly, in this order of Reptiles, the nasal bones have a posterior position also. The latter are much reduced in size, and have a very short suture with the frontals, being more extensively united with the lachrymal. They are entirely separated fiom each other by the anterior prolongation 
of the frontal, and are chiefly to be recognized by their position as roofing the nares posteriorly, and their connection with the frontal. In one of our crania I observe that they are absent.

The maxillary is much reduced, in connection with this position of the nares. It is separated from union with the prefrontal by the large lachrymal, which extends to both the frontal and the premaxillary.

Such a determination of the bones of the roof of the cranium differs materially from that of Cuvier and Owen. The former (Ossemens Fossiles, Tab. 257, figs. 1-5, and p. 103, V, 2 plates) laid a wrong basis by assuming the bones (figs. $2,3, \mathrm{Sq}$ ) to be the parietals: the parietals become then frontals, and the frontals are called nasals, the true nasals being entirely overlooked. Owen (Palæontology and Comp. Anat. Vertebrates) follows Cuvier in these points. Günther falls into error as regards the squamosal branches in Sphenodon, uniting them with the true parietal as parietals. The frontals he names correctly. The parietal in Sphenodon is shown by Günther's figure to be a simple medial element, as in Ichthyosaurus.

Having, however, observed a suture separating the squamosal from its supposed anterior plate in one young and one adult Ichthyosaurus cranium, it has occurred to me that possibly the specimen here described may have a coalescence of two elements really distinct. In that case the anterior bone will not be homologous with that in same position in Lystrosaurus, but may be, as usually stated, the parietal. The other bones in front of them would then retain their usual names, the supposed nasals $(n)$ remaining without determination.

Turning to the base of the cranium of Ichthyosaurus, we observe that the palatines and ectopterygoids are broad, flat bones, whose exterior margin is in contact with the maxillary and malar to opposite the posterior margin of the orbit, flooring the latter (fig. 3, Ectp). The pterygoids, on the other hand, contract abruptly behind this point, and support the columella. They then expand to a degree unusual in the Reptilia, and extend over the whole space between the basioccipital and the quadrate, joining both closely, and projecting behind their posterior plane. Its margin is recurved as far as the stapes ( $\mathrm{Pt}$, figs. 1, 2, 3).

The columella is very stout at its point of contact with the pterygoid, and above it; but higher it contracts much, and then expands anteriorly into the parietal branch of the? squamosal with 
which it seems to be continuous, as I cannot see any suture separating them.

The basis cranii is incomplete, and is formed of basioccipital and basisphenoid. The latter (Cuvier, Oss. Foss., Tab. 257, figs. $12,13)$ supports an alisphenoid on each side.

In considering the affinities of Ichthyosaurus as exhibited by the cranium, it may be premised that the structure of the limbs separates it as a very distinct order among Reptilia. The peculiar disposition of the squamosal is only paralleled among Anomodontia and Rhynchocephalia, and the character of the columella resembles only that of the former in its connections. The occipital elements have more the disposition of those of Sphenodon than of any other type, but there is a great difference in the position of the opisthotic. The arches are also those of the same genus, except that in the latter the quadratojugal is obsolete, or coössified with the malar. The structure of the front and base of the skull, and of the mandible, in Sphenodon, have no resemblance to those of Ichthyosaurus. The anteriorly unossified brain-case is that of several other Reptilian groups, while the presence of the alisphenoid furnishes a point of resemblance to the Crocodilia.

In general there are few points of affinity to the Crocodilia. The characters of the parietal bone are those of Sphenodon. The vertebra are intermediate between those of that genus and the Lacertilia, and those of the Anomodontia; for the capitular and tubercular processes are confluent on the former, and widely separated in the latter, the tubercular being elevated to the neural arch. In the Ichthyopterygia they are separated, but both are on the centrum.

Thus the Reptilian affinities are divided between the Anomodontia and Rhynchocephalia, and are not very close to either. They are much less with the Lacertilia, and still less with the Testudinata and Crocodilia.

There are some extra-reptilian indications worth observing. The most important of these is the great extent of the pterygoids backwards and inwards, paralleling only in this some Batrachia, e.g., Rana (fig. 21, Pt). The large size and form of the stapes are similar to that seen in Cœcilia. The posterior development of the squamosal is alluded to later, in the discussion of the homologies of that bone. 


\section{On the Cranium of the Anomodontia.}

The bones of the superior and palatal surfaces of the cranium of the genus Dicynodon have been described by Owen; and the structure of the internal walls of the palatal and nasal cavities, with the occipital and mandibular bones, have been described by Huxley, from the Ptychognathus murrayi. The relations of the elements of the lateral walls of the brain-case, and the attachment of the os quadratum, have, so far as I am aware, never been made out. As these points are of the first importance in determining the affinities of the Anomodontia, I take the favorable opportunity for elucidating them, furnished by the very complete cranium of the Lystrosaurus frontosus, Cope, kindly placed at my disposal by Dr. E. R. Beadle.*

The maxillaries articulate posteriorly and externally with the ectopterygoid bone. This is vertico-oblique in position, its depth twice as great as its length. The pterygoid, which articulates with it posteriorly, is seen laterally, a flat hour-glass shaped bone, the anterior extremity embracing the ectopterygoid by a superior and an inferior process, whose articular faces are at right angles with each other. The contracted portion presents a longitudinal external angle, which disappears on the posterior part of the maxillary. At this point the pterygoid is arched upwards and inwards: it is then deflected outwardly and downwards to the extremity of the quadratum.

The relations of the pterygoid to the bones forming the anterior walls of the brain-case are of much interest, and throw great light on the vexed question of the homologies of the columella of the Lacertilian and Rhynchocephalian Reptiles. The adjacent bones may be first described.

The presphenoid is a flat lamina with arched superior margin, resembling that of the Crocodilia. It extends forwards in this species to the line of the frontal tuberosity. The inward and upward expansion of the pterygoid behind its median contraction, already described, appears to be in contact with the inferior margin of the presphenoid. It is not likely that this expansion belongs to the presphenoid, though it is difficalt to perceive the suture. The expansion is subvertical. Posteriorly it expands backwards and outwards, forming the fundus of a deep subvertical groove, and unites suturally with the antero-interior margin of a bone,

* For description of this species, see Proceed. Am. Philos. Soc., 1870, p. 419. 
Fig. 4.
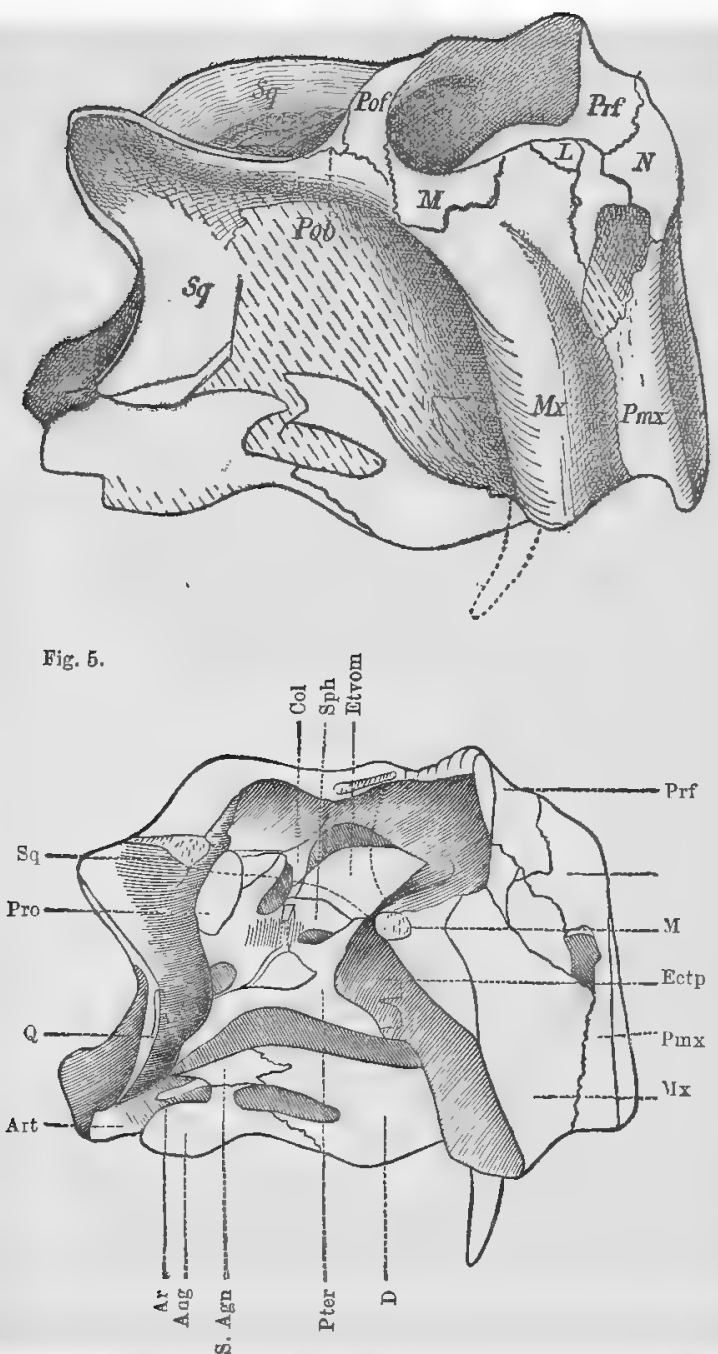

Figs. 4 and 5. - Iystrosaurus frontosus (from Cape Colony); profiles. (Fig. 5, diagram with arches removed.) Lettering as in figs. 1 and 2, with the following additions:-

Etrom. . Ethmovomerine.

Sph. ... Sphenoid.

Pro. ... Proötic.

Pter.... Pterygoid.
Col. .... Columella.

Ectp.... Ectopterygoid.

Subart. . Subarticular. 
which I suppose to be the proötic. From the anterior and more horizontal portion of the pterygoid expansion, a thin laminar bone rises, which presents an angle outwardly. Superiorly and inwardly it appears to be continuous with a slender prolongation of the anterior angle of the parietal plate already mentioned. Not suspecting its existence, I destroyed a portion of this rod, in removing the matrix ; but a piece from a point intermediate between the parietal and pterygoid extremities remains attached to the specimen in place. This element is, no doubt, the columella, whose existence in this group of Reptilia has not heretofore been suspected. It encloses a narrow vertical antero-posterior foramen with the presphenoid.

Two openings into the brain-case are visible: that between the parietal plates, common to most Reptilia, and the foramen, transmitting the fifth cranial nerve, the combined foramina ovale and rotundum. Another foramen is enclosed between the pterygoid and the element which bounds the proötic in front and below. A narrow bone with rounded edge extends from the superior origin of the columella, downwards and outwards to the proötic, bounding the foramen ovale above. It resembles the rod-like projection of the columella of Testudinata (see fig. 5), but that is below, not above, the foramen.

The exact composition of the suspensoria of the os quadratum is a little difficult to determine, owing to the obscurity of the sutures. The posterior parietal arches (fig. 7, $\mathrm{Pa}$ ) are narrow and short, the posterior boundaries of the temporal fossa being chiefly formed by the squamosals. The latter commence on each side of the parietals, a little behind the anterior extremity, and form the overhanging margin of the temporal fossa, inwardly as well as posteriorly. The posterior plate of the parietal on each side is proximally enclosed between the squamosal and supraoccipital, then between the former and a thin laminiform bone, which extends laterally from the supraoccipital, and above the exoccipital. It is in contact with the squamosal for most of its length, but does not extend to opposite the zygomatic arch, and of course not to the os quadratum. This element, in spite of its exclusion from articulation with the quadratum, appears to be homologous with that which in Iguana extends from the same position to that articulation, and which is evidently homologous with the opisthotic of the Testudinata.

The squamosal is very largely developed in Lystrosaurus. Con- 
tinuing round the temporal fossa, it sends forwards the usual zygomatic arch, and - what is noteworthy - unites with both postfiontal and malar, leaving the usual tripodal supplementary postorbital as a wedge-shaped plate, bounding the antero-inferior angle of the temporal fossa. The squamosal continues without interruption to the inferior extremity of the quadratum, concealing the latter entirely on a posterior view. I find no suture separating it from the superior portion already described, on either side of the cranium; and on reference to Owen's figure of Ptychognathus declivis, ${ }^{*}$ I find that he found them continuous in that species. He calls this element the "masto-tympanic," which would be the Cuvierian nomenclature for opisthotic-quadrate of modern anatomists. I find, however, that it does not include the quadrate which is situated immediately anterior to it, and does not appear to contain the opisthotic, which, as already described, is distinct. It is in fact figured by $\mathrm{O}$ wen in $\mathrm{Pt}$. declivis, and named parietal, the close squamosal suture separating it from the posterior arches of the latter bone not having been detected.

When the supposed quadrate bone is fractured, it is found to consist of two vertical plates, of which the anterior bears the narrow transverse articular face for the mandible, excluding the posterior one. This I take to be the os quadratum. Its width is not so great as that of the posterior plate or squamosal, and it does not ascend much more than half way to the zygomatic arch. Its superior margin appears to be received by the margin of the thicker superior portion of the squamosal, which somewhat overhangs it. I cannot trace its inner margin. A descending portion of the inner face of the squamosal approaches very near the posterior part of the pterygoid, and it is doubtful whether the quadratum extends interior to this point. The bony wall which appears below the proötic has been already alluded to as continuous with the pterygoid expansion, but it may represent the lateral processes of the sphenoid, or even part of the alisphenoid.

The squamosal or parietal sends down on each side a vertical plate, which terminates in a slender bony prolongation from its anterior margin. The plate is subquadrate, and twice as deep as wide antero-posteriorly. The osseous ethmovomerine septum extends posteriorly to between the anterior margins of these laminæ, and is prolonged inferiorly to the presphenoid, the suture with the latter extending beyond the anterior line of the above-mentioned

* In Proceed. Geol. Soc., Lond., xiv., Tab. 1. 
laminæ. I can find no suture separating these plates from the squamosal above, and am therefore disposed to doubt whether they do not belong to these rather than to the parietals.

The ? epiotic is a subovate bone with truncate extremities, which has its long axis directed upwards and inwards. It is in contact with the parietal and the descending anterior plate of the squamosal, and inferiorly with the bone described in the next paragraph as proötic. It occupies a position similar to that seen in Sphenodon, excepting that it does not appear to extend to the quadratum. It might be questioned whether this bone is not really the proötic. The element below and anterior to it (fig. 5, Pro) is emarginated for the exit of the fifth nerve (V); and though I cannot find its inferior borders, and the portion behind the above foramen is narrow, it appears to me to answer more nearly to the proötic of

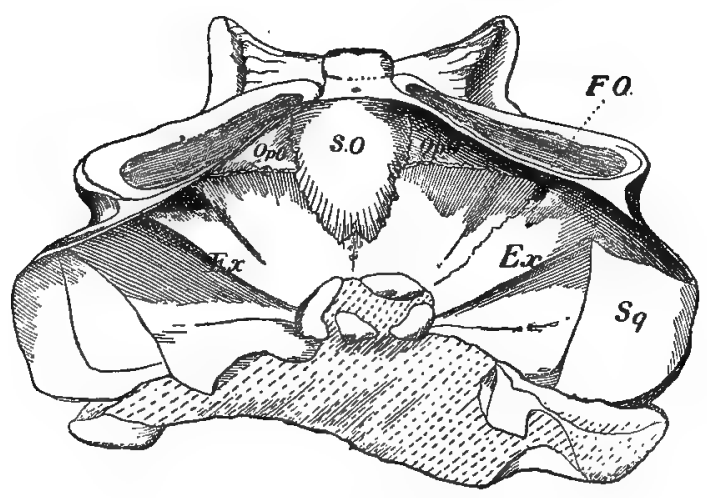

Fig. 6. - (Cranium from behind.)

Lacertilia than to an alisphenoid, which it would otherwise be. This is the more probable, in view of the fact that the supposed epiotic has its counterpart in Sphenodon, in which case this must be proötic.

The fenestra ovale (fig. 6, FO) is not readily discovered, but appears to be represented by a rather small oval foramen-like emargination of the exoccipital. It is situated just within the quadrate plate of the squamosal, and beneath the zygomatic process. I find no stapes. If it existed, it extended outwards beneath the overhanging margin of the squamosal, on the plane of the superior margin of the os quadratum.

A. A. A. S. VOL. XIX. 
Turning now to those portions of the cranium which are better known in allied species, I find the exoccipitals undivided, as did Owen in Pt. declivis, and Huxley in Pt. murrayi. I do not even find a median suture separating that of the right side from the left. Each presents a strong rib extending to opposite the zygomatic arch. The inferior portion is a subtriangular plate, continuous superiorly with the rib just mentioned. It is also raised

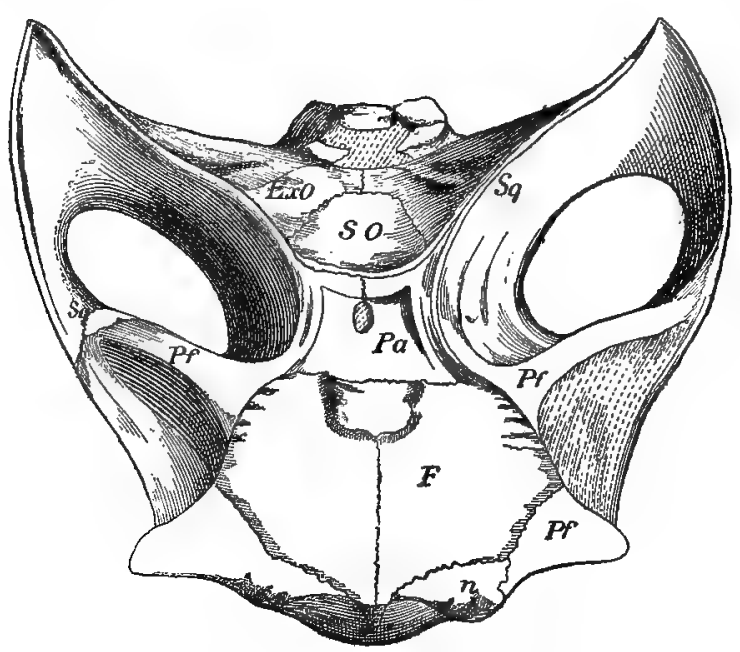

Fig. 7. - (Cranium from above.)

Lystrosaurus frontosus. (Lettering as in figs. 1 and 2.)

on the median line, and the inferior outline is concave and directed. downwards. The supraoccipital is vertically ovate, and separated from the parietals by squamosal sutures. It does not reach inferiorly to the occipital foramen.

The parietals viewed from above form together a subquadrate plate, with the angles much prolonged; the anterior broadly to the postfrontals; the posterior as laminæ between the squamosals and opisthotics forming the parieto-squamosal arch. They embrace a rather large fontanelle, from which the median suture is distinct posteriorly, but invisible anteriorly.

The frontals are marked posteriorly by a large tuberosity, which bounds inwardly a concave surface on each side between it and the raised margins of the orbits. These margins are continued poste- 
riorly. This raised margin is turned inwards above the postfrontals, giving the orbits a slight postero-superior notch, which is much less developed than in Pt. declivis, according to Owen's description: It is slightly rugose in consequence of transverse grooves. They are prolonged into the prefrontal tuberosities, which are very large, more developed than in any other species, resembling rudimental horns. They present a sharp edge outwardly, as the front margin of the orbits and the superior and anterior planes are at right angles to each other. The middle line of the front, descending more gradually, causes the angle between it and the premaxillary to be rather more open.

The premaxillary region is remarkably contracted; and its length from the front is about equal to the distance between the prefrontal horns, producing a T-shaped outline. the middle line it presents a high laminar keel, which separates two parallel sulci. These extend to the end of the muzzle, and are bounded externally by a strong longitudinal angle. The external face of the maxillary is occupied by a wider longitudinal concavity parallel to the last. The posterior angle of the bone flares

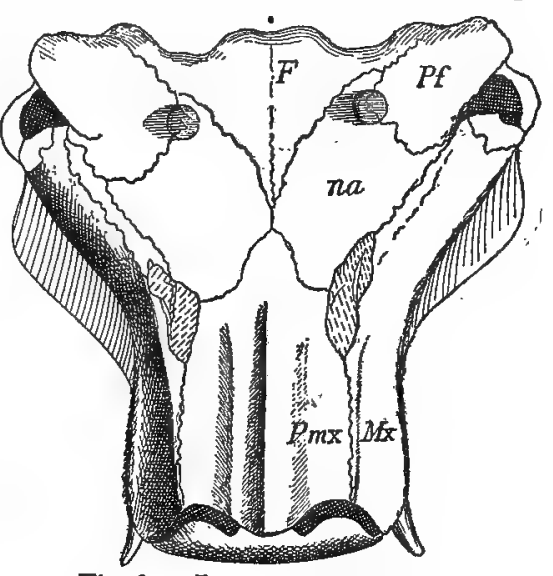

Fig. 8. - Lystrosaurus frontosus.

(Lettering as in fig. 1.) out behind it. The posterior (superior) "spine" of the premaxillary extends far between the nasals, and nearly to the anterior prolongation of the frontal.

The nasals are prominent, each presenting a low boss forwards, which enclose a concavity on each side with the tuberosity of the premaxillary spine. They overhang the nares superiorly.

The lachrymal is a small bone intercalated between the prefrontal and the maxillary. In front of and below it, a larger bone extends to the nostril, constituting the principal part of its posterior boundary. This bone is described by Owen in the Pt. latifrons. Its homologies are not determined.

The alveolar margin of the upper jaw is undulating, presenting a short median beak-like prominence, then a concavity, and poste- 
riorly a convexity to the tusk. The edge of the mandibular arch is correlated between these cutting edges, but its extremity is three-lobed. These lobes correspond to three grooves within the premaxillary portion of the edge of the jaw, which are separated by two ridges. The section of the tusks is cylindric, and where broken, at the alveolar margin, the pulp cavity is minute.

The malar bone is small, and of a subtriangular form, one apex being posterior. The antero-superior angle extends to the lachrymal, thus excluding the maxillary from the circumference of the orbit.

The dentary bone extends far posteriorly, and forms the greater part of the circumference of a longitudinal foramen, which pierces the middle of the ramus. The angular is prolonged into a keellike plate below, which is truncate behind, and rises gradually anteriorly. Its margin, which articulates with the articular, is cut out by a deep foramen.

The angular and articular bones are both horizontal. The coronoid appears to be broken off, interior, or wanting. The angular extends to the symphysis.*

The palatal surface is not exposed.

\section{Affinities of the Anomodontia.}

The attachment of the os quadratum, with the Mammalian type of rib articulation, and the elongate sacrum, induced me to regard the Anomodontia as a subgroup of the Archosauria. The absence of the quadratojugal arch, usual in the latter order, and the lack of information respecting the mode of attachment of the os quadratum, rendered it probable that the group was aberrant, or even not properly referable to it. The extension of the exoccipital bones, so as to close the parieto-squamosal arch, is found among Lacertilia in the Stenodactylus guttatus, and a very few other species; but its extension to the quadratum below the proximal articulation does not occur.

The immovable articulation of the quadratum throughout its length to the squamosal, and by its whole inner margin (as I suspect, but cannot see without too much injury to the specimen) to the exoccipital, removes the Anomodontia from the Lacertilia, and associates them with the Archosauria, in accordance with the indications furnished by the ribs, sacrum, etc. The withdrawal of

* See Trans. Amer. Pinilos. Soc., 1869, pp. 27, 33. 
the proötics and opisthotics from its support constitutes a step towards the liberation of the quadratum, and places it nearest the Lacertilia, in the order. This indication is confirmed by the simple premaxillary bone, and the lack of quadratojugal arch.

Among Lacertilia, the Chamæleontidæ make the nearest approach, though a remote one. This is seen in the posterior prolongation of the dentary bone, and the often rudimental dentition.

The nearest approach outside the Archosauria is to the Rhynchocephalia, as represented by the existing genus, Sphenodon.* Here the canine teeth begin to show an increased development, and the other teeth to become obsolete or confluent. The nearest approach to the great development of the squamosal in Anomodontia is seen in this genus, and they both possess an ossified septum orbitorum. In both, the posterior extremity of the pterygoid is much expanded, and supports a columella.

In summing up, the following significance may be attached to the above characters. From this it will be seen that the Anomodontia present a remarkable combination, and well deserve the appellation of a "generalized type." Characters of Crocodilia are: 1. Presphenoid keel; 2. Expanse of pterygoid to unite with it; 3. Foramen of the mandible; 4. Reduction of, zygomatic bone. Testudinata: 1. Edentulous jaws; 2. Coössified mandibular rami, with foramen. Rhynchocephalia: 1. Largely developed squamosal; 2. Osseous interorbital septum; 3. Distinct ? epiotic; 4. Biconcave vertebre; 5. Columella; 6. Foramen parietale; - the last two belonging 'also to the Lacertilia, which have further in common with Lystrosaurus: 1. Absence of quadratojugal arch; 2. Simple premaxillary bone (mostly).

Ichthyopterygia: 1. Parietal and quadrate branches of squamosal ; 2. Sessile suspensorium of quadrate; 3. Posterior flat opisthotic.

Dinosauria: 1. Elongate sacrum; 2. Ribs continued to sacrum; 3. Capitular and tubercular attachment for ribs on neural arch and centrum, respectively.

From the preceding evidence, it is clear that the Anomodontia constitute the most generalized order of Reptilia of which we have any knowledge; and occupying, as it does, almost the first or oldest place in geologic time among the Reptilia, - i. e., in the Triassic period,-it justifies the statement that the peculiarly older 
forms of life are the more generalized in structure than the later, and that this generalization is increasingly evident the further back we carry our inquiries.

\section{On the Homologies of the Opisthotic Bone.}

This elcment, distinguished by Huxley from those which compose with it the "temporal bone" of anthropotomists, has been called "mastoid" by Owen, and "external occipital" and "mastoid" by Cuvier.

Its position is exterior to the exoccipital, posterior to the proötic, and beneath and behind the squamosal.

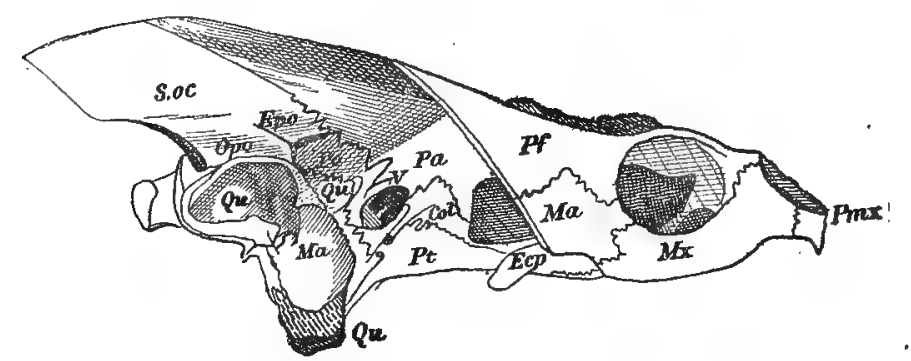

Fig. 9. - Chelydra serpentina ; cranium, with squamosal and postorbital bones removed. Epo, Epiotic; Pro, or Po, Proötic. Ma, Meatus Auditorius. Ecp, Ectopterygoid. V, Foramen ovale.

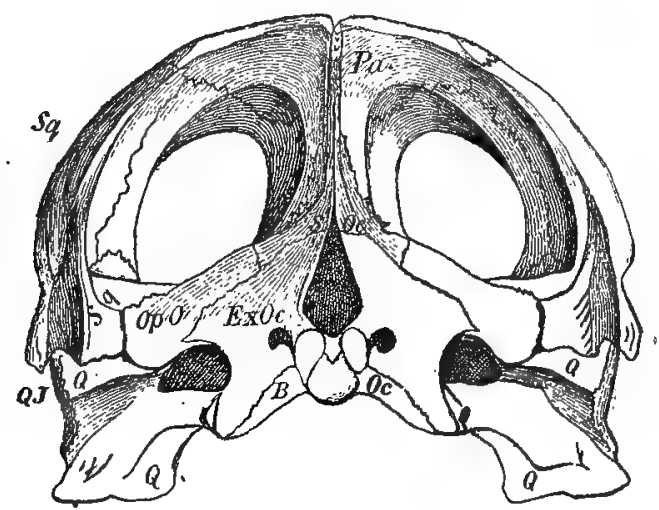

Fig. 10. - Chelone midas; cranium from behind. (Lettering as in fig. 2.) 
In Mammalia it is confluent with the elements mentioned, remaining distinct from the exoccipital, and forming part of the "mastoid and petrous portions of the temporal." (Huxley.)

In Aves it is early confluent with the exoccipital. (Parker.)

In Reptilia it is distinct in all the orders except the Crocodilia, where it is confluent with the exoccipital. (Fig. 11, Exo.)

This group resembles the higher vertebrates in the close union of the quadratum with the proötic and other cranial bones; and we pursue the line of extreme Reptilian divergence in following the gradual removal of the quadrate from the cranial walls, on the

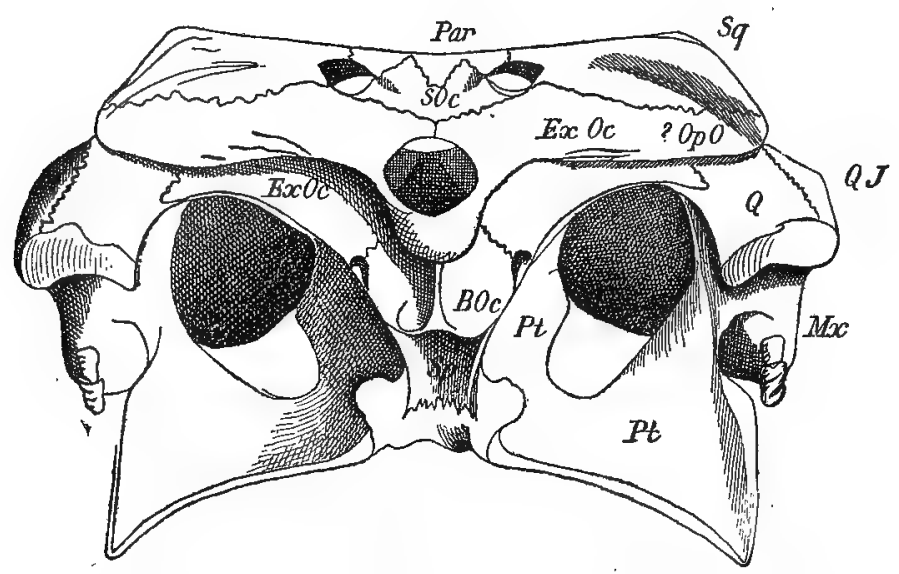

Fig 11. - Alligator mississippiensis ; cranium from behind.

extremity of a suspending cylinder, which reaches its highest expression in the Ophidia. First in this succession comes the separation of the opisthotic.

We have already seen its position in Ichthyopterygia (fig. 1, Opo) where it is peculiar in separation from the supraoccipital and connection with the basioccipital. We have also seen an element in the Anomodontia identified with it (fig. 6, Opo) which differs in its connections, by being attached to the supraoccipital and exoccipital only.

Passing to the Testudinata, the element maintains the same connections, with the addition of that with (fig. 10, Opo) the proötic anteriorly, and is extended externally over the proximal extremity of the quadratum, a connection not observed in the types just described. 
If we now turn to the Rhynchocephalia, as represented by Sphenodon,* we find the exoccipital greatly prolonged laterally, and carrying with it the opisthotic. It is carried apparently beyond any connection with the proötic (alisphenoid of Günther), but is less distant from the supraocipital, or rather the epiotic (paroccipital, Günther), which is here, according to Günther, not entirely separated from the supraoccipital, as in the Testudinata, though more so than in the latter. Its superior and anterior extent is remarkable in this geuus, forming a connection with the postorbital above and the malar below, peculiarities not noticed in any other reptile. Superiorly it rises into the parieto-quadrate arch, which it forms with the squamosal, the parietal not entering it; another peculiarity, the only parallel to which is to be found in the Anomodontia, where this arch is however depressed into close contact with the occipital segment of the skull.

The type exhibited by the Lacertilia is intermediate between that of the last and that of the Tortoises, and serves to reconcile

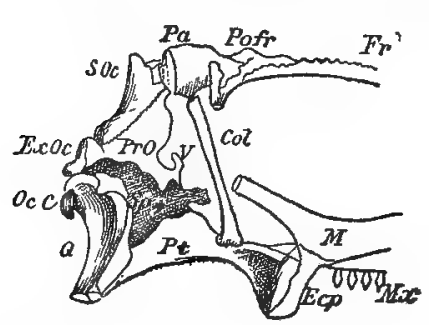

Fig. 12. - Iguana tuberculata; posterior arches removed.

them. Here, also, the opisthotic is carried beyond connection with the other otic elements. In Iguana it contributes largely to the formation of the parieto-quadrate arch, but with the parietal instead of the squamosal, and on the under instead of the upper side, as in the genus Sphenodon. (See figs. 13, 14, OpO.) In Chamæleo it is a mere wedge articulating with the proximal end of the quadratum, and not entering into the parieto-quadrate arch.

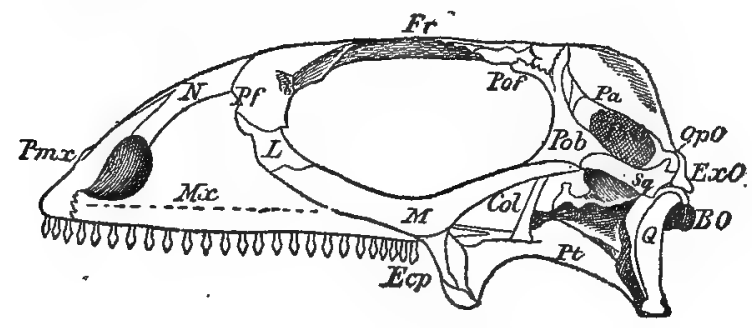

Fig. 13. - Iguana tuberculata; lateral view, with arches.

* I rely on the figures and descriptions of Günther, in his paper on the Anatomy of Hatteria (Philos. Trans., London, 1867). 
In the Pythonomorpha its character as "suspensorium" of the quadrate is still more pronounced; yet, though it forms part of a cylindric bar extended transversely from the brain-case, it maintains a sutural union with the proötic (see fig. 15, OpO), and to a slight degree in Clidastes, with the supraoccipital, or ? epiotic portion of it. If there

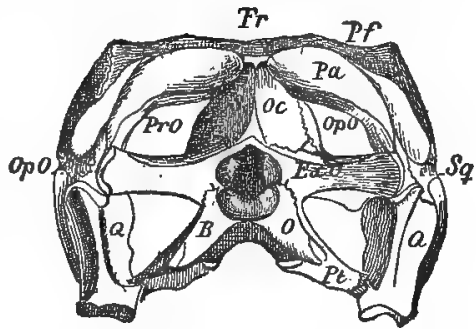

Fig. 14. - Iguana, from behind. be any parieto-quadrate arch (a doubtful point), it probably enters into it posteriorly.

In the Ophidia it exhibits an important range of variation. I have not been able to find it in Typhlops.* In Cylindrophis it is

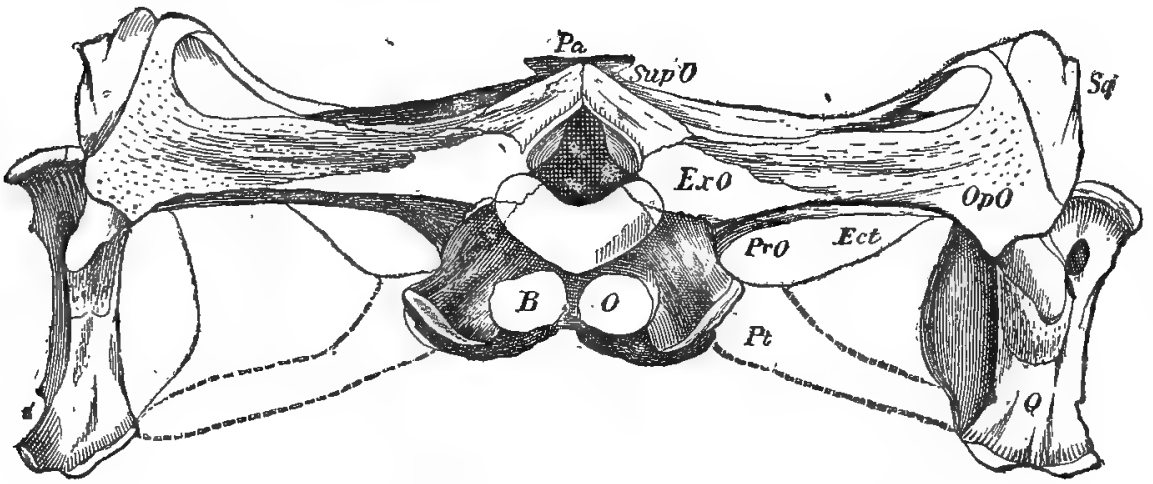

Fig. 15. - Clidastes propython, Cope; cranium from behind.

enclosed as usual between the exoccipital behind, the proötic anteriorly and inferiorly, the parietal above, and a small area enclosed between the latter and the exoccipital, which is either the extremity of the supraoccipital or a distinct element, perhaps epiotic. (See fig. 16: BO, Basioccipi-

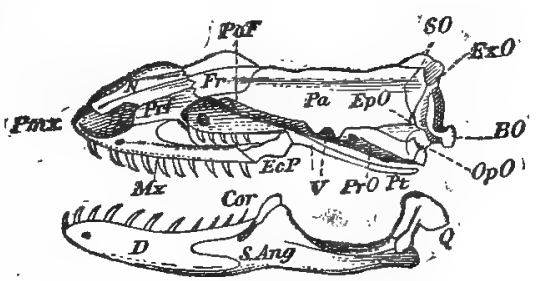

Fig. 16. - Cylindrophis rufa,

* In an osteological system of the scaled Reptilia, published in "Proceedings of the Academy of Natural Science," Phila., 1864, p. 224, an error occurs, in A. A. A. S. VOL. XIX. 
tal; ExO, Exoccipital; SO, Supraoccipital; OpO, Opisthotic; PrO, Proötic ; EpO, Epiotic ; Fr, Frontal ; PoF, Postfrontal ; Prf, Prefron-

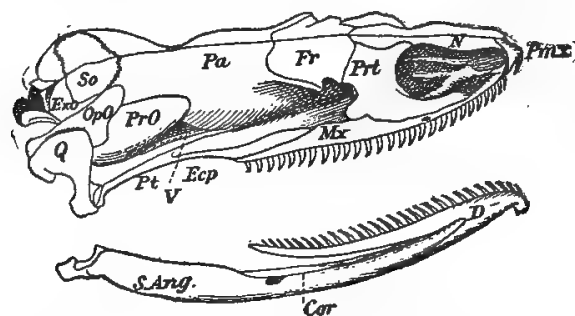

Fig. 17. - Xenopeltis unicolor (Siam). frontal; N, Nasal ; Pmx, Premaxillary; Mx, Maxillary; Ecp, Ectopterygoid; Q, Quadrate; Art, Articular; Cor, Coronoid; D, Dentary; V, Foramen ovale.) The obtuse extremities of the opisthotic and exoccipital support together the os quadratum.

In the rather more specialized Xenopeltis, the opisthotic is no longer intercalated between the proötic and exoccipital, but lies over the common suture of the two, united by a squamosal suture. This important change transfers us from the Tortricina to the Asinea, as defined by Müller. (See fig. 17, OpO.) Throughout the latter suborder it only increases in length, which prolongation reaches its highest expression in the venomous serpents of the. suborder Solenoglypha. It has been homologized with the squamosal in these groups by Huxley (Elements of Comparative Anatomy), but incorrectly, as I believe, and attempt to show in considering that bone.

Among the Batrachia this element is not distinct, except in Necturus. (See fig. 22, posterior view of cranium of Rana mugiens.) I have failed to find it entirely distinct in larvæ of various ages of Amblystoma, Spelerpes, and Gyrinophilus; for though a suture from the fenestra ovale to the foramen condyloideum sepa-

which I say in the definition of the Scolecophidia, p. 230, "no prefrontal." This should have read " no opisthotic." The prefrontal is largely developed in Typhlops, while the maxillary is much reduced, and concealed on the inferior face of the cranium alongside the vomers. In the portion devoted to the Lacertilia, p. 225, several expressions occur which need explanation, owing to the fact that the homologies of some of the elements were not at that time worked out. Thus the "temporal bone" is the proötic, and the "mastoid" is the opisthotic. I nust also correct the nomenclature of the elements of the mandible here, and in Clidastes, as published in Trans. Amer. Philos. Soc., 1870, pp. 214-16. Angular should read articular, articular should read surangular, and subarticular should read angular. In cut 51, figs. 3 and 5 belong to one bone, which is the angular. 
rates it inferiorly from the exoccipital in several species, the superior suture is wanting or invisible.

The opisthotic is known to be distinct in osseous Ganoids and Teleostei.

\section{On the Homologies of the Squamosal Bone.}

As this bone derives its name from its Mammalian representative, it will be well to trace it from that class. It may be defined as the bone which occupies the space between the proötic in front, the opisthotic behind, and the parietal above, which subtends the auricular bones or meatus superiorly, and forms the posterior extremity of the zygomatic arch.

In the Birds the zygomatic arch does not exist, and the malleus is produced from beneath it, as the os quadratum, for the support of the mandible (Parker).* Here then it first assumes the position of the external shield of the quadrate, which it continues to hold. throughout the series of Vertebrata below this point.

In tracing its homologies in the Reptilia, we commence with those in which the quadrate is most nearly sessile on the cranium, as in the Birds, and proceed towards those in which the latter is supported at the extremity of a prolongation of the posterior elements of the cranium, or a "suspensorium."

I may add here that the former relation of the quadrate, being most similar to that found in both the Birds and the Stegocephalous, and other tailed Batrachia, is the most generalized;

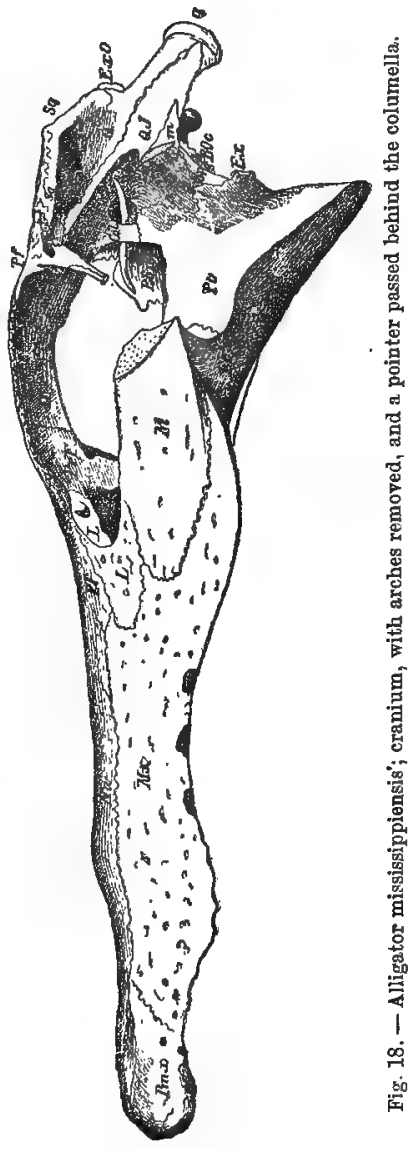

* On the Development of the Skull in the Ostrich Tribe (Philos. Trans., London, 1865, p. 113). 
while the suspensorial type is the most divergent from other Verte-

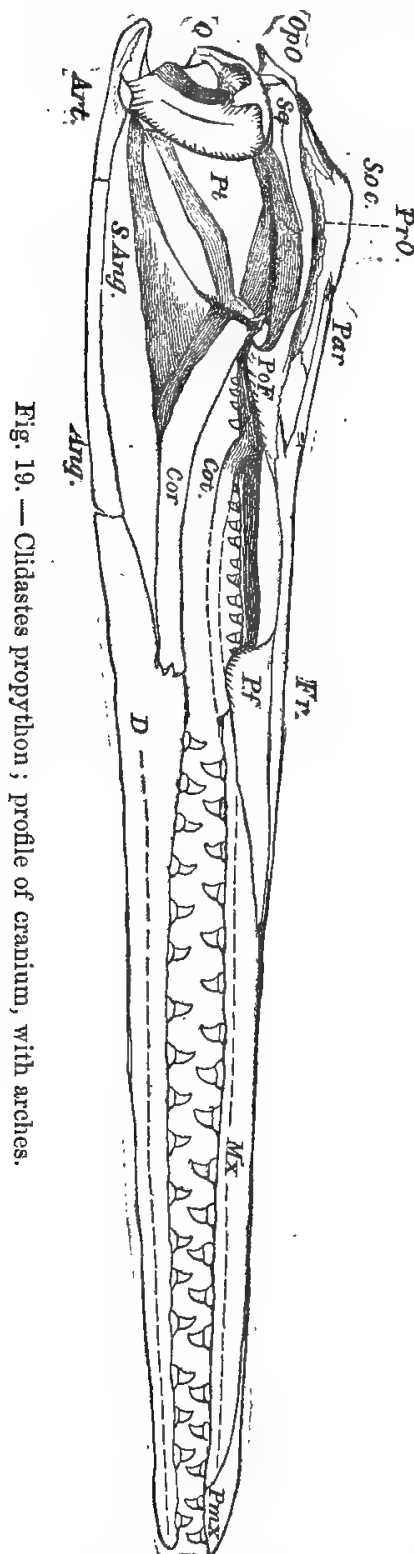
brata, and most specialized. Hence the successional relation of the orders of Reptilia is to be estimated by reference to their degree of approximation to either of these extremes, as will be considered further on.

If we seek for that element, in the Crocodilia, which fulfils the requisites of the squamosal as above defined, we find it on the posterior superior lateral angle of the cranium. (See fig. 18, Sq.) It sends forwards an anterior process, which completes the zygomatic arch posteriorly, and with the postfrontal (Pf) bone encloses the temporal fossa. As its union with the quadratum is on the under side of the latter, it is concealed from view in fig. 18, chiefly by the superior prolongation of the quadratojugal (QJ).

In the Testudinata, the quadrate being removed from the cranial walls, the position of the squamosal is more exterior. (Fig. 10, Sq.) In Chelone, it sends an extension upwards to the parietal, forming the parieto-quadrate arch, which is not observed in most other Testudinata. The enclosed space is much more expanded than in Crocodilia (fig. 11), where it is in fact reduced to a foramen above each supraoccipital.

The position of the squamosal in the Pythonomorpha is very similar to that seen in the last order, but it is further removed from the cranial walls (fig. 19, $\mathrm{Sq}$ ), in consequence of the greater length of the suspensorium.

In the Lacertilia it is carried far from the cranial walls by the increased length of the exoccipital, from 
which, as in the Testudinata, the opisthotic separates it. (See figs. $13,14, \mathrm{Sq}$.$) In most of the order it has no contact with the parie-$ tal, the parieto-quadrate arch being supported below by the opisthotic, as above pointed out. But in the Rhiptoglossa (Chamæleo) the squamosal sends a long process upwards, which meets a prolongation of the parietal, which is however single and median, and not bifurcate as is usual. The opisthotic does not rise with it. In the Ophiosauri (Amphisbænia), it appears to be wanting, as Müller has already indicated; and there are various stages of reduction to be observed among the Typhlophthalm lizards which approach them.* In the Aniellidæ it is wanting, while it exists in a rudimental state in the Acontiadidx. (Fig. 20, Ramus mandibuli, quadrate, and suspensorium of Acontias meleagris, Sq.)

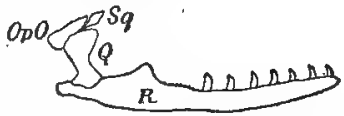

Fig. 20.-Acontias meleagris, $\mathbf{B}$. Africa; mandible and suspensorium.

In the Ophidia the squamosal is obvionsly wanting. This is proven in two ways: first, by the serial homology of the opisthotic, from Lacertilia through Pythonomorpha (fig. 15), or Tortricina (fig. 16), with the single suspensorium of the quadrate in typical snakes; and, second, by the successive diminution of the squamosal in the Lacertilia from the Leptoglossa through the Typhlophthalmi, where it is rudimental in Acontias (fig. 19), and wanting in Aniella, and in the succeeding group of Amphisbænia. Therefore its identification with the suspensorium in Ophidia, proposed by IIuxley, must be abandoned. $\dagger$

Returning to the earlier types of Reptilia, we may recall the features of the squamosal already ascribed to the Ichthyopterygia and Anomodontia. The first peculiar feature, the anterior prolongation on each side of the cranium, on the inside of the temporal fossa, separating widely the supraoccipital and parietal, was shown to exist also in the Rhynchocephalia. The question of the real pertinence of this prolongation to the squamosal may be raised, as it is remote from the position of that bone in most of the Lacertilia, and in some specimens of Ichthyosaurus is separated by suture from it. Its relations in Chamæleo throw much light on the point, and render it highly probable that the cranial prolongation in the three groups just mentioned is really continuous with it. As pointed out above, the squamosal in Chamæleo extends inwards to the parietal, forming the greater part of the parieto-quadrate

* See Essay on Primary Groups of Reptilia Squamata (Proceedings Academy of Natural Science, Phila., 1864, p. 230).

† See, on Pythonomorpha, Trans. Am. Philos. Soc., 1869, p. 178. 
arch, as in Ichthyosaurus and Lystrosaurus, differing only in its elevation above the occipital elements as an arch, instead of being closely depressed upon them. It has been already suggested in this essay, that this portion may include the epiotic element.

The second peculiarity is observed in Sphenodon, and is quite unparalleled. This is that the opisthotic expands over the external face of the squamosal, concealing it from outside view, and occupies the greater part of the posterior face of the parieto-quadrate arch. Its position suggests at first the inquiry whether the identification of the two elements here adopted is not the reverse of the true one. The relations of the opisthotic to the exoccipital are, however, as elsewhere; while the squamosal forms the inner side of the zygomatic arch behind, and occupies in part the position seen in Lystrosaurus.

The third peculiarity already described is the posterior inferior production of the squamosal in Ichthyosaurus and Lystrosaurus. In the latter it is very remarkable, and covers the outer side of the quadrate completely.

The last feature is alluded to for the purpose of carrying the homology of the squamosal into the Batrachia. Huxley

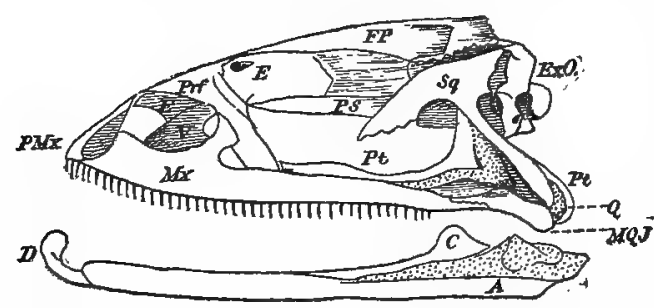

Fig. 21. - Cranium of Rana mugiens; profile. (Elements Comparative Anatomy) does not allow himself to compare any element in that class with this bone in the Reptilia, and, alluding to the "tympanique" ( $\mathrm{Cu}-$ vier) of the frog, says it is too different from the squamosal to be compared with it. If, however, he had had the cranial structure of Lystrosauruis, he could no longer have doubted, but would have homologized them at once. (Figs. 21, 23, Sq.) Dr. W. K. Parker has ventured on this step, and identified the squamosal in the Batrachia,

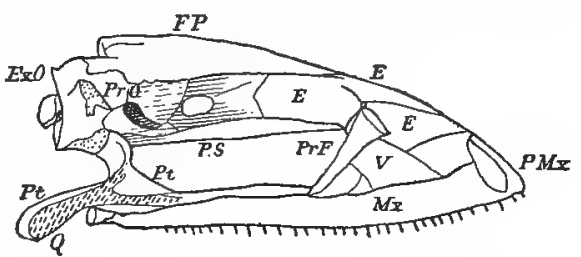

Fig. 22. - Same, with squamosal, prefrontal, and maloquadratojugal (MQ.J) removed. P.S, Parasphein accordance with the noid; V, Vomer; E, Ethmoid.

* See London Philos. Trans., 1865, p. 162. 
The quadratum, cartilaginous in the Anura, is osseous in the Urodela, and is obviously represented by a bone beneath the preoperculum of the Dipnoi, which, as Huxley has shown, is distinct from the latter. The preoperculum is here obviously the squamosal of Amphiuma and other Urodela (fig. 23,

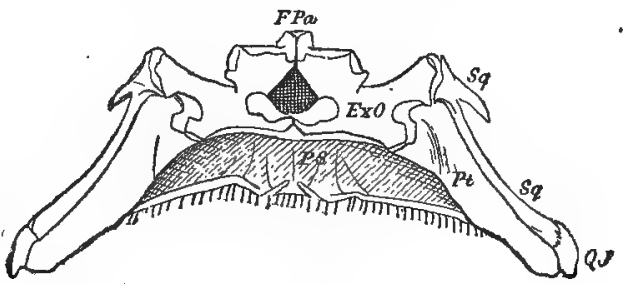

Fig. 23.

$\mathrm{Sq}$ ), so that we now have determined the identity of the reptile squamosal with the preoperculum of the bony fish. And, more, it

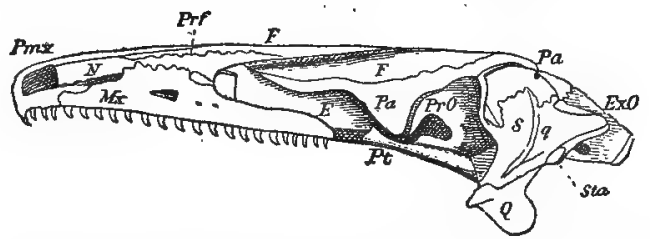

Fig. 24. - Amphiuma means (from Georgia); profile of cranium.

appears to be demonstrated that the squamosal portion of the temporal bone of the Mammal is the preoperculum of that type.*

\section{On the Homologies of the Columella.}

With regard to the character of the Reptilian columella, the following conclusions seem to be indicated by a study of the crania of Crocodilus, Lystrosaurus, Chelydra, and Iguana. There are two modes in which the parietal arch is completed laterally among Reptilia. The usual mode among Vertebrates is where an alisphenoid connects the parietal and sphenoid bones. This characterizes the Crocodilia and Pythonomorpha. $\dagger$ In the second mode, the peculiar bone called the columella stands pillarlike on the pterygoid, supporting the parietal (in Gecconidre not reaching the latter). This arrangement characterizes the Lacertilia, where the alisphenoid is entirely absent. In the Ophidia and Testudinata, the parietal sends down a plate-like border or process on each side, which in the latter articulates with a flat bone, which

* The bone homologized by Huxley (Elem. Comp. Anat., figs. 69-73, Sq) with the squamosal in the Telosei must, if the above determination be correct, have another interpretation.

$\uparrow$ The decurved margin of the parietal takes its place in the Ophidia. 
is in like manner united with the pterygoid.* The latter bone is longer than deep (see fig. 9, Col), and very different from the columella of Lacertilia, though its position would render it probable that it represents that bone. The existence of the parietal or squamosal plates in Lystrosaurus, continuous with a veritable columella, which rests by a laminiform extremity on the pterygoids, confirms the position that the Chelonia, like the Lacertilia, possesses a columella.

In Lystrosaurus (fig. 5, Col), the structure is analogous to that of the Crocodilia, already described. The continuity of the inner margin of the pterygoids with the presphenoid and sphenoid is common to both orders. From a position on this part of the pterygoid, in the genus Alligator, there rises, exactly as in Lystrosaurus, an osseous style. (Fig. 18, Col.) It is in front of the foramen ovale, and is separated from the alisphenoid by a narrow foramen, which opens anteriorly. Above the latter it is coössified in adult age with the superior part of the alisphenoid, and both together meet the lateral portion of the parietal, which here descends much less than in Testudinata, forming only a ridge. I regard the short column of Alligator, above mentioned, as functionally the columella.

In the Lacertilia and Rhynchocephalia, the columella is not continuous above with any determinable element. (Fig. 12, Col.)

In the Ichthyopterygia, it is continuous above with the parietal extension of the squamosal. (Fig. 3, Col.)

It appears, therefore, that there are at least four modes of origin of the superior extremity of the columella; viz.:-

Confluent with epiotic or parietal, - Ichthyopterygia, ? Anomodontia.

Confluent with alisphenoid, - Crocodilia.

Suturally united with parietal, - Testudinata.

Approaching or touching parietal without suture, - Lacertilia, Rhynchocephalia.

The first two types cannot therefore be homologized with each other, nor the second with the third and fourth. The latter two forms of columella are probably homologous.

Having reviewed the homologies of the opisthotic, squamosal, and columellar bones, I append a table of their synonyones, with those of a few others.

* This bone is overlooked by Stannius, who says the parietal plates rest on the pterygoids. 
ZOÖLOGY.

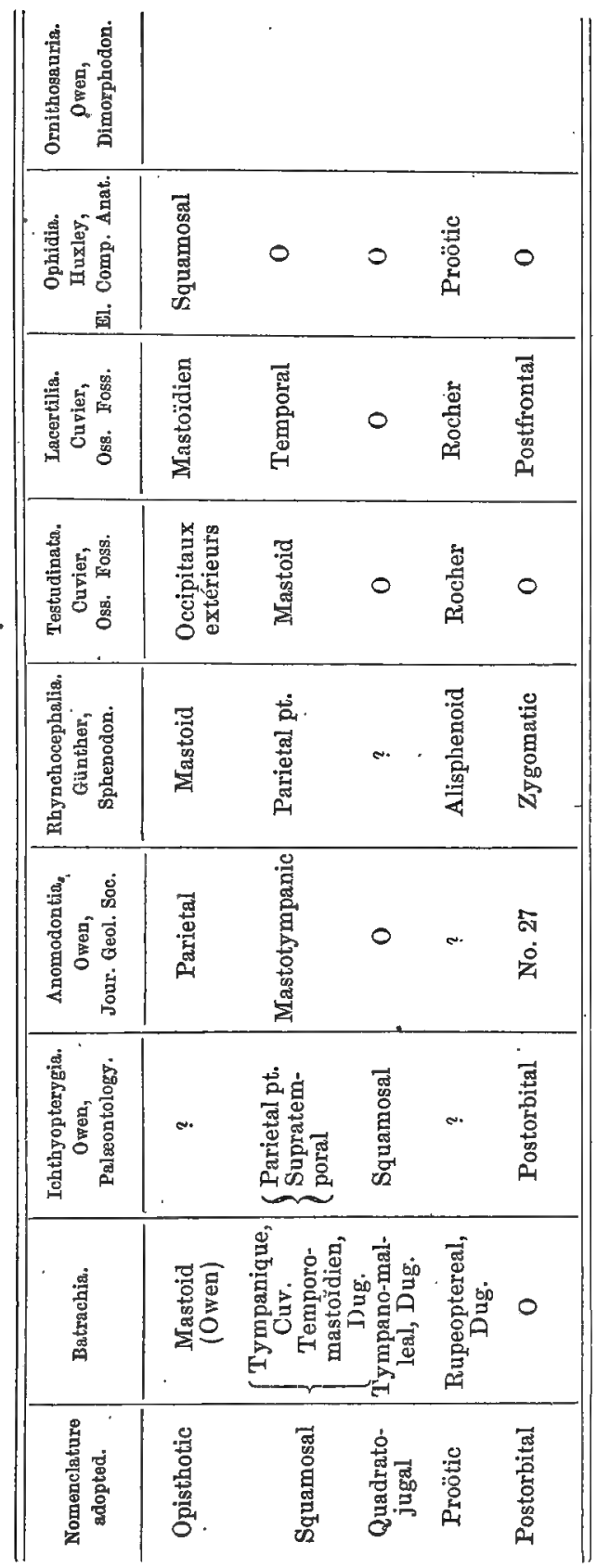

A. A. A. \&. VOL. XIX. 29 


\section{On the Systematic Arrangement of the Reptilia.}

\section{a. On Systematic Classification in general.}

The rationale of systematic classification, in zoölogy at least, is a problem unsolved in the minds of many. As Agassiz has observed, it reposes in most cases on a purely empirical basis; and such are the difficulties that a resolution of its true nature presents, that some of the best naturalists have been fain to admit that it does not rest on any basis of principle of natural order, but on the convenience of the student alone. Yet I presume that even these will hardly admit their position to be true, if brought face to face with such a legitimate deduction from it as that a classification based purely on coloration or size would be as satisfactory as that they adopt. Believing that a true classification of species of organic beings based on their structure will be the expression of some of the laws according to which their creation has been conducted, as well as of some of those which govern their mutual relations in the scenes of active life, 'I would propose to state the principle which I imagine to lie at the basis of a system which fulfils such requirements.

In practice, so general is the coincidence of external and readily visible characters with the deeper and more significant ones, that the usual practice of arranging groups of animals in accordance with some readily observed tangible character of the former kind is generally justified by the more conclusive test of an examination of the whole structure. Yet this method fails to stand such tests sufficiently often to render it obvious that external characters are not enough for the resolution of the problem of affinity, and that they may be deceptive in cases where we little suspect it. As an example of the first, the genus Sphenodon is sufficient. In characters usually employed by naturalists for distinguishing the families of Reptilia, it is an Agamoid Lacerfilian : a complete examination of its anatomy has shown that it is not even a member of the order Lacertilia. In the second case of deceptive characters, those of the corresponding genera of different homologous series may be mentioned, where the characters determining the series are rarely visible externally.

Some valuable propositions respecting classification are made by Professor Gill, in an essay on the Mammalia, read before the American Association (to be published in abstract in its volume, and in the "American Naturálist" for October, 1870). His first two prop- 
ositions are: "1st, Morphology is the only safe guide to the classification of organized beings, teleological or physiological adaptation being the most unsafe guide, and conducing to the most unnatural approximations; $2 \mathrm{~d}$, The affinities of such organisms are only determinable by the sum of their agreements in morphological characteristics, and not by the modifications of any single organ."

The first proposition we think so self-evident, that it is surprising that there are naturalists who, in practice at least, do not consent to it. Morphology is simply the determination of what the elements of an organism are; a question which obviously lies at the root of things, and demands attention before the question of the uses of said parts can be considered.*

The discussion of the second proposition involves the main question. I conceive it to be a very good expression of the views of many naturalists, yet, in my own, it does not go far enough; nor is the second clause, that "affinities are determinable" "not by the modifications of any single organ," one with which I can agree. The same objection therefore applies to the corollary following, that " the adoption of such principles compels us to reject such systems as are based solely on modifications of the brain, those of the placenta, and those of the organs of progression," etc. In other words, agreeing with the first part of Prop. 2, that "affinities" "are only determinable by the sum of their agreements in morphological characteristics," we do not regard the remainder of the proposition and its corollary as necessary consequences of it.

If we analyze the "sum of the agreements" of given groups, we cannot affirm that all of those separate characters which constitute that sum have been always, in past time, coëxistent. In fact, we know that they have not been so, and that the differences of groups consist in the abstraction of single characters from, or addition of single characters to, this "sum." Hence the history of this "sum" is the history of the single characters which compose it, and each one of them has a special value of its own, which cannot be sunk in a state of association. If this be true, systematic zoölogy stands upon what some naturalists are pleased to call a purely "technical" basis, as opposed to what they term a "natural" one. And this is distinctly our position. Every structural feature possesses some systematic value, and when our knowledge extends over a greater number of forms than the

* See Proceedings Academy of Natural Science, Phila., 1863, p. 50; Natural History Review, 1865, p. 98, etc., where this view is expressed. 
system at present includes, the definitions of our groups will rest upon single characters only, and. the history of the origin of those characters will be the history of the origin of the groups.

It is the proper discrimination of the relative values of these single characters which in our estimation determines the "naturalness" of a system; and the principle on which such discrimination reposes is the key to that perplexing question which often renders the conclusions of naturalists so different in appearance, while the objects of their investigations are the same. But by misusing "technical" or single characters - that is, by misinterpreting their values - the most erroneous approximations may be made, and systems constructed which well deserve the term "artificial" applied to them by those who, in their search for the "natural" system, are opposed to the use of "technical" characters. Perhaps the best known example of this misuse is to be found in the Linnæan system of botany, where the value of the numbers of stamens and pistils in determining affinity was placed much too high. Though this system has been utterly abandoned, yet Linnæus's characters are still of great importance in a lower grade of relations.

As the number of primary groups of the animal kingdom is but small, I will commence with the principle on which all subordinate divisions may be distinguished, and their value ascertained.

I. Given primary divisions, and given that such divisions present in some members greater resemblance (or unity of minor characters) to members of other primary divisions, and in other members especial diversity from the same, - the primary subdivisions of said first divisions are those which express the successional degrees of resemblance to or difference from the other divisions of first rank.

II. Given primary subdivisions, their subdivisions of first rank are estimated, as in Prop. I., by reference to the characters presented by their extremes of likeness to or diversity from the members of the other primary subdivisions. The value of characters of the groups contained in each of last grades mentioned to be determined by the same test.

For primary divisions, in Prop. I., might be read class ; for primary subdivision, order; and for subgroup of the latter, family. The same principle applies to genera, which is expressed in IProp. VI. of a series designed to render clear the basis of the theory of evolution, published in a "Monograph of the Cyprinidæ of Penn- 
sylvania." * The I., II., and III. propositions are prefixed as preliminary:-

I. That genera form series indicated by successional differences of structural character, so that one extreme of such series is very different from the other, by the regular addition or subtraction of characters, step by step.

II. That one extreme of such series is a more generalized type, nearly approaching in characters the corresponding extreme of other series.

III. That the other extreme of such series is excessively modified and specialized, and so diverging from all other forms as to admit of no type of form beyond it.

VI. That therefore the differences between genera of the same natural series are only in those characters which characterize the extreme of that series.

For the highest groups in the animal kingdom we must accept the definition of Cuvier, Von Baer, and Agassiz, for the present, that they are primary, because they represent different primary plans of structure. For the lowest grade of groups (genera) the definition above given (Prop. VI.) will be found to represent groups to which the definition given by Agassiz $\dagger$ will also apply; viz., that "their special distinction ( $i$. e., of genera) rests upon the ultimate details of their structure." I believe that the definitions given by Agassiz to the three intervening grades of divisions viz., of families, orders, and classes - are far nearer a representation of nature than any other ever given. They are as follows:-

Classes are defined "by the manner in which the plan of the branch is executed; Orders, by the degrees of complication of that class-structure; Families, by their form as determined by structure." Natural science is under great obligations to Professor Agassiz in this, as in other points.

These definitions are, however, better perceived after the groups are constituted, but in practice are not sufficiently exact to serve as the crucial test in the cases which may arise. The simple method indicated in our propositions above will, it appears to us, serve to solve many of the more difficult questions which arise during the attempt to state the true relations of organic beings.

We may now apply these principles to the groups of the class

* Trans. Am. Philos. Soc., 1866, p. 397.

† Contrib. Nat. Hist: U. S., i. pp. 163, 170. 
Reptilia, not only as an illustration of their meaning, but of their use.

\section{B. On the System of Reptilia.}

The points of resemblance to the other classes of Vertebrata presented by the Reptilia are, of course, to those below thema and those above them. Relationships to the class Batrachia are as yet doubtful, unless indeed the remarkable relations of the squamosal and quadrate in Anomodontia have such a significance. The extremities of the genus Ichthyosaurus present a remarkable structure not seen elsewhere in the class, nor in the classes above it; viz., in lacking all differentiation between the elements external to the proximal element, - the humerus and femur. So far as form is concerned, the ulna and radius, tibia and fibula, tarsus carpus, metacarpus, metatarsus, and phalanges, are identical. This type is only found below the Reptilia, approximately among Crossopterygian fishes and Elasmobranchi; and it is to the latter class that we must appeal, says Gegenbaur, for an explanation of their structure. No other resemblance of real importance has been observed to exist between the two groups.

The extension downwards of the squamosal over the quadrate region constitutes a point of remote resemblance to the Fishes. The? continuation of the? frontals to the premaxillaries in Ichthyosaurus is seen in the lower tailed Batrachia.

Resemblances to the classes above the Reptilia are seen in the groups Crocodilia, Dicynodontia, Ornithosauria, and Dinosauria. In the first, the presence of a vermis in the cerebellum, and quadripartite heart are points of equal affinity to the Mammalia and Aves. In the three others, the double-headed ribs, with capitular articulation on the centra of the vertebræ, and generally elongate or complex sacrum, are points of resemblance both to Mammalia and Birds. In the Dicynodontia, other resemblances to either class are wanting, but the case is different in the other orders. The pelvis and hind limbs of the Dinosauria are especially bird-like; while, according to Seeley, the Ornithochiræ had epipubic or marsupial bones as in Mammalia, a brain with infero-lateral optic lobes as in Aves, and even confluent metatarsi as in the same class. In fact, it seems quite evident that Seeley is right in referring that group to the Birds; but this does not necessarily remove the true Pterodactyles from the Reptilia. These have distinct tarsals and metatarsals, though their epipubic (marsupial) bones and other characters ally them most closely to the Ornithochiræ. 
Serial divergence from these lower and higher orders to an extreme of special peculiarity, such as is mentioned in Prop. III. above, has been alluded to in the discussion of the homologies of the opisthotic and squamosal bones. This is seen in the successive prolongation of the elements on the sides of the posterior region of the cranium into a "suspensorium," and the successive liberation of the quadrate bone from several sutural articulations, to a condition as a mobile fulcrum for the mandible. This succession is seen first in the Rhynchocephalia, where the suspensorium is produced, but the quadrate fixed; the Testudinata, where the quadrate is freed from a quadratojugal bone; in the Lacertilia, where the quadrate is movable, but the opisthotic not produced; in the Pythonomorpha, where the opisthotic is produced as suspensorium; the extreme being reached in the Ophidia, where the suspensorium itself becomes movable, and with it the elements which usually form the solid surface of the palate.

This series then, it is evident, is like that of the Teleostei, among the lower Vertebrata, a special divergence from the main line of succession to the higher classes. The reptiles which retain and increase the close contact of the quadrate bone with the periotic elements are evidently those which conduct us to the Mammalia. The highest group in this succession is the Crocodilia. Those which consolidate the periotic elements, but retain the partial freedom of the quadrate, on the other hand, lead to the Avine class. These are the Ornithosauria, and perhaps, when we come to know

- the cranium, the Dinosauria. At least this may be predicated, if the structure of the foot and ear bones are correlated in this group as. they are elsewhere.

The primary importance of this series is confirmed by the correlation with it of the serial modification of the modes of attachment of the ribs. These differences were first used in systematic work by Owen,* and later more fully by Huxley. The latter subdivides the Reptilia in accordance with it alone, and, while pointing out important affinities thereby, fails to recognize others from his neglect of the modifications of the quadrate and supporting bones.

In the most generalized form (represented by Ichthyosaurus), the capitular and tubercular articular surfaces are near together, but distinct, and situate on the sides of the vertebral centra. 
From this point two lines of modification can be traced. The one, coinciding with that in which the quadrate and suspensorial bones are received into closer cranial articulation, is characterized by the wider separation of the two surfaces. The inferior becomes marginal and sessile, remaining on the centrum; the superior rises, and on the dorsal region is supported on an elongate basis from the sides of the neural arch. Thus, in this point also, this series tends towards the Aves and Mammalia. The second, or special series, in correspondence with the liberation of the quadrate, etc., sees a fusion of the two articular surfaces, and their usual retention on the centrum. In one group (Sauropterygia) this fused basis rises to the top of the neural arch in the dorsal region : on the cervical region they are distinct.

In the Crocodilia, the capitular articulation does not rise to meet the tubercular in front of the posterior dorsal region; and they are united and rise from the neural arch on the lumbar region. These two orders are otherwise allied, and form a point of connection between the groups defined by the characters of the rib articulations.

In the Testudinata, the ribs are single headed as in this series, but the convexity is sometimes in contact with the transverse expansion of the neural spine. There appears, however, to be no true articulation here, nor any diapophysis.* The space between the vertebral expansion and the tubercular region of the rib is filled by a later and distinct ossification. The capitular articular facets are sessile, and at the point of contact of two centra. The majority of this order present a special peculiarity in the expansion of the ribs into an osseous upper shield: a similar expansion of abdominal elements (perhaps abdominal ribs), with the clavicles $\dagger$ and mesosternum (interclavicle, Parker), forms an inferior shield. As these characters are not developed in Sphargididx, they need not be necessarily regarded as ordinal.

A similar character is to be found in the Pythonomorpha and Sauropterygia, whose fore limbs are specialized into swimming organs or paddles. Since we see this last modification of the truly differentiated limb to be subordinated to the characters of the order in the Testudinata (e.g., in Cheloniidre and Sphar-

* In a young Testudo mauritanica the proximal extremities of the ribs are decurved to their capitular articular facets, without touching the expansion of the neural spine (vertebral bones of carapace), and without sending tubercle or process to meet them.

$\uparrow$ See Parker on the shoulder girdle. 
gididæ), I do not regard it as necessarily of ordinal value, but subordinate to characters already mentioned, of the posterior regions of the cranium, the tarsus, pelvis, etc. The forms of the articular extremities of the vertebræ have also a subordinate value.

The affinities of the Orders are most easily expressed in the following outline scheme :-

Series I., With two-rib ar-

ticulations and fixed

- quadrate.
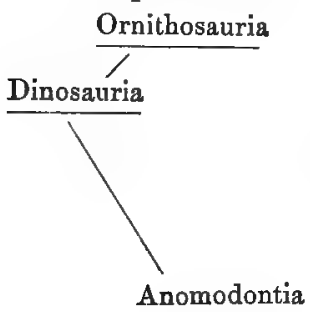

Intermediate.

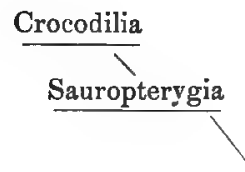

Series II., With one-rib articulation and free quadrate.

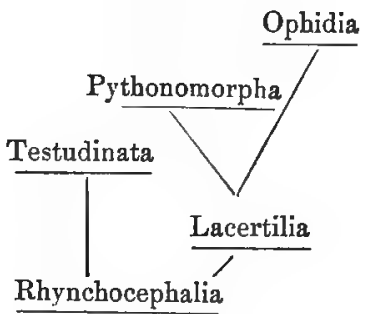

Ichthyopterygia

A tabular arrangement destroys expression of more than one line of affinities, but is most convenient for presentation of diagnoses. The above-named groups possess different degrees of relationship to each other, and have been combined into groups by authors, which are supposed to represent natural divisions. This presents some difficulties as yet, on account of our ignorance of the structure in certain orders. They may, however, be provisionally placed as follows:-

A. Extremities beyond proximal segment not differentiated as to form.

I. Tubercular and capitular articulations for ribs distinct, on centra. Os quadratum immovably articulated to squamosal, etc. No sacrum. IcrTHYOPTERYGL. Including one order, Ichthyopterygia.

B. Extremities differentiated.

II. Tubercular and capitular surfaces united. Os quadratum articulated with squamosal and opisthotic by ginglymus. Sacrum very small. STREPTostrulca, with the orders Lacertilia, Pythonomorpha, and Ophidia.

III. Tubercular and capitular surfaces united. Os quadratum articulated with squamosal, opisthotic, etc., by suture. Sacrum small. SrnaptosatRLA, with the orders Rhynchocephalia, Testudinata, and Sauropterygia.

IV. Tubercular and capitular surfaces separated; former on diapophysis, atter on centrum. Os quadratum articulated by suture with its suspensorium. Sacrum generally of several vertebræ. ARchosaurLa; orders, Anomodontia, Dinosauria, Crocodilia, and Ornithosauria.
A. A. A. S. VOL. XIX. 


\section{CATALOGUE OF THE FAMILIES OF THE REPTLIA.*}

\section{ORNITHOSAURIA.}

Bonaparte, Fitzinger, Seeley; Pterosauria, Owen.

Dimorphodontida; Dimorphodontæ, Seeley, 1. c.

Pterodactylida ; Rhamphorhynchæ et Pterodactylæ, Seeley, l. c. ,

\section{DINOSAURIA.}

Owen, Cope, Seeley; Pachypodes, Meyer. Ornithoscelida; Huxley.

\section{STMPHYPODA.}

Cope; Compsognatha, Huxley.

Compsognathidoe; Compsognathus, Wagner.

Ornithotarsida; Ornithotarsus, Cope.

\section{GONIOPODA.}

Cope; Harpagmosauria, Haeckel.

Megalosauridae; Huxley (part). Cope, Trans. Am. Philos. Soc., 1869, p. 99.

Teratosaurida; Teratosaurus, Plateosaurus, Meyer, etc. Cope, Trans. Am. Philos. Soc., 1869, p. 90.

\section{Orthopoda.}

Cope; Therosauria, Haeckel.

Scelidosauridae; Cope, Trans. Am. Philos. Soc., 1869, p. 91; Huxley, Jour. Geol. Soc., London, 1870, p.

Iguanodontidar; Cope, l. c.; Do. (in part), Huxley, I. c.

Hadrosauride; Cope, 1. c.; Iguanodontidæ, Huxley (part).

\section{CROCODILIA.}

Crocodilia et Thecodontia (part), Owen, 1841.

\section{Amphicelia.}

Belodontidae; Thecodontia, Owen (part). Cope, Trans. Am. Philos. Soc., 1869 , p. 32.

Teleosaurida.

* The extinct groups and synonymes are indicated by italics. 


\section{Procalia.}

Thoracosauridce; Thoracosaurus, Leidy, Cope.

Gavialidæ; Gavialidæ, Gray ; + Holops Thecachampsa, Cope, etc.

Crocodilidæ; Crocodilidæ + Alligatoridæ, Gray.

\section{SAUROPTERYGIA.}

Owen.

? Placodontida; Placodus, etc.

Plesiosauridee; Nothosaurus, Pistosaurus, Plesiosaurus, Pliosaurus, etc. Elasmosauridce; Elasmosaurus, Cimoliasaurus, etc.

\section{ANOMODONTLA.}

Owen.

Dicynodontidae; Owen, Palæontology.

Oudenodontida ; Cryptodontia, Owen, Palæontology.

\section{ICHTHYOPTERYGIA.}

1chthyosaurida.

\section{RHYNCHOCEPHALIA.}

Protorosauridae; Protorosaurus, Meyer (elongate sacrum).

Sphenodontidæ; Hatteriidæ, Cope (Proceed. Acad. of Nat. Sci., Phila., 1864).

Rhynchosauridae; Rhynchosaurus, Owen.

\section{TESTUDINATA.}

\section{AтHEC应.}

Sphargididæ; Gray, Annals of Philosophy, 1825; Bell, Fitzinger, Agassiz.

\section{Cryptodira.}

Cheloniidæ; Gray, Annals of Philosophy, 1825; Agassiz.

Propleuridae; Cope, Sillim. Am. Jour. Sci., 1870, p. 137.

Trionychidæ; Gray, Bell, Dum., Bibr., Agassiz.

Emydidæ; Emydidæ and Chelydridæ, Agassiz.

Adocidce; Cope, Proceed. Am. Philos. Soc., 1870, November.

Cinosternidæ; Agassiz, Contrib. Nat. Hist. U. S. ; Cope, Leconte (part). 
Testudinidæ; Gray, Agassiz, Cope emend.

Pleurosternidae; Cope, Proceed. Acad. Nat. Sci., Phila., 1868, October.

\section{Plieurodira.}

Duméril, Bibron; Chelyoidce, Agassiz.

Podocnemidida; Cope, Proceed. Acad. Nat. Sci., Phila., 1868, October; Peltocephalidæ, Gray.

Chelydidæ; Gray, Proceed. Zoöl. Soc., London, 1869; Cope, 1. c., 1868.

Hydraspididæ; Cope, l. c.; Gray, l. c.

Pelomedusidæ; Cope, l. c., 1865, p. 185, 1868, p. 119.

Sternothæridæ; Cope, 1. c., 1868, p. 119.

\section{LACERTILIA.}

Owen, Cope.

\section{RHiptoglossa.}

Acrodonta Rhiptoglossa; Wiegmann, Fitzinger, Cope. Chamceleonida; Müller.

Chamæleontidæ; Wiegmann, Gray, et auctorum.

\section{Pachyglossa.}

Cope; Acrodonta Pachyglossa, Wagler, Fitzinger. Cope, Proceed. Acad. Nat. Sci., Phila., 1864, p. 226.

Agamidæ.

\section{NYCTISAURA.}

Gray; Catal. Sauria Brit. Mus, ; Cope, 1. c.

Gecconidæ; Gray, et auctorum.

\section{Pueurodonta.}

Cope, Proceed. Acad. Nat. Scí,, Phila., 1864, p. 226.

$$
\text { a. Iguania. }
$$

Anolidx; Cope, 1. c., pp. 227, 228.

Iguanidæ; Cope, l. c., pp. 227, 228; Iguanidæ (pars), auctorum.

Anguidæ; Cope, 1. c.

$$
\text { b. Diploglossa. }
$$

Gerrhonotidæ; Cope, 1. c.; Zonurida (part), Gray.

Xenosauridæ; Cope, 1. c., 1866, p. 322.

Helodermidæ, Gray; Catal. Sauria Brit. Mus. ; Cope, 1. c., 1864, p. 228 , 1866, p. 322. 
Wagler, Fitzinger, Cope.

c. Thecaglossa.

Varanidæ.

\section{d. Leptoglossa.}

Wiegmann, Fitzinger, Cope.

Teidæ; Teidoe and. Ecpleopodida, Peters, Cope, Proceed. Acad. Nat. Sci., Phila., 1866, p. 228; Teidce Anadiidce Cercosauridce Riamida, Gray.

Lacertidæ ; Gray; Catal. Sauria ; Cope, 1. c. ; Lacertidæ et Cricosauridoe, Peters; Xantusiidoe, Baird.

Zonuridæ; Zonuridae (part), Gray; Lacertidce (part), Cope.

Chảlcididæ; Gray, 1. c.; Cope, 1. c.

Scincidæ; Gray, l. c.; Cope, l. c.

Sepsidæ; Gray, 1. c.; Cope, 1. c.

$$
\text { e. Typhlophthalmi. }
$$

Cope, Proceed. Acad. Nat. Sci., Phila., 1864, p. 228 ; Do. (pars), Duméril et Bibron. Erpet. Gen.

Anelytropidæ; Cope, l. c. name; Typhlinidex, Gray.

Acontiidæ ; Gray ; Catal. Brit. Mus. ; Cope, 1. c., 1864, p. 230.

Aniellidæ; Cope, l. c., 230.

\section{Ophrosauri.}

Cope, 1. c., Merrem; Annulati, Wiegmann; Ptychopleures Glyptodermes, Dum., Bibr.; Amphisbanoidea, Müller.

Amphisbænidæ; - $¥$, Wiegmann, Fitzinger.

Trogonophidæ; Trogonophes, Wiegmann, Fitzinger.

\section{PYTHONOMORPHA.}

Cope, Trans. Am. Philos. Soc., 1870, p. 175 ; Proceed. Boston Nat. Hist. Soc., 1869, p. 251; Lacertilia Natantia, Owen; Palæontograph. Society, Cretaceous Reptiles.

Clidastidoe; Cope, 1. c., p. 258.

Mosasauridae; Cope, 1. c., p. 260.

\section{OPHIDIA.}

\section{SCOLECOPHIDIA.}

Duméril; Scolecophidia et Catodonta, Cope, Proceed. Acad. Nat. Sci., 1864, p. 230.

Typhlopidæ; Epanodontiens, Dum., Bibr.

Stenostomidæ; Catodontiens, Dum., Bibr. ; Catodonta, Cope, l. c. 
Müller, Cope, l. c.

\section{Tortricina.}

\section{Tortricidx.}

Uropeltidæ; Uropeltacea, Peters; Rhinophida, Gray.

Müller, Cope.

3. Asinea.

Müller.

a. Peropoda.

Xenopeltidæ; Cope, 1. c.; Günther, Reptiles British India.

Pythonidæ; Cope, l. c.; Holodontiens, Dum., Bibr.

Boidæ; Cope, 1. c.; Aproterodontiens, Dum., Bibr.

Lichanuridæ; Cope, Proceed. Acad. Nat. Sci., Phila., 1868, p. 2.

\section{b. Colubroidea.}

Achrochordidx; Cope, 1. c., p. 231; Achrochordiens, Dum., Bibr.

Homalopsidx; Cope, Proceed. Acad. Nat. Sci., Phila., 1864, p. 167; Natricidae (pars), Günther; Potamophilida, Jan.

Colubridæ; Asinea Group $\beta-b b$, Cope, Proceed. Acad. Nat. Sci., Phila., 1864, p. 231 ; Calamarida, Oligodontida, Coronellida, Colubrida, Dryadidae, Dendrophidce, Dryiophide, Psammophidce, Lycodontidce, Scytalida, Dipsadidce, etc., Günther, Catal. Brit. Mus., et op. alt.

Rhabdosomidæ; Calamarida (part), Günther.

\section{Proterogltyena.}

a. Conocerca.

Elapidæ; Cope, 1. c., p. 231; Elapidce (pars), Günther, 1. c. Najidæ; Cope, 1. c.; Elapidae (pars altera), Günther, l. c.

\section{b. Platycerca.}

Hydrophidx; Hydridae, Gray; Hydrophidce, Schmidt, Fischer, Günther. Cope, Proceed. Acad. Nat. Sci., Phila., 1869, p. 75, 1864, p. 231.

\section{Solenoglypha.}

Duméril, Bibron ; Viperida, Cope, Proceed. Acad. Nat. Sci., 1859, p. 333. Atractaspididæ; Günther; Catal. Brit. Mus.; Cope, l. c., 1859, p. 334. Causidæ; Cope, 1. c., 1859, p. 334.

Viperidæ; Gray; Catal. Brit. Mus., p. 18; Cope, 1. c. ; Günther, Reptiles British India.

Crotalidæ; Gray, 1. c., Cope, 1. c., Günther, 1. c., et anctorum. 


\section{Critical Remarks on the System.}

1. In the "Transactions of the American Philosophical Society," 1869, part I. (August), I proposed a system in which the primary groups of the Reptilia were defined anew, and understood in some measure differently from those proposed by Owen. The system of the latter author, and that of Von Meyer, were the only ones extant previously; and additional discovery necessitated some modifications, while the meritorious portions of both it was intended to preserve. The groups, perhaps equivalent to "orders," retained, were the Ichthyopterygia, Archosauria, Testudinata, Pterosauria, Lacertilia, Pythonomorpha, and Ophidia. The form of attachment of the quadrate bone was regarded, after Johannes Müller, as an element of prime importance in the estimate of affinities, and of nearly equal value, the differentiation of distal elements of limbs, the opisthotic bone, the mode of attachment of ribs, etc.

Another systematic grouping of the orders was proposed by Professor Huxley in the "Journal of the Geological Society," London, 1869 (November), in which the position and character of the rib articulations to the vertebral centra were used exclusively in discrimination of the groups. The subclasses proposed were the Suchospondylia, which is our Archosauria; the Perospondylia, our Ichthyopterygia; * the Herpetospondylia, corresponding to our orders Ophidia, Pythonomorpha, Lacertilia, with the addition of the Sauropterygia. The last group is rendered unnatural by the presence of the latter order, which possesses the closely articulated quadrate bone of the Archosauria. I therefore omit it, and retain the three orders remaining, in one division, which has already been named by Müller the Streptostylica. Huxley's fourth subclass, the Pleurospondylia, includes the Testudinata only. This group I also recognized in the original memoir quoted, and I accept it with

* Some criticisms of Professor Huxley's in this essay, on my determination of the structures and relations of the Dinosauria, are so inapposite as to require notice. He quotes me as saying of the astragalus of Lælaps, that "one other example of this structure is known in the Vertebrata;" and adds, "but I shall show immediately that the astragalus is altogether similar in the commonest birds, and probably in the whole class Aves." This statement is so precisely the reverse of the fact, that I can only suppose it to be an inadvertence, or a double entendre, the latter being an impossibility in so fair a man as Professor Huxley. On page 35 he says: "Professor Cope has distinguished Compsognathus as the type of a division Ornithopoda, from the rest of the Dinosauria, which he terms Goniopoda (on the structure of the foot, etc.)... It seems to me precisely by the structure of the foot that Compsognathus is united with, instead of being separated from, 
new definition, so much so indeed as to constitute a substitution. The Rhynchocephalia (an order which Huxley has not recognized), Testudinata, and Sauropterygia agree in the essential structures of the quadrate element, and the simplicity of the rib attachment; they also agree in the abdominal ribs and plane vertebral centra. The capitular rib articulations are on processes in the last, in the Testudinata in pits, but in Sphenodon almost sessile on the centra. If Rhynchosaurus be a Rhynchocephalian, it has tortoise-like jaws; so has the Sauropterygian Placodus in some respects. Natatory fins of Plesiosaurus, etc., are repeated in the turtle Sphargis. So, though this association into the subclass which I have called Synaptosauria appears at first sight unnatural, it probably has a basis in nature.

2. The Ornithochira of Seeley do not appear to belong to the Ornithosauria, but to the Birds, where they would enter the subclass Saururæ with the Archæopteryx. This depends on the accuracy of Seeley's statement that the metatarsi are united, and there seems to be no reason to doubt it. This learned author does not state whether the tarsal bones are distinct or not; though confluent metatarsi suggest union of these also, since the Dinosauria lose the distinctness of the tarsals, and preserve separate metatarsals. This group will be annectant to the Reptilia by their near allies the Ornithosaurian group of Dimorphodontæ of Seeley.

3. The arrangement of the Lacertilia is the same as that proposed by the author in 1864, with three exceptions. The Rhiptoglossa are separated from the Pachyglossa by a wider interval, and the two groups are regarded as of primary value. In the system quoted they are united into one primary group, - the Acrodonta. Secondly, the Sphenodontidæ (Hatteriidæ) are removed from the

the Ornithoscelida." I united Compsognathus with the Dinosauria in 1867, on account of the foot structure (as quoted by Professor Huxley, p. 24), but regarded its subordinate modification of arrangement as indicative of a subordinate division, Symphypoda. This is exactly the course adopted by Professor Huxley in 1869 , only he changes the name of Symphypoda to Compsognatha, and gives different characters to it. As to the groups Ornithopoda and Goniopoda, as ascribed to me, they cannot be found in my papers. On page 24 Professor Huxley supports Cuvier's determination of the position of the tibia in Dinosauria, as different from mine, observing that "Cuvier was right from a morphological point of view, when he declared the tibia to be laterally compressed," etc. This point I never contested; but that Cuvier was wrong so far as actual position is concerned, as I have proposed, is evidently Professor Huxley's opinion, since he arranges the tibia in his descriptions and plates precisely as I did in 1867. 
Pachyglossa, and associated with certain extinct forms into the order Rhynchocephalia. This is in consequence with the full statement of its structural characters by Günther, and I accept the new order proposed for it by this author, with some change of diagnosis. Third, the Zonuridæ are regarded as distinct from the Lacertidæ on account of their papillose tongue.

4. In the Ophidia, the Typhlopidæ and Stenostomidæ are united into one order, the Scolecophidia, as already done by Duméril and Bibron. I separated them in the system proposed in connection with that of the Lacertilia in 1864, on account of the supposed absence of the prefrontal bone in Typhlops while it is present in Stenostoma. I find, however, that the large bone I supposed to be maxillary in Typhlops, is really the prefrontal, and that the maxillary is concealed on the inferior face of the skull; being represented by a narrow strip alongside of the vomer.

\section{On the Rhynchocephatia and supposed Lacertilia of the Trias and Permian.}

The existence of Lacertilia in the Trias has been asserted by Professor Huxley, as indicated by the genera Hyperodapedon, Telerpeton, Rhynchosaurus, and Saurosternum.* For us the evidence furnished by these and other genera is conclusive only as to the presence of the Rhynchocephalia in beds of that age, while the existence of the Lacertilia remains undecided. The other genera - are from Germany; viz., Proterosaurus, Sphenosaurus, and Phanerosaurus, of Meyer. Of these the first two are believed by Huxley to be Lacertilia. $\dagger$

The characters of the Rhynchocephalia have been in part. pointed out in the preceding pages. Other features, especially of the soft parts, can be learned by reference to Guinther's Monograph of Sphenodon, already quoted.

Of the above genera, Hyperodapedon has the remarkable pala-. tal structure characteristic of Sphenodon, and entirely unknown among the Lacertilia, and I have little doubt that the genus belongs to the same order; viz., the Rhynchocephalia. In all of the remaining genera, the vertebræ are flat or sub-biconcave as in Rhynchocephalia, and not procelian as in Lacertilia. In defence of the position of Telerpeton as a Lacertilian, Professor Huxley cites the biconcave vertebræ of the Gecconidæ. These are, however, fish-like, and enclose within the adjacent conic cavities of

* Jour. Geol. Soc., Lond., 1869, p. $49 . \quad$. † Ibid., p. 37.

A. A. A. S. VOL. XIX. 
two centra a mass of cartilage. In the Batrachia, the ossification of this mass produces the ball which adheres to the centrum in front or behind, producing the procelian or opisthocœlian vertebra. The vertebræ of Gecconidæ are therefore probably in the embryonic form of those of the other Lacertilia. Not so, however, with the Triassic genera in question. According to Meyer's figures, they are nearly plane, like those of Sphenodon and Dinosauria; and were probably developed round the chorda dorsalis, without retention of included ball.

In Phanerosaurus, the neural arches are united to the body by suture, a character unknown in the Lacertilia. In general the vertebræ by which the genus is known might as well belong to a Sauropterygian. In Proterosaurus (See Von Meyer's "Saurier aus dem Kupferschiefer," Plates), the forms of the inferior pelvic bones and the presence of inferior abdominal ribs, are so entirely unlike any thing in the Lacertilia, and so much like the same parts in Sphenodon, that this genus also, I have no doubt, is a Rhynchocephalian. Every thing is in favor of the supposition that Rhynchosaurus and Sphenosaurus are Rhynchocephalians, since the parts preserved correspond with those of known types of that order, and none of the special peculiarities of Lacertilians, as distinguished from the former, have been discovered.

The only genera remaining are Saurosternum (Huxl.) and Telerpeton (Mant.). In the latter genus the palatine bones are said not to be separated by the pterygoids, and there is no quadratojugal represented by Huxley: if these characters exist, it suggests the Lacertilia rather than Rhynchocephalia. The latter is the more important point; but further examination is necessary to decide on it, as the postorbital arch is also omitted in the figure, which is possibly an inaccuracy, consequent on the state of the specimen. The form is in its dertition equally like the Lacertilian Uromastix and the Rhynchocephalian Sphenodon; but the transverse direction of the parieto-squamosal arch, and the plane or concave articulations of the vertebral centra, are those of the latter, not of the former.

As to Saurosternum, not enough is known of the only specimen to ascertain whether it belongs to the Lacertilia or Rhynchocephalia. There is no cranium, and the parts preserved or described are as characteristic of one order as the other.

\section{Stratigraphic Relation of the Orders of Reptitia.}

This is most readily shown in tabular form, as follows: - 
zOöt.GY.'

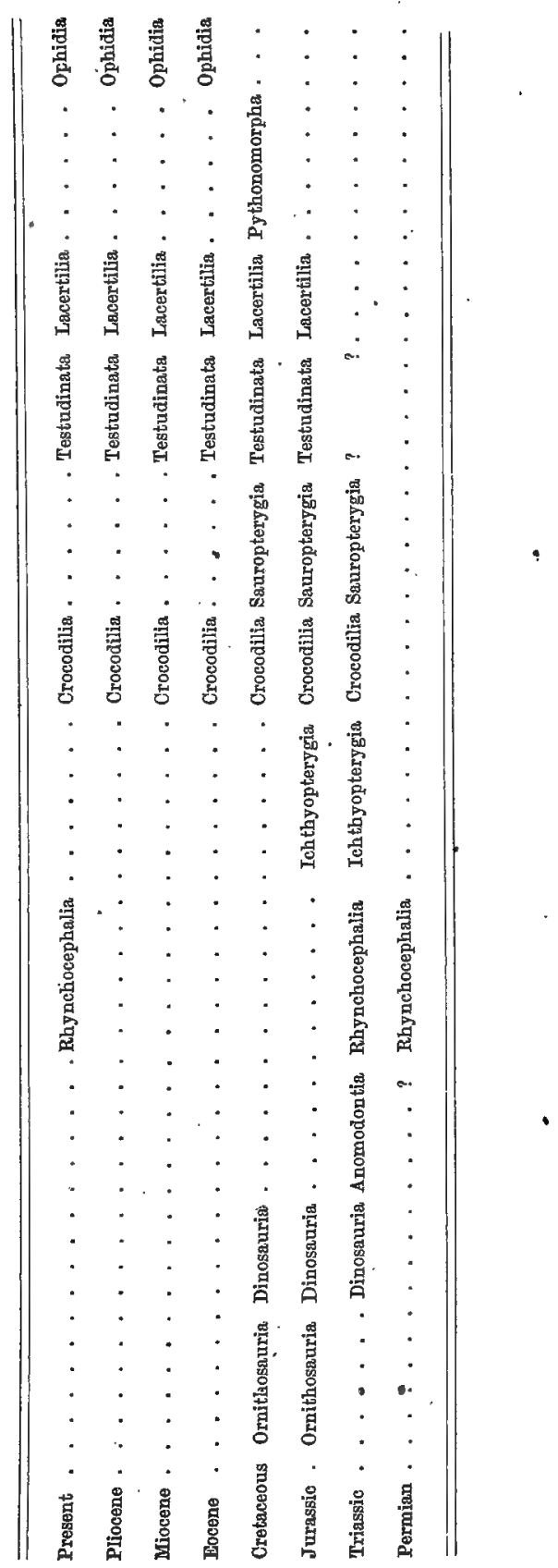


It will be observed, by this table, that the most specialized Reptilian order, the Ophidia, appeared last in time in the Eocene period; and that those which constitute the line of connection with the generalized reptiles appeared earlier as they approached the latter,the Pythonomorpha in Cretaceous, and Lacertilia in Jurassic times. The Reptilian groups most specialized in bird characters (Ornithosauria and Dinosauria) appear on the other hand very early ; the first and most Mammalian also, - the later of the two, - in Jurassic Beds. The Trias gives us in the Anomodontia and Ichthyopterygia, the two most generalized and lowest orders; while their contemporary, the Rhynchocephalia, almost as much generalized in Reptilian features proper, was already represented in the Trias. Strangely enough this order yet exists in the living Sphenodon of New Zealand. The Crocodilia, rather specialized in bird characters, accompanies the last in this wonderful persistency, beginning also in the Trias.

The inquiry as to the truth of the proposition that the more ancient types of animals are more generalized, and therefore more embryonic in the characters of a special nature* which characterized groups later introduced, is answered in a very imperfect way in the affirmative. It is like the shadow of a truth whose substance will shortly come before us. But when we come to compare the subdivisions of the orders themselves with each other, and with those of other orders, as we pass backwards in time, the weight of the affirmative answer to the above proposition is greatly increased. The oldest Ophidia are boæform, therefore approaching Lacertilia and Pythonomorpha. The oldest Tortoises have generally the most incomplete carapace and plastron; among them the Psephoderma allied to Sphargis, without carapace, and thus the most lizard-like of the order. The Lacertilia of European Jurassic strata are, some of them at least, acrodont, apparently Pachyglossa (e.g., Acrosaurus), and, as such, nearer the Rhynchocephalia, which preceded them in time. The position of Homorosaurus and Piocormus is not determinable, as the dentition cannot be understood from the descriptions and figures of Wagner. The form of the mesosternum of the former refers it to either the Pachyglossa or Iguania, as I understand those groups. It may be assumed that since the order Lacertilia has diverged from the line of other Reptilia, while it took on in its special peculiarities it lost in the features characterizing the main

* The identity of these two propositions has not always been noticed by authors. 
series with a higher tendency or terminus, thus retrograding in one sense. This is seen in the shortened sacrum, pleurodontu dentition, etc.

The Crocodilia of the Jurassic do not possess the ball and socket-jointed vertebræ of the recent genera, and exhibit the plane articular faces of all the Jurassic and Triassic Reptilia. Their basicranial region is also plane like that of other orders, instead of vertical as in the recent forms. The Triassic Crocodiles are still more generalized. Their ribs are extended to the pelvis, as in Dinosauria and Anomodontia: there are often three sacral vertebræ, an approach to the long sacrum of the same orders. The femur, with third trochanter, is an approach to that of the Dinosauria; and finally the position of the nostrils near the orbits (BeIodon) is a Sauropterygian feature. In the Sauropterygia the shortened vertebral column, and long muzzle (Pistosaurus) in the oldest types (Triassic), are approximations to the Crocodilia. The Dinosauria display an increasingly Crocodilian character as we pass into the Triassic period. The femur (Palæosaurus, Megadactylus) loses the bird-like head, and assumes the ill-defined convexity of the Crocodiles; the tibia (Plateosaurus) loses the bird-like "spine," or crest. The ilium is shorter (Palæosaurus). Every student of the subject knows how much more difficult is the separation of the bones of Sauropterygia, Crocodilia, Anomodontia, and Dinosauria, of the Trias, than those of the Cretaceous. There are types allied to the Rhynchocephalia, whose systematic position is doubtful, owing to the generalized character of the parts we possess. Thus the Rhynchosaurus of the Trias of England is allied to that order, and to the Anomodontia. The Rhopalodon of the Permian has a large canine tooth, like the single one possessed by the Anomodontia; but with others associated, like those of the Rhynchocephalia. The Triassic Sauropterygia and Rhynchocephalia also agree in the anterior production of the pterygoid bones between the palatines to the vomer. Compare, for this point, $\mathrm{Hy}$ perodapedon and Nothosaurus.

We learn from such considerations as the above, and similar ones derived from the study of the Mammalia, that the successional relation of the faunæ of the periods in geologic time is more strik ingly exhibited by the subordinate contents of the orders than by the orders themselves, in relation to each other. From this we decide that we must look for the origin of the orders in periods prior to those in which we now know them, if, as some suppose, 
they originated in still more generalized types. This accords with Huxley's view of the period of origin of the Mammalian orders.

It must also be remembered that the above deduction as to geological distribution is precisely that of geographical distribution; $i$. e, that the homologous groups of different continents are not orders, but subordinate divisions of orders, the orders being universally distributed. This coincidence is remarkable, and justifies the view I have taken of the origin of higher types on the basis of retardation and acceleration, and of the nature of synchronism.*

Note in reply to Dr. Seeley's remarks on my interpretation of the structure of the cranium of Ichthyosaurus.

A brief abstract of the portions of the preceding paper, which relate to Ichthyosaurus and Lystrosaurus, having been published in the "American Naturalist," for 1870, Dr. Secley publishes a criticism of the statements and conclusions therein contained, in the "Annals and Magazine of Natural History " for April, 1871. I will briefly reply to these remarks; and commence by saying that he discovers some errors in determinations of bones of the cranium of Ichtbyosaurus, which are due to errors of the artist and proof reader; such are more likely to occur in an abstract issuer early in a periodical, than in the essay itself. Thus he finds the lettering of the maxillary and lachrymal bones to be exchanged. This, as he supposes, is the artist's error, and one which was corrected on the proof which was not received in time. He also finds the nomenclature of the elements of the mandible to be erroneous. This resulted from a misconception by the artist of the lettering on my original drawing, which $I$ find to be correct, and which in the present memoir is correctly copied. In the same way the small "supersquamosal" will be found described in the present paper.

The question as to the determination of the bones forming the roof of . the cranium receives new light from Dr. Seeley's remarks. This has been much needed by American naturalists, for I have been unable to find in the whole range of the literature of the subject an English description of the osteology of the head of Icbthyosaurus, which is at all complete; and the figures are not more instructive. Dr. Seeley's statement, that the flat bone on the inner side of the temporal fossa, continuous in our specimen with the squamosal, is usually separated from the latter by suture, is valuable, and suggests that the element may be parietal and not homologous with the similar plate in Dicynodonts. This possibility has existed in my mind all along, but what are thus probably sutures in two of our specimens have looked as much like fractures. As to the bones suspected to be nasals, I find that of the left side present in a specimen of $I$. intermedius, besides that from Barrow, but wanting in one of I. tenuirostris. As observed by Seeley, the absence of a bone in a fossil has little weight in evidence of its

* Origin of Genera, 1868; Hypothesis of Evolution, 1870. 
non-existence, as compared with.its presence in evidence of its existence. Nevertheless, its absence in so many specimens as Dr. Seeley has had the opportunity of examining renders it necessary to ascertain whether the element in question is a dismemberment of some other bone or not. And this I must leave to those who have more extended material for examination. Dr. Seeley's objections to my determination of the frontals (? nasals) are not weighty, and are anticipated in the memoir itself.

On the whole, the probabilities of the Cuvierian nomenclature of the bones of the cranial roof being correct is rather increased by Dr. Seeley's remarks, but I have not been able to discover that any one has correctly determined the squamosal, quadratojugal, opisthotic, and stapedial bones before the reading of my paper.

2. On the Embryology of Limulus Polyphemus. By A. S. PACKARD, Jr., of Salem, Mass.

\section{(Abstract.)}

THe eggs on which the following observations were made were kindly sent me from New Jersey, by Rev. Samuel Lockwood, who has given an account of the mode of spawning, and other habits, in the "American Naturalist." They were laid on the 16th of May, but it was not until June $3 d$ that I was able to study them. The eggs measure .07 of an inch in diameter, and are green. In the ovary they are of various hues of pink and green just previous to being laid, the smaller ones being, as usual, white. The eggs are .simple, the ovarian eggs being formed of a single cell. The yolk is dense, homogeneous, and the yolk granules, or cells, are very small, and only in certain specimens, owing to the thickness and opacity of the egg-shell, could they be detected.

Not only in the eggs already laid, but in unfertilized ones taken from the ovary the yolk had shrunken slightly, leaving a clear space between it and the shell. Only one or two eggs were observed in process of segmentation. In one the yolk was subdivided into three masses of unequal size. In another the process of subdivision had become nearly completed.

In the next stage observed, the first indications of the embryo consisted of three minute, flattened, rounded tubercles, the two anterior placed side by side, with the third immediately behind them. The pair of tubercles probably represent the first pair of limbs, and the third, single tubercle the abdomen. Seen in out- 
line the whole embryo is raised above the surface of the yolk, being quite distinct from it, and of a paler hue. In more advanced eggs three pairs of rudimentary limbs were observed, the most anterior pair representing the first pair of limbs (false mandibles of Savigny) being much smaller than the others. The mouth

Fig. 1.

Fig. 2.

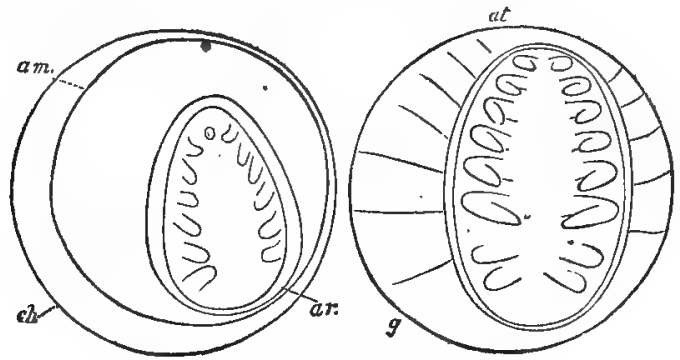

Embryo of Limulus.

opening is situated just behind them. In a succeeding stage (fig. 1, ar, areola ; am, inner egg membrane ; ch, chorion) the embryo forms an oval area, surrounded by a paler colored areola, which is raised into a slight ridge. This areola is destined to be the edge of the body, or line between the ventral and dorsal sides of the animal. There are six pairs of appendages, forming elongated tubercles, increasing in size from the head backwards; the mouth is situated between the anterior pair. The whole embryo covers but about a third of that portion of the yolk in sight. At this time the inner egg membrane (blastoderm-skin ?) was first detected.

The outer membrane, or chorion, is structureless; when ruptured, the torn edges show that it is composed of five or six layers of a structureless membrane, varying in thickness. The inner egg membrane is free from the chorion, though it is in contact with it. Seen in profile it consists of minute cells which project out, so that the surface appears to be finely granulated. But on a vertical view it is composed of irregularly hexagonal cells, sometimes fivesided, and rarely four-sided, hardly two cells being alike. The walls of the cells appear double, and are either strongly waved, or have from three to five long slender projections; with the ends sometimes knobbed, directed inwards. These cells are either packed closely together, or separated by quite a wide interspace.

In a subsequent stage (fig. 2) the oval body of the embryo has increased in size. The segments of the cephalothorax are indicated, and the legs have grown in length, and are doubled on them- 
TH E

\section{SIGNIFICANCE}

\section{PALEONTOLOGY.}

BY

PROF. E. D. COPE.

PHILADELPHIA :

REPRINTED FROM PENN MONTHLY, JANUARY, I 875 . 



\section{THE VALUE OF PALEONTOLOGY.'}

I.

Daleontology is an exact science. It embraces generalI izations or laws obtained by induction, which may be deductively applied to the unknown. The first law is an illustration of the uniformity of nature's methods; namely, the law of the persistency of type. An organized structure once created, and existing under circumstances not hostile to its working, is adhered . to with the greatest fidelity, and extended in time and space. This constant law is the key to this as to the other biological sciences, and occasionally surprises the student of evolutionistic proclivities. On this basis the possibility of reconstruction of the extinct forms of the past will always rest, and the certainty of the law is unconsciously admitted by every paleontologist who determines, names or classifies a fossil from anything less than a perfect specimen. It is assumed every day, and universally allowed, although occasionally even an expert is found who sometimes questions it, and still more frequently an inexpert who does not read nature aright.

The application of the law is, however, various as the given terms, $i$. e., the remains preserved, differ in significance. Thus, certain parts are common to all stoves, and distinguish them from all other articles of furniture; but certain other parts not only belong to a stove, but mark a given pattern of stove, since they belong only to it. A still more minute range of appearances is found only in one man's make of stoves, and others in that of another man. Hence, a person acquainted with stoves, sewing machines, etc., can readily determine the origin of a very small part by referring it to its proper kind and make.

1 From the Introduction to Hayden's reports of the results of the Geological Survey of the Territories, Vol. II. 
This law of persistency presupposes a knowledge of the pattern as essential to its deductive application. Hence a difficulty at once suggests itself as arising when a portion of an animal belonging to a new pattern is discovered. That patterns quite distinct from those known to zoölogists have existed in past ages, has been well proven by paleontologists. How can the structures of a species of such a kind be inferred from a fragment? Another law equally true with that of persistence, has been developed from the facts, but it is much more difficult of application. This is the one already defined in the pages of this journal, ${ }^{2}$ under the name of the law of "successional relation." It is absolutely certain that the types of nature, whether primary or subordinate, form series of steps passing from one condition of relations to another. The application evidently is, that if a portion of an animal exhibits a form intermediate between two known forms or types, the 'remainder of the animal's structure possesses the same kind of intermediacy. This law is tacitly admitted and employed by paleontologists, but there is a difficulty of application in consequence of the existence of other laws now to be considered.

The first difficulty arises from our possible ignorance of one terminus of the series or line in which our fossil represents a stage. This objection is more theoretical than real, because the living classes and orders are the structural extremes of the lines of succession; nevertheless, among divisions of lesser range many have reached their culmination and disappeared in times past. These points of culmination must be known in order to ascertain the direction of the succession. Every discovery, however, is not that of an advanced position on such lines; hence this difficulty is of only occasional recurrence.

The preceding considerations all express different phases of the law of uniformity. I now refer to the law of variation, which is in apparent conflict with it. It is the law which expresses evolution as opposed to persistence of types. It especially limits the application of the last law, that of uniformity in succession, $i . e$., that when one portion of structure occupies a position intermediate between two already known types, the remaining parts of the same animal or system of organs will occupy the same relation 
of structure to the corresponding parts of the known. This is not uniformly true. The law of variation intervenes, which states that it may occur, that while one part of an organization occupies a relation of intermediacy, the other parts do not exhibit exactly the same relation. It is by the unequal mingling of structural points that new lines of succession are marked out. Thus it is that the power of reconstruction from fragments is limited, but not sufficiently so as to justify the epithet "pretension," which has been applied to the claim made. Besides, two other laws remain, which are of great importance to the paleontologist.

Illustrations of the preceding laws may first be given. If a fragment of an animal be found, which contains a certain type of teeth known as the true selenodont, it is certain, in accordance with the law of uniformity of type, that the first bone of the hind foot of that animal (the astragalus) possessed two pulley-grooved faces, one above and one below, and not one only, as in most animals; also, that the lower pulley face was succeeded by two subequal toes, and that the lateral toes were either reduced in form or wanting. There is no mechanical relation between the structures of the teeth and foot; their accordance is simply a fact of type of a selenodont artiodactyle. ${ }^{3}$ Again; if we find a portion of a foot which presents a joint between the first and second rows of bones which form the sole, we are absolutely certain that the animal had the two outer ear bones external to the skull, forming a part of the lower jaw and the connecting rod by which the latter is attached to the skull. This is a type law of the bird and reptile. Again, if I find a part of a foot of the structure just named, where the first row of bones of the sole is united into one mass, and closely embraces the $\mathrm{leg}$ bone without being continuously united, I know that I have an animal with teeth, with a very long hip bone and a very long series of united vertebræ (or sacrum) rcsting upon it-in other words, a dinosaurian.

The law of uniformity in successional relation is well illustrated by the genus Loxolophodon. The first bone of the foot.(astragalus) of this animal, exhibits characters intermediate between that. of the elephants (Proboscidia) and odd-toed hoofed mammals (example, tapir); the remainder of the skeleton does the same; 
the neck vertebræ are similar to those of the former, while portions of the skull resemble corresponding ones of the latter. The foot of a dinosaur is intermediate between that of a reptile and that of a bird; so are the sacrum and pelvis. The sternum of a frog of the family Discoglosside is intermediate between those of ordinary frogs and salamanders; so are the vertebræ and ribs.

Examples of the limitation of the latter rule are still more numerous. They may be produced from the three cases cited. Thus in the Dinosaur it might once have been said that the jaws did not partake of the intermediacy, because they all present teeth, and are never smooth, like those of birds. Yet birds with teeth have recently been discovered, which deprives us of the use of this character as a definition. In the Discoglossid frog the cranium is not intermediate in structure between the frog and salamander, but is that of a frog. In the Loxolophodon the toothless front of the upper jaw is not a general character of either of the orders which it stands between.

These difficulties arise from the existence of the subordinate variations or sub-types of a general or major pattern, and for their resolution require only a new application of the first law of uniformity on the lower plane. If the sub-characters defining the sub-pattern be known, the existence of one presupposes that of the others. The structure of an artiodactyle astragalus will not enable me to infer the character of the incisor teeth of the animal; for this I require some other, more minutely correlated portion. So I can infer the ribs and vertebræ from the sternum of the Discoglossid frog, but not the cranium; for this I require some part correlated with Discoglossid characters only, and not only significant of the relations to the orders of Batrachians, as are the characters mentioned, although it happens by the accident of discovery that none but such frogs possess them to-day.

The two laws which further aid the deductions of the paleontologist are those of mechanical relations and of embryonic parallelism. One structure requires another in order that an animal be viable. Thus long legs in a grazer presuppose a long neck to enable it to reach the ground with its lips. Hooked claws presuppose carnassial teeth or a hooked beak. To be properly poised on two legs instead of four, the weight of the viscera must be transferred backwards and the anterior regions of the body 


\section{The Value of Paleontology.}

lightened. This we find to be the case with birds and Dinosauria. The lower bones of the pelvis with the contained organs are thrown backwards, while the fore-limbs are lightened and the head reduced in proportionate size.

The parallelism of types with transient embryonic conditions of other types aids the paleontologist essentially in the classification or proper location of a specimen. Its relation to known series must be first determined, as this obviously precedes in reconstruction all application of the law of uniformity. Such reference having been made either to a new series or to a place in a known series, the considerations heretofore adduced come into view, but not sooner. Hence the law of parallelism is as essential to the paleontologist, as it is all-pervading and all-expressive of nature herself.

II.

Paleontology in its relation to Geology is a partially empirical science. Thus while its indications are definite for one locality, they have not identical significance for all localities on the earth's surface. The lower we descend in the scale of being, the more uniform over great areas are its phenomena; but among higher animals, especially vertebrates, the greater the geographical peculiarities as compared with the stratigraphical. Prof. Agassiz once said that the existing geographical faunæ are more distinct than the extinct faunæ of two consecutive epochs of geologic time, a statement justified by many facts. Hence it has been believerl by some that fossil vertebrates cannot furnish conclusive evidence of the age of the rock strata in which they occur. For, say they, we have to-day existing on the Australian continent, animals that approach more nearly to those found fossil in the Jurassic formations of Europe than to any now living on the latter continent; so that were Australia to be presently submerged, and her strata and fossils again brought to light, the paleontologist would assert that the sun had not shone on that land since the days of the Jura. And so he would were he not at the same time a zoologist; just as the bare zoölogist would err in the opposite direction of assuming the modern age of the European Jurassic beds, because they contain the living types of Australia. Thus a foundation fact of zoölogy properly applied is essential to the paleontologist; namely, that the earth presents to-day four or more distinct faunal areas, the 
more prominent among which are the Australian, the South American, and the temperate lands of the Northern Hemisphere. Each of these possesses many peculiar forms of life not now found elsewhere. Has this distinction always prevailed? Paleontology answers decidedly in the affirmative, so far as extinct mammalia are concerned. There seems to be no doubt that the faunal distinctions have a very ancient origin, and are therefore to be first considered when estimating the age of strata from the contained mammalian remains. The explanation of this diversity is not yet attainable, but an important advance has been made by the discovery of the great similarity between the extinct forms of the Northern Hemispliere and the living or more modern ones of the Southern Hemisphere faunæ. The Jurassic character of much of the Australian fauna is known, while prevalent types of South America and Africa can be shown to have much relation to Eocene types of the north. In North America and Europe, tapirs, opossums, coatis, civets, kinkajous, lemurs and toxodonts belong to the Eocene; now these animals cliaracterize the southern continental life, or as is the case with toxodonts, have but recently become extinct there. This mode of defining those faunæ is not, however, exact, since many modern types have found their way into them, especially in the case of Africa.

How then is life significant of chronological station in the earth's strata? Since very many forms of animals are so widely spread and at the same time so distinctly limited in range on the earth's surface to-day, the same order must have prevailed in past time and have been of equal significance. That this law of uniformity has prevailed in the past as in the present is amply proven by the paleontology of a single zoölogical area taken by itself. The apparition of types over the northern land area has been nearly universal. This fact has only been placed within our reach by modern investigations in North America; for until the sister continent of Europe-Asia was explored, no one could be sure what degree of individual peculiarity her extinct life might present. Now it is certain that the succession of Tertiary beds was mutually similar, and that the cotemporaneous deposits contained in a large degree similar life, and that intermediate stages of the one can be properly intercalated in the vacant interspaces of the other. The resemblances between 
the Lower Eocenes of New Mexico and Wyoming and that of France are marked; similarity between the Pliocenes of the respective continents is evident. Descending in " the scale, the parallels between the North American and New Zealand cretaceous are very apparent, and the faunæ of the Carolinian and Würtemburgian Trias were the same. The great interruptions in life marked by the appearance of great land areas near the close of the carboniferous and cretaceous periods are universally observed in the zoölogical areas of the Northern Hemisphere or Arclogæa. The close of the cretaceous everywhere saw the end of Ammonites, Rudisites, and Sauropterygian and Dinosaurian reptiles, in spite, in North America at least, of physical continuity of deposits.

Was this succession of interruptions of life universal over the globe, and do these trenchant lines justify the old assumption of repeated destructions and recreations of animal life? The former question has already been answered in the negative by the explanation of the characters of the existing faunæ of the southern hemisphere, where ancient types stili remain in considerable numbers. Moreover, some of the later periods of both North America and Europe are characterized by a large predominance of forms of the corresponding southern continent. It is incleed evident that migration from the one continent to the other has taken place, and is amply sufficient to account for the abrupt changes in the life of each, without necessitating the intervention of creative acts. If glacial periods be dependent on cosmic movements, the obliquity of the earth's axis to the sun would cause an alternation of cold periods in the opposite hemispheres. This is well known as a most potent cause of migration and extinction, and the known relations of the faunæ would thus result from a greater or less alternate invasion of the one hemisphere by the life of the other.

But within the great time boundaries are distinct land faunæ, whose relation of distinction may not thus be accounted for. Thus the Miocene and Pliocene faunæ of Western America are entirely distinct, but with corresponding members. The alternate presence and absence of water areas adapted for the preservation of the remains of the animals will abundantly account for such minor interruptions. Such changing topography is well known as due to the slow vertical oscillations of the earth's crust. 
The original question, the exactitude of the chronological significance of structural types, has been momentarily beld in abeyance. Is paleontology a science so far exact as to furnish a chronological scale of terrestrial strata? The admission that the known tertiary faunæ, for instance, are but fragments of a continuous succession, would appear to invalidate any such claim. It would indicate that the restriction of a given type to a given horizon is only a matter of discovery, and that another accident may at any time give it a new range. This objection has but little weight. Fragments though they be, nearly related formations as the Tertiaries, are obviously the visible portions of a serial succession of life. Like the bright lines in a spectrum, the order is not disturbed by the temporary obliteration of a part of the colors, but the visible portions indicate the relations of the component parts with infallible certainty. The more universal the physical interruption, the more far-reaching the break in the succession of life in any one locality, and hence the greater the value of remains of animals as indication of relation in time. The change of faunæ in Arctogæa at the close of the cretaceous is a case in point. A dinosaur, sauropterygian, ammonite or rudist are as definite indicators of the life that preceded the change as a tapir or civet-like carnivore is of the age that followed.

It has been stated that the life of the present period in the Southern Hemisphere is not homogeneous. The same is true in a stiil smaller degree of the Northern. Thus, if we include India in the latter, the. elephant is a miocene form, and the true rhinoceros pliocene. Further north, the dogs are miocene. In North America the opossum, and probably the raccoon, are eocene; the wolves and foxes are miocene, and the weasels pliocene. Perhaps the cats first appeared in our pliocene. Comparatively few mammalian types mark the latest geologic epochs. Such are the ruminants, as deer, antelope and oxen, with the true horses, which all commence in the upper pliocene of Europe. Finally, man alone signalizes the last or glacial period, and is to reach his culmination in the ages that intervene between that great time boundary and one to come.

Thus a certain proportion only of the life of a given epoch is characteristic of it, that is, originates in it, the remaining members being legacies from preceding ages. $\quad$ E. D. CopE. 




On the supposed Carnivora of the Eocene of the Rocky Mountains.-A nimals which fulfilled the functions of the existing $C a r$ nivora were abundant in North A merica during the Eocene period. The Wahsatch beds of New Mexico have yielded remains of more than a dozen species, which ranged from the size of a weasel to that of a jaguar. Investigation into the structure of these shows that while they differ in minor points among themselves, they agree in possessing characters which distinguish them from the true Carnivora. I have already pointed out, that, in the genera Ambloctonus, Oxyæna, Stypolophus, and Didymictis, the tibiotarsal articulation differs from that of the existing Carnivora, and suggested that these forms might prove to be gigantic Insectivora. Further investigation has satisfied me that they cannot be included in the order Carnivora, and their systematic position proves to be of considerable interest.

A greater or less part of the cranial chamber is preserved in specimens of Oxyæna forcipata and Stypolophus hians. In these animals it has a long, narrow form like that of the opossum, and in the first named, where the interior form can be seen, it is evident that the cerebral hemispheres were small and narrow, and that the olfactory lobes were relatively large, and were entirely uncovered, projecting beyond the bemispheres.

In Ambloctonus, Didymictis, and three undetermined forms, the femur supports a third trochanter. In all the genera the ilium has a well-marked external anterior ridge, which continues from the acetabulum to the crest, distinct from the internal anterior ridge. The ilium has, therefore, an angulate or convex external face, as in Insectivora and Marsupialia, and does not display the usual expansion in a single plane of most of the placentals. In all the genera there is a strong tuberosity in the position of the anterior inferior spine, which is wanting in the Mammalia, excepting certain Insectivora and Prosimix ${ }^{2}$ although it marks the position of the origin of the rectus femoris muscle in all types.

The glenoid cavity of the squamosal bone is transverse, and well defined anteriorly and posteriorly, as in the Carnivora. of the first series of carpal bones of the four genera named, I have been able to learn nothing, but in the genus Synoplotherium from the Bridger Eocene of Wyoming, which probably belongs to this group, the scaphoid and lunar bones are separate and not united as in the Carnivora.

The above characters point to the Marsupialia or the Insectivora as the proper location for the flesh-eaters under consideration; and the evidence is much more weighty in favor of the latter order as their true position. For in the genera Oxyæna and Didymictis the posterior part of the inferior border of the mandibular ramus is not inflected as in Marsupialia, nor are the anterior inferior iliac tuberosity and thild trochanter seen in that order, while both exist in the Insectivora.

Cuvier describes ${ }^{8}$ the tibia of Carnivora as follows: "Quant à

I Systematic Catalogue of the Vertebrata of the Eocene of New Mexico, 1875, p. 7 .

2 See the figure of Solenodon by Peters, and Ohiromys by Owen.

3 Ossemens Fossiles, vii. p. 112. 
la tête inférieure, tous les carnassiers se distinguént de l'homme par sa figure plus étroite du côte externe que le l'interne, et par sa division en deux fosses oblique, an moyen d'une arête arrondie qui repond à la partie de l'astragale. . . Le phoque l'a cependant d'une forme très-particulière par l'excessif aplatissement de sa moitié supérieure, et par sa facette particulaire inférieure, qui est en concavité simple et peu profounde."

The astragalar articular face of the tibia in the genera above named is not divided into the two oblique fossæ by "a rounded crest which is applied to the groove of the superior pully-shaped face of the astragalus." It is uninterrupted and more or less oblique in the transverse direction; always so at the posterior border. The inner malleolar process is produced downwards, and rests in a concavity on the inner side of the neck of the astragalus. The astragalus, which I have seen in several of the species, presents a corresponding trochlear face. That is, instead of a groove, it presents an open angle upwards, which separates the superior from the oblique internal face. The superior plane is flat, but is interrupted on the posterior side by a groove. This groove is the posterior extremity of that which divides the superior face of the astragalus in the higher Mammalia, but here it contracts to a point and disappears next the fibular face just as it reaches the superior surface. The fibular face is vertical, and shares on its posterior part a large ligamentous fossa with the opposed part of the fibula. The distal end of the fibula is remarkably stout.

This structure finds its counterpart in the internal half of the astragalus of the opossum. The arrangement permits a rotary movement of the astragalus and thus of the whole foot, on the tibia, the fibula with its fixed articulation with the astragalus, rotating on the tibia, as in the pedimanous Marsupialia. The flatness of the inner malleolus in some of the species indicates that the capacity for rotation was less in them than in others. This arrangement exactly reverses the extensive oblique fibulo-astragalar articulation seen in the opossum, the Petaurista, Dasyurus, etc. Prof. Owen, in describing the astralagus of the wombat (Phascolomys), says: "The upper articular surface for the tibia is as usual concavo-convex, the internal surface for the inner malleolus flattened, and at right angles with the preceding, but the outer articular surface presents a triangular flattened form, and instead of being bent down parallel with the inner articular surface slopes away at a very open angle from the upper surface, receiving the articular surface of the fibula so as to sustain its vertical pressure. * * * This form of astragalus is also characteristic of the Koala, Petaurists, Dasyures, and the Pedimanous Marsupialia."

In one species where the cuboid bones are preserved, it is evident that the distal end of the astragalus articulated with this as well as with the navicular bone, although the facet of the astragalus is single and continuous. As the extensive transverse distal astragalar face is characteristic of all the species where it is preserved, the contact of the cuboid and astragalus is probably common to all of this division.

The dentition of this group is consistent with its reference to 
the sarcophagons Marsupialia or to the Insectivora. It has, however, decided resemblances in the form of the molars, and in the deficiency in the number of the inferior incisors, to such genera of Insectivora as Mythomys and Solenodon, while in the large canines, it more nearly approaches Sarcophaga and Carnivora.

I propose to include the genera Ambloctonus, Oxyæna, Stypolophus, and Didymictis in a special division under the name of Creodonta. This division may be regarded as a suborder of the Insectivora. It is possible that the genus Diacodon Cope belongs here also ; its species resemble Chiroptera in the inferior dentition, and are of small size. The genus Mesony $x,{ }^{1}$ which I discovered in the Bridger beds of Wyoming, cannot be referred to the Creodonta as here constituted, since the trochlear face of the astragalus is completely grooved above as in the true Carnivora, and its distal end presents two distinct facets, one for the cuboid and the other for the navicular bones. It represents on this account a peculiar family, the Mesonychida.

To the Creodonta must be referred the genera Pterodon and Palæonictis of De Blainville, from the French Eocene. This author and Pomel placed them in the Marsupialia, but Professor Gervais remarks (Geologie et Paleontologie Française) that the evidence is insufficient for such a course. Here also doubtless belong supposed Carnivora from the Wyoming Eocene, stated by Marsh to be allied to the Viverridæ.

The remarkable type first introduced to the notice of paleontologists by Leidy, represented by the genera Anchippodus, Ectoganus, etc., has been looked upon as an order of Mammalia by Marsh, and termed the Tillodontia. He gives, ${ }^{2}$ as its characters, the possession of claws, plantigrade feet with five toes, a third trochanter of the femur, and separate scaphoid and lunar bones. Also, that the dentition is characterized by "molars of the ungulate type," small canines, and large scalpriform incisors in both jaws, faced with enamel and growing from persistent pulps as in the Rodentia. He says this order "s seems to combine characters of the orders of carnivores, ungulates, and rodents."

Except in the dentition, the definition above given applies to the Creodonta; and an analysis of the dentition shows so many points of resemblance as to render it probable that they pertain to the same order of Mammalia. Also, except in the dentition, the characters given by Prof. Marsh do not differ from those of the Insectivora. 'The structure of the superior molars is not inconsistent with the same order, and the small canines and large incisors are even more like those of most Insectivora than are Creodonta. The singular form of these incisors, and their growth from persistent pulps, is rather characteristic of Rodentia. The transverse or tubercular premolars also distinguish this group from both the Creodonta and the true Insectivora. The definitions of the order and sub-orders will then be as follows:-

I Ann. Rept. U. S. Geol. Surv. Terrs., 1872, p. 550.

a Amer. Journ. Sci. Arts, $1875,231$. 
INSECTIVORA.-Mammalia with small cerebral hemispheres which do not cover the olfactory lobes, nor the cerebellum; with numerous clawed digits, and a third trochanter of the femur; with a transverse glenoid cavity for the mandible.

Superior incisors normal, not growing from persistent pulps; canines large; premolars compressed. Astragalus not grooved above, articulating with the cuboid as well as the navicular; five toes on the hind foot;

Creodonta.

Superior incisors large, growing from persistent pulps, and withont enamel on the sides; superior canines small when present; premolars wide or tubereular ;

Tillodonta.

These suborders of the order Insectivora do not differ among themselves more than do those of the Marsupialia, and constitute a series of parallels with them. Thus the Creodonta resemble the Sarcophaga, the Insectivora vera the Entomophaga, and the Tillodonta the Rhizophaga, typified by Phascolomys.

The genera of the Creodonta differ as follows:-

I. First and third inferior true molars without internal cusp. Last superior molar longitudinal ; last inferior molar carnassial; Ambloctonus.

II. Inferior carnassials with interior tubercle; no tubercular molar; last superior molar transverse.

Three tubercular carnassials ;

Two tubercular carnassials ;

Stypolophus. Oxyæna.

III. Inferior carnassial with interior tubercle; a tubercular molar.

One tubercular carnassial;

Didymictis.

The number of toes on the hind foot cannot be certainly stated in all the genera, but in Stypolophus hians and another species there were probably five, the inner being of reduced size. There is present in those species an ento-cuneiform bone which resembles that of Canis; it is compressed, with one truncate concave terminal facet, and an internal oblique one at the opposite and proximal extremity. The form of the truncate articular face of the distal end indicates the existence of an inner metatarsal bone of moderate proportions, which probably supported a small hallux. This thumb could not be opposable as in the opossum.

In general appearance the Creodonta differed from the Carnivora, in many of the species at least, in the small relative size of the limbs as compared with that of the head, and in some instances, as compared with the size of the hind feet. The feet were probably plantigrade, and the posterior ones capable of some degree of rotation. The probable large size of the rectus femoris muscle indicates unusual power of extension of the hind limb. They were furnished with a long and large tail. Probably some of the species resembled in proportions the Mythomys and Solenodon, now existing in Africa and the West Indies, but they mostly attained a much larger size. Published December 22, 1875.

1 For the meaning of these expressions, see Syst. Cat. Eoc., New Mexico, 1875, p. 6. 






\section{PALEONTOLOGICAL BULLETIN No. 24.}

$A$ continuation of Researches among the Batrachia of the Coal Mecusures
of Ohio.

By E. D. CoPE.

(Read before the American Philosophical Society, February '3, 1877.)

The material described in the following pages was obtained from the coal strata at Linton, Ohio, during the Summer of $18 \% 6$, by Prof. J. S. Newberry, Director of the Geological Survey of Ohio.

ICHTHYCANTHus oHiensis. Cope. Gen. et sp. nov.

Char. Gen. These are derived from the posterior dorsal and caudal vertebræ, with adjacent parts. Posterior limbs well developed, with dis. tinct tibia and fibula, osseous tarsus, and probably five digits. Ribs elongate, simple, curved. Abdominal armature consisting of bristle-like rods in anteriorly directed chevrons. Dorsal vertebræ not elongate, with simple neural spines. Tail large, its vertebræ ossified, and furnished with slender chevron bones which terminate in a hæmal spine. Neural spines slender and directed backwards; the caudal series somewhat resembling that of a fish. All the centra amphicœlian.

This genus differs from all those with enlarged and sculptured neural spines, and from those with abdominal scuta. It is equally distinct from those without ribs, abdominal rods, or limbs. It is possible that some of the species referred to Tuditanus, in which these parts are unknown, may belong to it, or that it may be established on a small species of Leptophrac-

PROC. AMER. PHILOS. SOC. XVI. 99. 3T 
tus, a genus only known as yet from cranial remains. With present knowledge the reference of the 1 . ohiensis to the latter genus is inadmissable. The cranium, thoracic region, and fore-limbs of Tchthycanthus are unknown.

Char. Specif. The centra of the dorsal vertebræ are about as long as deep, and their sides are deeply concave : there are four anterior to the pelvis which are without ribs. The caudal vertebræ are robust, and seven from the first, support a small tubercule-like diapophysis. The chevron bones are short and acuminate; the neural spines are a little shorter, narrow and truncate, and directed backwards at the same angle as the chevron bones. They are much reduced on the eighteenth caudal vertebra, where the chevron bones are considerably longer.

The abdominal rods are quite slender. The hind limb is quite stout for this order. The femur is regularly expanded at both extremities, but the distal is deeply and openly grooved, distinguishing the condyles, while the proximal end is plane. There is no trochanter visible. The ulna and radius are well separated, and are three-fifths the length of the femur. There is a large fibulare tarsal bone of a subquadrate outline. In immediate contact with it is the probably external digit with five phalanges or segments ; the ungual is simply conic. The femur is as long as five dorsal vertebræ. The ribs have expanded, undivided heads, and extend to the abdominal armature.

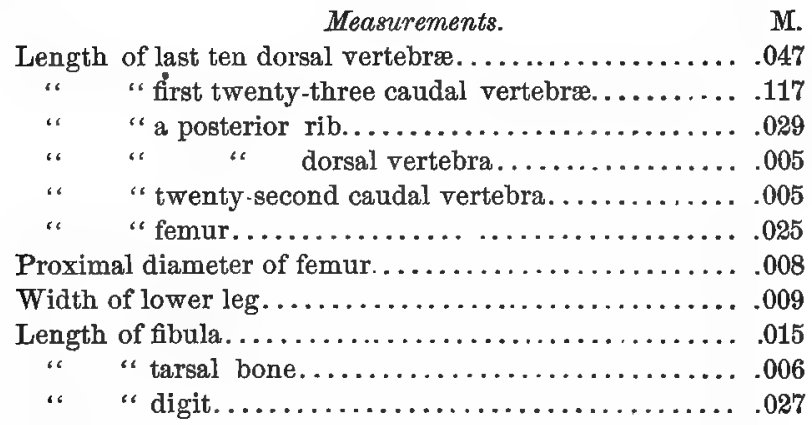

This salamander is about the size of the Menopoma allegheniense.

ICHThXCANTHUS PLATYPUS. Sp. nov.

This batrachian is represented by almost the same portions of the skeleton as the preceding species, furnishing a good basis of comparison. It is very well preserved. displaying the characters especially of the hind foot, which is almost entirely represented.

Several features distinguish it from the $I$. ohiensis, one of which is of more than usual value if correctly indicated by the fossil. There are ten vertebræ from anterior to the sacrum preserved in place, and none of them supports a rib, nor are there any ribs visible anywhere on the block of shale. I suspect that they exist on more anterior vertebræ, or may have been displaced to a more anterior position than they normally occupy. 
The abdominal chevrons are more anterior in position than are those of the $I$. ohiensis. The hind legs are longer than in that species; in this one the femur equals seven and a-half vertebral centra in length. The external digit on the other hand, while bearing five phalanges, is distinctly shorter. The fibular tarsal is of a transverse oval, not quadrate, form.

The dorsal centra are short and deeper than long; the neural arches are elevated, with short but distinct zygapophyses, and a flat subquadrate, superiorly truncate neural spine. They bear short, vertically compressed diapophyses near the bases of the arches. The neural spines of the caudal vertebræ become rapidly more slender, and also diminish in length, while the zygapophyses are conlinued to the fifteenth vertebra, where the series is broken off. The chevron bones are slender, and enclose a moderate hæmal arch.

The femur is gradually expanded to the extremities. Proximally there is a trochanteric ala besides the obtuse head. Distally the condyles are well distinguished, the external or fibular being truncate. The fibula is less than three-fifths the length of the femur, and is expanded at both extremities. Two proximal tarsals are distinct; the one next the fibula is larger than the other and transverse suboval in form. It has a median dividing ridge as though composed of the fibulare aud intermedium coössified. The tibiale is subtriangular. There are five distinct phalangeal tarsals. The toes are in the order of their lengths beginning with the shortest, 1-2-5-3-4. Their phalanges (including metatarsals) are, in the proper order, commencing with the hallux, 3-3-4-?5-5; the distal end of the fourth finger being lost. These bones are rather stout, and the unguals are simply conic. The form of the foot is short and wide. The number of phalanges is nearly similar to that I have found in the $A m p h i$ bamus grandiceps, excepting that in that species the fifth digit has but four. They are more numerous on most of the digits in Sauropleura digitata.

Measurements. $\mathbf{M}$.

Length of ten dorsal vertebræ................ 045

" " fifteen caudal " . ................. 055

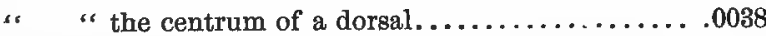

Total elevation of a posterior dorsal............... .014

" of posterior of zygapophysis of dorsal.......... 010

Length of femur........................ 032

Diameter of femur medially.................. 0045

" " " distally ................... .0083

Length of fibula............................ 018

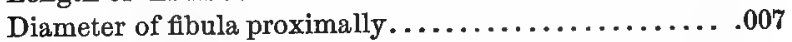

Width of sole at second row of tarsal bones. ......... 017

Length of foot to end of third digit....................

" " first digit.............................. .

" " third "

" " fifth " $\ldots \ldots \ldots \ldots \ldots \ldots \ldots \ldots \ldots \ldots \ldots . . . \ldots 20$ 


\section{LEPTOPHRACTUS LINEOLATUS. Sp. nOV.}

This large batrachian is represented by the middle portion of a cranium, including parts of both jaws with numerous teeth. It is not easy to determine which of the tooth-bearing bones preserved is maxillary and which dentary, but the lighter and thinner of the two is presumably the latter, although it has the greatest vertical depth. The opposing bone supports two types of teeth, and as this is only the case in the maxillary of Leptophractus obsoletus, the present bone may be provisionally referred to that position.

There is a great difference in the sizes of the two types of maxillary teeth, the larger having nearly three times the linear dimensions of the latter. The small ones are rather distantly placed, being separated by interspaces nearly equal to their lengths. They are cylindric at the base, but become compressed, and have two opposite cutting edges on the apical third. They are of rather slender form, and are striate at the base. The longer teeth have a similar form, but are less strongly compressed distally, where there are two opposite cutting edges. The basal portion is quite closely striate. These teeth are on a different basal line from the small ones, since when their bases are removed the latter appear behind them. Three smaller teeth stand in the spaces between two large ones.

The mandibular teeth are intermediate in size between the large and small ones of the maxillary series, having a little more than half the linear dimensions of the former. Their terminal three-fifths are compressed, and furnished with fore and aft cutting edges.

The surface of the bone, where visible, does not display the punctate sculpture of that of the $L$. obsoletus, but is nearly smooth, displaying only fine parallel incised striæ.

$$
\text { Measurements. }
$$

Depth of dentary bone at middle................. .030

Length of mandibular tooth. .................... .009

Antero-posterior diameter of mandibular tooth at base. . .0035

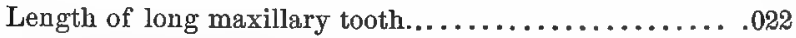

Antero-posterior diameter do. at base................006

Length of small maxillary tooth..................007

Antero-posterior diameter do. at base.............. .002

The smaller size and slender form of the smaller maxillary teeth, as well as the peculiar sculpture distinguish this species from the $L$. obsoletus.

Another specimen of Leptophractus resembles the one above described in the form and disposition of the teeth, and has the osseous surface of both maxillary and dentary bones marked with shallow grooves and punctate impressions which do not inosculate. In this it resembles the maxillary bone of the large specimen figured on Plate XXXVII of the second rolume of Paleontology of the Report of the Geological Survey of the State of Ohio. 
Tuditanus tabulatus, Sp. nov.

This species is indicated by a specimen which includes a cranium, and the anterior part of the vertebral column. It is very well preserved on a block of shale, on both faces, aud exhibits the constituent pieces of the cranium, the vertebræ, one of the thoracic shields with probable ribs. In al] respects it conforms to the genus Tuditanus in characters; presenting a broad, flat head; osseous vertebræ and ribs; thoracic shields present, and abdominal chevrons probably absent. The last character is not absolutely assured, since the posterior two-thirds of the vertebral columns are wanting.

The cranium is wider than long, and the muzzle is broadly rounded. The orbits are wide ovals, and their posterior borders fall little behind the transverse line dividing the skull equally. The interorbital width equals the longitudinal diameter of the orbit. The posterior outline of the cranium is truncate in a straight, transwerse line between the prominent epiotic angles. The distal extremities of the quadrates do not project so far backwards as the epiotic angles, and are still further removed from a transverse line marking the extremities of the occipital condyles. In this respect this species presents a strong contrast to the Pelion lyellii, where the ends of the quadrates extend posterior to the latter points. The composition of the superior cranial walls much resembles that of the Tuditanus radiatus. The epiotics are large bones, longer than wide, and present outwards strong angles, which correspond with the horns of Ceraterpeton. They enclose between them the posterior portion of the parietal, and the supra-occipital. The latter is a transverse bone, and not quite symmetrical in the specimen, one end having a greater antero-posterior extent than the other. The parietal is the largest cranial bone, is undivided, and is pierced by a median foramen behind the centre. Its general form is broadly wedgeshaped, the lateral borders expanding in front of the fontanelle, and contracting between the epiotics. The frontals are distinct and rather narrow. The post-frontals are rather large, are in close connection with the parietal on one side and the jugal on the other, and send a point backwards between the epiotic and supratemporal. The jugal widens fan-shaped backwards, joining two bones distally, a superior and an inferior. The former is the supra-temporal, but whether the inferior is quadratojugal or squamosal, I cannot determine. The boundaries of the bones of the extremity of the muzzle are not distinct.

The sculpture of the surface of the cranium consists of parallel ridges which are separated by grooves equal to them in width. The ridges radiate inwards on the epiotics and frontals, and ontwards on the squamosal, and are transverse and interrupted on the supraoccipital. The lateral thoracic shield is covered with a similar sculpture of uninterrupted somewhat radiating ridges. The vertebre are osseons, and rather small compared with the size of the skull. Opposite to the posterior extremity of the pectoral shields is a pair of slender bones, which are gently expanded and truncate at the extremities. It is not certain whether these belong to the 
forearm, or are a pair of short ribs. Impressions only of the teeth remain ; they indicate small pleurodont denticles like those of the Anura.

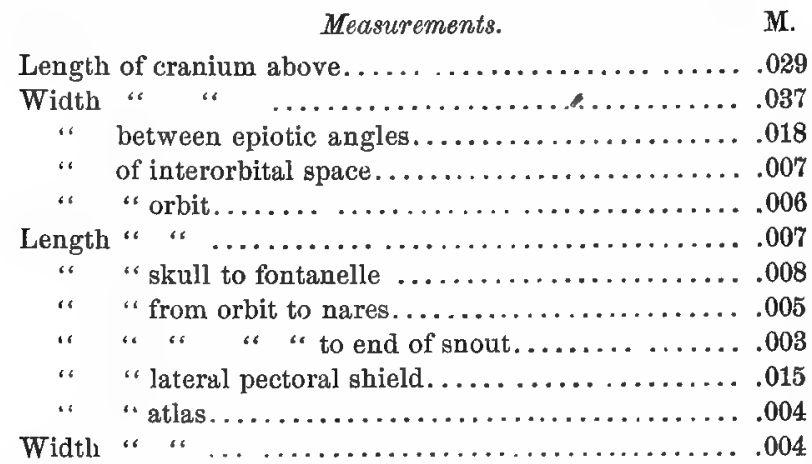

This species of Tuditanus differs from the T. radiatus in the larger and less anteriorly placed orbits, and in the large truncate posterior table of the skull. The proportions of the latter are more those of $P$. obtusus, but the epiotic angles have not been observed in this species, the sculpture is punctate not linear, and the form of the supraoccipital is quite different. Comparison with the other species referred to that genus is unnecessary, excepting in the case of the T. mordax. Further examination of the specimen on which the latter was founded leads to the belief that it is an imper. fect cranium of Oeraterpeton punctolineatum Cope. The latler name, as the preferable one, may be adopted, and the former becomes a synonym.

Colostedos scutemiatus, Newberry; Cope, Rept. Geol. Surv. Ohio, Paleontology Vol. II, p. 407.

Another specimen of this species was obtained by Prof. Newberry during the past season, which includes some parts of the skeleton not previously observed.

The specimen presents a superior view of the ventral and thoracic protective armature, and of the posterior portion of the cranium. As heretofore, I find no indications of vertebræ, but along one side of the ventral scutellation, a series of slender ribs lies in the matrix. These I lave not previously found in this genus. The cranial surface is only preserved on the lateral portions. Its sculpture consists of coarse grooves closely placed, directed outwards and forwards. 
On a Dinosaurian from the Trias of Utah.

By E. D. Cope.

(Read before the American Philosophical Society, February 16th, 1877.)

\section{Drstkophatus, Cope.}

This genus reposes on scanty remains, but which are in good preservation, and which present marked characters. The bones consist of the humerus, three metatarsals, some ?tarsals, and the distal end of an ? ulna, with a probable sternum and an inferior element of either the scapular or pelvic arch, probably the latter. There is aiso a number of fragments, which are not easily identified. The specimens were discovered by Prof. J. S. Newberry in South-eastern Utah, while acting as Geologist to the Engineer Exploring Expedition under the command of Captain McComb, United States Army, He excavated them from the red and green rocks usually referred to the Trias, hence from the same formation which yielded the Typothorax already described. Professor Newberry made sketches of the bones as he exposed them. They were all, he states, found in close proximity. the bones of the limb in nearly normal relation. It is altogether probable, according to Professor Newberry, that they belong to a single animal. I find nothing to forbid this supposition and much to confirm it.

One of the most remarkable bones is a broad, flat element, one of whose borders is digitate, the processes being long, and separated by deeply entrant sinuses. Two sides of the bone are broken away, but the others give origin to five digitiform processes. Two of these are larger and longer than the others, and externally on the right side is a shorter one. Outside of this is a larger process whose extremity is recurved so as to be subparallel with the longer processes, and which was connected with another bone by an articular surface. This information is derived from Prof. Newberry's notes made in the field. It is probable that this bone is the sternum, and that the articulation mentioned is costal. It is not certain whether the longitudinal meridian line passes through a sinus or a digitation, but a projection of the surface of the plate, which is probably median, is opposite one of the latter. Supposing then that the sternum is produced into a median posterior process, we find a resemblance to the corresponding element in many birds not heretofore known among reptiles. There are in that case three postero-externally directed processes on each side, of which the two posterior are free. Another interpretation might be that it is a coracoid with anterior digitations. In this case the articulation above mentioned would be anomalous. The number of digitations is too great for this element, and the space remaining for contact with the sternum is too small.

Another large flat bone approximates a right-angled triangle in form, the length greatly exceeding the width. The right-angle is massive and 
produced, and is evidently the point of connection with the other parts of the skeleton. The bone is flat on one side and convex on the other, and can only be identified with probability, with the scapula of a Dinosaurian reptile.

The large size of the anterior limb, which might be inferred from this scapula, is justified by the humerus, which is preserved in almost perfect condition. This humerus is one of the longest, and is distally the most contracted known in the Dinosauria; the proximal extremity is of the form usual in that order. A short distance below the head, the section is Tshaped, with one end of the transverse limb shorter than the other. The ridge of which this limb is a section, is almost wanting at the head, which

- is thus $I$-shaped. The limb representing the stem of the $T$ is stouter than the others, and forms the summit of a massive column, which soon sinks into the shaft. Its free extremity is obtuse and rounded, and though representing the head. does not rise above the level of the other crests, or tuberosities. The distal extremity of the humerus looks 'much like that of a tibia. It is truncate, and its long axis is in the plane of the tuberosities of the head. Its ontline is oval, one end narrowed to an angle, and the other broadly rounded. The surface is roughened with coarse pits.

The distal extremity of another long bone, most probably the ulna, is more robust than that of the humerus. The shaft is a flattened oval, and the articular extremity is a wide and somewhat irregular oval, the greatest transverse diameter being nearer one end. The articular surface is roughened with coarse pits.

Three metatarsals were found in immediate proximity to each other, two in nearly their normal relations, and one slipped forwards. They are neither remarkable for length nor abbreviation. The proximal ends are truncate, and the distal ones convex, but without distinct median grooves or lateral angles. Both extremities are moderately expanded, and the shafts are contracted at the middle. The external bone is a little shorter than the two others, and is more flattened. It has a slightly-defined convex head, with an adjacent prominent, but ill-defined, lateral crest. The larger of the longer bones has a crest at one angle, like that of an olecranon process. The proximal end of the same bone is massive, and is trapezoidal in outline; the outline of the corresponding head of the adjacent bone is triangular. A marked character of these bones is the rough or pitted surface of their articular extremities, except the distal end of the shorter bone. The shafts are solid, and filled with nearly equal, coarse cancelli.

The bones above described are evidently those of a Dinosaurian reptile, and they present characters which have not been previously observed in any other genus of the order. The form of the condyles of the humerus distinguishes it from the other known genera, especially from those of the European Trias, where the crest is weak or wanting.

The rugose articular surfaces are also peculiar, indicating less than the usual mutual movement of the bones upon each other. A cartilaginous cap is indicated, which was probably the element from which the mam- 
nalian epiphysis was derived. The sculpture of the surfaces is coarser than that to which epipliyses are attached in the Mammalic. The name of the genus expresses this character.

It is altogether probable that this genus embraced terrestrial animals, with powerful fore-and hind-limbs subequally developed. The typical species is of gigantic proportions.

\section{Drstrophats}

In the supposed sternum of this animal (which I have not seen, but which was sketched by Professor Newberry), a rather small, slender and compressed process projects from near the middle of one of the sides at right angles to it. Only two of the lateral processes are represented as complete. The longer is subspatulate; the shorter subacuminate. The scapula presents three complete borders, - the proximal and two lateral ; but the distal is not known. Without it, the length is two and one-half times the breadth. The point of junction of the longer (and perfect) short border with one of the long borders, is much thickened, terminating in a mass of bone which is unfortunately broken, but whose section in the line of the end border is a wide oval. From this point, the plate thins away to the various borders. The greatest thickness is nearer the border which terminates in the enlargement described. This surface is then gently convex in transverse section, while the opposite one is concave to a less degree. It is thicker at the widdle than at the anterior border in a longitudinal direction.

The proximal extremity of the humerus is much expanded. The greater tuberosity is a huge crest, as prominent as the hearl, and separated from it by a marked concavity which constricts the mass connecting it with the bead, thus forming a neck. This concavity extends about one-third the length of the shaft. On the opposite side of the head a similar concavity excavates the shaft, separating the internal from the interior ridge. The latter is in its middle portion as prominent as the external ridge, and extends as far downwards. The extensive external face of this part of the bone is nearly flat.

The internal ridge descending from the head, continues into the posterior border of the interior face of the shaft. The great tuberosity continues into the single external ridge of the shaft, which is thus near the niddle triangular in section, the base of the triangle internal. The external extremity of the distal end is therefore an angle, and the internal a convex side, shorter than the anterioi and posterior sides. A ligamentous groove marks the posterior border of the extremity at a point measuring one-third of its length from the externai angle. The expanse of the distal extremity is not more than three-fourths that of the proximal. The entire bone so resembles a tibia, as to have induced me to refer it at first to that element. The characters of the proximal end are such as to render such identification highly improbable. Such reference would also require that the distal extremity should have a fore and aft direction, an arrangement incompatible with the tibia.

PROC. AMER. PHILOS. SOC. XVI. 99. 3U 
The displaced metacarpal is flattened, and expanded at the extremities; One side is nearly flat, but slightly concave in the longitudinal direction; the other side is convex and nearly level in the longitudinal direction, The lateral borders of the shaft are thus narrowed. The distal end displays a convex condyle, and a flat, prominent ala, which is in the general plane. The ala is separated from the condyle by a deep groove on the convex side, The condyle is a half-hemisphere only, presenting only with the convex sicle of the shaft, from which it is not separated by a constriction. It is bounded at its distal edge by an angle, which is a continuation of the proximal edge of the ala. The proximal extremity is injured at nne angle, but, with this complete, would be nearly a regular rhomboid with parallel longer and shorter outlines; the acute angle of the latter being the continuation of the lateral border of the shaft. The extremity is subtruncate, and part of the surface is irregularly excavated by pits and grooves. The transverse extent of the proximal end, when perfect, was probably a little greater than that of the distal.

The two adjacent metacarpals are subequal in length, and longer than the displaced one by one-fourth the length of the latter. One of these bones is throughout rather thicker than the other, although the transverse diameter of the shafts is equal; but the stouter bone is considerably more dilated at the extremities. The distal end of the stouter bone is thickened in the direction at right angles to the plane of the limb; but the chief expansion is in that plane. The angle next to the other bone is protuberant, while the other angle is expanded into a sharp, convex crest, or ala. A section of this extremity is diamond-shaped, with one of the lateral planes produced into this crest, while the corresponding border of the opposite side drops down, being represented by a mere convexity of the surface which continues to the crest. The surface of the extremity is irregular. The section of the shaft is a broad oval, becoming subcircular near the proximal extremity. The latter is enlarged in both directions. It is a rectangle in outline, a little extended in the plane of the limb, with one of the angles cut off from the corresponding angle to the middle of one side. The long side thus left is slightly convex, and ends in an angle. The side subtended by this angle is slightly concave, and is approximated to the other bone: The opposite side is slightly emarginate near the middle. Its surface is very slightly convex, and is irregularly grooved and pitted.

The more slender of the two bones is but little and about equally ex: panded at the opposite extremities. The distal end would have an ovoid section, but for the fact that it is obliquely truncate at the extremity next to the other bone. It is convex in the antero posterior direction and plane in the transverse; its surface is grooved and pitted. The side next to the other bone is Hat or slightly concare at the distal end, and, though thicker than the external border, becomes rounded at the middle of the shaft, and is again flattened at the proximal extremity. The external border is distally produced into an obtuse angle; lower clown, the shaft has a thin, angular border. The proximal end has less antero-posterior diameter than 
the distal, and is stubtriangular in outline; the apex being acute and external. The surface is fat, and is strongly marked with deep grooves. The other surfaces of the limb-bones are smooth, except a few weak ridges near the distal ends of the two distal bones.

Meusurements., M.

Length of part of scapula preserved............. 0.680

Width at middle........................ 0.270

Thickness at middle........................... 0.048

Thickness at proximal angle................ 0.117

Total length of humerus.................. $0.76 \overline{5}$

Diameter of proximal end $\left\{\begin{array}{l}\text { at head } \ldots \ldots \ldots \ldots \ldots \ldots .0 .080 \\ \text { at tuberosties } \ldots \ldots \ldots \ldots\end{array}\right.$

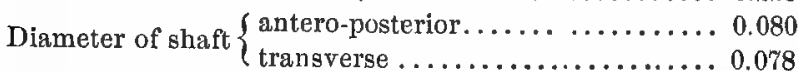

Diameter of distal end $\left\{\begin{array}{l}\text { antero posterior........... } 0.085 \\ \text { transverse }\end{array}\right.$

Transverse diameter of head of humerus.......... 0.160

Diameter of extremity of ? ulna $\left\{\begin{array}{l}\text { antero-posterior..... } 0.110 \\ \text { trgngverse }\end{array}\right.$

Length of external metacarpal. ................. 0.210

Proximal diameter $\left\{\begin{array}{l}\text { antero-posterior............... } 0.045 \\ \text { transverse.................... } 0.100\end{array}\right.$

Diameter of shaft $\left\{\begin{array}{l}\text { antero-posterior. . . . . . . . . . . . . } 0.033 \\ \text { transverse } \ldots \ldots \ldots \ldots\end{array}\right.$

Diameter distally $\left\{\begin{array}{l}\text { antero-posterior................ } 0.050 \\ \text { transyerse }\end{array}\right.$

Length of median metacarpal (stouter) ............ 0.245

Diameter proximally $\left\{\begin{array}{l}\text { antero.posterior............. } 0.057 \\ \text { transverse. . . . . . . . . . . . } 0.115\end{array}\right.$

Diameter of shaft (transverse) $\ldots \ldots \ldots \ldots \ldots \ldots \ldots . . \ldots . \ldots 55$

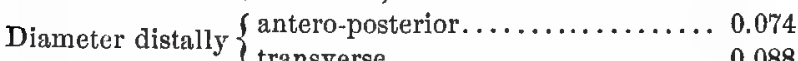

Length of median metacarpal (slender).......... 0.240

Diameter of proximal end $\left\{\begin{array}{l}\text { antero-posterior......... } 0.057 \\ \text { transverse . . . . . . . . . . } 0.089\end{array}\right.$

Diameter of shaft (transverse) ................. 0.049

Diameter distally $\left\{\begin{array}{l}\text { antero-posterior............... } 0.041 \\ \text { transverse..................... } 0.088\end{array}\right.$

More than usual interest attaches to this fossil. It is the first one found in the Triassic beds of the Rocky Mountain region, and was derived from an inhospitable region rarely traversed by white men. The locality is in the Painted Canyon not far from the Sierra Abajo in South-eastern Utah, near the Colorado boundary ; lat. $38^{\circ} 15^{\prime}$; lon. $110^{\circ}$. This canyon is one of those tributary to the Great Colorado River, and is without water. The rock is described by Prof. Newberry as the same as that which I 
have identified in New Mexico as the Trias, and is of the usual red color. The occurrence of a terrestial Dinosaurian at that locality tends to confirm the conclusion to which I have already attained, that this immensely extended deposit is of lacustrine character.

\section{On a Nezo Proboscidian.}

BY E. D. COPE.

\section{(Read before the American Philosophical Society, March 2, 1877.)}

I recently received from a correspondent in one of the Southern States, a fossil of unusual interest. It is a molar tooth of a proboscidian, whose color and mineral character indicate that it was derived from beds of the Upper Miocene or Loup Fork epoch. Its roots are largely broken away, while the crown is nearly perfect.

The crown consists chiefly of two transverse crests, which are separated by a deep uninterrupted valley. There is no general cingulum. Eacl crest is clivided into three lobes, which are not deeply separated, but cause the edge of the crest to be serrate with three conie eminences. Of these the median apex has a rounder section, while the lateral are more transverse, rising at the external borders like the extremities of the crests in Mastodon ohiotious. The appearance of the base of the crown at one extremity indicates that it was in contact with the preceding tooth. The opposite extremity of the base presents no such surface, and hence points to the conclusion that the tooth is the last one of the series. From the middle cone of the anterior crest a cingulum descends on each side, passing round the anterior base of the external cones. It is wanting at the extremity of the base of one of these, and little developed on the other, but they reappear on the side of the base bounding the valley. They are crenately tubercular, except at the base of the median anterior tubercle. There is no cingulum at the base of the posterior crest, except the ordinary filling between the bases of the lobes. One of the extremities of the crests is a little higher than the other, and the basis is a little wider than at the other end ; it is therefore probably external in position. At the posterior base of this end is a fractured surface indicating a cingular tubercle of stout proportions, such as is more in place at the external posterior angle of the last superior molar than in any other tooth.

The external cone is defined from the median by a fissure, while a better defined depression separates the median from the internal. This depression is filled by a worn tubercle in the anterior crest. Ridges descend along the adjacent borders of the constituent cones nearly to the fundus of the valley, and the bases of the external ones are considerably wrinkled.

Measurements. M.

Transverse diameter of crown...................130

Longitudinal "s "c internal............ "070

" " $"$ external ............090




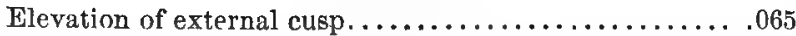

" internal " $" \ldots \ldots \ldots \ldots \ldots \ldots \ldots \ldots \ldots . . \ldots 55$

Length between apices of external cusps........... .043

The molar tooth described exceeds in transverse dimensions that of the Mastodon ohioticus, and evidently belonged to one of the most colossal of land animals. Its generic position is near to Mastodon and Dinotherium, but if the tooth on which my observations are based be complete, it is distinct from either. The possession of only two transverse crests separates it from the former, and would, were the tooth an anterior molar, refer it to the latter. As it appears to be a posterior molar, this view of its affinity becomes untenable, and I therefore establish for it a new genus, under the name Cænоваsileus. The tooth described resembles that of the genus Tapirus, but differs in the absence of the external trihedral enlargement of the cross crests seen in the superior molars of the former, and a]so in the tubercular and fissured character of the crests proper. The species may be called $C$. tremontigerus.

The typical specimen was probably obtained in Texas, but I am not yet informed as to the precise locality.

ISSUED MARCH 19, 1877. 
have identified in New Mexico as the Trias, and is of the usual red color. The occurrence of a terrestial Dinosaurian at that locality tends to confirm the conclusion to which I have already attained, that this immensely extended deposit is of lacustrine character.

On a Nero Proboscidian.

BI E. D. Cope.

(Read before the American Philosophical Society, March 2, 187\%.)

I recently received from a correspondent in one of the Southern States, a fossil of unusual interest. It is a molar tooth of a proboscidian, whose color and mineral character indicate that it was derived from beds of the Lpper Miocene or Loup Fork epoch. Its roots are largely broken away, while the crown is nearly perfect.

The crown consists chiefly of two transverse crests, which are separated by a deep uninterrupted valley. There is no general cingulum. Each crest is divided into three lobes, which are not deeply separated, but cause the edge of the crest to be serrate with three conie eminences. Of these the median apex has a rounder section, while the lateral are more transverse, rising at the external borders like the extremities of the crests in Mastodon ohioticus. The appearance of the base of the crown at one extremity inclicates that it was in contact with the preceding tooth. The opposite extremity of the base presents no such surface, and hence points to the conclusion that the tooth is the last one of the series. From the middle cone of the anterior crest a cingulum descends on each side, passing round the anterior base of the external cones. It is wanting at the extremity of the base of one of these, and little developed on the other, but they reappear on the side of the base bounding the valley. They are crenately tubercular, except at the base of the median anterior tubercle. There is no cingulum at the base of the posterior crest, except the ordinary filling between the bases of the lobes. One of the extremities of the crests is a little higher than the other, and the basis is a little wider than at the other end ; it is therefore probably external in position. At the posterior base of this end is a fractured surface indicating a cingular tubercle of stout proportions, such as is more in place at the external posterior angle of the last superior molar than in any other tooth.

The external cone is defined from the median by a fissure, while a better defined depression separates the median from the internal. This depression is filled by a worn tubercle in the anterior crest. Ridges descend along the adjacent borders of the constituent cones nearly to the fundus of the valley, and the bases of the external ones are considerably wrinkled.

Measurements. M.

Transverse diameter of crown.................130

Longitudinal " " internal.............070

" " " $"$ external .............090 


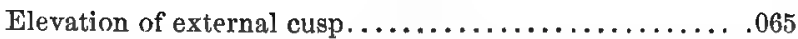

" internal "

Length between apices of external cusps............ .043

The molar tooth described exceeds in transverse dimensions that of the Mastodon ohioticus, and evidently belonged to one of the most colossal of land animals. Its generic position is near to Mastodon and Dinotherium, but if the tooth on which my observations are based be complete, it is distinct from either. The possession of only two transverse crests separates it from the former, and would, were the tooth an anterior molar, refer it to the latter. As it appears to be a posterior molar, this view of its affinity becomes untenable, and I therefore establish for it a new genus, under the name CAENOBAsILEUS. The tooth described resembles that of the genus Tapirus, but differs in the absence of the external trihedral enlargement of the cross crests seen in the superior molars of the former, and also in the tubercular and fissured character of the crests proper. The species may be called $C$. tremontigerus.

The typical specimen was probably obtained in Texas, but I am not yet informed as to the precise locality.

Issued MaRch 19, 1877. 





\title{
ON THE
}

\section{BRAIN OF PROCAMELUS OCWCIDENTALIS.}

\author{
BY E. D. COPE.
}

(Read before the American Philosophical Society, May 4, 1877.) 

On the Brain of Procamehes Occidentalis.

\author{
By E. D. CoPE.
}

(Read before the American Philosophical Society, Muy 4, 1877.)

I obtained a complete cast of the cranial cliamber of the Procamelus. occidentalis, which bears a fair proportion to the general dimensions of the skull. As compared with a llama of about the same size, the facial por. tion of the skull is longer, while the postorbital portion is as long, but narrower. This is indicated by the following measurements:

\begin{tabular}{|c|c|c|c|c|}
\hline \multirow{2}{*}{\multicolumn{4}{|c|}{ Length of skull anterior to orbit ..........180 }} & \multirow{2}{*}{$\begin{array}{l}\text { Auchenia } \\
\text { lạma. } \\
.153\end{array}$} \\
\hline & & & & \\
\hline “ & & posterior $\quad$ " $\ldots \ldots \ldots$ & ... 110 & .105 \\
\hline & & at anterior border of orbit. . & ... .080 & .090 \\
\hline & & middle of zygomatic fossa & a.. .062 & .065 \\
\hline
\end{tabular}

The olfactory lobes of the brain have nearly the same position in the two species, extending anteriorly to opposite the middle of the orbits.

The brain exhibits large cerebellum and hemispheres, and rather small olfactory lobes. The cerebellum is entirely uncovered by the hemispheres but is in contact with them. The lateral lobes and vermis are well devel. oped. The hemispheres are well convoluted, the longitudinal posterior convolutions giving way anteriorly to lobulate ones. The sylvian fissure is well marked. The sides of the medulla oblongata are compressed and vertical at the pons, in correspondence with the vertical position of the petrous bones. The origins of the ophthalmic and maxillary branches of the trigeminus nerve are not divided by a septum, while that of the man-

PROC. AMER. PHILOS. SOC. XVIX. 100, G 
dibular branch is quite distinct from the others. The optic nerves are large. The olfactory lobes are separated by a deep tissure below the extremity of the hemispheres; they project fieely beyond the latter, being separated by a deep fissure. Their free portions are short, truncate and compressed. The anterior py ramids are not preserved on the inferior face of the cast of the medulla oblongata. The hippocampal lobes are subround and protuberant.

From the detailed description following, it may be derived, that while the arrangement of the convolutions of the anterior lobes of the hemispheres is more simple than in any recent Ruminant, that of the middle and posterior lobes is essentially similar to that characteristic of the latter order of Mammalia.*

The brain displays the characters of the older types of Ruminantia, although not materially smaller than that of the llama, an animal which it equaled in general proportions. The hemispheres are, however, not produced so far posteriorly in the Procumelus as in the Auchenia, reaching only to the line of the meatus auditorius externus in the former.

The vermis of the cerebellum rises abruptly from the medulla, having a nearly vertical direction to a point a little lower than the superior plane of the hemispheres. The lateral lobes extend on each side of it, each one having a rather greater width that the vermis. Their posterior faces are sub-vertical, and are directed slightly forwards. Each projects laterally into an apex at the middle of its elevation, and then contracts downwards into the angular line which marks the posterior border of the petrous bone. From a point between each apex and the vermis a ridge rises obliquely inwards to the superior plane of the cerebellum, where each one enlarges and joins the median transverse line. The angle above described as descending from the lateral apex of the cerebellum curves forwards, forming a lateral angular border of the pons varolii on each side. The flat space enclosed between this line and the posterior border of the hemisplere is interrupted by two prominent tuberosities. The superior is small, sub-oval, and is near to the posterior border of the hemisphere. The other is a short prominent ridge directed downwards and forwards, just behind the lobus hippocampi. Its inferior end corresponds with the origin of the mandibular branch of the trigeminus, and perhaps the facial nerve.

The medulla oblongata is contracted at the foramen magnum, and has a sub-round section slightly flattened below. Its inferior face is then rounded, then flattened, and then concave between the anterior part of the lateral ridges. The bases of the maxillary branches of the trigeminus nerves are stout, and directly in line with the origins of the mandibulars. Between them the base of the brain is concave, and the optic nerves issue but a little distance in front of them. The lobi hippocampi are sub-round and rather prominent; they are terminated in front at the foramen sphenoorbitale by the contraction of the cranial walls. Their surface displays

\footnotetext{
* See Paul Gervais' Journal de Zoologie, I, $1 \times 72$, p. 459.
} 
slightly defined convolutions, the best marked being inferior and subround in form.

The cerebral hemispheres, viewed from above, have an oval outline, and are rather narrower anteriorly than posteriorly. They contract posteriorly from the sylvian convolution. The profile descends gradually to the olfactory lobes. The superior surface is little convex in the transverse direction. The fissure of Silvius is nearly vertical in position, and its superior extremity is visible from above. A strongly marked fissure extends posteriorly from it, defining the lobus hippocampi above. The sylvian convolution the thickest of all, and its outer border is emarginate in front and behind; below the postero-superior emargination it is thickest and most protuberant. Between it and the position of the falx there are three longitudinal convolutions, the external, the median, and the internal. These are slightly divergent posteriorly, but the posterior extremities of those of one side tend to unite on the posterior border of the hemisphere. Their surfaces are smooth. The external is widest medially; and it terminates anteriorly just behind the apex ef the sylvian convolution. The internal is double posteriorly; the median is simple, and unites with the internal above the apex of the sylvian convolution. The two conjoined continue for a short distance and terminate in a broad tuberosity. Below the external convolution on the side of the posterior part of the hemisphere there are four small longitudinal convolutions. The orbital portion of the hemispheres is extensive, and nearly smooth from the olfactory lobes to the supraorbital border. This is not prominent, but is represented by a short longitudinal ridge. Above each of these, on the superior or front aspect of the hemispheres, is a massive convolution bent crescent-shaped, with the convexity inwards. The posterior part of the convolution is a sub-round tuberosity which stands opposite to. and in front of, the furrow separating the sylvian and median convolutions. The middle part of the crescent is less prominent, but the anterior extremity forms another tubernity whose long ax is is directed downwards and outwards. The crescentic convolution of the nne side is separated from that of the other by a wide, shallow, median longitudiual groove, which extends transversely at the posterior tuberosities. The two tuberosities and the olfactory lobes form three descending steps.

As compared with the brains of the existing Bovidre that of the Procamelus differs in the forms of the cerebellum and medulla oblongata as already pointed out. The hemispheres differ in being shorter behind and more depressed in front. The convolutions of the posterior region are the same in number as in the sheep, but are less undulating in their outlines; but there is a marked difference in the anterior convolutions. The median convolutions do not, as in the sheep, extend to the extremity of the anterior lobe, but terminate above the sylvian fissure, so that there only remain in front of them the two large supraorbital convolutions, instead of the four common to existing Bovida and Cervide.* In this respect it mole nearly

* See Leuret et Gratiolet Anatomie comparee du Systeme Nerveux, 1839-57, Atlas, pls. vii-x. 
resembles Oreodon, but in this genus the internal convolution is rontinuous with the supraorbital.*

\section{Explanation of Plate.}

Brain of Procamelus occidentalis from a cast, two-thirds the natural size. Fig. 1. View of the left side.

Fig. 2. View of the superior surface.

Fig. 3. View of the inferior surface.

" Leidy, Extinct Fauna, Dak, and Nebraska, pl. xiv. fig. 11.

Published June 15, $187 \%$. 

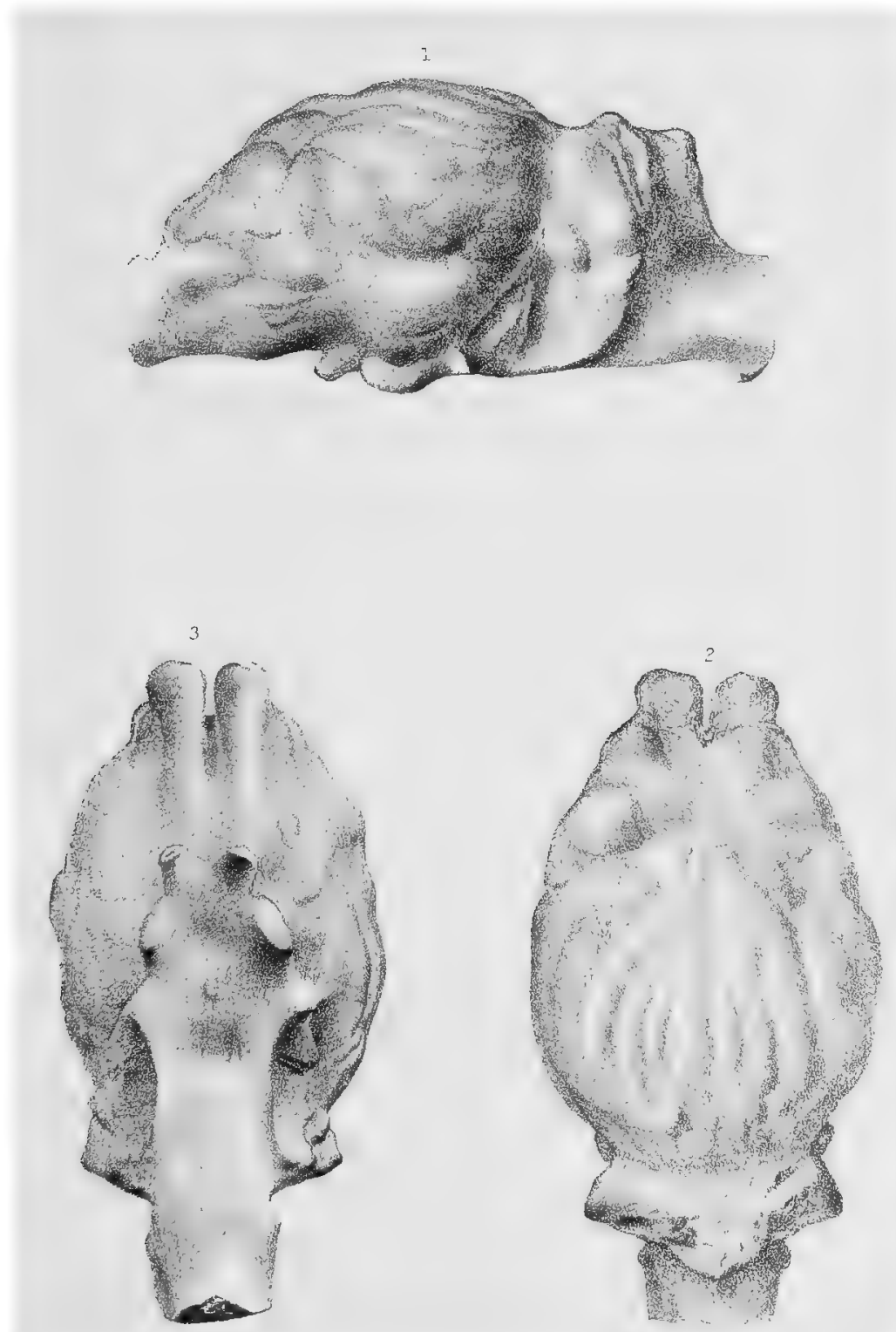

Procamelus occidentalis $2 / 3$. 





[Reprinted from The American NaturaList for February, 1877.]

\section{THE SUESSONIAN FAUNA IN NORTH AMERICA.}

BY PROF. E. D. COPE.

TN a paper read before the National Academy of Sciences at the 1 spring session of 1876 in Washington, the writer announced the identification of the Wahsatch Eocene formation of New Mexico with the Suessonian or Lower Eocene of France and England. The beds, which were explored while connected with the United States Geographical and Geological Survey, west of the one hundredth meridian, in charge of Lieut. G. M. Wheeler, in 1874, were found to contain the remains of a fauna, almost identical with that of the European beds in question. This was thought to be an important accession to American geology, as furnishing a basis for an estimation of the relative ages of the formations immediately above and below the Wahsatch horizon. The parallelism of the fauna includes the genera of reptiles, birds, 
and mammals, and among the latter, of the types both of carnivorous and of hoofed quadrupeds. Gar-fishes (Lepidosteus) appear in both countries, and the predominant mammalian genera of both are Coryphodon and Hyracotherium. Gigantic birds inhabited the land; in New Mexico they belonged to the genus Diatryma, and in France to Gastornis. The New Mexican genus Ambloctonus represents the carnivorous Paloeonyctis gigantea of the lignites of Soissons. The only marked difference between the faunas which the then state of discovery disclosed, is the existence of the order Toeniodonta in New Mexico, a type presenting characters of the Edentata, Rodentia, and Creodonta, which had not yet been found elsewhere. ${ }^{1}$

The characters of the mammalian fauna are very peculiar, displaying inferiority in many respects. Thus, among the flesheaters the brain of the Oxyona is of reduced size, the hemispheres being especially small, while the olfactory lobes are very large and uncovered; and other Creodont genera present the same character. According to Gervais the genus Arctocyon, from the Suessonian, presents the same type of brain. The hoofed type, Coryphodon, shows a similar inferiority in the constitution of the brain.

So far as these observations have gone, they coincide with those made eight years ago by Professor Edouard Lartet of Paris. He states" "that it is the result of a number of investigations undertaken in different horizons of the Tertiary strata, that the more we follow Mammatia into the antiquity of geological time, the greater is the reduction of the volume of the brain in comparison with the size of the head and the total dimensions of the body. Cuvier observed the form of the brain of the Anoplotherium in a cast of marl which was consolidated within the cavity of a skull of this animal, found in the gypsum of Montmartre. He says ${ }^{3}$ 'it has Jittle volume, and is flattened horizontally; the hemispheres do not present convolutions, but we find only a shallow longitudinal impression on each. All the laws of analogy authorize us to conclude that our animal was greatly deficient in intelligence.' In fact the skull of the Anoplotherium is six times as long as the cast of its cerebral hemispheres, and this animal, whose dimensions Cuvier compared to those of a mediumsized ass, had a brain smaller than that of the existing roebuck.

\footnotetext{
1 See American Naturalist, 1876, p. 379.

2 Comptes rendus, June, 1868.

8 Ossemens fossiles, iii., p. 44.
} 
"I owe to the kindness of Professor Noulet, of Toulouse, the possession of a fossil cranium in which I have found the cast of a brain still more ancient than that of the Anoplotherium of Montmartre, since the fragment comes from the Eocene of the Lophiodon of Issel. In the brain of this animal (which I call provisionally Brachyodon eocoenus, on account of the slight elevation of the crowns of the molar teeth), there are no longer any convolutions, but only certain folds irregularly defined; the olfactory lobes are much prolonged in front, and the cerebellum is entirely separated from the hemispheres. This brain is smaller in all respects, and less complicated in its structure than that of the Conotherium described by Gratiolet; but it must not be forgotten that the latter animal is from a formation much more recent, that is, the inferior Miocene of Allier.

"In proportion as we approach the present period, the differences between the fossil brains and those of living species become less marked, as has also been observed with reference to the elevation of the crowns of the molars. Thus the deer and the antelopes of the Middle Miocene of Sansan present many convolutions, while the cerebellum remains moderately uncovered, and the olfactory lobes are very prominent. In the superior Miocene of Pikermi the brain of the Hippotherium (Hipparion) shows itself a little less rich in convolutions than that of the existing horse; and in a fragment of a skull of a monkey from the same locality, which I have been permitted to examine in the museum, the cerebellum is less completely covered by the hemispheres, and the median vermis is more prominent than in the living Semnopitheci of the types most nearly related to those of Pikermi. But in order to show more clearly this disproportion of the fossil brains in relation to those of living Mammalia, it is necessary that comprrison should be made between species of the same family, or, better still, of the same genus. It has been possible for me to verify this point by the comparison of two carnivorous animals, the living Viverra genetta, and the extinct $V$. antiqua of De Blainville, from the inferior Miocene of Allier. From this it appears, that with a cranium one third longer and one fourth wider than the living $V$.genetta, the fossil $V$. antiqua has not a larger brain, and that this brain, more attenuated in its frontal convolutions, does not extend so far forwards. According to Gratiolet a great development of the olfactory lobes is a character of an inferior type. In fact the more we ascend into palæontological antiquity the more we find that the olfactory 
lobes display a great development in comparison with the cerebral hemispheres."

The Wahsatch horizon is lower than the oldest above referred to by Professor Lartet, and it is interesting to observe how his generalization with reference to the characters of the mammalian brain is confirmed. The Oxycena forcipata approaches more nearly to the viverrine type than to any other form of the Carnivora, although separated by a wide interval. I have been able to obtain a cast of the superior and anterior portions of its cranial chamber, from which it appears that the brain possessed characters of a much lower type than that observed in the $V$. antiqua. The olfactory lobes are enormously developed, rising ligher than the hemispheres, from which they are not only entirely free, but are separated by a constriction of their basal portions. The hemispheres are not wider at the middle than the olfactory lobes, and have therefore elongated proportions. Their superior portion is without convolutions. Although not a marsupial, the general form in Oxyoena is more like that of the opossum than that of any other living animal, but is still lower in character. Its inferiority is especially seen in its small size. The mandibular ramus of the O.forcipata is about the size of that of the jaguar, but the brain, even with its large olfactory lobes, is only about two thirds as long, and one third as wide.

The ankle-joint presents a great simplicity of structure in most of the Wahsatch mammals, both flesh-eaters and hoofed types. The astragalus is nearly flat, and not like a segment of a pulley as in most existing Mammalia, and it therefore permitted but little flexure of the foot on the leg. The only exception to this rule is found in the species of Hyracotherium and allies of the order Perissodactyla, which number ten species ont of a total of fifty-four.

As regards the elbow-joint a similar peculiarity was discovered to exist. In the majority of existing mammals, a ridge or bead divides the two facets of the humerus, which receive the ulna and radius respectively; it is called the intertrochlear ridge. In the $o x$ and horse this ridge is very near the external border of the humerus. In the mammals of the Wahsatch beds this ridge was found to be wanting, excepting in the ten species of Perissodactyla above mentioned.

In respect to the teeth, no species presenting the selenodont or double-crescent bearing type had been found. Of the simpler types, where tubercles are united into crests, twelve species out 
of fifty-four had been discovered. The teeth of the remaining forty-two species are bunodont or tubercular only, and in most cases simple forms of that type.

Another marked feature of the Suessonian or Wahsatch Mammalia is the possession by the greater number of them of five toes on both of the feet. The only probable exceptions to this rule are the ten species of Perissodactyla already mentioned, and perhaps a very few others. The genera of later and the present periods with three toes on all the feet, with two functional toes, and one toe, are wanting in this fauna.

It was also asserted that nearly all of the specie were plantigrade in their mode of progression, that is, that the soles of the fore and hinder feet were applied to the ground, instead of being obliquely elevated behind, the heel thus appearing to form an angle of the leg, as in most living mammals. It is well known that among recent quadrupeds the Quadrumana, Plantigrade Carnivora, Proboscidia, and some Rodentia and Edentata, are plantigrade, while the others are digitigrade. The only species of the Wahsatch fauna possibly digitigrade are the species of Perissodactyla, already mentioned, although it was stated that the structure in a few of the other genera is yet unknown.

The agreement of clawed and hoofed (unguiculate and ungulate) mammals of this period in the general imperfection of the structure of the brain, of the ankle and elbow-joints, and in the position and number of the toes, was dwelt on as an important fact. It did not however warrant the separation of all the Mammalia of the Suessonian as a distinct order, on account of the exceptions pointed out. The clawed types presenting these characters have been since ${ }^{1}$ defined as an order, under the name of Bunotheria, which it was believed might embrace also the existing Insectivora as a suborder. The ungulates of like character have already been erected into a distinct order, the Amblypoda, which includes two suborders, the Pantodonta and Dinocerata. The only mammalian orders of that period still existing are then the Perissodactyla and Rodentia.

1 Proceedinga Academy Philadelphia, 1876 page 88. 







\section{PALLEONTOLOGICALL BULLETIN,}

$$
\text { No. } 28 \text {. }
$$

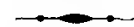

On New Saurians disoovered by Mr. Wheatley in the Trias of Penn-

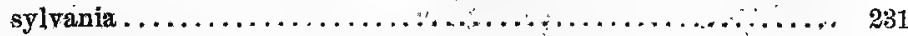

On the Vertebrata of the Dakota "Foch of Colorado............. 238 

Descriptions of Nen Vertebrate from the Upper Tertiury Frormations of the West.

\section{By E. D. Cope.}

(Read before the American Philosaphicul Society, December 21, 1877.)

Pithecistes Brevifacies gen. et spec. nov.

Char. gen. These are chiefly known from a mandible which supports the dentition of one side and part of the other. The dental formula is I. 1 ; C. 1 ; Pm. 3 ; M. 3. The single incisor of each side is weak and easily lost, and there is on one side only, a small alvenlus for a minute second incisor. It is therefore probable that in some individuals the incisive formula is 2. The canine is not large, and closes in front of the superior canine in the usual manner. The first and second premolars are one-rooted, and their crowns are wider than long. That of the third premolar is robust, but longer. The molars increase rapidly in size, and are not prismatic, but are well rooted. They are worn in the specimen, but their structure is probably shallow selenodont. The last molar has a long heel or fifth lobe.

Char. specif. The mandibular ramus is very deep posteriorly, and the incisive border is not prominent. The canine tooth is quite small, its transverse diameter being less than that of the first premolar, and equaling it antero-posteriorly. The exterior incisor is weak, and the crown expanded transversely, and obtuse. The crown of the first premolar is worn deeply by the superior canine. The transverse diameter at the base of the crown exceeds the antero-posterior. The crown of the second is wider than long, and of the third longer than wide. The molars increase rapidly in size posteriorly, so that the length of the third equals that of the three premolars plus the canine. The heel is long, and is connected with the remainder of the crown by a narrow plate, or in section, an isthmus. There are no cingula, but an accumulation at the bases of some of the teeth resembles the deposit of "tartar." The symplysis is very robust, and its upper surface is marked on each side by a low longitudinal swelling. The opposite premolar series are slightly convergent.

The form of the mandible of this animal, as well as the number and proportions of the teeth, curiously resemble that of the corresponding part of a monkey. The species was about the size of a red fox.

Measurements. $\mathbf{M}$.

Length of ramus from heel of molar III........... 057

"s molar series............................. 048

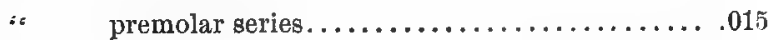

" second true molar.......................

Width " "

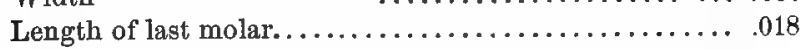

Width of " at front....................... 007

Length of symplyysis in front...................... 020

Depth of ramus at first premolar................ 017

" " second true molar.............. .095 
Brachymerty FeLiceps gen. et $s p$. nov.

Char. gen. These are derived from the superior dental series. These are I. ${ }^{2}$; C. ${ }^{1}$; Pm. ${ }^{3}$; M. ${ }^{3}$. The true molars have the bases of the crowns little swollen, and the last two of the superior series are but shortly rooted; the anterior ones have longer roots. The true molars are simply selenodont, with the anterior extremities of the external crescents forming prominent ribs. The last superior premolar consists of two columns posteriorly and a single trenchant one anteriorly, and the second (first of the series, ) is simple and trenchant. The worn posterior face of the canine shows that the first inferior premolar is the functional canine as in Oreodon. There is a very slight diastema in front of or behind the canine, the series being continuous, as in Oreodon.

This genus differs from Pithecistes in its canine like first inferior premolar, and in the trenchant character of the anterior premolars. With Cyclopidius it enters the family group of the Oreodontidce, but approaches the suilline types still more nearly in its probably coössified symphysis man. dibuli.

Char. specif. This ungulate was a little smaller than the species last described, and is represented in my collections by two nearly complete crania without mandibles. The head is depressed and the zygomata widely expanded ; the palate is wide, and the muzzle short. The infraorbital foramen is double and issues above the adjacent parts of the second and third (last) premolars. Immediately in front of it the side of the face is concave.

The projecting anterior angles of the external crescents of the molars are very prominent, forming strong vertical ribs. The external border of the last premolar is only interrupted by a little convexity. The anterior narrow portion of the second premolar is incurved. This tooth is tworooted; the first is one-rooted. The canine is small and strongly recurved. It is cylindric at the base, but beyond this is narrowed antero-posteriorly partially from the friction of the first inferior premolar. The anterior face is regularly convex. The first premolar has a very slight internal basal cingulum; its cutting edge is directed obliquely to the long axis of the cranium. There are no cingula on the other teeth. The enamel of the true molars is smooth on the external side of the crown. There is no enamel on the inner walls of the central lakes.

Measurements. M.

Length of dental series to anterior border of canine.... .050

" premolar series................... 017

" last true molar ..................... 012

Width of " " $\quad \ldots \ldots \ldots \ldots \ldots \ldots \ldots \ldots \ldots . . . \ldots 06$

Length of first true molar ................. 007

Width of " " $\quad \ldots \ldots \ldots \ldots \ldots \ldots \ldots \ldots . . . \ldots 06$

Length of first premolar.....................006

Width of " " $\ldots \ldots \ldots \ldots \ldots \ldots \ldots \ldots \ldots \ldots .006$

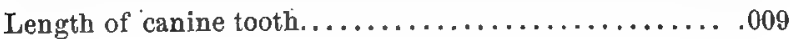


Measurements.

M.

Diameter of canine tooth (transverse) ............. .004

Width of cranium between first prebolars............ 016

" " " last molars............. 030

The cranium of this species is about the size of that of a large domestic cat.

Crclopidios simus. Gen. et. sp. nov.

Char. gen. Dental formula I. $\frac{2}{2} ;$ C. $\frac{1}{1} ; \mathrm{Pm} . \frac{4}{4} ;$ M. $\frac{3}{3}$. The superior canine is small and is separated from the first premolar by a very short diastema. First premolar simple, trenchant; second premolar two rooted, with one principal cutting edge; third with an external crescent and a rudimental internal one, not united in front. Fourth premolar with the inner and outer crescents only, and these well developed. Last true molar without heel. Inferior canine with much wider crown than the incisors with which it is in close association. First premolar canine-like, but not very large; second premolar simple. Third and fourth premolar with the anterior portions trenchant, the posterior with wide or double columns. Last true molar with large fifth crescent or column. True molars of both jaws prismatic. Symphysis mandibuli coössified.

Frontal bones much abbreviated in front by a large upwards-looking fossa on each side, which are separated by the very narrow and short nasal bones. There are lachrymal fossæ and a huge foramen in front of them, which communicate with the maxillary sinus. There is a prominent transverse supraoccipital crest, and the otic bullæe are greatly inflated.

This genus is related to Leptauchenia, Leidy, but differs in having but two lower incisors below. That genus belongs to a lower horizon, the miocene of White River, while the present form is its successor in the upper Miocene or Loup Fork beds. The remarkable character of the vacuities in the superior region of the front part of the cranium, reminds one of the existing genus Scega. Dr. Leidy partially described a similar structure in Leptauchenia. In this genus what are clearly nasal bones in Cyclopidius, he terms frontals, probably by error.

Char. Specif. This animal is rather larger than either of those above described, and is represented in my collection by one nearly complete cranium, one entirc left maxillary bone, and the under jaws of five, and probably of several other individuals.

The skull is wide and abbreviated in front. The maxillary bones are everted on each side of the external nares. The malar bone is very wide or deep, and sends upwards a strong postorbital process, which is broken off in part, but which probably completed the orbit. The superior facial fossæ reach backwards nearly as far as the middle of the orbit. They are longitudinal narrow ovals, open in front. The projecting supraorbital portions of the frontal bone with the nasals have a tripodal form. The lach. rymal fossa looks outwards, upwards and forwards, and the large maxillary foramen outwards. The infraorbital foramen is double, and issues above the contiguous portions of the third and fourth premolars. 
The external crescents of the true molar's present prominent anterior angles, which form strong vertical ribs. The first superior premolar has a weak, and the second premolar a very strong internal basal cingulum; there are no other cingula. The diastema is as wide as the diameter of the canine.

The first inferior premolar is one-rooted, and the second two-rooted, and both are longer than wide in horizontal diameter. The middle pairs of incisors are very small : the external one on each side is much larger, the diameter equaling half that of the canines. The first and second true molars are subequal, and are together longer than the third, which does not quite equal in length the three premolars. The heel of the last molar is not so long anteroposteriorly as each of the other columns. The symphysis is steep, but is everted at the incisive region.

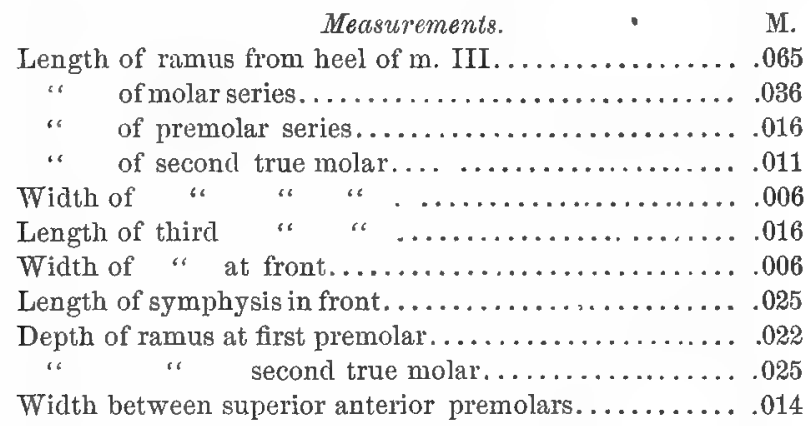

CYCLOPIDIUS HETERODON sp. nov.

This species is represented by a portion of the right maxillary bone, which supports the last premolar, first true molar, and portions of other teeth. It is a smaller form than the $B$. simus, and differs in several important respects. The infraorbital foramen is single and larger than those of the other species. The fourth premolar, while of the same constitution as that of $\boldsymbol{M}$. simus, is relatively much smaller; not equalling in the extent of its grinding face one column of the first true molar. The latter is prismatic, and of usual form. Its external crescents are not produced as in $B$. simus, so that there are no distinct vertical ribs.

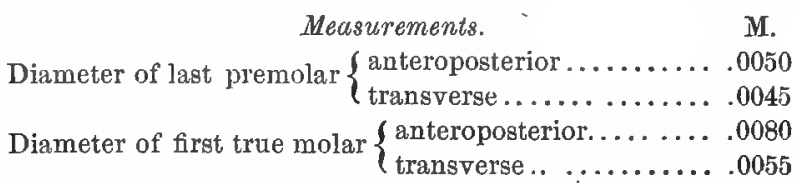

This species was found with the three preceding in the Upper Miocent of Montana by my assistant, J. C. Isaac.

Blastomeryx BOREalis sp. nov.

This genus was defined by me in the fourth volume of the Report of Lieut. G. M. Wheeler to the Chief of Engineers, 1877, p. 350, as not cer- 
tainly distinct from Dicrocerus Lartet. The discovery of a second species of the group, which displays the characters there pointed out, in a still more striking degree than the species on which it was formed, renders it necessary to introduce the genus formally to the system. In brief its molars differ from those of Dicrocerus much as those of the deer differ from the molars of the antelope. While Dicrocerus was probably the ancestor of Antilocapra, Blastomeryx was the ancestor of Cervus or Cariacus.

The superior dental formula is I. 0 ; C. $0 ;$ Pm. 3; M. 3. The molar's all have two pairs of crescents excepting the last premolar, where the posterior pair are rudimental. The external face of the anterior crescent in all the molars presents a groove, which is bounded posteriorly by a vertical ridge. The posterior crescent is directed a little inward posteriorly on the true molars. The palate is much contracted in front of the first molars. The horns stand above the posterior parts of the orbits; their section is triangular, the posterior angle being rounded, and the external produced and acute, bounding the orbit outwards and backwards. There is no trace of burr. The temporal fossæ approach so as to be separated only by a rather wide and low occipital crest.

Measurements. M.

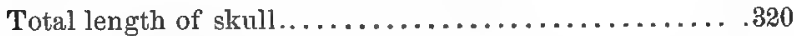

Length of molar series.....................107

" premolar " .................... 049

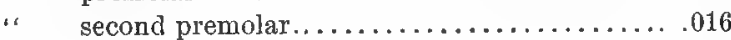

Width $"$ " $\quad \ldots \ldots \ldots \ldots \ldots \ldots \ldots \ldots . . . \ldots 11$

Length of first true molar .................... .020

Width " " $\quad \ldots \ldots \ldots \ldots \ldots \ldots \ldots \ldots \ldots \ldots .015$

Width between bases of horn-cores ................ .050

Transverse diameter of horn-core two inches from base. . ,040

Width between external borders of first true molars.... .078

Width of palate in front of first premolars........... .028

This species was as large as the black-tailed deer, Cariacus macrotis. It was found by my assistant, J. C. Isaac, in the Upper Miocene of Montana.

\section{Cervus fortis sp. nov.}

This deer is of large size, much exceeding any living species of the family Cervida. It is represented in my collections by a superior molar of the left side, and very probably by other remains which accompanied it, viz. : a mandibular symphysis with incisor and canine teeth; calcaneum. astragalus, vertebræ, etc. These were found at the same time and place by George M. Sternberg, M.D., U. S. A., already well-known by his interesting discoveries in the cretaceous formation of Kansas.

The plicre which mark the anterior extremities of the external crescents are very prominent, and are directed forwards rather than outwards. The median lakes are narrow and well separated medially. The posterior lake has a strong fold of its internal border, forming a lobe directed backwards. 
A cylinder of small diameter stands near the apex of the fold of the internal enamel wall, which separates the internal crescents. There is a cingular ridge descending inwards on the interior and posterior extremities of the base of the crown, and below and exterior to it the enamel surface is very rugose. The surface of the external enamel is smooth. The enamel of the lake borders is scamed with shallow vertical sulci. The crescents are wide and the lakes narrow.

The reference of this species to the genus Cervus may require reconsideration.

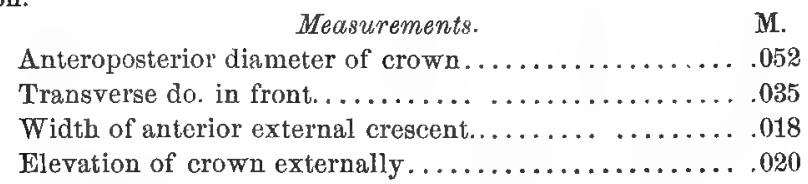

From the pliocene formation of Oregun.

The Loup Fork beds have been usually referred to the Pliocene horizon, but I have offered reasons why they should be regarded as of Upper Miocene age. The horizon from which this and some other species herein described, found in Oregon, represent the Pliocene formation much more nearly.

DrCotrues serus, sp. nov.

This species of hog is indicated by a mandibular ramus which lacks the angles, and supports the dentition of both sides excepting the third right molar. Other portions of the skeleton are associated. A second specimen is the symphysis with the incisor teeth. The remains indicate an animal something larger than the white lipped peccary Dicotyles labiatus.

Dentition of the mandible, I. 2; C. 1; P. m. 3; M. 3. Inferior canines triangular; superior canines decurved, triturating the inferior. Last inferior molar with well developed heel. Last premolar like the first molar. First premolar with anterior single tubercle and posterior lower tubercle heel ; second premolar similar but wider, and the anterior tubercle divided. Molare consisting of four principal tubercles opposed in pairs, with some accessory ones between them.

The rami are robust and of moderate depth; the symphysis is elongate and contracted. The suture of the latter remains on the inferior side, but is obliterated on the upper surface. The symphysis is trough-like and the narrow alveolar ridges of the diastema are concave inwards.

The incisor teeth are directed forwards, and are closely approximated and parallel. The fang of the second lies close to that of the canine, and the edges of the crowns together form a parabola, the enamel being prolonged posteriorly on the external side of the external tooth. The crowns of the median teeth are not expanded laterally, nor much depressed at the apex; as half worn in the specimen, they form a wide transverse oval. The canines curved upwards and outwards and present their triturating surface a little external to directly backwards. Their section is tri- 
angular, the lateral faces being longer than the posterior, and the anterior angle is a narrow one. The surface of the enamel cannot be described, as it is eroded at some points. The diastema is long.

The first (homologically second) premolar is narow, and is without lateral or posterior lobe or cingulum, but a third is a rudimental lobe at its anterior base. The heel presents an interior tubercle, and a narrow postero-external lobe which embraces a medeo-external tubercle. The latter becomes the external posterior tubercle on the true molars. The third premolar is larger and wider than the second; the medio-external lobe becomes more external and posterior, and a median tubercle appears in front of it. The posterior tubercle still sends a narrow ledge round to the outer base of the medio-external lobe. The anterior lobes are more elevated than the others, and are only separated by a fissure. In the fourth premolar the true molar structure is seen in the regular quadri-tuberculate form. There is a small tulyercle in front and behind the notch of lobes, and a fold descending forwards on the outer side of the external posteriur lobe. In the second true molar there is an additional tubercle on the middle line between the pairs of lobes. The median accessory tubercles are not distinct on the last molar, excepting the posterior, which becomes a large heel. The lobes of each pair are not deeply separated on the last two molars. These teeth are rather abruptly larger than the first true molar, which is little larger than the last premolar. Each of them has a narrow anterior cingulum, but no other. The enamel is nearly smooth.

Measurements.

M.

Length of maudible from end of posterior molar to incisive alveoli.......................... 0.190

Length of molar series....................108

" true molars.................... .062

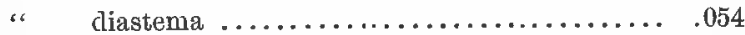

Width between bases of canines................. .020

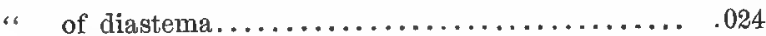

" between bases of first premolars............ .032

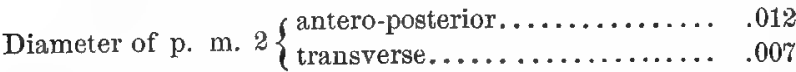

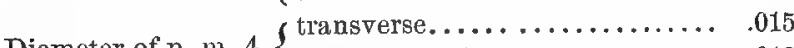

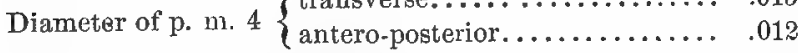

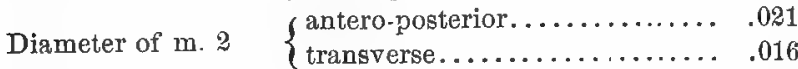

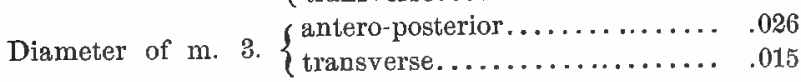

The animal from which the above description was taken was adult. It was discovered in the Loup Fork beds of North-Western Kansas by Russell Hill of this city.

TETRALOPHODON CAMPESTER sp. nov.

The cranium and under jaw, with nearly complete dentition, including tusks, of this species, were obtained by my assistant, Russell S. Hill. The

PROC. AMER. PHILOS. SOC. XVII. 100, 20. PRINTED JAN. 12, 1878. 
animal is mature but not old, as the second true (third intermediate) molar is present and much woln, and the last molar is worn on its anterior threefifths.

The posterior or fourth crest of the second true molar is narrower than the third, and is not followed by a heel. The third molar presents six transverse crests, and so large a heel that it might be said to be sevencrested. Each crest is sub-transverse, and is composed of a principal obtuse cone at each extremity and some smaller ones between, in close contact. The apices of the larger ones approach each other, and the median ones are less elevated. The section produced by wearing of the third and second crest each, is that of two trefoils placed base to base, and the lateral lobes of these, completely close the valley between those crests. The valleys between the other crests are closed by one or two distinct median tubercles, and the sections of those crests are less accurately trifoliate than those of the others. There is a very large cingulum at the anterior extremity of this tooth whose worn section is confluent with both of the trefoils of the anterior crest near the middle. A portion of it is isolated on the inner side of the crown, forming a flattened cone, or when worn, an isolated oval with the long axis directed inwards and forwards. This I have counted as the first crest, as it is as much entitled to it as the one so counted by Dr. Falconer, in the T. sivalensis. The palate is narrow, not exceeding the width of the second true molar.

The mandibular rami are of rather light tissue, and are compressed in form, the external face being little convex. The symphysis is produced, without abrupt contraction either laterally or below, into a robust beak whose depth is equal to the width five inches beyond the bifurcation. It is channeled above by a narrow and deep groove, and supports no tusks. From the appearance of the tissue when fractured transversely it is evident that there have been no alveolar cavities at any time. The beak is slightly decurved and the extremity is depressed and transversely flattened. The superior incisor possesses a broad band of enamel, which covers nearly one-third the diameter of the tooth.

Measurements.

M.

Length of crown of second true molar............. 118

Width " " " $"$ "

Length " " third

Width " " " $"$ " $" \ldots \ldots \ldots \ldots \ldots . .080$

" palate at anterior extremities of second molars .045

" " posterior crests of third " 095

Length of ramus from posterior border to bifurcation... . .560

Length of symphyseal beak (broken) .............480

Depth of do. five inches from bifurcation.............118

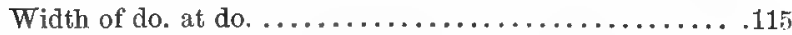

This fine new Mastodon is the second species of the genus Tetralophodon found as yet in North America, the first being the $T$. minificus of Leidy. 
It is well distinguished from this form by the structure of the component parts of the crown of the last molar tooth, and by its long symphysis, that of the $T$. mirificus possessing the more usual short spout. It is with the T. longirostris, of Eppelsheim and the valley of the Danube, that the closest affinity exists. In $T$. campester the symphyseal production is much more robust, not being separated from the rami by any constriction, as in $T$. longirostris. It is moreover without incisive tusks, but it is yet uncertain what value should be attached to this character, as it may turn out to be individual or sexual. In the intimate structure of the molars there is considerable resemblance to the $T$. longirostris; that species is however státed by Dr. Falconer* to possess but five crests and a heel on the last molar. The presence of the enamel band on the tusks also separates the $T$. campester from that species, where, according to Mr. Vacek, $\nmid$ it is wanting.

In comparison with $M$. sivalensis, this Mastodon differs in the transverse character of the valleys; in the Indian species the tubercles alternate and close them.

The dimensions of the $T$. campester are those of the African Elephant. From the Upper Miocene and Loup Fork horizon of Kansas.

Taxidea sulcata sp. nov.

This badger is represented by the nearly entire maxillary bone of the left side containing all the teeth excepting the canine and first premolar. It resembles the corresponding portion of the $T$. americana very nearly, but differs in two important features. The first of these is the abbreviation of the anterior portion of the dental series. The first premolar is closely wedged in between the canine and second premolar, so that its anterior root is almost obsolete. The head was thus doubtless relatively shorter than in the existing species where there are hiatuses between the roots of the first premolar and adjacent teeth. The second character is seen in the last or true molar. On its crown the tubercles are arranged in two well separated transverse rows, forming crests by their confluence, which are separated by a deep valley, and bound by a half valley in front and rear.

Measurements. $\mathrm{M}$.

Length of series, including canine.............. 038

" premolars. ...................... .023

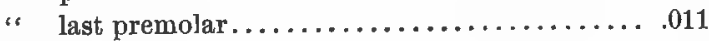

Width of " "

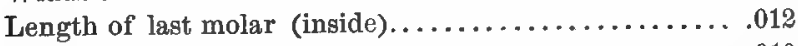

Width " " ....................... . 010

From the Pliocene of Washington Terr.; found by Major Truax, U.S.A.

: On British and European Fossil Mastodons, p. 19 (8 vo.).

† Ueber Oesterreichische Mastodonten Wien, 1877, p. 31 (Abh. K. K. Geol. Reichanstalt). 


\section{Pseudemys bisornatus sp. nov.}

This fresh water tortoise is represented by portions of three individuals. These exhibit a rather flattened convex carapace, with marginal bones united (behind the bridge at least), without gomphosis, by fine suture. There are no median or lateral keels. The vertebral bones are nearly as wide as long, and thick; the costals are thickest proximally and thinnest medially. The marginals are quite stout. The dermal scutal sutures are deeply impressed, especially those defining the marginal scuta.

The sculpture of the superior surface of the carapace is strongly marked and peculiar. The vertebral scutal area are smooth, or display only a fewobscure ridges directed backwards and inwards, on the proximal portions of the costal bones; the vertebral bones being smooth. The costal scuta present two forms of sculpture; posterior to the intercostal bony suture each is reticulated with inosculating sharp ridges whose general direction is longitudinal proximally and transverse distally. The sculpture is Trionyxlike, and rather coarse. The surface anterior to the osseous suture, is ornamented with raised, parallel ridges, which are separated more widely than those of the posterior half of the scutum, and which do not inosculate. They continue uninterruptedly to the succeeding osseous suture, to be followed again by the reticulate pattern. Thus each costal bone is divided into three areas; a proximal smooth one, and an anterior reticulate, and posterior ridges arex, separated by a cleep sutural groove.

A postero-lateral marginal bone unites subequally with two costals. Its superior surface rises in abrup $\dagger$ convexity beyond the costo-marginal dermal suture, and from the transverse intermarginal dermal suture. It is then concave to the recurved margin. Its sculpture consists of transverse ridges, separated by grooves of equal width.

$$
\text { Measurements. II. }
$$

Length of a vertebral bone.................... 035

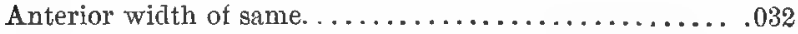

Thickness of same anteriorly ................. .009

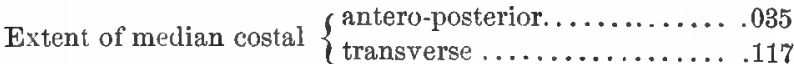

Median thickness of do....................... 006

Distal " " ".......................... 007

Lengih of a posterior marginal................030

Width " " $"$ "

Thickness " "

This tortoise is at first sight apparently singular in its marks of ornamentation. On comparison with existing species, however, it is seen to present an exaggerated condition of the sculpture characteristic of some of the existing Pseudemydes of our Southern rivers; e. g. the $P$. elegans. It is more robust in all its proportions than any of these.

The fossil remains were discovered by my friend, G. W. Marnock, in the pliocene of South-western Texas. 


\section{Cisisudo marnochit.}

Represented by the posterior lobe of the plastron of an individual of twice the bulk of the existing North American Cistudos. It is broadly rounded posteriorly, and there is an emargination at the femoro-anal dermal suture. The anterior suture is straight, as is also the lateral, which measures more than a third the length of the entire lobe. On the upper side of the angle included by these sutures is the fossa for fixed attachment with the carapace. The beveled face of the fore edge of the lobe is quite wide. The dermal sutures are well marked. The anal scuta are large, their median length being half that of the lobe. The common femoral suture is only half as long as the ventral. The inferior surface is nearly flat in every direction; and the surface is smooth. The posterior border of the specimen is broken away.

This species was obtained from the same formation as the last, by Gabriel W. Marnock, to whom I dedicate it.

\section{ANCHYBOPSIS BREVIARCUS sp. nov.}

The genus to which the above name was given, was established by the writer in 1870, for a species Cyprinoid fish, from the pliocene formation of Itlaho. Its aftinities were then stated to be to Alburnops (Bybopsis), and related existing genera. The present paper describes two additional species of the genus, both of which are represented by pharyngeal bones and teeth of both sides. The teeth are shown to be $5-5$, in contradistinction to the genera Hemitremia and Alburnops, where they are 5-4 and 4-4 respectively

In this fish the common base of the pharyngeal teeth rises upwards, so as to project well in front of the general plane of the bone. The superior teeth are more compressed than the inferior, and the first and second count. ing from below, have convex grinding faces. The pharyngeal bone has a short inferior and a long superior limb. The alate portion is regularly and strongly convex, without abrupt expansion. The nutritive foramina of the anterior face are two large inferior and several small superior ones.

\section{Measurements.}

M.

Vertical extent of bone in a straight line........... .020

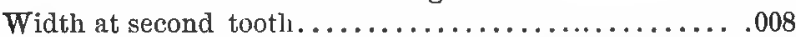

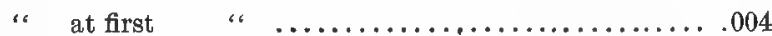

Length of tooth line $\ldots \ldots \ldots \ldots \ldots \ldots \ldots \ldots \ldots \ldots \ldots . . \ldots 11$

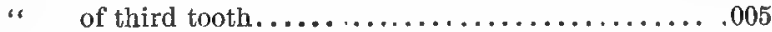

"6 of basal limb to first tooth................. .009

This species is of smaller dimensions than the $A$. latus.

AnChyopsts altarcus sp, nov.

The pharyngeal bones of this cyprinoid are larger and of more slender: proportions than those of the $A$. breviarcus. Specimens from both sides are preserved. The inferior and superior limbs are both elongate, the former slender, the latter flat. The ala is abruptly expanded at right angles to the long axis ; the external border is thence nearly straight to, and the angle of 
the superior border situated interiorly to, the line continuing the inner border upwards. The tooth line is elevated at the upper extremity. The basal teeth are more robust than the others, and do not present grinding faces. The nutritive foramina are more numerous and smaller than in the $A$. breviurcus.

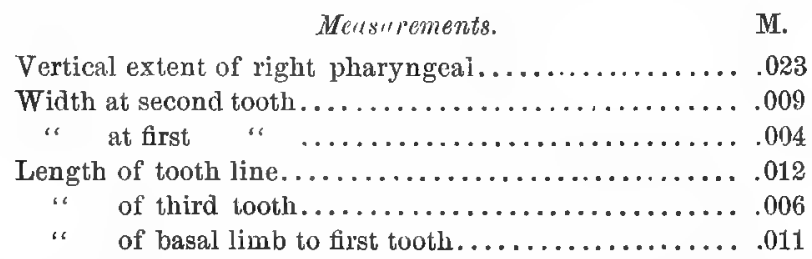

Found with the last species by Chas. H. Sternberg, in the Pliocene deposit of Oregon.

Alburnops angustarcus sp. nov.

Represented by the pharyngeal bones of both sides, of a species of about the size of the one last described. The characteristic marks of these are seen in the long extremities, both inferior and superior, and in the very slight convexity of the ala, which is less prominent than in any of the $\mathrm{Cy}$ prinidce here described. The superior end of the tooth basis is elevated and prominent. In one of the jaws all the teeth display a masticating surface. In the other the second tooth, the only onc preserved, is partially worn.

The length of the proximal limb distinguishes this pharyngeal bone from that of the Anchybopsis breviereus, if the generic characters be disregarded. From all the other species the slight prominence of the ala separates it.

Measurements. M.

Vertical extent of right pharyngeal............... .023

Length of proximal limb....................... 010

" of tooth line.......................... 010

" of distal limb...................... .012

Width at first tooth........................

“ of second tooth........................007

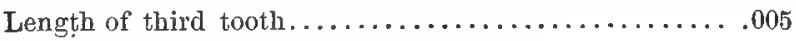

Found by Mr. Sternberg, with the last species.

\section{Alburnops gibbarcus sp. nov.}

One left and two right pharyngeal bones furnish the characters of this species. Their form is angulate, as in the Anchybopsis altarrus, but shorter in the vertical direction. The proximal limb is rather short, and the distal one not as long as in the species last clescribed. The ala widens abruptly at the inferior margin, and the thin superior edge of the superior limb is obtusely angulate. The nutritive foramina are rather numerous. The first and second teeth clisplay little or no grinding surface. 


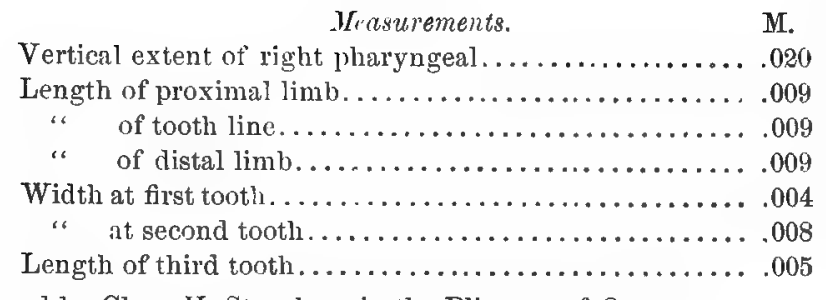

Found by Chas. H. Sternberg in the Pliocene of Dregon.

On some Saurians found in the I'riassic of Pennsylvania, by $O$. M. Whertley.

Bx E. D. Cope.

(Read before the American Philosophical Soriety, Dec. 21, 1877.)

Thecodontosaurus gibbidens sp. nov.

The only remains of this saurian which have come into my hands are two teeth. They are in good preservation, lacking only the great part of the root. They present the leaf-like outline characteristic of the genus, the crown being strongly distinguished from the narrower root. The form is quite robust, and contracts gradually to the apex. The cutting anterior and posterior edges bound the inner face of the crown, from which they are separated by a groovè along their bases. They are interrupted by coarse serrations, the apices of the denticles being directed upwards. These are much reduced in size at the base of the crown. The cutting edges are not separated from the external face by grooves. This face is very convex and perfectly smooth. The inner face is convex between the grooves and is marked with six or seven continuous sulci, which are obsolete at the base.

The saurian which possessed the tooth described was not of large proportions. The species differs from the English form in many respects ; e. g., the greater convexity of the external face; the basal grooves of the cutting edges, the grooving of the inner face, the abrupt constriction below the base of the crown, etc.

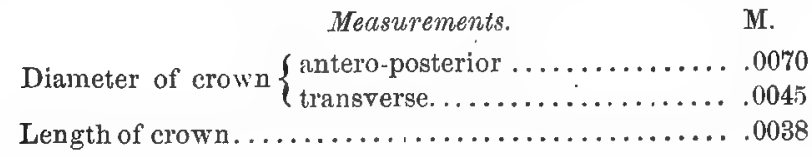


Pal agosaurus fraserianus sp. nov.

But few remains indicate this species. It is established primarily on a tooth, which presents the characters of Paloosuurus cylindrodon. It has opposite denticulate cutting edges, in anterior and posterior, of which the latter extends to the base of the crown, and the anterine but half way from the apex. The posterior is denticulate throughont, while denticulation is visible un the anterior edge for but one-third the distance from the apex. The posterior edge is more compressed. The surface of the cementum is obsoletely finely linear ridged, and there are no sulci or other sculpture. The crown is regularly and gently curved backwards.

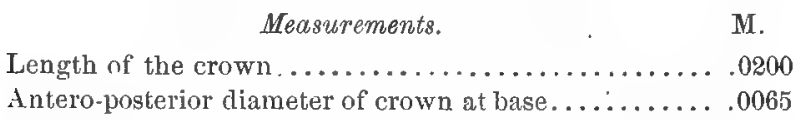

This saurian is dedicated to my friend, Persifor Frazer, Jr., in charge of one of the districts into which the State of Pennsylvania is divided for the conduct of the second geological survey. This district embraces the Triassic region, which has been extensively and ably investigated by Prof. Frazer.

\section{Suchoprion aulacodus Cope.}

Palcooctonus aulacodus Cope, Paleontological Bulletin, No. 26, p. 184.

Several additional teeth of this species show that the tooth from which I first determined it is one of the flattest of the series, and that those from other positions in the jaws, instead of being flatter as in Palceoctonus, are narrower, and of the usual form of those of Suchoprion.

This saurian possesses teeth of the size of the average of those of the $S$. cyphodon, and which are like them, well compressed in the antero-posterior direction. The surface is therefore very convex between the cutting edges, especially on the external face, and the transverse diameter at the base of the crown exceeds the antero-posterior. The cutting edges only extend half way from the apex, and are but little denticulated. The surface of the cementum is minutely and sharply linearly sculptured. It is in addition, thrown into coarse continuous grooves on the basal two-thirds of the crown, excepting for a short distance on the inner side of each cutting edge. There are seven grooves on the inner face, and eighteen on the outer face. On the latter the minute sculpture is least distinct.

\section{Measurements.} M.

Length of crown..................... 0260

Diameter of base of crown $\left\{\begin{array}{l}\text { fore and aft......................... } 0160 \\ \text { transverse. } \ldots 115\end{array}\right.$

The short slightly denticulate cutting edges and the strongly grooved surface distinguish the anterior teeth of this species at once from the $\$$. cyphodon. Several specimens have been found by Mr. Wheatley. 
On the Tertebrata of the Dakota Epoch of Colorado.

\author{
By E. D. COPE.
}

(Read before the American Philosnphical Soriety, December 21, 1877.)

Not long since I was informed by the Superintendent of Public Schools of Fremont County, Colorado, Mr. O. W. Lucas, that he had discovered the bones of an enormous saurian at an outcrop of the rocks of the Dakota group not far from Canyon City. I encouraged him to proceed with the exploration, and asked him to send some specimens which would explain the character of his discovery. One of the first objects sent, is a fragmentary lower jaw of a carnivorous dinosaurian, which he found on the surface of the ground. This fossil was found to belong to a species heretofore unknown, which I referred to the genus Laelaps, under the name of Laelaps trihedrodon.* The second sending included a number of vertebræ, which apparently represent a much more gigantic animal, and I believe the largest or most bulky animal capable of progression on land of which we have any knowledge. This reptile I described in iny paleontological bulletin No. 26, under the name of Camarasaurus supremus. Subsequent sendings included many of the more important bones of the skeleton, which render it comparatively easy to determine the general character of this monster. Later collections received from Mr. Lucas inclucte the teeth of two large species of a new genus which has been characterized under the name of Cuulodon; and the vertebræ of three genera new to science, which I have named Tichosteus, and Symphyrophus. He also procured remains of two additional forms of gigantic size, fit rivals of the Camarcasaurus, which I referred to the new genus Amphicolias. A species of tortoise was associated with these saurians, and appears to have been abundant. It is the oldest species of the order yet obtained from American formations, and is not very different from existing forms.

The above named genera are the only ones from the Dakota horizon of this continent which have been defined, up to the present time.

The species of Camarasaurus and Amphicelias, which attained to the most gigantic proportions, are remarkable for the light construction of the vertebræ anterior to the tail. In both genera the centra of the dorsal vertebræ are hollow, including two large chambers which are separated by a longitudinal median wall, and which communicate with the cavity of the body by a foramen on each side. They are also remarkable for the enormous elevation of the superior arches, and diapophyses, the result of which is to give the ribs an unusually elevated basis, and the cavity of the body much space above the vertebral axis on each side. On the other hand the bones of the tail and limbs are solid or nearly so, in great contrast with some of the Dinosauria of later geological periods. Another peculiarity of the genus Camarasaurus at least, is the probable great length of the an-

\footnotetext{
$\because$ Bullet. U. S. Geol. Surv. Terrs. III, 1877, p. 805.
}

PRoc. AMER. PHILOS. SOC. XVIr. 100. 2D. PRINTEd JAN. 12, 1878. 
terior limbs. The scapula is enormous as compared with the pelvic bones. The sacrum is also small and short, showing that the weight was not borne on the hinder limbs. The great length of the humerus in the probably allied genus Dystrophous, from the Trias of Utah, adds to the probability that the same bones were large in Camarasaurus. This character, taken in connection with the remarkably long neck possessed by that genus, suggests a resemblance in form and habits between those huge reptiles and the giraffe. While some of the later Dinosauria elevated themselves on their hind limbs to reach the tree-tops on which they fed, the general form of the body in some of these earlier types enabled them to reach their food without the anterior limbs leaving the earth.

Another remarkable peculiarity which these genera share with Dystrophous and Cetioscurus is the irregular and pitted character of the articular extremities of some of the bones. This indicates a cartilaginous covering, and probably in some instances an osseous cap or epiplysis.

Dr. Hayden visited the locality of Mr. Lucas' excavations, and informs me that the formation from which the Camarasaurus was obtained, is the Dakota. Prof. Marsh has attempted to identify what is, according to Prof. Mudge, the same horizon, one hundred miles north of Canyon City, with the Wealden of England. Specimens from the northern locality which I have examined render it certain that the horizon is that of $\mathrm{Mr}$. Lucas' excavations. Of this I may say that there is no paleontological evidence of its identity with the Wealden. The resemblance of the vertebrate fossils to those of the English Oolite is much greater, but not sufficient as yet for identification.

The discovery of Tertebrata in the strata of the Dakota epoch is an important addition to the geology and paleontology of North America. The numerous geologists who have explored its outcrops have failed hitherto to observe remains of this class of animals. Credit is due to Superintendent o. W. Lucas for this discovery, and also in an especial manner for the skill and care he has exercised in taking out and shipping the pondercus specimens.

\section{CAMARASAURUS Cope.}

Palæontological Bulletin No. 25, p. 5; (published August 2:; 1877).

The characters of this genus are derived from nearly all portions of the skeleton excepting the skull and ungues. The bones are generally in good preservation.

The vertebræ of the cervical, dorsal and lumbar region are all opisthocoelous or reversed ball and socket. The centra of the cervicals are very elongate, but those which follow them diminish rapidly in length, until in the lumbar region they have but a small anteroposterior diameter. The anterior caudal vertebræ are also very short and wide: but the length of the centra gradually increases, so that the distal ones are quite elongate. The caudal centra are all moderately amphicoelous.

The centra of the cervicals and dorsals are hollow, and the interior 
chambers communicate with the cavity of the body by a large foramen on each side, which is below the base of the diapophysis. In the cervical vertebra it is very elongate, and extends between the bases of the parapophysis and diapophysis. In the dorsal centra there are but two chambers, which are separated by a longitudinal median septum.

The neural arches are coössified with the centrum throughout the column. They are extraordinarily elevated, and their antero-posterior diameter is small. The zygapophyses are at its summit, and have extensive articulating surfaces. The anterior pair are divided by a deep median fissure, while the posterior are united, and support as a pendant from their inferior median line a hyposphen, a structure more fully described under the head of the genus Amphisoelias, where it is equally developed. When the vertebræ are in relation, the base of the hyposphen enters the fissure between the anterior zygapophyses, and maintains them in position. This structure is obsolete in the lumbar vertebræ.

The diapophyses rise from the neural arch to a considerable length upwards and outwards, in the anterior dorsals. They become shorter posteriorly, but in none of the vertebræ anterior to the sacrum do they issue from the centrum. In the caudal vertebræ they are short and robust, and issue from the superior part of the centrum, They do not continue far on the tail. Those of the dorsal vertebræ are light and concave below. They are supported by thin osseous buttresses, the most important of which are the two inferior ones. The anterior of these is much the most prominent, and bears the capitular articular facet for the rib. In no case is this surface seen on the centrum, but it descends somewhat in the posterior vertebræ, but not as low as the level of the neural canal.

The neural spines are rather short, and are set transversely to the axis of the animal. The superior portion is expanded transversely, and in an anterior dorsal vertebra, is widely emarginate above, so as to appear double. The neural spines of the caudal vertebræ are compressed and elevated, though thickened at the apex. The zygapophyses are situated low down, and are directed very obliquely. The chevron bones of the caudal vertebræ have short limbs which are not united at the base, and a long common median spine.

The sacrum is short and consists of only four vertebral centra, thoroughly coössified. The anterior articular extremity is convex; that of the posterior extremity slightly concave. Its transverse processes are, like those of the other vertebræ, much elevated, although they spring from the centra. The external face of their bases is not prominent, and the spaces between their projecting portions are deeply excavated. The centra are like those of the caudal vertebra, composed of dense bone. The extremities of the adjacent transverse processes are united, thus enclosing large foramina.

The scapula is relatively of large size. It is rather elongate, and the superior extremity is expanded. There is a very large mesoscapular process, which is wanting in Cetiosaurus, according to Phillip's figures. It appears to resemble the scapula in $D$ ystrophous.* The two proximal faces,

* See Report of Lt. Wheeler, Vol. IV, pI. LXXXIII, p. 31. 
the glenoid and the coracoid, are well distinguished, and their surfaces are like the corresponding faces of uther bones, pitted coarsely.

The coracoicl bone is of proportionately small size. It is of an irregularly quadrate form, with the proximal extremity the shortest. The articular face is large, and is presented obliquely away from the long axis of the plate. There are no emarginations nor intermediate processes, and the perforating foramen is well lemoved from the border.

Pelvic bones of two forms are present. Neither of them resembles pelvic bones of Dinosauria, and are least of all similar to the forms of ilium which are known in that order. One of them is a robust L-shaped bone, one limb of which is expanded into a wide fan-shaped plate; and the other is stouter and of sub-equal width, terminating in a stout sub-triangular articular extremity. The face of this limb of the bone which looks away from the fan-shaped plate is concave throughout its entire length, forming a large part of the acetabulum. Both edges of this cavity are free and rounded. The absence of articular faces abore the acetabulum renders the identification of the bone with either pubis or ischium difficult. The second pelvic bone is larger than the first, and unlike it, is in one plane. Its form is that of a low triangle with a long base, at each extremity of which the angles are truncated. The "basal" border is gently concave in the long direction and thick and convex in the cross-section, The two "sides" of the triangle are rather thin margins, but one of them is thicker than the other. One extremity of the bone is more robust than the other, and is divided into two planes. The one is transverse and sub-triangular, and applies to the extremity of the stout or acetabulum limb of the other pelvic bone. The other is smaller, is oblique and concave, and when the two bones are placed in relation, forms a continuation of the acetabular surface already described. Within this and the proximal portion is a large foramen which resembles the pectineal perforation of the pubis.

The femur is long and without prominent third trochanter, this process being represented by a low ridge. The condyles have an extensive posterior sweep, and are separated by a shallow trochlear groove in front. A tibia which was found with the other bones, is much shorter than the former, and has a much expanded head. It is very robust, especially at the distal extremity. The astragalus was evidently distinct from it. A metapodial bone is very robust. Its extremities are much expanded, and the shaft contracted, and it is furnished with a prominent median keel on one half of its posterior aspect.

Several genera have been described, which possess some of the features presented by those to which the present animal belongs. The following are characterized by the presence of the lateral sinuses of the vertebral centra: Megadactylus Hitch., Cetiosaurus Owen, Ornithopsis Seeley, Bothrospondylus Ow., and Pneumatarthrus Cope. The first of these may be dismissed with the remark that its caudal vertebræ possess the sinuses as well as the dorsals, which we have seen is not the case with the Colorado animal. The centra of C'ptioscurus according to Owen, and those of 
Pneumaturthrus, do not exhibit the cavernous structure above clescribed, but are uniformly spongy interiorly. Ornithopsis of Seeley, which Owen refers to his subsequently described Bothrospondylus, possesses a cavernous cellular structure, which I have not found in the reptile from Canyon City, Colorado, but which occurs in the huge samrian discovered by Prof. Lakes, near Golden, Colorado, in the same stratigraphical horizon. Another nawe (Chondrosteosaurus) has been introduced by Prof. Owen, but he gives no characters, nor points out how it differ's from Ornithopsis, which it resembles in its cellular structure.

A short time prior to my publication of the description of the genus Camarasaurus, Prof. O. C. Marsh of New Haven issued a description of a portion of a sacrum of a saurian found in the Dakota beds near Morrison, Colorado, a point one hundred miles north of Canyon City. To the animal to which the sacrum belonged, Professor Marsl gave the name of Titanosaurus montanus. As the name of the genus was not accompanied by any generic diagnosis or specific reference to its characters, it has no claim to adoption according to the rules of nomenclature, nor is the genus distinguished from some of those above enumerated. Especially is there nothing to indicate that it differs from Ornithopsis or Bothrospondylus. The name given has also been already employed by Dr. Lydekker of the Geological Survey of India.

Cautarasaturus supremes Cope.

\section{Paleontological Bulletin, No. 25, p. 7 ; Aug. $187 \%$.}

The bones of this species so far discovered by $\mathrm{Mr}$. Lucas are:-a cervical and twenty dorsal and lumbar vertebre, with twenty caudals. Both scapulie and coracoids were recovered, with one-half of the sacrum, and two pairs of pelvic bones. Of the hind limb I have the femur, with a tibia less certainly belonging to the same animal, although found among the other bones. There is one metapodial. There are many other bones which I have not yet reconstructed or determined.

The dimensions of this animal mar be inferred from the fact that the cervical vertebra is twenty inches in length and twelve in transverse diameter; and that one of the dorsals measures three and a half feet in the spread of its diapophyses, two and a half feet in elevation and the centrum thirteen inches in transverse diameter. Another clorsal is two feet ten inches in elevation. The scapula is five and a half feet in length and the femur six feet.

The centra of these vertebræ bear a ball and socket articulation of the opistliocoelian type, the cups and balls being well pronounced; just beneath the diapophysis is situated a huge foramen. A broken centrum from which Mr. Lucas removed the matrix, shows that this foramen communicates with a huge internal sinus, which occupies almost the entire half of the body of the vertebra. Those of opposite sides are separated by in septum which is thin medially. Thus the centra of the dorsals are hollow. The neural arches are remarkable for their great elevation, and the great expanse of the zygapohpyses. They are more remarkable for the 
form of the neural spines, which are transwerse to the long axis of the centrun. That of one of the vertebre is sirongly emarginate so as to be hifurcate. The widely extended diaphophyses support the rib articulations, and there are no capitular articular facets on the centra.

The cervical vertebra is depressed, the anterior or convex extremity of the centrum the most so. It is remarkable for its elongate form, exceeding the proportions found in known Dinosauria and Crocoditia, and resembling that seen in some fluviatile tortoises. Near the anterior extremity a short, robust parapoplysis has its origin, from which it extends outwards and downwards, and soon terminates in a truncate extremity which presents downwards. $\Lambda$ deep fossa occupies its upper base, and above this a deep linear foramen extends throughout the greater part of the length of the centrum. If this vertebra possesses a diapophysis it is rudimental.

The caudal vertebræ are amphicœlian, but not deeply so. They are subquadrate in section, and not so short as the corresponding ones of Hadro. saurus. The most anterior one of the series has short, robust diapophyses, and is more concave anteriorly than posteriorly. The other caudals are more equally biconcave, but the cavity is very shallow on the most distal of them. The centrum is relatively more elongate and compressed than those of the others. None of them display the lateral pneumatic fossa which exists in the dorsals, and where broken so as to permit a view of the internal structure, the latter appears to consist of rather finely spongy tissue. The chevron facets are not very well defined, and the neural spines are of usual forms, and on two anterior vertebre elongate.

Many peculiarities are exhibited by the vertebræ of this species, which are not described in saurians known up to the present time. Many of these would have been lost in less careful hands than those of Mr. Lucas, and science is much indebted to him for the preservation of many walls and buttresses of light proportions. In general the external walls of the centra are thin, and the processes are composed of laminæ united by narrow margins. The vertelire are lighter in proportion to their bulk than in any airbreathing vertebrate.

The anterior extremity of the centrum of the cervical vertebra is prominently convex, and much depressed. The posterior and concave extremity is wider, and of rather greater vertical cliameter. The base of the neural arch only occupies half of the length of the centrum, an equal extent of the superior surface extending freely beyond it at its anterior and posterior extremities.

The linear lateral foramen commences a little behind the anterior base of the neural arch, and descending somewhat in its direction, terminates beneath the posterior extremity of the base of the neural arch. The base of the latter overhangs the foramen and the base of the transverse process. The interior surface of the centrum is concave, the concavity being bounded in front by the inferior convex thickening of the extremity. Behind the middle the surface becomes plane, and is, near the posterior extremity, bounded on each side by at short angular ridge. 
Measurements.

M.

Length of centrum between anterior convexity and pos-

terior lip...........................565

Depth of posterior cup...................... 090

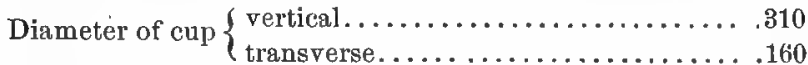

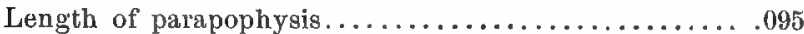

Width of neural canal. ................................

The dorsal vertebra which $I$ suppose the anterior one of those received, is characterized by the lack of the median portion of the neural spine, and the extension outwards of the median lateral processes described above. The diapophyses are much longer, and the zygapophyses more extended transversely. The centrum is constricted at the middle, and especially just behind the convex articular extremity, whose circumference forms a prominent rim. The edges of the lip are flared outwards, forming a deep basin, much wider than deep. The fossæ described in otber vertebræ are present in this one, but differs in proportions, owing to the greater size and expanse of the superior parts of the neural arch. The fossa posterior to the base of the diapophysis is neally plane, while that at the anterior base is deeply excavated, is narrower, and extends so far along the inferior side of the' process as to give it a semi-circular section near the middle. Distally the diapophysis has a trialate section, owing to its three longitudinal ridges, and the articular extremity is large and antero-posterior in direction. The process differs from that of the vertebra next described, in the possession of a facet near the middle of its anterior inferior bounding ridge, which is probably costal, as in the vertebra of Crocodilia. The lateral foramen of the centrum is subround. The general surface is smonth.

Measurements. $\quad \mathrm{M}$.

Total elevation of vertebra................. .770

" transverse extent of diapophyses........... 1.010

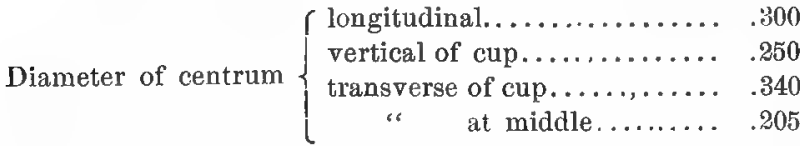

Elevation of zygapophysis above centrum...........310

Diameter of zygapophysis $\left\{\begin{array}{l}\text { transverse............. } \\ \text { antero-posterior. . . . . . . }\end{array}\right.$

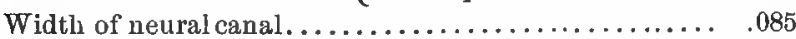

Transverse extent of neural spine.............. .440

Length of diapophysis from posterior zygapophysis.... 320

Antero-posterior width of end of diapophysis........ .135

A dorsal vertebra from a more posterior position, is characterized by its undivivided transverse neural spine. The entire neural arch is of enormous elevation, but as the zygapophyses are above its middle, the neural spine is not as long relatively as in various other genera or as in the 
caudals of this one. The sides of the centrum are strongly concave, and the borlers of the cup Haring. The neural arch is every where excavated, so as to reduce the bulk, and produce lightness so far as consistent with strength. The diapophysis rises from a point above the neural canal. It sends a narrow ridge down to the sides of the latter, on each side of which its shaft and base are deeply excavated. The posterior of these fossæ is overlooked by the wide zygapophysis; and the roof of the anterior one supports the anterior zygapophysis. The former are separated by another and vertical septum, which bifurcates below, forming two prominent borders of the neural canal. At each side of the base of the neura] canal there are two trilateral fossa, of which the anterior is much the larger and ex* tends higher upon the lateral edge of the spine, They are separated by a lamina. The diapophysis is not very long and is subtriangular in section near the extremity. The neural spine is thickened at the extremity as though for the attachment of a huge ligament, At the summit of its posterior basal fossa, at the middle of its height, is an outwardly curved process with a smooth extero-superior face.

\begin{tabular}{|c|c|}
\hline & \\
\hline & \\
\hline h of centrum. . & .275 \\
\hline vation of vertebra..... & .830 \\
\hline Elevation to posterior zygapophyses. . & .550 \\
\hline of superior edge of diapc & .350 \\
\hline " neural spine above posterior zygapophyses.. & .295 \\
\hline f diapophysis behind.................. & .215 \\
\hline$\ldots \ldots \ldots \ldots \ldots$ & .075 \\
\hline Transverse extent of sumu & .215 \\
\hline pine & 330 \\
\hline
\end{tabular}

In a dorsal vertebra from a more posterior position, the centrum is larger. The capitular costal articulation occupies a lower position, its inferior edge being in line with summit of the neural canal. The lamina which supports it is separated from the anterior lamina which is at the base of the diapophysis, by a deep cavernous sinus. The posterior zygapophyses send upwards to the broad neural spine a median buttress each, which enclose a fossa with the marginal buttress of the same. The hyposphen is repre. sented by a vertical lamina only.

M.

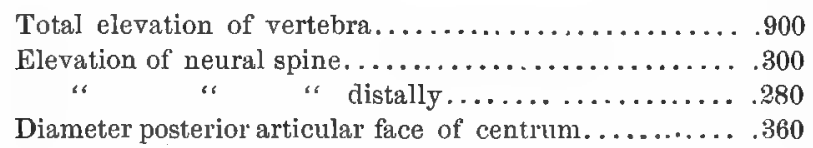

A lumbar vertebra displays a greater expanse of the posterior articular extremity, which is expanded like a dislı. The neural arch and transverse processes have a small fore and aft diameter, and the lateral caverns at the base of the diapophysis are obsolete. The pneumatic foramina are slightly higher than long. Posterior zygopophyses are wanting. 


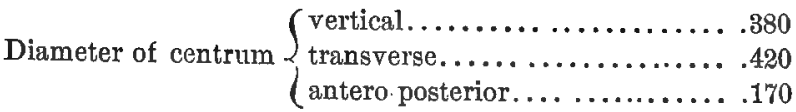

Expanse of diapophyses.................... .590

Vertical extent of base of diapophysis to capitular surface .200

A proximal caudal gives the following

Measurements.

Total elevation...........................560

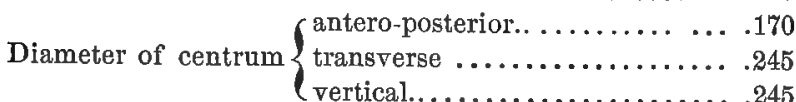

Antero-posterior diameter of neural spine........... 075

Elevation of the neural canal.................... .040

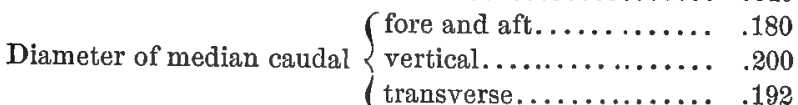

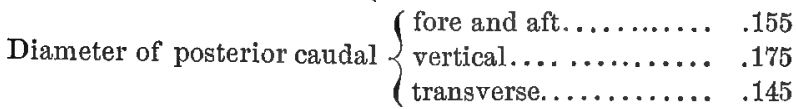

A distal caudal of the elongate type has the following dimensions :

M.

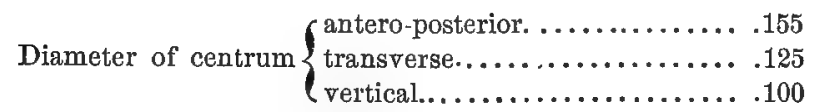

The long diameter of the basis of the transverse processes of the large anterior caudal vertebre is directed obliquely upwards and forwards. The anterior faces of some of these centra are flat.

The length of the sacrum is M. 0.900 ; elevation of first sacral rest, 0.500 .

The head of the femur is subround. One side of the shaft is damaged, so that the form of its section cannot be ascertained. The side of the inner condyle is quite flat, and without epicondylar rugosity.

Measurement of femur. M.

Length.................................. 820

Antero posterior diameter of head ................310

$$
\text { " internal condyle.....450 }
$$

The anterior and posterior edges of the scapula are thin. The posterior is slightly concave, with a slight projecting irregularity near the middle, and is then turned decidedly backwards, bounding the glenoid extremity. The glenoid face is concave, and longer than the coracoid suture. The anterior border is more strongly concave, the distal extremity being more expanded forwards. The sides of this extremity are slightly rugose with coarse grooves. The articular facets are pitted. A low keel extends along the external side of the mesoscapula.

PROC. AMER. PHILOS. SOC. XVII. 100. 2E. PRINTED JAN. , 1878. 


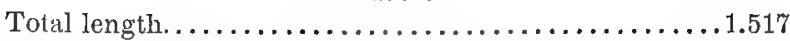

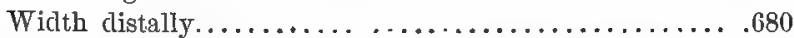

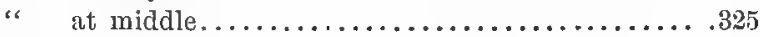

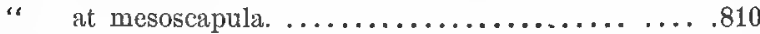

Length of glenoid face.......................400

The articular extremity of the coracoid is recurved and very robust. The borders of the bone are thick and roughened.

Measurements of Coracoid. M.

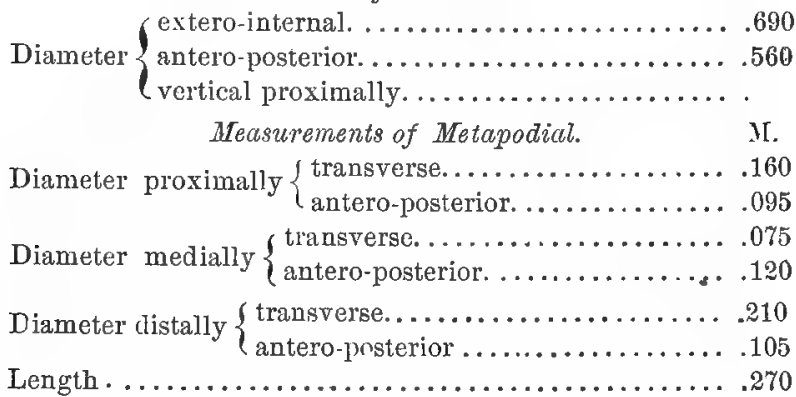

That this species was capable of and accustomed to progression on land is certain from the characters of the bones of the limbs and their supports àbove described. The extraordinary provision for lightening the weight of a portion of the skeleton has more than one significance. It must be borne in mind that the caudal vertebræ retain the solid character seen in those genera which stood habitually on their hind limbs. That the present species was herbivorous is suggested simply by its huge dimensions, and the natural difficulty of supplying it with animal food.

\section{AMPHICCELIAS Cope.}

Paleontological Bulletin No. 27, p. 2, (Published December 10, 1877).

The genus to which the above name is now given, is allied to Camarasaurus, of which, and the gigantic species $C$. supremus, I have given an account in my Paleontological Bulletin, No. 25. Both genera differ from their nearest ally Ornithopsis Seeley, in the excavation of the vertebral centra, so as to include large chambers separated by a septum, which communicate with the external medium by a lateral foramen. In the Ornithopsis it is stated that the vertebral centra are occupied by a number of coarse cells. In the more remotely allied Cetiosaurus, Owen has observed that the tissue of the centra is coarsely spongy.

The vertebræ from all parts of the column of Camarasaurus are known, and those of the dorsal and lumbar regions present the extraordinary character, of which a trace is seen in Cetiosaurus, of neural spines expanded transversely to the axis of the column. Numerous vetebræ of Ainphices. licas are known, and in the dorsals in which the neural spine is preserved, 
the latter displays the usual form, that is, it is compressed in the direction of the axis of the column. The centra differ from those of Camarasaurus in the form of their articular extremities, resembling more nearly in this respect the genus Tichosterus Cope (Paleontological Bulletin, No. 26, p. 194). They are unequally amphicolous, the posterior extremity being more concave, and with prominent margins; while the opposite one is less expanded and is but slightly concave. The neural arch is coössified to the centrum, and there is no capitular costal articulation on the latter.

The manner of the mutual articulation of the neural arches in this genus is peculiar, and is only paralleled in the genus Camarasaurus, so far as I can ascertain. The anterior zygapophyses are separated by a deep fissure, while the posterior zygapophyses are united on the middle line. From the latter from the point of junction, there descends a vertical plate which rapidly expands laterally, forming a wedge whose base looks downward. The supero-lateral faces are flat, and articulate with corresponding facets on the inferior side of the anterior zygapophyses, which look downward and inward, on each side of the fissure above deseribed. When in relation, the anterior zygapophyses occupy a position between the posterior zygapophy ses above, and the lyyposphen, as I have termed the inferior reversed wedge, below. This arrangement accomplishes the purpose effected by the zygosphenal articulation, that is the strengthening of the articulation be tween the neural arches, but in a different way. The additional articulation is placed at the opposite extremity of the vertebra, and it is the anterior zygapophysis instead of the posterior one which is embraced. This structure entitles the genera which possess it to family rank, and as the two genera mentioned above belong to different families in consequence of the different types of vertebral centra, the one opisthocœlous, the other amphicolous, they may be called Camarcisuridce and Amphicalizide respectively.

The pubis is a stout bone with one slightly concave, thicker border, and an opposite strongly convex, thinner margin. One extremity is truncate ; the other presents one transversely truncate and one oblique face. The femur is elongate, and presents a strong postero-external ridge or third trochanter near the middle of the shaft. 'The head is not separated by a well marked neck, and the great trochanter does not project beyond it.

Thus while there is a striking resemblance to Camarasaurus in what may be regarded as adaptive characters, in some important essentials the two genera are very different.

\section{Amphioglias altus Cope.}

Paleontological Bulletin, No. 2\%, p. 3.

The centrum of the dorsal vertebra of this reptile is contracted both laterally and inferiorly, so that the margins of the articular extremities fiare outwards. The sides are flat, and the inferior surface but little convex in the transverse direction. The pneumatic foramen is situated at the bottom of a large lateral fossa which exlends nearly the entire length of the superior 
portion of the centrum. Its inferior border is sunken abruptly, while the superior gradually shallows on the external surface of the base of the neural arch. The foramen is longer than high, in contradistinction to that of the Camarasaurus supremus, where it is round or higher than long.

The neural arch is very much elevated to the zygapophyses. It is strengthened by a prominent rib, which extends from the posterior base upwards and forwards to the base of the anterior zygapophysis. The surface above and behind this is occupied by an extensive excavation whose superior border is the line connecting the zygapophyses. The anterior zygapophyses are separated medially by a deep notch which extends to the base of the neural spine. The articular surfaces incline towards each other. Just behind the anterior zygapophysis, a process extends outwards and forwards whose extremity is lost in my specimen. Its posterior face is excavated by the lateral fossa above described. This process is probably the diapophysis which supports the rib. The diapophysis springs from the line connecting the zygapophyses, and extends upwards and outwards. Its inferior surface is deeply excavated. Its anterior border sends a lamina upwards, which probably reached the side of the neural spine, but is broken off in my specimen.

The neural spine is thin, but its anterior and posterior borders are thickened and double, the lateral rib-like edges being separated by grooves which expand at the base. The posterior groove continues to a more elevated point than the posterior. Each side of the spine is divided into two shallow wide grooves by a median keel. The apex of the spine is much thickened transversely, its obtuse extremity having the fore and aft and transverse diameters equal.

The pubic bone resembles that of the Camarasaurus supremus, but is less robust in all its parts. It is also less extended in antero-posterior width near the proximal extremity.

The femur is remarkable for its slender form. It is a few inches longer than that of the Camarascurus supremus, but is not so robust. The shaft is nearly round and somewhat contracted at the middle, where it is slightly convex backwards. It is slightly curved inwards at the great trochanter. Here the shaft is moderately grooved on the posterior face. This trochanter is only a prominent ledge below the head. The third trochanter is situated a little above the middle of the shaft; it is a prominent obtuse ridge directed backwards. The condyles are extended well posteriorly, and are separated by a deep popliteal groove, which originates on the inferior portion of the shaft. They are also separated anteriorly by a shallow open groove. The external condyle is rather more robust than the internal.

The length of the femur is six feet four inches; the elevation of the dorsal vertebra three feet three inches.

Measurements.

MT.

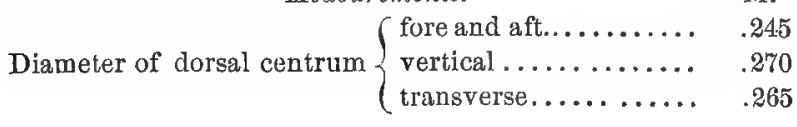


Total elevation of vertebra ................ 1.100

Length of neural spine.................... $\quad .600$

Elevation of anterior zygapophyses........... $\quad .500$

Diameter of neural spine $\left\{\begin{array}{rr}\text { antero-posterior ......... } & .160 \\ \text { transverse (at middle)... } & .065 \\ \text { " } \quad \text { at summit .... } & .140\end{array}\right.$

Depth of centrum below pneumatic foramen....... $\quad .120$

Fore and aft diameter of pneumatic formben....... $\quad .080$

Length of pubic bone...................... 1.060

Thickness of stoutest extremity.............. . . . . .

Length of femur........................ 1.524

Transverse extent of proximal end............. $\quad .420$

" " " condyles .............. .320

Diameter of middle of shaft................. .220

Distance from head to third trochanter........... $\mathbf{. 6 6 5}$

Diameter of head (compressed).............. $\quad .260$

Amphicelias lates Cope.

Paleontological Bulletin, No. 27, p. 4.

Of the wonderful fauna of the Dakota epoch of the Rocky Mountains the Camarasaurus supremus was p:eëminent in general proportions, the Amphicolias altus was the tallest, and the saurian now to be described, was the most robust. It is represented in MIr. Lucas' collection by a right femurand four caudal vertebræ which are in good preservation. They reveal the existence of another saurian of huge dimensions, and of great mass in proportion to its height.

The caudal vertebræ are apparently from the anterior part of the series. They are ail strongly bi-concave; the anterior face more so than the posterior. They all possess diapophyses of depressed form, which take their origin below the base of the nenral arch. The centra are short in antero. posterior diameter, and do not present lateral angles. They are compused of not very dense osseous tissue. The anterior zygapophyses are rather elongate, and their articular faces are directed steeply inwards. They are received by corresponding shallow excavations, one on each side of the posterior base of the neural spine. The neural spines are compressed and straight, and become very robust towards the apex.

The femur is extraordinarily robust. The great trocluanter is low, but the shaft is widest where it expands outward. The third trochanter is a ridge, is above the middle, and is short and little prominent. It is on the inner edge of the posterior aspect of the shaft, and looks backwards and inwards. The shaft in its present state is compressed so as to reduce the antero-posterior diameter. It is not however crushed or cracked. The condyles lave much greater transverse than antero-posterior extent. They are moderately produced backward, and are separated by a cleep inter-condylar groove, while the anterior trochlear groove is wide and well marked. The inner condyle is narrowed posteriorly, while the external one is obtuse and robust. 
The articular extremity is marked with irregular pits as in Dystrophous and Oetiosaurus.

\begin{tabular}{|c|c|}
\hline Measurements. & \\
\hline Diameter of anterior caudal vertebra. $\left\{\begin{array}{l}\text { fore and aft... } \\
\text { vertical........ } \\
\text { transverse..... }\end{array}\right.$ & $\begin{array}{l}.150 \\
.200 \\
.260\end{array}$ \\
\hline Elevation to zygapophyses of the same............ & .25 \\
\hline Total elevation of the same........... & .48 \\
\hline Length of femur............... & 1.40 \\
\hline 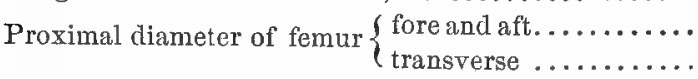 & $\begin{array}{l}.16 \\
.41\end{array}$ \\
\hline 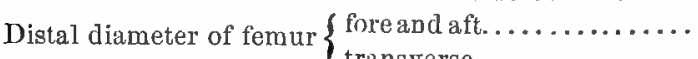 & .36 \\
\hline Diameter of middle of sliaft of fer & \\
\hline
\end{tabular}

The caudal vertebræ of this species are much more deeply biconcave than those of the Camarasaurus supremus; they also differ in their relatively and absolutely greater breadth of centrum.

\section{TICHOSTEUS Cope.}

Paleontological Bulletín No. 26, p. 194, (Published November 21st, 187\%.)

Loc. cit.

$$
\text { Tichosteus uucasanus Cope. }
$$

\section{SYMPHYROPHUS Cope.}

Vertebral centra moderately elongate, slightly amphicolous, and composed of uniformly and moderately clense osseous tissue. A narrow deep fossa in the floor of the neural canal. Neural arch coösified to centrum, with a lateral shallow fossa at its base. Neither costal articulation nor process on the centrum.

The coösification of the neural arch of this genus distinguishes it from the few amphicœlous crocodilian genera known from North America, and the fossa at its base is so suallow as to separate it from sauria of the Pneumatarthrus and Ornithopsis type.

Srmphrophus muscurosus Cope.

A vertebra of this species is strongly concave laterally and distinctly so inferiorly. The anterior articular facets plane, the posterior slightly concave. The superficial layer of bone is dense and smouth, excepting near the edges of the articular surfaces, where it is rugose. The rugosity is arranged in a line within the articular faces, and consists of numerous small irregular pits and grooves which inosculate. Near the border the grooves assume a transverse direction. There is a nutrilive formen near the middle of each side of the centrum. There are traces of the neurapophysial suture, showing that the netral arch is distinct in young animals.

$$
\text { Measurements i. }
$$

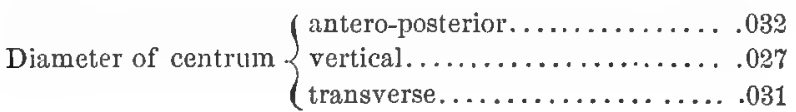


The extremity of a humerus is expanded transversely and displays two unequal condyles, separated by a shallow groove. There are no epicondyles on the external face, but fossæ instead.

Measurements. $\mathrm{M}$.

Width of distal extremity of humerus............... 086

Antero-posterior diameter of larger condyle of the same. .045

Discovered by Superintendent Lucas near Canyon City, Colorado.

\section{LAELAPS. Cope.}

Transac. Amer. Philos. Soc. XIV, 1869, p. 100.

Laelaps TRIHEDRODON. Cope.

Bulletin U. S. Geol Survey, Terrs. III, p. 805, August 15, 1877.

CAULODON. Cope.

Paleontological Bulletin, No. 26, p, 193, Nov. 21st, 1877.

Loc. cit.

Caulodon diversidens. Cope.

\section{Caulodon leptoganus. Cope.}

A second species of the genus Caulodon is represented by a single tooth from a locality distant from that from which the $C$. diversidens was derived. Another tooth found with it probably belongs to the same species.

The best preserved tooth possesses the same general form as that of the $C$. diversidens, but the borders of the spoon-shaped crown are thinner and more acute. The convexity of the cunvex face of the crown does not commence at these edges, but is separated from them by an open shallow groove. There is a median longitudinal swelling at the middle of the length of the concave face. The striking pecnliarity of this species is the very small amount of enamel which invests the crown. It is confined to the inner face, and exists there in "a thin layer, not more than half as thick as in the $C$. diversidens, which thins out and disappears towards the edges of the crown. Another peculiarity is seen in its absolute smoothness. In $C$. diversidens the enamel, even when polished by use, shows remains of the grooves.

Measurements. M.

Diameter of crown at base $\left\{\begin{array}{l}\text { fore and aft............ } 015 \\ \text { transverse............... } 019\end{array}\right.$

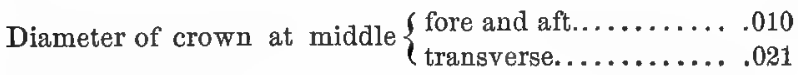

Found by Superintendent Lncas near Canyon City, Colorado.

COMPSEMYS. Leidy.

Compsemys Plicatulus Cope.

Paleontological Bulletin, No. 26, p. 195.

ExPLANATIONS OF THE FIGUREs will be found at the end of this volume.

PRINTED JAN. 12, $18 \% 8$. 



1877.] 85

[Cope.

Tenth Contribution to the Herpetology of Tropical America.

By E. D. COPE.

(Read before the American Philosophical Society, July 20, 1877.)

The greater number of the species described in this paper were sent to the Smithsonian Institution by its correspondents, and submitted to my examination by its Secretary, Professor Henry.

\section{Bufo melanochlorus Cope.}

B. valliceps var. Cope, Journ. Academy, Phila., 1865, p. 100.

Orbital borders elevated, and with parietal branch crests, which are prolonged; toes long, nearly free ; end of carpus reaching end of muzzle; paratoids large; a lateral dormal fold; tympanum large; green with deep black spots; throat and thorax black.

This toad differs very much in appearance from the Bufo valliceps, but is nearly allied in essentials, its other affinities are to the $B$. auritus. The fingers are quite long, but the posterior legs are short, the heel reaching the posterior border of the orbit. The parietal crest is long; the supratympanic is well developed, and preorbital very weak. The front is not narrower, nol does the muzzle project beyond the mouth. The diameter of the very distinct round tympanic disc is half that of the orbit, which is large. The tongue is long and narrow, and the ostia are only half as large as the rather large choanæ. The parotoids are quite small, sub-triangular and directed outwards and backwards. The skin is nearly smooth above, except on the scapular and iliac regions, and is minutely roughened below. There are two tarsal tubercles, and no tarsal fold. Length of head and body, .047; of head, .015; of hind leg, .070; of hind foot, .030.

The allied Bufo coniferus Cope differs from this species in its broadly palmate feet, etc.

East Costa Rica, W. M. Gabb.

\section{BUFO Canaliferus Cope.}

Orbital border reverted crest-like; a preorbital crest; tympanum distinct; head narrow, muzzle projecting; parotoids large, triangular, with scapular angle; rough; brown with dorsal and lateral light bands.

This handsorne species is characterized by the narrow gutter-like front, and prominent muzzle, together with the very large, angulate parotoids. The orbital borders are strongly everted, but without parietal branches. The preorbital crest is not very strong, and the supratympanic is quite short. The muzzle is contracted, and overhangs the mouth. The diameter of the distinct membranum tympani, is half that of the orbit. The parotoid reaches to above the middle of the humerus, has a straight external, and convex internal outline, and is rather lateral in position. Its lateral truncation is similar to that seen in $B$. homatiticus. The skin is tubercular everywhere, finely so below. The posterior limbs are of median length, 
the heel reaching to the tympanum. Two rather small tarsal tubercles, no tarsal fold. Soles rough, the palmation mosuring the middles of the shorter toes. The tongue is small and narrow; the ostia are a little smaller than the chonne.

Length of head and body, .054; of head, to posterior line of tympana, 013 ; width of head at do. .018; length of hind leg,. 071 ; of hind foot, .03:3.

The color is a light or dark deer brown, witl a light veriebral band (rarely absent). On each side of the latter are large brown spots with narrow pale borders. A dark band extends from the orbit to the middle of the side, and above it a broad pale band extends to the groin ; inferior surfaces, uniform light yellow.

'This species differs from the $B$. rergillaceus in its strong cranial crests, projecting muzzle, and large paratoid glands; in the last two characters, and in the narjow front, from the $B$. sternosignatus.

West Tehuantepec, Sumichrast.

\section{Hyja SPILOMma Cope.}

Fingers free; vomerine teeth in transverse series belind line of posterior nares; skin thickened above; tympanum two-fifths eye, frontal bones osseous in front ; eye spotted with yellow.

This species is remarkable for the ossification of the anterior portion of the fronto-parietal bones, which are in contact on the middle line near to the ethmoid bone. Posteriorly they are separated, leaving a fontanelle, which represents the posterior portion of the usual one. The species in this respect approximates the genus scytopis.

The head is lroad, and the muzzle very short; the canthus are obsolete, anil the nostrils a little nearer the end of the muzzle than the orbit. The tongue is wide and entire, and the choanæ small. The pallettes are nearly as large as the tympanic disc, and, the toes are quite short, and only about half webbed. The heel of the extended limb only reaches the posterior portion of the orbit.

The superior and lateral integument is thickened and studded on the back with rather large, obtuse, warts. The length of head and body is, .038 ; of head including tympana, .011; width of head at do., .014; length of hind leg, .052; of hind foot, .023.

The color in these specimens is a light purplish brown, without variations, excepting in one instance. In this one the darker dorsal region is separated from the sides by a broad blackish band which extencls from above the tympanum to the groin on each sirle. The iris is colored in a manner which I do not find in any other species. The pupil appears cruciform, and the interspaces are golden, with a black spot in the outer margin.

This species belongs to the series without webs between the fingers. Among these it is distinguished by the posterior position of the vomerine teeth, moderate tympanum, etc.

From Cosamaloapam Vera Cruz, from Francis Sumichrast. 


\section{Hyla bistincta Cope.}

Fingers free; vomerine teeth between nares; foot shorter than tibia and femur ; tympanum one-fifth diameter of eye; vomerine teeth in small fasciculi; frontal bones ossified in front; blue, sides pale varied; lip not white-bordered.

Size of Hyla carolinensis. The kead, particularly the interorbital region, is broad and flat; the canthus is distinct; the membranum tympani is exceedingly small, and is overhung by a thick dermal fold. The skin of the superior surfaces is smooth. The fore-limbs are very stout, and the animal being a male in breeding condition, the thumb bears two coracous plates on the inner side. The larger of these is the inferior, and forms a strong prominence on the metacarpal. The surface is composed of densely packed points. The posterior limbs are long, the heel reaching nearly to the end of the muzale. The feet are of moderate proportions, and not fully webbed; the membrane reaches the base of the penultimate phalange of the third and fourth digits, and farther on the fifth.

Length of head and body, .045; of head, .012, width of head at tympana, .015; length of hind leg, .067; of hind foot, .031.

Color, upper surfaces including femur and humerus, dark-bluisle plumbeous, without marks; inferior surfaces yellow. Sides marbled with the two colors; posterior face of femur pale brown, with a few yellow specks along the superior border. Eye unspotted.

Vera Cruz most probably; obtained by Dr. Sumichrast with the $H$. spilomma and $H$. miotympanum Cope ( $=H$. microtis Peters).

\section{Chorophilus verrucosus Cope.}

The length of the head to the posterior margin of the membranum tympani enters the total length to the vent three and one-sixth times. The head itself is narrow and acuminate, the muzzle projecting acutely beyond the labial margin. The external nares mark two-fifths the distance from the end of the muzzle to the orbital border. The membranum tympani is only one-fourth the diameter of the orbit. The canthus rostralis is distinct, but obtusely rounded. The romerine fasciculi are approximated. and near the line of the posterior border of the nares, which are larger than the minute ostia pharyngea. The tongue is large and wide behind and faintly emarginate.

The heel of the extended hind leg extends to between the orbit and nostril : the femur is short, while the tarsus is long, a little exceeding half the length of the tivia, and exceeding the length of the remainder of the foot, minus the longest toe. The skin of the gular and sternal region is smootl ; of the abdomen, areolate. That of the dorsal region is tubercular, smooth warts of large and small size being irregularly crowded over its entire surface, and not at all resembling the areolate surface of the belly.

Color above leaden, with three longitudinal rows of darker, light edged spots, extending, one on each side, and one on the median line. They are each composed of a series of spots joined end to end. Femur and tibia 
cross-barred. Upper lip dark plumbeous, with a series of five white spots; a similar spot below the tympanum. Inferior surfaces yellowish.

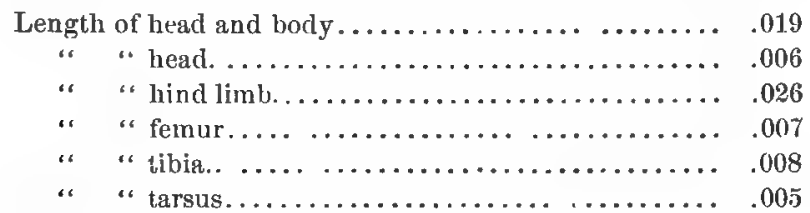

Width of head at tympana................. .005

From Volusia, Florida; Mrs. A. D. Lungren.

This Chorophilus is similar in proportions to the $C$. triseriatus, but is well distinguished by the characters of the skin, and the coloration. The tubercular upper surface is quite peculiar, and the smooth gular region is equally wanting to the Northern frog. The dorsal skin is somewhat like that of Arris gryllus.

\section{LTTHODYTES LANCIFORMIS Coje.}

Vomerine teeth in two fasciculi which are truncate posteriorly, and are situated behind the posterior line of the posterior nares. The supraorbital borders not thrown into ridges. Tympanum not narrowed. Heel reaching to extremity of nuzzle, when the posterior leg is extended. The head is nearly twice as long as the pelvis.

The head and muzzle are flat, the latter narrowed and convex at the extremity. The canthus rostralis is well defined, and the nostril is nearly terminal. The bones are nearly plane and vertical, and their length to the end of the muzzle is twice the diameter of the eye. The latter is onc-third greater than that of the tympanum. The choanæe exceed the ostia in size. There are no dermal folds on the back or inferior surface. The metatarsi are all somewhat separated, and connected by a thin membrane, but this is merely due to the attenuation of the usual solar integument. The hind legs are very long; the pallettes small on the hands, and of median size on the feet.

The color above is dark ashen penetrated with pink; there is a narrow median dorsal white line. A broad black band extends from the end of the inuzzle across the tympanum, where it contracts to a narrow black line which extends from the superior border of the tympanum to near the middle of the side. The concealed surfaces of the limbs are uniformly dusk $y$; the femur and tibia are pink with dusky cross-bands. There is a dark interorbital cross-band in front of which the muzzle is very pale. Upper lip without dark spots; below immaculate.

Tutal length M. .026; of head, .011, or 2.4 of the total. Hind limb, .050.

From the "West Coast of Central America," without more specific locality.

This species is easily distinguished by the great relative length of the head, especially as compared with that of the pelvis. 


\section{Lithodytes pelficulus Cope.}

Lateral borders of the fronto-parietal bones elevated into longitudinal crests, which on the vertex are abruptly incurved without meeting. Tympanic disc a broad vertical oval, as large as eyc; vomerine teeth in short, approximated, transverse, fasciculi, behind the line of the posterior border of nares. Head short, very wide, muzzle not projecting. Heel of extended hind foot reaching to middle of orbit. Gray varied with blackish above and below.

This species resembles nearly the L. megacephalus Cope, Journ. Acad. Phila., 1875, p. 100, but differs in a number of points. The first is the much greater size of tympanic disc, whose diameter is only about half that of the orbit in the latter; in the posterior incurvature of the superciliary crests (they are straight in L. megacephalus); in the much smaller size, the linear dimensions being less than half those of the $L$. megacephalus.

There are two suprascapular longitudinal dermal folds which converge towards' the middle line without meeting. Pallettes and tubercles small. Canthus rostralis straight, intercanthal region plane; muzzle a little retreating, nostrils terminal. General color ashen gray ; a large black spot below eye, and another above, and on tympanum; muzzle, interorbital, and interscapular regions dusky. Soles and posterior faces of femora black. Concealed faces of hind feet and limbs and abdomen, yellow coarsely reticulated with blackish; throat thickly dusted with the same. A dark band with a pale superior border above each ilium.

The $L$. pelviculus is said to have been found on the west coast of Central America, without more special designation of locality.

\section{Phyllobates cystignathoides Cope.}

This rather small species has the form of the species of Lithodytes, as $L$. rhodopis or some of the Cystignathi. The muzzle is rather elongate and the front rather convex. The limbs are rather long, and the tubercles on the inferior side of the digits are prominent. The terminal dilations of the toes are of moderate size, and equal on the two limbs.

The apex of the muzzle is narrowed, but rounded, and does not project much beyond the lip. Its distance from the nostril is one-third that between the latter and the orbit. The tympanic disc is very distinct, is subround, and its diameter is one-half that of the orbit. The tongue is pyriform and much narrowed in front. The nares are sublateral, and the ostia pharyngea very small. The end of the tarsus extends beyond the muzzle, and the heel marks the middle of the eye. Both tarsal tubercles are distinct. There are strong tubercles along the inferior face of each metatarsal. The skin is every where entirely smooth.

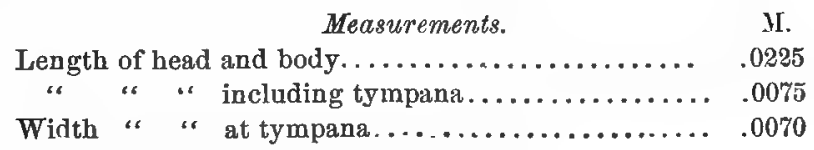

PROC. AMER. PHILOS, SOC. XVII. 100, t 
M.

Length of fore $\operatorname{limb} \ldots \ldots \ldots \ldots \ldots \ldots \ldots \ldots \ldots \ldots . .0140$

" " "foot

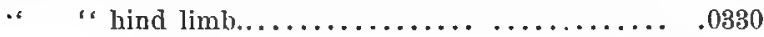

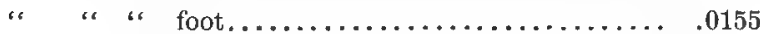

" " " tarsus ........................ .0055

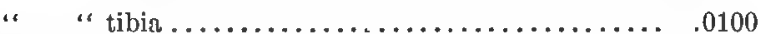

The color of the upper surfaces is a reddish brown; below, leather brown. The back is thickly spotted with large darker or blackisl spots, the largest of which reaches to between the eyes. The sides are marbled with lighter and darker, but the femora are unicolor. Limbs obscurely cruss-banded; below uniform, upper lip with a few pale spots.

Numerous specimens of this species were found by Francis Sumichrast at Potrero near Cordova, Vera Cruz, under decayed trunks of trees. It is of more lanciform proportions than the Central American species, $P$. hylcoformis and $P$. ringens.

\section{Cystrgnathus tabialis Cope.}

Vomerine teeth in transverse series behind the posterior border of the internal nares; toes without dermal border ; no abdomdinal discoidal fold ; posterior limbs short; end of metatarsus just reaching muzzle, muzzle short; not projecting; teeth much behind choanæ; one dermal fold on each side ; skin rough; below white.

This small species belongs to that division of the genus, in which the toes do not possess dermal margin, and there is no discoidal fold of the abdominal integument. Among these it is distinguished by the shortness of the series of vomerine teeth and the paucity of dermal plica. The muzzle is acuminate and rather narrow, but not projecting as in C. gracilis; the canthus is not distinct. The tongue is oval and a little notched behind; the choange are small. The diameter of the tympanic dise is one-half that of the orbit. The heel only reaches the orbit. The toes are not very long; there are two small tarsal tubercles, and a narrow tarsal fold.

Color chocolate brown, the limbs darker cross-barred. A brilliant white band extends from the anterior part of the upper lip, and describing a curve upwards, bounds the orbit below and descends to the canthus oris, from which point it continues in a straight line to the humerus, and ceases. In. ferior surfaces, pure white. Length of head and body, .020 ; of head, .007 ; of hind limb, .028; of hind foot, .013.

The precise habitat of this species is at present uncertain. It is probably a part of Sumichrast's Mexican collection.

\section{Siphonops proximus Cope.}

Tentacular fossa close to eye ; annuli complete ; muzzle depressed, elongate, narrow ; rings $\frac{0}{27} \frac{83}{8} \frac{3}{3}-19=129$ or $\frac{0}{28} \frac{74}{7}-27=129$; longer than $S$. mexicanus.

This Caecilian resembles so much the $S$. mexicanus that I referred specimens of it to that species in my Batrachia and Reptilia of Costa Rica. It 
possesses the spme produced, flattened muzzle, with distinct eye, and the coloration is similar, but the position of the tentacular fossa is quite different, and the general form is more elongate and slender. The diameter is about the same. Length, .425; diameter, .017.

Coast of Eastern Costa Rica; W. M. Gabb.

\section{Siphonops smus Cope.}

Tentacular fossa close to eye ; annuli complete; muzzle wide, truncate, nostrils terminal ; annuli 228 ; anterior 8 undivided; 22 posterior fully divided by intermediate plic $\mathrm{x}$.

The form of the head of this species is different from that of any other Siphonops of Mexico or Central America, and its annuli are more numerous. They continue to the anus, and those of the principal series are nowhere divided on the middle line. The form is not slender, but is more so than in the $S$. mexicanus, resembling in this respect the $S$. proximus. Length, .308; diameter at middle, .011. Color dark brown; below a little paler.

This species was found in Costa Rica, the exact locality being uncertain. From Dr. von Franzius.

\section{Sipronops oligozonus Cope.}

Tentucular fossa close to eye ; many annuli incomplete ; muzzle narrow, projecting ; eye invisible; nostrils lateral ; annuli of principal series 119 , of which 14 anterior and 42 posterior are complete; of second series (none in anterior 72 annuli), 34 incomplete and 13 complete.

This Batrachian resembles at first sight the Caecilia ochrocephala, as it possesses the same yellowish head and brown plumbeous body. It is abundantly distinct from the other species of the genus in various respects, combining the interrupted annuli of some of the Brazilian species, with a narrower, projecting muzzle, and invisible eye. The annuli continue to the vent, and those of the secondary series commence much posterior to the point of beginning in the other species. Length, 0.263 ; diameter, .005.

The precise habitat of this species is uncertain.

\section{Caecilia isthmica Cope.}

General form robust. Muzzle flat, rather wide, and projecting far beyond the mouth. Tentacular fossa near the edge of the lip a little bebind and below the line of the nostril. Eye distinct. Annuli one hundred and forty-two, of which only the last sixteen surround the body, the anterior one hundred and twenty-six being interrupted both on the dorsal and abdominal lines. Between the last seven rings are additional plicæ, which cross the dorsal line and extend on the side, but are not continued across the abdominal line. Length, . $570 \mathrm{~mm}$; diameter (which is about uniform), .020 ; length to rictus oris, $.01 \%$. The general color in alcohol is dark brown; the inferior surface is a little paler.

This species was included in the collection made by Commander Selfridge 
on the East side of the Isthmus of Darien. The species obtained are the following :

Dipsas cenchoa L.

Oxyrrhopus alelia $\mathrm{L}$.

Leptophis occidentalis Gthr.

Herpetodryas carinatus L.

Rhatinaa ignita Cope.

Pliocercus euryzonus Cope.
Ophibolus micropholis Cope.

Tothopsis rugosus Cope.

Ninia atrata Hallow.

Diploglossus monotropis Kuhl.

Anolis laticeps Berth.

Caecilia isthmica Cope.

\section{Helicops trivittatus Cope.}

Scales in seventeen longitudinal rows, all keeled excepting the inferior tro. The keels are moderately and equally developed throughout the entire length. The last maxillary tooth is not much longer than the others, and it is separated from the penultimate by a space which a little exceeds those between the anterior teeth. The internasal plate is nearly triangular, the rostral is wider than high, and the nasal is as long as wide, and is divided downwards from the uplooking nostril. Loreal 1 wice as high as lon $\stackrel{2}{=}$ oculars 1-2, the anterior narrow, and well separated from the frontal. Tro long large temporals on the external side of each parietal, the anterior occupying the space behind the postoculars. Superior labials eight, the eye resting on the fourth only; the fifth and sixth subequal, the seventh a little larger. Gastrosteges 121 ; urosteges is; anal divided.

Color above dark brown, with an indistinct pale vitta on the fifth row of scales, and a yellow vitta on the adjacent halves of the first and second rows. Belly yellow with three longitudinal dark brown bands; the median only preserved on the tail.

Total length, .540; length of head to rictus, .015; of tail, .180.

Habitat unknown, but supposed to be the Argentine Confederation.

\section{OXYRRHOPUS RUSTICCS Cope.}

Head but little distinct from the body, front convex, muzzle slightly protuberant. Grooved tooth not nuch longer than those preceding it. Rostral plate as high as wide, convex and produced backwards above ; internasals and prefrontals broader than long. Frontal with longer anterior than lateral borders, superciliaries narrow, parietals short. Nasals large, loreal longer than high, produced backwards to the orbit below the very small preocular, which is widely separated from the frontal. Postoculars two, in contact with one temporal. Temporals 2-3. Superior labials seven, eye resting on third and fourth ; fifth higher than long. Eye rather small. Inferior labials nine, the fifth the longest, and in contact with the postgeneial. Geneials equal. Scales equal, rather wide, with double fossæ, and in nineteen rows. Tail short. Gastrosteges 223; urosteges 54 ; anal entire.

Dark yellowish brown above, the scales indistinctly blackish bordered; below uniform yellow; upper lip yellow.

This Oxyrrhopus is distinguished by a robust and obtuse form in a higher 
degree than its nearest ally the 0 . plumbeus. The for'm of the rostral plate, peculiar relations of the loreal and preoculars, with the single temporal in contact with the postoculars, short tail, and color serve to distinguish it from that species.

From the same locality as the last. With them were collected the following species.

Hyla vauterii Bibr.

Dryophylax olfersii Licht.

Apurophis anomalus Gtbr. (L. ruti- Opheomorphus merrenii Neuw.

lus Cope).

Thamnodynastes nattererii Mik.

Dryophylax schottii Fitz.

Herpetodryas carinutus L.

Cnemidorhorus microlepidopus Cope.

A species distinguished by the small size of the scales on the brachium and thigh.

A few rows of large scales on the collar; the edge with much smaller scales; two preoculars and a frenoöcular; three supraorbitals ; larger gular scales few and in the centre of the throat; postbrachials numerous, small; brachials in 3 , femorals in 14 rows; olive, with eight indistinct pale bands, black between the two inferior.

There are several flat small scuta behind the parietals and interparietals.

There are a few points of coloration to be observed in describing this lizard. There are four yellow spots at the corners of an imaginury square which encloses the tympanic disc. There is another between the anterosuperior of these and the orbit, and another below the posterior part of the eye. The inferior yellow line is continued on the tail.

About the size of $C$. sextineatus; as the median dorsal lines are faint in the single specimen is not probably young.

West Tehuantepec, Sumichrast.

\section{Chemidophorus unicolor Cope.}

A small species distinguished by the absence of coloration marks.

A few rows of large scales on the collar; the edge with much smaller scales ; two preoculars and a frenoöcular; three suppaorbitals; larger gular scales few and in the centre of the throat; postbrachials larger, abore point joining brachials which are in 5 rows; femorals in 10 ; olive brown with one pale lateral line; four pale spots below and behind eye.

There are four yellow spots round the tympanic membrane, one below the eye, and one between the latter and the nearest one of the former, as in $C$. microlepidopus. The dorsal scales are minutely roughened. It is in general characters allied to the $C$. inornatus Baird from Northern Mexico. The latter differs in the presence of four supraorbital plates, smaller collar scales, and coarser and rougher dorsal scales.

West Tehuantepec, Sumichrast.

\section{CNemidophorus imutabilis Cope.}

This species attains to the largest size known in the genus, without losing its striped coloration, as do the other large forms. 
Several rows of large scales on the collar, the border row not larger nor much smaller; two prenculars and a frenoöcular; larger gulars median, three supraorbitals; postbrachials small; brachials in 3 , femorals in ten rows; adult with eight longitudinal bands; femora pale spotted.

The small size of the postbrachial and femoral scales, relate this species to the $(\because$ guttatus, but it lacks the small scales of the border of the fold seen in that lizard. The interparietal in an adult is narrow. The temporal region is covered with minute scales. There are numerous small scuta behind the parietals. There are two rows of antebrachial scuta well defined at the borders. Two rows between the inferior and infralabials. The inferior lateral brown band extends to the orbit. Throat pale; breast plumbeous.

West Tehuantepec, Sumichrast.

\section{CNemidophorus lineatTisstmus Cope.}

This swift lizard is of medium size in the genus, and maintains the lined coloration intact.

Several rows of large scales on the collar, the border row not larger nor much smaller; two preoculars; no frenoöcular; three supraorbitals ; larger gulars extending across throat; superior preocular not descending to labials; postbrachials large, continuous with brachials; femorals in eight rows; black, with ten or eleven pale bands ; sides and femora pale spotted ; throat black.

The muzzle is rather acute but not elongate, and the fronto-nasals have considerable mutual contact. The larger and smaller gular's are abruptly distinguished from each other, and the former are smaller than the scales of the collar. The frenal plates form a circle surrounding a large median scute, of which the two posterior plates are the largest.

There is a space between the two submedian lines, which is often divided by a median line. Below the lowest line the sides are black with large light spots, open below.

Colima, Xantus ; Giuadalaxara, Major.

\section{Cimemidophorgs mativitis Cope.}

Several rows of large scales on the collar, the border row not larger nor much smaller ; two preoculars, the superior not descending; no frenoörbital; supraorbitals 3; larger gulars extending across the throat; post brachials large, continuous; femorals 8 rows; olive, with eight wide bands, ground black between second and third.

The nostril is in front of the nasofienal suture. Parietals and interparietals of normal proportions, surrounded by a series of moderate scales, in a semicircle. One row between the inferior labials and infralabials. Brachials large, in five continuous rows, distinct, no postbrachials. Two rows of antebrachials. Scales of collar equal those of gular region, larger than postgulars, and smaller than abdominals. Femoral pores seventeen.

Color below bluish; pectoral region blackish; there are small yellow 
spots on the external abdominal scuta and on the femora. A longitudinal yellow line on the posterior face of the femora.

Total length, M. 0.255 ; length to tympanic drum posteriorly, .020; to vent, .076 ; length of hind limb, .051; of hind foot, .026.

Tuchitan, T'ehuantepec, Sumichrast.

This handsome species is, in the number of its longitudinal stripes, similar to the $C$. octolineatus of Baird. That lizard differs in having four supraorbital plates, and smaller collar scales; the stripes are also much narrower.

\section{Cnemidophorus communis Cope.}

This species is near to the $C$. sextineatus in its characters, but constantly differs in the presence of the frenoörbital plate. It is also much larger, the males equaling the large Amivas.

A few rows of large scales on the collar, of which the marginal is the largest; two preoculars and a frenoöcular; four supraorbitals ; large gulars extending across throat; postbrachials and brachials large, continuous ; three large preanals ; femorals in $8-9$ rows ; olive, with six light bands with light spots in the intervals, the former breaking into spots in the adult male.

There are two varieties of this lizard. In the first, there are rows of light spots in the spaces between the stripes in the females; while in the males the stripes are broken up into round spots so as to give a coloration like that of the $O$. guttatus. In the second variety there are no spots and the bands are unbroken. The specimens resemble the young of var. 1.

Var. I. Colima, Xantus ; Coban, Guatemala, Hague.

Var. II. Guadalaxara, Major; Cordova, Sumichrast; Guatemala, Hague; San Antonio, Texas.

\section{CNemidophords angusticeps Cope.}

This species is in general characters similar to the last, but it differs in the coloration, and in the very narrow form of the parietal and interparietal plates.

A few rows of large scales on the collar, of which" the marginal is the largest ; two preoculars and a frenoöcular ; four supraorbitals ; similar but interparietal and parietal scuta half as wide; ground color black and bands much wider and not broken up in male.

The color stripes of this species if assumed to be those of the paler color, are much wider than the ground, and instead of becoming broken up as in C. communis, send off lateral processes, which give the dark ground color a very broken character. The coior of the bands is an olive green. The adult male is of about the size of those of $C$. communis and $C$. guttatus.

Yucatan, Scliott.

Chemidophorus costatus Cope.

In general character's this lizard resembles the last two, but it differs in the shorter head, and strikingly in the coloration. 
A few rows of large scales on the collar, of which the marginal is the largest; two preoculars and a frenoöcular; four supraorbitals; similar to C. communis, but head shorter and scuta wider; brown with black crossbands on sicles, which join across the middle line on the lumbar region; sacral region and femora white spotted.

The short head of this species is accompanied by an abbreviation of the sutures of mutual contact of the fronto nasal and internasal pairs of scuta, wbich is not seen in the other allied species. The unique specimen is smaller than the temales of the two species last described, yet it presents no trace of stripes. From its coloration I should suppose it to be an adult male.

The locality of this specimen is only stated to be "Mexico."

\section{Gerrhonotid a.}

The important variations in the scutellation of the head of the species of this family lead to the view that several genera are indicated. The definitions of these are as clear as those of many genera of the system, and as it appears to me, may be profitably associated with names as elsewhere. There is a tendency to subdivision of the head-shields in some species, it is true, but a little patience in studying the homologies of the portions separated in excess, will refer them to their proper positions and reduce them to the types herein mentioned. Dr. Gray, in 1845, attempted to distinguish four genera among the species of the original genus Gerrhonotus of Wiegmann, but the characters he seized upon do not, with one exception, possess the importance he attached to them. The exception is that of Barissia, which lias maintained its distinctive feature, the absence of the interfontonasal scutum. Two species recently described by Bocourt exhibit, according to that herpetologist, the equally important feature of the absence of the frontonasal plates. The great subdivision of the plates of the internasal region distinguishes a number of species, one of which was named long since Pterogasterus by Messrs. Peale and Green.

Prerogasterus Peale and Green.

Three pairs of internasal scuta; interfrontonasals and frontonasals present.

Species: $P$. ventralis P. \& G.; P. tessellatus Wiegm.; P. ophiurus Cope; P. infernalis B. \& G.; P. lemniscatus Boc.; P. modestus Cope, sp. nov.

Gerrhonotus Wiegmann.

Two pairs of internasals ; interfrontonasals and frontonasals present.

Species: G. multicarinatus Blv.; G. grandis B.\& G.; G. scincicaudus Skilt.; G. principis B. \& G.; G. Kingii Gray; G. gramineus Cope ; G. auritus Cope; G. taniatus Wiegm.; G. deppei Wiegm.; G. formosus Bd.; G. vasconcelosii Boc.; G. rhombifer Pet.; $G$. monticolus Cope, sp. nov.

Mesaspis Cope, gen. nov.

Two pairs of internasals ; interfrontonasal present; frontonasals wanting.

Species : M. moreletii Bor.; M. fulvus Boc. 
Barissia Gray.

Two pairs of internasals; interfrontonasals wanting; frontonasals present.

Species: $B$. antauges Cope; $B$. bocourtii Pet.; B. lichenigera Wiegm.; B. imbricata Wiegm.; B. rudicollis Wiegm.

An extinct genus of the family has been found in the Miocene beds of the White River group of Colorado, which I have called Peltosaurus.* The scales in that genus were conjoined by sutural borders and not imbricate, as in the recent genera.

P'rerogast krus modestrus, sp. nov.

Scales $\frac{1}{1} \frac{0}{2}$ slightly convex above, but not keeled, excepting those of the tail, which are strongly and obtusely carinate or ribbed; an azygos scute between the two anterior pairs of internasals. Internasals of first pair reaching first labials. Internasals of third pair elongate, in contact with frontonasals behind, apparently including the small lateral interfrontonasals. Two postnasals; a large plate, the anterior canthal, descends to the labials, from the inferior part of which a loreal may be sepa rated. Preoculars two or one. Two pairs of large infralabials in contact, following the symphyseal, without a postmental; two pairs follow, of which the anterior are separated by one scute. Lateral fold extending from ear to vent; the granular area extending above the humerus. Appressed limbs separated by six cross-rows of abdominal scales, or the length of the fore arm. Rows of scales from nape to origin of tail, forty. seven; do. from front of humerus to vent, thirty-eight.

The tail is not very long and is grooved below as well as above. Total length, .150; length to meatus auditorius, .012; to vent, .072; length of hind leg, .019. Color above, brown; below, olivaceous. The sides are a reddish-brown or maroon, bordered above by a blackish line which separates it from the dorsal color.

This species differs from all others of the genus in the extinction of the small plate which truncates the lateral angle of the interfrontonasal. As a consequence of this, the latter has a diamond shape, as il does not reach the frontal plate behind nor the azygos plate in front. The smooth scales also separate it from all others of the genus.

The precise locality from which the specimens of this lizard were sent to the Smithonian Institution is uncertain, but is probably Guatemala.

Gerrionotus monticolds, sp. not.

"Gerrhonotus fulvus Boc," Cope, Journ. Ac. Phila., 1865, p. 118, nec Bocourtii.

Scales keeled on the middle line of the back, to the number of three or four rows; other dorsal ancl late:al series smooth; those of the superior surface of the tail keeled strongly. Lateral fold extending from ear to vent; granular scales extending above the humerus. Scales above and

* Annual Report U. S. Geol. Surv. Terrs., 1873, p. 512.

PROC. AMER. PHILOS. SOC. XVII. 100. M 
below $\frac{15}{1} \frac{5}{2}$; forty-five transverse rows between nape and origin of tail, and thirty-six rows between front of humerus and vent.

The interfrontonasal is transversely diamond-shapect, and has no external plates at its lateral margins. The frontonasals have considerable mutual contact. There are two postnasals; the anterior (and only) canthal descends to the labials, taking the place of the loreal, and there is one large preocular. A postmental follows the sympliyseal, and then one pair of infralabials in contact. Two pairs follow, the anterior interrupted by one, the second by two, scales. The auricular opening is nearly as long as the fissure of the eye. The appressed limbs are separated by the space of four ventral cross-rows, or the length of the longest digit of the manus. The tail is of moderate length.

Color of upper surface and sides, brown, the latter a little darker, and bounded above by a narrow black line. A somewhat irregular row of small black spots down the median dorsal line. Below yellowish olive, the scales of the abdomen with black borders, those of the gular and thoracic regions with black centres.

Total length, M. .143; length to auricular meatus, .012; to axilla, .023 ; to vent, .061.

From the summit of the Pico Blanco (elevation 11,500 feet) in the Eastern Cordillera of Costa Rica; W. M. Gabb.

This species I provisionally identified with the $G$. fulvus of Bocourt, which has been found in Guatemala. The two species are probably nearly allied, but present a difference in the cephalic scutellation, which is of generic value.

Published August 15, 1877. 






\section{ON THE BRAIN OF CORYPHODON.}

By E. D. COPE.

Read before the American Philosophical Society, March 16th, 1877. 


On the Britin of Corlyphodum.

By E. D. C'OPE.

(Read before the Anuricun Phitossphical Society, Mrarrh 16, 1877.)

The character of the brain in Coryphtorn being an important desideratam, I endeavored to obtain a cast of the cranial cavity of a well preserved skull of a C. elephantopus, from the Wasatch beds of New Mexico. The hard sandstone matrix which filled it, was removed with some diffculty; the more as its surfaces were indurated by a cement containing much iron oxide. The osseous walls were found in a good state of preservation. It was ascertained that there is a considerable foramon tacernm posterius, but which is not nearly of such proportionate size as that in the genus Tapirus.

The form of the brain-cast thus obtained is very remarkable. Its distinguishing peculiarities are, (1) the small size of the cerebellum; (2) the large size of the region of the corpora quadrigemina ; (3) the small size of the hemispheres; and (4) the enormous size of the olfactory lobes.

There is in the cast a strong constriction in front of the medulla oblongata on one side, which does not exist on the other side. It is uncertain which represents the true form, as regards the lateral portion, but that there was a step-like constriction across the base of the brain at this point, there is no doubt. The medulla is very stout and wider than the hemispheres; it is depressed, and a protuberance on the inferior part of each side has the appearance of the base of the eighth pair of nerves. The region of the cerehellum is depressed and does not present in the cast a distinct line of demarkation from the medulla. An indication of the vermis is seen in a low longitudinal median protuberance. In front of this a transverse shallow depression separates it from the middle brain.

The region of the corpor't quadrigemina is the most bulky portion of the 
brain. Superiorly it presents a large transverse tuberosity, with the lateral portions well defined, but not distinguished from the cast of the hemispheres on the median line. From its latero-superior prominences it extends downwards and forwards on each side, expanding laterally and narrowing as it approaches the inferior surface. Each lateral portion is separated from the hemisphere by a cleep fissure, into which a prominent crest of the lateral cranial walls projects. This crest commences above, nearly at the plane of the superior wall, and curves downwards and forwards to below the middle of the cavity which contuined the hemispheres. The inferior face of the middle region of the brain is bounded laterally by the projecting masses above described, posteriorly by the constriction in front of the medulla, and anteriorly by a slight contraction marking the boundary of the hemispheres. Its anterior lateral angles are continued into a fossa of the cranium, which I did not clear of the matrix, but which doubtless gives exit to the foramina sphenoörbitale and rotundum. The protuberance which occupies this fossa here, includes the base of the trigeminus nerve. A short distance posterior to this position on the inferior side of the lateral expansion of the middle brain, is the slight projection which covers the cavities of the foramen ovale and the foramen lacerum posterius. Between these on the middle line, is a pair of longitudinal elevations divided by a median longitudinal depression. Posteriorly they rise from the transverse constriction of the medulla; anteriorly they terminate rather abruptly, the one half at a point anterior to the other. This assymmetry is found in the osseous basis cranii, and is not due to accident. This median ridge is separated by a wide, shallow concavity from the lateral border on each side. A short distance anterior to the foramen sphenoörbitale is a small fossa which I have not explored, but which is the opening of the foramen opticum. They are of small size, indicating a corresponding character for the optic nerve.

The cerebral hemispheres are relatively and absolutely very small, their median long diameter being one-fifteenth the total length of the skull, or a little smaller than those of the Uintatherium mirabile, according to the figures and description of Marsh. They are together about as wide as deep posteriorly, but both diameters diminish rapidly forwards, the vertical the most rapidly. The profile slopes downwards and forwards to the base of the broad olfactory peduncles. There are no convolutions nor any decided indication of the Sylvian fissure,* but there are surface-casts of the small arteries that ramified in the dura mater. Owing to the prominence forwards of the inferior part of the middle brain, but a small part of the inferior surface of the hemisphere is visible. The olfactory lobes are the largest known among Mammalia, and greatly exceed those of Uintatherium, as described by Marsh, and even those of oxyona. Their peduncle is transversely oval in section, and is directed horizontally forwards for a

* Prof. Marsh (Amer. Journ. Sci. Arts, 1876, p. 166) states that both convolu'tions and a Sylvian fissure are present in Vintatherium. These assertions are not justifled by his figures, nor by the probably similar brain of Coryphodon. 
distance about half as great as the length of the hemispheres without change of form. The mass then expands laterally and superiorly, rising upwards on each side of an osseous septum, which does not divide the olfactory lobes to the inferior face. They are thus deeply grooved above, and finally become furcate near to the extremity. Posterior to this point the inferior face rises, and the apices project laterally and forwards from the superior part of the lobe. The olfactory lobes consist, then, of a massive peduncle supporting a grooved subconical enlargement, which is bifurcate at the apex.*

Since the internal walls of the skull show the foramina for the exits of the cranial nerves, we have a sufficient basis for the determination of the parts of the brain. In this attempt we are met by the difficulties which are inherent in the use of a cast to represent a brain. Although the foraminu sphenoörbitale and rotundum can be readily fixed, their position is such as to give the point of exit of the nervus trigeminus an unusually inferior position. This appears to be the case to a still greater extent in the Uintatherium, there the lateral descending masses are at the same time not nearly so largely developed as in Coryphodon. The large inferior area enclosed between these boundaries is then homologous with the pons varolii or that part of the encephalon which is covered by it. Its appearance in Gintatherium supports this identification, but its proportions and anterior position in Coryphodon depart more widely from the usual form. The two anterior submedian ridges of its surface, faintly indicated in Uintatherium, may be the homologues of the pronounced median ribs in Coryphodon which resemble a continualion of the anterior pyramids of the medulla oblongata. As they are notvery distinctly marked in the medulla of Coryphodon, their identification may be uncertain, but they look like that portion of the anterior pyramids which is continuous with the crura cerebri, and which are concealed in Mammatia by the pons varolii. Their prominence in Coryphodon indicates that the pons is wanting in this genus as in the Reptilia. A shallow concavity of the sphenoid bone between the origins of the trigemini indicates the position of a pituitary body or hypophysis.

- In profile the brain closely resembles in form that of a lizard, e. g., an Amiva, excepting that in the latter the cerebellum is more elevated. The extension downwards and forwards of the middle brain with its profection bolow the hemispheres is common to both, but the inferior portions at least, do not appear to be homologous in the two. In the Coryphodon, the lateral projections correspond with the exits of the trigeminus from the skull ; in the Amiva this part terminates in the optic tracts. The superior portions of the middle brain correspond in appearance and relative size with that of the Amiva, but a clear difficulty in identifying them in the

* Measurements of this brain are given in the article on Coryphodon elephantopus, in my furthcoming report on the vertebrate Paleontology of New Mexico, Vol. IV, of the report of Lieut. G. M. Wheeler.

f hee Amer. Journ. Sel. Arts, 1876, pl, iv, p. 165. 
two types, is derived from the difference in their inferior connections. One result of the examination is assured, viz. : that this region is no part of the cerebral hemispheres, and that it is entirely uncovered by them. As it is not the cerebellum, it stands in the position of the corpora quadrigemina, or perhaps the posterior pair more especially. As the homologies of this region in the vertebrate brain are not yet determined, further attempts to identify this part of it in the Amblypoda must be postponed for the present. The structure is in any event entirely different from that seen in any recent Mammalia, or in any Mammal of a period more modern than the Eocene period, and one that not only entitles these animals to a position in a peculiar order, but also in a special division of the class, even more distinct than those based by Prof. Owen on the modifications of the structure of the brain. The homologies of the olfactory lobes are simple, but their extent and form resembles nothing known among mammals, even far exceeding in size those of Uintatherium. On the other hand, they resemble those of reptiles, especially of the lizards, but are less deeply bifurcate anteriorly than in them. In the Coryphodon elephantopus they equal in length the middle brain and hemispheres together, and their bulb equals the hemispheres in transverse and vertical diameter.

The nearest approach to the firm of the brain in the Amblypoda, is seen in that of the Arctocyon primovus, a Creodont which represented the Carnivora in the same lower Eocene fauna, and was actually associated with Coryphodon in France. This brain is described and figured by Prof. Gervais, Nouv. Archives du Muséum, vi., 1870, p. 150, Pl. 6 f. 4 , who notices the remerkable exposure of the middle brain or corpora quadrigemina. Among Mammalia of later ages some of the extinct South American Edentata, present the greatest resemblances, although slight ones. Among these may be noticed the small and transverse cerebellum, and especially the lateral expansion of the region anterior to it. To what portion of the brain this expansion belongs, is not known, but it is not unlike the lateral mass in Coryphodon, as, e.g., in the Eutatus seguini, Gervais. There is, however, nothing exposed on the superior surface in the Edentata which appears to be the middle brain; hence the difference from the brain of the Amblypoda is very considerable.

In reviewing the evidence brought together up to the present time, the writer is of the opinion that the type of brain shown to exist in the Amblypoda, and Creodontrt, is as distinct from those characterizing the primary divisions of the Mummalia, as they are from each other; and that it necessitates the establishment of a special sub-class for their reception of at least equal rank with the groups Gyrenrephalc, Lissencephala and Lyencephala. This may be called Protencephala, with the following definition: Cerebral hemispheres smooth, small, leaving not only the cerebellum but the middle brain exposed behind, and contracting into the

*Figured in the important Memoir of Gervais, already quoted, Nouv. Areh. Mus., 1869 , v., p. 42. 
very large olfactory lobes in front. Cerebellum very small and flat; middle brain large. This character is sustained by that of the anle joint, which, existing in two such distinct divisions as the Amblypoda and Creodonta, may be found to characterize the entire sub-class, but this is not yet certain; it is as follows: Tibio-astragalar articulation flat, and without groove or segment of pulley.

This sub-class stands below the Lyencephala in its position, approximating the reptiles in the points above mentioned, more nearly than the latter do. It includes two orders, one ungulate, the Amblypoda, the other unguiculate, the Bunotheria.* To the former belong the sub-orders Pantodonta and Dinocerata; to the latter the Creodonta and probably the Tillodonta and Taniodonta. Whether the Mesodonta belong to it is not certainly ascertained, while the Insectivor $a$ do not belong to it, as they are rightly placed in the sub class Lissencephala.

Lartet first pointed out the fact of the successive increase in the size of the brain of the Mammalia with the advance of Geologic time; and Marsh has stated that this increase is to be observed principally in the relative size of the cerebral hemispheres. I would correct the latter statement so far as to add, that the increase of size is to be seen in the cerebellum as much as in the hemisphere. It is also evident that the relative decrease is in the middle-brain and olfactory lobes.

\section{Explanation of Plates.}

P1. I. Cast of brain cavity of Coryphodon elephantopus, two-thirds the natural size. The right bulbus of the olfactory lobe is probably too large above, owing to the want of preservation of the superior wall of the cavity.

Fig. 1. Superior view; fig. 2 , the left side; $t$. base of the trigeminus nerve.

Pl. II. The same. Fig. 1, from below ; fig. 2, posterior ; fig. 3, anterior views. t. base of the trigeminus nerve; md. base of the mandibular branch of the trigeminus; p, ribs continuous with anterior pyramids.

* See Proceedings Academy Natural Sciences of Philadelphia, 1876, p. 88. 

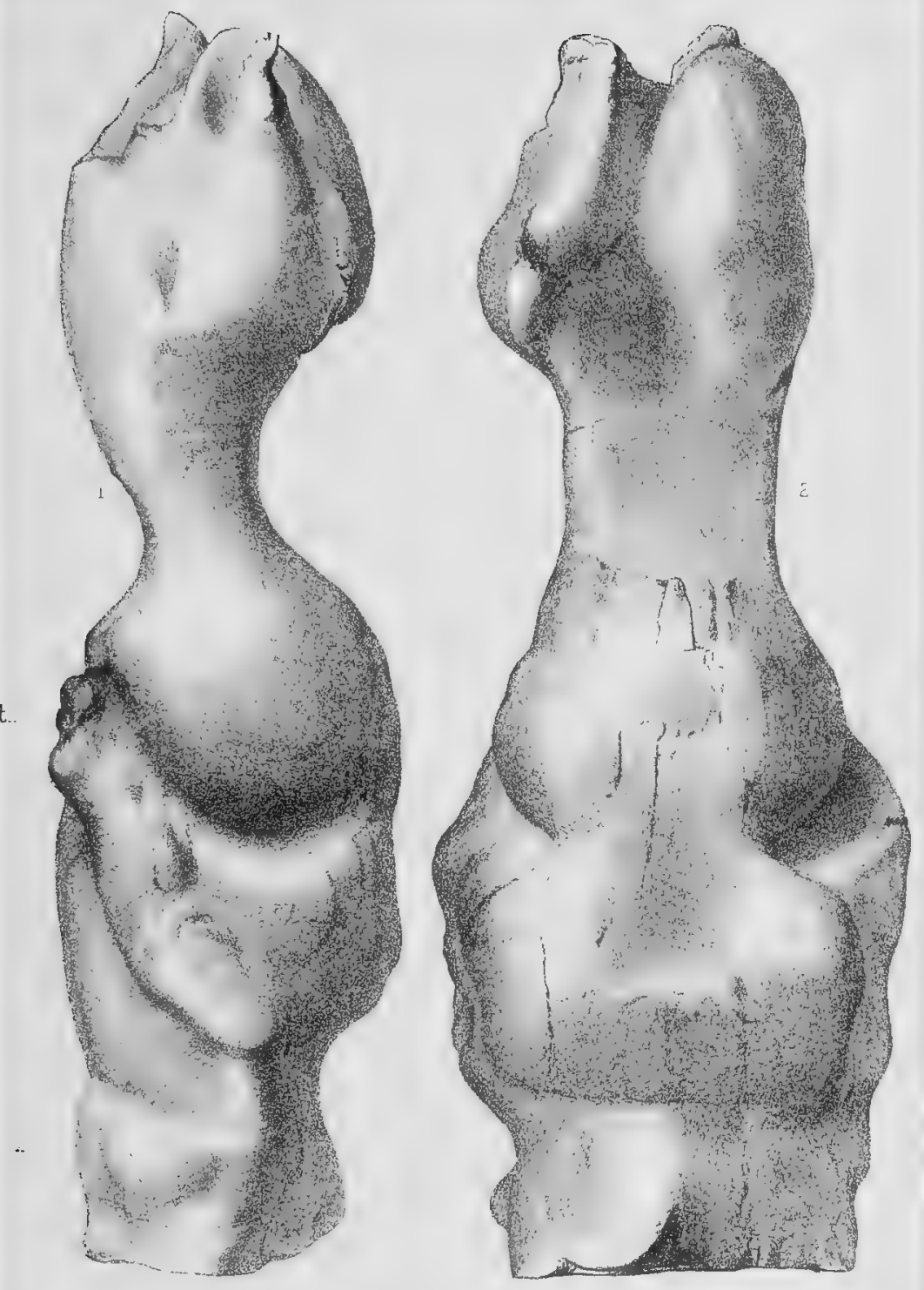

Coryphodon elephantopus $\frac{2}{3}$. 



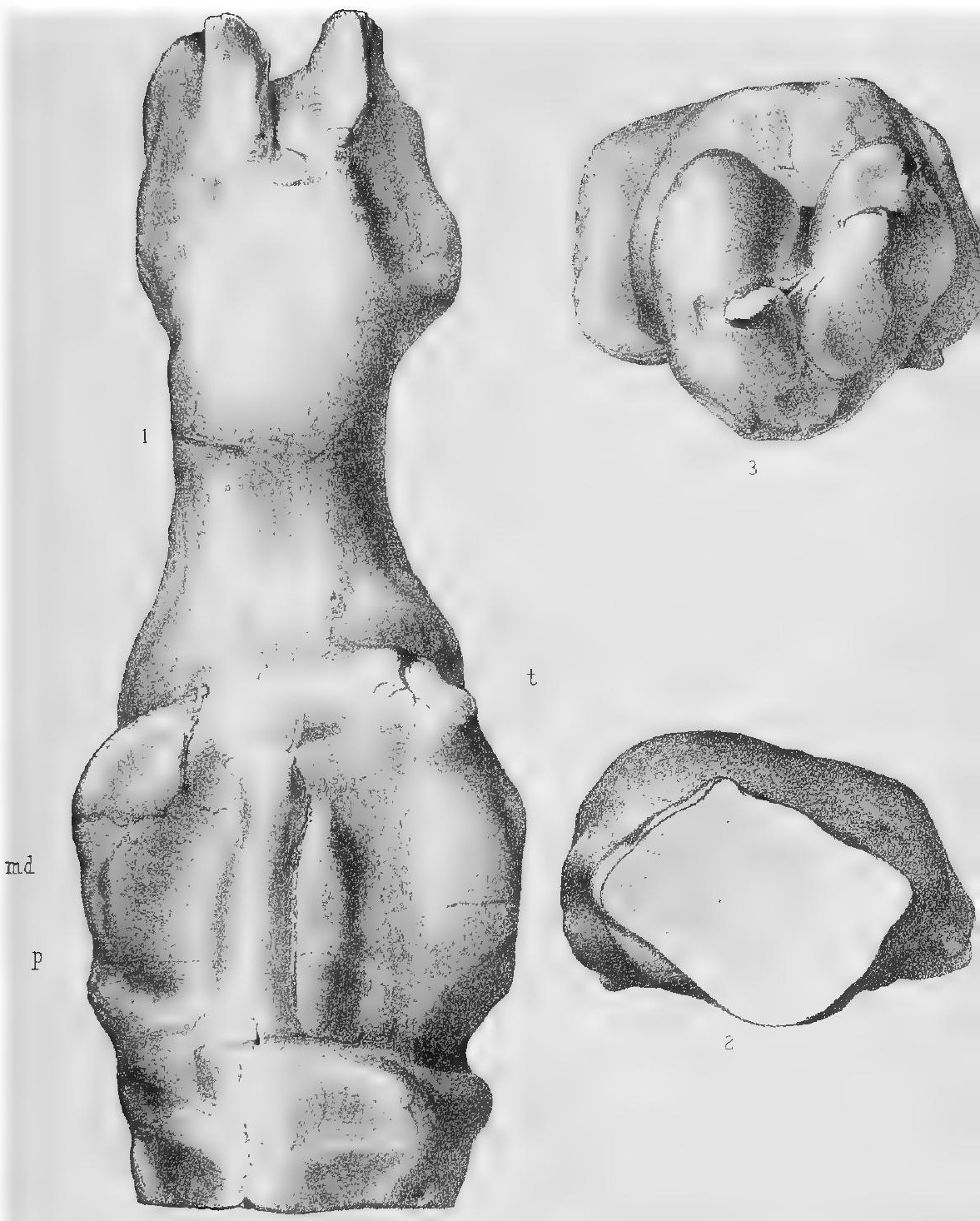

Coryphodon elephantopus $\frac{2}{3}$. 



\section{THE ORIGIN}

OF

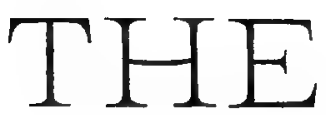

WILL:

BY

E. D. COPE.

REPHINTED FFOM THE PENN MONTHLY FOR JUNE, 1877.

PHILADELPHIA :

JUNE, 1877. 



\section{THE ORIGIN OF THE WILL.}

I. THE DEFINITION OF THE WILL.

\section{$\mathrm{D}$} EFINITIONS of the term "Will," as we find them in metaphysical writers, are not identical; and much apparent difference of opinion depends, as usual, on this diversity of statement. Locke regards the concepts "will" and "freedom" as entirely distinct in their nature, and not essentially related to each other. He says, "Freedom belongs as little to the will, as swiftness to sleep, or squareness to virtue. Freedom to do is one power, will to do is another: will, a power of the mind exerting dominion over some part of a man by employing it in or withholding it from any particular action; freedom, again, a power which a man has, to do or to forbear doing any particular action." It appears that what Locke here denominates will is that common activity of the mind which expresses itself in action, which may be readily considered apart from the question of choice. This doubtless expressed something to the metaphysicians of that time, but merely signifies to the physiologist of the present day, the movement derived from the metamorphosis of nutritive material in the arterioles of the brain, which when consciously performed, are called thoughts, and feelings, and are the necessary precursors of a class of muscular acts. The question of will properly so called is not yet entered on at this point. Doctor Willis ${ }^{1}$ elaborates Locke's position in the following language: "But there is, in fact, no one particular primitive faculty that wills in the human mind; will is a general term, and belongs to and is expressive of the activity of each of the primitive faculties of our nature; the benevolent faculty being active, causes us to will to do good and charitable offices ; the reverential faculty being active, to will to feel respectfully or reverently; the musical faculty active, to will to sing or hear music, etc.; and the willing. here is necessary; but whether we yield to the impulse of the benevolent, reverential, or musical faculty, and indulge therein their various willings is not so; here we are free, and can yield or abstain as we list." This passage renders it the more clear, that the latter part of Locke's statement, in which he defines freedom, is that in which he really refers to

\footnotetext{
1 Benedict de Spinoza : his Life, Correspondence and Ethics. 1870. p. 145.
} 
the will as generally understood; and Dr. Willis's assertion of the existence of our ability " to yield or abstain as we list," grants all that the advocate of "the freedom of the will" could desire.

The modern automatic school only avoid discarding the term will altogether, by using it in the sense of Locke's definition. They make it merely the conscious mental activity that precedes the act; the direction of that activity being necessary in its character; $i . e$. the result of impinging stimuli. In other words, on the automatic theory, the spontaneous activity of the body is directed or deflected by stimuli, whose ultimate form depends on the exist ing mental machinery through which they pass. There is avowedly no room for a self-determination in such a process, and its existence is therefore denied by this school. Inasmuch as a faculty of self-determination is what is here understood by the term will, and the question in the present article is, whether there be or be not such a faculty, the inquiry to which we address ourselves is whether a human" will exist or not. Says Dr. Carpenter:" "The psychologist may throw himself into the deepest waters of speculative inquiry in regard to the relation between his mind and its bodily instrument, provided that he trusts to the inherent buoyancy of that great fact of consciousness that we have within us a self. deternining power which we call will." The existence of such a faculty is in these words assumed by Dr. Carpenter, but I have looked in vain in his writings for a demonstration of the truth of this position. The same is true of the works of many other metaphysicians.

Will may be considered in two aspects: first, as a control over the origin of mental or bodily movements; and second, as a control over the direction which those movements take. The latter case is the one chiefly considered here, as the one involved in customary definitions of human will.

It need scarcely be added that the concept will, is an abstraction from supposed special exhibitions of it, and represents a supposed mental property.

\section{THE NATURE OF ACTIONS.}

The discussion between the advocates of the freedom of the will on the one hand, and those of the doctrine of necessity on the other, has often been obstructed by a petitio principii, which yields

2 Mental Physiology, p. 28. 
the case to the latter side at the outset. This is the dictum which has often passed unchallenged by both parties, that "human action is the product of the strongest inducement," or, otherwise stated, that "the will is the result of a balancing of opposing motives;" or that "the will obeys the strongest motive." This is simply the statement in reversed order, of what we might suppose without examination to be a general truth, viz: that the motives which precede the acts which we observe, are stronger than all others at the time. If this proposition be true without qualification, there is no further need of discussion, since it involves the negation of freedom, or of a power of choosing. But as such, it is an assumption in advance of a conclusion in the case under consideration; a begging of the question in a clear sense. Such a position can only be adopted as a result of the fullest investigation into the phenomena; it cannot be accorded before examination into the facts.

But the statement may be admitted with this important qualification, by which the argument is transferred to another stage of the subject, viz.: that we do not thereby explain why the inducements to act thus and so do, in many obvious cases, overbalance all others in a given human mind? This inquiry is not fruitless, so long as we have before us every day examples of men acting differently under identical circumstances. If there be any "liberty," it is exercised at the point of permitting inducements or motives of one kind to occupy the mind to the exclusion of those of another kind; and secondly, such occupation being granted, freedom might be exercised in removing restraint from the pressure of the present motive, so that the act can take place. If there be no inherent power of controlling the attention, and none of restraining the pressure of motive, then there is no will in any proper sense of the word, and man is an irresponsible automaton. The proof or disproof of this proposition must be the end, not the beginning of the discussion.

An inquiry into the origin of actions must be preceded by an examination into the nature of the acts themselves. The following classification is offered as expressing as nearly as possible their relations to the general developmental position of active beings, without any pre-suppositions as to their automatic or voluntary character. It is necessarily assumed that all acts are performed with reference to the acquisition of pleasure or the avoid- 
ance of pain; in other words, that all acts are due to motive, and are the expression of design on the part of the actor. This is as true of the simplest as of the most complex actions of animals, whether consciously or unconsciously performed. The movement of the Amoeba in engulfing a Diatom in its jelly, is as much designed, as the diplomacy of the statesman or the investigations of the student. And the motive may be the same in all three cases; viz.: hunger. But as the unconscious acts have been probably derived from conscious ones by organization, a fundamental classification must first recognize their relations to the two necessary terms of consciousness, the subject and the object. All actions may then be divided into two classes; those which are performed with the design of securing the pleasure of the subject, and those whose motive is to secure pleasure for the object as distinct from, i.e. opposed to, that of the subject. The tendencies thus defined have been named, in other connections, the appetent and the altruistic, and these names may be preserved as equally appropriate for the present purpose. Actions of the appetent class differ according to the developmental grade of the animal displaying them, or the grade of the organ of the body to which they are proper. In their simplest form they are mechanical movements, following a stimulus without the intervention of any rational process; the end being attained by movements, whose directions are determined by mechanical or physical laws only. Such acts belong to the lowest type of animals, and are also seen in the organic functions of all animals; they may be called the anaesthetic division. They may be performed consciously or unconsciously. Acts of another order are those which, while due to stimuli, are directed by a process of ratiocination. They are higher than those of the previous order because they successfully accomplish their object under changing circumstances, to which they adapt themselves as the others cannot. Like them they may be performed in consciousness or in unconsciousness, or in a still higher state of the mind, that of self-consciousness. The last condition is only possible to animals of a high order of intelligence, since it not only demands an exercise of the rational faculty, with reference to objects, but also with reference to itself-the subject. These three groups form the rational order. The unconscious actions of both the anaesthetic and rational kinds, are called "reflex;" and all of them are "automatic," in so far as they are performed without will; terms more 
fully defined in the following pages. The process of intellection in unconsciousness is called unconscious cerebration.

Actions of the second great class, the altruistic, demand for their performance the attributes necessary for the highest of the appetent class. They require intelligence enough for the perception of what is the pleasure of the object, and self-consciousness, to know that that pleasure is inconsistent with its own, or subjective pleasure.

The arrangement may be summarized as follows :-

I. Appetent class.

$\begin{array}{ll}\text { I. Anaesthetic. } & \left\{\begin{array}{l}\text { Unconscious (reflex). } \\ \text { Conscious. }\end{array}\right. \\ \text { 2. Rational. } & \left\{\begin{array}{l}\text { Unconscious (reflex). } \\ \text { Conscious. } \\ \text { Self-conscious. }\end{array}\right.\end{array}$

II. Altruistic class; rational and self-conscious.

Under the definition of will above given, it cannot be present in unconscious or reflex actions, and the inquiry is limited to the conscious groups exclusively. It may then be well to add a few words on the nature of consciousness.

This faculty is here understood in its broadest sense, namely, subjective perception. The term consciousness expresses the knowledge by the subject of the effects of stimuli on itself, which ranges all the way from the mere sense of contact, to the sense of an idea. An unprejudiced scrutiny of the nature of consciousness, no matter how limited that scrutiny necessarily is, shows that it is qualitatively comparable to nothing else. The attempts to correlate it with the physical forces have so far been utter failures, although the vital forces, to which it gives direction, are evidently not excluded from the laws of quality and quantity. The common hypothesis that consciousness is the product of evolution, appears to the writer, in view of this primary fact, to be irrational; while the converse, that evolution is a product of consciousness, is far more likely to receive ultimate demonstration. From this stand-point it is looked upon as a state of matter, which is coëternal with it, but not coëxtensive. Itself in its totality a reservoir of force, it is the source of all physical and vital forces, with which it has therefore an equivalency of quantities, but not of qualities. The cause of the difference between conscious and unconscious force must be secondarily due to different condi- 
tions of matter as to its atomic constitution; consciousness being only possible, so far as we can ascertain, to matter which has not fallen into fixed and automatic relations of its atoms. The condition appears to be one of tension, in which the automatic (crystalline) tendencies antagonize each other, the material being all the while in the metastatic condition of nutrition. This idea is parallel to that of Heraclitus, who held that the essence of all things lay in perpetual modification, a universal becoming, an eternal emergence and disappearance.

In accordance with the preceding views, the relations between consciousness and matter are thus depicted as of a mutually necessary character, the movements of conscious force involving consequences to itself from which the properties of matter necessarily preclude its escape.

If we trace the consciousness of animals to such an origin, it may be asked, why have not such beings the powers and perfections of their source, in quality if not in quantity? The answer to this query, in view of the fact that they have not such qualities, is only to be found in an investigation of the nature of memory. The absence of memory of the past would be equivalent to ignorance; while a new material vehicle might render memory possible for the future, and thus education, under new surroundings, create diverse beings from a primal common source.

We must include in our estimation of the distributions of consciousness and forces, not our planet alone, nor our system only, but the universe. Hence Sir William Thompson's idea that consciousnesss ("life") was originally exotic to our earth, is an altogether" permissible hypothesis.

If there be such a state of consciousness as will, it must have appeared in course of the evolution of animals, at some point in the series of stages of progress through which their mind has passed. Yet it is maintained by some thinkers that the doctrine of evolution necessarily excludes the idea of freedom from the nature of the minds thus produced. The case is, however, involved in that of consciousness, and the investigation of it must proceed in the same manner. If it has been shown that will does exist in connection with evolution, we must proceed to discover, if possible, the relation between the two facts.

The proof of the existence of a freedom, power of choice, or will, is found in the origin of the altruistic class of acts, which are 
probably only possible to the human species. These have been above defined as those in which the pleasure of the object, as distinct from, and therefore opposed to that of the subject, is the design of the act. This definition excludes acts for the benefit of others, in which the actor is also gratified, since the motive may be in that case the pleasure of the subject. No doubt, many generous acts are of this character, but they were not such the first time they were performed, since experience of their pleasurable character had not then been acquired, and the evidence of all dast experience was of a diametrically opposite character. In other words, the motives already organized in the mind of the subject, were all in favor of the subject. The laws of evolution render the introduction of a new element of character at this point absolutely necessary. It is well known that the development of mind, and through it of all the acts of the first or appetent class, has been due to the pursuit of pleasure and avoidance of pain on the part of the subject. The pursuit of an opposite course, by animals whose pleasures and pains are those of the successful fulfillment of the necessary functions of life, or the reverse, would insure their speedy extinction. Their survival has been due to their prompt discrimination of favorable and unfavorable conditions through their sensibilities, and the human species, as the product of evolution, displays these sensibilities in their highest form. Under these circumstances it is obvious that since none but the inherited motives, with refinements due to more complex circumstances, can be found in his mind, that without the intervention of will, an altruistic act is impossible.

It has also been pointed out that such can only be performed by a being capable of the highest state of consciousness, $i . e$, selfconsciousness; in other words, by a being capable of recognizing its own mental states. Under such circumstances only can it distinguish the mental states of a being apart from itself, towards whom the altruistic act is directed.

It being then conceded that will is exhibited in certain human actions, it becomes important to determine, if possible, the conditions under which it appeared in the course of the evolution of man.

III. THE ELEMENTS OF MIND.

Prior to considering the origin of states of mind, it is necessary to go over the well-trodden field of its original constitution. 
There are three primary conditions of consciousness, which naturally grade into each other, viz: pain, indifference, and pleasure. Consciousness is of one or the other of these types in all animals. The constant flow of activity either in movements of the whole body or of particular parts of the body, has brought animals from their beginning into contact with other bodies, either at rest, or animated by active forces, as light and heat, which have varied their sensations, rendering them more positive in each of the three directions named. These sensations soon cease, leaving consciousness where it was, but not without marks of their former presence in the organism. They are recorded, and continue in unconsciousness so long as the organism remains unchanged. This is the first part of memory, $i . e$., retention. Under the influence of what is called cohesion, the impressions may be returned to consciousness in a less distinct form by the occurrence of new impressions which have some near relation with them as to time, place, or qualities of other kinds. This is the second part of memory, or reminiscence. The sum of the impressions which are necessary to memory, constitutes experience. It is evident that reminiscence is pleasurable or painful, as the experiences recalled were pleasurable or painful. Another quality is rendered possible by the two faculties of retention and cohesion, viz: classification. This consists of a re-arrangement of retained impressions in accordance with different kinds of cohesions, $i$. $e$, different kinds of likenesses. The products of classification may be brought into consciousness just as sensible impressions are revived; but unlike these, they constitute in their totality a new experience of internal origin. When a cohesion between two circumstances is due to a repeated experience of the one as following the other, men entertain the idea that one is necessary to the other. From memory of the necessary results of our own activity, we have come to regard necessary sequences as the result of activity somewhere. If activity be discerned in the first of two coherent events, we regard it as a cause of the second; if the first be passive, the idea of cause does not arise in connection with it, but in some other active agent. Finally, all processes involving reminiscences are less distinct than the original impressions. Spencer calls the former faint, the latter distinct; the faint order are the processes of reason; the distinct, of perception.

Whether these processes are pleasurable, painful or indifferent, depends on the characteristics of the reminiscences which are 
their subjects. As the reminiscence is less distinct than the original impression, so there comes to be, as pointed out by Spencer, a faint order of pleasures and pains, which, with the indifferent class, form the material of the processes of reason. These mental states of pleasurable and painful consciousness, constitute that primary division of the mind, the feelings or affections, as distinguished from the intellect.

The feelings co-exist with intellectual operations of all grades of complication, since pleasures and pains are states which follow all kinds of activities, and therefore reminiscences. To seek pleasure and to avoid pain constitutes the business of the lives of all conscious organisms; and hence the feelings, as derived from experiences, are the directive and often originative conditions of movements or actions. In animals with higher intellectual powers, the general classification of experiences of given objects or actions results in a higher order of the mental feelings, which are called likes and dislikes. When these forms of consciousness assume an intense condition due to stimuli, they become emotions or passions.

These details are entered into in order to show that the feelings in their various grades are the motives of action in all animals, from the Amoeba to man. In the former they are mere reminiscences; in the latter, they are so generalized as to become enduring principles of action, which put the intellect to every conceivable labor. And it is evident from this foundation fact, how the intellect itself has been constructed. The activity stimulated by the feelings has resulted in new experiences, and the accumulation and elaboration of these into new combinations of the faint type of consciousness, has been the law of their development. This we can observe in the education of one generation of living animals, and it has doubtless been the law of the generations of the past as well. We may then review the probable method of development of mind through the ages of past time.

IV. THE DEVELOPMENT OF MIND.

In the first place, it is evident that the evolution of mind has been due to the activity of animal life. Although not asserted, it is sometimes implied that "circumstances," in which the animal is passive, have been the efficient cause of mental development. That this could have been the case is inherently impossible, and 
since animals of the lowest types possess powers of movement, their activity has nccessarily been an immediate cause, while surrounding circumstances have exercised a controlling influence.

Animal activity must be traced to the generation of force or motion by a protoplasmic body which is constantly supplied with nutriment. This production of force is the basis of the acts of animals, up to and including man; often, as remarked by Prof. Bain, displaying itself in aimless discharges or playful movements, as in lambs and boys.

But we observe even in very simple organisms, as the Amoeba, etc., that many movenents are not aimless, nor without design. We observe that these mere specks of jelly devour nutritious substances, and reject the innutritious, that they even distinguish between the Diatom which contains protoplasm within its shell, and the empty shell. Many facts of this kind lead us to believe in the consciousness of these pioneers of life, and seem to show that they have experiences of the pleasures of nutrition, and of the pains of retaining insoluble substances in the seats of assimilation. It would also appear that they remember these sensations, so as to seek the pleasures and reject the pains, when in the course of their wanderings they again come into contact with the material objects which have caused them. Given these two terms, sensibility (consciousness) and memory, and we have the conditions by means of which the entire complex superstructure of the affectional and the intelligent acts has been elaborated out of mere movements.

This has been accomplished by the well-known laws of organization of habits, and heredity. The performance of an act under stimulus, so modifies the structure of the bioplasts of the brain, as to facilitate its repetition. With further repetition the organization is soon complete, and action follows the stimulus without direction, so long as no adverse influence affects the consciousness. Whether the act be one of the Rational or Anresthetic orders, from this habitual stage it becomes automatic in the true sense, between which and the reflex act no line can be drawn. It is eviclent that the degree of consciousness present in animals will depend on the number of changes appearing in their surroundings, whether due to modifications of the external world, or movements of their own bodies. Inasmuch as the habits of the lower animals are few and simple, most of them must be automatically performed, the con- 
sciousness being only present at the commencements of the several processes. It is probable that the organization of mental functions was at the first identical with the so-called organic functions, ${ }^{3}$ so far as they consist of mechanical movements; and that the latter early became reflex and devoid of consciousness, developing subsequent forms through mechanical causes. The organization of mental functions, on the other hand, was by continued education, which requires the presence of consciousness at every step.

The well-known fact of the inheritance of mental qualities, shows that the evolution of mind has advanced by a continued process of accumulation as the product of animal experiences. The new generation has inherited the organization of the old, and all the reflex and automatic activities entailed by it, and has proceeded in proportion to its activity to acquire new experiences, habits and organization.

\section{THE BEGINNINGS OF DEVELOPMENT.}

(a) THE FEELINGS.

The intellectual faculties of every animal thus belong to two classes: first, those which have been inherited; and second, those which it has acquired by its own experiences. Of course progress consists in accessions to the latter class, since inheritance without addition is mere repetition. If no acquisitions were made, or to be made, the mental, $i$. e., the cerebral organization inherited by animals would continually repeat the form of their actions as unerringly as the nature of a machine gives the character to the movements propagated through its wheels and cranks. That much the larger proportion of animal acts are of this class, that is, are automatic, there can be no room to doubt. With an impetus to movement given, the strongest liking or disliking selects the object or direction, and the reason furnishes the mode of acquisition or avoidance. The known past teaches of the unknown future, and the established circle of the functions of life is fulfilled. But without acquisitions, development is impossible.

Acquisitions to experience are gained by movements of the bo'dy, and hence by the mental activity to which the latter are due. But it is evident that the primary movement has precedence in the order of time over the feeling which deflects it, or the experience

See On Consciousness in Evolution, Penn Monthly, 1875, Aug., where this view is held. 
which directs later actions. In the lowest animal the first movement was doubtless a mere discharge of force; but the first designed action, the appropriation of food, was due to a sense of want or hunger, which is a form of pain. This was followed by gratification, a pleasure, the memory of which constituted a motive for a more evidently designed act, viz. : pursuit.

These two mental states, the one painful, the other pleasurable, form the basis in the feelings of all appetent acts. The painful sense of want is the motive to the performance of the primary class of actions, and the experience of pleasurable gratification furnishes the motive for a class which must be regarded as secondary.

The primary organized feelings of animals are not numerous.

In man, the most highly developed, Professor Bain enumerates ${ }^{4}$ only eleven types, and some of these he states may be further resolved. From the stand-point of the evolutionist this is evidently necessary, and a corresponding reduction in number can be made. The development of the feelings has proceeded from the early beginnings above described, in subsequent ages, pari passu with that of the intellect. It is necessary in the nature of things that it should be so, since the finer and fuller the sensibility to pleasures and pains in all directions, the greater will be the complexity of experience, and hence of intelligence. It is not practicable to trace the history of the feelings here, but I allude briefly to one class of them-the social affections-as they have been treated by Herbert Spencer, whose contributions to this department of knowledge have been very important.

This author maintains that the social affections are the product, in the department of mind, of the function of reproduction. They are the organized products of experiences of pleasures derived from fellow beings, just as other kinds of likes and dislikes are derived from experiences of the qualities of various objects. It is sufficiently evident that this faculty must survive, and the social instincts become more and more refined or specialized. It is a remarkable fact in the successional relations, and hence evolution, of the vertebrata, that the only system that has accompanied the nervous in its progress from generalization to specialization and perfection, is the reproductive. Man, standing at the head of the series by his developed brain, possesses also the most specialized reproductive system. He is inferior to many other Mammalia in his osseous and

\footnotetext{
- The Emotions and the Will, p. 36.
} 
muscular type, and in his digestive organs, including dentition, etc., but the orders which are his superiors in these respects yield to him the supremacy in the two systems mentioned.

Functionally the two systems oppose each other, and that exercise of the one is at the expense of the other is a physiological law. Health of the individual, and persistence of the species, depend on the maintenance of the equilibrium between them. This is because success in obtaining food on the one hand depends on intelligence, and undue power cannot be expended in other directions without starvation. Thus the law of evolution lends full support to the doctrine first formulated by Kant, of the dual nature of the human mind, in its division into the intellect and the affections.

(b) IN THE INTELLIGENCE.

The intellect includes a record of experiences of resemblances and differences, of causes and effects, arranged in orders of place, time, and of qualities of all kinds. The importance of an intellect depends on the number of experiences it contains; on the clearness with which qualities can be brought into consciousness; on the correctness with which the classification expresses the quali.ties; on the relation which the qualities preferred bear to an object of pursuit; and on the rapidity with which any or all of these functions may be performed. The triumph of reason is foresight or predication, in which it brings into consciousness the unknown, by reproducing its experiences of the known. This is the service rendered by education, by the acquisition either of experiences themselves, or of the experiences of others.

Acquisitions then do not imply a predication of the unknown from the known, but an actual addition to the stock of the known. The automatic life above described includes no such process, but is a routine varying only in unimportant details, and changing in no great feature. Progress evidently depends on something besides knowledge, for in proportion to the degree of progress is the departure from the known, and in proportion to the novelty of a situation is experience worthless as a guide.

Designed actions which are performed without a basis of knowledge which is sufficient for predication, are not automatic. That is, while the activity may be physically spontaneous and compulsory, the direction it takes and the mode of its execution cannot be automatic, unless the machinery which must give the direction, and which creates the mode, be already in existence. 
The field of the known is very limited, as compared with that of the unknown, in the experience of the Amoeba. In its first movements, it has absolutely no basis on which to establish an anticipation of the future. Such is also the situation of the young of every animal. But the cases of the inferior and superior species present the important difference, that in the former there are few or no mental powers derived by inheritance, while in the latter such exist in proportion to the position of the species in the scale of intelligence.

The facts of evolution teach that the habits of animals have been modified during past geological ages, under the influence of changes in their physical surroundings. While these changes may perhaps, have furnished the stimuli to the adoption of new habits, the conditions have not often been so rigid as to define exactly what those habits should be, in some or all of their details. The animal has necessarily proceeded blindly in many instances; in others, his mental darkness has been illumined by a low grade of imagination. This may be believed in view of the many attempts which animals often make before succeeding in attaining a desired end. Imagination plays an important part in the origin of motives and of actions, and is related to predication. It is defined as the presentation or construction of images or representations from items of experience, which representations so far differ in the connection of their details from actual experience, or so far lack the qualities of experiences, as not to constitute a predication of future events. Predication may be defined as the certain knowledge of the unexperienced from the experienced; while imagination includes the grades of probable, possible, and impossible concepts, constructed from the same material as predication. Whether this faculty exists in the animals which cannot speak, is not readily ascertained; but, inasmuch as many of them predicate, it is probable that they possess some degree of imagination also. But it is obviously a quality of the highest types of mind, since its development depends primarily on the furniture of memory, derived from a long period of experience, whose amount depends on receptivity and retentiveness.

\section{THE ORIGIN OF MOTIVES.}

It has been said that the operation ordinarily called choosing, in which the will is popularly supposed to be free, consists merely of a sum in addition and subtraction, where various inducements are 
balanced, the resultant preponderance being expressed in the act. It will be easily seen that while this statement is true in regard to cases where the elements of the calculation are known, it is not true where any or all of them are unknown. The difference in the two cases is very great. All likes and dislikes are based upon experience or knowledge; and when there is no knowledge, likes and dislikes cannot be said to exist. Since likes and dislikes constitute motives, where the former are wanting the latter are also wanting. Whatever inducements are presented from beyond the field of knowledge, are derived from the imagination, and are in self conscious minds relatively weak as motives, or absolutely without weight. They might be regarded as motives in embryo, ready to become such on the acquisition of a corresponding experience. The imagination can prefigure one alternative as well as another, in a direction where experience is wanting, and might indeed be said under such circumstances to have no existence, and the expression, "I can't imagine," be thought to have foundation in fact. The influence of such a guide is not imperative, and raises no obstacle to the origin of a new feature of consciousness by an act of choosing, when the pressure to act at all, is sufficiently great.

There is, perhaps, but one situation of the mind where the pressure of feeling is strong enough, and predication and imagination sufficiently excluded, to develop a will which shall create motives ratber than obey them. This is in the cases where self-interest is weighed in the balance against the interest or good of other people. Here the feelings are most severely pressed, and the future results to self most uncertain. Self-sacrifice may be beneficial to self, or it may not: one may be the gainer by the general prosperity, or he may be the loser. Morality may promise future good to the community, but why sacrifice self for the community? Gratitude for services rendered is an uncertain anticipation. Man's most limited knowledge and greatest inability in predication is in the field of human motives and actions, and chiefly in respect to those which belong to his moral feelings. As already remarked the complication in this direction is so great, as to produce the effect of novelty: so that man, come into possession of an intellect which is the product of ages of development, finds before him a new field of his own making where his inherited powers fail.

This is the field where the most momentous decisions possible in human life are made. Since questions of right and wrong re- 
late to the happiness of men in their relations to each other, the social affections are the stronghold of the motives that bear on this result. It is evident that a thousand subordinate motives take their direction from the primary decisions between these two original alternatives of feeling.

It is true that the predication of human actions necessitated by bodily functions alone, is easy, even when they come to be of a highly complex character, as in the mercantile transactions of a populous business center. But so soon as the ethical element enters into the calculation, the difficulty is greatly increased, and with the majority of men predication ceases, and faith begins. This is illustrated in the many credit transactions, without which it is well known that trade on any but the most limited scale is impossible. So it must be admitted that many men practice faith in many affairs, and that this faith is chiefly reposed in the moral excellence of other men. Under these circumstances, that state of the affections arises in most men which is termed faith, and which is only present in the highest form of progressive action, whether the results of that action be beneficial or not. It is a condition of the affections, as imagination is a condition of the intellect. The lowest animal, when attempting a novel act in obedience to imperative stimuli, doubtless moves blindly, and adopts one of two or more alternatives through pure accident. In animals of a higher grade of intelligence, new situations are known to be such, and fear or suspicion is the usual result. Generally, animals of the higher orders do not adopt new habits excepting under severe pressure, and the majority of them have perished in past geologic ages, on account of their inability to assume new modes of life. Nevertheless, in so far as an animal or a man ventures into an unknown field of action, where he is without the guidance of a past experience, he or it performs an act of trust in the broad meaning of the word. So far as this state of mind is known to the subject, the act is one of true faith in the restricted or proper sense of the word. Imaginations may and do assume to men the importance of truths, and in so far they are such to them. But in proportion as this is the case, faith in its proper sense is wanting, and the action following is automatic. The highest form of intellect is necessary to the highest form of faith, since it is only by a knowledge of the absence of knowledge, that an act of faith is possible. In proportion to this knowledge of self is faith enlarged; in proportion 
to certainty, or supposed certainty in affairs, is faith diminished in its scope.

It is evident then that, abstractly speaking, occasions must arise in human experience where a decision between two alternatives is dependent on choice alone. That these occasions have arisen, and the choice been made, is shown by the existence of the altruistic class of actions. The number of these occasions may not be very great, but the consequences are very important. In whatever direction these decisions are made, long series of automatic actions are organized.

Although the existence of the altruistic class of acts affords the clearest proof of the origin of will, it is not denied that corresponding situations may not occur in other directions. It is also probable that will, once organized as a faculty of consciousness, can be exercised in many acts in opposition to habits, differing in accordance with the constitution of the individual; and that it can be inherited like any other quality of mind. But I will show later, that the organization of altruistic habits has narrower limits than that of those of the appetent class, because self-preservation depends on the latter, and not on the former, so that the appetent qualities are more certain to be inherited and survive.

The conclusion of this portion of the subject is, that that department of mind called the feelings ${ }^{5}$ is the primary source of action : that they act automatically with or without the aid of the reasoning powers, when dealing with the known; but when dealing with the unknown may develop, in self-conscious beings, the state of faith, and acts of will: that this freedom is born of tension of the affections and of inability of the intellect.

Thus have the irregular and fortuitous decisions of animals been replaced by volition, as the highest quality of the mind, and therefore the crown of evolution. No new "physical" force is here called into requisition. The determination of the direction of such forces already existing in or passing through the brain in executive action, need fot add to nor subtract from them. Will is, under these circumstances, looked upon as developed consciousness.

All this is of course opposed by the doctrine of the origin of moral excellence by development, on the basis of the utilitarian

6 Which appears to be identical with what Schopenhauer calls the will. 
theory of morals. I therefore proceed to a brief examination of its claims in this direction.

Good is well defined as the greatest happiness of the greatest number; and by a natural transfer, the term is applied to whatever is conducive to that object. It therefore includes not only present pleasures, but also the influences which conduce to future pleasures, and which may be sown in the mind long before they bring forth fruit. As present pleasures are not always consistent with greater ones in the future, so present pleasure is not always good. Evil being the reverse or negation of good or happiness, is avoided by all beings to whom it is consciously known; but what they regard as evil will of course depend on their intelligence in determining or predicating the future effects of actions. But no matter what the degree of intelligence, no responsibility, as usually understood, can be expected of beings which have no power of choosing, or will.

The utilitarian theory of the evolution of morals asserts that the development of goodness is simply due to the discovery and enforcement of the law of self-protection and preservation. The selfish interests require the protection of person and property without which a community is an impossibility. Law being thus established and enforced, moral habits are imposed upon men, which become incorporated into character and transmitted to succeeding generations. This is all doubtless true, but whether it is a fundamental or secondary truth is the point requiring attention.

The fundamental objection to this hypothesis is, that the altruistic affections are not inherited or transmitted. This is because the pains and penalties of wrong-doing as inflicted by law, cannot and ought not to overcome the inherent instinct of self-preservation in man. It is true that moral character is inherited, and that changes in this department for better or worse are transmitted to offspring. The mental organization of a race may be improved by the weakening of the emotional or the strengthening of the rational faculties. But since the affections are at the foundation of all activity whatsoever, of right-doing as well as of wrong-doing, it is obvious that no amount of legal restraint can render them innocuous. Their existence is necessary for self-preservation, and law only restrains their activities to certain directions. That intelligence tends to restrain wrong-doing is true; but although intellect is inherited, the manner in which its teachings are applied in practice is not. 
Each man must learn the merits of different courses of action in regard to morals for himself; his intelligence places before him the facts, and shows him how to execute his wishes, but the state of his affections determines the direction of his acts. Moral amelioration has attended the progress of intelligence on the one hand, and moral abasement on the other. Intelligence is the condition of the perception of moral truth; in other words, intelligence, as applied to moral questions, is the conscience. Consequences of acts are understood, and their relations to the pleasures and pains of men are weighed. Thus, no doubt, the world has advanced in the knowledge of good and evil, and of right and wrong. That it has improved in the practice of right has not been due to the inheritance of respect for law, but to the self-destructive nature of wrong. That continued wrong sooner or later ends in the destruction of the wrong-doer, either from within or without, must be generally admitted. Thus is the truth of the doctrine of "the survival of the fittest" vindicated in moral as in natural law. But it is also true that this law is restrictive only, and that the school of Hume and Bentham has overlooked the deeper originative law in moral philosophy, as the school of Darwin has done in biological philosophy.

It may still be urged that, if it be granted that experience of the pains of evil-doing be not transmitted as an intellectual acquisition from generation to generation, nevertheless such experience is sufficient to educate each separate generation as it passes, without any other than automatic action on their part. 'It may be replied to this that the results thus obtained are not due to will, but simply follow compulsion, the motive thus created only varying in strength with the characters of the individuals. Its success is restricted to circumstances where the penalties are sufficiently certain to constitute counter-inducements to effect the necessary restraint. This can only be the case with the weaker members of society. Wherever there is sufficient power to escape penalties, wrong-doing has no restraint. Under such a system might and right are identical; for the strongest needs no protection of law. It is true that society can combine against a single malefactor, but it is also true that malefactors can combine. In fact, it is one of the usual phenomena of human society, to find men becoming malefactors as soon as they attain to power; or to find society governed by a few malefactors who have an army to enforce their pleasure. 
While then inheritance does not secure the performance of altruistic acts, appetent affections may be so increased by accumulation in descent as to become uncontrollable, so that will either does not come into existence, or is extinguished, so far as regards those affections. In such a situation there is no such equivalency between opposing motives as gives opportunity for the will, the experience of appetent pleasure being too strong to allow of hesitancy. in the face of vague representations of imaginary consequences on the other side. Even in highly intelligent men, to whom consequences are best known, knowledge may be thrust from consciousness, by strong feeling in favor of one alternative at the moment of action.

VII. CONSEQUENCES.

It is now well to consider how far an automatic mind has any claim to personality or individuality, as generally understood. From the usual stand-point, a being without "liberty," or will properly so called, is without character, and is in so far a nonentity. Even the character of the Deity cannot escape this destructive analysis; for according to Spinoza, if $\mathrm{He}$ is good, but a single line of action, without alternatives, lies open to God, if $\mathrm{He}$ be at the same time omniscient. All this is changed if the element of spontaneity in character be pre-supposed. The existence of such a quality in man renders foresight of its decisions in some cases no more than a calculation of chances, and in other cases impossible; thus offering the only conceivable limit to omniscience, and hence to omnipotence. And as we regard the goodness of God as the anchor of the universe, if that goodness be in some respect inconsistent with omnipotence, we are strengthened if we discover that there is ground for correcting our traditional suppositions in regard to the latter. Can we not find this ground in a liberty or freedom which is the condition of what we suppose, in the absence of knowledge, to be the characteristic of the highest class of conscious existences? 


PARTIAL SYNOPSIS

OF THE

Fresh Water Fishes

NORTH CAROLINA.

By E. D. COPE.

SHCOIND FIITIOIT.

March, 18\%r. 

PARTIAL SYNOPSIS

OF THE

Fresh Water Fishes OF

NORTH CAROLINA.

By E. D. COPE.

SECOND EDITION.

March, 18\%ั 



\section{AUTHOR'S PREFACE.}

The present paper was read before the American Philosophical Society, June, 1870. Unfortunately, this Society publishes but a small edition of its Proceedings, the serial in which this article appeared, and only a part of this is sold. The number for the first half of 1870 is now on this account out of print, excepting a few copies retained for exchange. The demand for the present essay has been such as to induce ne to reprint it with the folio in which it originally appeared. I use the opportunity to add a few notes at its close.

Philadelphia, March 15, 1877. 


\title{
A PARTILL SXNOPSIS OF THE FISHES OF THE FRESH WATERS OF NORTH CAROLINA.
}

\author{
Br Enw. D. Cope, A.M.
}

Read before the Amer. Philosophiral Society, June 7, 1870.

The material on which the present investigation is based was, for the most part, procured by the writer during the autumn of 1869 . A journey from the Cumberland Mountains of Tennessee to the ocean, offered opportunity for making collections in the waters of five hydrographic basins, viz. : those of the Cumberland, Tennessee, Catawba, Yadkin and Neuse. The streams of the Tennessee examined were the Clinch and French Broad; the former in a tributary called Coal Creek, in Anderson Co., Tenn.; the latter at various points, both in the mountainous part of its course, and in the elevated and flat valley of Henderson Co., where it takes its rise. A small seine with fine meshes, kindly lent me by the administration of the Smithsonian Institution, was used in the smaller streams; and fishermen's apparatuses, especially weir traps, furnished most of the species inhabiting the river channels. Passing many of the latter at the time of year when the migratory fishes were descending, the writer was able to examine and procure them in great numbers. The opportunity of seeing fishes in life, it is believed, is no small aid to their proper specific determination.

\section{ACANTHOPTERYGII.}

PERCA, Linn.

1. Perca flategcens, Cuv.

Neuse River.

ROCCUS, Gill.

2. Roccus lineatus, Bloch.

Neuse River.

\section{STIZOSTEDIUM, Raf.}

\section{Stizostedium airericanum, C. V.}

This is the largest Percoid of the Western waters, occasionally attaining a weight of 35 lbs. : no specimen of more than 10 lbs. came under my observation. It loves the most boisterous and rapid streams, ascending them to near their sources, having much the manners, and haunting the same waters as the trout, but of much more voracious habits. Its swiftness enables it to take the black perch (Micopterus fasciatus) with ease, though that fish is, after it, much the most powerful swimmer of the rivers it inhabits. I took two from the stomach of a Lucioperca of eight pounds, one of which weighed $2 \frac{1}{2}$ lbs. Suckers are used as bait in taking them by hook; but the mode in which large specimens are most readily taken is by shooting. When the Lucioperca has gorged himself, he seeks some shallow bayou, and lies in a sluggish state, digesting his meal. Then 
the gun-fisherman, concealed in a tree close by. makes sure of him. It is the most valued food-fish of the French Broad, the flesh being very tender as well as rich.

Without the opercular armature of the Percae, its chief defence is in its numerous and powerful canine teeth, with which it makes serious wounds on the hands of the unwary fisherman. The common name on the French Broad is "Jack,"

\section{Stizostedium salmoneum, Raf.}

This fine species was described to me as an inhabitant of the French Broad, though I did not see it. As elsewhere it is called Salmon. A species of this genus occurs also in the Neuse.

\section{ETHEOSTOMA, Raf.}

\section{Etheostoma nevisense, Cope.}

Proc. Amer. Philos. Soc., 1870, p. 261.

Turbulent waters of the Neuse River.

6. Eтheostoma maculatum, Girard.

Putnam Bull. Mus. Conp. Zool., Cambridge, No. 1. Cope. Proc. Am. Phil. Soc., 1870, 262. Hadropterus maculatus, Girard. Proc. A. N. S., Phil., 1859, 100.

Abundant in the rapid waters of Buck Creek, which empties into the Catawba, in Marion Co., N. Ca.

\section{HYPOHOMÜS, Cope.}

Cottogaster, Cope, Journ. Acad. Nat. Sci., Phila. 1869, 210, not of Putnam.

The name Cottogaster, my friend Prof. Putnam informs me, was applied to species of the type of Boleosoma. It is, therefore, inapplicable to the $C$. aurantiacus, to which I apply the above generic name. The characters of the genus have been pointed ont as above cited. They are those of Etheostoma, excepting the median ventral series of shields, which are here wanting.

\section{Hrpohomus aurantiacug, Cope.}

Jour. Acad. Nat. Sci., Phila., 1868, 211.

One specimen from the French Broad River, in Madison Co., North Carolina, measuring 4 inches 8 lines in length, more than twice the size of the types, and larger than any species of the Etheostomine group, excepting Percina caprodes. Color in life bright yellow, with a black lateral bancl, and a few brown spots on each side of the dorsal fin.

POECILICTHYS, Agass.

8. Poecilichteiss vitreus, Cope.

Proceed. Am. Phil. Soc., 1870, 253.

This species is quite translucent in life. The only specimen taken was 
adult, and exhibited oraries well filled with well developed ova. Seven green dorsal spots, and eight or nine linear spots on the sides, of the same color.

Walnut creek, a tributary of the Neuse River.

9. Poecilicthys fladeliatus, Raf.

Cope, Jour. A. N. Sci., Phil., 1868, 213. Catonotus, Agass., Putn. Bull. M. C. Zool., I.

Var. Cope, Proc. Am. Phil. Soc., 1870, 263.

From the Catawba River.

10. Poecilicthys vulneratus, Cope.

Proceed. Am. Phil. Soc., 1870, 266.

A beautiful species from the Warm Springs Creek, Madison Co., N. Ca., a tributary of the French Broad River.

11. Poeciliohthys rufilineatus, Cope.

Loc. cit., 267.

Abundant in the same localities as the last, and one of the most ornate species of the genus.

12. Poecilichthys zonalis, Cope.

Jour. Acad. Nat. Sci., Phil., 1868, 212, Tab. xxiv., f. 1.

French Broad River.

\section{BoLEosoma, DeKay.}

Cope, Proc. A. P. Soc., 1870, 268.

13. Boleosoma effulgens, Girard.

Copc, 1. c. Artina effulgens, Girard. Proc. Acad. Nat. Sci., Phil., 1859,04 .

Deep River, Guilford Co., North Carolina, from Samuel C. Collins.

14. Boleosoma maculaticers, Cope.

Proc. A. P. Soc., 1870, 269.

Upper waters of the Catawba River.

HYOSTOMA, Agass.

Cope, Jour. A. N. Sci., Phil., 1868, 214.

15. Hyostoma cymatogrammum, Abbott.

French Broad River.

Grystes, Cuv. Val.

MICROPTERUS, Lac.

16. Micropterus fasciatus, DeKay.

Apparently not found east of the great Water Shed: I only obtained it in the state in the French Broad. Also from the Clinch and the Cumber]and. 
17. Micropterus nigrians, Cuv.

The green bass is abundant in all the rivers of the State. I have it from the Neuse, Yadkin, Catawba, upper and lower French Broad, and from the Clinch in Tennessee. Specimens from the Neuse and from near Norfolk, Virginia, six in number, differ from those of the other rivers, in having a deeper body, and generally longer and more prominent man. dible. The depth enters the length 2.75 times; in the more western forms always 3.25 times; in the former it is greater than the length of the head, in the latter it is considerably less. Other differences are not discoverable and I regard it as a marked variety only.

POMOXYS, Raf., Agass.

Neuse River.

18. Pomoxys hexacanthus, C. V.

Numerous specimens of this species and the Pomoxys storerius from Leavenworth, on the Missouri River, from Sami. H. Edge.

CENTRARCHUS, \%. V.

19. Centrarchus mideus, Cuv., Vaj.

Vol. III., p. 89, Holbrook Ichth. S. Ca., 18, Tab. III., fig 1.

From the Neuse River. A specimen presenting an additional dorsal and anal ray, as compared with the description of Cuvier and Valenciennes; but Holbrook adds one to the anal spines, thus agreeing with anal formula D. xii., 14, A. viii., 15. Of a brilliant pea green in life, without ocellus on second dorsal, as clescribed by the above authors. Soft dorsal and anal, with narrow, blackish bars. Not probably specifically distinct from specimens in Mus. A. N. Sci., from South Carolina.

\section{AMBLOPLITES, Raf., Agass.}

20. Ambloplites rupestris, Raf.

Centrarchus coneus, Cuv. Vall.

Abundant in the French Broad and head of Cumberland; none found east of the Alleghenies.

\section{CH ENOBRYTTUS, Gill.}

This genus, for which I have reserved the above name, is equally allied to Lepomis and Ambloplites. It agrees with the first in its entire and rather produced operculum, and three anal spines, but differs materially in possessing the additional maxillary bone of the latter, Centrarchus, $P_{0}$ moxys, etc. Gill defined it in consequence of its palatine and lingual dentition, characters which exhibit various grades of imperfection to en'ire extinction in the typical Lepomes. Hence, in my view of fresh water fishes from the Allegheny region of southwest Virginia, I united Lepomis, Bryttus, anı Chænobryttus. I now discover the importance of the presence or absence of the additional maxillary bone, which, with the 
emargination of the operculum previously pointed ont, enables me to define the genera more satisfactorily than my predecessors. Thus they may be arranged in groups.

I. Operculum emarginate; a supernumerary niaxillary bone;-Micropterus, Ambloplites, Pomoxys, Centrarchus, Acantharchus, Enneacanthus (?) Hemioplites.

II. Operculum emarginated; no supernumerary maxillary :-Mesogonistius.

III. Operculum entire, produced; an additional bone attached to the maxillary :-Chænobryttus.

IV. Operculum as last; no supernumerary maxillary:-Lepomis, Pomotis.

\section{Chenobryttus gillit, Cope.}

Lepomis gillii, Cope. Jour. Acad. Nat. Sci., 1868, 225.

This species is exceedingly common in all the streams of North Carolina east of the Allegheny Mountains. It does not occur in the French Broad. All the specimens have clouded markings on the sides, which in the young, are broad, distinct olive-brown cross-bands, which embrace pale spots, giving a chain-like pattern. Fins blackish, cross-barred ; four brown bands radiating backwards from orbit. Iris bright red. The species is rarely seen more than five inches long, and prefers rather still waters. It bites the hook very readily, and is called the red-eyed bream on the Catawba.

The C.mineopas, Cope, possesses the additional maxillary, and I have no doubt the C.melunops (Gill's type), and the $C$. charybdis, Cope, though I have not been able to verify it on the latter.

\section{ENNEACANTHUS, Gill.}

Jour. A. N. Sci., Phil., 1868, 218.

\section{Enneacanthus guttatus, Morris.}

Proceed. Acad. Nat. Sci., Phila., 185ั8, p. 3.

Abundant in the Neuse River in still water, as in Virginia and New Jersey.

\section{LEPOMIS, Raf.}

\section{Lepomis RUBRICAUdA, Holbr.}

This marked species, the southern representative of the $L$. appendix, is very common in the hydrographic basins of the Catawba, Yadkin and Neuse. In life the second dorsal and caudal fins are red, and there is a bay spot at the base of each scale forming interrupted stripes. Flap of operculum black, the continuation of a dark shade from the preoperculum, which is bordered above and below by a blue band; two blue lines on operculum below the latter.

24. Lepomis hegaiotis, Raf.

L. incisor Cuv. Va].

From the upper waters of the French Broad. 
There are several species allied to the present, which may be distinguished, as follows :

$$
\text { Scales 4-35-11. }
$$

Dorsal spines short, longest equal muzzle and orbit to pupil; mucous cavities small; eye four times in head with long flap," which is, black, red bordered below and behind; anal spine reaching base last anal ray.

$$
\text { Scales 5-7-36-47-2-14. }
$$

L. Peltastes.

Spines of dorsal shorter, equalling muzzle and half orbit; third spine of anal not reaching base of last anal ray; ear flap long, blue edged below ; pectoral scales large; a spot on second dorsal. L. MEGALOTIS.

Spines etc., as above; pectoral scales small, no spot on second dorsal.

L. c. $41-4$.

L. Nitidous.

Spines longer than the above, dorsal equal muzzle and orbit .5 or head; anal reaching base last ray; opercular flap very small not lighter margined; spot on second dorsal.
L. c. $36-9$.
L. NOTATUS.

Spines longest, more than muzzle and orbit; anal extending beyond last anal ray; ear flap very short, not light margined; spot on second dorsal.

L. SPECTOSUs.*

Eye .33 of head; scales $7-47$; spines long, equal muzzle and orbit; anal ray extending beyond base last anal ; opercular flap very small ; spot on second dorsal.

\section{Lepomus nitidus, Kirtland.}

L. PURPURESCENS.

L. megalotis, var. B. Cope, Journ. A. N. Sci., Phila., 1865, p. 220.

Common in Coal Creek a tributary of the Clinch River; not seen in North Carolina.

\section{Lepomis notatus, Agass.}

Amer. Journ. Sci. Arts, XVII, 302.

This species is allied to the $L$. ardesiacus. Cope (1. c., p. 222), but its scales are larger, there being but $36-9$ on the lateral line, and 13 below it, while there are 45, with 17 below, in the latter. The eye is also larger, entering the head only three times, while it is measured four times by the same in an L. ardesiacus of the same size.

The general form is elongate oval, the front of dorsal region steep, the muzzle conic and not obtuse. Eye large and round, its diameter measuring muzzle and half itself, and .2 more than interorbital width : R. D. X. 11, A. III. 10. Depth 2.33 times in length to end of lateral line. Four rows scales on cheek; no palatine teeth. Scales above lateral line, five large series and one small one. Length 3.5 inches. Color uniform green. ish brown, below yellowish; no band. No red on the very small opercular spot. Fins not cross-barred.

Very abundant in the upper French Broad River, North Carolina, and the tributaries of the Clinch, East Tennessee.

* Lepomis specrosus, Girard, L. heros, Girard. L. longispini, Cope Joura. A. N. Sci. 1868, 20; from Texas.

A. P. S. - VOL. XI. $-74 \mathrm{E}$ 
This is probably Agassiz species as above, but the orange on the opercular flap scarcely extends posierior to the biack spot, and is easily lost sight of in spirits.

\section{Leponis purpurescens, Cope.}

\section{Species nova.}

This is an elevated compressed fish, with vely small or rudimental opecular flap, like the L. notatus, $L$. ardesiacus and $L$. nephelus. It is similar to the first, and different from the $L$. ardesiacus in its large eye, which enters the head scarcely three times, and the interorbital width .75 times, but agrees with the latter in its small numerous scales. Thus there are six rows of equal scales above the lateral line, and one small one, and 47 on the lateral line and 13 below it ; (in the $L$. ardesiacus there are 17 below it). Depth 2.25 to 2.33 in length (exclus. caudal fin). The spinous rays of this fish are nearly as long as in the $L$. speciosus. The caudal fin is longer than usual, equalling at least, the head. Length of latter, three times in length of body + head. Six rows scales on the cheek. Length three inches. Mucous cavities small.

Color in life a pale silvery lilac, darkest in four or five vertical shades across the sides, which disappear in alcohol. Fins unicolor except dark shades on middle of ana], and second dorsal and edge of caudal, with a black spot at lower posterior portion of second dorsal.

Abundant in a tributary of the Yadkin River in Roane County, North Carolina.

\section{Lepomis peltastes, Cope.}

A deep stout species of small size, distinguished for its large scales, short spines and bright color; mucous caverns small. Eye large, equal muzzle, four times in length of head with long opercular flap, just equal interorbital width. Head with flap 2.5 times in length; depth 2.1 times in same. Caudal fin and peduncle considerably more than one-third the length. Longest dorsal spine equal from end muzzle to middle of pupil; longest anal reaching base last anal ray.

Five rows scales on cheek, three large and two small rows above lateral line; those of middle of sides larger than those on lower part. The profile is regularly descending to end of muzzle : front but little concave. Radii D. X. 11. A. IIX. 10. Length three inches.

Color above golden brown, sides and belly golden, top of head blackish. Large black opercular spot, red margined below and behind. I dorsal fin blackish, II D. blackish at base orange above, anal similar, caudal blackish, ventrals more or less black. The pectoral fins do not quite reach the base of the anal fin.

This species is from the Huron River, Michigan, whence it was procured through the kindness of my friend Prof. Alexander Winchell, Ann Arbor, Michigan. Its relationships are to the $L$. oculatus, Cope, but in that species the eye is smaller, and the tail and peduncle are .33 of the length. In $L$. anagallinus the mucous caverns are much larger. 
POMOTIS, Cuvier.

27. Ромotis maculatus, Mitchill.

Morone Mitchill, $P$. vulgaris, Holbr.

From all the rivers of North Carolina east of the Allegheny Range. Identical with specimens from Pennsylvania and Michigan.

URANIDEA, Dekay.

28. Uranidea Carolinge, Gill.

Proc. Bost. Soc. Nat. His., 1861, 41.

Abundant in the French Broad River in Madison County, North Carolina.

APHREDODIRUS, Lesueur.

29. Aphredodirus sayanus, Gilliam.

Journ. A. N. Sci., Phila., IV, 81, pl. III ; Dekay, N. Y. Fauna, Fishes p. 35, pl. xxi., fig. 62 .

Abundant in sluggish waters tributary to the Neuse River in Wake County, North Carolina.

\section{LABIDESTHES, Cope.}

Fam. Atherinidce. Premaxillary bones prolonged anteriorly into a roofshaped beak of elongate form, moderately projectile; reaching posteriorly to the line of the orbit: its teeth in several series. Mandible as long as the muzzle. No palatine teeth.

This genus differs from Chirostoma (Atherinopsis, Blkr.) in the ducklike muzzle, which is almost exactly like that of the Belonesox betizanus, though shorter. Like it, the premaxillaries are not con̈ssified, and are separated on the superior surface by a groove between the median portions. The general characters remind one so of Belonesox, as to strengthen the belief in the close relationship existing between Atheri. ridæand Cyprinodontidx, though the former is Acanthopterygian, and the latter Malacopterygian.

\section{Labidesthes sicculus, Cope.}

Ohirostomu sicculum, Cope. Proc. Acad. Nat. Sci., Phila., 1865, p. 81. Form slender, the depth contained in the length (without caudal fin)

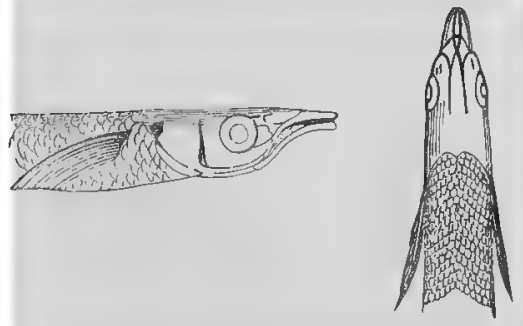
seven times; the length of the bead 4.33 times in the same. The eye is large and round, contained 3.6 times in the head, 1.5 times in the length of the muzzle and once in the interorbital space. The top of the head and muzzle are plane, the latter convex transversely, and not exceeded by the extremity of the mandible. Front with a median ridge. A distinct ? mucous pore above each orbit. The teeth 
are elongate, slender and simple. The premaxillaries are a little projectile; extremity of maxillary acuminate. The first dorsal commences at a point mid-way between the basis of the tail and the anterior margin of the orbit, or opposite the $3-4$ th anal radii. The second dorsal commences above a point a little in front of the middle of the anal. Radii D. IV. 10 ; A. I. 22-3; V. I. 5 ; P. 12. The scales are small, in 14 longitudinal, and 75 transverse series.

In life this fish is translucent, with a silver band on each side, which covers one scale and two hitlves, and is lead-edged above. The dorsal region and top of head are dusted minutely with black. Operculum and cheek silvery.

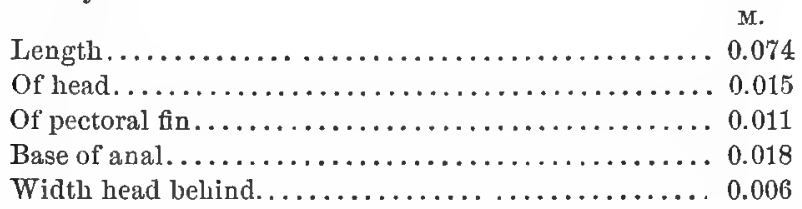

This little fish I took in great abundance in Coal Creek, a tributary of the Clinch, in East Tennessee. It was very abundant, and easily caught in ratber sluggish water. The stream named passing through a limestone region, is liable to partial desiccation in the Autumn, and in several pools, thus formed, I obtained this species.

In the original description I gave D. V., which should probably be as here stated, D. IV.

\title{
MALACOPTERYGII.
}

\author{
FUNDULUS, Lac.
}

30. Fundolus catenatus, Storer.

Cope, Journ. A. N. Sci., Phil., 1868, Tab. xxiv,, fig. 2. Clinch River, abundant.

\section{HAPLOCHILUS, McClelland.}

I refer the following species to this genus, without going into its synonymy, following the arrangement given by Günther in the Catalogue of the British Museum. In consideration of the peculiar views of this anthor respecting specific and generic characters, I consider this a temporary arrangement, to be rectified by a more thorough analysis of the subject at some future time.*

* Fundulus nisorius, Cope, Sp. nov.

Stont; head four times in length to basis caudal; orbit four times in length of head, and twice in inter-orbital width. Depth 3.75 times in length. Anal fin commencing about opposite the middle of the dorsal. Cheek scaly, operculum smooth. Seales of body in. 36 transveree. and 12 longitndinal series. Radii D. 12 A. 10 or 11 , extending mure than half way from basis of first ray to basis candal. Leng th of female. four inches. Color uniform light brown. yellowish below.

Most of the specimens of this species (seven) are females, and in them the oviducts are pritlonged in a tube to near the extremity of the first ray of the and fin. Several have muny well developed eggo in the former. Small, fuintly cross-banded specimens, perhaps males, do not pre- 


\section{HAPLOCHILUS MELANOPS, Cope.}

Sp. nov.

First dorsal ray opposite middle of anal. Scales in. 31 transverse, and 9 longitudinal series. Radii D. I.6, A. I.8, V. 6. Head 3.66 times in length, exclusive of caudal fin; eye 3 times in head, 1.6 times in interorbital width. Dorsal and anal fins each short, each measuring less than half the distance from their first ray to to the basis of the caudal fin. Caudal narrowed, rounded.

Above, yellowish brown, scales darker edged, a few longitudinal lines on some dorsals; in some specimens, a median brown dorsal line. Dorsal and caudal fins each with a row of black dots across the middle, and one near the margin. Belly golden. Length 1.5 inches, the largest size. A blue-black spot below the eye in most specimens.

Very abundant in still waters of the Neuse basin, Wake Co., N. Ca. ESOX, Linn.

32. Esox AFFinis, Holbrook.

Ichth. S. Carolina, 198, Pl. xxviii., fig. 1.

This species is near to but distinct from the $E$. reticulatus of the North. In life it is of a bright light emerald green, with dark reticulations. Common in the Neuse River.

33. Esox RAVENELII, Holbrook.

Iclthyology South Carolina, p. 201, Pl. xxvii., flg. 2.

Length from muzzle to pectoral equalling length from pectoral to ventral fin; latter space embracing 37 transverse series of scales. From end muzzle to orbit less than from orbit to opercular border. Br. XIII. D. II. 12. Brown above with brown cross-bars; edge of dorsal and caudal fins red.

This species is near E. cmericanus, but has a relatively longer head. Size and color similar. From the Catawba River, N. Ca.

Putnam, Cope. SEMOTILUS, Rafinesque.

34. Semotilus corporalis, Mitchill.

From the French Broad, Catawba, Yadkin, Deep, and Neuse Rivers.

\section{CERATICHTHYS, Baird.}

Four species of this genus were observed, of which two are new to Zoology. They both belong to

Sect. II., mouth more or less inferior, small ; teeth $4-4$ or 4. 1.-1. 4; size small.

Depth less than length head ; last dorsal ray more than half first ; muzzle narrow, beards long; small ;

C. LABROSUs.

sent this character. There are no pseudo-branchiae. From Gaboon, W. Africa. P. B. DuChaillu. It may be stated in this connection that the genus called Lycocyprinus by Peters, for Haplo. chiluid flshes with pseudo-branchire, was previously numed Epiplatys by Gill. The type of the latter, E. sexfasciatus (1862), from Gaboon, is different from the $E$. ( $I$.) sexfasciatus (]8lit), the type of Peters. The latter may, therefore. take the name of E. infrafasciatus (1865), which Gidther gave the same species, subsequent to Peters. 
Depth equal length head; last dorsal ray less than half first; muzzle broad, beards small.

C. HYPSINOTUS.

Spec. nov.

35. Ceratichthys labrosus, Cope.

This is a peculiar species of slender proportions. The top of the head is gently decurved to a muzzle which scarcely overhangs the thick, projectile upper maxillary arch. The mouth is entirely horizontal, and the ex tremity of the maxillary bone attains the line of the orbit. The latter enters the length of the head 3.75 times, and is just exceeded by the interorbital width. The head enters length to origin caudal from 4 to 4.5 times. Front arched in transverse section. Depth 5.5 times in length. The dorsal line is nearly plane, and the elevation of the first dorsal rays is contained twice in the length from its base to the anterior rim of the pupil : it stands over origin of ventral. Scales large $6-34-5-4$. Radii D. 8 ; A. 8 .

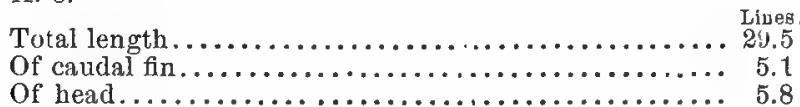

Teeth 4. 1-1. 4 .

This fish is silvery from the middle of the sides downwards. In some specimens there are numerous blackish scales above the lateral line, which are arranged so as to form indistinct cross-bars in life; in other specimens the color is quite transparent, indicating two varieties. The latter are frequently a little more slender than the former.

The beards of this species are relatively longer than in any other species of the genus. The prominent lips remind one of Phenacobius. The species is not uncommon on the bottom in clear and rapid creeks which flow into the upper waters of the Catawba River, in Macdowell and Burke Counties, N. Ca.

Spec. nov.

\section{Ceratichthys hypsinotus, Cope.}

This little species has a stout robust form. The head and muzzle are broad and flat; the muzzle is not prominent; the mouth is inferior and horizontal ; the maxillary just reaches the line of the orbit. The form is characterized in the genus by the gradual elevation of the dorsal line to the base of the first ray of the dorsal fin, and its rather abrupt descent from that point. The base of this fin is thus oblique and the distal outline is vertical ; the posterior ray being less than half as long as the anterior. This produces a characteristic appearance. The head is short. and eaters the length $3^{\prime \prime} \%$ times, equalling the depth. Body coinpressed. Orbit 3.5 times in length head, and once in inter-orbital space. Lips, especially inferior, thin ; beards small. Scales, 4-5-38-41-3. Teeth 4. 1-1. 4. Dorsal fin originating a little in advance of above ventrals ; 8. A. smaller than dorsal, 8.

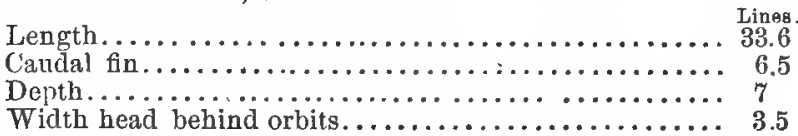


Color in life silvery, with a clouble series of black specks along the lateral line, and a lateral band of dusted blackish; a dark line round muzzle between orbits. Membrane of dorsal fin often shaded with blackish.

Common in creeks heading the Catawba R., in Macdowell Co., N. Ca., or tributary to the Yadkin River in Roane Co., in the same State.

37. Ceratichthys hyalinus, Cope.

Jour. Acad. Nat. Sci., Phil., 1868, 226.

From the French Broad and Clinch Rivers in North Carolina and Tennessee; not found east of the Alleghenies.

38. Ceratichings biguttatus, Kirtl.

Trans. Amer. Philos. Soc., 1866, 366.

Found in the rivers of East Tennessee and North Carolina, from the heads of the Cumberland, to, and including, the Neuse.

ARGYREUS, Heckel.

39. Argyreus lunatus, Cope.

Proc. Acad. Nat. Sci., 1864, 278. Jour. Acad. Nat. Sci., 1868, 228, Tab. 23, fig. 3.

Common in the tributaries of the French Broad and Holston Rivers, in North Carolina and Tennessee. The absence of any species of this genus in the rivers of North Carolina east of the Alleghenies is a peculiar feature. They no doubt occur in the Roanoke, as I lave taken $A$. atronasus from that river in Virginia.

\section{HYPSILEPIS, Baird.}

40. Hypsilemis coccogenis, Cope.

Proceed. Acad. Nat. Sci., 1867, 160.

Common in the French Broad and Clinch Rivers. Not found in the Beech Fork of the head of the Cumberland.

41. Hypsilepis corndtus, Mitch.

Var. frontalis, Agass., Cope, 1. c., 158.

Abundant in Coal Creek, a tributary of the Clinch River in Tennessee :

Var. cornutus, Cope, l. c. From the Neuse River.

42. Hypsilepis analostands, Girard.

Cope, 1. c., p. 161.

Found in abundance in the Catawba River, but nowhere in the tributaries of the Tennessee or Cumberland. Found in the Neuse River.

43. Hrpsilepis galaciurus, Cope.

Loc. cit., 160.

Most common in all the tributaries of the French Broad, Clinch and Cumberland. It does not occur east of the Alleglienies. 
Loc. cit., p. 163 .

Hypsilepis ardens, Cope.

Abundant in the headwaters of the south fork of the Cumberland River in Tennessee. In my examination of the Virginia streams, I did not find it in any western water, but only in the Roanoke and James Rivers.

\section{HYBOPSIS, Agass.}

Cope. Transac. Amer. Philos. Soc.; 1866, 379.

G R O U P A.

44. Hybopsis amirus, Girard.

Proceed Acad. Nat. Sci., Phila., 1856, 210. Hybopsis phaёnna, Cope, 1. c., 1864,279 .

Specimens from the Catawba River all have a relatively longer head than typical examples from the Potomac; former 4 times in length to basis caudal fin; latter 4.5 times. They have also teeth $4.1-1.4$, in place of $4.2-2.4$; the three inferior of the outer row obtuse, without hook, the superior one only with masticatory face. Both varieties may really belong to the $\mathrm{H}$. luudsonius, as indicated in Monograph Cyprinidæ Pennsylvania.

G R O U P B.

Hybopsis longiceps, Cope.

Journal Acad. Nat. Sci., Phila., 1868, 231.

Abundant in the headwaters of the Cumberland River, and Coal Creek, a branch of the Clinch River, Tennessee. Originally found in the Roanoke and James Rivers, Virginia.

Loc. Cit. 231.

45. Hybopsis spectrunculus, Cope.

From the tributaries of the French Broad in the high valley of Henderson County, North Carolina.

\section{G R 0 U P B B.}

Teeth $+4.4+$; mouth horizontal, lower jaw received beneath upper.

Spec. nov.

46. Hrbopsis niveus, Cope.

Char. Head 4.5 in length: depth 5 times in the same; eye 3.3 in head, equal muzzle. Scales $\frac{6}{38-40:}$ anal I. 8 . White, a black spot on dorsal fin behind.

Description. This is a regularly fusiform fish, the dorsal region more arched than the ventral. Head conic, muzzle obtuse, not projecting, mouth nearly terminal; preorbital large, longer than deep. Occipital region arched, its breadth at superior extremity of operculum equal from end muzzle to middle pupil. Muzzle about equal orbit, preorbital bone elongate; end of maxillary extending to opposite anterior rim of orbit. 
Mouth slightly oblique downwart, mandible included ; isthmus medium. Fins D. I. 8, A. I. 8 ; the osseous dorsal ray separated from the first cartilaginous by a narrow membrane, and originating above the ventrals. Posterior ray 3.5 length of the anterior.

Length 31.3 lines; of catdal 5.8 lines; to basis dorsal 12.9 lines. .From basis to apex pectorals 4.1 lines; same to basis ventrals 13.1 .

Color in life very pale, sides and below silvery; a blackish spot at basis caudal, and a large dark spot at upper posterior part of dorsal fin.

Common in the upper waters of the Catawba River, North Carolina.

\section{GROUP D.}

Teeth 4.1-1.4; lateral line little decurved; scales $\frac{(59)}{3} ;$ muzzle short obtuse ; interorbital region wider ; depth 5 ; head 4 times in length. A. I. 8.

B. CHIOROCEPHALUS.

Teeth 4.2-2.4; lateral line much decurved; scales $\frac{7 \pm-7}{2}$; muzzle acuminate; interorbital space narrower; depth 5.5, head 4 times in length. A. I. 8 .

H. chiliticus.

Spec. nov.

47. Hyвopsis chlorocephalus, Cope.

This small species is rather stout and has a deep caudal peduncle. The head is broad with large orbit, descending muzzle, and descending mouth, orbit in head three times, diameter exceeding length of muzzle. End of maxillary extending beyond line of orbit; premaxillary margin barely reaching plane of lower margin of pupil. Interorbital width much more than length of muzzle. Lateral line moderately decurved. Dorsal fin above ventrals, elevated : R. I. 8, A. I. 8.

Length (total) 27 lines; to origin dorsal 11.9 lines ; to basis caudal 21.6 lines. Everywhere, except on belly and below orbits thickly dusted with blackish, especially gathered into a lateral band which terminates in a basal caudal spot. Fins unspotted, in life a metallic green line on the vertebral line, and one from the upper angle of each operculum to caudal, visible in several lights; below the latter, dark crimson; dorsal and caudal fins, operculum and cheek with end of nose, all crimson. Part of operculum, properculum, postfrontal region and top of head metallic green.

This surpassingly beautiful fish is abundant in the clear waters which it inhabits, viz.: the tributaries of the Catawba River.

This species may be compared with $H$. rubricroceus and $H$. plumbeolus as its nearest allies. The former has a relatively larger head, and more slender caudal peduncle, A. I. 9. The latter is much shorter and deeper fish; its depth enters the length 4.6 times ; the eyes the head only 2.75 times.

A. P. 8. - VoL. XI. $-30 \mathrm{E}$ 


\section{Hybopsis chiliticus, Cope.}

Spec. nov.

This species is an ally of the last ; it has a more clupeoid aspect, seen in strongly decurved lateral line and more acuminate muzzle. Head broad behind occiput, convex, interorbital width less than length of muzzle, orbit 3 times in head, exceeding length of muzzle; maxillary extending beyond its anterior rim. Teeth 4.2-2.4. Dorsal small, originating above ventrals, R. I. 8, A. I. 8. Line of premaxillary margin opposite middle of pupil.

Length 24.4 lines ; to basis dorsal 12.41; to basis caudal 24.4 1. Lengtı pectoral from base 5 ; from same base to do. ventrals 5.7 lines.

In life pure silver white to the dorsal line; the dorsal scales brown edged; a rermilion bant through anal fon and one through dorsal; the lips vermilion all round the mouth.

This species is as beautiful as the $\mathrm{H}$. chlorocephalus; if not as rich, its tints are much more transparent. Common in the tributaries of the Yadkin River, in Roane County, North Carolina.

\section{HEMITREMIA, Cope.}

\section{Genus novum.}

Char. Dentition 5 5, with marked masticatory surface. Alimentary canal shorl, with the nsual two flexures. The lateral line one-half wanting, and generally imperfect. First (osseous) dorsal ray adherent. Premaxillary projectile.

This genus is Hybopsis with teeth 5-4, and undeveloped lateral line. Perhaps it will be necessary in future to refer $H$. heterodon and $H$. bifrenatus to it.

\section{Hemitremia vittata, Cope.}

This is a stout species with very short head and obtise muzzle. The latter is rounded hori/ontally from the orbits. The mouth is short and oblique; the end of the maxillary does not reach the orbit. Diameter of orbit equal muzzle, 3.5 in head; 1.33 times in interorbital width. Lengtl head 4.2 times to base caudal; depth 4.5 in same isthmus rather wider. The first dorsal ray originates a little behind above the ventrals; scales $\frac{6}{\frac{38}{4}}$ Radii D. I. 8 ; A. E. 7. Length to basis caudal 24.4 lines. Do. to basis dorsal 13.2 lines; length pectoral 4.2 .

The specimen is alcoholic, and I do not know the colors in life. There is a conspicuous dark shade along the median lateral line, and a pale band above it ; above this the whole dorsal region is of a dark color.

This species is from the tributaries of the Holston River, near Knoxville, Tennessee, and was procured by my friend, Prof. Harrison Allen, who submitted the specimen to me for examination.

\section{PHOTOGENIS, Cope.}

Proceed. Acad. Nat. Sci., 1867, 163. 


\section{Photogents leucops, Cope.}

Var. aaaa. Depth into length to basis caudal fin 6.5 to 7 times; head

in same 4.5 times; scales $\frac{6.7}{98}$ abundant in the French Broad River.

Var. aara ${ }$. Depth into length 5 times; length head into same 4 times; $5-6$

scales 38 - color silvery, a double row of black specks on lateral line. Very abundant in the head waters of the Catawba River. This fisl when taken from the water, always sustains a rupture of some of the branches of the ophthalmic artery by which blood is suffused beneath the cornea. The altered condition of pressure on transfer to a rare medium, is no doubt the cause.

Also from the Neuse River, near Raleigh.

50. Photogenis telescopus, Cope.

Loc. Cit. 165.

Very abundant in the French Broad River; a variety with large eye in a tributary of the Clinch.

51. Photogenis Leuciodus, Cope.

Loc. Cit. 165.

Abundant in the waters of the tributaries of the French Broad River.

52. Photogenis Pyrrhomelas, Cope.

Spec, nova.

This species is in most characters related to the Hypsilepides, and it combines remarkably the characters of the $H$. cornutus, $H$. analostanus, and H. diplamia. Thus it has the head of the first, the form, with milky paired, and black spotted dorsal of the second, and the long anal of the third. As the teeth are without masticatory surface, I refer it for the present to this genus.

The extremity of the muzzle descends obliquely to the mouth, which is itself oblique, the end of the maxillary descending to a line from the anterior margin of the orbit. The mandibular and premaxillary margins are in the same vertical line when the mouth is closed. The diameter of the eye ball enters the length of the head 3.6 times, and 1.25 times in interorbital width. Length of head four times in length, depth about the same. The body is therefore rather deep and compressed. Teeth sharp, hooked, 4.1-1.4. Radii D. I. 8, A. I. 10. V. 8. The extremities of the pectorals barely reach the ventrals, and the ventrals attain the anal. Scales $\frac{6}{34-6 ;}$ most of them with narrow exposed surfaces, as in typical Hypsilepis. Total length $40 \mathrm{l}$.; to or bit, $2.8 \mathrm{l}$; t to origin dorsal fin $16.5 \mathrm{l}$.; to origin caudal 32.71 .

In coloration this is aguin one of the finest of our Cyprinidie. Specimens taken in autumn were steel blue above, the scales darker edged; the belly silver. The muzzle and upper lip to the end of the maxillary, are vermil- 
liou; also, the iris above and below the orbit. The dorsal fin has a large black spot on the posterior lualf; the fin is anteriorly vermilion. The tail has a rather broad black posterior margin, and a wide vermilion crescent following it into the points of the fin; base of the fin pale. Anal and ventral fins with milky pigment.

Small horny tubercles appear on the upper surface of the head in spring, as in the species of Hypsilepis.

In this case $I$ have assigned this species to its genus in accordance with its technical characters, but it is probable that it will be necessary to change the arrangement at some future time, - when the structure of these fishes is better know.

The P. pyrrhomelas is the most abundant fish in the tributaries of the upper Catawba River, North Carolina.

\section{ALBURNELLUS, Girard.}

Several species of this genus were obtained, and may he compared with others already known, as follows :

I. Ventral fins extending beyond dorsal, reaching anal.

Scales 5-36-2; dorsal much elevated. A. 8.

A. ALTIPINNIS.

II. Ventrals extending to opposite last dorsal ray; not to anal.

$\alpha$. Scales above lateral line 5-6.

p. Scales large, lateral line 33 .

Orbit large.

ß,. Seales smaller, 1. 1. 38-40.

A. MEGALOPS.

Scales $\frac{5}{3}$; head smaller, body stouter. A. 8, eye smaller. A. AMAmILIS.

Scales $\frac{5}{2}$; head larger. body slender. A. 10, eye larger.

Scales, etc., as last ; eye much larger.

A. JACULUS.

a.a. Scales above 1. 1. 7 .

A. ARGE.

Scales $\frac{7}{4} \frac{7}{3}$ slender. A. 11 .

A. matutinus.

auc. Scales above 1. 1.9.

Rather stout.

A. Umbratilis.

III. Ventrals only extending to line of middle of dorsal.

Head 4.5 in length ; scales $\frac{6}{39}-$

A. MICROPTERYX.

\section{Alburnellus altipinnis, Cope.}

Spec. nov.

This species is much less elongate than such typical forms of the genus as A. jaculus, etc. The head is short, but not widle. Orbit very large, diameter exceeding muzzle, entering length of head 2.75 times, one-third greater than the interorbital width. Head 4.33 times in length to basis of caudal, depth five times in same. Anterior dorsal radii unusually prolonged for the genus, equal just half distance from the base to end of $\mathrm{muz}$. zle. D. I. 8. A. I. 9. The pectorals do not quite reach the base of the 
ventrals. Total length 26 lines; to basis of dorsal 11 lines; to basis caudal 21 lines.

Color white, a broad lateral silver band punctulated with strong black dots. A black band across operculum to orbit, and black spot on preorbital bone. Top of head to origin premaxillaries black shaded.

Two marked bony ridges connected with the system of mucous tubes, diverge from the apices the premaxillary bones to the epiotic region on each side enclosing an urceolate interspace.

From the Yadkin River, Roane County, North Carolina.

\section{Alburneluds matutinus, Cope.}

A compact slender species with small scales. Orbit large, contained 3.5 times in length of head, and scarcely larger than length of muzzle, equal also interorbital width. Length of head contained 4.25 times in total less caudal fin, depth six times in same. Length of first dorsal ray just .33 distance from its base to end of muzzle. Pectorals considerably short of ventrals, ventrals short of anal. R. A. I. 11. Twenty-five rows of scales across dorsal line in front of dorsal fin.

Length 32 lines; to basis dorsal 14.4 lines; to basis caudal 26 lines.

Above olivaceous, edges of scales brown shaded ; lateral band plumbeous ; sides and below silvery, a dark spot at base of caudal fin. End of muzzle and chin bright rufous.

From the Neuse River, in Wake County, North Carolina. The first species of the genus found in Atlantic waters.

\section{Alburnellus micropteryx, Cope.}

Journal Ac. Nat. Sci., Phila., 1868, 233.

Several specimens of this species were taken in Coal Creek, a tributary of the Clinch River, Tennessee, and preserve exactly the characters by which this species was originally distinguished from A. jaculus m.

\section{CLINOSTOMUS, Girard.}

\section{Cuinostomus affinis, Girard.}

Jour, A. Nat. Sci., Phila., 1868, 228.

Very abundant in the waters of the Catawba and Yadkin.

\section{STIIBE, Dekay.}

57. Stjlbe Americana, Linn.

Common in still and sluggish water of the Catawba, Yadkin and Neuse Basins.

HYBOGNATHUS, Agass.

The species of this genus are few, and have a.wide distribution. Those known to the writer are distinguished as follows:

I. Suborbital bones broad, short; speculum on postfrontal region large. Scales $\frac{6}{4}$; eye small, one-sixth of head, twice in muzzle; A. 8.

H. Placitus. 
Scales 5-39 $\frac{1}{4}$, eye 4.25 to 4.5 , less than length muzzle; bead wide, entering length 4.66 times; A. 8.

H. NUCHALIS.

II. Suborbital bones long, slender; speculum on postfrontal region little marked.

Scales 6-38-4; head 4.75 times in length, wide; eye large 3 times in head, larger than length muzzle; A. 7 .

H, OSMERINUS.*

Scales 5-6-36-3-4; head narrow 4.25 times in length; eye large, diameter exceeding muzzle, 3.3 times in head; A. 8.

H. ARGYRITIS.

58. HybOGNıthus argyritis, Girard.

Proc. Acad. Nat. Sci., Phila., 1856, 182. U. S. Pac. R. R. Surv., vol. $\mathrm{X}$. Tab.

This species was described by Dr. Girard, from specimens obtained by the U. S. Explorations for the Pacific Railroad route, from the Milk and Arkansas Rivers. It appears to be very abundant in the Catawba River, North Carolina. Specimens from it cannot be distinguished from those from the Arkansas in the Museum of the Smithsonian Institution.

CAMPOSTOMA, Agass.

\section{Campostoma anomaldm, Raf.}

\section{Rutilus Raf., Campostoma, Agass.}

From the Cumberland, Clinch and French Broad Rivers, west of the Alleghenies and the Catawba River east of them.

\section{CATOSTOMID ÆE.}

Prof. Gill proposed to distinguish this group from the Cyprinidæ as a family (in Proc. Acad. Nat. Sci., Phila., 1861, p. 8), basing the latter on the peculiar characters of the pharjngeal bones and teeth. This course has not been followed by subsequent writers, and the character assigned does not appear to me to warrant the proposed separation. I find, however, that while the premaxillary bone completes the superior arch of the mouth in the Crypinidæ, in the Catostomidæ, those bones form but a slight portion of the same, the maxillary bones entering into it extensively on each side. This feature is evidently of importance sufficient to define the family, and I therefore adopt it as left by Prof. Gill.

\footnotetext{
* Hybognathus osmerinug, Cope spec. mov.
}

The characters of this species are expressed in the above table. It is very near the $\mathrm{H}$. arg yritis Gir. but has a materially shorter bead and smaller anal fin. The head is relatively wider. The preorbital bone is about as long as deep. The mandible very attenuate, and with a slight symph yseal tubercle. End of maxillary not beyond line of posterior nares. Orbit large. D .I. 8. A. 1.7. (H. regius has II -9 A, according to Girard.) Total length 31.2 . lines; of head 51 .; to basis dorsal 12.51 .; to basis caudal 12.71. Pectorals and ventrals very short ; first articulated dorsal ray 6 lines long. A broad silver lateral band; brjght olive above it, pale below it : no black spot on basis caudal. Speculum on postfrontal region small and Jittle visible.

This species is abundant in the Ruritan River, New Jersey, in early spring ascending the river with the smelt (Osmerus). Discovered by my friend. Dr. Chas. C. Abbot, of Trenton, who is investigating the ichthyology of New Jersey. 
Genus novum.

\section{PLACOPHARYNX, Cope.}

Allied to Ptychostomus, Ag. The pharyngeal teeth much reduced in number, only seven on the proximal half of the bone, cylindric in form, with a broad truncate triturating surface. These play against a broad crescentic chitin-like shield on the posterior roof of the pharyngeal cavity. Three divisions of the vesica natatoria.

With a great superficial resemblance to Ptychostomus, the masticatory apparatus is different from that of any Catostomoid form known to me, and combines peculiarities observed in forms of true Cyprinidæ. The chitinlike shield is found in some of the latter; it is represented in Catostomus, Ptychostomus and Carpiodes, by a narrow and very thin pellicle of the same material, frequently interrupted in the middle line.

I know as yet but one species of the genus.

Species nova.

\section{Placopharynx carinatus, Cope.}

The physiognomy and proportions of this sucker are those of the Pt. erythrurus or the "red horse" of the Western Rivers.

The lips are large and plicate, the anterior pendent like that of the $P$. collapsus, the posterior full like that of $P t$. cervinus. Muzzle vertically truncate. Length of head in that of body four times; depth of body in same 3.66 times; scales $6-41-5$. Radii D. XIV, V. 9. A. 7. Free margin of dorsal straight, not elevated anteriorly. Occipital region more elevated medially than in $P t$. erythrurus, superior ridges well marked, with a special addition characteristic of this species, and of none other with which I am acquainted. This is a median longitudinal frontal ridge, extending from the fontanelle to between the nasal ridges. Only the posterior extremity of this ridge appears in some Ptychostomi. Crbit longitudinally oval, 4.5 times in length of head, twice in interorbital width. Type, fourteen

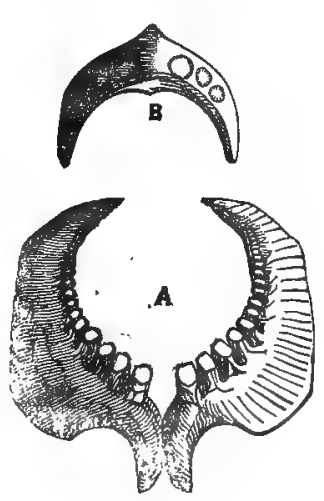
inches in length.

Color in alcohol like that of other species, uniform straw or whitish silvery.

The pharyngeal bones of this species are much stouter than those of other species of its own and greater size, e.g., Pt. aureolus of eighteen inches, where they are comparatively slight. The exteroposterior ala is twice as wide as the body inside the teeth is deep, and but for its short base and narrowed tip would do for that of a Semotilus. But while there are seven broad teeth without heel or cusp on the basal half, there are at least forty on the distal half, they becoming more compressed and finally like those of other allied genera. There are fourteen with truncate ex- 
tremities. The pharyngeal plate has narrow horns directed upwards and forwards, and is thickened medially. It is placed immediately in advance of the opening of the oesophagus. I have but one specimen of this curious species, which I obtained at Lafayette, on the Wabash River, in Indiana.

CATOSTOMUS, Lesueur.

60. Сатоstomus Teres, Mitchill.

- Cyprinus teres, Mitch. Catostomus teres, C. communis and C. bostoniensis, Les.

Common in all the rivers of the State and on both sides of the Allegheny water-shed.

\section{Catostomos nigricans, Les.}

C. planiceps, Cuv. $\nabla a l$.

Common in the Clinch, Cumberland and French Broad Rivers.

An especially western species, and abundant, where it occurs.

\section{Moxostoma, Rafinesque.}

Moxostoma oblongum, Mitch.

Catostomus tuberculatus and vittatas, Lesueur. Labeo oblongus, Dekay.

In North Carolina, as in Pennsylvania, this species is confined to the sea-board streams. I only found it in the Neuse.

\section{PTYCHOSTOMUS, Agass.}

Amer. Journ. Sci., Arts XIX. 88. Teretulus, Raf. Cope emend. Journ. Acad. Nat. Sci., Phila., 1868, 235.

The species of this genus are found in the United States, South of New York and East of the Rocky Mountains, including the waters of the great lakes. They are especially numerous in the Rivers of North Carolina, which flow into the Atlantic, and constitute one of the peculiarities of 'that shed of the Allegheny range, as distinguished from the streams of the western slope in Tennessee, where a smaller number of species is found. Wherever Ptychostomi occur they are abundant in individuals.

The development of the lips furnishes important diagnostic indications in this genus. In those most nearly allied to Moxostoma, the inferior lip resembles that of that genus, in being narrower, and deeply incised -emarginate posteriorly forming a figure $V$ with the apex forwards; at the same time the superior lip is very thin, and often narrow. Such species are shorter, and tend to a large development of dorsal fin. Others of this type are more elongate. The more typical forms have a large inferior lip, which is generally produced posteriorly to a square transverse margin. Most of these are more elongate species than the last groul). Some species of both are distinguished by their very prominent conic muzzle, and minute inferior mouth, reminding one of the Carpiodes. In one species the surface of the lips is pappillose instead of plicate. In some species the mouth is very projectile, in others scarcely so at all. 
Rafinesque proposed a genus Teretulus on the characteristic peculiarity of nine ventral radii, belonging to most of the species of this genus. He, however, included species of two other genera. On this account Agassiz, in rearranging the suckers, imposed on it the name standing at the head of this article, regarding the plicate lips as a primary character. I think Rafinesque's name is to be rejected, owing to its ill application; the more as I find two species in which there are ten ventral radii. I adopt that of Agassiz, though I showed, when describing the $\mathrm{Pt}$. cervinus, that the tricellular natatory bladder is a more distinctive feature. This becumes the more obvious now that I have found a species where the lips are tubercular instead of plicate.

The following scheme will render the identification of the species more simple.

A. Lips pappillose, inferior, $\Lambda$ shaped.

Head elongate, muzzle truncate.

$A A$. Lips plicate.

P. Pappillosus.

a. Inferior lips infolded, $\Lambda$ shaped.

$\beta$. Oblong species; head one-fourth the length.

Eye large; D. XVI; form compressed.

Eye smaller; D. XV; compressed.

Eye smaller; D. XII ; subcylindric.

P. Velatus.

P. COLlapgus.

$\beta$ 3. Fusiform species; head one-fifth the length.

Muzzle conic ; mouth minute inferior.

P. PIDIENSIS.

$\alpha \alpha$. Inferior lips narrow, crescentic.

Head one-fifth length, muzzle sub-conic.

Head long, truncate. $\frac{1}{4}$; fins white.

P. COREGONUS.

$\alpha \alpha a$. Inferior lips well developed, truncate posteriorly.

$\beta$. Compressed species.

$\gamma$. Head 4, 4.5 in length.

$\delta$. Dorsal radii XII.

Stout, elevated ; muzzle short, fins crimson. P. Roвustus.

$\delta \delta$. Dorsal radii XIII.

$\varepsilon$. Ventral radii IX.

Head longer, occipital region Hat, muzzle truncate, eye smaller 4.5; scales $5-42-4$; scales white.

P. ERYTHRURUS.

Head shorter; occipital region convex; muzzle projecting, mouth inferior, eye larger 3.5 in head; scales black at base.

P. MACROLEPIDOTUS.

Head elongate, convex with ridges above occiput; eye 4.5 in head; muzzle prominent, mouth inferior; scales white. P. LACHRYMalis.

$\varepsilon \varepsilon$. Ventral radii $\mathrm{X}$.

Head 4 times ; muzzle conic.

P. DUQUESNEI.

$\delta \delta \delta$. Dorsal radii (XVII) XVIII.

" "Eye small; depth 3.25, head 4.3 times in length."

A. P. S. $-\nabla 0 L$. XT. $-31 \mathrm{E}$

P. CARPIO. 
$\gamma$. Head five times in length; occipital region strongly convex.

$\delta$. Ventral radii IX.

D. XIII. muzzle little prominent, dorsal truncate.
D. XII. Muzzle projecting; lips large.
P. AUREOLUS.
P. CRASSILABRIS.

$\delta \delta$. Ventral radii $\mathrm{X}$.

D. XIII. Muzzle projecting, mouth inferior. incised.

D. free border deeply

P. BREVICEPS.

$\delta \delta \delta$. Ventral radii unknown.

D. XIV. Muzzle produced convex, mouth very small, back elevated.

$\beta \beta$. Cylindric species.

P. CONUS.

D.XI, XII. Head one-fifth length; sides lined.

P. cervinus.

Species nova.

63. Pttchostomus Pappillosug, Cope.

Body deeper than thick, the dorsal outline not at all elevated. Head elongate not more than one-fourth the length to base of caudal, the orbit small and bordering the frontal plane. Preorbital region most elongate in the genus; muzzle truncate in proble; the upper lip hanging free, the lower deeply incised behind so as to be $\Lambda$ shaped, and with the upper, finely granular, not plicate. The muzzle very projectile, more so than in any species of the genus. The top of the cranium is everywhere plane. Dorsal fin truncate, with XII radii. Scales large, about as in P. collapsus, Cope, i. e. $6-42-5$.

Color everywhere a silvery white, except some blackish shades at the bases of the scales of the dorsal region. The fins, unlike those in most other species, are pure white in life. They attain one foot in length, and do not exceed one pound in weight.

This species is quite abundant in the Catawba and Yadkin Rivers, in North Carolina, and is highly valued by the inhabitants as an article of food. It is regarded as the best of the Catostomi for this purpose. It is less frequently caught on a hook than some other species, but in the autumn they come on the weirs in considerable numbers; from these I procured many specimens. The fishermen call it the "Shiner." Its characters are very constant, and not likely to be confounded with those of any of the known Ptychostomi.

\section{Species nova.}

Ptychostomus velatus, Cope.

This is a stout species, with a short head, large eye, and more than usually elongate dorsal fin. Scales 5-6_-42-5; head scarcely 4 times in length; superior plane nearly flat; orbit 3.75 times in length of head; 1.5 times in interorbital width. D. XVI. with straight superior margin; V. IX. Upper lip pendent. Dorsal outline arched to the first dorsal ray; greatest depth 3.2 lines in length (exclus. caudal). Total length 11 inches. 
The color of this species I cannot give, as I have not lately seen it in life; in spirits it is uniform silvery, the dorsal fin dusky.

I know this fish from two specimens which I caught in the Youghiogheny River, in Western Pennsylvania.

\section{Prychostomus collapsus, Cope.}

\section{Species nova.}

This very abundant fish is in the form of its lips similar to the last. It is stout and short, the head not entering the length (exclus, caudal) quite four times. The dorsal line is somewhat elevated to the first ray of the dorsal fin, the depth entering the length 3.5 times. The eye is smaller than in $P$. velntus, entering the length of the head 4.75 and 5 times, and the interorbital width 1.75 times. Top of head plane; muzzle moderately prominent, intermediate between $\mathrm{P}$. elythrurus and $\mathrm{Pt}$. conus in this respect, being more compressed than in the last. Mouth small, little projectile, superior lip pendent. D 15, V. 9. Thoracic region with small scales.

The specimens of this species from most of the North Carolina Rivers are rosy on the sides, the larger, light golden; the inferior fins all orange. The specimens from which the above description is taken are small, only a foot long, but I have seen several specimens in the Catawba River, of three and four pounds in weight.

It occurs in the Neuse, Yadkin and Catawba Rivers, in North Carolina, the Clinch River in Tennessee, and I have a specimen from the Wabash River, in Indiana, and three others without locality, but probably from the Western States or Great Lakes. In the Yadkin and Catawba Rivers it is immensely numerous, and is caught on weir traps in the spring and autumn in quantities, and used as food by the inllabitants. It is not as good a fish as the $P$. pappillosus and $P$. robustus, but it is not at all to be rejected.

There seemed to be a larger number of smaller specimens in the Yadkin than the Catawba Rivers at the time of my visit. The specimens from the Neuse have the muzzle a little more prominent. Some specimens from the Yadkin possess only XIII and XIV D. rays.

\section{Pтrсhostomus PIDiensis, Cope.}

\section{Species nova.}

A smaller species than either of the preceding, of more cylindric and less compressed form. The dorsal fin is shorter, containing only XII rays Head elongate, about four and a lialf times in length exclusive of caudal fin. Muzzle not conic, but truncate. Scales similar to those of the list species. Length about ten inches.

Color light brownish yellow, fins light red.

This fish resembles at first, the $P$. cervinus, both in color, form and size. I obtained a few specimens from the traps in the Yadkin River, at the plantation of John Kuntz, and dicl not see it in any other river.

I took a variety in a tributary stream, characterized by a longitudinal black spot at the base of each scale, giving a handsome longitudinal 
striation. (A similar variety of Hypsilepis analostanus (q.v.) was taken in the same stream.) Scales 6-44-5. V. IX. A. VII. Head flat above; eye 4 times in head, 1.5 times in interorbital breadth. Dorsal and caudal fins black edged.

Species nova.

\section{Ptychostomos coregonus, Cope.}

This fish is very easily distinguished by its very small head, with conic muzzle, and elevated arched back, combined with a small size, and other characters.

The head enters the length not less than five times, and is much arched in transverse section posteriorly above. The diameter of the eye is large, entering the head between three and four times; the muzzle is regularly conir, and projects far beyond the mouth. The latter is remarkable for its small size, and lack of projectility ; in ordinary individuals it would about admit a pen. The upper lip is not pendent below the front of the muzzle. The shape is broadly fusiform, the dorsal line rising to the fin. It is, nevertheless, more compressed than the species already described. D. XIV constantly.

The ground color is silvery, the scales shaded with leaden above, and with black pigment at their bases, giving a dusky hue to the whole, as is not seen in the species alreadly described, except the $P$. pappillosus. Belly and inferior fins pure white, lacking the red and orange of many others.

This fish never exceeds a foot in length, and is very abundant in the Catawba and Yaclkin Rivers. It is caught with the preceding two species and is used for food, but is the least valued of all the species. It is called at Morganton, "blue mullet."

Spece. nov.

\section{7. Ртүсhо一тomus albus, Cope.}

This large species has the small head of the last, without the small mouth and many of its other peculiarities. The head enters the length not less than five times; muzzle is prominent, but the mouth is less inferior than in Pt. coregonus. The eye, in a specimen sixteen inches long, is relatively larger than in $P$. collapsus, and about as in $P$. coregonus. The muzzle is less prominent than in the last named fish, but more so than in Pt. collapsus. The month is of ordinary size, but the upper lip does not form a free projecting rim as in the latter. The under lip is a narrow crescent following the boundary of the mandible, not folding so as to meet on the middle line as in the species already described.

Dorsal outline a little elevated. rays XIV.

Colors very light; the inferior fins white. In size this species is one of the largest, reaching four pounds and over. It is much valued by the people living in the neighborhood of the Catawba River, North Carolina, as an article of food. They call it the "White Mullet." I have not seen it in the Yadkin or any other river.

\section{Pтxсhostomus thalasinus, Cope.}

species nova.

This fish approaches the $P t$. collapsus, Cope, in many respects. The head 
is elongate, about one-fourth the length (exclusive of caudal fin), and is plane above. The muzzle is not very prominent, nor the mouth smaller than usual in the genus. The lower lip is quite different from that of Pt. collapsus in its narrow crescentic form. The eye is similar in size to that of that species. The dorsal line is elevated; dorsal radii XIV-XV. Color sea green above, white below; fins white. Reaches four or five pounds, and still greater weight.

It may be that this fish is a form of the $P$. collapsus, but the different mouth and coloration seem to separate it. Its whole proportions differ from those of $P$. albus. I have only observed it in the Yadkin River, where it is abundant, and used for food.

\section{Species nova.}

69. Pтrchostomus robustus, Cope.

Witl this species we commence the most numerously represented section of the genus, in which the inferior lip is large and full, entirely covering the space between the rami of the mandible, and having a transverse or convex posterior margin. In this it resembles the true Catostomi, and diverges from the type of Carpiodes, etc.

In $P$. robustus, we have a species stout in all its proportions, and with marked coloration; with the gibbous or elevated dorsal outline of $P$. coregonus, it combines the short body of the Pt. collapsus. The head is short and deep, the muzzle not prominent, truncate in profile. Eye between four or five times in length of head. Dorsal fin short with straight superior margin, radii XII. Scales as in $P$. collapsus.

Color smoky or clouded above, mingled with golden reflections; sides similar, below yellowish. Dorsal, caudal and anal fins dark crimson. Size large. I examined one of six pounds weight.

This species is distinguished by its form and color, from all the others inhabiting the Yadkin. I did not see it in any other river area. It is highly valued for the table by the people living near the river. With the $P$. thalussinus and $T$. erythrurus var, it is taken in spring-nets. These nets are attached by four corners and suspended to the extremity of a lever whose fulcrum, as high as a man's head, is on the river bank. Bait is thrown on it, and when the fishes congregate, the land end of the lever being suddenly depressed, the suckers do not escape. If fishing were confined to this mode, and the autumn weirs not made too tight, an abundant supply of food from the rivers might be promised the State of North Carolina for future time. But unfortunately, too many of the people with the improvidence characteristic of ignorance, erect traps, for the purpose of taking the fishes as they ascend the rivers in the spring to deposit their spawn. Cart loads have thus often been caught at once, so that the supply is at the present time reduced one half in many of the principal rivers of the State. The repopulation of a river is a very different matter from its preservation, and involves much time, attention and expense. It would be far cheaper for the State of North Carolina to enact laws preservative of this important product of her waters, similar to those in force 
in many of our older States. The execution of such laws is, however, the important point, and the destruction by officers, of the spring traps and weirs in the Neuse, Cape Fear, Yadkin and Catawba Rivers, every spring, at the time of running of the fishes, would allow of the escape of immense numbers of them, before the traps could be repaired.

70. Ртrchostomus erythurts, Raf.

Ichthyologia Ohiensis, p. 59. Ptychostomus duquesnei, Agass part. Am Journ. Sci. Arts., XIX 90. Cope Journ. Ac. Nat. Sci., Phila., 1868, 236.

This species is probably the most widely distributed as well as one of the largest of the genus.

The form is somewhat compressed, but the dorsal line is not much arched; the head is of medium size, entering the length 4.5 to 4.66 times. The end of the muzzle is nearly vertical in profile. The lips are full, the posterior truncate or openly emarginate posteriorly; the plicate coarse. Eye 4.5 times in length; 1.66 lines in interorbital width. Depth of body three and two-thirds times in length (exclus. caudal). Top of head nenrly plane. Scalcs 5—-42-4. Radii D. XIII, V. 9., dorsal with straight superior outline. Color silvery, rosy and gray above; dorsal caudal and anal fins orange.

The above description is taken from one of several specimens from the Youghiogheny River, in Western Pennsylvania. I have procured other and similar individuals from the Holston and French Broad Rivers, in Tennessee. It is, as Rafinesque observes, a most abundant sucker in all the rivers tributary to the Mississippi from the East, and is that which is known everywhere as "red horse." It is the common fish-food of the people, sharing the distinction with the "blue cat." Ichthaelurus coerulescens. It reaches as large a size as any species of the genus and $I$ have seen them of six and eight pounds. The largest I have lieard of, was caught in the French Broad, and weighed twelve.

With various authors, I liave formerly regarded it as the Pt. duquesnei of Leseuer, but I suspect it to be distinct, as already indicated by Rafinesque. The characters of the latter are pointed out below.

A species resembling the present, as well as the $P t$. robustus, bears the name of "red-horse," in the country of North Carolina, east of the mountains, but whether the same or not, the present inaccessibility of my specimens, prevents me from deciding. A specimen from the Catawba of seven $\mathrm{lb}$. weight had a relatively larger head, and was otherwise stouter than the above described. D. 1.12 ; scales $6-43-5$. The fish is common in that river, and equally so in the Yadkin. Those from the latter have D. XII ; muzzle not prominent; head and body rather elongate; shaded with yellow, particularly on sides of head; fins orange. It will be observed that the eastern fish agree in having D. 12 soft rays.

\section{Ptrchos'romus lachrymalis, Cope.}

Spec. nov.

This species is quite near the last, and may at some future day be shown to be only a local variety of it, but in this case Pt. macrolepidotus must 
follow also. Its characters are very similar; our specimen differs in its more numerons scale series, a point in which the $P$ t. erythrurus agrees with all the other species with scarce an exception. I do not know of any genus where the number of scales is so similar in all the species, as in Ptychostomus. Scales $7-46-5$, in a larger specimen, in a smaller they are $6-44-5$. The cranium, however, presents us with the oblique superopercular region and elevated vertex with a ridge on each side, as in the Pt. macrolepidotus. The premaxillary spines and nasal cartilage also projects, leaving quite a depression across the muzzle in front of the nares, a feature not seen in Pt. erythrurus, and less marked in Pt. macrolepidotus. The mouth is quite inferior, but is large and the lips large and thick. The inferior has a slightly concave posterior margin, and the median posterior fissure is stronger than the others. The orbit is smaller than in Pt. macrolepidotus, and enter's the interorbital space twice. Depth 3.75 times in length. The dorsal outline is gently arched, and reaches its high. est point a little in advance of the dorsal fin. The latter has the superior outline but little concave, rays XII in the larger, XIII in the smaller; V. 9.

The scales of this species are as in $P t$. erythrurus, not black at base; a trace is seen in the smaller specimen. This mark is seen in Pt. macrolepidotus and Pt. crassilabris, the latter also from the Neuse river. The fins are white.

This species reaches a length of eighteen inches. One like it is sold in the market of the city of Newbern, N. C., with a second species much resembling the $P t$. crassilabris, but whether identical or not, I cannot be sure, as my specimens were lost.

Ptychostomus macrolepidotus. Lesueur.

Agassiz in Sillim. Amer. Journ. Sci., Arts XIX. 89. Catostomus macrolepidotus, Les. Journ. Acad. Natl. Sciences, I, 1817, 94 Tab.

Fusiform compressed, the depth entering the length $3 \frac{5}{8}$ times; the head short, contracted anteriorly, the occipital region elevated, very convex transversely. Length of head 4.6 to 4.5 times in length; orbit large, diameter 4 to 4.3 times in length of head, and twice in interorbital width. Scales 5-45-5, radii D. XIII; V. 9. The lips are well developed, and the posterior is transverse posteriorly.

The length of the specimen described is about a foot. The color in life including fins, is white, yellow shaded above.

Ten specimens have been compared, all from Pennsylvania and Delaware. Of five from the Conestoga Creek, a tributary of the Susquehanna, two have the parietal, median frontal, and nasal bony ridges very prominent, while in two they are almost without trace. In the former the dorsal radii are XIII, in the latter XII. I cannot discover the sexes of these specimens as they have been eviscerated. In the other five there are several with weak crests, but none with XII D. rays.

In a large specimen from the Wabash River, the only departure from the typical form is the more emarginate inferior lip.

This species is especially abundant in the comparatively sluggish streams 
of Maryland and Delaware, and is but little valued for market. It is no doubt the species described first by Lesueur, as it is the only one of the genus seen in the Philadelphia market. I did not meet with it in North Carolina.

\section{Ptychostomus duquesnei, I,esueur.}

A specimen of this fish from near Pittsburg, Lesueur's original locality, suggests the correctness of the opinion of Rafinesque, that his Pt. erythrurus is a different species. The characters are seen in the 10 ventral radii, and the considerably more prominent muzzle, with correspondingiy inferior mouth. The scales are also smaller $7-48-7$ (to front of ventral). Dorsal fin little incised above, R. XIII. Length of liead 4.6 in that of head and body; orbit four times in head 1.75 times in interorbital space. Cranial crests moderate, the parietal region elevated as in $P t$. macrolepidotus, not so plane as in Pt. erythrurus. Depth 3 in length. Lips moderately developed. Dentition as in Pt. erythrurus. The coloration in spirits is quite like that of other species, except that the dorsal region is a dark steel bluish, which the other species do not exhibit. Scales without black spot at base.

Length of a moderate specimen from the Youghiogheny River, Pennsylvania, one foot.

Kirtland's description in Proc. Boston Sci. Nat. Hist. V. 268, leaves it somewhat uncertain as to whether this species or the $P t$. erythrurus was before him; his figures resemble the present fish. I should not be surprised to find that his female "red-horse" described as so different from the male, was our $P t$. collapsus.

\section{Ptychostomus carpio, C. V.}

This species differs from its near allies in the more numerous dorsal radii, etc. The form appears to be that of Pt. erythrurus. Its habitat is given by the French authors, as Lake Superior, and Günther adds St. Lawrence River and Lake Erie. I have not seen it. The lip characters separate it from $P t$. velatus.

\section{Ptychostomus oneida, Dekay.}

Geological survey New York, III, 189.

This species is also similar in general proportions to the $P$ t erythrurus, but has, according to Dekay, more numerous scales and a much smaller eye. Dekay says : seventeen longitudinal rows of scales counted at dorsal fin. Head and body 10 in.; tail 2.; head 2.5 (one-fourth); eye, .4 inch (one-sixth head). Radii D. XIII ; V. 9. He does not describe the lips.

Oneida Lake.

Ptychostomus aureolus, Les.

Agass. 1, c. 89. Catostomus aureolus. Lesueur J. A. N. Sci. Phila. I, $95 \mathrm{Tab}$.

With this species we enter a series characterized by the relatively small size the head bears to the body, and consequent apparent elevation of the latter. The head enters the length exclusive of the caudal fin, five times. 
This species resembles the $P t$. macrolepidotus Les., more than it does the Pt. erythrurus, but the proportionate size of the head is less. In a specimen 8 inches long, the scales are 6-49-4; radii D. XIII, V. IX. The supraoccipital region is much elevated and convex, the interorbital region convex, but without keel. The muzzle is prominent, and separated on the upper surface by a deep transverse depression. The mouth is but little overpassed by the muzzle, and is large. The lips are rather narrow. Eyes five times in length, 2.5 times in interorbital breadth of head.

I do not recollect the colors of this sucker in life; Lesueur states the fish to be orange above, bases of scales darker; inferior fins red.

A single specimen from Saginaw Bay, Lake Huron, has furnished me with means of comparison. It agrees exactly with Lesueur's account of it. The basis of the scales of some dorsal series are blackish. The species is supposed to be confined to the Great Lakes.

\section{Ptychostomus sueurii. Rich.}

Catostomus sueurii, Richardson Fr. Journ. 1823, 772. Fauna Boreali Americana III, 118.

This species appears to me to be very near the last, and agrees with it in proportions of head to body, of depth, fin radii, squamation, etc. He says, however, that the muzzle projects an inch bey'ond the mouth, in a specimen nineteen inches long, which is certainly not the case in the species last described. Hence I suspect it to be distinct, and that it will be found to possess other characters when re-examined. Gunther, (Catal. Brit. Mus.) refers it to the $O$. macrolepidotus, to which it is evidently nearly allied.

From the Fur countries, British North America.

\section{Ptychostomus crassilabris, Cope.}

Species nova.

This sucker is near the $P t$. aureolus, but has a more contracted conic muzale, and smaller moth; it is also a flatter and more clupeiform fish. Supra-occipital region elevated, convex; orbit 4.2 in length of head, 2 times in interorbital width. Depth 3.75 times in length. Scales large, 5-44-5. D. XII ; V. 9. Length of specimen described, one foot.

Color in life silver, above with a smoky shading, and the scales black at the bases. Dorsal fin blackish, inferior fins white. Top of head blackish; a black band from occiput to pectoral fin.

The lips of this species are thick, the lower truncate, but the mouth is vory small. In these features it is between $P$. conus and $P$. aureolus. The dorsal fin in the specimen described is elevated in front, the basis being only .75 the first soft ray, in length. The margin is deeply concave. The fewer dorsal radii, as well as the less prominent muzzle, distinguish it from Pt. conus.

From the Neuse River, near Raleigh, N. Ca.

A. P. s.- vol. XI. $-32 \mathrm{E}$ 
Species nova.

\section{Ptychostomus breviceps, Cope.}

An elongate species with small head, and very convex occipital region, characterized by the presence of $\mathrm{X}$ ventral radii.

Depth .25 the length; orbit 3.75 in head, 1.75 in interorbital width. Cranial ridges not strong. Basis of dorsal five-sixths the anterior height, radii XIII ; free margin deeply concave. Body compressed, dorsal line very narrow. Scales 6-45-5. Muzzle short conic, projecting beyond mouth. Latter small, lips short, the posterior well developed, not emarginate.

Color white, yellowish below; scales above with a little black at their bases.

Length of specimen examined, ten inches.

This fish belongs to the basin of the Ohio. I have a specimen from the Youghiogheny. The number of the ventral radii is very constant in this genus, but if the increased number should prove to be accidental, the general chaarcters of this fish would approximate it to Pt. aureolus.

A peculiarity of the type specimen consists in an additional ray in the anal fin-eight instead of seven in the other species, and the alteration of the third and fifth to perfectly simple, unbranched rays, scarcely attaining the edge of the fin. This may be abnormal.

\section{3. Ртхсноsтomus conus, Cope.}

Species nova.

This fish represents the $P$. coregonus in the section of the genus with fully developed lips.

Form flat, with elevated dorsal line, and small conic head. D. radii always XIV. Eyes large, mouth exceedingly small, far overpassed by the conic muzzle. The superior regions are smoky and the scales with black bases; below, with the inferior fins, white. Dorsal fin dusky.

The lips of this species are smaller than in Pt. crassitabris, though the inferior is similarly truncate behind. The muzzle is much more conic and produced than in that fish. The dorsal radii are more numerous.

Numerous specimens from the Yadkin River, North Carolina, where it is taken in large numbers with $P$ t. collapsus, Pt. robustus, etc., but is of less value than they.

\section{4. Ртұchostomus cervinue, Cope.}

Journ. Acad. Nat. Sci., Phila. 1868, 235, Tab. iii, fig. 4.

This species constitutes a well marked section of 'the gent1s, characterized by a cylindric form, the transverse diameter of the body being equal to the vertical. Before describing this species in detail, I may premise that I have found no little difficulty in attempting to identify the Pt. melanops, Raf., of Dr. Kirtland's fishes of the Ohio. The figure resembles the Pt. crassilabris very closely, but the description of "body full, cylindric," will not allow of the identification. Should the fin formula of $P t$. breviceps be abnormal, the compressed body and lack of spots point to specific diversity. I had thought the present species intended, but the 
figure given by Kirtland precludes the idea, for the $P$. cervinus is in form much like the Catostomus nigricans, and has a much less elevated dorsal region than the $P t$. melanops. It differs also in the form of the dorsal fin, which in that species displays XI XII D. radii instead of XIII. For the present, therefore, I introduce the $P t$.'melanops by name only.

Head of $P$ t. cervinus one-fifth the length, as broad as deep, plane above. Muzzle truncate, low in profile, lips large, the superior pendant. The inferior lip thick, more produced than in any other species, and with a median longitudinal fissure, the plicæ are more or less broken up. Body sub-cylindric, scales large. Dorsal short, radii XII, margin straight. Above yellowish brown, below yellow; fins not recl. The dark of the upper surfaces often forms broad transverse shades. After death the colors above become a dark emerald green. This fish never exeeds a foot in length, and rarely attains that size. It exists in great numbers in the Catawba River, but I did not meet with it in the Yadkin or elsewhere. It has a peculiar habit of leaping from the water, whence the fishermen call it "jumping mullet." It is but little valued as food, though many specimens are caught on the weirs.

Also from the Roanoke River in North Carolina and Virginia, and the James in Virginia.

Günther again confounds this species, so well known to the fishermen of the Southern rivers, with the Pt. duquesnei.

\section{CARPIODES, Rafinesque.}

Agassiz, Am. J. Sci. Arts, XIV, 74, 1865.

The species of this genus are extensively distributed in the fresh waters of North America, east of the Rocky Mountains. I am not acquainted with any from the Atlantic streams to the eastward of the Delaware, though they may exist, while they are found in the Great Lakes and the tributaries of the St. Lawrence. Agassiz defined this genus as above, and indicated four species, one described by Lesueur, one by Rafinesque, and two by himself. 'I have not seen specimens from the Eastern waters of North Carolina, though they no doubt exist, while they are also abundant in the French Broad and other tributaries of the Tennessee. My specimens of those from the latter being lost, I give an account of other species known to me. I add five to the four already known.

I. Anterior rays of the dorsal fin very much elevated and attenuated, excceding or equaling the length of its basis.

$a$ The muzzle very abruptly obtuse.

Anterior suborbital much deeper than long; anterior margin upper lip below orbit.

C. DIFFORMIS.

Anterior suborbital similar; upper lip before nares; eye 4.6 times in head.

C. CUTISANSERINUS.

Anterior suborbital sub-triangular, longer than deep; upper lips before nares, eye 3.6 times in head. C. SELENE.

$\alpha \alpha$ The muzzle conic, projecting.

Size medium, back elevated.

C. VELIFER. 
II. Anterior rays shorter, measuring the anterior half or a little more of the base of the dorsal ; (muzzle conic or projecting).

D. XXIV. A. VII. Depth $2 \frac{5}{6}$ in length; head 4.3 in same; back much elevated, anterior dorsal rays measure to the 15 th ray.

\section{GRAYI.}

D. XXVIII, V. X. A. VII. Depth 2.5 in length; head 4.25 in same; seales $8-5$; short, stout; long dorsal rays measure to 22 ray.

\section{THOMPSONI.}

D. XXVI-VII, V.X. Depth 3 times in length, head 3.5 times; muzzle elongate conic; eye median, large; anterior $\mathrm{D}$. rays not thickened, nearly as long as base of fin.

c. BIBON.

D. XXVII to XXX; A. VIII ; scales $6-5$; oblong, long dorsals to 22 ray in adults; depth 2.7 in length, eye small anterior. C. crPRINUs.

D. XXX A. VII ; anterior dorsal rays thickened, osseous, short, reaching 16 th ray; head small, .4 .5 to 5 times in length; eye small anterior; fusiform, depth 3 times in length.

C. NOMMIFER.

In the number of the radii of the ventral and anal fins, the species are not always entirely constant; thus in one $C$. bison there are VI, in another VII anals. In $C$. cyprinus some have IX and others $\mathrm{X}$ ventrals. In young examples of the species just named, the long anterior dorsal rays are longer than in the adult, but not so much so as to be confounded with the long rayed species of section one. The margins of the scales in this genus and Bubalichthys are serrate, their structure thicker than in the Ptychostomi.

Gill has adopted the genera of the Catostomi as left by Agassiz, while Günther rejects mont of them. Moxostoma, Ptychostomus and Catostomus I regard as distinct genera of the typical form, to which I add Placopharynx. Of those with finer and more numerous pharyngeal teeth, Cycleptus is distinct in its completely ossified cranium, as I have pointed out in an essay on the Cyprinidæ of Pennsylvania. Bubalichthys is well characterized by the form of its pharyngeal bones, as shown by Agassiz. The remaining Rafinesquian genera Carpiodes and Ichthiobus, are but doubtfully distinct from one another. Carpiodes is the older name, with which Selerognathus, Cuv., Val., may be associated as a synonyme.

\section{Carpiodes difformis, Cope.}

Spec. nov.

This species has a remarkably obtuse muzzle, which with the large eye, almost gives it the appearance presented by monstrous perch and carp where the prenaxillary bones are atrophied. Viewing the top of the head from a position opposite a point mid-way between the dorsal fin and end of the muzzle, the spine of the premaxillary bone is not visible. In the $C$. selene these spines are very distinctly prominent, in the $C$. cutisanserinus slightly so.

The dorsal outline of this fish is arched, elevated to the anterior dorsal radii, and then regularly descending. The long dorsal rays extended, reach to beyond the origin of the caudal. Lateral line nearly straight, 
scales $6-35-4$. The end of the pectoral is in line with the origin of the first dorsal ray. Radii, D. XXIV, A. VIII, V. IX.

The head is very obtuse and has a very large eye, beyond whose anterior rim the extremity of the nasals project but a little way. The spines of the premaxillaries project upwards and forwards, but not so far as the line of the nasals, and fail by .25 inch of reaching the line of the inferior rim of the orbits. The anterior edge of the mandible is in line with the anterior rim of the orbit, and the end of the thin upper lip reaches the line of the anterior rim of the pupil.

The diameter of the eye enters the length of the head 3.6 times, and the length of the liead the total (exclus. caudal) 4.22 times. Opercle radiate-ridged. Supraoccipital region much elevated, with lateral ridges. Anterior suborbital trapezoid, deeper than long. The size of this species is medium; average length, one foot. The color is uniform brownish golden.

From the Wabash River in Indiana.

\section{Carpiodes cutisanserinus, Cope.}

\section{Species nova.}

This species is near the last, but present various distinctive features. These may be summed up as follows:

The dorsal fin originates mid-way between end of muzzle and basis of caudal fin-considerably nearer end of muzzle in $C$. difformis. The eye is smaller, 4.5 times in length of head. The spines of the premaxillaries project considerably in advance of the line of the nasal bones, and reach the line of the lower rim of the orbit. The upper lip is much in advance of the orbit, and the end of the sume barely reaches the line of the anterior rim of the latter. Scales $7-37-5$. Anterior suborbital bone vertical ovate.

The lips are minutely tuberculate. Operculum and suboperculum rugose, former radiate. Long rays of dorsal and anal extending a little beyond the basis of the caudal fin. Head four times in length head and body. Depth 2.6 in the same. Length, a foot; color silvery. In a male in spring, the muzzle and front are covered with closely set small papillose corneous excrescences. Radii D. XXVI, V. X, A. VIII.

From the Kiskiminitas River, Western Pennsylvania.

\section{Carpiodes selene, Cope.}

\section{Species nova.}

Anterior dorsal outline steeply elevated, also the supraoccipital region: vertex convex above middle of orbit, concave above anterior rim of same, as in the two preceding species. The present fish is intermediate in many ways between the two last, and adds characters of its own. Thus the anterior suborbital bone is longer than in either, longer than high, and narrowed posteriorly. The orbit is large as in $O$. difformis, entering the length of the head $\mathbf{3 . 6}$ times, while the muzzle is more elongate than in either. The head is narrowed vertically; the spines of the premaxillaries extend beyond the nasal crests, but do not quite reach the plane of the 
lower limbs of the orbit. The premaxillary border is far in advance of the orbit. and the extremity of the maxillary attains the anterior rim of the orbit. Dorsal and caudal radii extended, reach the basis of the caudal; the origin of the first is equidistant between the latter point and the end of the muzzle. Rays; D. XXVI; V. 10. A. VIII. Scales 7-37-5. Color silvery white. Length, a foot. Three specimens of this were taken in the Root River, Michigan, in all probability, though the label which accompanied them has disappeared.

\section{Carpiodes velifer, Rafinesque.}

Catostomus, Sp.? Lesueur Journ. Acad. Nat. Sci. Phila. I $110 . C$. velifer Raf. Ichth. Ohiensis 56. Bclerognathus cyprinus "Val." Kirtland Fishes of the Ohio. Proc. Bost. N. Hist. Soc. V. 275 Tab. XXII fig. 2, not of Valenciennes.

I have referred my specimens to this species chiefly on the strength of the figure and description of Prof. Kirtland, and from the fact that Lesueur regarded it as so near the C. cyprinus, which he would not have done with the $C$. cutisanserinus of the Olino before him. I had two specimens of the present fish, one of them from the Wabash.

It has a shorter dorsal fin than the preceding, having but XXII rays, of which the anterior two are exceedingly elongate. The prominence of the muzzle is the most distinctive feature; it is conic, the spines of the premaxillaries projecting at an angle of 450 to beyond the nasal crests, and the extremity not reaching the line of the lower rim of the orbit. The extremity of the mandible extends to the nares. Eye 4.25 in length of head. Head 3.75 in length; depth 2.4 in the same. Scales as in the last species. Second suborbital long as deep, trapezoidal. Origin of dorsal .2 nearer end of muzzle than basis of caudal. Length of type specimen ten inches.

Rafinesque says that this species is called skim-back and sailor, from its elevated dorsal fin which appears above the surface of the water, and that it often throws itself from the water. The name sikip-jack is applied to a clupeoid of the same streams, the Pomalobus chrysochloris. Prof. Kirtland says the present species is not much valued as food.

Spec. nov.

\section{Carpoides grayi, Cope.}

In this species we have the form and proportions of the last group, with shortened dorsal radii of the succeeding forms.

The origin of the first dorsal radii is nearer the end of the muzzle than the origin of the caudal by one fourth of its basis. This embraces XXIV ractii. Anal radii just to base of caudal. Orbit .25 the length of the head; interorbital width $13-5$ the former. Occipital region elevated; muzzle much prolonged conic, month posterior, as in $C$. velifer. In general this species is quite near the latter; the number of scales is the same, and the proportions quite similar. The orbit is not so elevated, and the long dorsal radil about half as long as those of that species. Length of type eight 
inches. Locality not well ascertained, but as it accompanied species of Bubalichthys, it is probably from one of the western States.

Dedicated to my friend, Dr. John Edw. Gray, for many years the energetic direclor of the zoological department of the British Museum.

\section{Carpiodes thompsonii, Agass.}

Amer. Journ. Sci. Arts, XIX 7ō. Catostomus cyprinus Thompson, Nat. Hist. Vermont. Sclerognathus oyprinus pars Kirtland, Fishes of Ohio, Proc. Bost. N. H. Soc. V. 275.

This is perhaps the handsomest species of the genus, and is distinguished by its stout form, numerous narrowly exposed scales, and little elevated dorsal fin. The eye is small, entering the length of the head 5.2 times, and 2.2 times the interorbital width. The muzle is more elongate, but not so conic as in the two species last described, and projects far beyond the nasal crests, having an obliquely truncate profile. Heace the end of symphysis mandibulii is much in advance of the line of the nares, and the rim of the upper lip just reaclies the line of the orbit.

Dorsal line much arched, origin of the first dorsal radii midway between end of muzzle and origin of tail. Scales $8-41-6$. V. 10, A. VII. Oper. culum flat, slightly ridged. Length averaging a foot. Color silvery, with a greenish golden band along the middle of each of the series of scales near the dorsal region, producing longitudinal golden bancls.

Specimens from Lake George and Saginaw Bay, Lake Huron.

\section{Carpiodes bison, Agnss.}

Amer. Journ. Sci. Arts, XVII, 356.

The original description of this species is rather too brief to allow of a perfectly satisfactory determination of my specimens. These are from the Wabash, and Tennessee; those described by Prof. Agassiz are from the Osage, in Missouri.

This species has the general form of the buffalo fish, but lias not so elevated a dorsal outline. It is therefore, mucl less elevated than the Carpiodes above clescribed. It is especially cliaracterized by the elongate form of the muzzle, in which it exceeds any other species of the geuus. The profile descends obliquely posteriorly from the end of the muzzle to the mouth, and the end of the mandible is but little in advanes of the nares, while the canthus is in line with the anterior limb of the orbit. The lips are weil developed for the genus, and delicately longitudinally plicate. The eye is large, the middle line of the cranium falling within its posterior rim ; in other species it falls posterior to this point. Its cliame ter enters the length of the head 4.5 times, and the interorbital width, twice. Scales $7-40-5$. Pectoral fin barely reaching line of anterior dorsal ray. Caudal furcate lialf its length.

In general proportions this fish is a good cleal like the European carp. The occipital region is elevated and narrowly convex. The long dorsal ray is almost as well developed as in the species of group first, extending 
nearly to the end of the fin in one specimen .75 the distance in another. Color, brownish golden. Length, one foot.

\section{Carpiodes CXPRINUS, Lesueur.}

Catostomus do., Lesueur, Journ. Ac. Nat. Sci. Phil. I, 91, Tab. Carpiodes, Agassiz, 1. c. Günther, Cat. Brit. Mus. VII, 24. Carpiodes vacca, Agass., 1. c.

This is another elongate species with shorter dorsal radii, and rather large scales. In six small specimens there are 7 rows above the lateral line, and in two young and one adult, six. Length of head 35 times in length same and body; eye small, .25 times in interorbital widtl, nearly six times in head in adult of a foot in length, 4.5 times in young of five inches. Muzzle quite prominent, but obtuse. Front scarcely concave between orbits or in front of nasals (thus differing from most of the other species). End of mandible extending beyond line of nares. Lips faintly plicate. Supraoccipital region elevated, little ridged. Anterior dorsal rnys midway between origin of caudal and end of muzzle. Color silvery, dorsal fin black, paired fins white-margined.

Common in the tributaries of the Chesapeake and Potomac, rare in those of the Delaware in Pennsylvania.

C. damalis, Gird., from the Platte R., is very near this species.

Species nova.

Carpiodes nummifer, Cope.

The largest species of the genus, from the Wabash River, Indiana.

The detailed characters have been given in the synopsis of the species. The form is characterized by elongation, and the small proportions of the head. The body is compressed, and the dorsal line elevated to the first dorsal ray, which is considerably nearer the end of the muzzle than the origin of the caudal fin. Its rays are more numerous and the anterior shorter than in any other species here enumerated. The bony ancl first cartilaginous rays are stouter than in any other species, the latter presents no segmentation on the surface for the basal half.

The orbits are more anterior than in other low-finned Carpiodes, the middle line of the cranium falling .25 inch behind the orbit in a specimen of 20 inches lengtlu. Diameter 4.6 in head, nearly twice in interorbital width. Scales 7-36-5. Muzzle short, rather obtuse but projecting much beyond mouth. Symphysis mandibuli extending to nares.

Color of scales an olive silver or nickel color, whence the name nummifer, money-bearer. Sides of head yellow. Length 18 and twenty-four inches at least. Wabash River, Indiana; three specimens.

NOTURUS, Rafinesque.

76. Noturus marginatus, Baird.

From the Catawba and Yadkin rivers. 
AMIURUS, Raf. Gill.

This genus is by far the most numerously represented by species among the Siluroids of the United States. Twenty-five are known to the writer, and several others have been described which are not satisfactorily distinguished. Besides the United States, China is included in the range of the genus. In North America they are a most noticeable feature of the ichthyological fauna of the Eastern Coast Streams, abounding there in individuals and species, far more than in the tributaries of the Mississippi, where Ictalurus is the prevailing form. The tributaries of the Great Lakes furnish another resort for them, and the rivers of Texas, according to Girard, also abound in them. This distribution in relation to Ictalurus is to be found in the fact that they are lovers of mud and sluggish waters, while the latter genus prefers running streams and river's.

The species of Amiurus fall into four sections as follows :

I. Caudal fin rounded or truncate when spread open.

$A$ The anal radii tew, 17-22.

aBody slender, depth 1-8 length.

Anal radii 17 ; eye rather large.

A. PLATYCEPHALUS.

$\alpha \alpha$ Body stouter ; depth 1-5 or less length.

$\beta$ Lower jaw longer than upper.

Anal radii 20, its basis 5.5-6. times in length; head narrowed anteriorly, body not shortened.

A. DEKAYI.

A. 22, head broad, body short.

A. AELURUS.

$\beta \beta$ Upper jaw equal or exceeding lower.

* Anal radii 17.

A. PULLUS.

* Anal radii 19-22.

+ Ventral radii 8.

Head width 4.5 to 4.66 times in length; diameter eye 4.5 times between orbits; depth 3.75 in length, beards rather short, humeral process smooth.

A. NEBULOSLS.

Width head four times in length, depth 3.66 times; eyes 4.5 between orbits ; colors light ; beards as above.

A. Catulus.

Width head 4 times in length; eye 4 ; other characters as above ; colors dark.

A. catulus, val.*

it Ventral radii 7 .

Eye larger, 3.75 times into interorbital width; head narrowed, width 4.66 times in length; black.

A. MISPILLIENSIS.

$A A$ The anal fin longer, the radii 24-8.

To this group belongs A. cupreus, Raf., A. cupreoides, Gird., A. atrarius, DeK., A. catus, Linn, A. nigricans, Les., A. conosus, Rich'n, A. felinus and A. antoniensis of Girard.

II. Caudal fin furcate or strongly emarginate.

$A$ Anal fin with few radii, (19-22).

a Caudal fin merely emarginate.

* I refer a specimen which I took at Poughkeepsie on the Hudion R1ver, tin this species.

A. P. s. - VOL. XI. $-23 \mathrm{E}$ 
Head less than one-fourth length. A. 20 ; eye 4.5 tim 3 between orbits; dorsal nearer adipose fin than muzzle.

A. CONEINIS.

Head as above; orbit 4 times between orbits; A. 23; dorsal nearer muzzle than adipose fin.

A. HOXI.

$\alpha \alpha$ Caudal furcate.

Width of head from 4.6 times in length; eye large, 3 to 5 times in interorbital space; barbels long ; caudal fin deeply forked.

A. LYNX.

Head very wide, width 3.6 times in length; eye six times between orbits, barbels very short, caudal not deeply furcate.

\section{A. A Anal fin large; radii 24-5.}

A. LOPHIUS.

Cauclal emarginate; pectoral spine not denticulate; barbels reaching gill opening; head wide as long.

A. BOREALIS.

Cauclil deeply furcate; head narrow, pectoral spine dentate, barbels to end of humeral process.

A. NIVEIVENTRIS.

Of other species of the genus, I have omitted A. puma Gird. A. natalis Les., and A. felis Agass, all belonging to section I, owing to the imperfections in the descriptions. A. albidus Lesueur, is, I think, founded on adults of A. nebulosus Les. A. obesus Gill of which I have examined numerous specimens from Minnesota, two from the Miami, Ohio, and one from the Kiskiminitas River, in West Pennsylvania, I cannot distinguish from A. catulus Girard (U. S. Pac. R. R. Rept. X). Of species adopted, A. catulus Girard, may be found eventually to be varieties of A. nebulosus. The A. mispilliensis, A. lophius and A. niveiventris, are now described for the first time.

\section{Amiurus Platyceperalus, Girard.}

Proc. Ac. Nat. Sci. Phila. 1859, 160.

This well marked species approaches nearer the genus Hopladelus than any other Amiurus, in its elongate, flattened body and head, and in the large number (11) of its branchiostegal radii. It abounds in the Catawba. and Yadkin Rivers, where it is justly valued as an article of food.

Spec. nov.

\section{Amiurus mispilliensis, Cope.}

This species is related to the common $A$. nebulosus, but has a narrow muzzle, larger eyes and a ventral ray less than any other species of the section. Width of head 4.66 times in length; eye 3.25 times between orbits, maxillary beard extending beyond base of pectoral fins. Pectoral spine dentate, dorsal spine smooth. DI. 6 ; V.1.6 ; A. 21. Above entirely black ; below, white anterior to anal fin. The mental barbels blackish. The maxillary barbels extend to beyond base of pectoral fin, and the mentals to the branchiostegal margin. Entire length 8 in.; depth 1 in. 8 lines.

I took this specimen in the Mispillion Creek, a sluggish stream in the southern part of the State of Delaware. It doubtless occurs in similar streams in "the Peninsula." 


\section{Amurus LynX, * Girard.}

This is a variable species in the size of the orbits and width of the head. In the younger of six inches in length, the diameter of the former is contained in the interorbital space three times; in specimens of 9.5 inches four times; up to this size the width of the head enters the length with. out the caudal 4.5 times. Between this size and eleven inches the width of the head varies from 4.5 to four times; the orbit being one fifth the frontal width in those of larger size. This is the greatest relative width of head I have seen in this species. The upper jaw always projects below the upper, the humeral process is always rugose and swollen proximally, and the maxillary barbels pale edged below.

The younger forms describel, are the Ictalurus kevinskii of Stauffer (Mombert's History of Lancaster County, Pa., 1869, 578). The following description applies to such.

It has the narrow head, large eye and furcate tail of Ictulurus. The dorsal spine is nearly smooth, other rays 6 ; A. 22 ; V. 8 ; C. VI-17-VII. The depth enters the length times. The largest specimen of this species $I$ have seen does not exceed eight inches in length. The color above is a lively brown, sometimes tinged with purple; sides silvery, belly silver white.

The larger form with relatively smaller eye is $I$. macaskeyi, Stauffer, of the same work. The same form I took in the Mispillion Creek, Delaware. It differs from old examples of the $A$. lynx in its more slender form, the width of the head entering the length 4.66 times between orbits; barbels and color as in $A$. lynx. Specimens intermediate in character between this and the wider-headed form served as Girard's types. They were from the Potomac. Two specimens in my possession from that river have the with head 4.25 times in length, eye $4-4.5$ times between orbits; long maxillary; short mental barbels; dorsal nearly equidistant between muzzle and adipose; humeral process swollen, rugose.

One specimen from the Susquehanna exhibits the width of the head one-fourth the length, as above mentioned. This renders the distinction of Girard's $A$, vulpeculus, questionable, since the only essential characters he mentions are the following :

Head 4 times; orbit $\frac{1}{4}$; caudal 6.5 times in length, dorsal nearer muzzle than adipose fin.

I have seen many specimens of this cat-fish from the Conestoga Creek, from the Susquehanna, and from the Delaware, in Pennsylvania.

Some specimens which I obtained at Newberne, on the Neuse River, were lost, but I surpect them to have been this species. As it is common in the James River, it probably occurs also in the Roanoke.

\section{Species nova.}

\section{Amiurus lophius, Cope.}

This, perhaps the largest species of the genus, is distinguished by the

* In Origin of Genera, 43, I state that the Gronias nigrilabris Cope resembles the Amiurus lynx most closely among the Amiuri. This is an error; the comparison should be made with A. nebulo"us, from which the form of the anal fin, short burbels, etc. distinguish it. 
greater width of its head, and the gape of the mouth, together with the decided but shallow furcation of the caudal fin. The barbels are considerably shorter than in any other species of the fork-tailed section.

Head and dorsal region very flat, the width of the former contained $\mathbf{3 . 5}$ times in the length of the body and head, and the length of the same entering the same three times. The depth at the first dorsal ray, enters the same 5.4 times. That ray is exactly intermediate between the end of the muzzle and the posterior margin of the base of the adipose, having thus a more posterior position than in A. lynx, where it measures the middle of a line terminating at the anterior base of that fin. The free extremity of the adipose is in line with the same of the anal. Radii D I.6; A. II. 19 ; V. 8. The eye is small, its long diameter entering the length of the head, measured on the middle line above, seven times, and six times in interorbital space. Pectoral spine weakly; dorsal not, serrate. Humeral process strongly rugose to near extremity.

Maxillary barbel reaching two-thirds to three-fourths the distance from its base to the upper part of the branchial slit, the outer only half way to the branchiostegal margin, the inner three-fourths the length of the outer. The extremity of the muzzle is regularly rounded, the upper jaw projecting a little beyond the upper. Branchiostegal rays nine. Total length eighteen inches; length dorsal spine 18 lin.; do. pectoral spine 18 lin.; do. basis of anal 35 lin.; width of head 531.

Color above brown; lower surfaces, including lower lip, (yellow or) white in alcohol; mental beards white.

This species is nearest the A. lynx, Girard, which inhabits the same rivers, but is readily distinguisbed as above pointed out, and in addition by the shorter barbels and lower body. In the width of its gape it exceeds any other North American cat-fish, and will allow of a remote comparison. with Lophius in this respect.

I obtained three specimens in the Washington, D. C., market, which came from the lower course of the Potomac river. It occurs in the other tributaries of the Chesapeake Bay, and I think I have seen it in the market of Baltimore. I have not yet observed it in Philaclelphia. In the former cities it is deservedly esteemed for the table, and is more valuable than the $A$. bynx and $A$. nebulosus, on aecount of its superior size.

The last named fish is sold in Philadelphia and neighborhood. It often attains a foot in length. I cannot distinguish the Pim. albidus, Lesueur. Pale and piebald varieties of the fish occur.

Spec. nov.

\section{Amiurus niverventris, Cope.}

This fish presents a great contrast to the last, resembling in fact the Ictalurus corulescens, Raf., in its slender proportions.

Width of head 4.75 times in length, exclusive of caudal fin. Orbit nearly four times into interorbital width. Depth 5.22 in length as above. Dorsal spine three inches from end muzzle, 3.5 inches from origin adipose fin ; its posterior margin with a concealed serration. Pectoral spine strongly 
serrate. Radii D I. 6 ; A. 24 ; V. 8 . Maxillary barbel to near end of humeral process ; latter very rugose to near extremity. Outer mental barbel to branchiostegal margin. $\mathrm{Br}$. rays ix.

Color above blackish, sides silvery leaden bluc; below, including margin of upper lip and outer margin of maxillary barbels, pure white. Fins edged with dusky. Length of specimens 8.5 inches.

From the Neuse River, N. Ca.

In this species, as in all the fork-tailed Amiuri here described, the lower lobe of the caudal fin is wider than the superior. The young of these species, at least in and $A$. lynx, are much more silvery than the adult, as is the case with some of the Ictaluri.

In concluding my observations on this genus, I may add that I took A. cupreus in the Clinch River, in Tennessee.

\section{Gill emend.}

\section{ICTALURÜS, Raf.}

\section{Ictalurus coerulescens, Raf.}

This species abounds in the French Broad and other tributaries of the Tennessee, as it does in those of the Ohio. It is everywhere much used as food, though in my estimation inferior to the large Amiuri of the East, for though the flesh is whiter, it is drier.

\section{SALMO, Linn.}

\section{Salmo fontinalis, Mitch.}

This species is found in the rapid streams in which the tributaries of the Tennessee and Catawba Rivers head, in the highest tracts of the Allegheny Mountain Region. I only took them in one of the heads of the French Broad, where the size was much inferior to that of trout from similar localities in Pennsylvania. The experience of other fishermen in this respect was similar to my own. According to Dr. Hardy, a naturalist long resident in Asheville, well known to the old generation of students South and North, this fish occurs in the headwaters of the Chattahoochee, on the south slope of the Alleghenies, in Georgia. This is the first authentic instance of its occurrence in any water flowing directly into the Gulf of Mexico, with which I have met. From the habits of the spe. cies it is hardly to be looked for in any other of the Gulf streams eastward of the Mississippi. According to Dr. Peck, of Mossy Creek, Tennessee. it is not found in the Cumberland Mountains. I did not find it there in the heads of the Cumberland or Clinch.

\section{OSMERUS, Artedi.}

Although I am not informed as to the occurrence of any species of this genus on the coast or in the rivers of North Carolina, I introduce it here for the purpose of illustrating some species which have been placed in my hands by my friend, Dr. Chas. C. Abbott, of Trenton, N. J. These were procured and forwarded to him at his request, by Chas. G. Atkins, the efficient Commissioner of Fisheries of the State of Maine, whose authority 
is here given for the notes on their habits and places of abode, appended. Interest attaches to the fact that the greater part of the fishes are derived from the fresh waters of that State, and that species of this genus, like those of the other Salmonoid genera, Coregonus and Salwo, are proven to have a lacustrine distribution in the northern part of the United States.

Land-locked Osmeri occur in the lakes of Norway. According to Professor Esmark of Christiana, they are found in Lake Mjosen, which is 500 feet above the sea, and discharges into it by a stream which has a very high fall; also in Nors Vandsjö, near the town of Moss, and in the Stinksild.

I find three species among our lake smelt, as follows :

Eye large, one-third length of head; head short, 4.25 times in length; scales, 1. long. 66 ; 1. transv. 10.

o. SPECTRUM.

Eye smaller, 4.5 times in head; head shorter, 4.75 in total; scales smaller, 1. long. 68 ; 1. transv. 16.

o. AтBOTTII.

Eye 4-4.25; head 4, longer ; scales, 1. long. 65-7; 1. transv. 13 (14).

o. VIRIDESCENS.

\section{Osmerus spectrum, Cope.}

Species nova; smelt of Wilton.

Established on two specimens sent from the above locality in Franklin Co., Maine. Form slender, the head short, with remarkably large eye, and short mouth and maxillary bones. Mandible prominent when closed, as in $O$. viridescens, the end of the maxillary bone not extending beyond the line of the middle of the pupil. Both the length of the muzzle and the interorbital width are consiclerably less than the diameter of the orbit. The form of the body is more slender than in the 0 . viridescens, the depth entering the length without caudal fin, 8.33 times. Radii D. 10 A. 1.15. V. 8. The pectorals extend $\frac{3}{5}$ the clistance to the base of the ventrals. Length of a medium sized specimen, 3 in. 6 lin. Scales in about as many transterse, but several fewer longitudinal series than in the other species.

Color probably translucent in life, a silver band along the upper part of the sides. Side of head and operculum silver. Top of head, middle dorsal line and caudal fin so thickly punctate with black as to be colored.

Wilton Pond is near the head of the south-west branch of the Kennebec River in S. W. Maine. The characteristics of this species, according to Commissioner Atkins, are seen in specimens of larger size than those here described, which were taken in breeding condition.

\section{Species nov".}

\section{Osmerus abbottii, Cope.}

This fish is in general characters more like the $O$. viridescens than the last; it is similar in the size of the orbit and posterior prolongation of the maxillary bone, but the scales are more numerous and the head is shorter. Like the last, it is considerably smaller than the common smelt.

The depth enters the length without caudal fin, seven times; the head the same, 4.75 times. The orbit is less than the length of the muzzle, and scarcely equal to the interorbital width. The maxillary is delicately 
toothed, and reaches the line of the posterior margin of the pupil. The pectoral measures half the distance to the base of the ventral. There are five specimeas of this fish, which measure about four inches in length, and they are stated in the accompanying notes to be of medium size. The colors, like those of $O$. spectrum, are darker than those of $O$. viridescens, in spirits. The median line above is dusted with black, and the lateral scales, in several specimens, bordered with the same. Fins blackish, especially the base of the caudal. From Cobessicontic Lake, in Kennebec Co., in Southwest Maine.

According to Commissioner Atkins, this species spawns immediately after the ice disappears, and instead of runuing into swift brooks, like the varieties of 0 . viridescens, hereinafter described, lays its eggs on the borders of meadows. The specimens described were taken in breeding. condition at the breeding season.

As I owe the opportunity of describing these interesting Osmeri to my friend Dr. C. C. Abbott, I dedicate the present species to him.

\section{Osmerus viridescens, Mitchill.}

Osmerus sergeanti, Norris. Proceed. Acad. Nat. Sci. Phila., 1868, 93 ; loc. cit., 1861, March.

Two localities furnish specimens of land locked smelt, which I can only distinguish from those of salt water by color. The first from. Lake Messalonskee, Kennebec Co., have a yellowish color on the sides, and black dorsal line, top of head, chin, and edges of lateral scales, The specimen is 14 inches long, said to be of medium size, therefore exceeding the average of the $O$. viridescens seen in Philadelphia market, and considerably larger than the $O$. abbotti and $O$. spectrum. They are called the Belgrade smelt.

Commissioner Atkins states that between the 10th and 20th of April, while the lakes are still covered with ice, this fish runs up into the brooks and lays its eggs by night, the eggs adhering to grass and stones. The spawning is complete always before the ice breaks up in the lakes. The temperature of the brooks is from $32{ }^{\circ}$ to $400 \mathrm{Fahr}$.

The second locality is Cochnewagn Pond, Kenuebec Co. Specimens of "medium size" are smaller than the sea smelt from the mouth of the Kennebec, and larger than those of $O$. abbottii. They are generally similar to the last variety. These the notes state, breed later by 25 days than the last; that is 12 or 15 days after the ice disappears, the temperature of the water being $43^{\circ}$ to $45^{\circ}$.

The breeding season of the $O$. abbottii intervenes between those of the above varieties.

Commissioner Atkins says that the majority of the lakes of Maine contain smelt of some kind, and that he frequently finds smelt in the stomachs of trout from these lakes.

ANGUILLA, L.

Species not identified, very abundant in all the Atlantic waters of North Carolina (82). 


\section{GANOIDEA.}

Lepidostens osseus, L., occurs in the Yadkin and other eastern rivers of the State, and probably L. huronensis in the French Broad, as I have specimens of it from near Dandridge, E. Tennessee. Polyodon folium (Spatudaria) ascends the same river to near Aslieville, N. Ca. Various species of Accipenser abound in the Atlantic rivers, while descriptions of a fish called "Black fish" or "Brindle fish," found in the Neuse River, induce me to believe that $A$ mia occurs there (83-7).

\section{ON THE GEOGRAPHICAL DISTRIBUTION.}

The table appended, shows readily the characteristics of the faunæ of the four rivers of the State examined, though many species are no doubt omitted from each, certainly nearly all the larger ones, which I had not facilities for procuring.

The differences between the ichthyologies of the streams on opposite sides of the Allegheny shed, are rather greater in this State than in Virginia; the mountains here constituting a much more important topographical feature, both as to elevation and number of ranges.

The following points distinguish the two kinds of waters:

The western presents greater abundance of Percoids allied to Etheostoma, of Uranidea, and is the exclusive range of Ambloplites, Micropterus fasciatus, and Polyodon.

On the East, the Catawba and Yadkin are peculiar in their poverty in Etheostomine Perch, and the absence of the forms just named, while the extraordinary development of Catostomidæ, and abundance of Auniurus, Anguilla, and Esox, strike at once the naturalist who travels and collects from one to the other. The Neuse adds to these peculiarities a greater affinity to the more northern streams of Maryland and New Jersey, in the occurrence of Enneacanthus, Aphredodirus, Moxostoma, and Hybopsis amarus. Its pike and Centrarchus are of the South Carolina type.

After a similar investigation of the rivers heading on opposite sicles of the Alleghenies of S. W. Virginia, I came to the following conclusions :

I. That after deducting species generally distributed, certain remain which occur in streams separated by high ranges of mountains.

II. That the distribution of species is not regulated by community or difference of outlet, rivers having diverse discharges having sometimes more in common than those having the same destination.

As regards the first, the present investigations are confirmatory While nearly all the Percidæ, Cyprinidæ, and Catostomidæ, and all the Siluridæ of the French Broad River, differ from those of the East, we have the following common to both sides of the range:

Pœcilichthys flabellatus.

Micropterus nigricans.

Photogenis leucops.

Compostoma anomalum ;

All species of pretty wide distribution. A peculiarity of distribution is 
the occurrence of the Photogenis leucops, confined in Pennsylvania to the heads of the Ohio, and in Virginia to the Kanawha, not only in the Catawba, but in the Neuse. In further illustration, I append a list of species from the South Fork of the Cumberland, in the Cumberland Mountain region, near Kentucky.

Micropterus fasciatus.

Ambloplites rupestris.

Lepomis nitidus.

Percina caprodes.

Etheostoma blennioides.

Pocilichthys coeruleus.

" camurus.

" sanguifluus.

Hyostoma cymatogrammum.

" simoterum.

Ptychostomus erythrurus.

Catostomus nigricans.
Semotilus corporalis.

Ceratichthys biguttatus.

Hypsilepis cocogenis.

“ galacturus.

" ardens.

Alburnellus micropteryx.

Hybopsis longiceps.

Photogenis telescopus.

Campostoma anomalum.

Although separated from the waters of the French Broad by the highest ranges of the Cumberland Mountains, and flowing to the North, while the former flow to the South, there is no important difference between their fish inhabitants observable. The difference as compared with the case of the Catawba River, has reference in part to the difference in ele. vation of the mountain ranges separating them. Those of North Carolina rise to $6740 \mathrm{feet}$, while according to Prof. Safford, the highest point of the Cumberland is only 3000 feet.

Two curious points in the above list may be observed, viz.: the occurrence of Hypsilepis ardens, and Hybopsis longiceps; species which I only found in the James and Roanoke in Virginia, and not in the Western waters, and which, while they occur in the Cumberland (the $甘$. longiceps in the Clinch also) I did not find in the State of North Carolina!

Mimetic Analogy. A curious case of this occurred to me in three species of fishes which I took in a small tributary of the Yadkin River, in Roalle Co., N. Ca. Among several others there were varieties of the widely distributed species, Chænobryttus gillii, Hypsilepis analostanus, ancl Ptychostomus pidiensis, (each representing a different family) which cliffer from the typical form of each in the same manner, viz. : in having the back and upper part of the sides with longitudiual black lines, produced by a line along the middle of each scale. This peculiarity $I$ have not observed in these species from any other locality. Until I had examined them I thought them new species.

The only other species presenting such marking in the Yadkin River, is the large perch, the Roccus lineatus. According to the theory of Natural Selection, a resemblance to this well-armed species might be of advantage to the much weaker species in question, yet the same species co-exist in other rivers without presenting the same mimicry.

A. P. S.-VOL. XI. -34 E. 

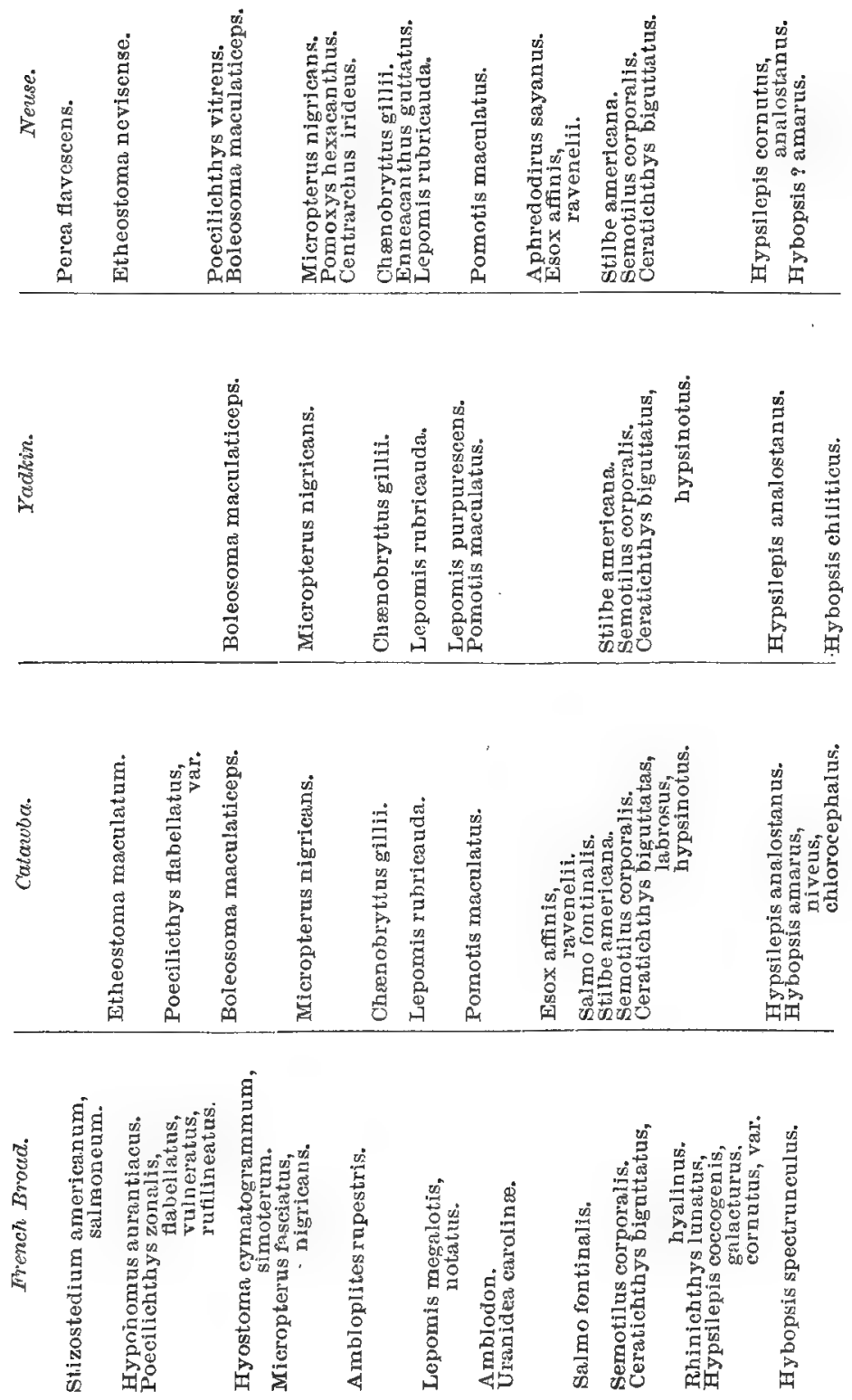

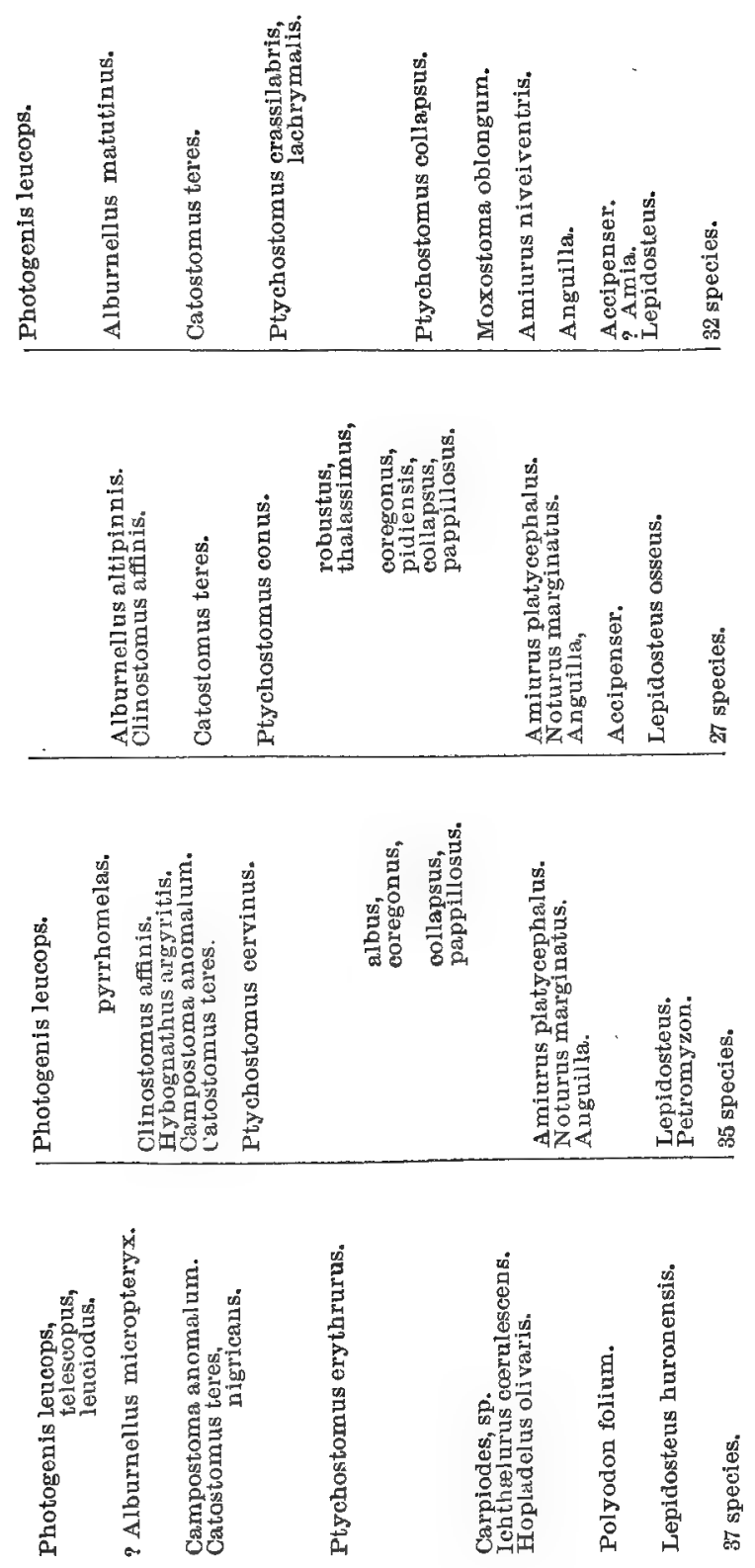


\section{NOTES TO SECOND EDITION.}

Pacitichthys vitreus, p. 449. This is probably a species of Pleurotepis, as given by Prof. Jordan in his catalogue of the Fresh Water Fishes of North America. See Proceed. Buffalo Society Nat. Hist., 1877, p. 一.

Ceratichthys hyalinus Cope. p.459. This species is regarded by Prof. Jordan as the Rutilus amblops of Rafinesque. I have another species taken from the Ohio at Louisville, Kentucky, the original locality of Rafinesque, which I have supposed to be the $C .(R$.) amblops, which is readily distinguished from the C. hyalinus.

Placopharynx carinatus Cope, p. 467. This species Prof. Jordan informs me is not rare in the Wabash River, and he has also found it in the Scioto River, Ohio.

Ptychostomus Agass., p. 468. The name Morostoma Raf. must be employed for this genus as has been shown by Prof. Jordan, and Teretulus must be used for that called Moxostoma by Agassiz, and Erimyzon by Jordan.

Carpiodes grayi Cope, p. 482. The habitat of this species was ascertained by Dr. Yarrow, of the Wheeler Engineer Survey, to be the Rio Grande, New Mexico.

Carpiodes carpio Raf. Carpiodes nummifer Cope, p. 484, is believed by Prof. Jordan (Manual Vertebrata N. E. U. S.) to have been originally described by Rafinesque under the above name. 



\title{
Notes and Descriptions of Foreign Reptiles.
}

\author{
BY E. D. CODE.
}

TESTUDINAT.A.

The following species of Tortoises were brought by Mr. P. B. Duchaillu from equatorial West Africa, the present Autumn.

Kinixys erosa Gray. This curious species appears to be abundant through out Gaboon, and the country of the Camma and Ogobai. Its range northward extends as far as the Gambia.

Sternothærus Derbian us Gray. Length, including head and neck, 14 in. 8 lin.; length of plastron, 6 in. 6 lin.; greatest breadth of do., 5 in.; breadth of head just before the tympani, 2 in. 5 lin.

Inbabits swamps in the Camma country.

This is probably the above named species, but judging from figures and descriptions, it approaches closely the S. s in u at u s Smith, of South Africa, differing mainly in the form of the upper mandible, which is obtusely hooked in the former, bidentate in the latter. The habits of the two appear to differ; the S. African species inhabiting deep rivers, and remaining long at a time beneath the surface. It is considered by Dr. Gray (Catalogue Brit. Mus.) as identical with the S. castane a s Bell, but there is a manifest discrepancy between Smith's description, and the brief one of castaneus in the "Catalogue,"-principally with regard to the form of the vertebral scuta. The resemblance to the $\mathrm{S}$. De rbia $\mathrm{n}$ us is much closer, but judging as before, it is our impression that it is distinct from both.

\section{HhPTATHYRa nob.}

Cartilaginous border obsolete at the sides of the disc, and destitute of ossicles posteriorly. Sternum with two cartilaginous flaps, which cover the posterior extremities when retracted. Sternal callosities seven; one on each side corresponding to the closely connected hyo- and byposternals, one to each of the 
epi- and xiphisternals, and one to the discoid entosternal. Hyo- and hyposternals united to the disc by suture, and separated from the episternals by a large cartilaginous interval. Head acute, parietal region depressed, frontal slightly arched. Nostrils not subdivided by a transverse process of the septum. Lips greatly dereloped, forming biangular flaps on each side of the mouth.

Heptathyra A ub r y i. Cryptopus Aubryi Dumeril. Revue et Magasin de Zoologie; 1856, page 364 .

Total length 2 feet, 6 in.; of sternum 15 in. 6 lin.; of head and neck 11 inches Numerous specimens from the Fernando Vas river, Equatorial W. Africa.

The Dogania s u blana of India doubtless exbibits the extreme of the Trionychoid modification of the Chelonian type, in the tardiness of the only partial union of the ribs into a carapacial disc, and the imperfect development of the sternal bonts. There are but two callosities. Aspidonectes exhibits a superior grade of organization. The union of the ribs is more complete, a comparatively small part of their extremities extending beyond the disc in adult age. The sternal bones are better developed, especially the hyohypo- and xiphisternals. There are four external callosities.

Those species which agree in possessing cartilagioous flaps upon the posterior lobe of the sternum, are included by H. Dumeril in the single genus Cryptopus; but in some respects they are strikingly dissimilar. T. p u n tatus and T. Se n egalens is are very interesting, as possessing in the fiee marginal ossicles the analogues of the marginal bones so universal among higher Chelonians. This far from unimportant peculiarity is wanting in the T. freat a s and $\mathrm{P}$ e tersii; while the alditional character of every sternal bone being protected by a correspondit.g exiernal callosity (their number thus amounting to nine), proves the propriety of the generic name $\mathrm{C}$ y cloderma assigned by M. Peters. T. A ubry i, it is seen, agrees with the last in the absence of ossicles, but maiutains the more typicaI Trionychoid peculiarity of one undivided callusity covering the hyo- and hyposternal bones. The extent of the union of these, (bsemapophyses,) with the disc, (pleurapaphyses,) without lateral cartilaginous or osseous "appendage," offers as good an example of a normal "hamal arch" as is to be fuund in the order.

The object of generic nomenclature being, as we understand it, to indicate the modifications of Nature's types and the sensible steps by which they approach each other, to ignore any such step appears to us unphilosophical. Hence we ven'ure to propose for the species under consideration the generic appellation of Heptuthyra.

Aspidonectes as pilus nob.-Head acute, plane, not sloping as in Platypeltis. Lips thin, not developed into flaps. Septum of the nasal orifice with a short process on each side. Ribs eight pairs, projecting in the adult about two inches beyond the disc. Disc subeircular, broadly truncate behind, vermiculately rugose. Vermiculations transwerse alnng the sutures of the costal plates, longitudinal between. Vertebral line slightly depressed. Cartilaginous border extending two inches beyond the edge of the anterior sternal callosity, and 9 in. 10 lin. from the posterior margin of the disc, to within 3 in. 6 lin. of the end of the tail. Sternal callosities four. The posterior subtriangular, auterior and posterior angles divergent, the inner almost in contact. Anterior angle with an emargination corresponding to an angular process in the posterior border of the hyposternal. The interior and exterior borders of the anterior callosity made nearly right angles with its auterior edge. This is not pertectly transverse, so that the inner borders approach to within 1 in. 11 lin. of each oth $r$, they then round off and extend much father posteriorly than the external borders. Episterubl bones small, cuasiderably separated, direrging anteriorly. Claws nearly straight, compressed, sharp at their inner edges, dirty white. Diwc brown, vermiculations shaded with yellow. Border, extremities, neck and heal dirk browu, wathout spots or markings of any kind. Sternal callosities whutish.

1859.] 
Length of disc 17 in.; of head and neck 19 in. 6 lin.; total, four feet. Length of sternum $20 \mathrm{in} .6$ lin.

Irabitat.-The Rembo and Ovenga rivers, tributaries of the Fernando Vas, Equatorial West Africa.

Nothaving at hand specimens of the Aspidonectes n i lotic us of W. and S. Africa, we bave been unable to compare the only specimen of the a silu s with it; their differences are, however, sufficiently obvious. In the latter the sternal callosities are much smaller, and the anterior pair have their anterior and posterior borders nearly parallel, and the outline of the inner semicircular. The tail is shorter, and the colors are brownish green with white and yellow spots.

The old World Aspidonectes possess eight pairs of ribs; we do not know how it is with the American species, as there are no autbentic specimens in the Acad. mus., but our Amyda and Glatypeltis have but 7 pairs.

\section{EMYDOSAURIA.}

Crocodilus marginatus Geoffr.-Brought by Mr. Duchaillu, from the Ogobai. This species is principally abnudant in the Cape colony, but is found in other parts of Africa.

\section{OPHIDIA. \\ COLUBRIDAL-CALAIIRIN.E.}

\section{Olisthenes nob.}

Head scarcely distinct from the body, depressed, especially in front. Muzzle elliptical in outline, projecting much beyond the under jaw, as does also the superior labial region. At the posterior extremity of the superior maxillary bone are two curved teeth, larger than the other maxilluries, separnted from them by an edentulous space, and grooved in front. Ceplalic shields normnl. Vertical broad; loral small. Rostral prominent, broad, dividiug the anterior frontals somewbat; not recurved. Preocular 1, postoculars 2. Urosteges and anal shield entire. Scales very smooth.

o. e upha eus nob.-Scales subequally hexagonal on the flanks, more elongate on the back, very little imbricate; ia nineteen rows. The rows diminish in number upon the tail, by two or more running together upon the dorsal region, thus forming short series of from four to six scales twice or thrice the usual width. Vertical plate broad, hexagonal, the anterior angle very obtuse, the posterior acute, dividing the accipitals. Superciliaries rather small, broader hehind in consequence of the convergence of the sides of the vertical. Posterior frontals large, extending on the side of the head half way along the preocular. Anterior frontals rather small. Nostril between two nasals; the anterior large, separating the rostral and first labial, and nearly reacbing the edge of the mouth. Rostral broad, triangular, depressed, sligbtly dividing the anterior frontals. Postoculars two. Superior labials eight, the first three small, the eye resting on the fourth and fifth. Pupil erect, elliptical. Inferior labials eight, the fourth largest, and in contact with the posterior geneials, of which there are two pairs.

Gastrosteges 205, anal 1, urosteges 75 .

Color uniform brown, dark on the head and anterior part of the body, lighter posteriorly, and pale beneath.

Length 2 ft. 9 in. 6 lin. Tail 17 in. 6 lin.

Had Dr. Güntber placed bis Hologerrhum $\mathrm{ph}$ il ip p in u m among the Calumarinæ, instead of Scytalian Colubridæ, we should have felt well satisfied in recording this as a second species of that genus; we are not positive indeed, that it Inay not yet be so considered; hut with our present k. owledge we must distinguish it generically. The bead of this serpent is very Calamarian in its indistinctness from the body, its depression and projecting rostral. Besides these, a brouder vertical and more distiuclls divided rostrals distinguish it from Hologerrhum. 
R h i nosim u s ( $D$. and $B$.) placed by Günther among the Calamarinæ, differs only in the keeled, recurved rostral, and $\mathrm{R} h$ i nosto $\mathrm{m}$ a Fitz, the unly other genus with grooved maxillaries, has the recurved rostral, with divided urosteges.

The form and glossy smoothness of the Olisthenes e u p a e u admirably adupt it for making its way among pieces of bark, decayed logs, and other debris of the forest. Its native country is unknown to us, but, as it was obtained in a jar containing a specimen of the species below mentioned, it probably came from South America.

\section{CORONELLIN EA.}

Liophis vittatus. Coluber vittatus Hallowell, Proceed. Acad. Nat. Sci., Vol. ii. p. 242. The serpent deseribed as above, from specimens brought by Mr. Ashmead from Venezuela is a true Liophis, resembling the L. reg in tæa iurus, and conirostris, but withont the transverse markings of the first and second, and the peculiar plating of the last. There are numerous specimens in the Acad. Mus. It does not appear to be known to Ruropean berpetologists. 



ONT TEY

\title{
BRAIN OF PROCAMELUS OCCIDENTALIS.
}

\author{
BY E. D. COPE.
}

(Read before the American Philosophical Society, May 4, 1877.) 

On the Brain of Procamelus Occidentalis.

\author{
BY E. D. CoPE.
}

(Read before the American Philosophical Society, May 4, 187\%.)

I obtained a complete cast of the cranial chamber of the Procamelus oritlentalis, which bears a fair proportion to the general dimensions of the skull. As compared with a llama of about the same size, the facial por. tion of the skull is longer, while the postorbital portion is as long, but narrower. This is indicated by the following measurements :

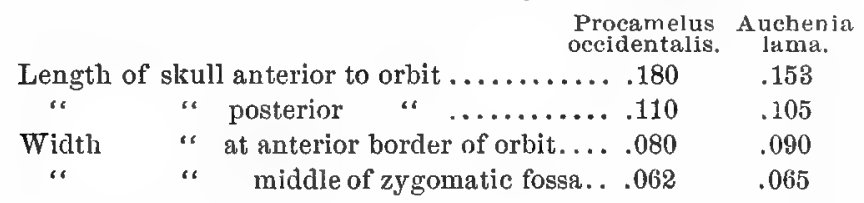

The olfactory lobes of the brain have nearly the same position in the two species, extending anteriorly to opposite the middle of the orbits.

The brain exhibits large cerebellum and hemispheres, and rather small olfactory lobes. The cerebellum is entirely uncovered by the hemispheres but is in contact with them. The lateral lobes and vermis are well developed. The hemispheres are well convoluted, the longitudinal posterior convolutions giving way anteriorly to lobulate ones. The sylvian fissure is well marked. The sides of the medulla oblongata are compressed and vertical at the pons, in correspondence with the vertical position of the petrous bones. The origins of the ophthalmic and maxillary branches of the trigeminus nerve are not divided by a septum, while that of the man-

PROC. AMER, PHILOS. SOC. XVIr. 100, G 
dibulal branch is quite distinct from the others. The optic nerves are large. The olfactory lobes are separated by a deep tissure helow the extremity of the hemispheres; they project freely beyond the latter, being separaled by a deep fissure. Their free portions are short, truncate and compressed. The anterior pyramids are not preserved on the inferior face of the cast of the medulla oblongata. The hippocampal lobes are subround and protuberant.

From the detailed description following, it may be derived, that while the arrangement of the convolutions of the anterior lobes of the hemispheres is more simple than in any recent Ruminant, that of the middle and posterior lobes is esseutially similar to that characteristic of the latter order of Mammalia.*

The brain displays the characters of the older types of Ruminantirt, although not materially smaller than that of the llama, an animal which it equaled in general proportions. The hemispheres are, however, not proluced so far posteriorly in the Procumelus as in the Auchenia, reaching only to the line of the meatus auditorius externus in the former.

The vurmis of the cerebellum rises abruptly from the medulla, having a nearly vertical direction to a point a little lower than the superior plane of the hemispheres. The lateral lobes extend on each side of it, each one having a rather greater width that the vermis. Their posterior faces are sub-vertical, and are directed slightly forwards. Each projects laterally into an apex at the middle of its elevation, and then contracts downwards into the angular line which marks the posterior border of the petrous bone. From a point between each apex and the vermis a ridge rises obliquely inwards to the superior plane of the cerebellum, where each one enlarges and joins the median transverse line. The angle ahove described as descending from the lateral apex of the cerebellum curves forwards, forming a lateral angular border of the pons varolii on each side. The flat space enclosed between this line and the posterior borler of the hemisphere is interrupted by two prominent tuberosities. The superior is small, sub-oval, and is near to the posterior border of the hemisphere. The other is a short prominent ridge directed downwards and forwards, just behind the lobus hippocampi. Its inferior end corresponds with the origin of the mandibular branch of the trigeminus, and perhaps the facial nerve.

The medulla oblongata is contracted at the foramen magnum, and has a sub-round section slightly flattened below. Its inferior face is then rounded, then flattened, and then concave between the anterior part of the lateral ridges. The bases of the maxillary branches of the trigeminus nerves are stout, and directly in line with the origins of the mandibulars. Between them the base of the brain is concave, and the optic nerves issue but a little distance in front of them. The lobi hippocampi are sub-round and rather prominent; they are terminated in front at the foramen sphenoorbitale by the contraction of the cranial walls. Their surface clisplays

\footnotetext{
* See Paul Gervais' Journal de Zoblogie, I, 1872, p. 4.59.
} 
slightly defined convolutions, the best marked being inferior and subround in form.

The cerebral hemispheres, viewed from above, have an oval outline, and are rather narrower anteriorly than posteriorly. They contract posteriorly from the sylvian convolution. The profile descends gradually to the olfactory lobes. The superior surface is little convex in the transverse direction. The fissure of Silvius is nearly vertical in position, and its superior extremity is visible from above. A strongly marked fissure extends posteriorly from it, defining the lobus hippocampi above. The sylvian convolution the thickest of all, and its outer border is emarginate in front and behind; below the postero-superior emargination it is thickest and most protuberant. Between it and the position of the falx there are three longitudinal convolutions, the external, the median, and the internal. These are slightly divergent posteriorly, but the posterior extremities of those of one side tend to unite on the posterior border of the hemisphere. Their surfaces are smooth. The external is widest medially; and it terminates anteriorly just behind the apex ef the sylvian convolution. The internal is double prsteriorly; the median is simple, and unites with the internal above the apex of the sylvian convolution. The two conjoined continue for a short distance and terminate in a broad tuberosity. Below the external convolution on the side of the posterior part of the hemisplere there are four snall longitudinal convolutions. The orbital portion of the hemispheres is extensive, and nearly smooth from the olfactory lobes to the supraorbital border. This is not prominent, but is represented by a short longitudinal ridge. Above each of these, on the superior or front aspect of the hemispheres, is a massive convolution bent crescent-shaped, with the convexity inwards. The posterior part of the convolution is a sub-round tuberosity which stands opposite to. and in front of, the furrow separating the sylvian and median convolutions. The middle part of the crescent is less prominent, but the anterior extremity forms another tuberosity whose long axis is clirected downwards and outwards. The crescentic convolution of the one side is separated from that of the other by at wide, shallow, median longitudinal groove, which extends transversely at the posterior tuberosities. The two tuberosities and the olfactory lobes form three descending steps.

As compared with the brains of the existing Bovidre that of the Procamelus differs in the forms of the cerebellum and medulla oblongata as already pointed out. The hemispheres differ in being shorter behind and more depressed in front. The convolutions of the posterior region are the same in number as in the sheep, but are less undulating in their outlines; but there is a marked difference in the anterior convolutions. The median convolutions do not, as in the sheep, extend to the extremity of the anterior lobe, but terminate above the sylvian fissure, so that there only remain in front of them the two large supraorbital convolutions, instead of the four common to existing Bowidas and Cervidce* In this respect it more nearly

* See Leuret et Gratiolet Anatomie comparée du Systeme Nerveux, 1839-57, Atlas, pls. vii-x. 
resembles Oreodon, but in this genus the internal convolution is continuous with the supraorbital.*

\section{Explanation of Plate.}

Brain of Procamelus accidentalis from a cast, two-thirds the natural size. Fig. 1. View of the left side.

Fig. 2. View of the superior surface.

Fig. 3. View of the inferior surface.

Leidy, Extinct Fauna, Dak, and Nebraska, pl. xiv. figr. 11.

Published June 15, 1877. 

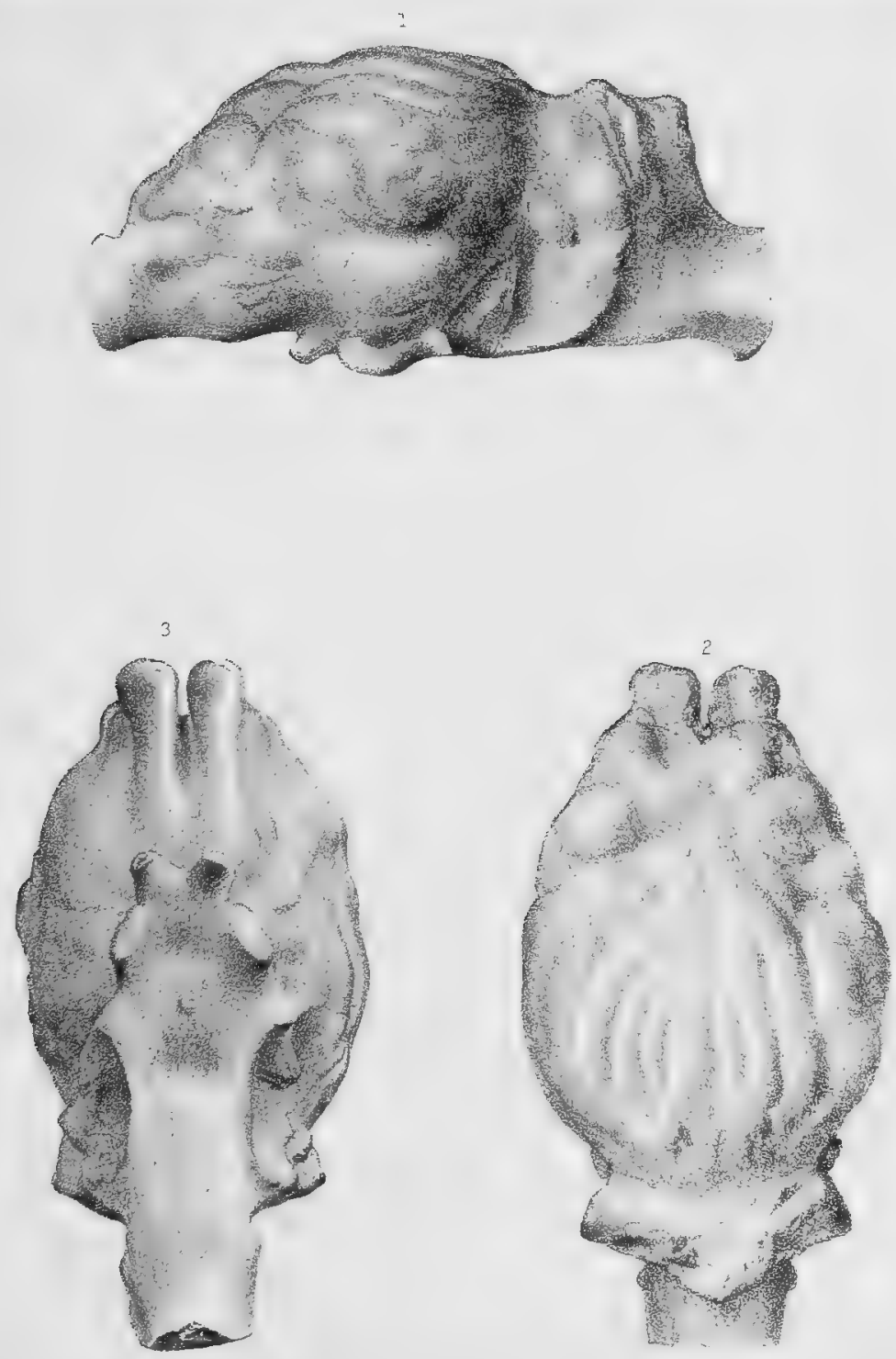

Procamelus occidentalis $2 / 3$. 



DEPARTMENT OF THE INTERIOR. UNITED STATES GEOLOGICAL AND GEOGRAPHICAL SURVEY. F. V. HAYDEN, U. S. Geologist-in-Charge.

\section{XXXIII.-ON A CARNIVOROUS DINOSAURIAN FROM THE} DAKKO'A BEDS OF'COLORADO.

XXXIV.-A CON'TRIBUTION TO THE KNOWLEDGE OF THE ICHTHYOLOGICAL FAUNA OP THE GREEN RIVER SHALES. XXXV.-ON THE GENUS ERISICHTHE:

$\mathbf{B Y}$

E. D. COPE.

EXTRACTED FROM THE BULLETIN OF THE SURVEY, VOL. III, NO. 4. 



\section{ART. XXXIII.-ON A CARNIVOROUS DINOSAURI AN FROM THE DAKOTA BEDS OF COLORADO.}

By E. D. Cope.

The vertebrate fauna of the Dakota epoch of the regions west of the Mississippi having been heretofore unk now $\mathrm{n}$, it is satisfactory to be able to state that I have recently received, from a new locality, evidence of the existence of some colossal species of Dinosauria during this period. This is derived from a skeleton discovered near to the town of Canyon Cit5, on the Arkansas River, near the point where the latter issues from - the cañon through the Greenhorn Range of the Rocky Mountains.

At present, I only describe a portion of the right dentary bone, which supports eight teeth, and contains a cavity at the anterior extremity, from which one tooth was probably shed. The deutition is of the carnivorous type, and does not differ from that of the species of the genus Lolaps, to which have been referred numerous species from Cretaceous Nos. 5 and 6. The crowns exhibit the gradual modification of form in the succession from rear to front which I have already described in the Lclaps incrassatus.* There are subordinate characters.exhibited by the present animal which show that it is quite distinct from ans of the species heretofore known.

Five successional and two functional teeth exhibit crowns complete, or nearly so. The posterior exhibit a nearly straight posterior edge and an anterior one curved backward to a subacute erect apex. Both are denticulated, but the denticles of the anterior edge do not descend so near to the base of the crown as those of the posterior. The anterior series turns inward toward the base. The section of the crown is here (at the ninth tooth from before) not quite symmetrical, the internal face being the more convex near the apex. Soon the greater convexity of the outer side of the crown near the base becomes apparent, and as the in ward curvature of the anterior denticulate edge increases, the conrexity becomes more pronounced. On the second tooth, which is the first one preserved, the posterior edge is median; the anterior edge is on the inner side of a gently convex anterior face, which passes into the external face by an abrupt convexity. The long axis of the section of the crown does not connect the cutting edges, but passes from the posterior edge to the extero-anterior convexity mentioned, and parallel to the symphysis mandibuli. The enamel is smooth and with a fine silky luster. Two stages of succession are erident in these teeth. Successional crowns

* See Proceedings Academy Phila., Jauuary, 10ir. 
are seen, as in $L$. aquilunguis and $L$. incrassatus, in the dentary bone on the inner side of the roots of the functional teeth. As these derelop, they appear to take position immediately below the crown of the old tooth, and grow vertically in its axis, finally displacing the latter in the manner so characteristic of the Crocoditia.

The dentary bone is not deep, but is robust in the transverse direction. The external side is little convex in the vertical direction, and displays a smooth surface. A series of rather large foramina, rather closely placed, extends near the superior alveolar margin. The inner face of the dentary is divided into two subequal planes by a wide, open, longitudinal groove, which terminates at the posterior border of the symphysis. The surface is smooth. The symphysis is a short plane, oblique to the long axis of the dentary bone, and having the usual antero-superior oblique direction. It is short, and is characterized by its absolute smoothness. Near its anterior inner border, there is a large foramen.

This reptile differs from the $L$. incrassatus from the Judith River beds of Montana in many respects :-(1) There is no tooth having the form of the canine of that species, $i . e$, having the transverse greater than the longitudinal diameter, and the cutting edges opposite ; (2) the anterior edge is not carried to the middle of the inner side of the crown in the anterior tooth preserved; as to the ramus, (3) the groove of the inner side is much inferior in position in the Colorado animal; $(4)$ there are no symphyseal rugosities, as in $L$. incrassatus; (5) the ramus is shallower and thicker.

The species may then be named Lalaps trihedrodon, frow the form of the second tooth.

\section{Measurements.}

Depth of ramus at posterior extremity of symphysis . . . . . . . . . . . . . . . . 0.090

Width of ramus at the same point................................. 0.050

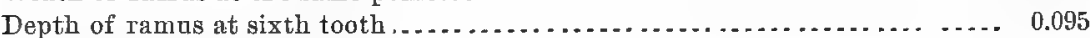

Width of ramus at sixth tooth ................................... 0.045

Depth of ramus at sixth tooth to the internal groove ...................... 0.050

Length of portion of ramus supporting nine teeth ...................... 0.260

.

Diameter of base of crown of fourtb tooth $\left\{\begin{array}{l}\text { transwero-posterior ................ } \\ \text { anter. }\end{array}\right.$

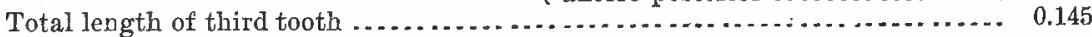

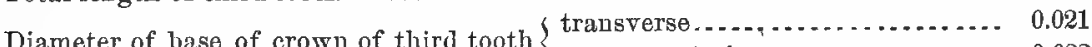

Diameter of base of crown of third tootb $\begin{cases}\text { tratero-posterior } \ldots . . \ldots \ldots \ldots \ldots . . . . & 0.022\end{cases}$

Width of anterior (convex) face. ................................. 0.017

Length of crown of second tooth ................................... 0.045

Width of inner face................................................. 0.019

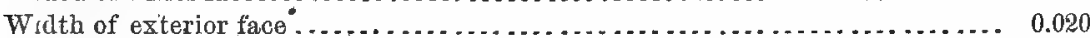

Width of anterior face .......................................... 0.012

In this connection, I may mention that Prof. O. C. Marsh, of New Haven, has recently created another synonym by renaming the genus Lelaps. This is done on the supposition that the latter name is preoccupied in entomology. The name has been used in that science, it is true, but simply as a synonym, and was therefore not employed or occupied when $I$ applied it to this genus of extinct reptiles. 
ART. XXXIV. - A CONTRIBUTION TO THE KNOWLEDGE OF THE ICHTHYOLOGICAL FAUNA OF THE GREEN RIVER SHALES.

By E. D. COPE.

The railroad-cut through the blaff on the west side of Green River, Wyoming, at Green River City, has been known for some years for the numerous fishes preserved in the shales through which it is excavated. An investigation into the ichthyology of this horizon and locality was undertaken by the writer, and a report published in the Anuual Report of the United States Geological Survey of the Territories for 1870 . Eight species of fishes were there described. Subsequently, in my expedition of 1872 , I discovered a second locality, sixty miles north of the "Fish-cut", near the mouth of Labarge Creek, from which several species of fishes and insects were obtained. A third locality, nearer the main line of the Wasatch Mountains, has been more recently found, and a very fine collection of fishes procured and forwarded to me by $\mathrm{my}$. friend, H. Schoomaker. The specimens are mostly in a fine state of preservation, and are preserved on slabs of a calcareous shale, with leaves and insects. The mineral is of softer consistence than the slate of Green River, and thus permits of a more complete exposure of the bony structure of the fishes. Iu the following pages, sixteen species from this locality are described, all of which are new to science. Many of them are nearly allied to the species. already known from the cut at Green River, belonging to the same genera, but none of them are ilentical. Three genera not previously represented in the fauna are added. General remarks follow the descriptions.

Dapedoglossus testis, Cope, gen. et sp. nov.

Char. gen.-Family Osteoglossidce. A single row of elongate acute teeth on the prewaxillary, maxillary, and dentary bones; vomer, tongue, and (?) basibyal bones closely studded with short corric grinding teoth. Mouth rather short. Pectoral fin with the anterior ray elongated; dorsal fin not elongate, with the anal well separated from the caudal. No beards.

This interesting genus presents the characters of the family to which I refer it in its segmented scales, posterior dorsal fin, etc., and does not differ widely in essentials from Osteoglossum. The principal-differences 
between the two genera are the small mouth in Dapedoglossus, the absence of barbels, and the generally abbreviated form. From Arapama, it differs in proportions, and in the abundance of teeth on the bones of the roof and floor of the mouth. To this genus is no doubt to be referred the fish found in the Green River Shales which I called* Osteoglos. sum encaustum, so that the name of that species will stand Dapedoglossus encaustus.

Char. specif.-Form oral, contracting subequally to the muzzle and caudal peduucle. The front is gently conrex and the mouth is terminal The depth is little less than half the length minus the caudal fin, and the length of the head enters the same 3.4 times. The dorsal fin is shorter than the anal, and its first ray stands over the sixth of the latter. The ventrals are small, and extend about one-half the distance from their base to the first anal ray, which equals the distance to the base of the pectoral. The latter is elongate, especially the first ray, which, although jointed, as in Osteoglossum bicirrhosum, reaches nearly to the end of the ventral. Radii: D. 22-23; A. 27-30. The caudal fin is slightly concave. Scales five or six series above the vertebral column and seven below it. Their exposed surface is rather wide, and is minutely granulated and without grooves. The cells are invisible except when this surface is remored, and they are rather large. Vertebroe : 21 dorsal; 25 caudal.

The orbit is rather large, and is reached by the end of the maxillary bone. The suborbital bones are not much enlarged, as is the case in the recent genera. Preoperculum entire; suboperculum very narrow. Branchio. stegals slender, rather numerous; coracoid wide, forming a vertical keel, which is not produced. Length of the longest specimen $0^{\mathrm{m}} .230$; of the shortest, $0^{\mathrm{m}} .165$.

The fire specimens of this fish which I possess do not differ widely in size, and are one-third and less of the dimensions of the D. encaustus. A scale of this or of another large species occurs in the present collection.

\section{DIPLOMYS'IUS DENTATUS, gen. et $s p$. nov.}

Char. gen.-Family Clupeidoe, and nearly related to the genus Clupea. It differs from Clupea in the presence of a series of dorsal scuta, which extend from the supraoccipital region to the base of the dorsal fin, corresponding in position with those of the rentral surface. Unlike these, they have no costal processes. The dorsal fin originates in front of the aual. In the t5pical forms, teeth are well dereloped in a single series on the dentary, premaxillary, and maxillary bones; but, in the small forms; they are invisible. Mouth moderate.

There are two sections of this genus, the species of which differ in the form of the dorsal scuta. In section I, these shields are transrerse, and their posterior borders are pectinate, a median tooth being especially

" Auuual Report lis.s. Geol. Surv. Terr., 1870, p. 430. 
prominent. In section II, the scuta are not wider than long, and bare but one, a median tooth, which is the extremity of a median longitudinal carina. The species of section $I$ are $D$. dentatus, $D$. analis, and $D$. pectorosus; those of section II are D. humilis and $D$. altus.

Char. specif.-Fin-radii : D. I-13; A. I. 35. Vertebræ: dorsal, 18; candal, 21. The greatest depth enters the length without the caudal fin two and a half times, and the head enters the same nearly three and one-third times. The eje is large, its horizontal diameter a little exceeding the length from its border to the inferior edge of the premaxillary bone, and a little greater than one-fourth the length of the head. The premaxillary and dentary bones are short and deep, the latter with a deep notch on the anterior border; both are directed upward. The maxillary bone is long and narrow, and curved backward at its lower end, which reaches a point below the anterior border of the orbit. The profile behind the premaxillary bone is nearly horizontal; above the posterior part of the orbit, it rises, and a compressed supraocipital crest carries it to the gentl 5 convex dorsal line. The abdomen is convex, and is about as long as the caudal region. The last dorsal ray rises above a point anterior to the first anal ray. The caudal is deeply forked. The ventrals originate at a point barely in advance of a vertical line from the first dorsal ray. The pectoral fins are short. The scuta of the inferior median line are large and acute. The scales are rather small, and are delicately grooved; twenty rows may be counted between the vertebral column and the dorsal fin.

Measurements.

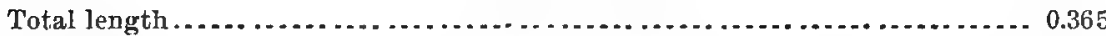

Length of head.................................................. 0.083

Length (axial) to below first dorsal ray ................................ 0.145

Length to above first anal ray ....................................... 0.185

Length to hase of external caudail rays ................................ 0.285

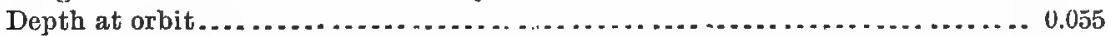

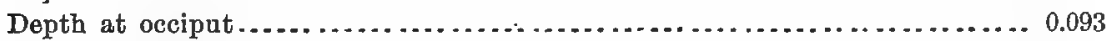

Depth at first dorsal ray ......................................... 0.118

Depth at middle anal ray ....................................... 0.050

Depth at base of caudal fin................................... 0.030

This species is represented by a single specimen of the size of a small Shad and exceeding the Herring. It is in fine preservation.

\section{Diplomystus an:ALIS, Cope, sp. nov.}

Radial formula: D. I. 11 ; A. I. 40. Vertebræ: dorsal, 17-18; caudal, 23-24. This species is more elongate in proportion to its depth than either of the other species, the length being three times the greatest depth. The anal portion of the bods is considerably longer than the abdomen, and the anal fin is long and with short rays. The ventral fin commences well in front of the dorsal, whose last ray is considerably in advance of the first anal ray. The pectoral fin reaches the ventral, and 
contains thirteen rays. The greatest depth is at the pectoral region, the outlines contracting to the base of the anal fin. The dorsal outline is convex. The profile descends gently. The muzzle is half as long as the diameter of the orbit, which enters the length of the head three times. The latter enters the length without the caudal fin three and three. fourths times. There is a row of short, conical teeth along the middle line of the mouth, which is not on the vomer, but is on the parasphenoid or axial hygal bones. Similar teeth exist in the mouth of $D$. dentatus. The jaws may be furnished with minute teeth, or they may be wanting. The scales are thin and dificult to count; there are fifteen rows between the rertebral column and the anterior anal rass.

\section{Measurements.}

Total length....................................................... 0.195

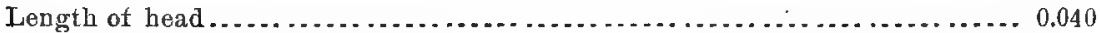

Axial length to below first dorsal ray . . . . . . . . . . . . . . . . . . . . . . . . . . . . 0.073

Axial length to above first anal ray .................................. 0.092

Axial length to base of external caudal rays ............................ 0.140

Depth at orbit...................................................... 0.030

Deptl at occiput................................................... 0.044

Depth at first dorsal ray . . . . . . . . . . . . . . . . . . . . . . . . . . . . . . . . . 9.047

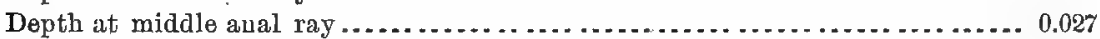

Depth at base of caudal fin ........................................... 0.016

This Herring is represented by a great numer of well-preserved specimens, and was, next to the $D$. humilis, the most abundant fish of the waters of the ancient Green River lake-basin. It is distinguished from the $D$. dentatus by the larger number of anal and smaller number of dorsal radii, and by the shorter head and relatively more slender body. The specimen measured represents the average size; the largest ob. tained is half as large again, and much smaller than the type of $D$. den. tatus.

\section{Diplomystus Pectorosus, Cope, sp. nov.}

This Clupeoid is represented by small specimens of a deeper form than that seen in the two preceding species. It is also characterized by a smaller number of dorsal radii than either of them. Formula: D. I. $8-9$; A. I. 40-44. Vertebræ: dorsal, 16-17; caudal, 22. The greatest depth is in the pectoral region, and enters the length miuus the caudal fin a little less than tbree times. The outlines contract from the ventral fins, and the anal region is longer than the abdominal. The eye is a little more than one-fourth the length of the head, and the latter enters the total minus the caudal fin three and a half times. The ventral fins are small, and commence well in advance of the line of the dorsal. The last dorsal ray is nearly above the first anal ; the caudal is deeply forked. As in the two preceding species, the neural spines in front of the interneurals present a laminar antero-posterior expansion. The 
dorsal scuta are furnislred in the $D$. pectorosus with an especially prominent median keel.

\section{Measurements.}

I'otal leugth

Letal length .

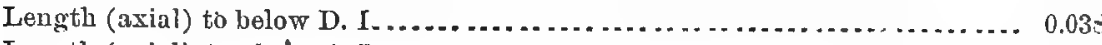

Length (axial) to above A. I......................................... 0.043

Length (axial) to base of eaudal fin .................................. 0.070

Length of head...................................................... 0.02 ?

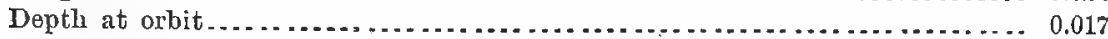

Depth at pectoral fin ............................................... 0.026

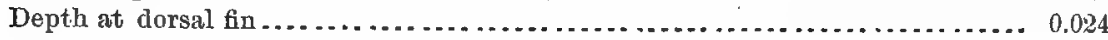

Depth at caudal peduncle....................................... 0.008

This species is represented by sereral specimens.

\section{DIPLOIYSTUS HUMILIS, Leidy.}

Clupea humilis, L eidy, Final Report U. S. Geol. Surv. Terr. i, p. 195, pl. xvii, fig. 1 .

This and the following species, already referred to a distinct section of the genus Diplomystus, differ from those above described in sereral points. They have a much shorter anal fin, and the caudal part of the vertebral column is thus shorter. The anterior neural spines do no present the antero-posterior laminar expansion. The ventral fin commences a little behind the origin of thedorsal. The formulæ for the D. Tumilis are as follows :-Radii : D. I-11; A. I-14. Vertebræ: D. 21; C.13. Depth to length as $3: 8$. 5. The Diplomystus theta (Clupea theta Cope, Ann. Rep. U. S. Geol. Surv. Terr. 1873, p. 461) is intermediate Detween the species of the two sections in the structure of its anal fin, which includes trenty-six rays.

As at the Green River localit, 5 , so at this one, this Herring is the most abundant species. One-third the entire number of specimens are referable to it.

Diplomystus altus, Leidy.

Clupea alta, Leids, loc. cit. p. 196, pl. xvii, fig. 2.

Also abundant. Formulæ:--Radii : D. I. 11;. A. 1. 13-15. Vertebræ: D. 22 ; C. 12 . Depth to length (without caudal fiu) as $4: 8$.

\section{ERISMATOPTERUS ENDLICHI, $s p \cdot n o v$.}

This fish displays the characters of the ge nus to which it is referred, and of which a description will be found in the Annual Report of the United States Geological Survey of the Terri tories for 1870 , p. 427. The ventral fins are neither abdominal nor pectoral, but intermediate, and the dorsal fin is above the abdomen. Both it and the anal are short, and are supported in frout by two or three strong appressed spines. The vertebræ are hourglass-shaped, and the scales cycloid. The rentral rays are seven in num ber in $E$. endlichi and $E$. rickseckeri. 
The radial formula in this fish is : D. III-11; C. 6-19-6; A. III-7. V. 7. The rertebre are: D. 13; C. 17. Centra between the lines of the first interneural and first interhæmal spines, 10. Ten rows of small scales risible above the vertebral column.

The general form of the fish is stout, and the caudal peduncle is deep. The top of the head is convex, and the eye large. The front descends abruptly to the rather projecting muzzle in the specimen, but whether this is a distortion or not is uncertain. The coracoid is wide and well prodnced backward, while the clavicle is, as usual, directed forwari. The femur* is slencler, and connected with its fellow by a posterior transverse bar. The greatest depth is a little less than one-fourth the length without the caudal fin. The diameter of the eye is one-fourth the length of the head. The origin of the ventral fin is in advance of the first dorsal ray; the origin of the anal is below the penultimate dorsal raj. The caudal fin is openly forked.

\section{Measurements.}

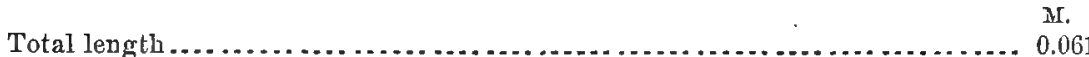

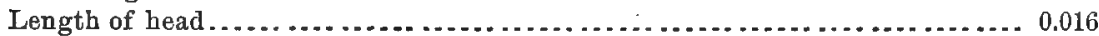

Length to line of ventral fin ...... .................................... 0.020

Length to line of dorsal fin......................................... 0.022

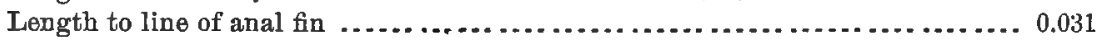

Length to base of caudal fin .......................

Depth at caudal peduncle............................................. 0.008

Depth at dorsal spine............................................. 0.011

The more numerous rays of the dorsal fin and more numerous scales are among the characters which distinguish this species from the two heretofore known, It is dedicated to Dr. Frederick M. Endlich, geologist in charge of one of the parties of the United States Geological Survey of the Territories under Dr. F. V. Hasden.

AMPHIPLAGA BRACHYPTERA, Cope, gen. et sp. nov.

Char. gen.-Generally as in Erismatopterus, but with strongly ctenoid scales. The dorsal fin is over the abdomen, and is supported by a few strong, adherent spines in front, which rest on stout interneurals; the soft rajs have no interneurals, either in this fin or the anal. They are present in Erismatopterus. The ventrals originate a little in advance of the line of the dorsal, and the candal fin is deeply forked. This genus approximates Aphrodedirus.

Char. specif.-Radii: D.II-8; A. II I-4. Vertebre of the caudal series 15. Scales: transverse row, 22 ; longitudinal row behind first interneural bone, 40. The only specimen I possess lacks the head, so that various characters cannot be ascertained. The depth of the body at the first dorsal spine enters the length from that point to the base of the caudal fin two and a half times, giving a general form of medium proportions.

* Before the homologies of these bones were studied, authors frequently called them pubes. 
Caudal pedincle stout. The vertebra are contracted medially, and not shortened; they have two or three longitudinal keels, which are some. what irregular in their connections. This species is larger than any of the Erismatopteri yet known.

\section{ileasurcments.}

Length from first dorsal spine ..................................... 0.073

Length from first anal spine.......................................... 0.051

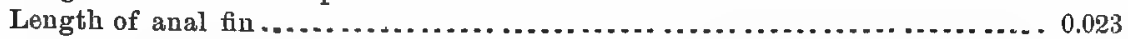

Length of second dorsal spine ........................................ 0.015

Length of third anal spine......................................... 0.013

Depth at first anal spine ......................................... 0.018

Asineops Paudiradiatus, Cope, sp. nov.

This Perch is represented by a single specimen, which is larger than any of those of the $A$. squamifrons, which hare yet been found, and which is of more robust proportions. It differs materially in the radial and vertebral formuli, and in the greater relative shortness of the dorsal spines. I obserre at the base of these a series of short subhorizontal basilar interneural bones.

Formulæ:-Radii : D. IX-12; A. II. 7. Vertebræ:D. 9; C. 13. One or two vertebræ may be concealed behind the epiclavicle, but these, as in the description of $A$. squamifrons, are uncounted. The depth enters the length 2.25 ti mes, the caudal fin being omitted. The length of the head is little less than the depth. The dorsal spines are not very robust, and are (excepting the first) of subequal length. The longest equals only half the depth of the body at the middle of the second dorsal fin. The caudal is rounded, and the rentrals are below the pectorals. The origin of the latter. is a little in advance of that of the first dorsal spine. Its base is attached to four short basilar bones, of which the inferior two are stout in proportions. There are about ten rows of cycloid scales below the vertebral column. Scales extend on the top of the head as far as the orbits. The month is terminal. The total length of the type-specimen is $0^{\mathrm{m}} .243$, of which the head constitutes $0^{\mathrm{m}} .075$. The longest (ninth) dorsal spine measures $0^{\mathrm{m}} .027$, and the second anal spine $0^{\mathrm{m}} .024$.

\section{Mioplosus abbreviatus, Cope, gen. et sp: nov.}

Char. gen.-Allied to Labrax and Perca. Branchiostegal rajs, 7 or 8; ventral rays, I. 5.; scales ctenoid. Two dorsal fins slightly connected at base; only two anal spines. Operculum rounded, without spines or emargination. Preoperculum without spine, and smooth on the posterior border; inferior border with teeth. Premaxillary and dentary with small uniform teeth in a narrow series. Clavicle unarmed. Vertebro with two lateral fossæ. Caudal fin emarginate.

The discorery of this genus in the Green River Shales is of no small importance to fossil ichthyology, proving the existence, at that early 
period, of the type, which is one of the highest among the true fishes. It probably belongs to the Percide, although I have not ascertained the presence of teeth on the vomer, and there may be eight branchiostegal rass. As compared with the genera, recent and extinct, which are allied to Perca, it differs in the unarmed operculum and the preoperculnm with teeth only on the lower limb, and in the presence of but two anal spines. It is therefore a weaker form than they, and, though of a higher type, less strongly protected by spines than the cotemporary Asineops. Mioplosus embraces the largest Physoclystous fishes yet known from this formation, and specimens are not rare at the. locality from which they have been procured. They are often in a state of excellent preservation. The type of the genus is the $M$. labracoides.

Char. spec.-The $M$. abbreviatus is represented by but one specimen, from which the muzzle has been broken away. It is the stout species of the genus, and the others succeed it in this enumeration in the order of their greater elongation of form. The depth at the firstdorsal fin enters the total length (including caudal fin) three and a half times; and the depth at the first anal ray enters the length of the vertebral column two and eight-tenths times. Vertebre visible behind clavicle: D. 9; C.14. Radii : D. IX-I. 11; A. II-11; P.14. Ventral with a very weak spine. The last dorsal spines, as in all the other species, are very short, the anterior ones slender and moderately long; in this species, they are curved. The anal spines are short and slender, the first a rudiment. There are six rows of scales above and six below the vertebral column on the caudal peduncle.

\section{Measurements.}

M.

Length of vertebral column ........................................ 0.125

Length of third dorsal spine......................................... 0.025

Length of ninth dorsal spine........................................ 0.007

Depth at middle of first dorsal fin ....................................... 0.060

Depth of caudal peduncle.......................................... 0.025

Mroplosus LabracoIdes, sp. nov.

This Perch is represented by five specimens, mostly in good preserra. tion. They have much the proportions of the Rock-fish. The origins of the pectoral and ventral are in nearly the same vertical line, and that of the first dorsal is not far behind them. That of the first ray of the anial is below the second or third ray of the second dorsal. The rays of none of the fins are prolonged; the dorsal spines are slender and nearly straight, the longest (third), when depressed, reaches but four-tenths the distance to the first ray of the second dorsal. The last dorsal spine is very short. The soft dorsal rays are rather longer than the spinous. Formulæ:-Rays: D. IX-I. 12; C. 8-17-8; A. II-14; V.I. 5. Vertebræ: D. 10 ; C. 15 .

The depth at the first dorsal fin enters the total four times; the depth at the first anal ray enters the length of the rertebral column three times. 
The length of the head enters the total four'times, and that of the orbit enters the head 4.66 times, and into the length of the muzzle one and one-third times. The protile of the top of the head is slightly convex, and the dorsal line is also slightly convex. The mouth opens somewhat obliquely upward. The end of the maxillary bone reaches a point below the middle of the orbit. The teeth of the inferior border of the preopereulum are strong, and are directed forward; they number five. The angle of the lower jaw is not produced, but the inferior edge of the ramus is laminar and acute; the symphysis is shortly truncate. The superior edge of the maxillary bears a supernumerary bone at its distal portion. There are six branchiostegal rays preserved, with impressions of two others: the anterior three are slender; the others wide, as in allied gen. era. There is a low supraoccipital crest. The abdomen bears fourteen rows of scales below the vertebral column, and six rows may be counted above it; on the candal peduncle I count $5-5$.

\section{Measurements.}

Total length ...................................................... 0.280

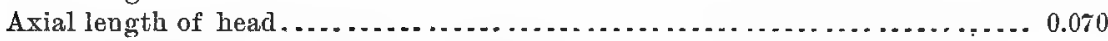

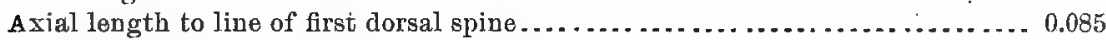

Axial length to line of first ray of second dorsal . . . . . . . . . . . . . . . . . . . . . . 0.143

Axial length to line of first anal spine.............................. 0.152

Axial length to base of caudal . . . . . . . . . . . . . . .

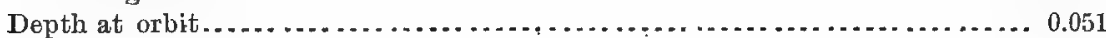

Depth at first anal ray .................................................. 0.055

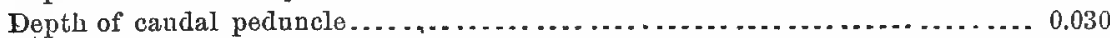

Length of third dorsal spine . . . . . . . . . . . . . . . . .

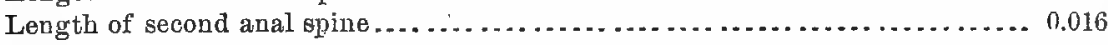

\section{MroplosUS LONGUS, sp. nov.}

I have questioned the right of the form to which the abore name is given to be maintained as a species distinct from the $M$. labracoides. It is represented by two individuals of much smaller size than those of the latter, and which are of a more elongate form. They have also two anal radii fewer.

The formulæ are:-D. IX-12; A. II. 12. Vertebræ: D. 10; C. 15. The depth at the first dorsal fin enters the total length five times, and the depth at the first anal ray three and one-half to three and eight-tenths times. The dorsal spines are straight and slender, the posterior ones very short. The caudal is forked. The teeth of the inferior border of the preoperculum are strong and acute; there are three large and two. small ones.

\section{Measurements.}

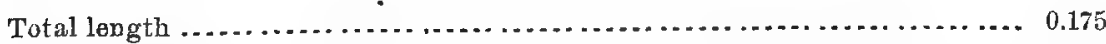

Length of head ................................................... 0.042

Length to line of first dorsal ... . . . . . . . . . . . . . . . . . . . . . . . . . . . 0.054

Length to line of second dorsal ................................... 0.085

Length to line of anal. ............................................ 0.091 
Length to caudal................................................. 0.140

Depth at orbit ................................................... 0.025

Depth at first dorsal.............................................. 0.037

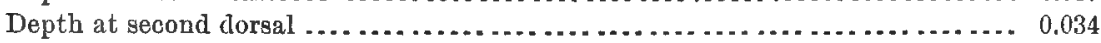

Depth of caudal peduncle ............................................ (i) 0.020

The scales are similar to those of the. . labracoides.

\section{Mioplosus BEANT, sp. nov.}

The most slender species of the genus is represented by one specimen, which is the smallest obtained, which is referable to this genus. The depth enters the total length six times, and the depth at the first anal spine enters the length of the vertebral column a little more than four times. Radii : D. IX-I. 13; A. II-12; P. 13. Vertebræ: D. 10; C. 15. The general characters are as in 11 . labracoides, but the scales are not preserved. The form of the head is that of a younger fish, but its proportions as compared with the body are not those of immaturity. The length enters the total 4.2 times, and the orbit enters it 4.5 times. The profile of the front is descending. The teeth of the inferior limb of the preopercle are obtuse and not well defined. There are impressions of seven branchiostegals preserved.

This perch is named in honor of my friend Dr. T. H. Bean, of the United States Fish Commission.

Measurements.

M.

Total length .......................................................... 0.131

Length of head ................................................ 0.031

Length to line of first dorsal . . . . . . . . . . . . . . . . . . . . . . . . . . . . . . . . . 0.040

Length to line of second dorsal ...................................... 0.064

Length to line of anal fin ....................................... 0.070

Length to line of caudal tin ..................................... 0.109

Depth at orbit ..................................................... 0.020

Depth at first dorsal ray .... . . . . . . . . . . . . . . . . . . . . . . . . . . . . . 0.023

Depth at first anal ray ............................................. 0.019

Depth of caudal peduncle............................................. 0.011

Priscacara serrata, gen. et sp. nov, Chromididis vel Pomacentridis affinis.

Char. gen.-This type might be included in the Pomacentrida, but it differs from the genera now known in the possession of vomerine teeth, and apparently in having eight branchiostegal rays.

In general, Priscacara may bo characterized as $P$ haryngognathi, with ctenoid scales and well developed spinous rays. The preoperculum is, in the typical species, sharply serrate on both borders. There are three anal spines, and the lateral line is well developed, not extending near the dorsal line. The caudal fin is rounded. The jaws are toothless. The pharyngeal bones, both superior and inferior, are closely studded with short, sessile, conical, teeth; a row of small ones stands on the ex. ternal border of the inferior pharyngeal. One dorsal fin.

Char. specif.-Form a regular wide oval, with a subequal contraction at both extremities. The spinous dorsal rays become longer than the 
soft ones, but the posterior spines are shorter than the anterior soft rays, so as to produce a wide emargination in the superior ontline. The spines are very robust, especially those of the pectoral and anal fins. The first anal spine is near two-thirds the length of the second. The pectoral fin does not extend to the anal, and the soft parts of the anal and dorsal, which are equal, do not overlap the base of the caudal. Radii : D. X-11; A. III-10; C. ?-17-?. Vertebræ: D. 9; C. 14. The centra have a strong median lateral ridge, which separates two fossæ.

The greatest depth is at the base of the ventral fins, or the third dorsal spine; it enters the total length (with caudal fin) two and fourtenths times. The length of the head enters the same three and fourtenths times. The orbit is large, its diameter exceeding the muzzle and entering the length of the head a little orer four times. The mouth is terminal, and the premaxillary extends obliquely downward and backward; the maxillary reaches the line of the anterior border of the orbit.

The scales are longer than deep, and the rough surface has but a small extent, and is finely granulated. The remainder of the scale is marked with strong concentric grooves. Those on the gular region are swall. On the belly, there are seventeen rows (about) below the vertebral column. A row of scales extends along the postero-inferior edge of the operculum. This part is well preserved in only one of the three specimens which represent the species.

\section{Measurements.}

Total length

Length of head ................................................... 0.064

Length to line of first spine of first dorsal ........................... 0.070

Length to line of first spine of second dorsal ......................... 0.121

Length to line of anal ............................................... 0.122

Length to base of caudal ......................................... 0.173

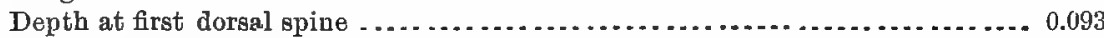

Depth at first dorsal soft ray ..................................... 0.070

Depth of caudal peduncle......................................... 0.027

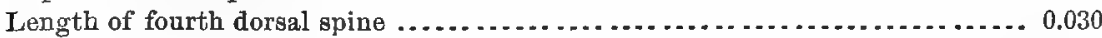

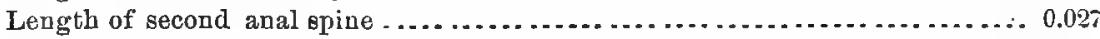

This species is about the size of the Crappie, Pomoxys annularis.

\section{Priscacara CYPHA, sp. nor.}

This species is nearly related to the last, but presents a number of differences which require its separate consideration. These are:-(1) The more arched or convex dorsal outline; (2) The relatively longer head; (3) The presence of an additional dorsal spine; (4) The entire covering of the operculum with scales. There is also probably a smaller number of dorsal vertebrx, but this is not certain, as that region has been somewhat disturbed. Formulæ:-Rays: D. XI-10-11; A. III-9; P. 15. Vertebræ, 6-14. 
The greatest depth enters the total length 2.6 times; the length of the head enter's the same 3.3 times. The spines are more robust, and the serrature of the preopercle more produced in the individual now described than in any of those of the $P$. serrata in my possession. The size is about the same as that of the latter species.

\section{Priscacara liops, sp. nov.}

A smaller fish than either of the preceding is referred to this genus, although it differs in one feature, regarded as important among the Pomacentride, $i . e$. , the preopercular border is entire. It conforms closely to the $P$. serrata in other respects, as the form of the dorsal fin, three anal spines, form of caudal fin, character of scales and lateral line, edentulous jaws, and, incleed, in form to such an extent as to lead me to suspect that in this genus, as in Lepomis, etc., the serration of the preopercle is not of much systematic value. One character by which the $P$. liops may be distinguished from $P$. serrata, in addition to the smooth preoperculum and small size, is the constantly larger number of rays in the second dorsal fin.

Formulie:-Rays: D. X-13-14; C. 5-19-6; A. III. 10-11. Vertebræ: D. 9 ; C. 13. The form is characterized by the down ward production of the muzzle, or a descending slope of the front. One specimen does not present this character, perhaps on account of distortion. The pectorals originate below the first dorsal spine, and the rentrals a little behind it. The spines are moderately stout, and the emargination of the dorsal fin is not deep. There are twenty-five rows of ctenoid scales trav. ersed by a vertical line from the middle of the spinous dorsal, and smaller scales cover the operculum and more or less of the preoperculum.

\section{Measurements.}

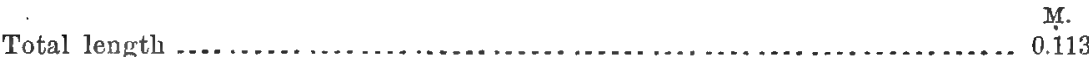

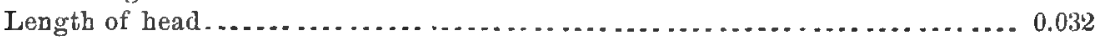

Length to first dorsal spine ......................................... 0.034

Length to first dorsal soft ray ...................................... 0.057

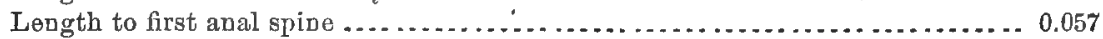

Length to base of candal. ............................................ 0.086

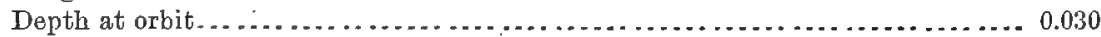

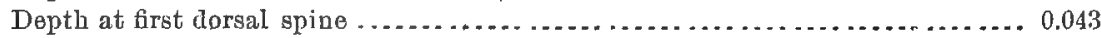

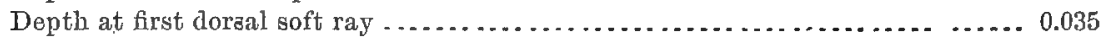

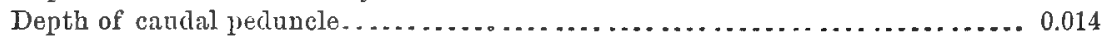

Five specimens of this fish hare been receired.

GENERAL OBSERVATIONS.

The species of this locality are distributed as follows, in their respectire genera. A corresponding list of all the species known from the Green Iirer Shale is also given:- 


\begin{tabular}{|c|c|c|}
\hline & \multicolumn{2}{|c|}{ Number of species. } \\
\hline - & $\begin{array}{c}\text { This lo- } \\
\text { cality. }\end{array}$ & $\begin{array}{c}\text { Entire for- } \\
\text { mation. }\end{array}$ \\
\hline 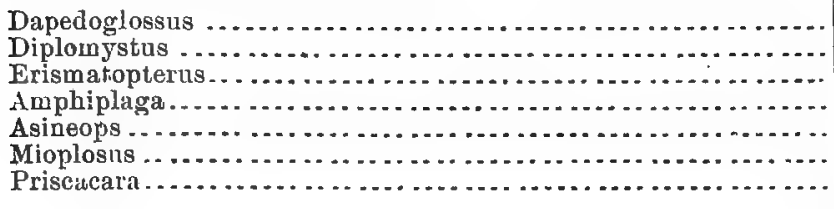 & $\begin{array}{l}1 \\
5 \\
1\end{array}$ & $\begin{array}{l}7 \\
7 \\
7\end{array}$ \\
\hline & 16 & 23 \\
\hline
\end{tabular}

The Herring (Diplomystus) exceed all others in number of species and individuals. One of the species $(D$. humilis $)$ is more abundant than all the other species of all genera put together. Long after these come, in point of numbers, the more typical spinous-rayed species, which doubtless preyed upon them. The following species are represented by but one individual each :-Diplomystus dentatus, Erismatopterus endlichii, Am. phiplaga brachyptera, Asineops pauciradiatus, Mioplosus abbreviatus, $M$. beanii, and Priscacara cypha.

A consideration of the fauna with the additional light derived from this accession of new material is of some ralue in connection with the question of the relation of this formation to the oceans and lakes of the Eocene period. I have heretofore expressed the opinion that the Green River water-area in which the shales were deposited may have had, like the Wasatch Lake of New Mexico, connection with the sea, and pointed out the broad distinction between its fish-fauna and that of the - undoubtedly land-locked lakes of the South Park of Colorado and of Elko, Nev. The fishes of the latter formation are nearly.related to fresh-water types only, and to those at present inhabiting North Amer ica. On the other hand, the Green River Shales contain two striking representatives of families which do not now exist in North America, and very rarely in any of the northern realms of the earth. These are the Osteoglosside, whose genera are all fresh-water, and the Pharyngograthi, with ctenoid scales. Some of these are marine (Pomacentrida), and others are fresh-water (Chromidida). The Green River genus Priscacara is, in some respects, more nearly allied to the latter than the former family, but not entirely so.

The remaining genera (excepting Asineops) correspond to existing North American genera, viz:-Diplomystus, to Clupea; Erismatopterus and Amphiplaga, to Aphredodirus ; and Mioplosus, to Labrax. The firstand last-named recent genera are anadromous, and Aphredodirus exists in tide-water; it has also been found near the Great Lakes. We look for further material to throw light on the question of possible marine communication with the Green River lake. 



\title{
ART. XXXV.-ON THE GENUS ERISICHTHE.
}

\author{
BY E. D. Cope.
}

Erisichthe is a genus of fishes which was described by the writer in 1873, and subsequently referred to the Saurodontidoe. In the Final Report of the United States Geological Survey of the Territories," the typicul species, $\boldsymbol{E}$. nitida, was again described, and also figured, so fir as the material permitted, and the existence of a second species, $E$. angulata, $\uparrow$ was pointed out. Subsequent accunulation of material enables me to add to the knowledge of the structure of the genus and to increase the number of known species.

The $\boldsymbol{E}$. nitida Cope was originally represented by a few portions of the skull; among other pieces, the premaxillary and dentary bones being present. The latter element was correctly determined, but the premaxillary was called maxillary in my description. A fine specimen of this species, obtained the present season from the Niobrara Cretaceous of Kansas, by Charles H. Steruberg, includes the greater part of the cranium. From this and other specimens I discover that the anterior portion of the skull, probably the ethmoid bone, is produced into a long beak, in general form similar to the sword-like snont of the Sword-fishes of modern seas. I had already been in receipt of fragments of these beaks, associated with loose teeth of the genus Erisichthe, bat it was Prof. B. F. Mudge who first pointed out that both belong to one aud the same genus. $f$ The specimen above mentioned includes also the maxillary bones, so that their true character is now clear. A remarkable feature of the genus is displayed in the mandibles. Eich of these is compound in the region usually composed of the simple dentary bone. It there consists of three parallel elements, an internal and an external embracing a median element. The inner bears a band of teeth en brosse on its inner and superior aspect, and the external a few teeth of similar character on its superior edge. The large lancet shaped teeth are borne by the middle element, excepting some of the largest near the symphysis. Two of these on the inner side of the ramus originate in the internal bone. The maxillary bone forms the greater part of the arcade of the mouth, and has no superior articulation with the facial part of the skull. It is attached by a simple sutural articulation with the premaxillary, so

* Vol. ii, 1875, p. 217, pl. xlviii, figs. 3-8.

† Portheus angulatus, Geolog. Survey N. Carolina, by W. C. Kerr, p. 32.

$\ddagger$ Bulletin U. S. Geol. Survey Terrs. 
as to permit some lateral motion. The premaxillary also has no superior coudyle articulating with the cranium, but the entire length of its superior margin is applied in a groove of the ethmoid bone, so as to be immorable. Anterior to the premaxillary bones, on the inferior aspect of the ? ethmoid, is situated a pair of large, compressed, double-edged teeth, whose alveoli are close together. Only one of these teeth is in functional service at a time. In the Erisichthe penetrans, the superior surface of the skull is swollen abore the fundus of this alveolus, while no such enlargement marks the position of its joung companion.

The compound character of the mandible, and the peculiar mode of articulation of the premaxillary and maxillary bones, entitle this genus to recognition as the type of a family distinct from the Saurodontida, which may accordingly be called the Erisichtheidce. It is allied to the Saurodontide in the mode of implantation of its teeth and in the relative extent of the bones of the maxillary arch.

Three species are represented by the specimens received. They are readily distinguished by the forms of the beaks. In the $E$. nitida, this reapon is distingnished by the flat superior surface of its distal half. The section in this region is semicircular, a strong angle on each side bounding the superior plaue, while at the base the section is a transverse cral. The flat surface is only finely rugose, while the remainder is closely marked with raised ridges, which are generally parallel, but which send off many lateral free or inosculating branchlets. This beak is stout, and contracts abruptly at the tip. It is also recurved, and the form does not appear to be due to distortion. Length from the inferior pair of large basal teeth $0^{\mathrm{m}} .155$; transverse diameter at base $0^{\mathrm{m}} .025$; depth at base $0^{\mathrm{m}} .021$.

The second species, which 1 call Erisichthe penetrans, has a snout of uniformly oval section at all points. The long diameter of the section is transverse. The axis is straight and the form acuminate, the contrac. tion being uniform and gradual to acute apex. Thus it follows that a beak of greater diameter at the base than one of the $E$. nitida has a more slender shaft. The teeth of the inferior basal pair are, in the specimen described, of large size, and, as in other species, smooth, compressed, and with opposite fore and aft cutting edges. The surface of the beak is throwu into numerous sharply defined longitudinal ridges, which more or less inosculate witl each. There is no difference between the superior and inferior surfaces in this respect. Length of beak from basal teeth $0^{\text {r. }} .150$; transverse diameter at base $0^{\text {m }} .035$; vertical diameter at the same point $0^{\mathrm{m}} .020$; width at middle of the fossæ for the premaxillary bone $0^{\mathrm{m}} .060$.

The third species of Erisichthe is represented by a muzzle of an old individual, which has lost a good deal of its apex by attrition. Its surfice lacks the sculpture of the other species; but whether this smoothvess is due to attrition or not is uncertain. The alveolæ for the basilar teeth are empty and almost filled up with bone. The form of the muzzle 
is quite peculiar. Its shaft is depressed, with a strongly convex inferior sturface and a slightly convex superior surface, the two separated by an obtuse angular border. Behind the alveolæ, the inferior surface is narrowed by a strong lateral contraction, in which the superior surface shares in a slight degree. The latter is continued in a prominent border. The inferior surface is divided by an angular depression, the apex of which is directed forward. It is perhaps the articular face for the ex. tremity of the vomer. As compared with the other species, this one is characterized by the lateral longitudinal concavity at the base, which appears to be an anterior prolongation of the grooves for the premaxillary bones. The small size and anterior position of the alveolæ of the basal pair of teeth is also a marked character. The superior surface of the skull at the base of the beak is apparently unworn; it is smooth. In $E$. nitida, it is sculptured with ridges. Length preserved, anterior to dental alveolæe, $0^{\mathrm{m}} .045$; transverse diameter in front of alveoli $0^{\mathrm{m}} .025$; vertical diameter $0^{\mathrm{m}} .020$. This species may be called $E$. ziphioides, from the Ziphius-like form of the beak.

A fourth species has been found in England, and figured by Dixon in the "Geology of Sussex". The portions represented in this work are the mandibles, which resemble those of the $E$. nitida, and which were supposed at that time to belong to a species of Saurocephalus. A muzzle, perhaps of the same species, was regarded as a Sword-fish, which was called Tiphias dixonii by Agassiz. It should be now termed Erisichthe dixoni. 



PALEONTOLOGICAL BULLETIN, No. 30.

CONTERBUTIONT

TO THE

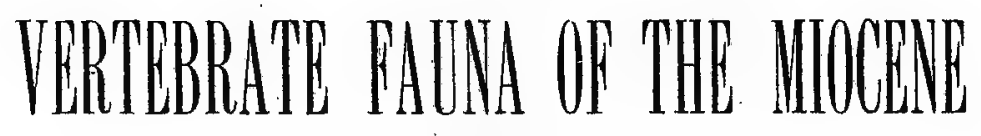

QT Qriserer.

By E. D. COPE.

FOR SALE BY

A. Ii. FOOTE, 1223 Belmont Avenue, Philad'a. 



\title{
On some of the Characters of the Miocene Furna of Oregon.
}

\section{(Read before the American Philosoptical Soriety, November 15, 1878.)}

\author{
BY E. D. COPE.
}

We have been for some time in possession of information as to the ungu late forms which inllabited Oregon during the Miocene period. Through the labors of Profs. Leicly, Marsh and Bettany, we have learned of the existence there of Dreodontida in considerable variety; of Anchitherizda ; of peccary-Tike species; of Elotherium, and of Rhinocerus. But of the unguiculate types, of Iindentiu, and of the inferior orders of Manmalia, almost nothing is yet known. Having recently received a number of specimens from the deposits in question, I am in a position 10 offer a number of new identifications. The following species alrearly known from the Mincene of Colorado, I find contained in the collection, viz.: Palcolagus hayrleni; Canis gregarius; Cunis lippincottianus; Hyperragulus calcaratus; Leptomeryx evansi.

\section{RODENTIA.}

Steneofiber gradatus, sp. nov.

This species is represented in my (*)llection by a cranium which is nearly perfect, the principal deficiency being the absence of the manclibular rami. It is of smaller size than the S. nebriscensis and $S$. pansus, and differs from both these species in the relative sizes of the superior molar teeth. The first of these is the largest, and the others diminish regularly in size to the last, whose grinding face does not present more than one-lhird the extent of that of the first. The triturating surfaces of the second and third have their long axes transverse. In all the clowns, besicles the internal and external enamel inflections, there is but one fossette, which is anterior to the external inflection. The latter las become isolated from the superficial enamel on the last three molars, by attrition. The superior incisors are flat anteriorly with the external angle rounded, and its clentine presents the transverse undulations seen in S. prensus.

\section{Measurements. M.}

Length of skull from incisive alveolus........... . 050)

Width between summits of first molurs. . . . . . . . . .0060

" " fourth " ........... .0095

Length of molar series..................... .0115

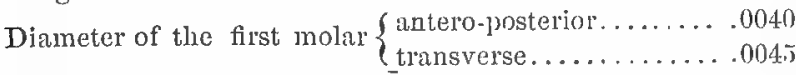

Diameter of third molar $\left\{\begin{array}{l}\text { antero-posterior . . . . . . . . .0028 } \\ \text { transverse }\end{array}\right.$

Diameter of fourth molar $\left\{\begin{array}{l}\text { antero-postcrior.......... } 0020 \\ \text { transverse........... 0024 }\end{array}\right.$

From the above measurements it is apparent that the molar series in this species is equal in length to the anterior three molars cf the $S$. nebrascensis 
and S. pansus. The posterior fossettes of the crowns seen in those species are wanting in the si. gradutus.

Entoptyohes cavifrons, gen. et sp. nov.

Char. gen. Probably of the fumily hiosomyide.* The cranium is elongate, and presents inflater periotic bones, and slender zygoma. The foramen infraorbitale is small and anterior in position, entering the maxillary bone near its suture witlı the premaxillary.

Aneric charurters. Molars $\frac{4}{4}$, rootless, and identical in structure. The crowns are prismatic, and in the young stage present a deep inflection of enamel from one side, the external in the supcrior teeth, the internal in the inferior. After a little attrition, the connection with the external enamel layer disappears, and there remains a medith transverse fossette, entirely enclosed by enamel. The tooth then consists of two dentinal columns in one cylinder of enamel, separated by a trinsrerse enamel-bordered tube. Incisors not sulcate.

The teeth of this genus differ from those of Perognathus in being without distinct roots, and in having the enamel loop cut off and enclosed. In Dipodomys, the molars are undivided simple prisms.

Specif. Char. This species is represented by some entire crania, and numerous separated jaws. The postolbital part of the skull is subquadrate in outline, and depressed in form. The interorbital region is narrowerl, but the superciliary margins ds not meet. nor converue to form a sagittal crest. They are thickened, forming two subparallel ridges which are separated by a shallow concavity of the frontal bone. The nasal bones are very narrow, and their posterior apices just altain the line of the supero-anterior angle of the orbit. The base of the malar bone is much elevated and very oblique. The molar teeth are directed obliquely backwards, the alveolus of the first issuing below the anterior part of the orbit. The first superior molar is the largest, and the proportions of the others diminish regularly posteriorly. The first inferior molar is a little smaller than the second and third, and is about equal to the fourth. Its anterior column is contracted, while the last molar is like the second and third. The face of the inferior incisor is flat, and its enamel is smooth. The external face of the jaw is bounded below by a strong angle, as far anteriorly as below the first molar.

Measurements. M.

Length of skull to incisive alveoli................ .041

Width of skull at mastoids.................. .020

" " between orbits....................... "

" " at midale of muzzle. .............. .010

Elevation of skull from second molar............... .011

Length of molar series.................... .007

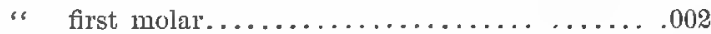

Width of " " ..................... 002

Length of crown of last molar.........................

"See Coues' Report U. s. Geol. Surv. Terrs. XI, p. 191 . 


\begin{abstract}
Meusurements. $\mathrm{M}$.
Width of crown of last molar.................. .0015

Length from M. 1 to infraorbital foramen............. .007

Depth of mandibular ramus at M. $2 \ldots \ldots \ldots \ldots \ldots \ldots . . \ldots 06$

Width of face of inferior incisor ..................... .0016

Entoptychus planifrons, sp. nov.
\end{abstract}

A larger species than the $E$. cavifrons, represented in my collection by parts of crania, and rani. The former show that hesides the superior size, this species differs from the $E$. cavifrons in the absence of the superciliary ridges, and lence perfect flatness of the interorbital region. The latter is also wider, measuring five-sixths the width of the muzzle at its middle, while in the $E$. cavifrons it is only half as wide. The subjoined measurements give the characters in detail.

Measurements. M.

Width of interorbilal space. . . . . . . . . . . . . . . . .00

" muzzle at mirldie.................... 0086

Elevation of skull from second molar.............. 0130

Length of inferior molar series. ............... .0072

Deptl of ramus at M. 2................... .0072

Width of inferior face at M. $2 \ldots \ldots \ldots \ldots \ldots \ldots \ldots . . . \ldots 043$

" "incisol .................... 0018

Distance between infraorbital foramen and M. 1...... .0050

Entoptychus crassiramis, sp. nov.

This, the largest species of the genus, appears to have been less abundant than the two already described. I refer to it portions of two crinia and three mandibular rami, found separately. The superior size of the parts is obvious, the posterior three superior molars having the same longitudinal extent is the entire series of the $E$. cavifrons. The gradation in the size of these teeth, is as in that species, the grinding surfaces diminishing rapidly in extent posteriorly. The superciliary ridges are not well preserved, but were probably thickened as in $E$. cavifrons, and the interorbital space was relatively as narrow, and not so wide as in E.planifrons. The measurements below exhibit the characters more exactly.

Mertsurements. M.

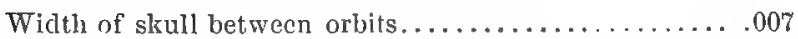

Elevation of skull from second molar............. 015

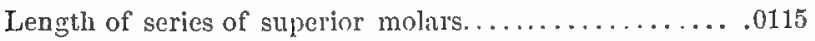

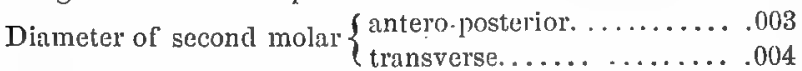

Diameter of fourth molar $\left\{\begin{array}{l}\text { antero-posterior. . . . . . . . 002 } \\ \text { transverse. . . . . . . . . . } 02\end{array}\right.$

In the mandibular rami the inferior masseteric ridge extends to below the anterior border of the first molnr, and is very prominent and acute. It results that both the exteriol and inferior aspects of the ramus are con- 
cave to the anterior extremity of the crest, which slopes upwards. The incisive alveolus, thongu not prominent as in the IIystricomorpha, is on the inner side of the base of the ramus in front, and the enamel-face of the incisor tooth is clirected more inwards than downwarls. Above the alveolar prominence, the inner face of the ramus is gently concave. The anterior origin of the coronoid process is opposite the posterior borter of the second molar.

Mectsurements. M.

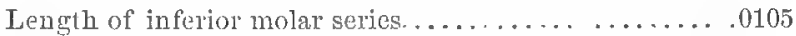

Width of anterior face of inferior incisor........... .0028

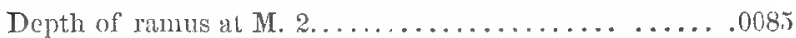

Wichth of ramus below at II. 2. . ............. .0070

Pledrolicus sulcifirons, gen. et sp. nov.

Char. gen. Fam. Saccomydice. Superior molars rooted and short-crowned. The crowns with a lateral fissure bordered with an inflection of the enamel sheath, extending to their bases. In the superior molars this inflection is on the external side, and does not divide the crown. Superior incisors not grooved.

This genus is curiously near to the existing Eeteromys and Perognathus, the two genera of Succomyida with rooted molars. The former differs in having the molars divided into two columns, each of which is slicathed in. enamel, while Perognuthus only differs so far as $I$ abl aware, in having the superior incisors grooved.

Sipcif. Chan. This speries res(mbles those of the allied genus Entoptyctus in many respects. The superciliary borders are thickened upwards, forming two ridges, which onclose a groove between them which is more pronounced than in the Entoptycluus cavifrons. The muzzle is plane above and considerably wider than the interorbital space. The base of the malar is thin and oblique, and the foramen infrarbitale exterius is well in advance of the molar teeth and at the anterior part of the maxillary bone. A groove passes backwards from its inferior border, terminating in a small foramen which marks a point nearly half way to the first molar. Within this, another shallow groove bounds the more prominent median line. The palital surface exlibits two shallow lateral grooves, which commence opposite the posterior border of the first molar.

The grinding sturfaces of the molar's are transverse ovals, only interrupted by the exterior fissure. The first molar is slightly different in form, being larger, and its section, when not much worn, being nearly round. Its anterior portion extends towards the alveolus, giving an antero-posterior oval, on prolonged wear. Each tooth has three loots, one interior and two exterior ; in the first they may be described as two posterior and one ante. rior. The last molur is the smallest, the series exhibiting a regulin grada. tion in size.

Mecusurements. M.

Interorbital width....................... .0050

Widtl of nuzzle at middle.................. .0080 
Micisurenuents. M.

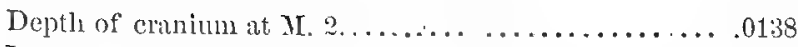

Length of molar series along base............... 0080

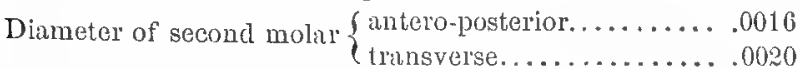

Width of fuce of superior incisor............... .0020

Meniscomys mippodus, gen. et sp. nov.

Gen. Chir. The characters of this genus are derived from the dentition of both jaws, and from portions of the crinium which are preserved. The molars are rooted, and number $\frac{4}{4}$. Those of the superior series are without enamel inflections, and the trituratiug surfuce exhibits two external and one internal crescentic sections of the investing enand. On the second superior molar there are three external cruscents in the typical species ; and the first molar is simply conic. Between the inner and external cres. cents, there are the curvel edges of enamel plates directed obliquely and transversely. The grinding surfuces of the inferior molars display in the unworn condition, two L-shaped transverse crests, connected longitudinally on the median line; on rearing. the laternl emarginations of the enamel become shallower, disappearing from the inner side, but remaining on the outer. Incisor tecth uot gronved. Furmen infrombitale anterius, if present, elevited in position and near orbit.

The churacters of the dentition of this genus res:mble those of the genus Pteromys, which is now confined to Asia and the Mataysian Archipelago. The superior mol:urs differ from those of Pteroneys in vanting all reëntrant enamel inflection. Specinens in ny collection indicate two species of I. niscomys.

Sperif. Chrer. Superior molars with a rertical ridge from the points of junction of the creseents nn the external sicle; there nre thus two on the second mular, and one each on the third and fourth. Within each of the external crescents is another crescentic elge of a pair of vertical enamel plates, and the inner marginal creseent sends off a short transverse branch towards them. With attrition, all these crests mite by their extremities, cnclosing four distinct lakes, which, after still further wear, disappear. Attrition produces a similar result in the inferior molars, viz.: two jairs of crescents enclosing four lakes, which ultimately wear out. The inferior incisor has a shallow concavity on its anterior face.

The maxilary bone, anterior to the molar teeth, is shorter than the premaxillary. The incisive foramina are entirely in the lntter. The sides and superior aspect of the muzzle are regularly convex in transverse section. The inferior incisive alveolus is enclosed entirely in the plane of the ramus, and extends posteriorly to below the last molar tooth. The masseteric ridge is very oblique, and rises to a median point below the second molar. The coronoid process rises from the front of the last nular.

Mrcusurements. M.

Length of superior molar serics...............008 


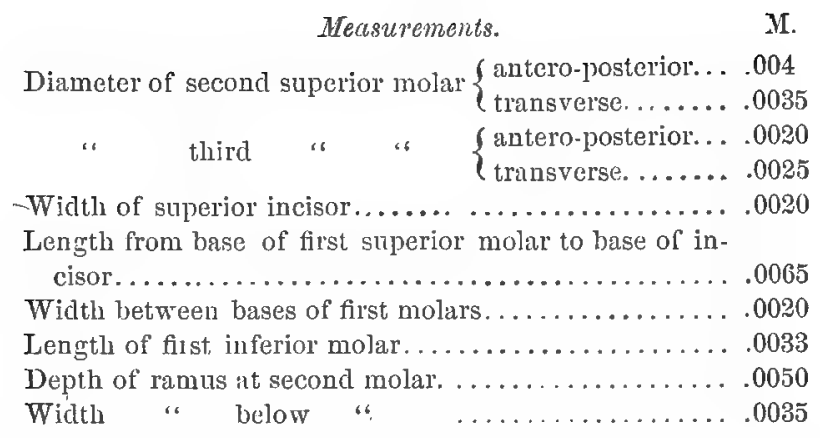

Meniscomys sultiplicates, sp. nov.

This species is considerably larger than the. M. hippodus, and differs in the greater complication of the enamel plates of the inferior molars. The four crescentic areas are cliscernible on the worn surfaces of the crown, of which the posterior inner is reduced in size on the middle two molars. The two enclosed lakes have very plicate borders which form many small loops, and sometimes they are fused into a single irregular area. The last molar is extended a little posteriorly, and all present an entrant argle between the inner columns. The coronoid process originates opposite the third molar, and the masseteric ridge ceases bolow the middle of the jaw below the second molar.

Mectsurements. M.

Probable length of inferior molar series........... .0120

Length of posterior three molars.............. .009

Diameter of second molar $\left\{\begin{array}{l}\text { antern-posterior. . . . . . . .0030 } \\ \text { transverse . . . . . . . . .0025 }\end{array}\right.$

Length of fourth molar. ..................... . 0040

Depth of damis below second molar............ .0070

Width " " "

C.arxivora.

TEMNOCTON ALTIGENis, gen, et sp. nov.

Gen. Char. This genus is only known from a mandibular ramus which sul ports all the teeth exceptiug the incisors and probably the last molar. There are four premolars and probably three true molars, all having the general character of those of Cunis. The only character by which I dis. tinguished the new genus Temnosyon is seen in the form of the heel of the sectorial tooth. Instead of presenting a concave surface bouncled by ridges or tubercles, it presents a more or less median cutting edge as in the poste. rior premolars of Oryma. In the typical species, there is but one row of cusps on the first tubercular molar, but they are not elevated, and stand on one side of the crown. In comparing this genus with types other than Cunide, one can recognize in its characteristic peculiarity of the sectoria 1 
tooth, one well-lsnown in the typical genera of Viverridce and Mustelida. Temnocyon is, liowerer, truly canine in other details, and appears to approach the genus Palaocyon of Lund. According to this author, the posterior inner tubercle of the anterior part of the crown of the sectorial tooth is wanting in that genus, so that it is distinct from the North American form.

Spccif. Char. The mandibular ramus is rather deep and compressed, much more so than in the Canis latrans, witl which it agrees in the length of the dental series. As compared with the existing species of Canis and Vulpes of North America, the sectorial tooth is relatively smaller and the premolars larger. In this respect it agrees with most other dogs of the Lower Miocene, and differs fron those of the Lpper Miocene (Loup Fork).* The posterior tubercle is wanting from the premolars, excepting the last, where it is large and obtuse, differing in this respect also from most recent dogs, and from the cotemporary Canis gregarius. In the sectorial tooth the princilal cusp is much elevated above the anterior, while the inner median is small, with its apex in line with the anterior. The cutting edge of the heel is not acute, and is a little external to the median line; there is a weak cingulum-like angle at its inner base. The first tubercular tooth is large, nearly equaling in antero-posterior diameter the base of the third premolar. It is parallelogrammic in transverse section, and supports two principal cusps and an anterior ledge. The cusps are pronounced and stand exterior to the middie line; their inner side slopes to the base of the crowu where there is no cingulum. The ledge is higher on the inner than the external side. There are no basal cingula on either sicle of the bases of any of the teeth. The second tubercular molar is lost.

The alveolar margin of the jaw rises behind the sectorial tooth, and the inferior margin begins to ascend below the middle of the same tooth more decidedly than in $C$. lupus, latrans or cuspigerus. The two large mental forimina, are situated, the one below the second, the other below the third premolal's.

Measurements. M.

Length of anterior six molars. ............... .078

" " four " $" . \ldots \ldots \ldots \ldots \ldots \ldots \ldots \ldots . . . \ldots 45$

" base of second premolar.............. .011

Elevation of crown " " " . . "........... 011

Length of base of fourth " " ............. ".

Elevation of crown " "

Length of base of sectorial tooth............... 0185

Elevation of principal cusp of sectorial tooth ......... 0160

“ anterior " “ " " . ........ 009

Length of heel of sectorial. ................. 007

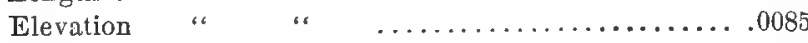

Length of crown of first tubercular............... .0115

* See Proceedings Academy Philadelphia, 1875, p. 22, where I have discusscd the origin and history of the sectorial tooth. 
Hecosurements. II.

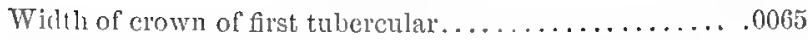

Deptl of ramus at P. II. $2 \ldots \ldots \ldots \ldots \ldots \ldots \ldots \ldots \ldots . . . \ldots 24$

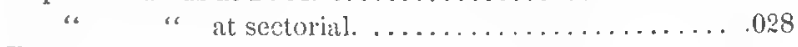

Thickness "f " $\ldots \ldots \ldots \ldots \ldots \ldots \ldots \ldots . . .610$

CANis CUSigigrus, sp. nov.

This peculiar species is inclicated by the greater part of the cranium with dentition, to which are united both rami of the lower jaw with nearly all of the teeth in place. These inclicate a dog of small size, about equaling the Canis gregarius Cope, but one presenting marked characters.

The third premolar tooth in both jaws cliffers from the corresponding one in the C. gregarius and in most recent species, in lacking the lobe of the posterior cutting eclge, agreeing in this (as regards the inferior series) with the Temnocyon altigenis. It is present in the fourth inferior premoJar, which has besides, a low heel. The inferior sectorial tooth is characterized by its great robustness; the internal median tubercle is much elevated, while the principal cusp is short. The heel is wide and basin-shaped. with the inner border as much elevated as the outer. The first tubercular molar is cliaracterized by its wichle as (ompenteel with its length being nearly as wicle transerescly as fore and aft. It has two anterior cusps followed by a hasin with elevated borters simulating two posierior cusps. There are an anterinl and a exterior cingulum. The second tubercular is a miniature of thie first, differiug in the more robust esteral posterior cusp, and the alsence of externul basal cingulum. There are no complete cingula on the exterma hases of the other inferior teeth. The second superior tubercular is well developed, having two external tubercles. The anterior inner cusp of the superior sectorinl is dis'inct and neute, ancl there is a cingulum along the inner bnse of the crown. The exsertert portion of the canines is long, sleuder, and with an oral section narrowed behinit. The enamel of all the molars is more or less rugose, a character which is only

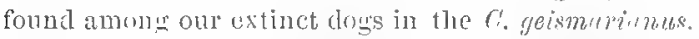

The mandibular lami are shallos, and their inferiol marmin is not stout. A gentle elevation of the latter commences 1 clow the firm tubercular tooth and the alveolar border rises but little behind. The masseteric fussa is cleep and well defined.

Menurements. II.

Length of inferior molar series. . . . . . . . . . . . . . 041

" bases of firur premolin's . . . . . . . . . (1):3

"b base of second " $" \ldots \ldots \ldots \ldots \ldots \ldots .005$

Elevalion crown " " "

Length of base of fourth "

Elevation of crown " "

Length of hase of sectorial. . . ...................

Elevation of principal clisp................... .006

Wiclth of lieel of sectorial................... .006 
Measurements. $\mathrm{Mr}$.

Diameler of first tubercular $\left\{\begin{array}{l}\text { antero-posterior ........006 } \\ \text { transverse . . . . . . . .00 J }\end{array}\right.$

Antero-posterior cliameter second tubereular.......... 0037

Length of base of superior sectorial. . . . . . . . . . . .009

" bases of two tuberculars................. 01 .

" base of first tubercular................ 0064

Canis getsmarianUs, sp. nov.

This species of clog may be placed with reference to the size of its inferior sectorial tooth between the $C$. lippinoottianus and $C$. hartshornianus. In the robust proportions of this tooth it more nearly resembles the $C$. cuspigerus. The mandibular ramus is robust and shallow, and quite dis. tinct from the cleej) jaw of $C$. hartshormirnus. The sectorial has perlupps twice the bulk of those of the $C$. bippincotticnus and $C$. cuspigerus. From that of the latter it diflers further in the small inner tubercle and contracted heel.

The sectorial part of the tooth is relatively small, not exceeding the heel in length, and its cusps are low. The heel is notable for the elevation of the tubercle of the inner sile-which exceeds that of the outer; the latter' also, is contracted, standing within the extcrnal base, which is represented by a short cingulum. A weak cingulum below the sectorial blackes. Surface of the enamel rugose where not exposed to friction.

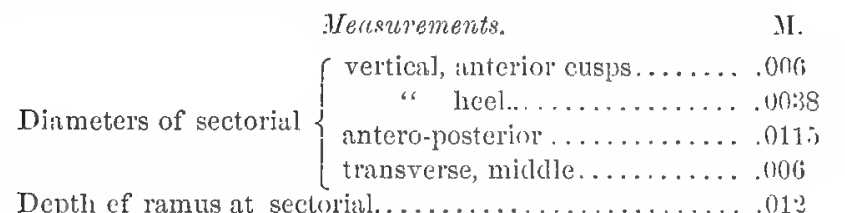

Trickness of " "

The affinities of this species are evidently with the C. cuspigerus. It is named in honor of Jacob Geismar, a skillful naturalist of Philadelphia.

Macherodus strigidens, sp. nov.

This obvionsly distinct species is only represented by the crown of a superior canine tooth, from which the apex has been l)roken. Its characters are so peculiar that I recold it uncler the above nane, rot knowing whether I shall liave better specimens.

The tooth is long and very much compressed, much more so thin in any species of the genus known to me. Its anterior and posterior edges are finely and very perfectly denticulate without lateral flexure near the base. The centre of each side of the looth is occupied by a wide open gutter, so that the grentest transverse diameter of the crown is not at its midlle. These gatters become planes towarcls the apex, giving an elongated hexagonal section. The size indicates an animal of the proportions of the M. primozus, and smaller than the ir. brachyops. 
As compared with the superior canine of the Duptophilus squalidens, which the present specimen resembles in its compression and fine denticuJalion, it differs in its greater relative length and in the presence of the lateral open suici.

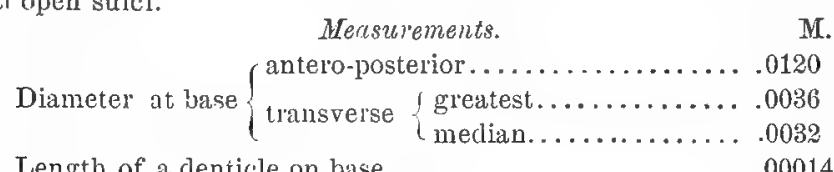

CHARODUS BRACH YOPS, sp. nOV.

This species, which ranged in size from that of the puma to that of the jaguar, is represented in my collection by parts of two crania ; by an entire cranium; by a left mandibular ramus with parts of the skeleton, and by several isolated teeth. The characteristics of the molars in both jaws are those of the other species of this genus. The first superior premolar is two-rooted and small, occupying the middle of the short space between the canine and the second premular. The latter is large, and has no anterior basal tubercles. Sectorial without anterior basal tubercle. 'Tubercular tooth small, transverse.

The crania of the three individuals mentioned agree in many particulars; and especially in the very short face and muzzle. This may be nore exactly expressed by comparing the interspace separating the second and third premolar from the canine with the length of the base of the latter. From this it is seen that the two dimensions are equal, while in the $M$. primesvus the first mentioned is much the Jonger of the two. In the mandible referred to this species another character is seen in the relatively large size of the premolars, which much exceeds that of the corresponding teeth in W. primcevus. The first is stated by Leidy to have an anterior basal cusp, which is wanting in the $M$. brachyops.

In the first cranium the sagittal crest is well developed. The canine tooth has an oval section at the base of the crown, whose long diameter somewhat exceeds the distance between it and the anterior base of the second premolar. The infraorbital foramen is large. The second specimen, the left maxillary and part of malar bones with tecth, shows that the length of the base of the sectorial tooth equals the space between it and the middle of the first premolar. The superior aspect of the proximal portion of the malar bone is horizontal, constituting a surface not seen in the species of Felis. The canine is robust, with an oral section at the base. The posterior denticulate cutting edge extends higher up than the anterior, and ceases it the base of the enamel. The anterior cutting edge is on the inner side of the anterior fuce of the tooth.

\section{Measurements.}

\section{No. 1.}

M.

I ength of muzzle in firont of cunine.................. 017

Diameter of canine at base $\left\{\begin{array}{l}\text { antero posterior. . . . . . . . } 018 \\ \text { transverse. . . . . . . . . . } 011\end{array}\right.$

Distance from canine to p. M. 2............... 017 


\section{Measurements.}

No. $2 . \quad$ M.

Length of base of series to canine............. 062

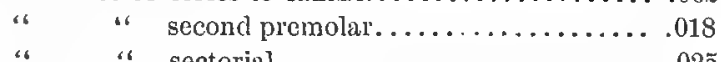

" " sectorial.................... .025

Elevation to summit of infraorbital foramen......... .033

The characters displayed by the second cranium lead me to suspect that it is that of a female. A striking feature of the superior dental series is the small size of tine canine, which is also not much compressed at the base. As regards the cranium, the sagittal crest is only distinct over the posterior part of the brain case; the zygomata are not very widely expanded, and the muzzle is narrowed. The external infraorbital foramen is Jarge.

The mental border of the mandibular ramus is not fiared downwards but is continuous, but the external is separated from the anterior and in. ferior faces by strong angles. The diastema is long. Three molars, all large ; the first without anterior basal tubercle, the second with a large one. Sectorial tooth the longest, with well cleveloped simple cutting heel.

Measurements. $M$.

Total length of craninm ...................192

Greatest width " $\ldots \ldots \ldots \ldots \ldots \ldots \ldots \ldots \ldots \ldots .123$

Length of dental series with canine.............. 077

Diameter of canine at base $\left\{\begin{array}{l}\text { antero-posterior........... } 012 \\ \text { trausverse. . . . . . . . . . . 008 }\end{array}\right.$

Distance between canine and second premolax"........ .019

Length base second premolar................... 019

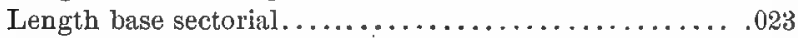

Length inferior dental series, with canine.......... 94

" diastema.............................. 025

Length base of first premolar. ................. 015

" " secturial...................... .027

Depth of ramus below second premolar...............

" " superior canine............. .027

This sabre-toothed tiger is larger than the Macharodus primcevus, and is more like the animal indicated by a fragment of the lower jaw named by Leidy, $M$. occidentalis. But the latter agrees with the $M$. primanus in the relatively small size of teeth, especially of the first premolar, and in their oblique position, characters not seen in $M$. brrecluyops.

\section{Perissodactyla.}

ANCHITHERIUM EQUTCEPS, sp. nov.

This animal is represented by a portion of the skeleton including a complete cranium of one individual with mandibular rami of several others The characters of the species are well marked, and do not approach very nearly to those of any other known to me.

The skull is considerably larger than that of $A$. bairdi, and the length 
is grenter as compared to the transverse and vertical cliameters. The preorbital region is but little concave, and the anterior boreler of the orlut is above the posterior half of the first true molar. The molar teeth present a tuberele between the anterior lobes, and a weak cingulum extends round the inner base of the anterior one, and in the second premolitr, round the base of both inner lobes. Thence it passes round the anterior base of the crowa and ceases in a tubercle which lises in contact with the anterior meclian crest. On the posterior side of the crown the cingulum in like manner terminates in the large three-sided posterior marginal tubercle. The anterior median tubercle-crest is well clistinguished fom the anterior inner tubercle and is clirected very obliquely. The posterior meclian crest is continuous with the inuer, and is well separated from the externat crests. The external basal cingulum is robust, the columns are promirent, aud the outer finces of the external crescents deeply inspresser but with a wall marked median ridge. The external cingulum and its margins is rthgose; other parts of the enamel smooth. The first premolur has two roots; the second premolar is as long as the fourtl, and longer than the liss: true molar.

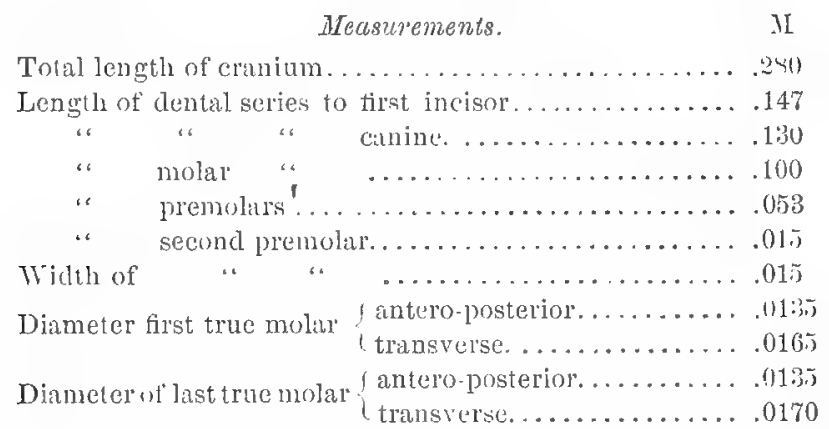

From A. condoni Leidy, this species differs materially in the composition of the superior molars In that species there are no inner tubercle and cingtum; the anterior median crest is more completcly separated the anterior cingulum does not cease with the anterior marginal tubercle, and the posterior marginal tubercle is linear, not triliedral.

Axchífhertum brachylopium, sp. nov.

Portions of the maxillary bones supporting molar teeth, inclicate a species of the size of the $A$. (quiceps, but differing in ritrious respects.

The median and inner tulyercles are not deeply separated, and the former are cut off from the extermal crescents by a deep fissure. There is no tubercle lietween the bases of the inner cones, nor is there any internal ringulum. The anterior cingulum cloes not develop a distinct tubercle, and does not extend to the anterior extremity of the anterior outer crescent. The posterior cingulum develojs a large triluedral unbercle, and then extends nealy to the extermal crescent. The exterual cingulum is 
robust, and the cxternal columns are prominent; the intervening spaces are impresced, and have a distinct median ridge. Enamel smooth or slightly luguse at base of crown.

Measuriments. MI.

Length of two superior molars................ 030

Diameter of first superior molur $\begin{aligned} & \text { antero.posterior. ...... .015 } \\ & \text { transrerse.......... } 017\end{aligned}$

These dimensions are those of the A. cquiceps.

ANCHITHERIUM LONGICRISTIS, sp. nov.

This is a smaller species than the two above desaribed, having the dimensions of the 1. bairli. The trest specimen representing it consists of a right maxillary bone, which supports all the molars excepting the last. The infraorbital foramen issues alove the third premolar. The first premolar is two-rooted; the second is not clongate, aud is equal to the other premolurs, or the penultimate true molar, in antero-posterior cliameter. There are no interior basal tubercles or cingula, but the anterior cingulum has a tubercle which is appressed closely to the anterior median. The posterior cingulum expands into a large tribedral posterior marginal tubercle. The anterior median tubercle-crest, appears in the worn state to be moderately clistinct from the interual; both it and the posterior middle are characterized by theix production ontwards; the latter passing between the exteriol crescents and forming a junction with their common connection. The external cingula are not strongly marked, nor the-external faces of the crescents impressed ; the latter are convex, and with the median ridge little distinct. Enamel smooth.

Measurements.

IVI.

Length of anterior six molars................. .062

premolar series..................... 044

Diameter of second premolar $\left\{\begin{array}{l}\text { antero-posterior........ .013 } \\ \text { transverse........... .014 }\end{array}\right.$

Diameter of second true molar $\left\{\begin{array}{l}\text { anteru-posterior. . . . . . 0125 } \\ \text { transverse........ 0105 }\end{array}\right.$

In the Annual Report of the U. S. Geol. Surv. Terrs. for 1873, " I gave the comparative characters of the three species of this genus then known to me, viz.: $A$. bairdi Lcidy; $A$. cuneatum Cope, and $A$. exoletum Cope. I now give a talule in which the three species above described are introduced, with the A. condoni Leidy.

A A tubercle between the internal lohes of the superior molars.

Larger; median tubercles well separated; large anterior and posterior marginal tubereles......................... equiceps.

Sunnller; median tubercles not separated ; no anterior marginal and a small posterior marginal tubercle. ..................... bairdi.

A.t To tubercle between inner lobes.

* Page 496. 
i. External cingulum robust.

$\beta$ Anterior median crest little or not distinct.

Larger; median crests cut off externally; no anterior marginal tubercle; external fuces impressed....................... brachylophum.

Small; posterior median crest confluent with external crests; an anterior marginal tubercle; external face little impressed........ A. longisristis.

B, 9 Anterior median crest isolated.

Larger; a large anterior marginal tubercle; posterior marginal linear;

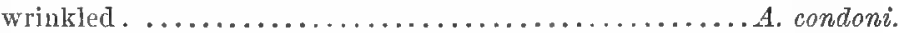

Small ; anterior marginal tubercle minute, josterior triangular; median crests short; smooth ......................... cuneatum.

ii. External cingulum narrow .

External faces withont median rib; median crests short, the anterior cut off ; marginal tubercles small . ................... exoletum.

STYLoxts seversus, gen. et sp. nov.

Gen. Char. These are derived from superior molar teeth Stylonus is allied to Hippotherium in details, including the isolation of the anterior internal enamel covered column, which thus forms an island of dentine, and in the prismatic character of the tooth. It differs from it in the fact that the posterior internal column is isolated in the sume manner as the anterior, thus forming a second island on the triturating sulface of the crown.

This inleresting new genus adds one to the already numerous forms of extinct equine animals. It carries to its limit the line of dèvelopment which retains the inner tubercles of the molar crown distinct from the median. The preceding station on this line which we know is the genus Anchippus, where the median crests have not assumed the antero-posterior clirection belonging to the higher equine genera, and where the molars lave short crowns ancl long roots. We may then believe that the line which includes Anchippus, Hippotherium, and Stylonus, is a side branch from that which terminated in Equus. The line of Equus must be traced from Anchitherium through Protohippus and Hippidium.

Specif. Char. Two superior mnlar teeth were accompanied by a number of inferior molars as having been all found together, but whether they belong to one individual is nncertain. The dentinal lakes of the superior molar are confluent by the medinn transverse valley, and increased wear would probably join the posterior pair by their posterior angles. The borders of the cementum lakes are simple, except one or two plications on their opposed adjacent borders, and one at the posterior inner part of the posterior. The internal columns are small, and their sections form two equal ovals with their long axes antero-posterior. The anterior dentinal lake sends off a narrow loop towards the posterior part of the anterior column. The slaft of the tooth is incurved, and the external face is unequally divided by the usual ridge. The wide gutters on each side of the latter are uniformly concave, and contain a rather shallow deposit of cementum. 
In the inferior molurs the two median interior tubercles are stout, and the loops which they bound, are nearly enclosed. There is a tubercle between the bases of the external columns.

Measurements. M.

Length of crown of superior molar. ........... 028

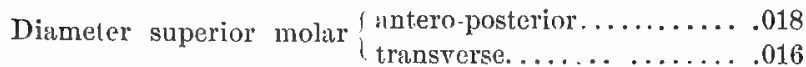

Long diameter internal column-lake............. .005

From the Pliocene formation of Cottonwood, Grant co., Oregon.

D AODON sHOSHONENSIS, gen. et sp. nov.

Gen. Char. These are indicated by the terminal portion of the lower jaw of a huge nammal, which does not resemble that of any known genus of this ordel. It supports on the side, three incisors, one cunine, and two premolars, which form an uninterrupted series. The first pre molar has two roots; and the canine is of huge proportions. The mandibular symphysis is coössified, and there are no osseous tuberosities on it nor on the adjacent parts of the rami.

- The characters of the piece on which this genus is established inclicate that the latter probably pertains to the Chalicotheridde along with Menodus and Symborodon. From these its six inferior incisors distinguish it, while the absence of a diastema separates it from Chalicotherium. From Palceosyops and Limnohyus it may be known by the large two rooted first premolar, or more correctly, in all probability, by the absence of the first premolar of the inferior series. In the relatively powerful canines it resembles the last named rather than the first named genera.

Specif. Char. The canine teeth are very robust, as in the species of Elotherium. The inferior face of the symphysis is not steeply inclined. and is quite elongate. It is narrowed near the bifurcation and expands to a rounded incisive border. The first incisor is narrower than the second and third, which are robust. There are two small mental foramina, the larger below the anterior root of the anterior premolar; the second below the anterior root of the second premolar.

Measurements. M.

Length of symphysis above...............155

Width between bases of canines................... 100

Antero-posterior diameter of base of cavine........ 055

Transverse " " second incisor.... .022

Diameter of base of first prenaolar $\{$ antero-posterior... . 040

This species is the largest of the North Amcricun Perissodnctyla, with the possible exception of the Menodus proutii.

\section{ARTIODACTYLA.}

Hropotamos guyotianes, sp. nov.

This species of a grenus little known in North America, is represented by 
a portion of the left manclibular ramus, in which only the last molar is sufficiently well preserved for identification. The latter is, however, perfect, and furnishes clear eridence of the former existence on the west side of the Rocky Mountains of a species distinct from the H. americanus Leidy from the more enterm regions. The cones are in pairs and are directly opposed; their section is sub-trihedral, the two external sides of the external cones, forming a regular convexity. The cusps are acutely produced and slightly divergent. The posterior side of each outer cusp is excavated; the exterior side of the same presents a median rib with a con cavity on each side, which is terminated below by an imperfect cingulum. The latter terminates on each side of the base of the cusp in a rudimental cusp, of which there are thus four on the external sicie of the tooth. The boundaries of the inner lace of the external cusps are angular ; the posterior one joins a corresponding riclge trom the inner cusps, but there is no descending ridge on the anterior inner side of the internal cusp, which therefore forms no junction with the opposite part of the external cusp. The fifth cusp is well developed, and sends a crest inwards to the interior base of the interior cusp of the adjacent pair.

Ireasurements. M.

Diameter of last inferior nolar $\left\{\begin{array}{l}\text { antero-posterior........ .022 } \\ \text { transverse.......... .010 }\end{array}\right.$

This species is smaller than the $H$. americanus, and differs much in de. tails. It is dedicated to Prof. Arnold Guyot, of Princeton, New Jersey.

Printed Dec. $3,1878$. 




May 17, 1878.]

673

[Cope.

Synopsis of the Irishes of the Peruvian Amazan, obtained by Professor Orton during his Expeditions of 1873 and $187 \%$.

BY E. D. COPE.

(Read before the American Philosophical Society, May 17th, 1878.)

The present paper consists of a catalogue of one hundred and twenty species of fishes which were obtained by the late Professor James Orton, from the head streams of the Amazon. The localities from which the specimens were derived, are the following: Cuzco, on the Urubamba near the head of the Ucayale; Moyabamba and Balsa Puerto on or near the lower course of the Huallaga; Nanta on the Marañon at the mouth of the Ucayale, and Pebas below the mouth of the Napo. The larger part of the collections of 1873 came from Nauta, while those of $187 \%$ were partly obtained near Pebas. The specimens from the Urubamba are the only ones taken at a great elevation, that of 11,000 feet. A recapitulation will be given at the close of the Catalogue. The collections contain numerous species previously known, as well as a number of interesting novelties.

\section{HOLOSTOMI.}

SYMBRANCHID A.

1. Symbranchus marmoratus Bloch.

Coll. 1873.

\section{NEMATOGNATHI.}

\section{HYPOPHTHALMID必.}

\section{Hrpophthalmus edentatus Spix.}

Coll. 1873.

3. Hxpophthalmus perporosus, sp. nov.

Established on a rather large specimen in good preservation. Radii ; D. I. 6 ; A. 67 ; V. I. 5. The dorsal fin is small, and is situated $35 \mathrm{~mm}$. nearer the end of the muzzle than the base of the superior fulcra of the cautal fin ; it originates above the seventh ray of the anal fin. The extremities of the ventrals do not extend beyond those of the pectorals. The spine of the latter is very wcak, although longer than that of the dorsal, and is one. third the length of the head. The head enters the length minus the caudal fin four and one-seventh times, and is just equal to the depth of the body at the anterior part of the anal fin. The eye is one-thirteenth the length of the head, and one-sixth the length of that part of the head anterior to it. The fissure continued from the canthus oris extends to below its center. One eye is a little more elevated than the other, the one having some inferior range, the other none. The maxillary barbels coinmence nearer to the angle of the mouth than to the base of the posterior mental barbels, and extend to a little beyond the base of the ventral fin. The mental barbels are on nearly a transverse line, and are broadly margined posteriorly ; they

PROC. AMER. PHILOS. SNC. XVII. 101. 4F. PRINTED JUNE 1878. 
are sub-equal in length, and when extended reach nearly to the opercular border. A peculiarity of this species, which I do not find in the $H$. edentatus, is the porosity of the skin. A series of pores extends along each border of each myoconman, forming clouble rows, extending from the dorsal to the ventral line $3 \mathrm{~mm}$. apart. The pores in each row are from one to two millimeters apart.

The general color of this species is silvery, with the head and dorsal region lead colored. Total length M. .500; of head .108; to the line of the base of the anal .160; to base of caudal fin .4.35.

Probably from Nauta.

\section{SILURID A.}

4. Sorubim lima B1., Sehn. Coll. 1873-77.

5. Pratystoma fasciatum Linn. From Nauta, coll. 1879.

I find the anal rays of the specimen to count II-9; Dr. Günther gives 14.

6. Hemisorubim Platyrhynchus Cuv. Val. Coll. 1877.

7. Phractocephalus hemliopterus Schn. Coll. $187 \%$.

8. Pseudorhamdia piscatrix Cope, Proceed. Amer. Philos. Soc., 1870, p. 569.

Coll. $187 \%$.

9. Prmelonds humilis Gthr., Catal. Fishes, Brit. Mus: v 129.

A specimen of about the size of those described by Dr. Günther agrees with them very closely in all important respects. There are some differences, however, which should be noted, especially since the typical specimens are said to have come from Venezuela. In the latter the distance between the dorsal fins is said to equal two-thirds the length of the adipose fin : in my specimen this space equals two-fifths the length of the adipose. The diameter of the eye in the former is described as one-half the width of the interorbital space; in the Peruvian specimen, the cliameter of the eye is a little more than one-third the same dimension. There is a dark cloud at the base of the rayed dorsal fin, whose superior border is abruptiy contrasted with the paler color above it. The anterior part of caudal region is a little more elevated than the dorsal region.

From Rioja, near Moyabamba, coll. of 1873.

10. Pimelodus bathyurus, sp. nov.

Head covered with thin skin, and not granular, but somewhat ridged above. Supraoccipital process long and narrow, not reaching the basal bone of the dorsal spine; adipose fin contained 4.3 times in the length minus the caudal fin. The candal portion of the fish is considerably deeper than the abdominal, entering the length (less the cauclal fin) six and three-tenth times. The head (to the opercular border) enters the same three and one-half times; it is flat and rather elongate, ancl the mandible projects beyond the 
premaxillary borter. The eye's cliameter is just half the interorbital width. The maxillary barbels exceed the length of the fish; and the postcrior mandibulars reach to a point below the middle of the dorsal fin.

Raclial formula; D. T. 6 ; A. 9. Dorsal spine very slender, smooth, and not so long as the pectoral spine. The latter is as long as from the premaxillary border to the middle of the orbit; it is finely serrate on both edges. Operculum roughened with radiating lines; suprwocciptal process six times as long as wide. Total length M. .070, interorbital width .007; length of base of rayed dorsal .008. Color uniform plumbeous.

Collection of 1877 ; two specimens.

11. Pinelodus ophthalmicus, sp. nor.

Head covered with a thin skin above which is involved in osseons wrinkles on the post frontal region. Supraoccipital process four times as long as wide, reaching the basal bone of the dorsal spine. Length of adipose fin contained 2.8 times in the length minus the caudal fin. Form quite slender; the greatest depth (which is at the middle of the dorsal fin) entering the length (minus the caudal) 6.5 times. The length of the head enters the same 4.75 times. The maxillary barbels reach to the middle of the anal fin, and the posterior mentals to the middle of the pectoral fin.

The eye is large, entering the length of the bead three and three-eighth times, and exceeding tlie interorbital wiclth by $2 \mathrm{~mm}$. The upper lip projects a little beyond the lower. The two dorsal fins are separated by a space about equal to three-fourths the base of the anterior fin. The latter is higher than the depth of the body, and nearly equal to the length of the bead; the spine is slender, and finely dentate on both edges. The pectoral spine is finely serrate on both edges and is nearly five-sevenths the length of the head. Radial formula ; D.I. 6; A. 13 ; V. 6 ; P. I. 8 . Humeral process extending to middle of pectorai spines, striate grooved. Axillary pore present. Color brown lead-color; top of head blackisll; dorsal fin brown at base, then clear, then blackish. Total length M. .145.

Coll. of 1873 .

This species belongs to the group with Pimelodus cristatus, P. elongatus, $P$. agassizii, $P$. wesselii, etc. It appear's to approach most nearly the first named, but that fish has, according to the descriptions, fifteen anal rays, and the mental barbels extend beyond the extremity of the pectoral fins. Günther also states that its dorsal fin is nearly twice as high as long, which is not the case in my specimen, and the dorsal spine is not so long in the latter, being only three-fourths as long as the head instead of equal to it. The Pimelodus cyanostigma (Rhamdia cyanostigma Cope, Proceed. Amer. Philos. Soc. 1870, p. 569) is an allied species; but it has a shorter adipose fin, which enters the length three and one-fourth times, and which is separated from the rayed dorsal by a space equal to the length of the latter. Its maxillary barbels are also longer, extending to the end of the adipose fin.

12. Pimelodus Bufonius Cuv. Val.

Coll. $1873-1877$. 
13. Callophysus lateratis Gill.

Coll. 1877 .

14. Ageniosus brevifilis Cuv. Val. Coll. 1873.

15. Euanemus nuchalis Spis.

Coll. $1873-1877$.

16. Euanemus brachyurus, sp. nuv.

A single specimen of this species compared with three of the E. nuchalis, exhibits the following differential characters: With the head and abdomen of about the same length, the caudal region is only two-thirds as long; hence the anal fin is shorter, and is supported by fewer rays. The dorsal spine is materially longer and stronger. The head is much wider than in a $E$. nuchalis of the same total length. The teeth are much more numerous, forming wide bands on the dentaries, and a well-detined premaxillary band. The humeral process is naked; in $E$. nuchalis it is covered by a soft skin.

The depth at the first anal ray is one-sixth the length less the caudal fin. The length of the head enters the same 4.8 times. The length of the eye enters the head three times, and the interorbital width, one and two-third times. The dorsal spine is weakly serrate behind, smooth in front. The pectoral spine is strongly serrate behind, and is smooth in front; it is about as long as the head, and one quarter longer than the dorsal spine. Radii D. 1.7 ; C. $+17+;$ A. 37 ; V. 14 , the first ray enlarged; P. I. 12. The inner rays of the ventral fins adhere to the integument of the abdomen, but not to those of the opposite fin. The ventrals are wider than the pectorals and nearly reach the anal fin; the pectoral spines do not reach the base of the ventrals. The humeral process is smooth, and reaches the end of the basal fourth of the spine. The maxillary barbels reach nearly to the extremity of the pectoral spine, while the anterior mentals reach to the base of the same.

Total length. M. .145; of head.025; do. to base of anal fin .070 ; of base of anal fin .040. I Lead-colored, sides of abdomen silvery ; base of caudal fin blackish, the color extending into the superior and longer lobe.

17. AUChENIPTERUS BREVIBARBis, sp. nov.

Form robust; Jength of head entering total, without caudal fin, a little over four times; the deptl of the body at the ventral fins entering the same five times. Head above coarsely granular, frontal fontanelle reduced to a small round hole. MLandible projecting a little. Anterior mental barbel as long as three cliamelers of the eye ; the postelior not reaching the line of the posteriur border of the operculum. IIaxillary barbel reaching to the middle of the pectoral spine. Diameter of eye less than one sixth the interorbital width. Humeral process half as long as pectoral spine. Lateral postemporal process decurved so as to be nearly in contact with the middle of the liumeral process.

Radial formula: D. I. 5 ; P. I. 6 ; V. 7 ; A. 22-3. Dorsal spine very ro- 
bust, denticulated in front; pectoral spines twice as long, equaling (axial) length of head, rolust, and serrate on both edges. Their extremities ex. tend behind the line of the last dorsal ray, but do not reach the origin of the ventral fin. Caudal fin truncate with a slight obliquity inwards and downwards. Total length M. .230; of dorsal spine.023; of pectoral fin .045. Color above blackish, below brown; lower part of sides, chicfly behind pectoral fin with dark spots on the brown ground.

This robust species is related to such as the $A$. obscurus Gthr., but differs from them in the short beards, fewer fin rays and other claracters.

Coll. 18 ir.

18. Auchenipterus isacantuus, sp. nov.

Head rather wide, not steeply shelving at the sides posteriorly, and finely rugose above, without a dermal layer, so that the segmentation of the bones is distinctly visible. Its length enters the total (less caudal fin) four times; which is an expression of the robust form of the fish. The body is highest at the front of the anal fin. Radii D. I. 5 ; A. 22; V. 7. Dorsal and pectoral spines of equal length and a little shorter than the length of the head, both serrate on both edges, the dorsal much the more finely. Eye obscure; operculum covered with smooth skin. Anterior mental barbels about equal to diameter of orbit; maxillary barbels reaching end of pectoral spine. Mandible projecting a little beyond premaxillary. Humeral process reaching beyond the middle of the pectoral spine, its surface coarsely striate, the striæ nodular. No thoracic dermo-ossification. Anal fin with nearly straight free border. Total length .085 ; of head above .025 ; of dorsal spine .016 ; interorbital width .C11. Uniform lead color ; dorsal fin with a black spot above.

This species is much smaller than the last, and very different in many respects, although it agrees with it in the rugosity of the head. It has, however, a large fontanelle open in front, while that of the A. brevibarbis is very small, and completely enclosed.

Two specinens; Coll. 1877.

\section{Centromochlus heckeli Filippi.}

Coll. 1877.

20. Epapterus dispilurus, gen. et sp. nov.

Chur. Gen. Group Doradince of Gunther, with anterior dorsal fin in front of the ventrals, and gill membranes confluent with that of the throat. No adipose tin; soft portion of dorsal rudimental. Six barbels; teeth wanting from jaws and palate. Dorsal and pectoral spines preseut; ventral fius united to each other and to the middle line of the belly. Anal fin long, distinct from the caudal.

This new genus is related to Euanemus, but is distinguished by three characters, viz: (1) absence of adipose fin; (?) absence of teeth, and (3) rudimental soft part of first dorsal fin. The rudimental character of the teeth in Euanemus nuchalis offers an approximation to the edentulous condition of Epapterus. 
Char. Specif. The proportions are elongate and the head is short, entering the length less the caudal fin six times. The anal fin is long, extending far forward, and the greatest depth of the fish is at its anterior part. 'This is a little more than one-tifth the length (less the caudal fin). The head is narrow, and rises rather steeply to the base of the dorsal spine withou interruption. The supraoccipital process is rather wide, and continuous with the basal bone of the dorsal spine. The latter is bifurcate and sends a process outwards and backwards behind the base of the spine. The frontal fontanelle is long, and the head is covered with smooth skin. The eye is large and without free dermal border; its diameter enters the length of the head to the opercular border three and one-third times, and the interorbital width one and two-third times. The superciliary and prefrontal borders are prominent and form together an acute angle. The supraoccipital region is not keeled, but its sides form a steep roof.

Radii D. I.; A. $61 ;$ C. $+17+$; V. $15 ;$ P. I. 13 . The dorsal spine is slender and nearly as long as the pectoral. It is directed somewhat forwards, and is entirely smooth. The caudal fin is notched to liwlf its deptl, and is rather small. The ventrals are large, and are united by the entire length of their inner rays. The external or first ray of each, is larger than the others, and the apex of the fin reaches the first anal ray. The closed pectoral spine barely reaches the base of the ventral ; it is set witl recurved teeth belind, but is sinooth in front. The soft part of the fin is contracted and is much smaller than that of the ventral fin. The humeral process is short and smooth and is covered by a smooth skin; the postcoracoid processes are rather long and are very acute at the apex.

The maxillary barbels continue from the extremity of the long maxillary bone to the middle of the pectoral spine; the anterior ventrals, which are very little in advance of the posterior ventrals, reach the base of the same. The eyes have nearly as much inferior as superior range, and the mouth does not extend beyond their anterior angle. Lips equal.

Color in spirits light brown, the dorsal region blackish. A black spotin the middle of each lobe of the tail. Total length M. .125; length of head .019 ; to the base of anal fin .046; of anal fin .062. Width between bases of pectoral spines 016 .

Two specimens from the collection of 1873 .

21. Cetopsis candira Agass.

Coll. of $187 \%$.

22. Reinodoras prionomus Cope, Proceed. Academy Philada. Septenber 1874, p. 184. Rhinodoras teffeanus Steindachner, Sitzungsberichte Akademie Wiss. Wien, 1875 ; read January, published ? Pl. III.

From Nauta, Coll. 1873.

23. Rhinodoras niger Valenc.

Coll. 1873. Nauta.

24. Zathorax nauticus Cope, Proceed. Acad. Phila. 1874, p. 133.

From Nauta.

In some specimens of this species the adipose dorsal fin is wanting, 
though generally present. The naked inferior surface of the scapular arch distinguishes this geuus from Doras, and I now think that the peculiar form of the prefrontal bone has a similar value. The superior and anterior borders of the latter are free and pectinate as in Physopyxis.

The Doras pectinifrons $\mathrm{m}$. presents the same character, but the scapular arch is covered below by thick skin as in Doras. I therefore regard it as representing a genus between the latter and Zathorax, which may be called Agamyais. Doras grypus $\mathrm{m}$. belongs to Doras.

25. Hypoptopoma bilobatum Cope, Proceed Amer. Philos. Soc. 1870, p. 566 .

Coll. of 1873.

26. Hтpoptopoma gulare, sp. nov.

This species is more robust than the $H$. bilobotum, and differs in various respects. There are but 21 shields crossed by the middle line of the side instead of 25 ; the space between the sub-orbital bones and the clavicle is filled with an osseous shield wanting in $H$. bilobatum, and there is no median series of abdominal scuta. As compared with the H. thoracatum Günth, this fish exhibits similar proportions, having the head wider in proportion to the length than in $H$. bilobatum. But the scuta of the throat and thorax in $H$. thoracatum are as in $H$. bilobatum, as well as the number of scuta crossing the lateral line. The caudal fin has the lobes sub equal as in $H$. bilobatum.

Radii D. I. 7; A. I. 5; V. I. 5; P. I. 6. Pectoral spine reaching end of ventral spine; dorsal spine not branched at extremity, rather stout. nearly as long as the pectoral, its base $4 \mathrm{~mm}$. nearer end of muzzle than base of caudal fin. Head very flat, quite wide, its width behind orbits about one-fourth the length to the base of the cauclal fin; its length to the superior angle of the gill opening, 3.8 times into the same. The spine supporting the adipose fin, stands on the anterior border of the fourth clorsolateral scute counting from the base of the first superior caudal fulcrum. Some scuta between this point and the last dorsal ray. Each border of the muzzle supports a wide band of segments, within which a narrower band of segments bounds the median wedge-shaped area on each side. Inferior border of end of muzzle prickly; eye with some inferior range. Scuta of head above, and those below as far as vent, finely granular; the others smooth. Color olive brown, each scute of the body, and the three nuchal ones with a pale border within the edge. Caudal with the rays brown, except a wide margin, and a vertical line beyond base, which are pale. The dorsal fin is deep brown at the base, and has some dark spots on its middle. Length M. .105; to base of pectoral fin .028; to base of anal .052 : elevation of dorsal spine .021.

Coll. of 1877 .

27. Chanothorax bicarinatus. Gen. et sp. nov.

Char. Gen. Callichthyiform fishes with osseous dorsal and pectoral spines, a produced occipital shield, and 9-11 soft rays in the dorsal fin. 
The coracoid shields are lateral, and do not cover the abdomino-thoracic region.

This genus is similar to Gastrodermus $\mathrm{m}$. excepting in the increased number of dorsal radii, in which it is identical with Brochis. It might be called Brochis without coracoid breast shield. A synopsis of the species of this group is given below.

Char. Specif. Radii: D. I. 11 ; A. II. 6 ; V. 6 ; P. I. 7. The dorsal and pectoral spines are of sub-equal length and serrate behind only ; their length equals the distance from the pupil of the eye to the end of the muzzle. The profile is rather steep; the hcad is compressed, and the muzzle is produced. The diameter of the eye is a little more than one-fourth the length of the head, is one-half the length of the muzzle, and half the interorbital space measured over the convexity. There are two azygous bones between the supra-occipital crest and the first dorsal spine. There are twenty three vertical scuta between the supra-temporal, and the base of the caudal fin; no dorsal or ventral azygous scuta. The postcoracoid plates are nearly smooth and sub-vertical, projecting downwards so as to form an obtuse keel on each side of the belly. Inferior bridge of scapular arch covered with soft skin. Maxillary beard nearly attaining gill fissure ; inferior lip broadly reverted, produced into a short barbel on each side. Facial ossification extending one-third the distance to the maxillary; half way to the end of the muzzle, and not enclosing nares. Color olivaceous; top of head darker; fins immaculate. Length M. .059; of head .014; do. to base of ventral fin (axial) .022; to base of anal .035. Length of clorsal spine .011. Coll. 1877.

A second species of this genus is the $O$. semiscutatus (Corydoras Cope, 1872). The species and genera of this group are the following:

Brochis Cope, Proc. Ac. Nat. Sci. Phila. 1871. Corncoid shields covering the breast; dorsal soft rays 9-11. The Cullichthys taiosh Cast. probably belongs to this genus.

B. coruleus Cope, loc. cit. 1872, p. 277.

B. dipterus Cope, loc. cit. 1872, p. 278.

Chanothorax Cope, supra. Caracoid shield not enclosing the breast and belly; dorsal soft rays 9-11.

C. bicarinatus Cope, supra.

C. semiscutatus Cone, Proceed. Acad. Phila. 1872, p. 280.

This species differs from the $O$. bicarinatus in the horizontally extended coracoid shields, the greater development of the facial ossification, the shorter muzzle, larger eye, and greater relative thickness of the head.

Corxdoras Lacep. Bleeker; Hoplisoma Sws. Coracoid shields enclosing ventral region; dorsal soft rays $6-7$.

C. punctatus Lac. Günther, Catal. จ. 229.

C. aneus Gill. Günther, 1. c.

C. eques Steind. Sitzungsberichte Wien Akademie, 1876 (July), p. 92, Pl. XII, fig. 3. 
Gastrodermus Cope. Coracoids not enclosing the ventral region, which is covered with soft skin; dorsal soft rays $6-7$.

G. ambiacus Cope, Proceed. Acad. Phila. 1872, 280.

G. trilineatus Cope, 1. c. 281, Pl. VI, fig. 2.

G. acutus Cope, 1. c. 281.

G. amphibelus Cope, 1. c. 282.

G. armatus Günth. Proceed. Zool. Soc. Lond., 1868, 230, cut.

G. agassiai Steind. loc cit. sup. 90, Pl. XII, f. 2.

G. elegans Steind. 1. c. 93 .

G. nattereri Steind. 1. c. 95, Pl. XI, f. 1.

28. Gastrodermus amiatus Gthr.

Coll. 1873.

29. Gastrodermus ambiacus Cope.

Coll. 1873. Nauta.

30. Callichthys asper Quoy. Gainn.

Coll. 1873. Nauta.

31. Hoplosternum lowgrillis Cuv. Val.

Coll. 1873. Nauta.

32. Loricaria cataphracta L.

Coll. 1873. The Marañon.

33. Loricaria rostrata Spix.

Coll. 1873.

34. Liposarcus Jeanesianus Cope, Proceed. Acad. Phila., 1874, p. 135. Coll. 1873. Nauta.

35. Liposarcus scrophus Cope, 1. c. p. 136.

Coll. 1873. Nauta.

36. Plecostomus virescens Cope, 1. c. 137.

Coll. 1873.

3\%. Arges sabalo Cuv. Val.

Rio Urubamba ; altitude 10,000 feet.

38. Trichomrcterus dispal Tsch. Cope, Proceed. Amer. Philos. Soc., $1877, \mathrm{p}, 30$.

Sources of the Ucayale at Urubamba, 10,000 feet, and Tinta, 11,400 feet.

39. Trichomycterus gracilis (?) Cuv. Val., Cope, loc. cit. p. 30.

Tinta, 11, 400 feet.

\section{AspredinIDA.}

40. Bunocephatus melas Cope, loc. cit 1872, p. 132.

Coll. 1873. Nauta.

41. Drsichrey coracordeus Cope, 1. c. p. 133.

Coll. 1873. Nanta.

PROC. AMER. PHILOS. SOC. XVII. 101. 4G. PRINTED JUNE 1878. 


\section{PLECTOSPONDYLI.}

\section{STERNOPXGIDA.}

42. Carrapus fasciatus Pallas.

Coll. 1873-1877.

43. Sternarchus bonapartil Castelnau.

Coll. 1877.

44. Sternarghus albifrons Linu.

Coll. $187 \%$.

45. Sternarchus schotti Steindachner.

Coll. $187 \%$.

46. Sternatichus balizaros, sp. nov.

Profile oblique, with a depression between the orbits; snout short, and much narrowed. Lower jaw large, projecting beyond the upper both anteriorly and laterally, enclosing the latter somewhat as in a whalebone whale. The fissure of the mouth is short, only reaching the vertical line from the anterior nostril. Eyes small, without frec border, much nearer the snout than the gill opening, one-twelfth the length of the head, which latter enters the length without caudal fin, 8.5 times. The depth at the base of the dorsal thong is equal to the length of the head. Anal radii 171. Scales very large, in only nine longitudinal rows at the base of the dorsal thong. Color olivaceous, with a pale dorsal band which reaches the dorsal thong, and a pale narrow band on each side near the dorsal band. Length M. . 165 ; length to origin of anal .020 ; Jength to base of dorsal thong .096 .

This species resembles remotely the $\$$. schottii of Steindachner, but differs from it and from all the other species in the much enlarged mandible and the large scales.

Coll. 1877.

47. Rhamphos'sernarchus macrostoma Gthr., Catal. Brit. Mus. VIIT, p. 4.

Coll. $187 \%$.

48. Rhampaichthys pantheirinus Castelnall.

Coll. 1sir.

49. Sthinopygús Viresoens Valenc.

Coll. 1873-1877.

50. Sternopygus troscheli Kaup.

Coll. 1877.

51 Sternopygus macrurus Bl. Schn.

Coll. 1877.

\section{Characinid an.}

52. ANOdUs MELANOPOGON, sp. nov.

Char. Gen. Jaws edentulous; abdomea not serrate. Branchial fissures very extensive. Branchial arches furnished with long rakers, which are present on the fifth arch as well as the others. 
This genus is Curimatus with a clupeiform branchial apparatus. In both the species the rakers on the anterior four arches are bristle-like, while those on the fifth resemble somewhat the pharyngeal teeth of Catos. tomidce, although flexible.

This genus luas nevel been distinguished from Ourimatus until the present time. It is aot unlikely that the second species included by Spix in Anodus (An. lutior) is a Curimatus, but the A. elongatus must be regarded as the type of the genus. Guvier established Curimatus on the C. cyprinoides (Salmo edentulus Bl. fide Gthr.) but included in it erroneously the Anodus elongatus, in which he is followed by Günther.

Since the above was written I learn that Professor Gill lias described this genus under the name of Elopomorphus, in a recent number of a popular journal.

Char. Specif. General form slender, head elongate, and with acuminate muzzle, with the mandible projecting, beyond the premaxillary border. Length of head entering total without caudal fin, three and two-thirds times; depth of body at dorsal fin, less than one-sixth of the same. Eye large, one sixth of length of head entering one and one-fourth times into length of muzzle and interorbital space, which are thus equal. Opereular bone as long as deep; interoperculum large; extremity of maxillary extending a little beyond vertical line from anterior rim of orbit.

Radii ; D. 110 ; A. 1. 10 ; V. 11; P. 19 . Base of first dorsal ray $3 \mathrm{~mm}$. nearer end of muzzle than base of dorsal fin, pectoral fin reaching half way to ventrals, and ventrals half way to anal. The scales are small, in about 128 transverse rows, and at the origin of the anal fin in 23 longitudinal rows. The origin of the veutrals is below the middle of the dor'sal fin. Total length M. .075.

Color blackish above and one-third way down the side ; sides and abdomen, with sides of head silvery. Dorsal and caudal fins dusky and without spots. End of mandible black.

Coll. of 1873 ; numerous specimens.

53. Anodus steators, sp. nov.

While the preceding species has rather clupeiform character, the present one looks like a Hemiodus, and particularly the H. microlepis, with which it was found associated in the collection. It differs nouch from the $H$. melanopogon in the even lips, and the extensive adipose membrane which closes the eye to an even greater degree than is found in the H. microlepis, reclucing it to a vertical fissure. Radial formula D. I. $10 ;$ C. $3+19+3$; A. I. $11 ;$ V. 12 ; P. 19 , reaching half way to ventrals; ventrals reaching half way to vent. The ventrals originate below the middle of the dorsal fin, which originates exactly half way between the end of the muzzle, and the base of the superior cauclal fulcra. Scales small, $\frac{\frac{13-14}{10}}{10}$. The general form is slender, the depth entering the length less the caudal fin 5.3 times; and the length of the head entering the same 3.6 times. The diame- 
ter of the eye as seen through its adipose covering is a little less than one-fifth the length of the head; and is one-half the interorbital width measured over the strong convexity of the frontal bone. The maxillary bone makes an angle with the premaxillary, and extends as far as the line of the anterior border of the orbit ; the greater part of its length passes beneath the edge of the preorbital bone. The opercular apparatus is elongate, but the operculum is deeper than long. Total length M. .205; length of head .047 ; length to origin of dorsal fin (axial) .082; do. of ventral .090 ; do. of anal fin .134.

Color in spirits steel blue, paler below; base of the caudal fin extensively black; other fins unspotted. Sides of head golden; chin and top of head black; a golden speculum above the orbit.

Coll. of 1877 .

54. Curimatus altamazonrcus, sp. nov.

This is a robust species with small scales. The form is elongate-oval, and the head wirle. The pectoral region is not flattened nor covered with roughened scales, while the ventral line from the ventral fins to the vent is keelch, but not serrate. The dorsal fin is elevated, its anterior rays being four-fifths as long as the head.

Radii ; D. I. 10 ; A. I. 12 ; V. 9; P. 13 . The pectorals do not reach the ventrals, nor the latter the vent. The ventrals originate below the fifth dorsal spine. First dorsal ray much nearer the end of the muzzle than the base of the caudal fin. Scales "25-94-22. Depth at first dorsal ray entering length minus caudal fin 2.7 times. Length of head in the same three and two-fifth times. The eye enters the leugth of the head four and four-fifth times, and twice in the moderately convex interorbital width. Lips equal, the inferior closing within the superior. Maxillary bone short, not extending behind the line of the nares. Color silvery without spots on the body or fins. Total length M. .200; length of head .049; do. to origin of diorsal fin (axial) .070 ; do. to origin of ventrals .080; to origin of anal fin .124.

This species appears to be nearest the $C$. latior Spix. judging from descriptions. In that fisl the anal rays are said to be 14-15, and the dorsals 12 . Coll. 1873.

55. Curmatus spilurus, Günth. Steind.

Coll. 1873.

\section{Curimatus trachystethus, sp. nov.}

This is a moderately elongate species with the preventral region flattoned, and covered with large, thick striate and dentate scales; and with the postventral region also flattened, and without distinct median keel. Raclial formula D. I. 10 ; C. $2+19+2$; A. I. 8 ; V. 9 ; P. 16 . The pectorals nearly reach the ventrals, which originate below the middle of the dorsal fin, and reach to the vent. The anal fin has a short basis which is equal to its distance from the vent; folded backwards it reaches the base of the caudal fin. The elevation of the dorsal fin exceeds the length of the head. The depth at the front of the dorsal fin is one-third the length of the caudal; the length of the head is one-fourth the same. 
The eye is large, entering the length of the head 3.25 times and the flat interorbital space 1.5 times. The muzzle is flat and projects a little beyond the lower lip. The mouth does not extend to the line of the orbit. The inferior suborluital hone is much longer than the others. Total length M. .128 ; length of head .026; to base of dorsal .040; of ventral .047; of anal .080. Scales 8-48-6.

Color silver, with bluish reflections above; a bright line along the middle of each row of scales. Fins immaculate except a round spot on the dorsal fin below its middle.

This species is allied to the $C$. asper of Günther, but that fish has smaller scales, more anal rays and other characters. (See Proceed. Zool. Soc. Lon., 1868.)

Coll, of 1877 .

57. Potamorhina PRistigaster: Curimatus pristigaster Steindachner, Sitzungsberichte Akad. Wiss. Wien, 1876, July (separata p. 25). Pl. VI.

This species, well described and figured by my friend Dr. Steindachner, is too distinct from the species of Curimatus to remain in that genus, in my opinion. It presents between the ventral and anal' fins not only a keel, as in many species of the genus named, but the keel is surmounted by a series of acute recurved spiniform scales, quite unlike the normally formed ones which bound it in the keeled species of Curimatus. I therefore propose for it the generic name above written. The spinous processes are stronger in my specimens than in the figure given by Dr. Steindachner.

Coll. 1873.

\section{Prochilodus ortorianus, sp. nov.}

Radial formula D. I. 10 ; C. 3-19-2 ; A. III. 8; V. 9 ; P. 14. Scales 9-44-7. Depth of body at dorsal fin entering the length less the caudal fin $3_{\overline{\mathrm{T}}}^{2}$ times; Length of head entering the same 3.7 timus. Diameter of eye entering head 4.5 times, or one and a half times in the muzzle and two and a half times in the interorbital width. From these figures it is evident that this is a moderately elongate species, with rather elongate and wicle head. The frontal region is convex, and the upper lip does not project beyond the lower as in $P$. harttii Steind. The pectoral fins reach the ventrals, but the latter fall far short of the anus. The belly between the latter and the base of the ventral is keeled, but not serrate. The dorsal fin is situated a little in advance of the ventrals, and is quite elevated, equaling the length of the head. Caudal fin rather short and robust. Total length M. .200; length of head .046 ; do. to base of dorsal (axial) .072; do. to ventral (axial) .083 ; to base of anal .134; depth of chudal peduncle .020.

Color silvery, above shaded with blackish; the scales at the base of the anal fin inserted in a blackish skin. Dorsal fin with six or seven crossrows of blackish dots, which only mark the rays. Caudal fin with four cross-bands of rather obscure character, which follow the posterior contour of the fin, except the posterior, which cross the apices. A large specimen, measuring II. .350, is uniform silvery everywhere.

From Nauta, Peru, coll. 1873. 
This species is dedicated to the memory of my late friend, Prof. James Orton, as a slight expression of my respect for him as a man, and of my admiration for his fearlessness and energy as an explorer.

59. Prochllodus cephaiotes, sp. nov.

'There are several points of affinity to the $P$. argenteus to be observed in the small specimen referred to this species. Radij D. I. 10 ; A. II. 10 ; scales 10-? 41-? depth entering length without caudal fin 2.7 times; length of head three times. The head is wide, the interorbital width being half the length, and nearly twice the diameter of the eye. The latter is rather less than the length of the muzzle. The pectoral fins are small, not reaching the ventrals, which in turn do not reach the vent. Dorsal fin with three or four transverse rows of brown spots. General color plumbous; above blackish.

'Total length .071; length of head .021; to dorsal fin (axial) .024; to ventral fin.029; to anal fin .045.

The much larger head and the spotted fins distinguish this fish from the $P$. argenteus, which it resembles in scale and fin formula, and depth of body.

Coll. of 1873 .

60. EMtodus MicRoz.epis Kner.

Coll. $1878-187 \%$.

61. Raboides myersir Gill, Proceed. Acad. Phila. 1870, p. 92.

Radii ; D. I. 10 ; A. I. 48 : scales $24-80+5-23$. Head entering total length less caudal fin, 2.33 times, and head entering the same, 3.6 times.

Coll. of 1877 .

62. Anacrrtus sanguineus Cope, Proceed. Acad. Phila. 1872, 266, Pl. 9, fig. 1 .

Coll. 1873 .

63. ANACRytus limasquamis, sp. nov.

A species of robust proportions, distinguished by its small rough scales. The body is rather deep, and the head wide with very convex interorbital region. The depth enters the length less the caudal fin 2.8 times, and the liead enters the same 3.7 times. The eye enters the head five times, and the interorbital region over its convexity 2.5 times. Scales 27-112-28; the exposed surfaces covered witl minute prickles. Radii D. I. 10 ; A. I. 41 ; V. 7; P. 16, reaching beyond the base of the ventrals, which nearly reach the vent. The first anal ray commences below the seventh dorsal ray.

The top of the head is concare in profile, and the jaws are equal. There are two lows of premaxillary teeth, of which the inner consists of very few teeth. One series of mandibular teeth including three canines, of which the middle one is the largest. Two canines in the premaxillary bone, the anterior much the larger. Maxillary teeth numerous. Maxillary bone extending considerably beyond the posterior border of the orbit. Opercular bones narrow.

Color gray, with a broad golden lateral band above the lateral line. In 
the anterior part of the latter is a large black spot which is situated nearer the opercular fissure than the line of tle first dorsal ray. An indistinct black spot at the base of the canclial fin. Total length M. .220; of head .025 ; to base of ventral fin (axial) .075; do. of dorsal fin (axial) .088; do. to origin of anal .115 .

Coll. 1877.

64. Xrphorhampius abireviatus, sp. nov.

Form stout and robust, the depth of the ventral fin entering the length minus the caudal fin three and a half times. Length of head entering the same about three times. The muzzle is relatively short, being only one and a half times the length of the long orbit. This enters the head 4.75 times, and the flat interorbital space 1.5 times, which therefore equals the length of the muzzle. There are two distant large canines on the anterior part of the maxillary bone and four smaller ones; the maxillary teeth are nuinute. There are two distant canines on the premaxillary, and four large ones on the dentary, with a terminal tooth of small size. The maxillary is covered for its entire length by the preorbital, and extends to a half orbits diameter behind the posterior border of the orbit.

Radial formula D. I. 10 ; A. II. 21 ; V. 8 ; P. 16 , reaching base of ventrals, which reach vent. Dorsal fin elevated, equaring length of head without muzzle, originating behind line of ventrals, and terminating just in front of line of first anal ray. Scales $25-90+3-10$, smooth, those of the lateral line not longer than the others. Breast below slonlder girdle, keeled.

Color silvery bluish, with a wide paler shade along the side; a black humeral and basal caudal spot. Fins immaculate, pectorals and ventrals dusky. Total length M. .212; of head .033; to origin of ventrals (axial) .090 ; do of dorsal .109; clo. of anal .130.

Coll. 1873-1877.

65. Xiphorhamphos heterolepis, sp. nov.

An elongate species in which the depth enters the length with the caudal fin six times, and the head enters the same three and six-tenth times, or three and three-tenth times without the caudal fin. The muzzle is narrowed and convex above, and is not so long as from the anterior border of the orbit to the preopercular border. The dorsa fin is in the posterior part of the second third of the length (without caudal fin). Formula; D. I. 10 ; A. II. 25 ; V. 8 ; P. 15 , reaching more than half way to ventrals, which extend half way to vent. Scales very small, those of the lateral line larger than the others, and crossed by a vertical ridge beyond their miclle : formula $38-121+8-23$.

The diameter of the bony orbit enters the head 5 times, and the interorbital space 1.25 times. The front and ethmoid region exlibit a few longitudinal ridges, and there is no rugosity on the epiotics. There are two foramina for the accommodation of two inferior canine tecth on each side. Total length M. .360. The first suborbital bone behind the preorbital, is narrow. Color silvery, on the side golden; a basal caudul, no humeral spot.

Several specimens : colls. of $1873-77$. 
This species appears to be allied to the $X$. falcatus, from Guiana, as defined by Günther, but this author does not allude to some of its prominent characters. According to his description, that is a stouter species having the depth one-fifth the length, and the head smaller, or one-fourth the same. It has also a humeral spot. All my specimens have 25 anal rays, not 28-30 as given by Dr. Güntber.

\section{Xiphorifampiros malcdrostris Cuv., Günther.}

This species, of which I have two specimens, differs from the last as follows: Anal radii (soft) only 21; dorsal fin in the posterior third of the length minus caudal fin; scales equal, 36-151+8-15. Head and muzzle wider, the latter without ridges above, and with ouly one foramen for the inferior canines. First suborbital bone wider. It differs from Günther's description in having the muzzle considerably shorter than the distance from the anterior border of the orbit to the preopercular border. I add that the supraoccipital crest is short, and the epiotic region rugose. Depthonesixth length without caudal fin; length of head in same 3.7 in the same. There is a caudal but no humeral spot. Total length M. .285.

Coll. $1878-77$.

67. Hydrolycus Pectoralis Günther, Ann. Magaz. Nat. Hist., 1866.

Coll. 1873-77. Nauta.

68. Raphiodon vulpindes Spix., Agass.

Coll. 1873-77.

69. Raphrodon arbios Spix., A. 75.

Coll. 1873.

70. Xiphostoma temo Cope, Proceed. Acad. Philada., 1872, p. 267, Pl. XIII, fig. 2.

Specimens of this species in better preservation than the types, show that the belly is black, and that there is a large black spot on the inferior side of the cauclal peduncle at the base of the caudal fin. They also show that all but the anterior portion of the lateral line is wanting. These claracters indicate that this is a distinct species from the $X$. maculutum with which it is united by Steindachner. At least they are not found in author's figures and descriptions of the latter.

71. Charactdium STFindaChNeri, sp. nov.

This, the third species of the genus, is of more slender form than either of the two known hitherto, and has a smaller number of longitudinal rows of scales. The number of transverse rows is as in $O$. fasciatum the type, and larger than in $C$. etheostoma. The fin rays are less numerous than in O. fasciatum.

Radii; D. 9 ; A. 7; V. 9 ; the first ray a little behind the origin of the dorsal fin, and the produced apex of the fin nearly reaching the anal. The pectoral fin is also prolonged, attaining the base of the ventral. The length of the head is greater than the depth of the body entering the length less the caudal fin, 4.33 times. The greatest depth enters the same 6.5 times. Scales $4-37-2$ or $1 \frac{1}{2} ; 5 \frac{1}{2}$ rows on the stout caudal peduncle. Lateral line complete. 
The muzzle is acuminate and the mouth very small. The orbit is large, its diameter exceeding the muzzle, and entering the head four times, and exceeds the interorbital width by nearly its half.

The color is plain, with the row of scales bearing the lateral line silvery and without dark borders. There are nine narrow rather weak vertical blackish bars, between the caudal fin and the occiput. Inferior fins unspotted; caudal with a dark shade at the base, and one at the extremity. Total length M. .029; of head, .006; to line of dorsal fin .010; to do. of anal, .018; to basis of caudal .026.

This species is dedicated to my friend Doctor Franz Steindachner, of Vienna, the distinguished zoölogist, who has added much to our knowledge of the fishes of the Amazon. I have derived much instruction in this department from his very full diagnostic analyses.

Coll. of 1873.

\section{Aphyocharax pustulus Günth.}

Coll. 1873.

\section{Schizodon rasciatos Spix.}

Coll. of 1877 .

74. Schizodon sagittarius, sp. nov.

This species is more elongate and slender than any of the known representatives of the genus ; the vertical diameters of both head and body being reduced. The extension of length is in the post dorsal region. Length of head into the total, less the caudal fin, a little more than five times; depth of body into the same nearly six times, hence less than length of head. Radii, D. I. 11 ; C. $2+19+2$; A. I. $9 ;$ V. 9 ; P. 16 . Dorsal fin origin. ating anterior to the point marking two-fifths the distance from the end of the muzzle, to the base of the caudal fin; its elevation equal to the length of the head. Pectoral fin not reaching the ventral, which does not reach half way to the vent, and originates below the fourth dorsal ray. Orbit entering the length of the head 4.2 times, and the interorbital width twice; the inferior range of vision is a little greater than the superior. Mouth terminal, the mandible a little longer than the premaxillary, and armed with six teeth. These are smooth externally, and have two principal cusps. The superior are denticulate, the denticles arranged into three cuspidate groups. In both jaws the median teeth are larger than the lateral. Total length, Y. .165; length of head .027 ; length to origin of the dorsal fin .051 ; do. to origin of ventrals $.05 \%$; do. line of origin of anal fin .110 . Above dusky to second row of scales below the lateral line; below this point silvery. Fins unspotted except the caudal, which has a dark longitudinal shade along the middle of each lobe.

This species is probably allied to the Rhytidodus argenteofuscus of Kner, but in that species according to Kuer, the superior teeth have but one point, those of both jaws are keeled externally, and the depth of the body exceeds a little the length of the head. The inferior tootl figured by Kner is entirely unlike those of this fish.

Coll. 1877.

PROC. AMER. PHILOS. SOC. XVII. 101. 4F. PRINTED JUNE , 1878. 
75. Schizodon Trimaculatus Kner.

Coll. $187 \%$.

76. Leporinus vittatus Cuv. Val.

Coll. $187 \%$.

\section{LEPORINUS FREDERICI Bloch.}

Coll. $187 \%$.

78. Leporinds hypselonotus Günth. Proceed. Zool. Soc. London, 1868, p. 244.

Coll. $187 \%$.

79. Leporinus holostictus, sp. nov.

This landsome species is distinguished by the continuation of the very distinct brown cross bands on to the head, the first one covering the end of the muzzle. The depth of the body is about equal to the length of the head, entering the length less the caudal fin four and a quarter times. The orbit is large, its diameter entering the length of the head four times, and the interorbital width one and five-sixth times. Scales 6-41-5. Radii D. I. 11; A. I. 9 ; V. $10 ;$ P. 14 , reaching half way to ventrals, which originate below the fourth dorsal ray. There are eight teeth in each jaw ; those of the mandible are small, excepting the median pair, which are much prolonged, and acute. The color is silvery, darker shaded above, crossed by seven black cross bars on the body, one additional on the nape, and two on the head. Those on the head are on the muzzle, and between the orbits; the five behind the ventral fins pass entirely round the body. There is in addition a dusky shade at the emargination of the dorsal fin. Fins otherwise unspotted. Length M. .107; of head .026; to line of dorsal fin .049; to base of anal .082 ; to base of caudal .104 .

Coll. 1877 .

80. Leporinus mUtitifasciatus, sp. nov.

Depth of body and length of head sub-equal, and entering the length less the caudal fin 3.66 times. The eye is large, its diameter being a litle less than one-third the length of the head, and five-eighths of the interorbital diameter. The length of the muzzle is five-sixths the length of the head posterior to the orbit. Scales 4-36-5. Radii ; D. I. 11; A. I. 10. Ventral fin below the fourth dorsal ray; pectoral reaching half way to ventral.

Color brown, with fourteen vertical darker brown bands, the first at the nape, the last near the base of the caudal fin, with its middle interrupted, the interruption being followed by a dark spot. Fins unspotted. Total length M. .065; of head .015; to line of dorsal fin .024; of anal .044; to basis of caudal .055.

No other species presents the numerous cross bands of this one.

81. Hemiarammus robustulus Cope, Proceed. Amer. Philos. Soc. 1870, p. 561.

Coll. 1873. 
82. Tetragonopterus inauxwellianus Cope, Proceed. Amer. Philos. Soc. 1870 , p. 560 .

Coll. 1873.

83. Tetragonopterus chalceus Agass.

Coll. 1877, from the Marañon.

84. Tetragonopterds ortonir Gill. Proced. Acad, Phila. 1870, p. 92. Coll, 1873.

85. Tetragonopterus agassizir Steindachner, Sitzungsber., K. K. Akad. Wiss. Wien, 1876 (July) 41, Pl. VIII, fig. 2.

Two specimens from near Pebas resemble the species above named in all points excepting in the more elongate body, so that I suspect them to represent a local race. There are 1.24 anal radii, and the longitudinal rows of scales are 5-1+3-4. The total length without caudal fin is M. .034; depth .013 ; length of head .0105 . The caudal spot is very large, covering the basal half of the fin, while the humeral spot is obsolete.

86. Tetragonopterus LONGTOR, sp. nov.

One of the more elongate forms of the genus. Radii D. I. 10 ; A. I. 24 . Longitudinal series of scales twelve. The greatest depth enters the length less the caudal fin 4.7 times, and the length of the head the same 4.2 times. The diameter of the orbit enters the length of the head 3.5 times, and the interorbital width 1.33 times. The maxillary bone is toothless, and rather wide, and extends little beyond the line of the anterior border of the orbit. The origin of the dorsal fin is behind the line of that of the ventrals, and is nearer the origin of the caudal fin than the end of the muzzle by the length of the latter.

There is a broad silvery lateral stripe, on which is a strong black humeral spot. There is no distinct basal caudal spot. Total length .095 .

Coll. of 1874, from Moyabamba.

87. Tetragonopterus, sp. indet.

Coll. of 1873 .

88. Tétragonopterus, sp. indet.

Coll. of 1873.

89. Tetragonopterus diaphands, sp. nov.

An elongate species distinguished by the small number of its anal rays. D. I. $9 ;$ A. I. $18 ;$ V. 7 , originating a little anterior to line of dorsal, and not reaching anal : P. 13, not reaching ventrals. Dorsal fin nearly equi-distant between end of muzzle and base of caudal fin. Anterior rays of dorsal and anal fins markedly longer than the posterior. Depth entering length less caudal fin three and one-serenth times; length of head into the same, four and two-fifth times. Scales 4-35-3.5 ; lateral line complete. Maxillary bone toothless, extending near to the line of the anterior border of the orbit. The latter enters the length of the head 2 and 3-4th times, equaling the interorbital space.

Total length M. .052; of head .011; to line of ventral fin .020; to line of 
anal .028. Color silvery, with a broad bright silver lateral band, and no bright spots.

Coll. 1874.

90. Tetragonopterus ipanquianus Cope, Proceed. Amer. Philos. Soc. 1877, p. 28. Urubamba River ; elevation 11,500 feet.

Coll. of 1877 .

01. Stethaprion chryseum Cope, Proceed. Academy, Phila. 1872, p. 261. Coll. $187 \%$.

92. Chalcinus culter Cope, 1. c. 265.

Coll. 1873.

93. Triportheus nematurus Kner.

Coll. $187 \%$.

94. Serrasalimo immaculatus $\mathrm{sp}$. nov.

This species belongs to the restricted genus Serrasalmo. There are six premaxillary teeth, of which the third is much smaller than the others. Each tooth has a denticle at its posterior base, which in the case of the external tooth is longer horizontally than the principal cusp, and is not apiculate. There are seven in the lower jaw, of sub-equal size, each with a posterior basal denticle, except the anterior, which has two basal denticles.

The form is discoid, the depth entering the length less the caudal fin $\mathbf{1 . 8}$ times, and the length of the head entering the same three times. The dorsal and ventral outlines are equally convex, but the steeper slopes are opposite the anterior above, and the posterior below. Scales small 34-10033. Radii ; D. 17 ; A. I. 32 ; V. 7, not reaching vent; P. 15, reaching base of ventrals. Spines 33-4. Gill rakers of first arch short, and with short apices. Diameter of eye entering length of head (including chin) five times; and nearly twice in the interorbital space measured over its convexity. The origin of the dorsal fin is above the ventral, and equi-distant between the base of the superior marginal ray of the caudal fin and the posterior border of the orbit. The superior caudal rays are not so long as the inferior. Second sub-orbital bone as high as long. Muzzle a little longer than diameter of orbit. The color is silvery without distinct spots ; in certain lights numerous small lead-colored spots may be detected on the dorsal region, extending half way down to the lateral line. Caudal and anal fin broadly black bordered; no yellow band. Total length M. .190; of head .055 ; to line of dorsal fin .090 ; to line of anal .116 ; to basis of marginal caudal rays .161 .

This species is near the $S$. cesopus Cope, but is readily distinguished by the much more numerous scales, and the longer muzzle.

Coll. of 1877.

95. Metynnis luna, gen. et. sp. nov.

Char. Gen. This is Myletes with an external horizontal cultriform spine at the base of the dorsal fin as in Serrasalmo and Stethaprion. The premaxillary teeth are in two series, and have an oblique, more or less in- 
conspicuous cutting edge, as in Myletes. Two conical teeth behind the mandibular series. The belly is armed with spiniferous ? interhæmal bones.

This form is related to Myletes precisely as Stethaprion is to Tetragonopterus. But one species is known to me.

Char. Specif. Form orbicular, the dorsal region very convex; the abdominal outline still more so. The depth is eleven-twelfths of the length less the caudal fin, and the length of the head enters the latter three and twotenth times. The depth of the head from the superior border of the posttemporal bone equals the length. The eye is large, entering the length of the head three and one-sixth times, and the convex interorbital space one and one-half times. The chin projects a little beyond the premaxillary border, and the end of the toothless maxillary bone is immediately below the proximal extremity and below the nostrils.

Radii ; D. I. 17 ; A. 39 ; V. 7 ; P. 14. The ventral fins are very small, and their base is contracted, so that the spines are arranged nearly in a circle, the inner and outer being of equal length. The pectorals are small, marking only the third of the distance to the line of the ventrals. The base of the anal makes an angle of only $25^{\circ}$ with the vertical ; its anterior rays are little prolonged. The base of the dorsal is oblique downwards and backwards, and the first ray marks a point at .4, the distance between the bases of the pectoral and ventral fins. The length of the base of the adipose dorsal is two thirds that of the rayed dorsal. Ventral spines 25, the anterior recurved and simple, the posterior more or less bifurcate. The head of the predorsal spine is anvil-shaped. The suborbital bones are narrow ; the anterior is the widest, and is triangular with the long apex superior.

Scales between the lateral line and the ventral fins, 39-40, those of the lateral line (in front) larger than the others. Total length, M. .075; of head, .020; to line of ventral fin, .033; of anal, .046; of caudal fin, 060 . First dorsal ray equidistant between base of caudal marginal ray and end of muzzle, measured in straight lines. Color golden, excepting the superior half of the region above the lateral line, which is dove-color in spirits. No spots of any kind.

Coll. of $187 \%$.

96. Mrletes herniarios Cope, Proceed. Acad. Phila. 1872, p. 268. Coll. of 1873.

The specimen here recorded, differs slightly from the type in some details. Dorsal radii in both, 17 ; anal in type, 32 ; in new specimen, 35 ; spines in type 46 ; in new specimen 51 . There is a faint eye-like spot on the side in the new specimen, not seen in the type, and some indistinct vertical shades.

Coll. of 1873 .

\section{Mrletes nigripinNis, sp. not.}

Premaxillary teeth in two series, which are is close contict. The anterior series is curved, and consists of ten teeth with a space as wide as a tooth in the centre; the posterior series is uninterrupted, and consists of 
four teeth. The mandibular series is uninterrupted, and consists of seven teeth on each side, the posterior four being much smaller than the others. The two posterior mandibulars are in contact with the median pair of the anterior series, and are separated by a narrow interspace from each other.

The general form is broadly rhombic. The depth is one-half the length with the caudal fin, and the length of the head enters the same three and one-half times. Radii; D. I. $15 ;$ A. $23 ;$ V. $8 ;$ P. 16 . The inferior paired fins are very short; the others are well developed. The adipose fin is furnished in its superior part with jointed rays, the inferior portion is scaly. The base of the anal fin is covered with minute scales. The origin of the first dorsal ray is a little behind that of the ventral fin, and the anal begins under the last third of the former. Ventral spines 46 , all simple and recurved. Scales $26-65+6-21$; the lateral line considerably decurved behind the head. The head is wide and depressed above the orbits. The latter enter the length of the head 4.5 times; the inter-orbital space 2.5 times, and the muzzle once, axially measured. The frontal region is moderately convex in cross section. The mandibular teeth close within the premaxillaries, and the upper jaw projects beyond the mandible. The lips are equal, however, in consequence of the thickness of the lower, which fills the space. Its superior surface is pappillose, and at the points where it comes in contact with the maxillaries it is continued as a free beard on each side, reaching to below the centre of the nares when extended. The maxillary is folded nnder the preorbital, but its posterior border cannot reach the line of the anterior border of the orbit.

Total length. M. .130; of head, .040; to line of dorsal fin, .055; to line of anal, .079; to base of caudal fin, .103. Color silvery, plumbeous above; the sides marked with rather large round plumbeous spots. A silver band on each side of the ventral spines. Anal fin, caudal, except superior and inferior border, and terminal halves of paired fins, black. Dorsal dusky.

In a larger specimen, probably from Nauta $(230 \mathrm{~mm}$.), the scales are finely ctenoid, those at the bases of the median fins coarsely so. The head is furnished with minute rugosities, and there are no labial beards nor color spots.

Coll. 1873-1877.

98. Mrletes bidens Spix.

Coll. 1873.

99. Macrodon trahira Spix.

Coll. 1873-77.

100. Erythrinus salmoneus Gron.

Coll. 1873-7\%.

101. Errthrinus Brevicauda Gthr.

Coll. 1873.

102. Pyrrhultal argyrops, sp. nov.

Radii ; D. I. 9 ; A. I. 9. Scales in seven longitudinal, and about twenty. 
five transverse series. The scales are lost from the anterior part of the body in two specimens, so that the number given is not absolutely certain, but very probable. Origin of dorsal fin immediately above that of ventral, and exactly half way between the base of the superior marginal ray of the caudal fin and the anterior border of the orbit. Pectorals not reaching the rather large ventrals, which fall considerably short of the anal. Head in total length less caudal fin, four and one-sixth times, and equal depth of body at dorsal fin. Eye large, its diameter entering length of head three times, exceeding muzzle by nearly half, and entering interorbital space 1-5 times. Suborbital bones reaching pre- and interoperculum. The mandible projects, and the maxillaries are very short and subdiscoid, closing into an external concavity at the base of each ramus. Color olivaceous, except a silver spot at the center of each scale. Fins unspotted, except the dorsal. which has a large black spot over its middle portion, no black band on head, which is silvery on the sides.

Coll. 1877.

\section{ISOSPONDYLI.}

OSTEOGLOSSID正.

103. Osteoglossum bicirrhosum Vancl.

Coll. 1873.

104. Arap fma gigas Cuv. Probably Nauta, 1873.

\section{HAPLOMI.}

CYPRINODONTIDE.

105. Rrvulus Microp us Stein., Gthr.

Coll. 1873.

\section{SYNENTOGNATHI.}

BELONIDA.

The genus Belone must be placed in a family group distinct from that which includes the genus Exocertus and its allies. I have already pointed out the fact that it possesses a distinct coronoid bone; in addition to this, the vertebræ display zygapophyses, a character unusual among fishes. On these two characters I propose the family Belonida. Professor Gill has already created this name, but he did not define the group to which he applied it.

106. BeLone tamiata Günther.

Coll. $1873-77$.

\section{PLECTOGNATHI.}

\section{TETRODONTID赵.}

107. Tetrodon Psittacus Bl. Schn.

Coll. 1873.

\section{PERCOMORPHI.}

Chromidid在.

108. Heros AUTOCHTHON Gthr.

This species is stated by Dr. Steindachner to be confined to the coast 
rivers of Brazil, and not to occur in the valley of the Amazon. I cannot distinguish my Peruvian specimens from the descriptions furnished by him and by Dr. Günther.

Coll. 1877 .

109. Heros Brmaculatus Linn. Cope; Acara Gthr.

Coll. $1873-7 \%$.

110. Acara flavilabris Cope, Proceed. Amer. Philos. Soc, 1870, p. 570. Proceed. Acad. Phila. 1872, Pl. XI, fig. 4.

Dr. Steindachner in the Sitzungsberichte of the Vienna Academy for 1875, p. 6 (separata), expresses the opinion that this species is the $A$. tetramerus Heck., basing it on a presumed error on my part in the counting of the scales on the cheek. He finds my figure above cited to disagree with my last description, in possession of three rows of cheek scales while I have stated that only two exist. An examination of numerous specimens additional to those already in my possession, shows that they only exhibit two rows of cheek scales as I have described. Dr. Steindachner has evidently misunderstood my figure, for there are but two rows of cheek scales represented on it as described. The third row belongs to the inferior limb of the peroperculum. The figure only is defective in the dark shading of the inferior lip, which is yellow in life.

Coll. 1873.

111. Acara syspilus Cope, Proceed. Ac. Phila. 1872, p. 255, Pl. XI, fig. 3.

In a larger specimen of this species than the type, the body is relatively deeper, and the eye a little smaller, and the vertical bands are less decided.

Coll. $187 \%$.

112. ACARa stbocularis, sp. nov.

Radii D. XIII, 11 ; A. III, 8; V. I. 5, nearly reaching vent, and originating below the fourth dorsal spine. Scales 3-30-2-8-9; on cheek five rows. Form rather elongate; head not robust, its length entering the total less the caudal fon 3.4 times. The depth at the ventral fin enters the same 2.75 times. The preorbital bone is as wide antero-posteriorly as the orbit, and exceed the interorbital space by $1 \mathrm{~mm}$. The orbit is thus behind the middle of the head, into whose length it enters 3.6 times. Its superior rim is in the frontal plane. The fourth and longest dorsal spine is as long as the cranium from the superior extremity of the branchial fissure to the anterior border of the orbit. The profile descends from the supra-occipital crest in a nearly straight line, with a slight concavity at the front of the orbit.

Color light brown, with a narrow vertical black spot just below the lateral line opposite the middle of the ventral fin. A black spot on the upper anterior portion of the spinous dorsal fin. A vertical black band from the eye to the inferior edge of the preoperculum.

Total length M. .075; of head .017; to basis of ventrals (axial) '.022; to basis of anal .039 ; of cauda1.058; depth .021.

This species resembles the Geophagus cupido.

Coll. of 1877. 
113. ACARA hyPOSTICTA, sp. nov.

Radii ; D. XIII 19; A III 15 $\frac{1}{2}$. Scales 6-30-3-17-8 ; six rows on cheek. The ventral fins commence under the third dorsal spine. The longest (fourth) dorsal spine is equal to the diameter of the bony orbit, which nearly equals the flat interorbital space. The preorbital bone is as long antero-posteriorly as one-third the diameter of the orbit, which is one-third the length of the head, exceeding a little the length of the muzzle. The extremity of the maxillary bone extends a little beyond the line of the anterior border of the orbit.

The form is a moderately wide oval, with the profile from the base of the dorsal fin a perfectly straight line to the end of the muzzle. The depth at the ventral fins enters the length less the caudal 2.1 times, and the length of the head enters the same 2.6 times. Total length M. ,095; of head, .027; to origin ventrals, .031; of anal, .049; of caudal, .070.

The single specimen in my possession is in rather bad condition. It is of a light brown color, the dorsal, caudal and anal fins with brown spots. The ventrals are cross-banded with deep brown; and anterior to them, five similar bands, separated by silvery interspaces, cross the inferior surface, the anterior three of which rise to the superior border of the inferior ramus of the preoperculum. A brown horizontal line extends posteriorly from the mouth.

The soft radii of the median fins are more numerous in this than in any of the described species. This character, with the peculiar coloration, will distinguish it from all of them.

Coll. of 1873 .

114. Acara ocellata Agass. (Steind.) Hygrogonus Gthr.

Coll. 1877.

115. Geophagus cDPIDo Heck.

116. Geophagus temiatus Gthr.

Two specimens; one of which exhibits a deep brown band along the middle line of the abdomen, which is wanting in the other.

A third species from Pebas, the Geophagus badiipinnis Cope, is thought by Dr. Steindachner to be a Choctobranchus. It has, however, the branchial structure of the genus to which I referred it.

117. CrCHLA OCELLARIS Bl.

Probably Nauta 1873.

118. Crentcichla Proteus Cope, Proceed. Acad., Phila. 1872, p. 252. Coll. 1877.

119. Crenicrchla Lucius Cope, Proceed. Amer. Philos. Soc., 1870, p. 570.

Coll. 1873. From the Cachyiacu, an affluent of the Huallaga, near Moyabamba.

120. Crenictchla joanna Heck.

Coll. 1877.

PRoc. AMER. PIILLOS. sOC. XVII. 101. 4I. PRINTED JUNE , 1878. 


\section{GENERAL OBSERVATION.}

The 121 species enumerated in the preceding pages are distributed among the following natural families.

Symbranchidæ.................................. 1

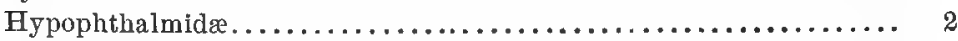

Siluridæ........................................ 36

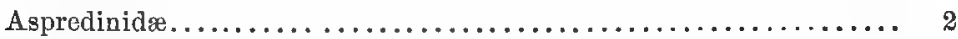

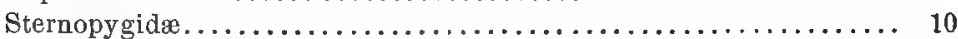

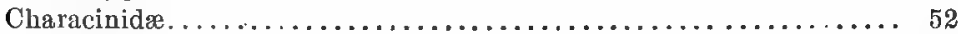

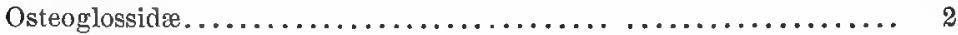

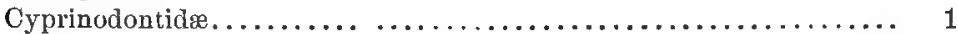

Belonidx......................................... 1

Tetrodontidæ................................... 1

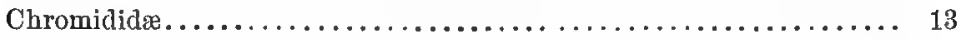

The preceding families have all been known heretofore as occurring in the fresh waters of South America, so that an analysis of the contents of this catalogue must relate chiefly to the genera and species. In so doing I first point out two genera which are characteristically marine, which have been shown by Günther and Steindachner to inhabit the Brazilian Amazon. I have proven that their distribution extends even to the Peruvian Amazon, 2500 miles from the sea. They are:

I. Belone L. Tetrodon L., represented by one species each.

I next enumerate four species which are confined to the Alpine waters of the Amazon, having been brought by Prof. Orton from the elevations of from 10,000 to 11,400 feet. These are :

II. Arges sabalo, C, V.

Trichomycterus dispar Tsch.

Trichomycterus gracilis C. V.

Tetragonoptemus ipanquianus Cope.

These represent the two families of Silurida and Characinida, which are distributed everywhere in the neotropical realm. Of the Characinida, Tetrngonopterus is universally distributed of the Siturida, Arges is Alpine, but whether found in the waters of the Pacific Slope as well as the Atlantic, I am not informed. The other genus, Trichomycterus, is Alpine and West Coast, occurring from Equador to Southern Chili. The two species enumerated above are the only ones from Atlantic waters yet known. This is one of the few cases where a West Coast form crosses the great water-shed. It is well known that many genera are common to the waters of both coasts, and even, according to Günther, the species Macrodon trahira.

I next note the gener: which have so fur not been found on the lower or middle Amazon, and which may be regarded as characteristic of the Peru- 
vian portion of its course. This list is obviously only provisional, as exploration of the Amazonian basin has not progressed sufficiently to enable us to assert the restricted distribution of any type. Thus the genus Otocinclus Cope, first obtained from the Peruvian Amazon, has been ascertained by Steindachner to occur near Rio Janeiro. Zathorax and Triportheus first determined from western species, occur on the Lower Amazon. The genera remaining are :

III. Silurida; Brochis Cope; Chcenothorax Cope; Physopyxis Cope; Agamyxis Cope; Pariolius Cope.

Characinida; Aphyocharex Gthr.; Iguanodectes Cope; Stethaprion Cope.

Finally, the species which have not yet been found below the Peruvian boundaries are as follows. I include species previously described by myself from Pebas, in the essay on The Fishes of the Ambyiacu River, * also those described by Gill from Orton's first collection, and by Günther from those of Bartlett,

IV. Silurida...............

Pseadorhamdia Blk..........

Pimelodus Lac ..............

Euanemus M. T. ............

Epapterus Cope..............

Anchenipterus (. V...........

Centromochlus Kner...........

Doras Lac....................

Zathorax Cope...............

Agamyxis Cope.............

Physopyxis Cope.............

Dianema Cope..............

Brochis Cope...............

Chænothorax Cope...........

Gastrodermus Cope...........

Hypoptopoma Gthr...........

Otocinclus Cope............

Liposarcus Gthr............

Plecostomus Art .............

Chætostomus Heck...........

Pariolius Cope.............

Trichomycterus............

Aspredinidos..............

Bunocephalus Kner.........

Dysichthys Cope...........

Characinida.............. 53

Anodus Spix ...............

Curimatus Cuv..............

Prochilodus Agass..........

Rœboides Gthr...............
44 Anacyrtus Gthr........... 3

Xiphorhamphus M. T........ 2

4 Hydrolycus M. T............ 1

1 Xiphostoma Spix............ 1

1 Characidium Reinhd.......... 2

Aphyocharax Gthr.......... 2

1 Schizodon Agass............. 1

1 Iguanodectes Cope ........... 1

2 Odontostilbe Cope........... 1

Leporinus Spix............. 3

1 Hemigrammus Gill........... 1

1 Brycon M. T............. 4

Tetragonopterus Cur......... 6

Triportheus Cope............. 1

5 Stethaprion Cope........... 2

Chalceus Cuv.............. 1

1 Serrasalmo Lacep.......... 2

Metynnis Cope.............. 1

Myletes Cuv............... 3

Pyrrhulina C. V........... 1

Holotaxis Cope............. 2

Chromidida............. 10

3 Acara Heck............... 6

Geophagus Heck........... 1

1 Crenicichla Heck. .......... 3

5 Total number of species not yet known below the Peruvian Amazon............... 120 


\section{$A D D E N D U M$}

\section{PERCESOCES.}

Mugilid

Gastropterts arch

Char. Gen. A broad band of teeth on the premaxillary and dentary bones, and a patch on the vomer. Dorsal spinous fin with four rays. Ventral fins abdominal. Second dorsal opposite to anal. Dermal fold not crossing superior portion of premaxillary region, hence the jaws are only partially protractile.

This genus is an interesting form, probably of Mugilida, related to Protistius Cope, and Myxus Günther. The wide bands of teeth, consisting of numerous series, are not found in the last named genus, but belong to the first. Here, however, the spinous dorsal fin is rudimental, and there are no teeth on the vomer.

The pectoral fin has the elevated position usual in the Percesoces, but the ventral fin is more posterior than in Mugil, having the position usual in Physostomous fishes. The spinous dorsal fin is very small, and the caudal fin is forked. A lateral line of pores extends along the lower part of the side.

The characters of this genus render it probable that Protistius * should be referred to the Percesoces. These forms add to the number of existing relationships between the cold blooded vertebrate faunæ of Australia and the West Coast of South America.

Char. Specif. Radii. D. IV. I. 11 ; A. I. 15 ; V. I. 5 ; P. 15. The dorsal spines are very small, the first about as long as the diameter of the orbit, and originating above a point half way between the bases of the ventral and anal fins. The pectoral fin is wide, and extends three quarters way to the base of the ventral. The latter extends three-fifths the distance to the anal fin. The anterior rays of the anal are much longer than the posterior, and the margin is concave. Caudal lobes sub-equal and acute. Scales, counting from spinous dorsal to ventral fin ; 20-93-3. Anterior to the ventral fin the scales become smaller and rather irregular along the lateral line. Between the occiput and first dorsal spine there are 50 rows. The top of the head is scaled to the line of the anterior borders of the orbits.

The muzzle is prominent and parabolic in outline, projecting very little beyond the mandible. The outline of the latter is similar to that of the muzzle, and the mouth is horizontal to a point a half the eye's diameter in front of the orbit, where it is cut off by the decurvature of the premaxillary bones. Orbit one-fifth the length of the head, and 15 times in length of muzzle, which is one mm. less than the slightly convex interobital space. The length of the head enters the total minus the caudal fin, fourtimes; the greatest depth of the body enters the same, six times. Total 
length M. .166; of the head, .035; to origin of ventral fin, .063 ; of anal fin .090; of second dorsal fin, .096; of caudal fin, .141.

Besides the generic characters mentioned, this species'differs from the Protistius semotilus of the same region, in the larger number of soft rays, the smaller eye, narrower interorbital space, etc. The lateral line is better defined in this species, but is not continued beyond the anal fin; a few isolated tubes occur on scales on other parts of the sides.

The color of the Gastropterus archous is silvery, darker shaded on the upper surfaces, and without spots on the body or fins.

Two specimens ; coll. of 1874 ; obtained by Prof. Orton, at Arequipa on the Pacific slope at an elevation of 1500 feet.

Published June 26, 1878. 







\title{
ABSTRACTS OF THE PROCEEDINGS
}

OF THF

\section{GEOLOGICAL SOCIETY OF LONDON.}

No. 364.]

[Session 1878-79.

\author{
Annual General Meeting. \\ February 21, 1879.-H. C. Sorby, Esq., F.R.S., \\ President, in the Chair.
}

The Stcretaries read the Reports of the Council and of the Library and Museum Committee for the year 1878, in which it was stated that, owing no doubt chiefly to the widespread depression in commercial affairs, the number of Fellows elected during the year was unusually low ; and there had been a corresponding, though probably temporary falling off in the income of the Society. The Report, however, announced the receipt of a bequest of $£ 1000$ under the will of the late Sydney Ellis, Esq., which had been invested in Reduced 3 Per Cent. Stock for the benefit of the Society. The Report further mentioned the awards of the various Medals and the proceeds of the Funds, and stated that the proceeds of the Barlow-Jameson Fund would be devoted to the purchase of a new microscope, and the improvement of the instrument already in the possession of the Society.

In presenting the Wollaston Gold Medal to Prof. RaMsar for transmission to Prof. Berdard Stoder, F.M.G.S., the President addressed him as follows:-

\section{Professor Ramsay,-}

In forwarding the Wollaston Medal to Bernard Studer, I trust that you will tell him with what unanimity the Council awarded it to him as a token of their high esteem for his long and arduous services in the eause of science, commencing upwards of sixty years ago, and continued uninterruptedly down to the present time. We must, I think, regard him as the father of Swiss geology, and to him we are greatly indebted for our present knowledge of the structure of his native country, to which his publications have been mainly, though not exclusively devoted. I may especially refer to his earlier and later works on the geology of Switzerland and the adjoining countries, and to his map of Switzerland, which, though published twenty-seven years ago, is still the best we possess. In faet, Studer's name is so indissolubly associated with that country, 
and his services in the cause of our science have been so long known to British geologists, that I need say little more than that we present the Medal to him as our great instructor in the geology of one of the most interesting and attractive districts of Europe.

Prof. Ramsar, in reply, said that he held in his hand a letter from Prof. Studer, in which he offered his best thanks to the Geological Society for having judged his endeavours to advance the geology of the Alps and Switzerland worthy of the Wollaston Medal, and expressed his regret that his advanced age of nearly eighty-five years prevented his being present to receive it in person. Prof. Ramsay added that he felt it a great privilege to be allowed to receive the Medal, and that he should have much pleasure in forwarding it to his venerable friend, who, he was sure, would be much gratified by the terms in which the President had spoken of him. Prof. Studer spoke of his eighty-five jears; but Prof. Ramsay had seen him in Berne only five years ago, when he was as bright and almost as active as the youngest Fellow of the Society.

The President next handed the Murchison Medal to Prof. Morris for transmission to Prof. M`Coy, F.G.S., and addressed him as follows:-

\section{Prof. Morris, -}

In forwarding the Murchison Medal to Prof. M`Coy, you will, I trust, inform him that the Council has awarded it to him for his palæontological researches. These, to a considerable extent, have been directed to the older Palæozoic rocks, of which the donor of this medal was the distinguished expounder. During his early labours, Prof. M:Coy described many forms collected by the late Sir Richard Griffith from the Silurian and Carboniferous rocks of Ireland, and subsequently, while at Cambridge, associated with Prof. Sedgwick, he published; in the Synopsis of the British Palæozoic Rocks, descriptions of the fossils collected by that veteran geologist. During his residence in Australia for some years past as Professor of Geology in Melbourne University, he has chiefly directed his attention to the Palæontology and Geology of that country, more especially of the Colony of Victoria; and besides other published papers, he has prepared five decades of Victorian organic remains, characteristic of the different formations.

\section{Prof. Morris replied,-}

\section{Mr. President,}

I have much pleasure in receiving for transmission to Prof. M`Coy this token of the value with which his labours for the advancement of geological and palæontological science are regarded by the Council of the Geological Society. I cannot but feel that in his distant, adopted home Prof. $\mathrm{M}^{\circ} \mathrm{Coy}$ will highly estimate and fully appreciate this recognition of his researches on Palmozoic organic remains and 
allied subjects. At the same time I trust it will still further stimulate him to continue the publication of those illustrated works which he has so successfully commenced on the geology, palæontology, and recent natural history of the Colony of Victoria.

The President then handed the Lyell Medal to Mr. Warington W. Sмyтн, F.R.S., F.G.S., for transmission to Prof. E. HEвERT, of Paris, and addressed him as follows:-

\section{Mr. WarINGTON SMYCH, -}

In handing to you the Lyell Medal for transmission to M. Hébert, I have to express the sense entertained by the Council of the extreme value of the work done by that gentleman. For more than thirty years he has been engaged in the investigation of the Cretaceous and Tertiary formations, and the results of his labours, which have been published in an immense number of elaborate memoirs, have thrown a vivid light upon the phenomena presented by these formations, both in this country and on the continent. M. Hébert has treated in great detail upon the subdivisions of both the above systems, and has also summarized the results of his labours in diagrammatic and tabular forms, which make them more easily and generally intelligible. He has also paid considerable attention to the supposed transitions existing between the Jurassic and Cretaceous systems on the one hand, and between the Cretaceons and Tertiary on the other. For these reasons the Council had much pleasure in awarding the Lyell Medal to Prof. Hébert.

Mr. Waringron Smrrh, in reply, expressed his regret that Prof. Prestwich, as an old and intimate friend of Prof. Hébert, was unable to attend and receive the Medal on his behalf, as M. Hébert himself could not be present. $\mathrm{He}$ had received from M. Hébert a letter, in which he expressed his thankfulness for what he called "a precious indication of sympathy" on the part of the Council of the Society, and proceeded to say that, among geologists foreign to France, Lyell was the one with whom he had been longest connected, and one of those who, more than thirty years ago, most contributed to decide him to devote his life to geology. By the award of the Lyell Medal he felt honoured in the highest degree.

The President next handed the Bigsby Medal to Prof. Seeley, F.G.S., for transmission to Prof. E. D. Cope, of Philadelphia, and addressed him in the following terms :-

\section{Prof. Steleder, -}

Through the further kindness and liberality of Prof. Bigsby, we now for the first time are able to give this Medal in gold. The Council of the Geological Society have awarded it to Professor E. D. Cope, in recognition of the genius and skill which have enriched the 
sciences in which he has laboured with original thoughts and important additions to knowledge. In Comparative Anatomy and Palæontology his researches are based on profound knowledge of the structure of existing animals; while in some departments of Zoology and Field-Geology his labours would have commanded more than respect were they not eelipsed by immense and varied work among the fossil vertebrata.

Following out the work begun by Leidy, Professor Cope laboured successfully at the Reptiles in the Greensand of New Jersey, and in 1866 made known the remarkable genus Loelaps. Subsequently, in 1870 , he published a synopsis of the Extinct Batrachia and Reptilia of North America, including many new types, especially among Plesiosaurs, Pythonomorpha, and Dinosaurs. Subsequently, when Professor Cope became Palæontologist to the United States' Geological Survey of the Territories, he published from time to time, in the 'Bulletins' and 'Reports,' descriptions of many of the more remarkable fishes, reptilia, and mammals discovered in Wyoming, Montana, Colorado, and other regions of the far west. Some of these researches on Cretaceous Reptiles and Fishes have since been issued by the United States Government in a sumptuous quarto volume; while a no less important work on the Palæontology of New Mexico is devoted ehiefly to the Tertiary Mammalia. Professor Cope's labours in these fields of work are familiar to every geologist; and I rejoice that we are able to offer him this evidence of the esteem and admiration in which his researches are held by the Geological Society.

Professor Sketex said it was a peculiar pleasure to him to receive this award on behalf of Professor Cope; for no naturalist of our time had more felt and shown the importance of profound knowledge of living animals and their structures in the interpretation of fossils. He believed there was every reason to anticipate that Prof. Cope's labours in time to come would be no less important than in the past; and it was pleasing to know that one who had accomplished so much still pursued his studies as a student, that he might increase the value of his comparative work. Prof. Seeley was sure Prof. Cope would value this medal highly, since it expressed the admiration which the Geological Society felt for his labours, though Prof. Cope had found it reward enough to have contributed something to the seiences to which he had devoted his life.

In handing to Prof. Bonney, F.R.S., F.G.S., the balance of the proceeds of the Wollaston Donation Fund, for transmission to Mr. Sardete Altport, F.G.S., the President said :-

\section{Professor Bonney,-}

The medals and other awards have been given this year to eminent field-geologists or palæontologists, but to $\mathrm{Mr}$. Allport for subjects which elaim my own very particular sympathy, since the 
greater part of his publications have been on the Microscopical Structure of Rocks, and have shown the great geological value of a knowledge which can be gained only by examining thin sections with the microscope. In his papers, published in the 'Quarterly Journal' of this Society and elsewhere, he describes the mode of occurrence, structure, and composition of some of the principal basalts, dolerites, perlites, pitchstones, and felsites of the United Kingdom; and his memoirs are characterized, not only by great accuracy of detail, but also by much breadth and power of generalization. In his paper on the Wolf Rock he was the first to point out the existence of phonolite in the British area. He has for many years devoted much time and care to the prepararion of the thin sections necessary for the proper study of the structure of rocks; and I well know, by long experience, what a great amount of patience is needed to obtain satisfactory results. The Council of the Geological Society considers such researches deserve every encouragement, and has gladly awarded to him the balance of the Wollaston Fund. I feel sure that our late benefactor would have fully approved of such an appropriation.

Professor Bonner, in reply, said:-

\section{Mr. President,-}

Although I very much regret the absence of $\mathrm{Mr}$. Allport, I cannot but feel glad of the opportunity afforded me by representing him of expressing the many obligations which I am under to him for help in that microscopic study of rocks in which he is so proficient. $\mathrm{He}$ again and again has removed for me those difficulties which beset every one commencing so new and difficult a subject. He has requested me, Mr. President, to express his regret at being prevented by urgent and important business from being present to receive this award-which he regrets the more because it would have been a peculiar pleasure to him to receire it from your hands, seeing that it was the study of one of your papers, "On the Microscopic Structure of Crystals," which suggested to him the importance of applying the same method of investigation to rocks. He wishes me to state how highly he appreciates the honour which the Council has conferred upon him, and to render his thanks for this substantial help in the prosecution of his investigations. It will have the effect of stimulating him to further exertions in the future; he will regard the fund placed at his disposal as a trust, to be devoted to the cultivation of the field on which he has already worked; and he hopes that it will enable him to produce a more abundant harvest, although it will certainly be expended on very rocky ground.

The President next handed to Dr. HenRI Woodward, F.R.S. F.G.S., the balance of the proceeds of the Murchison Geological Fund, for transmission to Mr. J. W. KIRKBY, and addressed him as follows :- 
Dr. WOODWARD,-

It is now nearly twenty-five years since Mr. Kirkby's attention was prominently directed to the Magnesian Limestone of the neighbourhood of Sunderland, and to the collection of the various included organic remains. These were assiduously studied, and their relationship to both fossil and recent forms carefully determined. These researches have added much to our knowledge. The organic remains in the Carboniferous strata, and their close relation to those of Permian age, as well as the order and special characters of the rocks themselves, have also been elucidated by his observations. Subsequently, when employed at the Pirnie colliery, near Leven, in Fifeshire (which gave him opportunities for collecting numerous fossils, chiefly Entomostraca), he published, either alone or in conjunction with other authors, information which has materially increased our knowledge of the Carboniferous fauna. The Council of the Geological Society considers that such investigations deserve every encouragement, and begs that he will look upon the award to him of the Murchison Fund as an acknowledgment by his fellow-workers of his well-directed efforts, which we appreciate the more since we know how much his time is occupied with other necessary employments.

Dr. WoobwaRd, in reply, read the following letter from Mr. Kirkby :-

\section{"Mr. President,-}

"I have great pleasure in receiving the balance of the proceeds of the Murchison Geological Fund. The balance in itself is valuable; but to be thought worthy of being awarded it is of greater value-more especially when associated, as it is, with a name so famous in Palrozoic Geology as that of Murchison.

"The Permian and Carboniferous Entomostraca, which have been mentioned as special objects of my study, owe more to my friend Professor Rupert Jones than to me; though I deem it an honour, with him, to assist in their elucidation. There is much still to do in this interesting group of fossils. So far as I am concerned, I shall look upon your award as an incentive and an aid to further research, rather than as a reward for what I have done.

"J. W. Kirkвy."

The Presment next handed to Prof. JoDd a moiety of the balance of the proceeds of the Lyell Fund, for transmission to Prof. H. Alumpe Nrcholson, F.G.S., and addressed him as follows:-

\section{Professor JudD, -}

The Council having awarded to Prof. H. Alleyne Nicholson a portion of the proceeds of the Lyell Geological Fund, I have much pleasure in placing the same in your hands for transmission to bim. 
Prof. Nicholson's various researches upon the Palæozoic Palæontology of Britain and the Northern part of the American Continent have thrown much light upon many points in connexion with the lower forms of animal life as presented to us in the fossil state. The Graptolites, those peculiar structures so abundant in some of the Silurian rocks, and many of the obseure forms of Corals and other lowly organisms which constitute the great difficulties of students of the palæontology of the earliest fossiliferous rocks, have in a special manner attracted Prof. Nicholson's attention, and constitute the subjects of numerous memoirs which have appeared in various journals. Of independent works, I may mention his 'Monograph of the British Graptolites' (of which, unfortunately, only the first part has appeared) and his 'Palæontology of Ontario,' the latter published in 1875. In conjunction with Mr. R. Etheridge, Jun., he has commenced the publication of a "Monograph of the Silurian Fossils of the Girvan District,' which contains some exceedingly valuable palæontological results, and promises to be of much interest. Besides these publications, Prof. Nicholson has done much for the advancement of his favourite science by the production of several useful manuals and popular treatises on palrontology.

Prof. JUDD, in reply, said that he had much pleasure in receiving this award on behalf of Prof. Nicholson, from whom he read the following extract of a letter :-

"It is with much regret that I find myself preclnded by unavoidable previous engagements from expressing in person my very grateful sense of the honour conferred upon me by the Council of the Geological Society in the disposition which they purpose to make of the Lyell Fund. "It is hardly necessary for me to say in so many words that I feel the honourable distinction which I have received to be meant rather as a stimulus to future exertion in the cause of palæontological science than as a mark of recognition for any thing that I may have been able to achieve in the past. I can only beg to assure the President and the Council of the Socioty that I loyally aecept this interpretation of their kindness and goodwill, and that I shall not fail to do what may be in my power to prove myself more than merely theoretically grateful for an honour which I did not expect, and which I appreciate highly as a mark of friendly recognition on the part of the President and the Council."

The President then presented to Dr. Henry Woodward, F.R.S., F.G.S., one moiety of the balance of the proceeds of the Lyell Fund, and addressed him in the following words :-

Dr. WOODWARD,-

In awarding to you a portion of the proceeds of the Lyell Geological Fund, the Council of the Geological Society have commissioned 
me to convey to you the expression of their high sense of the value of your labours for the advancement of the science for the cultivation of which the Socicty has its being. For many years you have devoted yourself with great assiduity to the study of the Fossil Crustacea, founding your work upon those objects upon a thorough systematic acquaintance with their existing relations; and by this combination of zoological and palæontological knowledge, you have been enabled to work with great profit upon an exceedingly difficult branch of the science of extinct organisms. It would be a work of supererogation on my part (even did. I feel capable of doing it) to enumerate the many valuable contributions to this department of natural history with which you have enriched the pages of our "Quarterly Journal" and of other periodicals ; but I may refer especially to your most important memoir published by the Palæontographical Society, on those remarkable types of Palæozoic Crustacea which have been united to form the order Merostomata. Your catalogue of British Fossil Crustacea, although one of those works which may appear to be mere products of laborious industry, nevertheless shows many evidences of critical acumen, which raises it far out of the ordinary level, and will render it a most useful aid to all future investigators of that branch of British Palæontology. Besides these, which may be regarded as your special studies, you have further contributed to the elucidation of other fossil forms, and especially of some of those obscure remains of Insects and Arachnida the interpretation of which is always a matter of doubt and difficulty. In recognition of the value of the labours to which I have most imperfectly alluded, and of your other services to the science of geology, and to aid you in the further prosecution of your researches, I have much pleasure in handing to you this small testimony of the Council's appreciation.

\section{Dr. WoodWaRD, in reply, said,-}

\section{Mr. President, -}

I am fully sensible of the honour conferred on me this day by the Council of the Geological Society in selecting me to be one of the recipients of the "Lyell Award," and particularly grateful to you, Sir, for the kind manner in which you have spoken of my scientific work. There is a special pleasure in this award derived from the fact that in 1864 Sir Charles Lyell (then President of the British Association) took a warm personal interest in my first paper (read at the Bath meeting), "On the Discovery of some new forms of $\mathrm{Pa}$ læozoic Crustacea." If any incentive were needed to induce me to continue the work upon which I am engaged, it would be found in the kind words of encouragement which I have received from you to-day.

The President then procceeded to read his Anniversary Addrese, which was devoted to an examination of the structure of limestones, 
and the means presented, especially by optical investigation, for determining the origin of their constituent particles. The Address was prefaced by some obituary notices of Fellows and Foreign Members of the Society deceased during the past year, including Sir Richard Griffith, Prof. Harkness, Rev. W. B. Clarke, Prof. Oldham, Mr. Thomas Belt, Prof. Gastaldi, Mr. Daintree, Mr. T. Sopwith, Mr. J. G. Sawkins, and Mr. J. S. Dawes.

The Ballot for the Council and Officers was taken, and the following were duly elected for the ensuing year :-President : H. C. Sorby, Esq., F.R.S. Vice-Presidents : Sir P. de M. Grey-Egerton, Bt., MP., F.R.S.; Prof. P. Martin Duncan, M.B., F.R.S. ; Prof. J. Prestwich, M.A., F.R.S. ; Prof. A. C. Ramsay, LL.D., F.R.S. Secretaries: Prof. T. G. Bonney, M.A., F.R.S. ; Prof. J. W. Jndd, F.R.S. Foreign Secretary: Warington W. Smyth, Esq., M.A., F.R.S. Treasurer: J. Gwyn Jeffreys, LL.D., F.R.S. Council: H. Bauerman, Esq. ; Prof. T. G. Bonney, M.A., F.R.S. ; Prof. P. Martin Duncan, M.B., F.R.S., ; Sir P. de M. Grey-Egerton, Bt., M.P., F.R.S.; J. Clark Hawkshaw, Esq., M.A.; Henry Hicks, M.D.; W. H. Hudleston, Esq., M.A.; Prof. T. McKenny Hughes, M.A.; J. W. Hulke, Esq., F.R.S.; J. Gwyn Jeffreys, LL.D., F.R.S.; Prof. T. Rupert Jones, F.R.S.; Prof. J. W. Judd, F.R.S.; Prof. N. S. Maskelyne, M.A., F.R.S.; J. Morris, Esq., M.A.; R. W. Mylne, Esq., F.R.S.; J. A. Phillips, Esq. ; Prof. J. Prestwich, M.A., F.R.S.; Prof. A. C. Ramsay, LL.D., F.R.S. ; Prof. H. G. Seeley, F.L.S. ; Warington W. Smyth, Esq., M.A., F.R.S.; H. C. Sorby, Esq., F.R.S. ; Admiral T. A. B. Spratt, C.B., F.R.S.; Rev. T. Wiltshire, M.A., F.L.S. 




\section{ON THE EXTINCT AMERICAN RHINOCERUSES AND THEIR ALLIES. ${ }^{1}$}

BY E. D. COPE.

WELVE species of mammals which may be called rhinoc-
eroses, have been defined from materials obtained from the Tertiary formations of North America; and five additional species have been distinguished, which may be regarded as more or less nearly allied to that family. A few additional names have been proposed for supposed species whose characters are not yet established. In the corresponding formations of Europe and Asia, the fossil remains indicate a still larger number of species. The forms included in the family, first appear in both continents in the Lowest Miocene or Oligocene epochs; that is, in North America in the White River formation. The family still exists in Asia and Africa, but in Europe it disappeared during the glacial epoch. In North America it became extinct at a still earlier period, no remains of rhinoceroses having been found in beds of later age than the Loup Fork, or Upper Miocene period.

The genus Hyracidon (Leidy) which has a full series of incisor teeth, was formerly included in this family, and it agrees with the various genera in the structure of the molar teeth of both jaws. But I have ascertained that it differs so widely from them in some other respects, that it became necessary to regard it as the type of another family, the Hyracolonticle. The mastoid bone forms part of the external wall of the skull as in tapirs, and the neck is quite elongate. It fact the Hyracodon arcidens must have had the proportions of some of the horses in this respect. There is also no posterior tuberosity of the mandibular condyle, so conspicuous in the rhinoceroses.

The following table explains the relations of the two families:

IV. Anterior exterior crescent of supe ino molars much reduced; inferior molars with cross-crests; superior molars and premolaris alike, with cruss-crests.

6. Mastoid bone forming part of the external wall of the skull; no postcotyloid tuherusity of the mandible; neck elongate..............Hyracodontida

7. Mastoid bone exclucled from the walls of the skull by the contact of the occipital and squamosal; a postcotyloid tuberosity of the mandible; neck short ............................... Rhinocerida.

The genera of Rhinoccritle differ from each other as follows:

I. Four anterior digits.

Incisurs ${ }_{1}^{2}$; canine $\frac{0}{1}$; no horn; posttympanic bone distinct......Aceratherizm.

${ }^{1}$ Arlapted from a paper pubished in the Bulletin of the U. S. Geol. Surv. Terrs., Val $y$ No, 1870 
II. ? I Iigits.

Incisors $\frac{2}{1}$; canine $\frac{0}{1}$; posttympanic bone distinct; an osseous tuberosity on each side the muzzle........................... Diceratherium.

III. Three anterior digits.

Incis srs ${ }^{2}-\frac{1}{1}$; canines $\frac{0}{2}$; no horn; postympanic bone distinct...... Aphelnts.

Incisors $\frac{1}{1}$; canines $\frac{0}{1}$; a dermal horn; posttympanic distinct... Ceratorhinus. Incisors $\frac{3}{2}$; canines $\frac{0}{2}$; a dermal horn; posttympanic?............ Zalabis. lnzisors $\frac{1}{1}$; canines $\frac{0}{2}$; a dermal horn; posttympanic process coössified with postglenoid process; no nareal septum................ Rkinocernes.

Incisors $\frac{0}{0}$; canines $\frac{0}{0}$; a dermal horn; posttympanic process not united with postglenoid; no nareal osseous septum.................. Atelodzes.

Incisors $\frac{0}{0}$; canines $\frac{0}{0}$; a dermal horn; posttympanic coössifed with postglenoid; an osseous septum dartum.................. Calodonta.

My catalogue of species of the above genera contains twenty-eight names, of which six belong to living species. The latter are Ceratorkinus sumatranus Cuv.; C. lasiotis Scl.; Rhinocerus unicomis L. ; and $R$. sondaicus Cuv., all from Asia and Malaysia; and Atelodus bicornis $\mathrm{L}$. and $A$. simens Burch., of Africa. It is possible that a species of Aphelops still exists in some of the Indian islands, in the R/inocerus inermis Less. There are probably several distinct fossil species not in the list; but their characters have not yet been sufficiently made known to enable me to refer them to their proper places. It will be observed that eight species have been found in North American formations, ten in European, and three in those of Hindostan. It appears also that no extinct species of the true genus of Rhinoceris has yet been found in North America or Europe, and that no extinct rhinoceros of North America which is known, possessed a median dermal horn.

It can readily be seen that the genera above defined form a graduated series, the steps of which are measured principally by successive modifications of four different parts of the skeleton. These are, first, the reduction of the number of the toes of the anterior foot; second, the reduction in the number and development of the canine and incisor teeth; third, the degree of closure of the meatus auditorius externus below; and fourth, in the development of the dermal horns of the nose and its supports. While these characters have the tangible and measurable quantities which render them available for generic diagnosis, there are others which possess a similar significance, and which I now notice, so far as they are observable in the extinct species of North America.

I premise by observing that the Aceratheria and Diceratheria of this continent have only been found in the eastern and western divisions of the White River formation, while the species of Aplelops are confined, so far as is known, to the Upper Miocene 
$771 \mathrm{C}$ Extinct American Rhinoceroses and their Allies. [December.

The posttympanic process is, it is well known, well separated from the postglenoid process in the tapir, so as to leave the auditory meatus widely open below. The arrangement is similar in Hyracodon. In Rhinocerus, as shown by Flower, the meatus is closed below by the coosssification of the two processes. In the oldest genus of the family Aceratierium, the relations of the parts are as in Hyracodon. In Aphelops the two processes approach each other, but do not come in close contact as in the genus Ceratorhinus.

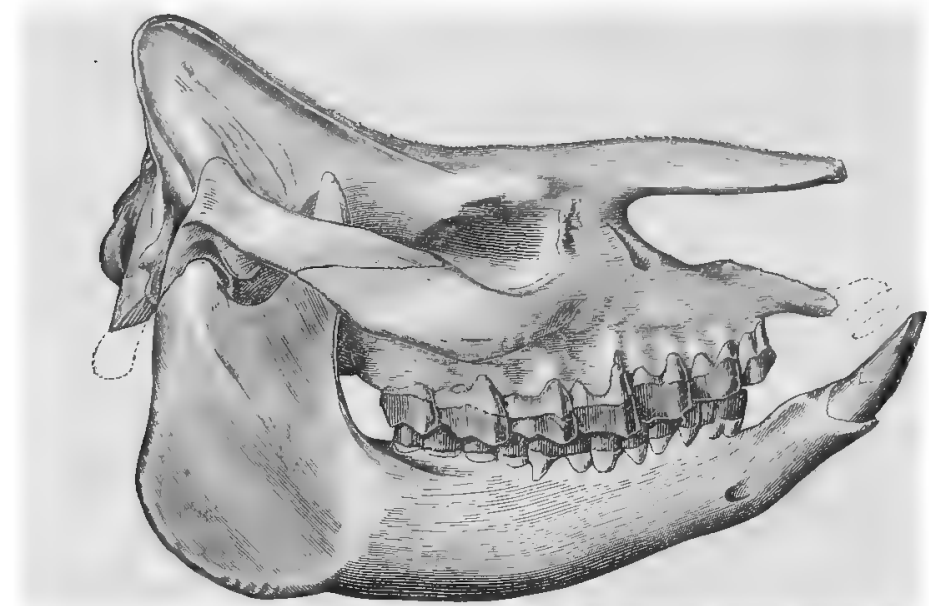

Fig. 1.-Aphelops megalodus Cope, one-sixth natural size. Loup Furk beds, Colorado.

The postglenoid process is low and transverse in the tapirs; in Rhinocerus it is long and has a triangular section. In some species of American Aceratheria its form is much like that of the tapirs (A. mite, A. occidentale); while in Diceratherium pacificum and in the species of Aphelops, the form of this process is as in R/inocents.

In the iapirs, the foramina sphenoörbitale and rotundum are distinct. They are also distinct in Aceratherium mite. In D. pacificum they are confluent, but the walls of their orifice present two opposite projections, which are the rudiments of a dividing septum. In Aphelops these foramina are one as in Rlinocens. At the same time, the external wall of the alisphenoid canal is shorter and thinner in the Aceratheric than in the Aphelopes.

In the older types of Perissodactyla, e. g., Symborodon, the foramen ovale is situated well in advance of the foramen lacerum medius, and is separated from it by a considerable space of the sphenoid bone. The same structure is seen in Hyrarndan and in 
Aceratherium. In Aphelops, the foramen ovale approaches near to the f. lacerum, so as ta be separated by a narrow bridge only in $A$. megalodus, which is wanting on one side in a specimen of A. malacorhinus. In the genus Rhinocerus, these foramina are not divided.

In the structure of the teeth, the same serial order is to be observed. Commencing with the incisors $\frac{3}{3}$ in the tapiroid types and Hyracodon, and canine $\frac{1}{1}$, we find $\frac{3}{2} \frac{0}{1}$ in Zalabis; $\frac{2}{1} \frac{0}{1}$ in Aceratherium; $\frac{2-1}{1} \frac{0}{1}$ in Aphelops; $\frac{1}{1} \frac{0}{1}$ in Ceratorhinus and Rhinocerus, to $\underset{0-1}{0} \frac{0}{0}$ in Atclodus and Coclodonta. As to the molars, in those of the upper jaw the series of modifications consists of successive complication of the transverse crests. In Hyracodon, as in the tapiroid genera, the external wall of the posterior molar is

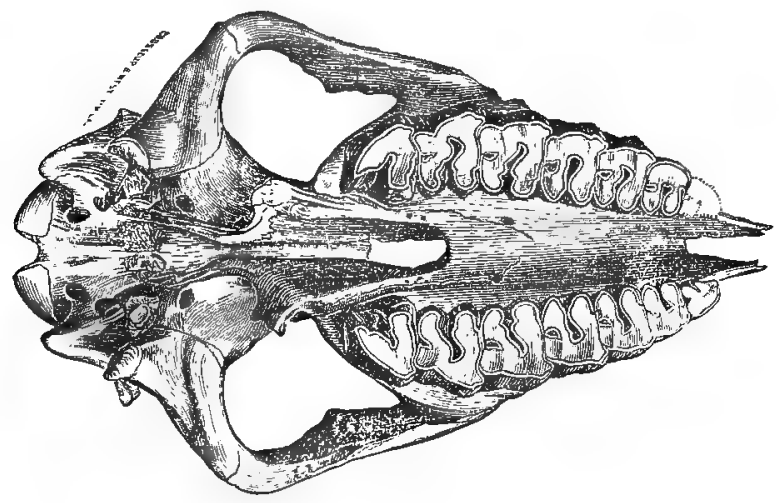

FIG. 2.-Aphelops megalotus Cope, inferior view of cranium represented in Fig. I.

continued beyond the posterior cross-crest; in the Rhinoceridce, generally the external wall is not continued beyond this crest, but is in line with the posterior cross-crest. In a specimen of Aceratherium occidentale, the posterior superior molar of one side is like that of Hyracodon, while that of the other side is like that of Rlinocenus. The cross-crests in Aceratherizm are quite simple, having slight bulges into the median valley. In the species of Aphelops these bulges are more prominent, especially that of the posterior crest, which is more externally situated than that of the anterior cross-crest, so that the fundus of the valley is turned abruptly backwards. In several of the existing species, this bulge becomes an antero-posterior crest, and the fundus is further divided by other crests from the outer wall and elsewhere. The cingula become so elevated as to cause an isolation of the valleys as fossæ at a comparatively early stage of wear. This 
$77 \mathrm{I} e$ Extinct Anerican Rhinoceroscs and their Allies. [December, state of things commences in the extinct species of Kansas, the Aphclops fossiger.

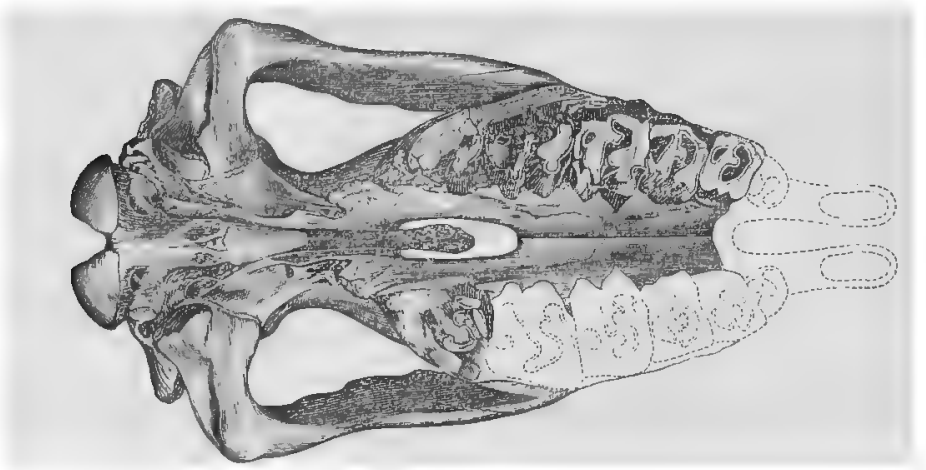

Fig. 3-Aphelops fossiger Cope, skull from below, one-sixth natural size. Loup Fork beds of Kansas.

In the bones of the skeleton, modifications accompanying those of the cranium and dentition may be observed. The femur of the species of the earlier formations may be readily distinguished from that of those of the later Tertiaries by the forms of both the extremities. In the Aceratheria this bone resembles that of the tapirs in the form of the great trochanter. This process is produced at its external border, has a recurved apex, and encloses a deep trochanteric fossa. In Aphelops it is precisely as in Rhinocerus, obliquely truncate externally, without prominent apex or well marked fossa. In the Aceratheria the inner crest of the rotular groove is but moderately prominent; in Apliclops and Rhinocerus it is greatly developed.

The succession of development of the line of the Rhinoceride is now not difficult to trace, and I give the following diagram in explanation of it.

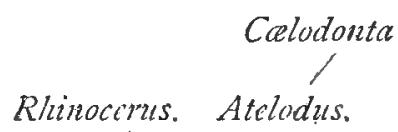

Ceratorhinus.

Zalabis.

Apleelops.

Aceratherium.

Dicirathcrium.

It is evident that the descent diverged at a comparatively late period of geological time into two lines, which are represented at the present day by the African and Indian species resnectivelv 
The earliest species of the toothless or African series is the Atelodus packygnathus of Wagner, whose characters have been so well worked out by Gaudry in his great work on the Fossil Fauna of Attica. That species sometimes presents a single small incisor or canine tooth in the mandible. ${ }^{1}$ From what has preceded it is also apparent that the generally most specialized type of rhinoceros, the genus Coelodonta, has become entirely extinct. Its three species yet known, were confined to Europe and Northern Asia, and the most formidable of them extended its range with the hairy mammoth within the Arctic circle. The Coelodonta antiquitatis (the wooly rhinoceros) was evidently the most effectively armed of the family, as it had two horns, which, judging from the character of the surface of the skull to which they were attached, must have been of unusual size. To provide further against the shocks incident to their use in combat, the nareal septum was ossified, thus becoming a solid support to the nasal bones, etc., on which they stood.

It remains to look backwards, and to discover, if possible, the probable origin of the family in that of its earliest known genus, Aceratherium. A late survivor of this ancestral type is seen in the genus Zalabis Cope, of which one species, the $Z$. sizalensis, has been discovered by Cautley and Falconer in the late Tertiary of Hindostan. In this form, according to Falconer, there are $\frac{3}{2}$ incisors and $\frac{0}{T}$ canines. The early type, which corresponds most nearly with this genus, and which preceded the Aceratheria in time, is the genus Amynodon Marsh, which has left a species in the Uinta or Upper Eocene of Utah. Here the incisors are $\frac{2}{2}$ and the canines $\frac{1}{1}$. . This' formula is intermediate between that of Aceratherium and that of the Eocene tapirs, where the normal numbers $\frac{3}{3} \frac{1}{1}$ prevail. According to Marsh, Amynodon further differs in the primitive condition of the premolars above, which, as in the Lophiodontide, differ from the molars in their greater simplicity. Thus it is probable that tapiroid animals, probably Lophiodontida, gave origin to the Rhinoceridee, as Marsh has suggested. And it is further altogether probable that the general type of dentition presented by the Rhinocerida, Lophiodontide, etc., which I have named the palæotheriodont, took its origin from the type which is intermediate between it and the bunodont, viz: the symborodont, as I have pointed out in an essay on this subject. ${ }^{2}$

I The large tooth of the mandible described by the older authors as an incisor, has been regarded as a canine by Gervais, Subsequently Marsh adopted the same view.

${ }^{2}$ The Homologies and Origin of the Molar Teeth of Mammalia, etc. Journal w. . .... nhind rend nn 13-14. 
The first appearance of dermal horns was apparently in a pair placed transversely on the nasal bones, in species of Eocene Lophiodontida, of the genus Colonoceras. The same character has been observed by Duvernoy in species of the Lower Miocene, which belong to the true Rhinocerida, and which Marsh has called Diceratherium. This genus appears to have terminated the line exhibiting this structure, and the family in North America remained without horn. As we have seen, the types possessing the median horn arose in Europe, in the Ceratorhinus schleiermacheri of the Middle Miocene, and still survives.

It may be observed in conclusion, that a successive increase of size in the species of this line has taken place in North America with the advance of geologic time. Thus, their probable ancestors of the genus Hyrachyus were the least of all. The Acera-

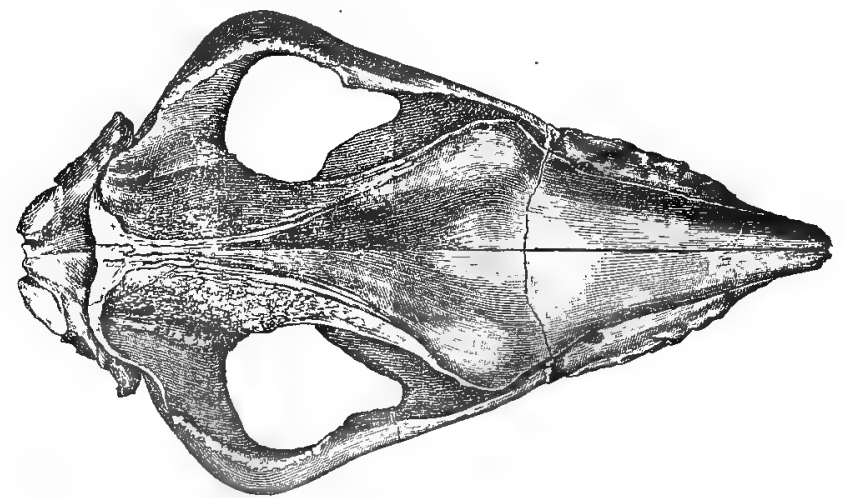

Fig. 4.-Aphelops megaloulus Cope, skull from above (same as FIG. I), one-sixth-natural size.

theria of the White River formation were larger, the oldest, $A$. mite, being the smallest. The Diceratheria of Oregon were larger still. The species of the Loup River or Upper Miocene formation were larger, and nearly equal to the large existing species.

Aceratherium Kaup. is characteristic of the Miocene or Middle Tertiary formations of Europe, and is the primitive form of the true rhinoceroses. Its four anterior digits relate it to the lower or more generalized perissodactylous types of the same and of older geological horizons, which are equally allied to the tapirs. The dentition differs from that of the genus Rhinocerus in the presence of two superior incisors, but agrees with it in the exis. ence of one incisor and one canine on each side below, and in $t$. forms of the premolar teeth. The species display great simplici, in the character of the crests of the molars. They also possess, 
the tapiroid feature of the non-closure of the auditory meatus below by the posttympanic process; and the postglenoid process is generally more like that of the tapirs than are those of the later genera Aphelops and Rhinocerus. The form of the femur is also quite characteristic, presenting tapiroid characters again in the shape of the great trochanter. This process is not flat and obliquely truncated as in the genera above named, but is horizontal proximally, and with a produced recurved apex and posterior crest, which bound a large fossa. The species are the smallest of the family, the $A$. mite having the dimensions of the Malayan tapir.

In the species of Diceratherium (Marsh) the cranium and limb bones present the characters above ascribed to the Aceratheric. In size they are intermediate between the latter and the Aphelopes. The two American species are known from the beds of the Truckee epoch of Oregon; a third species, D. pleurocerus (Duv.) has been found in France.

Aphelops (Cope) occupies a position intermediate between Accratherium Kaup and Rhinocerus Linn. It agrees with the former in the presence of incisor and canine teeth, and in the absence of indication of a nasal horn, but differs from it in lacking the fifth digit of the anterior foot. In the last respect it is identical with the genus Rhinocerus, differing from it in characters already mentioned, in which it agrees with Aceratherium. From Atelodus Pom.

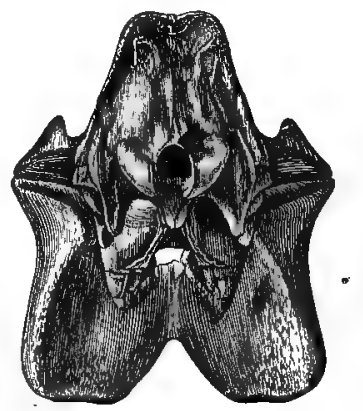
it differs still more widely, as that genus wants incisor and canine teeth.

The evidence on which this genus rests is furnished by two species, the Aphelops megalodus, and the A. fossiger. In both of these animals, the number of anterior digits is known to be only three and in the former the inferior canines an ${ }^{1}$ alveoli for incisors can be seen in

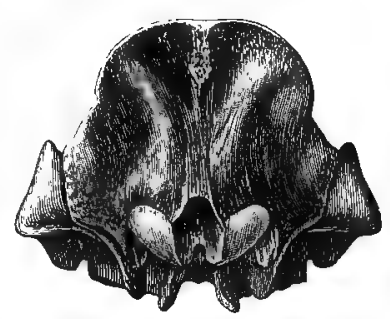

FIG. 5.-A. mzegalodus figurell $\rightarrow$ specimens. In two other species above, posterior view of skull. , visionally referred to the same genus, Fir. $6 .-A$. fossiger, skull figAe $A$. crassus and $A$. malacorhinus, the size.

wits and incisor teeth are unknown but the last named species was certainly hornless, and it is supposed that the first named was 
so also. Of the many mandibular symphyses from the Loup Fork formation which I have seen, none lack the canines and incisor teeth, so that it is probable that this character belonged to the two species above mentioned. A fifth species, the $A$. meridianus Leidy, I have provisionally referred here, on account of the similar character of the mandibular dentition; but its nasal bones and feet are unknown. Still another species, the A.jemezanus Cope, has been referred here, but on no other ground than that it is found in the same formation as the others.

Specific characters. - The species above named all present wellmarked cranial or dental characters, or both. But it is important to take into consideration the general structure of the skeleton. I am in position to do this with three of the species named, the

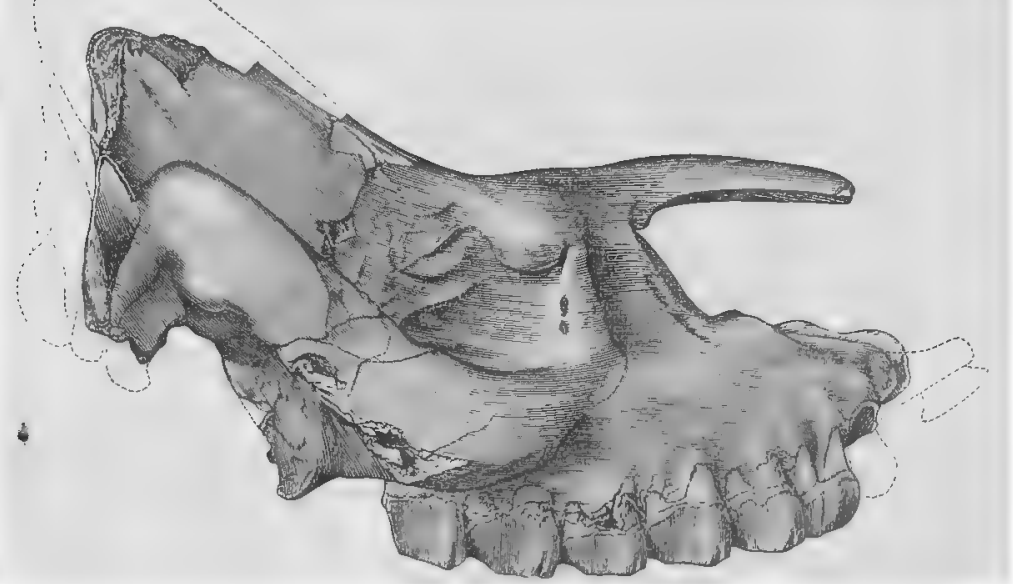

FIG. 7.-Aphelops malacorfinus Cope, skull one-sixth natural size, restored behind from another cranium.

$A$. megalodus, the $A$. fossiger (of this paper), and the A. malacorlimus and find distinctive characters present in nearly all their bones which I have observed. The A. malacortinus is a comparatively long-limbed animal, and its apparent elevation was increased by the shortness of the body, and especially of the neck. There was probably a great development of the upper lip, or snout, and the face was concave in profile. The A. megalodus was somewhat intermediate in proportions between this species and the A. fossiger Its limbs were shorter than in the A. malacorhinus, and the neck was longer. The feet were more slender. The $A$. fossige had still shorter legs, and the length of the neck was about as in A. malacortinus. In its form it must have been like a Hippopotamus. Its limbs, and especially the feet, were very robust. " 
Position.-The longest known species, the $A$. crassus, was found by Dr. Hayden on the Niobrara River, Nebraska. Teeth presenting the same characters have been found in Northern Kansas and Eastern Colorado. The other species are more restricted geographically. A considerable exploration in the Loup Fork beds of North-eastern Colorado, conducted by myself in 1873 , yielded four individuals of $A$. megalodus, but no fragments refer. able to the other species. Explorations in Northern Kansas by Russell S. Hill, of Philadelphia, produced five individuals of $A$. fossiger and five of $A$. malacorhinus, but not a fragment of $A$. megalodus.

History.-In my original definition of this genus, I relied on

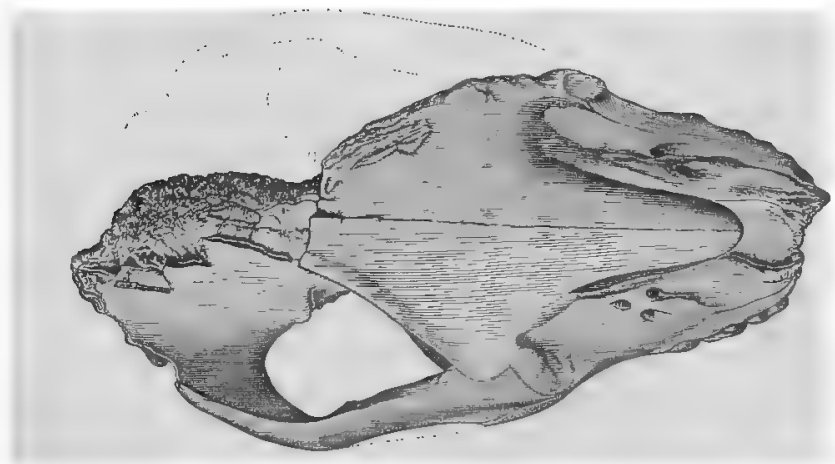

FIG. 8.-A. malacorhinus skull, represented in Fig. 7 from above, one-sixth natural size.

the number of premolars in distinguishing it from R/linocerus as well as on the absence of the horn. These teeth are generally $\frac{3}{3}$ in Aphelops, and are said to be $\frac{4}{4}$ in Rhinocerus, in most works, on the subject. These numbers are not constant; on one side of both jaws in Aphelops from Colorado, I have observed a first premolar, and on one side of the upper jaw of $A$. malacorhinus there are four premolars; the other side is injured. In several species of Rhinocerus, three premolars only are usually found in the mandible. I may add that Lesson and Peters ${ }^{1}$ have described a Rhinocerus inermis Less., which is found living on some of the islands at the mouth of the Ganges. The only known specimens are the skulls, with portions of the skin, of a female and young. These are hornless, and in general structure allied to the $R$. sondaicus, yet presenting some important differences. ${ }^{2}$ Should the characters of this form prove to be specific, and the male be found to lack the horn, it must be regarded as a species of Aplelops.

2. Monatsberichte Berlin. Akademie, 1877, p. 68, pl. I-2.

${ }^{2}$ Peters represents the posttympanic as not coössified below the meatus as in $R$. sondaicus. 



\section{THE MODERN MUSEUM:*}

THE sentiment which forms the text of the following remarks; 1 is this: that of all the grand edifices which men are accustomed to erect for public uses, none is more necessary than the museum. I firmly believe that the spirit of the present age has made it that of great museums. This is the day of colossal exhibits of the works of creation, as the middle ages were the ages for the building of immense temples, or cathedrals. These, it must be confessed, were too frequently erected to an unknown God. But with the field of nature exposed before us, as it has been by the labors of many men during the present century, we have now acquired, it is to be hoped, some knowledge of that God who had been previously unknown, so far as relates to those works which interest us most immediately.

Now, as regards the method of presenting the results of the great and all embracing process of creation, I will offer a kind of synopsis of the order in which it appears to our minds as we stand within our civilization, and thence cast our eyes over the past, gradually unfolding the history of the world from its commencement. Some of the statements which I shall make will doubtless be trite, for I chiefly hope to exhibit the connection between facts already recognized, upon which the classification of this great exposition may be securely based.

It is well known that man as an animal commenced his existence with but few appliances for protecting and supporting himself. There is still a state of savagery in which even the making of the vessels for holding food and liquid is unknown. Implements of all kinds, at an early day, and in a still existing state of savagery, were nothing but fragments of rocks, mostly of flint, and the use of metals was unknown, except as shining ornaments with which the savage was amused in leisure moments. The making of pot-

* An address delivered by Professor E. D. Cope, at the opening of the Permanent Exposition, in Philadelphia, May roth, 1879. 
tery and the use of the bow and arrow were advances of much more importance than we can now well conceive. 'The discovery and making of the bow and arrow, simple as we now consider the method to be, was only attained after the expiration of ages.

In the discovery of the art of weaving, man became at last independent of the wild animals and of their migrations, as a source of supply of clothing; and by domestication of animals, he was enabled to control them also for the purpose of furnishing him with food. In spite of all the changes of the seasons, he could then keep his flocks and herds and make his stuffs, and clothe himself and his families. He ceased to rely upon the chase, and became pastoral. Here we have the indication of one of the great stages in the progress of man. But, until agriculture was discovered and manufacturing as a separate occupation was commenced, he was compelled to be nomadic; he was'under the necessity of moving his tent from place to place, in order to find food for his flocks and herds. When agriculture came, civilization in its true sense began. When the soil of one locality was capable of yielding food year after year, so that there was a surplus, commerce had a serious beginning. One set of men could produce food enough for all, and another set of men could then have time to make clothing for all; and so food and clothing became interchangeable, according to the people's needs, and organized society, with its commerce, had its origin.

But in order to carry on agriculture and the chase, something more than stone hatchets and stone diggers were necessary. Hence, doubtless, the experiments in the effort to utilize more tenacious metals were innumerable. Then was discovered the working of soft metals occuring native, such as copper; an important advance. Later, success crowned the efforts of early man when the discovery of the art of working iron was made, and a wonderful impetus to his control over nature was given. We are all familiar with the results that followed. New weapons were made. The building of larger vessels to float upon the water, and the creation of new hand machinery, necessarily became possible. When in modern times steam was harnessed, all processes were accelerated tenfold, and now electricity has bound the human race together so that the most rapid interchange can take place in answer to all demands; and supplies of food and clothing need no longer be 
wanting to any one of its widely scattered nations. One may say that such was the physical establishment of the human race upon this world. The great triumph over nature was accomplished by this process.

In accordance with this history of development, the present exhibition is to present the results of human.industry from its earliest appearance, representing them in five departments, viz. :

The department of archæology and ethnology.

The department of agriculture.

The department of architecture.

The department of model homes.

And finally, the department of machinery and manufactures.

We can readily see what interest attaches to the department of manufactures and machinery, if we are at all familiar with the progress of our species, with the history of his supplies of clothing and daily food, of how our ancestors lived, and how the first men were, as it were, turned loose upon the world to shift for themselves. We know that they lived and survived, and that we are standing, to-day, surrounded by all the conveniences of civilization. We anticipate that the department of machinery and manufactures will elucidate the subject in the extensive space which has been devoted to it within the building.

We now pass to the departments devoted to the supply of the necessities of his mind. It is evident that man in his first existence upon earth, began with sufficient rationality to enable him to support and protect himself against fearful odds; for as of all animals the least perfectly furnished with natural defences, he was compelled to rely upon his own skill and activities. He inherited what he had to start with; and doubtless found abundant necessity for using it in his combats with the lions, tigers, hyenas, wild oxen and bears which shared with him the field and forest. The brain, at some periods of its life, is, probably of all organs of the body, the most capable of growth changes, as it is most susceptible to sense impressions. Hence it is developed by exercise to a remarkable degree. The development of mind under use is familiar, though not sufficiently so, to us all. Its degeneracy in consequence of disuse is equally well known. As man's life has been from the start a struggle against the forces of nature, without weapons or protection, save those of his own making, so man's 
history is the history of the development of his mind. The progress of rationality is the progress of the most perfect of the animal creation, but it is not the only progress. The development of the sentiments has also advanced with the opportunity of exercising them. From our social relations, our affections have sprung; from the necessity of law imposed for mutual protection, our moral ideas have been derived. In these two fields, man appears as a higher being, apparently preparing for a still higher destiny. Further than this glimpse, I will not refer to the future. We have much to do in the present. Si quaeris [laborem] amocnum circumspice.

As representing purely intellectual objects, there are thrce departments represented within the walls of this exposition.

Firstly, the department of industrial training, to develop and stimulate mechanical knowledge and skill.

Secondly, the department of schools and libraries, in which is exhibited the apparatus used in the training of the mind while most plastic, in all that is necessary for its adult life.

And finally, the department of the fine arts, which are used to develop and keep alive the affections and sentiments, and remind us ever of the beautiful, the good and the true.

Of necessity, we first look at these subjects with the eye of physical utility. I hope that I have made it evident that the contemplation of man by himself has of all subjects the highest utility. In considering the laws of our being and the conditions which gave rise to our existence, let us return to the starting point of human progress, and endeavor to carry our view into that past where man's agency was unknown, and where life struggled toward the creation and birth of its latest offspring, mind. Here we have the history of the battles of life with its environment, with hunger and thirst, with flood and earthquake, ever defeated, yet ever rising indestructible. It has been taught by disaster, learning new defences and safeguards. To-day, after these æons of change, life is everywhere. The soil is full of it, the waters teem with it, the air is clouded with it. Wherever it can exist, there life comes. We eat it, we drink it; it abounds in the centres of human population, as in the wastes of the ocean and of the prairie. There are five hundred thousand species of animals and as many of plants, and there are few of these that are not represented by millions of individuals. If 
now we seek to express in one word the grand distinctive feature which this term implies, life may be described as the condition which can feel; not indeed the condition which does feel, for there are many functions of life which involve no feeling or consciousness; but these are exhibitions of mechanical or automatic force, originated in consciousness, which, when its work is done and its machinery is in working order, has the happy characteristic of passing on to other scenes where new necessities call for it.

The laws which have carried this life through ages of time, and also clothed it in so many wondrous forms, are also laws of our own life. What life has done in the past can be done again, if it be worth doing; so that we find utility as well as pleasure in contemplating its history. Here, as elsewhere, this exposition should be an educator, for

The department of Organic Material will display the handiwork of life in the dwellings and machinery it has built for itself from the beginning of geological time.

As we approach non-living matter, or the inorganic world, we are led to speculate on the origin of life. This raw material, as we can call it, represented here by

The department of Inorganic Material,

is the product of a laboratory whose processes are coextensive with time, and whose boundaries are those of the universe. In its history we find material for ceaseless wonder, for perpetual admiration, and also for serious thought. Our minds necessarily become earnest in the presence of the vastness of the stellar masses, and we feel something akin to horror in observing the stupendous effects of force. We are compelled to pause and ask ourselves the meaning of the tremendous conflict of the forces which raged for æons before the earth was fit for life. We see processes of world-making, with their successive storms of matter, substance after substance descending to their centres, either in gentle mists or in thundering avalanches, as the case might be, with the dissipation of heat or decrease of temperature. We see the atmospheres of planets gradually cleared, so as to admit the light of the great solar bodies, and the worlds become habitable.

But why or how the fire of life caught the material of life as it exists here, we cannot yet perceive. It did come, whether by communication from an outside source, or whether actually pro- 
duced by processes in dead matter, we do not know. In its essence, as consciousness or sensibility, I do not believe it to be the offspring of anything, but to be additional to matter and force; the third fact of the universe, to which the two others are necessary. It spreads from place to place, whenever the conditions of matter and force are suitable for it. It is like a fire let loose, whicl now creeps through low cushions of moss and grass, now smoulders in old wood, then blazes high as heaven in fruitful meadows and towering forests, - it dies out in the earth, avoids bare rocks, and ceases abruptly as it strikes the edge of the water. But matter capable of displaying it there doubtless always has been, if not in one planet then in another; if not in one solar system then in another; and so it penetrates the universe, derived from the great reservoir of consciousness-wherever that may be-perhaps all around us. The labor and time consumed in making the living world of to-day, is only realized by those who can read the history of creation. What ages have passed since life began the struggle whose outcome is mind! What millions of attempts, so to speak, were made before the best working machine, man, the triumph of mental organization, was turned out! What immeasurable waste, from one point of view, was necessary before this result was achieved. Mountains of limestone bespeak the ruin of countless myriads of animals; coal and oil and other similar substances are the quintessence of forests and other cohorts of living things. Even the solid flint has been laid down in incredible masses by the gentle showers of the shells of minute plants upon the floor of the ocean, and square leagues of rocks in all parts of the earth are filled with the remains of the inhabitants of land and water. Tribe after tribe, nation after nation has fallen, and we ask as we wonder,How many pleasures and pains lie buried with these millions? How many songs have been hushed? How many discordant cries silenced, before the relentless advance of the law of progress that has allowed no laggards. Such is the explanation of the hecatombs of the past, such the lesson man finds set before him. In considering the time occupied in the creation of man, and the waste involved in the process, it is incumbent on us that the value of the result is not diminished through any fault of ours. In this view, the creation of exhibitions like the present one finds its best justification. There is no more certain way of teaching of the future than by the knowledge of the history of the past. 
As before remarked, there is no doubt that the present time is the age of these great museums; it is becoming more and more evident that there can be no greater benefit to society than to have the evidence of the laws of progress before their eyes. They will then learn that the species cannot go backwards, and that if society goes backwards, the world will leave it behind; that progress is a pleasure, and that retrogression will sooner or later become a pain. That thousands and millions are nothing in opposition to the progress of nature, and that, as in the past so in the future, she can bury her dead no matter how many they be. That this building is the place for such an exhibition, as adapted to the means of this city, I think no one can for a moment doubt. It is the only building, to my knowledge, which is sufficiently large and extended to present in order the millions of objects which we ought to exhibit. The space which is contained within these walls, well supported by iron columns, and bound together by iron girders as they are, can hold the contents of the British Museum and the South Kensington Museum combined; it would contain the contents of the Louvre and the Fardin des Plantes conveniently under one roof. Here the visitor or the citizen can pass from one department to the other, without having traversed the length and breadth of this great city, and without missing any part of them.

Shall this city, the second in population on the American continent, in the front rank of the cities of the world, neglect this opportunity? Shall it refuse material aid ; shall it entomb its dollars and bury its talent, so to speak, in the earth, by erecting new and costly museum buildings in scattered localities? A distinguished author says that the work of science is generally in inverse ratio to elegance of buildings and appliances; and it certainly is unwise for men to put money into structures, and not leave enough to support the work to be carried on within their walls.

I sincerely hope that this important opportunity will not be lost, and that Philadelphia may fully avail itself of the facilities which are presented within the immense space which is covered by the roof above us.

E. D. Cope. 

[Extracted from the Proceedings of the Acndemy of Natural Sciences of Philadelphia, July 8, 1879.]

\section{ON THE GENERA OF FELIDE AND CANID正.}

BY E. D, COPE.

\section{FELID正.}

The discovery of extinct species from time to time, renders it necessary to re-examine the definitions of the families and genera into which living forms naturally fall. We thus learn the character's of their primitive types, and the successive steps through which they passed in attaining their present characteristics. The Felidre are known as that family of Carnivora in which the feet and teeth are most specialized for the functions of seizing and lacerating living prey. The number of living species enumerated by Dr. Gray is sixty-four, which he throws into a number of genera. The extinct species yet known are less numerous, but they present a greater variety of structure than the former. Two types or series may be recognized among the genera, namely those represented by the genera Felis and Macharodus respectively. All of the latter are extinct.

The greater number of the genera allied to Macharodus are distinguished by the great development of the superior canine teeth, whose crowns are generally compressed and trenchant. The corresponding part of the mandible is expanded downwards so as to furnish a protection to the slender crown from fracture by lateral blows when not in use, but in some of the genera, e. $g$. Nimravus, this flange is not developed. The only definition which can be used to distinguish these sections of the family, is found in the angular separation of the anterior and lateral planes of the ramus of the mandible, and this character cannot be expected to remain unaffected by future discovery. Forms will doubtless be found in which the angle is obsolete, and in which the lateral and anterior faces pass gradually into each other. Other characters which distinguish the extinct genera are found in the numbers of molar teeth, and, what has been leretofore neglected, the number of lobes of the molars themselves.

As regards the existing genera, Dr. Gray' has brought out their

1 Catalogue of Carnivorous, Pachydermatous, and Edentate Mammalia in the British Museum. By John Edward Gray, F.R.S., V.P.Z.S., F.L.S., etc. London, 1869. 
characters more fully than any other author. He points out the fact that in some of the species the orbits are closed behind, and in others open. He first examined into the manner of the contraction and closing of the pupil in the presence of light, and pointed out the fact that in the large cats it is always round and approximates a point in closing, while in the smaller forms the pupil closes as a vertical slit. He shows that the cats of the former group have the smaller orbits of the cranium, and the latter the larger. Dr. Gray, however, uses other characteristics in the discrimination of the genera, which are, in my estimation, quite inadmissible; as the relative length of the muzzle and of the premaxillary bones; also of the hair on different parts of the body and tail. Sneli features of proportion are essential as characters of species, but not of genera. In accordance with these views, I have united several of Dr. Gray's divisions into groups, which I call genera, and which repose on some definite structural characters. Thus I combine his Uncia, Tigris, Leo and Leopardus into a genus for which I employ his name Uncia, as the least objectionable, ${ }^{1}$ after having confirmed by antopsy the circular character of the pupil. This I was enabled to do throngh the courtesy of my friend Arthur E. Brown, Superintendent of the Philadelphia Zoological Garden, who aided me in examining the eyes of these animals both by sundight and the light of a bull'seye lantern." The detailed characters of the genera will now be given :-

I. The anterior and lateral faces of the mandible separated by an angle.

a. Inferior sectorial with a heel; no anterior lobe of superior sectorisl; no posterior lobes of the premolars.

* An inferior tubercular molar.

Premolars $\frac{2}{3}$.

Dinictis.

Premolars $\frac{2}{2}$.

Nimrauus.

${ }_{1}$ I assume that this name is derived from uncus, a hook, which is appropriate to the weapons of these auimals.

2 I add the following notes on some other Carnivora, which do not come within the scope of this paper :-

Hycena crocuta. Pupils a vertical slit.

Viverrida. Three species of Ichneumon and Viverricula, a horizontal oval.

Nasua. A horizontal oval. 
** No inferior tubercular molar.

Premolars $\frac{2}{2}$; incisors $\frac{3}{3}$.

Hoplophoneus.

Premolars $_{T}$; incisors $\frac{}{2}$.

Eusmilus.

aa. Inferior sectorial without heel; an anterior lobe of the superior sectorial, and posterior lobes of the premolars.

Premolars $\frac{2}{2}$, first inferior two rooted.

Machærodus.

Premolars $\frac{2}{2 \text { or } 1}$; first inferior one rooted.

Smilodon.

II. The anterior and Iateral faces of the mandible continuous, convex. (No inferior tubercular molar.)

a. Inferior sectorial tooth with a heel.

Premolars $\frac{2}{4}$, no posterior lobes; second superior with internal heel (plantigrade).

Cryptoprocta.

Premolars $\frac{2}{4}$ with posterior lobes; no heel of second superior.

Pseudælurus.

a.a. Inferior sectorial without heel; premolars with posterior lobes; superior sectorial with anterior lobe.

$\beta$. Superior sectorial with internal heel.

$\gamma$. Pupil round.

Premolars $\frac{2}{2}$.

Premolars $\frac{1}{2}$.

Uncia.

Neofelis.

$\gamma \gamma$. Pupil vertical.

Orbit closed behind; premolars $\frac{2}{2}$.

Orbit open; premolars $\frac{2}{2}$.

Orbit open; premolars $\frac{1}{2}$.

Catolynx.

Felis.

Lyncus.

$\beta \beta$. Superior sectorial without internal heel.

Pupil round, premolars $\frac{2}{2}$; orbit open posteriorly.

Cynælurus

The following catalogue includes the species of the Felidx, the names of the recent ones being derived from Gray's Catalogue, and printed in Roman letters. These are probably too numerous in the genera Felis and Lyncus, but I do not possess the means of properly disposing of them.

Dinictis, Leidy. Aelurogale, Filhol. ?Daptophilus, Cope.

D. intermedia, Filhol. Phosphorites, France.

D. squalidens, Cope. White River, Colorado.

D. felina, Leidy. White River, Nebraska.

D. cyclops, Cope. White River, Oregon.

Nimravus, Cope.

N. brachyops, Cope. White River, Oregon. 


\section{Hoplophoneus, Cope.}

H. primævus, Leiry. White River, Nebraska.

H. occidentalis, Leidy. White River, Nebraska.

Eusmilus, Gervais.

E. bidentatus, Filhol. Phosphorites, France.

Machærodus, Kaup. Agnotherium, Kaup. Drepanodon, Nesti.

M. palmidens, Blv. Falunian Sansan.

M. ogygius, Kaup. Oeningian, Epplesheim.

M. antiquus, Nesti. Pliocene, Italy, France.

M. falconeri, Pomel. Upper Miocene, India.

M. cuttridens, Cuv. Pliocene, Europe.

M. latidens, Ourn. Pliocene, England.

M. aphanista, Kaup. Oeningian, Epplesheim.

M. maritimus, Gerv. Pliocene, Montpellier.

Smilodon, Lund.

S. neogæus, Lund. Pliocene, Brazil.

S. necator, Gervais, Buenos Ayres.

Cryptoprocta, Bennett.

C. ferux, Bennett. Madagascar.

Psedæælurus, Gervais.

$P$. hyænoides, Lartet. Falunian Sansan.

$P$. intrepidus, Leidy. Loup River, Nebraska.

P. edwardsi, Filhol. Phosphorites, France.

P. ? intermedius, Filhol. Phosphorites, France.

$P$. sivalensis, Lydekker.

Catolyux, Gray. Vivericeps, Gray.

C. marmoratus, Martin. India, Borneo.

C. charltoni, Gray. Nepal, Darjeeling (Charlton).

C. viverrina, Bennett. East Indies.

C. planiceps, Vig. and Horsf. Malacca, Sumatra, Borneo.

C. ellioti, Gray. Madras.

C. rubiginosa, I. Geoff. India, Madras.

Felis, Linn. Pardalina, Felis, and Chaus, Gray.

F. pardalis, L. America, tropical or subtropical.

F. grisea, Gray. Gautemala.

F. melanura, Ball. A merica.

F. picta, Gray. Central America.

F. pardoides, Gray. Tropical America. 
F. macroura, Pr. Max. de Wied. Brazil.

F. mitis, F. Cuv. Mexico.? Paraguay.?

F. tigrina, Schreb. South A merica.

F. geoffroyi, D'Orb. South America.

F. colocolla, Molina, South America, Chili (Molina), Surinam (H. Smith).

F. jaguarondi, Lacép. South America.

F. eyra, Desm. Tropical America.

F. serval, Schreb. South and West Africa.

F. rutila, Waterhouse, Sierra Leone.

F. neglecta, Gray. Gambia.

F. servalina, Ogllby. Sierra Leone.

F. celidogaster, Temm. Guinea.

F. senegalensis, Lesson. Senegal.

F minuta (pars.), Temm. Sumatra.

F. javanensis, Horsf. Java.

F. nepalensis, Vig. and Horsf. India (perhaps a bybrid or domesticated).

F. chinensis, Gray. China.

F. pardinoides, Gray. India (Capt. Junes.)

F. pardochroa, Hodgson. Nepal (Hodgson). Tenasserim (Packman).

F. tenasserimensis, Gray. India, Tenasserim (Packman).

F. jerdoni, Blyth. Indian Peninsula, Madras.

F. herscheli, Gray. India, "Zanzibar."?

F. wagati, Elliot. India.

F. caligata, Temm. Africa, North, South, Central, and East.

F. inconspicua, Gray. India (domesticated or perhaps a variety).

F. domestica, Brisson. Syria.? Domesticated in most countries.

F. manul, Pallas. Thibet.

F. catus, Is. Europe.

F. megalotis, Müller. Timar.

F. himalayanus, Gray. Himalaya (Cross, Warwick).

F. jacquemonti, J. Geoffr. Africa and Asia.

F. ornata, Gray. India (Capt. Boys).

F. catolynx, Pallas. Nepal (Hodgson). 
Iyncus, Raf. Pajeros, Lymx et Caracal, Gray.

L. pajeros, Desm. South America. The Pampas.

L. borealis, Gray. Northern Europe, Sweden.

L. canadensis, Geoffr. North America.

L. pardinus, Temm. Southern Europe, Turkey.

L. isabellinus, Blytl.. Thibet.

L. rufus, Güldenst. North America.

L. maculatus, Vig. and Horsf. North America, Mexico, and California.

L. caracal, Schreb. Southern Asia and Africa, Persia and . Arabia.

Neofelis, Gray.

N. macrocelis, Temm. Himalaya (Hodgson), Malacca.

N. brachyurus (Temm), Siam. Swinhoe, Formosa (Swinhoe).

Uncia, Gray, Cope emend. Len, Tigris et Leopardus, Gray.

U. concolor, L. North and South America.

U. auratus, Temm. Himalaya, Sumatra, Borneo.

U. onca, L. South America, Mexico, Texas.

U. chinensis, Gray. Pekin, mountain forests of the west.

U. japonensis, Gray. Japan.

U. pardus, L, Southern A sia, North, South, and West Africa.

U. tigris, L. Asia.

U. leo, L. Africa, India.

U. irbis. Thibet.

Cynælurus, Wagler. Gueparda, Gray.

C. jubatus, L. Africa, Asia, Persia, Cape of Good Hope.

? C. ferox, Leidy (Aelurodon). Loup River, Nebraska.

The successive order of the modifications of structure which define the above genera is not difficult to perceive, and it is interesting to discover that, as in other cases, it coincides with the succession in geologic time. The typical genera Uncia, Felis, etc., are characterized by great specialization, and it is they which now exist. The oldest found Dinictis, Nimravus, etc., are the least specialized in most respects, and they disappeared before the close of Miocene time.

Since one of the special character's of the Felidæ is the reduction in the number of the molar teeth by subtraction from both ends of the series, an increased number of these constitutes re- 
semblance to other families. The genus Diniclis, above defined, has been shown by Leidy to possess two more inferior molars than Felis, or three more than Neofelis and Lynx, as in the Mustelidæ. The extinct Pseudælurus and the living Cryptoprocta have but one less molar than Dinictis, lacking the posterior tubercular. Nimravus has the same number of molars as Pseudælurus, but lacks the first premolar instead of the last true molar. In Hoplophoneus we first find the number of molars as in the existing genera, viz., $\mathrm{Pm}$. $\mathrm{m}$. $\frac{1}{1}$. Other characters of this genus are, however, of a generalized kind.

I here recall the statement that the genera of Felidæ fall into two series, which are distinguished by the forms of the anterior part of the mandibular rami, and generally by the large size of - the canine teeth to which the former are adapted. This distinction appeared early-in Miocene, or Oligocene time, in fact in the oldest of the cats of which we have any knowledge. The genera with large canines or Machærodontine line were then represented by Dinictis, and the Feline line by Pseudælurus. It is interesting to observe that these genera differed from their latest prototypes in the same way, viz.: (1) in the presence of more numerous inferior molars; (2) in the presence of a heel of the inferior sectorial; (3) in the absence of an anterior cusp of the superior sectorial. In the case of Dinictis one other character of primitive carnivora may be noticed, viz.: the absence of the cutting lobes on the posterior edges of the superior and inferior premolars, so distinct in the existing cats. The same feature characterizes the superior premolars of Pseudælurus, but the inferior premolars have the lobes. In the existing Cryptoprocta, which Gervais has shown to be nearly alliede in dentition to Pseudxlurus, the lobes are wanting from both jaws, but this genus adds to this primitive character another of modern significance, viz., the presence of the anterior cusp of the superior sectorial. Moreover Cryptoprocta has another peculiarity which recalls the genera of the Eocene Creodonta, in the well-developed interior tubercle of the third premolar, a character unknown in Miocene or existing Carnivora. That genus is evidently, like the Lemuridæ, also of Madagascar, a remnant of the Eocene Fauna, which once covered most of the earth, and may be regarded as, on the whole, the most primitive of the Felidæ, recent and extinct.

Following the two lines of Felidæa already indicated, we attain 
the same conclusion in both, by the same stages. The primitive form of the Machærodont line represented by Hoplophoneus has its extreme in Eusmilus, where the second inferior premolar and an incisor tooth are wanting, giving a formula of I. 2, C. 1; Pm. $1 ;$ M. 1. In Machærodus we have the modern characters of the molars seen in Felis, viz., no heel of the inferior sectorial; the superior sectorial with an anterior lobe, and posterior lobes of the premolars. The extreme of this line is reacled in Smilodon, where the second inferior premolar is one rooted or wanting. This genus then stands related to Machærodus, as Eusmilus to Hoplophoneus. In the Feline line proper, on reaching the existing genera, we have lost the heel of the inferior sectorial and gained the posterior lobes of the premolars and anterior lobe of the superior sectorial at once. A further modification of the dentition of the superior series of the recent forms, is sfen in the loss of the first superior premolar in Lynx and Neofelis. Still another, which is one step beyond what is known in the Machærodont line, is the loss of the interior tubercle of the superior sectorial, which characterizes the genus Cynolurus. A superior sectorial tooth having the character of that of this genus was discovered by Dr. Hayden in the Lonp River formation of Nebraska, and was referred to a species by Dr. Leidy under the name of Aelurodon ferox. It was much larger than the $C$. jubatus.

As already remarked, the genera of the Machærolont line are extinct, and this in spite of the fact that they presented the most perfect weapons of destruction in their canine teeth, from the earliest times. Their other modifications of structure advanced pari passu with those of the Feline series, and, among others, the feet presented in the latter forms at least (e. g., Smilodon necator, Gew.), the most perfect prehensile power of the lions and tigers of to-day. As nothing but the characters of the canine teeth distinguished these from the typical felines, it is to these that we must look for the cause of their failure to continue. Prof. Flower's suggestion appears to be a good one, viz.: that the length of these teeth became an inconvenience and a hindrance to their possessors. I think there can be no loubt that the linge canines in the Smilodons must have prevented the biting off of flesh from large pieces, so as to greatly interfere with feeding, and to keep the animals in poor condition. The size of the canines is such as to prevent their use as cutting instruments, excepting 
with the mouth closed, for the latter could not have been opened sufficiently to allow any object to enter it from the front. Fven were it opened so far as to allow the mandible to pass behind the apices of the canines, there would appear to be some risk of the latter's becoming canght on the point of one or the other canine, and forced to remain open, causing early starvation. Such may have been the fate of the fine individual of the S. neogaeus, Lund, whose skull was found in Brazil by Lund, and which is familiar to us through the figures of Dr. Blainville, etc.

\section{Dinictis cyclops.}

\section{Description of New Species.}

The species of Dinictis differ in the proportions of their anterior molar and canine teeth as follows:-

First inferior molar one rooted; first superior molar two rooted; superior canine short, robust; large.

D. intermedia. ${ }^{1}$

First inferior molar one rooted; superior canine complessed; two inferior incisors.

D. squalidens.

First inferior molar two rooted; first superior molar one rooted; canine long, compressed. D. cyclops.

First molar of both jaws two rooted; canine long, compressed.

D. felina.

In the D. cyclops the first superior molar is rudimental, and will probably be found to be wanting in some specimens. The second premolar has a distinct anterior tubercle on the inner side, a character not seen in $D$. felina; the anterior angle of the superior sectorial is more produced than in that species. The crown of the superior tubercular looks partly inwards, is rather long, and has three roots. The superior canine is quite long, and has a regularly lenticular section, withont facets. Its anterior and posterior edges are denticulate. 'The external incisors are much larger than the internal, and have subconic crowns. The crowns of the others are subcuneiform. The inferior canines are considerably larger than the.incisors. The latter are regular, and do not overlap each other. The second and third inferior premolars have well-developed basal lobes anteriorly and posteriorly. The

1 Aeturogale intermedia, Filhol. 
heel of the sectorial is well developed. The tubercular is very small.

The form of the skull is short and wide; the zygomata are much expanded, and the profile is very convex. The muzzle is short, and the orbits are rather large. The interorbital region is wide and convex, and the postorbital processes are robust, acuminate, and directed downwards. The infra-orbital foramen is very large. The apices of the premaxillary bones are elongate, but do not reach the frontals. The nasals are rounded posteriorly. The sagittal crest is prominent, and the inion elevated. The posttympanic process is short, and the paroccipital is short and is directed backwards. The cranium is constricted behind the orbits. The mandibular ramus is low posteriorly, and the anterior inferior flange is well-developed, but not large.

\section{Measurements.} M.

Length of skull on base $\quad$. . . . . . . . . .

Width of skull, measured below . . . . . . 111

Length of palate . . . . . . . . .060

Width of palate between posterior angles of sectorials . . . . . . . . . .062

Width of palate between canines . . . . . . . 026

Length of skull to front of orbits (axial) . . .050

Vertical diameter of orbit . . . . . . . . . . . . .

Interorbital width (least) $\quad . \quad . \quad . \quad . \quad .045$

Elevation of inion from foramen ..$\quad$. $\quad .032$

Length of inferior molar series . . . . . . . . .

Length of inferior sectorial . . . . . . . . . . . . . .

Length of base of inferior first premolar $\quad$ • .055

Depth of ramus at sectorial . . • • . .016

Depth of ramus at first premolar . . . . . . . . . . .

Depth of ramus at flange . . . . . . 026

From the Truckee beds of John Day River, Oregon.

\section{CANID无.}

The range of variation presented by the species of Canidæ includes several generic divisions, recent and extinct. These genera are, however, as elosely intergraded as are those of the cats, and their definite characters are subject to occasional failure from ab- 
normal variations. These are, however, not so frequent as to invalidate the classification to which they form the exceptions.

The Canidæ appeared in the Upper Eocene period, and the genus Canis was well represented by species in the lowest Miocene in Europe and the United States. The other genera are represented by fewer species, and many of them are extinct. The foxes ( $\nabla$ ulpes) are the most numerous of them, and but few extinct species of them are known. A merica presents us with the greatest variety of genera, as Enhydrocyon, Temnocyon, and Palæocyon extinct, and Icticyon, extinct and recent. Speolhus, extiuct in America, still exists in Asia.

The most complete catalogue of the species Canidæ is that of Dr. Gray. In his work the author brings together observations of various naturalists, and adds a number of his own. He admits a large number of generic divisions, but many of these, like those of his Felidx, are simply founded on specific characters. A few good genera, however, exist, and a synopsis of their character's is given below. The genus Mugalotis is here excluded from the Canidæx on account of the unspecialized character of the superior sectorial tootl, as is done by Dr. Gray :-

I. True molars $\frac{3}{3}$.

Premolars $\frac{4}{4}$; inferior sectorial with internal tubercle. Amphicyon.

II. True molars $\frac{2}{4}$.

Premolars $\frac{4}{4}$; inferior sectorial with internal tubercle.

Thous.

III. True molars $\frac{2}{3}$.

a. Premolars $\frac{4}{4}$.

$\beta$. Inferior sectorial without internal tubercle.

Heel of sectorial cutting.

Palæocyon.

及3. Inferior sectorial with internal tubercle.

$\boldsymbol{\gamma}$. Four toes in the mauus;

A sagittal crest.

Lycaon.

$\gamma \gamma$. Five toes in the manus.

$\delta$. Heel of sectorial simply cutting.

A median sagittal crest (? toes).

Temnocyon

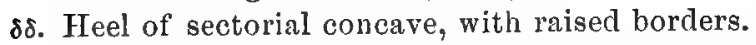

Pupil round; temporal fossa with simple superior border.

Canis. 
Pupil erect; temporal fossa with simple superior border. Vulpes.

Pupil erect; temporal fossa bounded above by a rib-like crest.

Urocyon.

a.a. Premolars $\frac{3}{3}$.

Inferior sectorial with internal tubercle and cutting heel.

Enhydrocyon.

Inferior sectorial with internal tubercle, and wide tubercular. heel.

Tomarctus.

IV. True molars $\frac{2}{2}$.

a. Premolars $\frac{4}{4}$.

Inferior sectorial with internal tubercle.

Speothus.

Inferior sectorial without internal tubercle (superior ruolar sometimes one).

Synagodus.

a. Premolars $\frac{2}{2}$.

Inferior sectorial without internal tubercle (incisors caducous).

Dysodus.

V. True molars $\frac{1}{2}$

Premolars $\frac{4}{4}$; inferior sectorial with internal tubercle.

Icticyon.

It is discoverable that the series represented by the above genera is a part of the greater line of the digitigrade Carnivora, embracing the greater part of it which is less specialized than, or inferior to, the part covered by the Hyænidæ and Felidæ. Without entering into the relations of the Canidx with the civets and Mustelidx, it may be remarked that the genera display a successive reduction in the number of premolars and molar's from the more ancient to modern geologic times. It is interesting to note that the genera presenting the greatest reduction in all respects, Synagodus and Dysodus, are now only known in a domesticated condition. Another reduction is seen in the number of tubercles of the inferior sectorial.

Amphicyon, Lartet.

This genus is better represented in Europe than in North America, but two species being certainly known from the latter. No recent species.

Thous, Gray, Dusieyon, Smith (nomen nudum).

Existing species of South America only. 
Palæocyon, Lund.

Extinct species of Soutl America only.

Iycaon, Brooks.

Existing species of Africa, only known as yet.

Temnocyon, Cope, Proceedings Amer. Philosophical Society, 1878, p. 68.

In this genus the heel of the inferior sectorial tooth rises into a single more or less median crest; in Canis the corresponding front is basin-shaped, with tubereles on each side. The superior molars of the typical species, $T$. altigenis, are unknown, but those of a new species, described below, do not differ from those of the genus Canis. The Cynodictis crassirostris of Filhol, from the French Phosphorites, approaches this genus.

Temnocyon coryphæus, sp. nov.

This is the most abundant dog of the Truckee beds of the John Day country. I have identified it heretofore as my Canis hartshornianus, but I find on examination of the inferior sectorial tooth that it is a species of Temnocyon. This genus was characterized by me on evidence furnished by a mandible of a species which I named T. altigenis, ${ }^{1}$ which is of considerably larger size than the present one, but which agrees with it in the presence of a cutting edge instead of a basin on the heel of the inferior sectorial. The $C$.hartshornianus, known as yet from few fragments, is intermediate in dimensions between these two.

Several crania, and more or less of the skeleton of the $T$. coryphæus, are present in my collection. A nearly perfect skull displays the following characters: The orbits are entirely anterior to the vertical line dividing the skull into halves, and the muzzle is proportionately shortened. It is also narrowed anteriorly, and its median line above is shallowly grooved. The interorbital region is greatly convex to the supra-orbital region, and is grooved medially. The postorbital processes are mere angles, and are flattened from below. The cranium is much constricted behind the orbits, where its diameter is not greater than the width of the premaxillary incisive border. The sagittal crest is much elevated, and forms a perfectly straight and gradually rising outline to its junction with the incisor. The borders of the latter are very prominent, extending backwards considerably beyond

1 Proceedings Amer. Philosoph. Soc., 1878, viii. p. 68. 
the brain case. The zygoma is rather slender, is elongate, and but little expanded. The otic bullæ are very large; the paroccipital processes are directed backwards, at an angle of $45^{\circ}$, and are rather elongate and acute; they cap the bullæ posteriorly. The lateral occipital crests bound a fossa of the occipital region near the condyles. The occipital surface is directed horizontally backwards above the foramen magnum. This part of it, and its superior portion, are divided by a median keel.

The basioccipital is keeled on the middle line below. The sphenoid is not keeled, and is concave, its borders descending on the inner side of the bullæ. The pterygoid fossa is rather narrow, and the hamular process is short. The posterior border of the palate does not extend anterior to the posterior edges of the last tubercular molar, and its middle portion projects backwards in a triangular process. The palatine fossa for the inferior sectorial is shallow. The superior surface of the postorbital region is roughened.

The foramen infraorbitale exterius is rather large, and issues above the anterior border of the sectorial tooth. The $f$. incisiva are short, not extending posterior to the middle of the canines. The $f$.palatina are opposite the posterior borcler of the sectorial. The $f$. lachrymale is al together within the orbital border. The $f$. opticum is rathe: large. 'This species is peculiar in having the $f . f$. spheno-orbitale, rolundum, and alisphenoidale anterius united in to one large external orifice. The alisphenoid canal is larger in Canis latrans, and its posterior foramen small. The fovale is further removed from the $f$. alisphenoidale than in the coyote, and is exterior to and a little behind the $f$. carotideum.

The nasal bones extend to above the nuiddles of the orloits, and contract gradually to their apex. Their combined anterior border is a regular concave, and the lateral angles at this point are produced outwards and forwards. The posterior apex of the premaxillary bone is separated from the anterior apex of the frontal by a short space. The maxillo-malar suture is deeply notched in front below, and it extends upwards to above the infra-orbital foranen. A very narrow surface of the lachrymal is exposed on the external surface. The pterygoid bone is distinct, and is nearly equally bounded by the sphenoid and palatine on the outer side The inferior suture of the orbito-sphenoid runs in a groove, which is deepest anteriorly. 
The crowns of all the incisor teeth are narrow or compressed, and, though slightly worn, present no indication of notch. As usual, the external ones are much the largest in antero-posterior diameter. The canines have robust fangs and rapidly tapering crowns, which are but little compressed. The first superior premolar is one-rooted, and the crown is simple. The crown of the second is without posterior heel and tubercle, while the third possesses both. The sectorial is relatively short, less so than in $C$. latrans. The blades are low and obtuse as compared with receht species, and the notch separating them is quite open. The anterior external heel is small, and there is no anterior external tubercle. The first tubercular molar is large, and the crown is nalrower than that of C. latrans. It has an obtuse external cingulum, two external conical cusps, a $V$-shaperl median ridge, and a wide internal cingulum. This crown differs from the corresponding one of $C$. latrans in having conical instead of compressed external cusps, and a simple $V$-shaped crest within instead of two adjacent cusps. The second tubercular is smaller than in C. latrans, and its tubercles are less distinct. There are two outer tubercles, a V-shaped ridge, and an inner cingulum, all very obscure. The enamel of all these teeth is smooth.

\section{Measurements of Cranium.}

M.

Length along base of skull, including incisive border and occipital condsle . . . . . . . . . . .

Length of skull to palatal notch . • • • . . . . • •

Length of skull to posterior border of pterygoid

bone . . . . . . • . . . . . . . . .

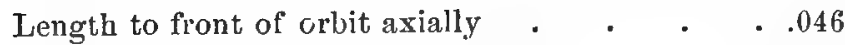

Width between zygomas (greatest) • • . . .094

Width between orbits (least) . • . . . . . . . . . .

$\dot{W}$ idth at postorbital constriction . . . . . . . . .

Width between bases of canines . . . . . . . . . . . .

Width between bases of second tuberculars . . . 027

Width between otic bulæ . . . . . . . . . .

Width between apices of paroccipitals . $~ . ~ .042$

Width of foramen magnum . . . . . . . . . .

Width of occiput above . $\quad . \quad+\quad . \quad+\quad .032$

Six well-preserved crania of this species are embraced in the collection, and the manulible remains attached to some of them. 
One of these exlibits the following characters: there is a welldeveloped marginal lobe of the posterior 'utting edge of the third and fourth premolars as well as a low posterior heel, and a rudiment of an anterior one. The heel of the sectorial is shorter than the remaining part of the tooth, and rises to a cutting edge a little external to the middle line; there is a small tubercle at its interior base. The anterior blade-cusp of the sectorial is much lower than the median, which is conical; the two diverge, climinishing the shear-like charactel and action of the tooth. The internal cusp is well developerl. The first tubercular is of moderate size, and is a longitudinal oval in outline. The crown supports two low tnbercles anterior to the middle, of which the external is the larger. The last molar has a single compresser root, and the crown is a longitudinal oval in outline. Its position is on the ascending base of the coronoid ramus, so that the crown is slightly oblique. The masseteric fossa is profound and well defined; its anterior termination is below the midale of the second tubercular tooth. The horizontal ramus is not robust, but is compressed, and ratler deep.

Meusurements of Mandible.

M.

Length along bases of posterior five molars . $\quad .049$

Length of base of fourth premolar . . . . . . . . .

Elevation of crown $\quad . \quad . \quad . \quad . \quad . \quad .008$

Length of base of sectorial . . . . . . . . . . .

Elevation of crown of " $\quad . \quad . \quad . \quad . \quad .012$

Length of buse of first tubercular . . . . . . . . . . .

Width " " " . . . . . . . . 0050

Length of base of second tubercular . . . . . . . . •050

While the characters of this dog do not separate it widely from the genus Canis, many of them are quite different from those presented by the recent species of the genus with which I am acquainted. Thus the union of the furamina spheno-orbitale and rotunda, the anterior position of the orbits, and the postorbital constriction are not seen in the wolf, domestic dog, coyote,jackal, or the North American and Furopean foxes. The size of the brain was evidently less than in those species, and the sectorial teeth quite inferior in the efficiency of their blades. These characters may be considered in connection with the low geological position of the beds in which the species occurs. 
From the Truckee beds of the White River formation in Oregon. Canis, Linn.

The names proposed by Smith, Gray, and others, and which must be regarded as synonyms of Canis, are Lupus, Dieba, Simenia, Chrysocyon, and Lycalopex. Many of the species, referred to by European paleontologists under the name of Cynodictis, Pomel, appear to me to be undistinguishable from Canis. Throngh the great kindness of M. Filhol, I possess specimens of the jaws of 'several of these species. A mandible with nearly complete dentition of the Cynodon velarnum of Aymard, agrees very nearly with the jaws of some of the smaller species from the American White River beds, which I have referred to Canis. Helocyon, Aym. may be distinct, but may not belong to the Canida.

The dentition of many of the recent species of Caris differs in very slight characters. The following may be detected in an examination of the superior molars of the three larger species most accessible in the United States.

Last superior tubercular short, wide; inner cinguluna and crest nearly confounded.

Inner crest of tub. m. I. composed of two low tubercles.

C. familiaris.

Vars. molossus, terrarius, graius.

Last superior tubercular narrower, transverse ; inner cingulum very distinct.

Inner crest of tnb. M. I., a ridge higher anteriorly. O. lupus.

Inner crest of tub. M. I. with two sharp cusps. C. latrans.

It is worthy of note that the wide oval form of the second superior molar of the Canis familiaris, exists equally in the extreme races or species, the grayhound and bulldog, as I observe by examination of several crania of each. This has also been shown by De Blainville. It is also seen in the terrier, and in various other races. But in some Saint Bernard crania in the Museum of the Academy of Natural Sciences, this tooth is more elongate; and in some of the specimens of Canis lupus from Europe its form is quite the same. So this character, as might have been anticipated, is not of universal application. Another character is seen in the crania of three specimens, which are supposed to belong to Canis terrarius. 'The superior border of the foramen magnum is interrupted by a deep vertical excavation. This is not seen in the St. 
Bernard, the bulldog, greyhound, and other races, nor in any of the feral or extinct species of the genus examined. It appears to be associated with an incrensed size of the brain, and to be an adaptation to the vermis of the cerebellum. The expansion of the brain is also indicated by the protuberance of the frontal region, and the ride separation of the temporal fosse by a smooth space on each side of the sagittal suture. This space does not exist in the greyhound, hat a narrow one is found in the bulldog. These characters are important on varions grounds, but are here mentioned in reference to the species of Synagodus and Dysodus, where they reappear. The alosence of the second inferior tubercular molar is also not uncommon in the "black and tan" terrier.

I do not see the propriety of retaining the generic name Nyctereutes, Temm. for the Canis procyoninus of Japan. The peculiarity it presents in the form of the first superior tubercular molar, the only one $e^{l}$ on which the genus reposes, I would regard as specific only.

\section{Vulpes.}

I would, with Gill, refer to this genus the species mentioned by Gray and otbers under the generic names Pseudalopex, Fennecus, and Leucocyon. The form of the post frontal process certainly does not furnish generic characters.

\section{Urocyon, Baird.}

The peculiar cranial ridges, in which this genus resembles one of the extinct genera of Mustelidx, appears to me to be the character which warrants its separation from Vulpes.

Enhydrocyon, Cope, Bulletin U. S. Geological Survey, Terrs. v, 56, 1879.

'T'wo species from the White River beds of Oregon are known.

Tomarctus, Cope, Ann. Report U. S. Geol. Surv. Terrs. 1873 (74). p. 519. Paleontological Bulletin, 1873, Aug. 20, 1873.

One species known from the Loup Fork beds of Colorado. It is uncertain whether this genus has two or three premolars. Should it have three it must be compared with the Brachycyon of Filhol. But the inferior sectorial tooth of that genus is as yet unknown.

Speothus, Lund, 1843. Cron, Hodgs.

One extinct species of this genus was found by Lund in caves in Brazil. Another species, Speothus primæuus, is now living in

1 According to the figures of Temminck and Schlegel. 
the Himalaya region. Several other recent species have been named, but they are said by some authors to be varieties only of the S. primæuus.

Synagodus, Cope, gen. nov.

The eharacter's of this genus have been pointed out in the analytical key. They ar'e evidently as important as those which define the divisions which are regarded as genera by naturalists. It is not unlikely that the typical species has been heretofore estimated as a variety of Canis familiaris, but it exhibits two trenchant generic dental characters not found in Canis, and three unique specific character's in the teeth, besides two characters of the cranium found in but one or two of the subspecies of Canis familiaris.

The generic characters allurled to are: (1) the absence of the second inferior tubercular molar, and (2) the absence of the internal tubercle of the inferior sectorial. The absence of the second inferior tubercular is evidently not one of those abnormal cases which occur in various species of Canis from time to time; for the first tubercular molar is smaller than in any known species of Canis, and has but one root, a character which some persons might regard as being the third of the generic category. The premolars are 4-4, and of the usual form; the first in both jaws is one-rooted.

It is uncertain whether any species of this genus exists in the wild state. Should such not be the case, we can only predicate the former existence of such an one entirely different from the Canis familiaris, and which has given origin to the existing one below described.

synagodus mansuetus, sp. nov.

Two crania represent this species in the Museum of the Academy of Natural Sciences. They agree in all essential particulars. The incisor and premolar teeth present no peculiarities (the latter are without marginal lobes), and the superior sectorial is normal. The first tubercular has less transverse extent than in the Canidæe generally, and its median crest and inner cingulum are confoundell, a character which I have not found in any of the other species accessible. Thus the crown of this tooth consists of an external pair of tubercles, a basin, and a stout inner marginal prominence. The second tuberculars are abnormally small in one 
specimen, and in the other they are wanting. The IIJ. and IV. inferior premolars have marginal posterior lobes. The inferior sectorial, as already stated, las no inner tubercle. Its heel is peculiar in the great elevation, and submedian position of one of its borders, approaching Temnocyon in this respect. The other edge is, however, distinct, thus forming an unsymmetrical basin. 'The first inferior tubercular is small, one-rooted, and the crown is subround, and with a single median tubercle. In the other usual species of Canis, Vulpes, and of many other genera of the family, this tooth is elongate, two-rooted, and supports at least two tubercles.

The general form of the crania resembles those of some of the terriers. The brain-case is full and convex, the orbits are lateral, and the muzzle is moderately elongate and narrowed. The osseous surfaces are generally smooth, and there is no indication of the ridge bounding the temporal fossa above. There is a deep sinus of the superior border of the foramen magnum, a character above noted as occurring in a subspecies included under Canis familiaris.

I have been unable to ascertain whether the species now described is one of the forms which have been referred to Canis familiaris under a subspecific name. One of the specimens was presented to the Academy many years ago by Dr. Paul Goddard, under the name of lap-dog. The form of the head shows that it is not one of the forms of Canis extrarius hispanicus (of Fitzinger's Work on Dogs), which are represented by the King Charles Spaniel, and other lap-dogs. As I can find nothing concerning it in the books I give it a provisional specific name.

The origin of the characters of this genus is doubtless to be traced to prehistoric time, if not to an early tertiary geologic age. Perhaps some of the species' character's are of later origin; such as the obliteration of the superior border ridges of the temporal fossæ, and the large sinus of the foramen magnum. These characters, seen in a lesser degree in a domesticated true Canis, as above mentioned, are evidently an adaptation to an enlarged brain; the one to the increased cerebral hemispheres, the other to the protuberant vermis of the cerebellum. Whether these characters are due to a prolonged domestication, and abnormal nutrition within human habitations, remains to be ascertained. I remark here that two crania of dogs found mummied in Egypt by Mr. 
Gliddion, and now in the Museum of the Academy, present all the normal details of structure of Canis familiaris.

The reduction in the number of teeth has been carried further, and is probably of more modern origin in the new genus to be described below.

Dysodus, gen, nov.

The characters of this genus, already indicated in the analytical table, are as follows: I. $\frac{3}{3}$; C. $\frac{1}{1} ;$ P. m. $\frac{2}{2} ;$ M. $\frac{2}{1}$; inferior sectorial without internal tubercle. The incisive formula might with pro. priety read $\frac{0}{0}$, since these teeth are shed at an early age; and for the same reason the tuberculars might be stated $\frac{1}{1}$, since the last one of the upper jaw is equally evanescent. I, however, give the genus the benefit of the possible future discovery of species in which the teeth in question may not be so early caducous, and rely on the restricted diagnosis. It is thus apparent that the genus Dysodus is distinguished from Synagodus by the absence of two premolars from each jaw. While the genera agree in other respects, their typical species are very different.

This genus probably diverged from that now represented by Synagodus, at a comparatively late period. Although it exhibits a degree of dental reduction greater than that form, I admit that the possibility of its having come off from Canis rather than from Synagodus is worthy of consideration. This is suggested by the fact that the remaining (first) tubercular molar of the inferior series is, in D. pravus, more like that of the species of Canis in all respects, among others, in having two roots.

In D. pravus the superior third premolar is sometimes shed, like the incisors, having the formula, I. $\frac{0}{0} ;$ C. $\frac{1}{1} ;$ Pm. $\frac{1}{2} ;$ M. $\frac{1}{2}$. I have excluded this character from the generic diagnosis, as in the case of the incisor and superior tubercular teeth, because they are at the present time unstable; that is, the parts in question are in pro. cess of metamorphosis. When characters are thus variable, they cannot be used as the bases of natural divisions, but when they are stable, we are compelled to recognize them. The characters which I have included in the diagnoses of Synagodus and Dysodus I have thought to be of this character, and I am by no means sure that the absence of the superior incisor teeth should not be placed in the same category. But none of these characters, whether stable or unstable, can be regarded as monstrosities, such as mul. tiplied digits, fissured palate, etc. They are, on the contrary, in 
the direct line of numerical succession of parts already represented by the genera of Canidx, and of all digitigrade Carnivora. This, as already stated, consists in the reduction in the number of the teeth and their tubercles, forming a series which, commencing with the generalized extinct type Amphicyon, approaches more and more nearly to the Felidx. In the inferior sectorial, the genus Dysodus approaches nearest of all Canidx to some of the earliest genera of cats, as Hoplophoneus (although easily distinguishable), while in the reduction of its premolars it approaches the modern forms of that family. In the early shedding of the incisors it reaches a condition not found in any carnivora, but one which marks the extreme of development of the ungulate mammals in varions lines; e. g., Ruminantia, Onnivora, and Amblypoda.

Dysodus pravus, sp. nov.

This species, which is known as the Japanese sleeve dog, is represented in the Museum of the Academy of Natural Sciences by a complete skeleton, with the crania of two other individuals. These all belong to adult animals of a single litter, which were born in the United States. The parents of these dogs were procured in Japan by Dr. W. S. W. Ruschenberger, U. S. N., now President of the Academy. Other specimens have been brought to the United States by officers of the navy. Dr. J. E. Gray. figures a skull of the same $\mathrm{dog}$ in the Proceedings of the Zoölogical Society of London for 1867 .

The crania in the Academy's collection are almost exactly alike, and resemble the one figured by Dr. Glay so far as can be discovered. But Dr. Gray's specimen was probably young, as the incisor teeth and a premolar in each jaw have not yet been shed, and there are some cranial fontanelles still remaining.

'The characters displayed by the skulls are as follows: The muzzle is excessively abbreviated, and the forehead very convex. The brain-case is almost globular, and the zygomata proportionably prominent. The superior marginal ridge of the temporal fossa is prominent, and those of opposite sides are well separated as far as the posterior parietal region. Here they approach each other abruptly, forming a wide sagittal crest. The muscular insertions and other osseous ridges of the supra, ex-and basi-occipital regions are strongly marked. The postorbital process is prominent and decurved. The vertical sinus of the superior border of the 
foramen magnum is deeply excavated. The external surface of the brain case and of the zygomata is minutely rugose.

There are no lobes of the posterior border of the anterior superior premolars, while they are present on the two inferior premolars. The superior sectorial is normal, while the first superior tubercular is like that of Synagodus mansuetus, without distinct median crest or tubercle. The heel of the inferior sectorial is also like that of the species just mentioned; one border is much more elevated than the other, and forms a cutting edge. The inferior tubercular is small, is longitudinally oval, and supports two low tubercles. This is one of the most important points of difference between this species and the $S$. mansuetus. In none of the specimens is there any trace of the second tubercular.

The skeleton is that of a dog of the size of a rather small blackand-tan terrier.

Dr. Ruschenberger states that the incisor teeth of the dogs were shed at an age of about six months. He also informs me that they did not hreed after coming to this country. Dr. Gray states that these dogs are fed largely on vegetable food in Japan, and have an artificial existence in various respects. They are, according to Dr. Ruschenberger, uncommon and expensive in Japan.

I have been unable to discover that any name whether varietal or specific has been given to this dog.

\section{Icticyon, Lund.}

One existing and one extinct species have been found in Brazil; the latter in the caves. I describe a species from Oregon which I cannot separate from them generically.

\section{Icticyon crassivultus, sp. nov.}

This dog is so far represented by a skull, which, while it lacks the parietal and occipital regions, is otherwise nearly complete, having both mandibular rámi. The dental formula is, I. $\frac{3}{3}$; C. $\frac{1}{1}$; Pm. $\frac{4}{4} ;$ M. $\frac{1}{2}$. The single superior tubercular molar is similar in general to that of other Canida. The inferior sectorial has an internal cusp, and posterior heel, the latter with a low cutting edge on one side. Inferior tubercular well developed.

The dental formula of this animal is that of Icticyon, Lund, of which a species has been found in the cave deposit of Brazil, and another still lives in that region. 
Char. specif. The snout is short and robust, and the profile from the parietal region is straight and descending. The premaxillary border projects but little beyond the line of the extremity of the nasal bones. The muzzle is slightly contracted in front of the orbit and above the fundus of the canine alveoli. The latter cause a swelling on the side. The infraorbital region is somewhat cracked, but appears to have been nearly flat medially; laterally it descends steeply to the supraorbital border. The orbit is not large, and the zygomatic fossa is short. The nasal bones are narrowed posteriorly, a little contracted medially, and expanded anteriorly, their lateral portions being produced along the pre-maxillaries. Their combined nasal border is concave, and is without the notches of some forms. The foramen infraorbilale exterius is of medium size, and issues above the interval between the sectorial tooth and the one in advance of it. The mandibular ramus is quite robust, and its inferior border is gently convex. The masseteric fossa is bounded by elevated borders, especially inferiorly, and the angular hook is prominent and robust. The condyle is situated on the horizontal line of the tubercular molar, or a little above the others, and has a wide transverse extent, chiefly inwards. The coronoid process is high and wide, and is turned backwards so as to vertically overhang the condyle. Its anterior border is wide below, and becomes horizontal above.

The teeth partake of the robust character of the skull, with the exception of the incisors. Of these the crowns of the external are long and narrow, and the median small in the premaxillaries, while those of the lower jaw are all small. The canines in both jaws are quite robust, and those of the lower jaw are rather abruptly recurved. The first premolar is small, and has a simple crown and single root. The crowns of the other premolar's are wide at the base, and form each a simple coue, with a short posterior basal heel. The upper sectorial is relatively not long, but is robust, and with thick blades. The internal heel is well developed, as in Canis, while a cingulum represents an anterior lobe. The tubercular molar is narrower in fore and aft diameter than in Tennocyon coryphous or Canis latrans, although it presents the same details. These are a wide obtuse external cingulum; two external tubercles; a median obtuse tubercle, and a wide internal cingulum. The premolars of the lower jaw are similar to those of the maxillary bone. The inferior sectorial is quite robust, and 
the internal cusp is well developed. The beel is shorter thian the blades of the crown, and is wide and without tubercles in its somewhat worn condition. Its external border rises to an edge. The tubercular is wider than the corresponding tooth in the cotemporary species of Canidæe, although not so wide as long. Its crown rises in two low tubercles which stand transversely near the middle.

\begin{tabular}{|c|c|c|c|c|c|c|c|}
\hline \multicolumn{8}{|c|}{ Measurements. } \\
\hline Length of skull to & orbit & $t(\operatorname{axi}$ & al) & . & ${ }^{\circ}$ & & .049 \\
\hline Depth of sknll to & orbit & (axia & & . & . & & .042 \\
\hline Interobital width & $\cdot$ & . & & . & . & & . .040 \\
\hline Width of nares & & & • & . & . & & .017 \\
\hline Length of superiol & mols & ar ser & ries & . & & & .038 \\
\hline Length of bases of & thre & e pre & molar & & & & . .019 \\
\hline Len & secto & rial & - & . & . & & . .015 \\
\hline Width of secto & in $\mathrm{fr}$ & ont & . & . & - & & . .005 \\
\hline Width of first & ereula & ar ant & teropo & & & & . .006 \\
\hline Width & ereula & ar tra & nsvers & & . & & . .0I4 \\
\hline Leng & le to & angle & & . & • & & . . .093 \\
\hline Ele & loid & & & . & ${ }^{\circ}$ & & . .05 \\
\hline Elevation at secto & & & ${ }^{\circ}$ & . & - & & . .02 \\
\hline Length of in feri & mola & ir ser & & . & . & & . .04 \\
\hline Len & secto & rial & - & . & . & & . . .01 \\
\hline Iuens & nferic & or se & ctorial & & . & & . .00 \\
\hline Leng & tuber & reular & & . & . & & . .006 \\
\hline Width of inferior & suberc & cular & & . & ${ }^{\circ}$ & & . .00 \\
\hline
\end{tabular}

Van der Hœven has given ${ }^{1}$ descriptions and figures of the skull and dentition of the Icticyon venaticus of Lund, of Brazil. From these it appears that the present species differs from the latter in the greater development of the inner part of the tubercular molar of the superior series; in I. venaticus this part is much reduced. The tubercular molar of the lower jaw is also mucl smaller in the living species, the angular and coronoid processes less developed, and the condyle less extended transversely. The cranium of the $I$. crassivultus is much more robust, but not much longer than that of $I$. venalicus.

Discovered by J. L. Wortman in the Truckee beds of the White River, Tertiary of the John Day River region of Oregon.

1 Over het Geslacht Icticyon; wis. en natuurk. Verh. der Koninkl. Akademie, Amsterdam, Deel. III. 


\section{General Observations.}

In both Canidx and Felidx the reduction of the dental series is connected with a contraction of the facial part of the skull, either posteriorly or anteriorly. Enhydrocyon is an example of anterior abbreviation, and Icticyon of posterior contraction among Canidx, while Smilodon and $\operatorname{Lyn} x$ exhibit the anterior reduction in Felide. I have already pointed out that this reduction is accompanied by a corresponding increase in the size of the sectorial teeth. But the reduction in the number of teeth in geologic time has not been confined to the Carnivora, but belongs to the Ungulates and Primates as well. The small number of teeth is generally associated with high specialization among Mammalia generally. The genera Synagodus and Dysodus are the most specialized of the Canidx.

I may here refer to the frequently observed reduced dentition of man. Darwin first pointed out the significance of the absence of the third molars from the standpoint of evolution, ciling American cases; and $I$ have observed the similar bearing of the absence of the external superior incisors.' 'These reductions are very frequent in the United States, and probably elsewhere among civilized nations, hut statistics on this point are yet wanting. My friend Dr. C. N. Pierce, an experienced and scientific dentist of this city, informs me that he knows of twenty-eiglut families in which the external superior incisors are absent; to these, four families may be added, which have fallen under my own observation: that the absence of one or both pairs of the third molars is still more common, is confirmed by Dr. Pierce's experience.

It is evident that we have characters which, if stable, would indicate two or three genera of Hominidæ additional to Homo. They are unstable at present; that is, they are not yet invariably found in any race or species of man, or, in oulser words, are not so associated with other physical characters as to form a correlated index of them. But experience in paleontology and zoölogy renders it almost certain that these dental characters will at some future time assume this degree of importance by becoming stable. This is already indicated by the fact of their being constant in families at the present time. As to what races will be thus distinguished

1 Proceedings American Philosophical Society, 1871, p. 234. 
generically, it is not easy to indicate, but all those with prognathous crania may be safely excluded. It is improbable that Mongolian races will early participate in such a modification, as they have a tendency to prognathism, and a generally strong dental development.

Since the reduction in the number of teeth is intimately connected with orthognathism, it is easy to suppose that it is primarily due to the diminished space allowed by the contracted maxillary arcade. This contraction is doubtless due to a deficiency of building material, consequent on a transfer of force to some other part of the structure during the period of growth. This transfer may be to the superior parts of the cranium, which is extended to contain an enlarged brain. As the loss of a tooth from each side has so far been sufficient to accommodate the dentition to the space which it is to occupy, it is not likely that the absence of both I. 2 , and M. III. will become established. The reduction in the inferior series is less, and I do not know of any examples of the absence of the external incisors of the lower jaw. The loss of the third inferior molars is, on the other hand, very common. It then may be reasonably maintained that two genera of Hominida will be at some future day added to Homo; that the latter will include the inferior races of men, and the future the superior; that, although in specific characters there may be a want of greater constancy in the species of the new genera as compared with each other than as compared with the primitive and true Homo, they will present cases of what is elsewhere known in zoölogy, that the same or nearly the same specific characters may be found in different genera. Under such circumstances the form referred to a new genus becomes at the same time distinct species. The genera of Hominidæe will then, if the characters become constant, be as follows:-

I. $\frac{2}{2} ;$ C. $\frac{1}{\mathrm{~T}} ;$ Pr. $\frac{2}{2} ;$ M. $\frac{3}{3}$;

Homo.

I. $\frac{1}{2} ;$ C. $\frac{1}{1} ;$ Pm. $\frac{2}{2} ;$ M. $\frac{3}{3}$;

I. $\frac{2}{2} ;$ C. $\frac{1}{1} ;$ Pm. $\frac{2}{2} ;$ M. $\frac{2}{2}$;

Metanthropos. Epanthropos. 

Paleontological Bulletin, No. 32.

\author{
SECOND CONTRIBUTION
}

TO THE

History of the Vertebrata OF THE

PERMIAN FORMATION OF TEXAS. BY 叉. D. OOPE. 



\title{
PALEON'TOLOGICAL BULLETIN, No. 32.
}

\author{
Second Contribution to the History of the Vertebrata of the Permian Forma- \\ tion of Texas. By $E, D$. Cope**
}

(Read before the American Philosophical Soeiety, May 7, 1880.)

Since my synopsis of this subject, published in May, 1878, the accession of much new material had enabled me to make a number of important additions to it. Notes which record scme of these may be found in the American Naturalist for September and December, 1878, and for April and May, 1880. The substance of these is included in the present essay.

At the meeting of the National Acudemy of Sciences, held in New York, in November, 1878, I pointed out that the scapular arch in the Pelycosauriat consists of scapula, coracoid and epicoracoid, which form a continuum in the adult, in the same way as the three elements of the pelvis in the same group form an os innominatum. The tibiale and centrale of the tarsus unite to form an astragalus which has no movement on the tibia. The fibulare forms a calcaneum. The distal side of the astragalus presents two faces, one of which receives a large part of the proximal extremity of the cuboicl.

The structure of the scapular and pelvic arches is identical with that already described by Owen as belonging to the Anomodontia. Several impurtant characters distinguish this group from the Pelycosauria, but the two together form an order which I have thought must, for the present at least, be retained as distinct from the Rhynchocephatia. The character's of this order, with its two sub-orders, are as follows:

Theromorpha Cope. Scapular arch consisting at least of scapula, coracoid and epicoracoid, which are closely united. Pelvic arch consisting of the usual three elements, which are united througlıout, closing the obturator foramen and acetabulum. Limbs with the phalunges as in the ambulatcry types. Quadrate bone proximally united by suture with the adjacent elements. No quadratojugal arch.

Pelycosauria. Two or three sacral vertebræ; centra notochordal ; intercentra usually present. Dentition full.

Anomodontia. Four or five sacral vetebræ; centra not notochordal; no intercentra. Dentition very imperfect or wanting.

The Rhynchocephalie have no distal ischio-pubic symphysis, and appar. ently no epicoracoid bone. They have an obturator foramen, and a quadratojugal arch.

The order Theromorpha approximates the Mammilia more closely than any other division of Reptilia. This approximation is seen in the scapular arch and humerus, which nearly resemble those of the Monotremata, especially Echidna; and in the pelvic arch, which Owen has shown in the sub-orcler Anomodontia to resemble that of the Mammals, and as I have

* A bstract read before the Natimal Academy of Sciences, April 20, 1880 .

† See Proceed. Alwer. Philus. Soc., 1878, p. 511 and 5.18, 
pointed out, especially that of Echidna. The tarsus is also more mammalian than in any other division of reptiles. In the genus Dimetrodon the coracoid is smaller than the epicoracoid, as in Monotremes. The pubis has the foramen for the internal femoral artery.

A not less remarkable characteristic of the Pelycosauria, as represented by Clepsydrops and Dimetrodon, is their resemblance to the Batrachia in some important respects. This is seen in the scapular and pelvic archcs, which resemble very much those of the Urodela, and of such types as Eryops. The small coössitied coracoid only differs from that of Eryops in having two deep sinuses of its free border. The general form of the pelvis is similar, but the ilium has a special and peculiar articular face for the sacral diapophysis, which is wanting in Eryops. In the inferior arches, the absence of obturator fommen, and geneml boat-like form, are the same in both; but in the Pelycosauria the symphysis is not so deep, and the walls less massive. But the resemblance of these arches to those of the $B a$ trachia in question is greater than to those of any order of reptiles.

Another point of resemblance to the Batrachia is seen in the humerus. In my previous essay on the Pelycosauria above cited, I defined six types of humerus as ocurring in the Texas Permian. Two of these were described as wanting the foramen,* while the others were stated to possess it ; other differences between these types exist, but they were not mentioned. Since then Gaudry has added a third form to the former group, which he has ascribed to a reptile under the name of Hiuchirosaurus. I have detected this form in my Texas collections together with another, which has no condyles at either extremity. Thus eight forms of humerus are found in this formation.

That the type with the supracondylar foramen belongs to the Pelycosauria has been satisfactorily shown by its presence in the skeleton of Clepsydrops natalis and in Cynodraco majur, where Owen first identified it. I find the type without this foramen frequently associated with the skeletons of Eryops, and other Stegocephali. There is no other element that can be regarded as the humerus of this type. It moreover las distinct points of resemblance to the humerus of existing Batraritix, parallel with similarity traceable in the femora of the extinct and recent genera. There is then every reason for believing that we have in the humerus of Eryops and its allies, an element which approaches closely in its charucters to that of the Pelycosauria, and hence to that of the Monotrematr.

There are some other peculiarities which constitute resemblances of the same kind. The tooth bearing elements of the roof of the mou.h have batrachian character. Such is the densily packed body of teeth seen in Dimetrodon; and so are the tecth on the vomer in Eimpedocles. There is also a possible existence of epiphyses, judging from valious specimens of humeri in my possession of both Pelycosauria and Stegocephalous forms.

In spite of these approximations, the Pelycosaturia are distinctively rep-

"This word was misprinted " fossil" 1. c. p. 529. 
tilian in their single occipital condyle, ossification of the basicranial cartiluge, and single vomer.

Thus the reptiles and batrachia of the Permian period resembled each other and the Mammalia, more closely than do the corresponding existing forms.

\section{PELYCOSAURIA.}

\section{THEROPLEURA Cope.}

Paleontological Bulletin No. 29, May, 1878, p. 519, Proceed. Amer. Philos. Soc., 1878, p. 519.

A more complete specimen of the Theropleura uniformis than any hitherto obtained gives the following generic characters.

The teeth are generally similar to those of Clepsydrops and Dimetrodon, having compressed crowns with fore and aft cutting edges. The incisors are distinguished by the presence of a diastema. Posteriorly to this the teeth increase in size, and then diminish; one tooth near the middle of the series is the largest, but does not in this species very much exceed the otbers. There is at least one large incisor tooth. The bones of the head are smooth, and not sculptured ; a character distinguishing the genus from Ectocynodon. The symphysis of the mandible is short.

The neural arches of the vertebræ are all distinct from the centra. Intercentra are not present in any of the thirteen vertebræ preserved, but there was probably one below the centrum of the atlas. The ribs are twoheaded, the capitular process extending downward to the anterior border of the centrum. The neural spines of some of the vertebræ are greatly elevated as in the species of Clepsydrops and Dimetrodon. The scapula is long; the ilium is similar to that of the genera named. A character which has not been detected in either of the genera named is the presence of dermal rods, which from their pnsition adherent to the vertebræ, I suspect to be abdominal, and similar to those of the genus Oëstocephalus. This is a batrachian claracter. The neural spine of the axis is extended fore and aft. The odontoid is distinct and is of large size. It las lateral and inferior articular surfaces.

\section{Theropleura uniformis Cóp.}

Paleontological Bulletin No. 29, p. 519, 1878.

This species is about the size of one of the larger Varanida, and about equal to the Clepsydrops natalis. It is characterized by a long and acuminate head, with a large lateral nostril on each side, well forwards, and approachjng near the border of the diastema. In the specimen the top of the head is crushed and the postorbital portion is wanting. Anterior to the large lateral tooth there are nine teeth; posterior to it there are eighteen. The anterior cutting edge of the crown does not extend so near the base as the posterior, and is best marked on the auterior teetl. In the crowns prescrved the edges are not serrate. 
Measurements.

M.

Lengtlı of alveolar edge of mandible..............120

" from diastema to canine tooth............... .030

" of centrum of atlas...................... 010

" " " " axis..................... 018

“ " centra of following five vertebrx.......... .07 [

" " "ilium at acetabulım.................... .040

The lanciform shape of the skull with its consequent peculiarities distinguishes this species from the Clepsydrops natalis, and the Dinetrodon incisivus. The cauine tooth is more posterior, the teeth more numerons, and the alveolar borders less curved than in either of those species. The diastema is less excavated, and the muzzle less obtuse.

Themopleuta obtusidens, sp. nov.

This species is represented by nearly all parts of the skeleton, including jaws of both sides with teeth, numerous vertebræ, and bones of the limbs. Many of these pieces are preserved in continuous masses, thus greatly aiding in the identification of parts.

Although the species is not larger than the Theropleura retroversa, the neural arches are coössified with the centrum.

The jaws are long and rather slender, and there is no such inequality in the sizes of the maxillary teeth as in the genera Dimetrodon and Clepsydrops; the canine being scarcely larger than the others. The crowns are elliptical in section at the base, with straiglt sides; the sections of the crowns are lenticular, and the apices are not very acute. The superficial coating is striate with fifteen or sixteen rather obtuse ridges The cutting edges are not very acule, nor are they denticulate. The number of teeth in the dentary bone cannot be precisely stated, but is about twenty-one.

The mandibular articular face consists of two open parallel grooves, one shorter than the other, extending obliquely to the long axis of the jaw. The palatal clentigernus bone is quite different from that of Dimetrodon. Its inferior fuce instand of being narrow, is rhombic. The ascending process arises from one of the terminal angles of the rhomb, and the lorizontal process continues from the opposite angle in line with the inferior surface. The borders of the rhomb next to the ascending prozess are dentigerous; the one bears a single series of four large teeth; and the adjacent angle and sicle bear numerous small teeth.

The vertebra have the elongated neural spines of the allied genera, and they are simple: The centra have curved articular margins indicating the presence of intercentri, which are, however, not preserved. Traces of sutural articulation with the neural arch remain. Many of the centra are much compressed and have a narrow sharp median keel. In a few vertebræ, apparently from the posterior part of the column, an angular ricige extends posteriorly l'rom the base of the diapopliysis; this is apparent also on a caudal centrum. This point is charncteristic of the $T$. retroversa, but I do not find the large capitular facet of that species in the $T$. obtusidens. The 
lateral ridges of $T$. trianyulata are situated low down on the centra. The diapophyses supporting the tubercular articulation are frequently eJongate.

The scapular and pelvic bones are of the usual type. The humeri belong to form second of my Pal. Bull. No. 29. They have rather slender shafts, and much expanded extremities. The proximal articular surface is well defined. The supracondylar foramen and other points are as in the Pelycosauria generally. There were probably distal condyles, but this is not absolutely certain.

Measurements.

M.

Length of mandibular series of teeth (nearly complete),

on block ................................110

Length of crown of mandibular tooth.............008

Anteroposterior diameter of mandibular tooth........ .004

Diameters of articular extremities of a ver- f vertical ... .021

tebra on the same block............ transverse. .020

Length of another centrum on same block........... .020

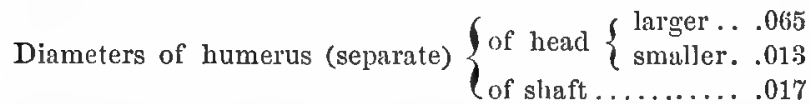

The above description replesents the parts which belong either certainly or very probably to one individual. Bones of a second and larger animal are mingled with these. The species to which they belong is tucertain, but they resemble very much those of the Theropleura obtusidens, and may belong to a larger individual of that species. A femur has the form already described uncler the head of Clepsydrops natalis. (Paleontological Bulletin, No. 29, p. 510.) Some phalanges belnnging no doubt to one or the other of the two animals, are like those I have alrearly ascribed to Clepsydrops. They are depressed, and are expanded at the articular extremities. The distal extremities expand the most abruptly. and their convex trochlear face is without groore or keel, and is more extended on the inferior than the superior surface.

\section{DIMETRODON Cope.}

Proceedings American Philosophical Society, 1878, p. 512.

The accession of a considerable amount of material representing this genus enables me to add importaut pointe to our knowledge of its osteology. The most noteworthy additions include the greater part of the skeletons of two indivicluals of $D$. incisious; and vertebræ attached to the pelvis and femora of $D$. gigas. There are also vertebræ of soveral inclividuals of $D$. cruciger, and various parts of the skull of a species clistinct from the $D$. incisivus.

In both specimens of $D$. incisivus, portions of the palatopterygoid arch are attached to the maxillary bone. One of these elements is an oval plate with a thickening of its inferior side, so as to bevel the long border farthest from the maxillary bone. The surface thus produced is thickly studded with small conical teetlı irregularly disposed.

A second tooth-bearing element of the palate is adjacent to the last. It 
is a massive plate, the ends of which are produced in opposite directions ; the one into a massive shorter prominence; the other longer and plate-like. Between these prolongations, the inferior edge of the bone bears a single row of well developed tecth. The patch of small teeth first described, commences at the extremity from which the longest process rises on the opposite side of the series of large teeth. This Z-shaped bone is, from its massive character, generally preserved, and I was long familiar with it, before $I$ could refer it to its position. In one specimen, a part of it bearing teeth, adheres to the upper jaw at the diastema.

The posterior part of the skull of one of the specimens above mentioned displays ty pical reptilian characters. The occipital conciyle is not perforated, nor divided by sutures. The exoccipital bones project well backwards. The lateral walls of the brain-case are massive as far forward as the exit of the fifth pair of nerves; anterior to this point they were thin or wanting. The basisphenoid carries two parallel descending laminæ, which bound a deep median fissure, and then unite anteriorly. Posteriorly they abut on a descending process, which is followed by a lid-like element which is applied to a circular fossa with a raised border near the occipital condyle.

The articular face of the articular bone of the mandible consists of two parallel cotyli, divided by an ridge of articular surface. This part of the jaw is much depressed, as in Eryops. The large teeth of the lower jaw are at the anterior extremity.

The neural spine of the axis is flat and elongate antero-posteriorly. From this point the neural spines rise rapidy in elevation until on the dorsal region they are many times as long as the diameters of the centra. The latter are not very unequal in their proportions in different parts of the column. Those from the posterior regions are less compressed than the dorsals and cervicals. The dorsals are separated by intercentra below, which are small in the $D$. incisivus, and larger in the D. gigas. All the ribs are two-headed, commencing with the axis. All the crevical and dorsal vertebræ have diapophyses with tubercular facets. The head of the rib is prolonged downwards and forwards to the prominent border of the anterior articular face, ngainst which it abuts, but so far as yet observed. without a corresponding facet. On the caudal vertebræ the two facets of the ribs are approximated and finally are not distinguished. They are here coössified with the centra.

The humerus accompanying one of the specimens of $D$. incisivus, is of the form No. 3, of my description of humeri in the Paleontological Bulletin No. 29, p. 528. The extremities are expanded and the shaft is without diagonal ridge; the supracondylar foramen is enclosed, and the condyles are robust. The pelvis of the $D$. gigas is in general like that of $C_{\text {bepsydrops natali: }}$ (l. c., p. 510). The elements are coössified, but the ischiopubic sy inplysis is not so deep as in the Butrachia of the same beds. The ilium is shortened above, and its direction is at right angles to the long axis of the inferior elements The foramen of the internal femoral artery is distinct. The femur of the 
same individual of $D$. gigas has no head, but a regular wide crescentic proximal articular surface. Below this on the posterior side is the large trochanteric fossa, which is bounded by lateral ridges, which are at first equal, but one soon exceeds the other in height, forming a trochanteric ridge a little above the middle of the shaft. The condyles are distinct from each other and are flattened below. One of them bears a robust longitudinal crest above, which makes it much larger than the other, and causes the groove that separates them above, to look outward, or to the side which supports the trochanter.

Three of the species may be distinguished as follows:

Vertebral centra much compressed, acute below; neural spines without

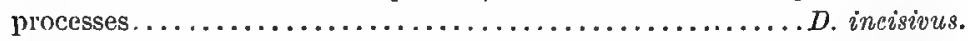

Vertebral centra less compressed, obtuse below; neural spines without processes ; larger............................ gigas.

Vertebral centra compressed, not acute below ; neural spines with cross projections ................................. er.uciger .

\section{Dimetrodon cruciger Cope.}

American Naturalist, 1878, p. 830.

This species is not uncommon in the Permian Formation of Texas. It is characterized by the enormous length of the neural spines of the lumbar vertebræ, which form the dorsal fin seen in other species of the genus. They are found in masses adhering together like sticks or branches of bushes. In this species the spine sends off, a slort distance above the neural canal, a pair of opposite short branches, forming a cross. At various more elevated positions there are given off tuberosities which alternate with each other. They form on several consecutive spines oblique rows. The spines are broadly oval in section, the long axis antero-posterior, and have a shallow groove on both the anterior and posterior aspects. The centra are elongate as compared with their other diameters, and are much compressed between the articular extremities, leaving a strong inferior median obtuse rib. Articular faces of zygapophyses oblinue. Diapopliyses short and robust, with large costal faces, and standing below the prezygapophyses.

Measurements. M.

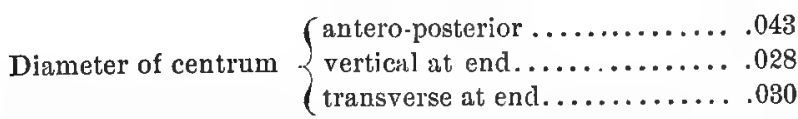

Elevation of posterior zygapophyses above centrum... .025

“ cruciform process " " $\quad \ldots . .058$

Expanse of posterior zygapophyses............... 034

" cruciform process................... 048

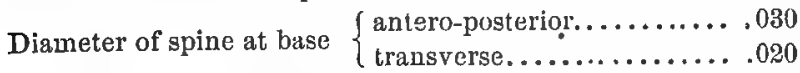

“ “. .090 above base $\left\{\begin{array}{l}\text { antero-posterior.... } \\ \text { transverse......... .016 }\end{array}\right.$

Length of several pieces of neural spines........... 140 


\section{DIADECTID无.}

I have obtained threc skulls of the Empedncles molaris, a species of this family, which display the occiput, and two of them the basis of the cranial and facial regions. From them I derive the following characters.*

The relations of the quadrate and zygomatic arches are as in the Thero. morphe generally. The pterygoids extend to the quadrates, and the vomer bears teetl. The brain-case extends to between the orbits, and its lateral walls are uninterrupted by fissures from this point to near the origin of the os quadratum. There is an enormous frontoparietal foramen. The mode of connection with the atlas is peculiar. There is a plane facet on each side of the foramen magnum, which then expands largcly below them. The bone which bounds it inferiorly, presents on its posterior edge a median concavity. On each side of this, is a transverse cotylus. much like those of an atlas which are applied to the occipital conly]es of the Mammalia. They occupy precisely the position of the Mitmmalian condyies. The median point of their upper borler, which forms the floor of the foramen marnum, is produced in the position occupied by the median occipital condyle of a reptile. From its position between the cotyli, the section of this process is triangular. The element in which the cotyli are excavated has the form of the mam. malian basioccipital, and of the reptilian sphenoid. It is not the batrachian parasphenoicl. - Its extreme external border on each side where it joins a crest descending from the exoccipital, is excavated by a circular fossa which looks outwards.

The character of this articulation is so distinct from any thing yet known among vertebrated animals, that I felt justified in proposing (l. c., p. 304) a new division of the Theromorpha to include the Dialectide, to be called the Cotylosanria. The superior facets described, indicate the presence of atlantal zygapophyses as in the Ganocephala.

There are three genera of Diadectida, one of which is now introduced for the first time. They are disisinguished as follows :

I. Molar teetl in one series ;

A distinct canine.................... Diadectes.

No crnine......................... Empedocles.

II. Molar teeth in two series;

A canine.......................... Helodectes.

I am acquainted with six species of this family, two of each of the genera.

\section{DIADECTES Cone.}

Proceeds. Amer. Philos. Society, 1878, p. 505. American Naturalist, April 22, 1878.

The typical species of the genus has compressed teeth, with one end of the crown much more elevated than the other. In the lower jaw the inner extremity is the elevated one, and vice versa. There is a large tooth in the position of a canine in the inferior series, but it is not certain whether or not it is an incisor. $\boldsymbol{\Lambda}$ new species is now described which is intermediate

* These were first described in tho American Naturalist, 1889, p. 301. 
between the D. sideropelicus and the Empedocles molaris in the form of the molar teeth. The species are distinguished as follows:

Much inequality in the elevation of the extremities of the molars; lower tubercle small ....................... sideropelicus.

Extremities of molars not very unequal in height; lower tubercle

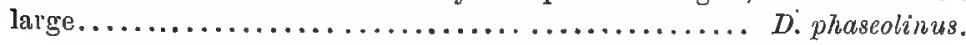

Diadectes Phaseolincs Cope. sp. nov.

This species is represented in my collection by the maxillary bones of three animals, and a portion of the mandible with most of the tooth line of a fourth. These fragments are of about the size of the $D$. sideropelicus and Eimpedocles molaris.

The molars possess a low cusp which is nearly in the middle of the tooth. of the lower and external cusps, the internal is the witer and more rounded ; when unworn it is as clevaled as the external, but it is soon reduced by attrition. The external part of the tooth is somewhat narrowed, and there is no horizontal surface on eilher side of the median cusp, as in Empedocles molaris. The last maxillary tooth is rather small; preceding it are eight wide transverse ones, and then two less extended transversely before reaching the broken end of my best specimen. The anterior of these is elongate, and may be caninilorm, but its apex is lost. External layer smonth; some wrinkles round the base of the inediun cusp.

The broken base of the molar bone is subround and small, and shows that that element is sleniler below the orbit.

The portion of mandible preserved is quite deep, and is incurved at the sympliysis. But few of its teeth are preserved, and it is not possible to say how long the anterior ones with subround bases may have been. The molar whose crown is preserved does not differ materially from those of the maxillary series. The alveolar line does not retrent inwards from the external border as in Empedocles lrutibuccatus, resembling in this respect the $D$. sideropelicus. The external surface of the lower jaw is roughened by shallower and deeper small or minute pits closely placed.

Measurements. M.

Length of series of eleven maxillary teeth.......... .07.5

Length of series of seven widest molars............. .048

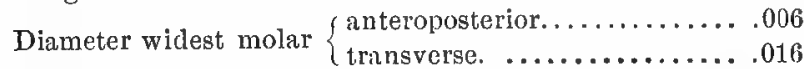

Depth of mandible externally.................... 0

Widtlı of mandible at midlle...................... .096

It is possible that it may yet be necessary to refer this species to $E m$ pedocles.

\section{EMPEDOCLES Cope.}

Proceedings Amer. Philos. Soc., 1878, p. 516. American Naturalist, April 22, 1878; April, 1880.

I am acquainted with two species of this genus, $E$ molaris* and $E$. lati-

* Diadectes molaris, A mer. Naturalist, 18i8, p. 56 . 
buccatus.* The latter is represented by portions of two mandibles in my collection; the former by two or three slsulls, with part of the mandible accompanying one of them. The difference in the forms of the mandibles is well marked. In $E$. molaris the dental series is parallel to the external border of the jaw; in $E$. latibuccatus the tooth line is deflected inwards from the border, leaving a wide space.

\section{Empedocles molaris Cope.}

Diadectes molaris Cope. Anterican Naturalist, 1878, p. 565.

The molar teeth are wicler in this species than in any species of the fumily yet known. The internal and external extremitics of the crown are about equally wide and equally elevated, and there is a low median cusp. A portion of the grinding surfice both internal and external to the cusp is horizontal; the surface of this portion is wrinkled. The last molar is smaller than the otleers. The inner border of the maxillary brnes forms a curved ridge on each sicle of the palate, which is separated by a groove from the vomer. The latter forms a median keel at the anterior portion of the palate, where it supports two rows of small conical teeth. The palatines have their prominent internal edges juxtaposed as far as the transverse line of the last molars. There they diverge a little, and extend as two nearly parallel keels to a prominent angle on each side, opposite the middle of the zygomatic foramen. There the inner borders cease to project, and arc directed obliquely outwards to the inner extremities of the quadrate bones. The exfernal border's of the pterygoids are more elevated than the internal. The median keel of the basisphenoid arises between the internul angles of the pterygoids above mentioned, and ceases before reaching the inferior border of the occipital condyle. The external border of the ex. occipital is sigmoidally flexed.

It has occurred to me that the peculiar condition of the occiput described under the head of the family Diadectido, may be due to the loss of the basioccipital bone. It would be a remarkable coincidence if this accident should have befallen the only three crania which have come into my possession.

The anterior border of the orbit is above the anterior part of the fourth molar, counting from behind. The distinct incisive formina are longitudinal and rather large. The anterior border is opposite to the fourth tonth counting from the first incisor. The nostrils look out laterally and a little forward; the united spines of the premaxillaries form a stout septlim. The incisor's are not more than three or four on each side (I cannot find the premaxillo-maxillary suture), and they form a regularly convex series. With the maxillaries, the entire dentition of one side forms a gentle sigmoid curve. The median incisors are the largest; the sizes regularly diminish until the smallest are reached on the anterior part of the maxillary bone. Posterior to this point they enlarge again. Their apices are not preserved.

* Diaclectes latibuccatus, Proceed. Amer. Philos. Soc., 1878, p. 505. 
The superior surface of the skull is only partly preserved in one specimen. This renders it probable that there is a crotaphite foramen as in the crocodiles, etc. The surfaces of the external cranial elements are finely pitted, or rather punctured.

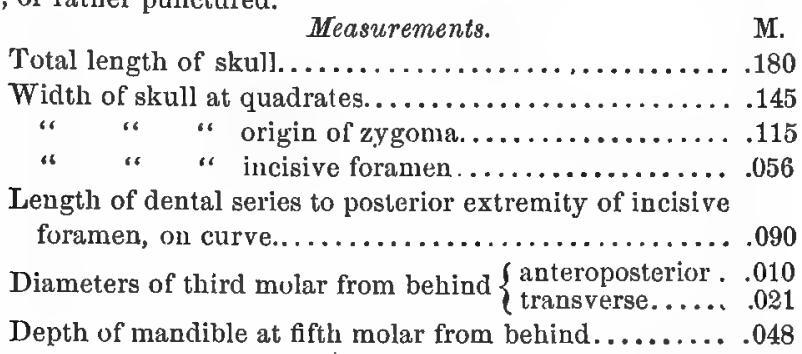

Maxillary series of seven, and parts of the mandibular series of four, individuals, are in my collection.

HELODECTES Cope. Genus novum.

Maxillary bones of two species, which I refer to this genus, were found associated with many bones of appropriate size, among which are vertebræ of the type of Empedocles. The characters observable are generally similar to those of the Diadectida, where I accordingly place the genus. Its principal characters, the presence of two rows of teeth in the jaws, has already beeu pointed out. I may add that there is apparently a large tooth in the position of anterior incisor, in the typical species.

The species differ in the arrangmment of their teeth, as follows :

Molar teeth of the two rows subequal in size, and equally numerous

H. paridens.

Molar teeth of one row wider, and more numerous than those of the

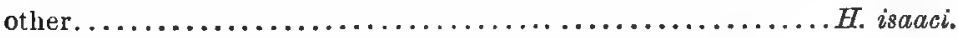

Helodectes PaRIDens Cope. Sp. not.

The smallest species of the family, is of about half the linear dimensions of the Empedocles molaris. It is represented by a left maxillary and probably premaxillary bune, which are so far covered with the adhesive, hardened ferruginous mud of the formation, as not to expose a clean surface. The apices of all the teeth are broken off, so that the bases alone remain to indicate their number, form and positions.

of the molar teeth proper I count six in the inner, and eight in the ex. ternal row. The two series are close fogether, and are gently convex inwards. The bases of the teeth are wide ovals, transversely placed. In front of the eighth tooth of the external row (from behind), are two teeth without apparent mates of the internal row (possibly the latter lost). Then follows a tooth of each row, and in front of these another pair, the external being the larger. Anterior to these, the jaw is so split as to remove any teeth of the inner row, if there are any, and one large tonth of the external series stands at the extremity of the fragment. This latter exceeds the 
in Eryops and Cricotus, gives the folluwing result: The glenoid cnvity is an excavation in two coössified elements, of which the inferior and posterior is probably coracoid. The latter is then much smaller than in Reptilia and Batrachia anura, but resembles that of the salamanders. Tle scapular arch proper resembles that of the Urodela. The pelvis is intermediate between that of the antrous and urodelous Batrachia. There is no obturator foramen, and the common symphysis is deep. The humerus closely resembles that of the Pelycosuuria, differing chiefly in the non-enclosure of the supracondylar foramen; and as in that sub-order, some genera possess condyles and some do not.

Prof. Owen proposed the order Ganorephala chiefly for Archegosaurus, but he included in it also the genera Derderpeton and Pelion (Paleontol(ugy, p. 18:-3). This division lias not been geuerally adopted, the genera mentionel being usually placed in the Labyrinthotlontia. Of the eleven characters given by Prof. Owen in evidence of the existence of this order, one only does not helong also to the Labyrinthodontic; this is the absence of occipital condyles. On this account I thought that the group should be retained, but not as an order. Besides this group and the Labyrinthodintia, there were the types called Microsurria by Dawson, some of which have simple enamel, all agreeing in general characters, and differing from other Batrachia. I therefore combined the three groups into one orcler, the Stegocephati. (Proceedings, Academy, Philada., 1868, p. 219.) This order was most distinctly characterized in the Report of the Geological Survey of Olio, Paleontology, ii, p. 354, 1875.

Von Meyer has given us enough of the charncters of Archogosaurus to enable me to refer the forms of the Texan Permian to the same order. Prof. Owen, in his discussion of the affinities of that genus (l. c., p. 170), remarks, that the vertebræ and numerous very short ribs, with the "indications of stunted swimming limbs, impressed me with the conviction of the ncar alliance of the Archegosunus with the Proteus and other perennibranchiate reptiles." As it is now woll known that perennibranchiate batrachians belong to three different orders of the class (T'rachystomata, Proteida and Urodela), the aloove expressions lose point, and esrecially as the characters mentioned as indicative of affinity are of the most subordinate importance, or as in the struclure of the vertebrs. are totally distinct from what is found in those orders. When we read later (p. 173), that the fuct that the superior " ossifications of the skull liave started from centres more numerous than those of the true vertebral system, gives the character of the present extinct order of Batrachia; " we find that Prof. Owen las quite failed to perceive aither the definitions or aftinities of his new order. He commits an error in describing a distinct pulbic bone; an element which Von Meyer siates (Paleontographica, vi, 179, 1858) that he had not discovered. Von Meyer describes the coössified inferior elenents of the pelvis as ischia. My numerous Texan specimens show that each of these bones includes both pubis and ischinm.

In now defining the Ganocephata anew, T confine myself to characters 
which I know to be common to the known genera. Some of them possess two occipital condyles. For the purpose of avoiding the multiplication of synonymes, I employ Prof. Owen's name.

Vertebre consisting of centra and intercentra, the former not extending to the base of the vertebra, the latter not rising to the neural canal. The centrum consisting of two parts distinct from the superior neural arch; viz., a lateral piece (pleurocentrum), on each side. Atlas consisting of separate segments, the superior of which are not united above the neural canal, and the inferior (intercentrum) divided on the middle line, into two segments.

Genera. A. Basioccipital bone without condyles: Trimerorhachis Cope; Archegosaurus Meyer. A.A. Basioccipital condyles two: Actinodon Guadry ; Rachithomus Cope ; Eryops Cope.

All the above genera have well-developed neural spines except Trimerorhachis.

\section{ERYOPS Cope.}

Paleontological Bulletin No. 26, p. 188. Nov. 21st, 1877. Proceedings Amer. Philos. Society, 1877 (1878), p. 188.

In the essay ahove cited, the crinial characters of this genus were pointed out with some of those of the vertebre. It remains to describe the other parts of the skeleton. Notices of some of these have already appeared in the American Naturalist for September, 1878 and May, 1880.

The iargest element of the vertebra is the intercentrum. This, which occupies the entire inferior surface of the vertebra, is a segment, representing the sixth part of a sphere, with a slight central vacuity. The element representative of the centrum is wedged in between the superior external angles of adjacent intercentra, as in Trimerorhachis. These, as well as the intercentra, differ from those of that genus in their greater degree of ossification, which is so far completeras to greatly contract the conalis chordos dorsalis. The central elements of opposite sides do not unite on the middle line below, although in contact. The neurapophysis is produced downwards and outwards, terminating in the simple diapophysis, with rib articulation. The inferior articular faces of the arch are two on each side, one for the central element in front, and the other for the one behind it. The whole is surmounted by a continuous neural spine, which is expanded at the summit, in the known species. The vertebræ do not differ much in different parts of the column. The cervicals are not distinguished in any way from the dorsals, but their anterior intercentra have more extensive costal surfaces, which give the inferior posterior border lateral angles. The diapophyses of the second and third cervicals are of reduced size. The neural spine of the axis is a little less elevated, and is longer anteropos. teriorly than that of the third and succeeling cervicals. I do not possess an entire atlas free from matrix. Att,ached to the axis of this specimen are two elements which connected it with the skull, as they are separated from it only by closely fitting tractures. The elements are lateral, and each presents a semi-spherical articular face in front, and a long process with acute aprex at light angles to it, posteriorly. These processes lie, one on each 
side of the nenral spine of the axis, above the position which would be occu. pied by its prezygapophysis ; they represent the distinct halves of the arch of the atlas. At the superior base of each process near the edge of the articulation is a button like tubercle, which represents a prezygapoplıysis ; the inferior articular faces correspond with those of the occipital condyles in form but not in position, which is inverted. The inferior elements of the atlas are lost.

The intercentra are rather longer and more elevated in the sacral region. One only can be properly said to belong to the sacrum, and this is closely united with the one that follows it by a rough surfuce of contact. In old animals it may become coössified. What the relations to the intercentrum immediately preceding may be I am unable to state, owing to the condition of the specimen. A pair of caudal vertebræ are peculiar. T'heir intercentra are in contact throughout, excluding the pleurocentra. The latter rest above the intercentra, and between the inferior parts of adjacent neural arches. Each intercentrum supports a coüssified chevron bone, and these, in the two vertelrre in question, become cuössified with each other, forming a robust rod directed backwards, whose double base is perforated by the hæmal canal. This peculiar structure probably belongs near the extremity of the caudal series, as the anterior caudals observed in other specimens, are much like the dorsals.

The costal articulations are everywhere undivided, and have an obliquely vertical extension. The articular surface extends to the intercentrum in the $E$. megacephalus, forming a slort. superficial depression which enters from the supero-posterior border. The costal surfaces of the dia|'ophyses become more robust anteriorly, and are mole narrowed, especially at the middle and inferior portions, posteriorly. The diapophysis of the sacral vertebra is very robust, and presents a large tubercnlar fuce downwards, and a little backwards. The external side of the intercentrum about its superior angle is also covered by a large capitular facet, and the two facets support a sacral rib. This element is much more robust anteriorly than the true ribs, and its capitular and tubercular facets are distinct from each other, although they are separated by but a slight interruption. The body of the rib is plate-like, and is directed downwards and backwards, its union with the ilinm being squamosal. The costal elements posterier to the stcrum diminish rapidly in size. From the size of the vertebræ in $E$. megacephalus, the tail is probably of medium length only.

The coracoid is but little incurved; its internal border is convex, and is roughened as though for cartilaginous attachment. Its superior portion forms a convex continuum with the scapula. The direct line or external face of the scapula extends in a nearly plane surface to the glenoid cavity, em. bracing a perforating foramen above the latter, precisely as in the Pelycosauria. Its surfuce is continuous anteriorly with a wide expansion forwards, whose fine inner borcler is continuous with that of the coracoid. This plate doubtless includes a third element, but its borders are not preserved, on account of the obliteration of the sutures. It is probably epicoracoid, as in the Pelycosauria. In its form it is less produced than in the known scipular arches of the latter. 
The coössified pelvic elements resemble, in their compression below, the corresponding purts in the Anura. The ilia are, however, shorter and worn as in the Urodela. They are tat, and stand at right angles to the line of the ischiopubic symphysis. There is an open concavity of their inferior posterior free border, and a facet-bearing clevation on the inferior border, or that entering into the formation of the acetabulum. The latter is large and lualf as long anain as deep. The anterior and posterior borders of the pelvis descend regularly to the inferior edge, forming with it a triangle. The ischiadic or posterior borler is but little thickened; the anterior, or pubic is tlat in front and presents a reverted edge outwards. This expands prominently where it is joined by a ridge which bounds the acetabulum below; it there contracts to an inferior apex. Beneath the anterior point of the acetabulum it is pierced by the usual foramen, which issues on the inner edge of the anterior face, just above the sympliysis.

The humeral bones of this genus I probably possess ; but I have several forms between which I am not able to decide. They are in general like those of the Pelycosauria, but differ from them in not having an enclosed supracondylar arterial foramen, but only the buttresses of its enclosing arch. Two such forms I have already described, * and a third has been obtained from the French Permian by Professor Gaudry. One quite similar to the latter I have since obtained from Texas. Not having been aule at first to determine the proper reference of these liumeri, I suggested to Prof. Gaudry that his liumerus belongs to one of the Pelycosauria, and lie accordingly described it as Euchirosaurus rochei.t I now think that there is greater reason for believing that it belongs to a species of the same group as Eayops and Actinodon.

In all these humeri the extremities are expanded in different planes, and the shaft contracled. The articular surfice of the proximal extremity is band like and passes obliquely from one side to the other as in the Pelycosaurix. The condyles are large, consisting of a globular portion and a depressed trochlea without ridges at one side of it.

'The femora are very different from the huneri, but in much the same way as in the corresponding bones of existing Batrachit. There are no condyles at either extremity, but outlines of such, enclosing roughened surfaces. These look as thougl the bases of atiachment of cartilaginous caps or epiphyses. The proximal extremity is convex, and is extended in one direction. One border, the anterior, is regularly gently convex; the opposite are is strongly convex near one end only. The articular face is in two planes, one larger than the other. The trochanteric fossa is at first shallow, and occupies the entire widih of the bone, it narrows with the shaft downwards and the borclers rise, one more than the other. The two join in a strong protuberance, which looks directly backwards, and may be called for the present the third trochanter. The shaft is keeled below and in continuation of the trochanter, to where it expands for the distal articu-

* Paleontol. Bulletin, 29, 1878, p. 529.

t Bulletin soc. Geol. France, Dec , 1878. 
lar extremity. The latter looks partly downwarks, and is divided by a deep groove above into two parts representing the usual conclyles. One of these is comparatively depressed, while the other has a massive superior crest, which makes its long axis vertical instead of horizontal, as is that of the other condyle.

There is considerable resemblance between this femur and that of Dimetrodon gigas, and in a less degree to that of Clepsydrops natalis, but both the latter have well developed condylar surfaces. They are also larger in proportion to the size of the rest of the skeleton, in the Pelycosauvians mentioned.

Further characteristics of this genus and of the species it embraces will ke given at a future time.

\section{TRIMERORHACHIS Cope.}

American Naturalist, 1878, p. 328 (April 2\%). Proceedings American Plilos. Society, 1878, p. 524.

This genus, as has been pointed out, differs from $\mathbb{E}_{r}$ yops in the superficial character of its vertebral ossifications, and in the absence of ossified neural spines.

A well-preserved cranium, and purtions of several others referrible to this genus, furnish characters which have been hitherto inaccessible. They probubly belong to the $T$. insignis, but this is not certain.

Generic Characters, etc.-The type of skull is that of the urder of Stegocephati generally. The superior walls are thin, and are sculptured on the superior surface. The mucous grooves are distinct, but do not form a well-defined lyra. There is a groove which is parallel to the anterior borders of the orbit for a short distance, and which then turns forwards and then inwards. The dermal ossification is distingnished from that of the maxillary bone by a squamosal suture. A mucous groove descends to it ohliquely forward from the superior quadrate region, and sends a branch at right angles to its anterior extremity to a point posterior to the orlut. Of superficial ossifications, the boundaries are difficult to determine, owing to tho obscurity of the sutures. Enough can be seen to demonstrate the presence of suprmaxillary, epiotic, and supraoccipital dermal bones. The nostrils are large and well-separated, and look upwards.

The teeth are acute, and of subequal size; their superficial layer is deeply inflected at the base.

The parasphenoid bone is wide posteriorly, but contracts abruptly, and extends forwards on the middle line. Owing to crishing of a part of the surface, I am unable to ascertain its anterior, or vourerine suture. The basifacial axis bone is quite narrow, and is edentilons. It is connected with the superior cranial walls by a vertical osseous plate on each sicle, which may represent alisphenoid, orbitosphenoid and ethmoid. The palatopterygoid arch is a longitudinally extended sigmoid, enclosing with the axial elements, an enormous choanoörbital foramen. It extends from the middle line below a short distance posterior to the position of the nostrils 
outwards, and follows closely the maxillary bone well posteriorly. It then turns inwards, extending to the parasplenoid bone, with the wide portion of which it has an extensive contact. It then turns outwards as pterygoid bone, and rapidly narrowing, joins the inner distal extremity of the quadrate. It thus encloses a foramen with the quadratojugal bone, which is much smaller than the choanoörbital foramen. The posterior part of the inferior surface of the bones of this arch, not including the slender pterygoid portion, is roughened with hard nodules resembling teeth in material, and serving the purpose of such organs.

Two rod-like bones extend outwards and backwards from the posterior part of the parasphenoid and the basioccipital, which belong to the inferior arches. The anterior is the larger, and is bent backwards at an obtuse angle; its proximal extremity is a truncate oval. This bone occupies the position of the stapes. The second is extensively in contact with the basioccipital by its proximal extremity. It is curved backwards at its distal third. The occipital condyle is represented by a fish-like cotylus, which has a deep notch at its superior border.

The mandible has a short angular process, vertical by lateral compression. The symphysis is very short and the Meckelian cavity large, and completely enclosed.

The anterior cervical vertebræ consist of the same elements as the dorsals. The intercentra of the second and third vertebræ support capitular costal articulations, somewhat elevated above the surrounding level. T'he pleuro. centra do not support the ribs, but the neural arches terminate below in diapophyses. There is a pleurocentrum in front of the second intercentrum, and above and in front of it a neurapophysis, which bas no distinct diapophysis. Its superior portion is a subacute process which is not in contact with that of the other side, but is separated from it by a vertical osseous plate, which is probably the neural spine of the second vertebra or axis. This is similar to the structure already observed in Eryops, and the parts being in place, should explain those of that genus. The portion of the atlas which represents the intercentrum is divided into two lateral portions, each of which has the form of an entire intercentrum, i.e., crescentic. The intercentrum of a cervical of a large species of this group, is wider than that of the other vertebre, and presents two articular facets anteriorly.

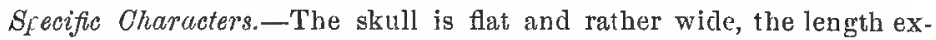
ceeding a little the transverse posterior diameter. The posterior borders of the orbits mark a point half way between the extremity of the muzzle, and the posterior supraoccipital border. The orbits themselves are of medium size, and are separated by a space about equal to their transverse diameter. Their form is a wide oval, with the long axis obliquely anteroposterior. The diameter of the external nostril is nearly half that of the orbit, and the form is similar to that of the latter. The interorbital and ethmoid regions are concave; the prefrontal regions are convex. The supraoccipital border is strongly concave; and the notch separating the upiotic angle from the quadrate angle is as deep as the supraoccipital. The 
surface of the cranium is thrown into wrinkles which form no regular pattern, and which inosculate to a moderate extent, most so on the preorbital region. The anterior parts of the maxilliary and mandibular bones are marked with small pit-like impressions.

Mersurements.

M.

Total length to quadrate angles measured on median line ..................................170

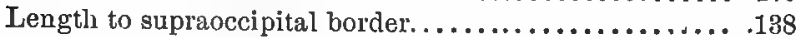

Total width posteriorly....................155

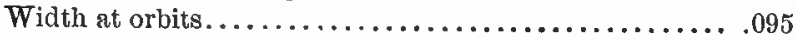

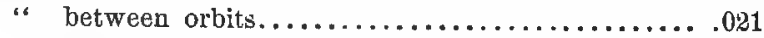

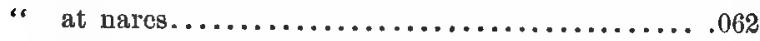

" between nares.......................... 030

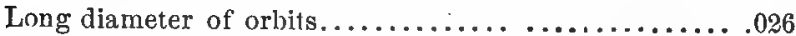

Transverse diameter of occipital cotylus............ .012

This cranium is much shorter and wider than that of Archegosaurus decheni, and has the orbits more anteriorly placed.

CROSSOPTERYGIA.

ECTOSTEORHACHIS Cope, gen. nov.

Tribe Crossopterygia; family Rhombodipteridce Traquair; sub-family Saurodipterini Huxley. Pectoral and ventral fins rather acutely lobate, with few or no radii on their external horders. Dorsal and anal fins unknown. Scales imbricate, rhombic, smooth. Ganoine wanting from top of head in specimens examined, but present on sides and inferior surfaces. Coronal suture distinct. End of the muzzle covered with separate scales. Distinct sub. and postorbital bones. Gular bones, an anterior azy gus and two laterals on each side, the posterior the shorter. Teeth acutely*conic, rather small ; a few large ones at the anterior part of each jaw. Vertebral centra represented by osseous rings which enclosed a notochord.

This new genus is apparently nearly related to Megalichthys, and in a less degree to Osteolepis and Diplopterax. Pander, Miller and other's represent the ventral fins of the two genera last named as not lobate, but sessile, a state of things entirely different from what is observed in Ectosteorhachis. The sub-division of the dermal bones of the muzzle is also rather characteristic of Megalichthys. From the latter genus it differs in the form of the vertebral centra. Both Agassiz and Huxley describe those of Megalichthys as completely ossified, and as biconcave. In Ectosteorhachis they are represented by annular ossifications resembling somewhat those of the stegoce phalous genus Cricotus, but with a larger foramen chorda dorsalis.

The elongate-lobate axis of the fins of this genus render it probable that those of Megalichthys present the same character.

Ectosteorhachis nitidos Cope, sp. nov.

This fish is represented by several specimens, the best preserved of which includes the head and body inclusive of the ventral fins. These form an chitlyyolite nearly denucled of matrix, the inferior side being best preserved. 
No indications of dorsal fin are to be found in the specimen, and those which exist must originate behind a point above the base of the ventral fins. The pectoral fins originate further behind the head than is usua]. The ventrals are well posterior, and close together.

The skull is transversely fractured at the coronal suture, as I suppose it to be, which clivides the front, just anterior to the point of attachment of the hyomandibular bone. At the antero external angles of the parietals, are distinct post-frontal bones of a sub-triangular form, which send a process posteriorly from their external angle. The hyomandibular presents a narrow convex external edge, and is directed backwards and downwards. It leaves a wide space posterior to the postorbital bones. Of the latter there are two, the inferior connected with the front of the orbit by a single wide, suborbital bone. The orbits are as much lateral as vertical, and are in front of a transverse line dividing the skull equally. The muzzle is broadly rounded, and is covered with rounded plates of ganoine. Several of these have median perforations. The opercular apparatus is obscured by matrix in the specimens; a small bone lies on the inferior part of the suspensorium on both sides, and may be the preoperculum. The top of the head behind the muzzle is entirely without ganoine layer in two specimens; its surface is smooth, or weakly finely ridged. On the other hand, the premaxillaly, maxillary, mandibular and gular bones are invested. with perfectly smootl ganoine.

The pectoral fins are quite wide, and their rays diverge exclusively from the inner border, and are very fine. The axial portion is thick and acuminate, and has no fulcra on the external edge, but is covered with quadrate and rhomboidal scales, of very much smaller size than those of the body. The axial portion of the ventral fins is not quite so large as that of the pectoral.

The scales of the body are quite large and overlap each other by both the free edges. Though their form is rhombic, the apex is rounded. The surface is ganoid, and entirely smootl. There are five rows between the internal bases of the ventral fins, and twelve between the external bases of the pectorals. The gulars of the posterior pair are about as long as those of the anterior. There are anteriorly one and posteriorly two rows of plates between the anterior gulars and the mandible.

This fish was probably three feet in length.

Measurements.

Length of head to base of first distinct lateral body scale (posterior border of skull damaged)................161

Length to base of pectoral fin.................... 180

" (axial) to canthus oris.......................

" of skull to coronal suture........................

Width " " at " anterior border of orbit....... " $"$ "
" of front between " 


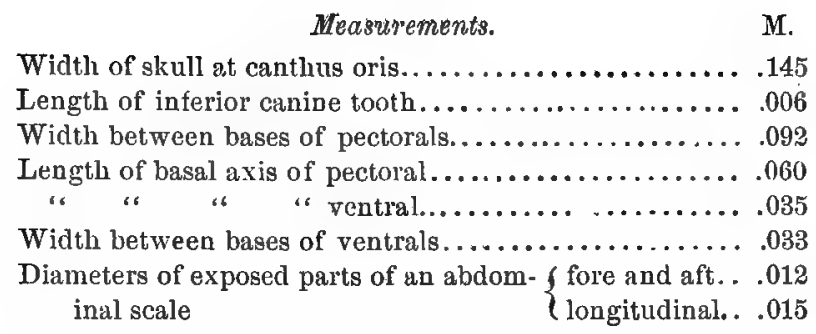

The Megatichthys hibberti Ag., which this species resembles in some degree, is represented by authors as laving the scales minutely granulated on the surface. The ganoine layer also covers the superior surface of the sixull, a peculiarity which is not present in the Ectosteorhachis nitidus. 


\section{Explanation of Figures.}

Figure 1.-\$lkull of Eryops megacephalus from above, one fifth natural size.

Fig. 2.-The same skull, profile.

Fig. 3.-The same from below.

Fig. 4.-Mandibular ramus from ahove, one-fourth natural size.

Fig. 5.-A large part of the vertebral column of a second specimen from the left side, one-fourth natural size.

Fig. 5. -The same from below.

Fig. 7.-Anterior view of atlas and axis, natural size.

Fig. 8.-Posterior view of a dorsal vertebra, natural size.

Fig. 9.-Inferior part of scapula with coracoid, of same animal, external side.

Fig. 10.-Same, interno-posterior view.

Fig. 11.-Pelvis of the same individual, left side.

Fig. 12.-Same, from front.

Fig. 13. - Same, from behind.

Fig. 14. - Same, from below.

Fig. 15.-Femur of same individual, from above.

Fig. 16. - Same, from below and belhind.

Fig. 17.-Proximal end.

Fig. 19.-Distal end.

Fig. 9.-Inferior view of skull of Empedocles molaris, one-half natural size.

Fig. 10.-Posterior view of the same skull, balf natural size.

Fig. 11.-14 bones of Dimetrodon incisivus, one-fourth natural size, from a single individual.

Fig. 11.-End of muzzle, left side.

Fig. 12.-Lateral view of a large part of the vertebral column.

Fig. 13.-Thirteenth vertebra, lacking the summit of the neural spine, from behind.

Fig. 14.-Fourteenth vertebra, lacking apex of neural spine, from front.

Fig. 15. - Nineteenth vertebra of same skeleton, lacking most of neural spine, from behind, two-thirds natural size.

Fig. 16. -Sacrum of same from front, two-thirds natural size.

The above figures will appear in the Proceedings of the American Philosophical Society.

Published, June 5, 1880. 




\section{ON THE}

FORAMINA PERFORATING THE POSTERIOR PART

OF THE

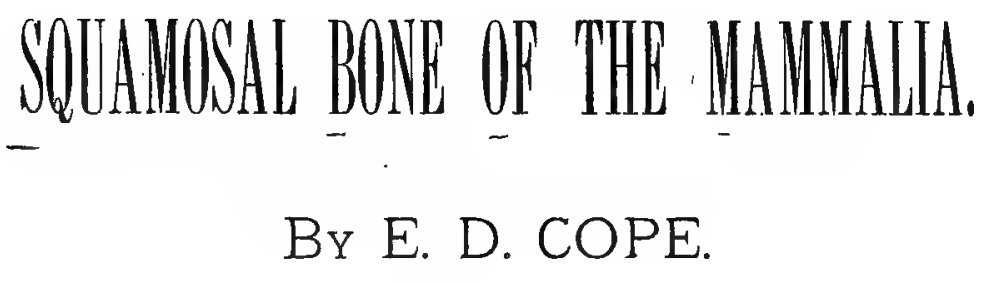



ON THE

\title{
FORAMINA PERFORATING THE POSTERIOR PART
}

\author{
OF THE \\ SQUAMOSAL BONE OF THE MAMMALIA. \\ BY E. D. COPE.
}

The number of perforations of the posterior part of the squamosal bone in the Mammalia is considerable, and they have not attracted that attention from anatomists which their importance cleserves. As I have found them to be especially valuable in cliagnosis, I have thought it might be useful to place on record the manner of their occurrence in various recent genera with whose structure we are more or less familiar in other respects.

The one of these formina of which some notice has been taken, is the postglenoid, which is mentioned by Flower (Osteology of Mammalia) as occurring in the dog and bear, and as absent in the cat. I find five other: foramina which usually form the outlets of canals which arc connected with the lateral venous sinus. The principal canal extends from the postglenoid foramen upwards and backwards between the os petrosum and the squamosal, and enters the cranial cavily at the superior border of the for. mer. At a point in the parietal bone, often on or very near the squamosoparietal suture, it issues on the surface again, in the foramen which may be called the postpririetal. A branch of the canal may take a posterior direction and issue on the occipital face of the skull in the suture between the ossa petrosum and exoccipitale, forming the mastoid foramen. Or a posterior branch may issue in the posterior part of the squamosal bone in a lateral foramen, the postsquamosal. In certain Mammals a large foramen perforates the base of the zygomatic process of the squamosal from above, entering the canal after a short course of its own; this I call the supraglenoil foramen. Still another inlet to the canal is found in some Mam: mals, perforating the squamosal below the crest which connects the zygoma with the inion, occupying a position posterior and exterior to the postglenoid, and generally looking more downwards than outwards. I call this the subsquamosal. These foramina may bearranged in four sets, as follows :

I. Looking downwarls ;

Postglenoid.

Subsquamosal.

II. Looking outwards ;

Postsquamosal.

Postparietal.

III. Looking upwards ;

Supraglenoid.

IV. Looking backwards ;

Mastoid. 
Some formina of the same region are not necessarily connected with the sinus lateralis. Hyrtl, in his essay* on the arterial system of the Edentata, shows that a foramen near to the postsquamosal of the Tamandua tetradactyla, gives passage to an "arterix diploëtica," which is formed by the junction of the occipital bxanch of the carotid with an ascending branch of the temporo-maxillaris division of the carotid. The a. diploëtica issues in a foramen which perforates the parietal bone on the orbital border. These two foramina may be called the $f$. diploëticum posterior and $f$. $d$. anterior, respectively. The former enters from the fundus of the same small fossa, which is also perforated in its superior portion by the f. postsquamosace, the canal from the latter formen taking the usual vertical direction.

Still another foramen ex'sts, which is, so far as my present knowledge goes, confined to the Monotremata and Marsupialia. It enters the posterior base of the zygomatic portion of the squamosal, and is directed forwards.

In Tachyglossus it passes through the base of the zygoma, issuing in the base of the zygomatic fossa. In the Marsupialia it enters a fossa of the squamosal bone, which may or may not be partially filled with cancellous tissue. I call this the foramen postaygomaticum.

I now give the results of my observations on the crania of the most important genera which I have observed, one hundred and sixteen in number.

\section{Monotremata.}

Tachyglossus. The only foramina are the f.f. diploëtica anterior and posterior, and the postaygomatioum. The anterior half of the canal connerting the former two lirs no external wall.

Ornithorhynchus. Postzygomatic large and passing through the zygoma; postsquamosal large; no other formini.

\section{Malisupiatita.}

The types of this order generally lave the postglenoid, and hardly ever have the supraglenoid or postparietal. They are generally distinguished by the presence of the subsquamosul, but ia Hypsiprymnus and Maeropus this foramen becomes the postsquanosal, through the failure of the postzygomatic crest. It need not be confounded with another foramen also found in these genera, which enter's above the meatus auditorius externus, and communicates with the tympanic chamber, and which I call the $8 u$ pratympanic forcmen. The subsquamosal enters the sinous caral, and in Phascolarctos, where the postglenoid is wanting, constitutes its only external outlet. The order is further characterized by the presence of the postzygomatic foramen.

Phascolomys; postzygomatic chamber enormous, extending above mea-

* Denkschriften Wiener Akademie, 185t, T. III, pl. 1.

$\dagger$ Most of these are preserved in my private collection; for a few I am indebted to the Museum of the Philadelphia Academy. 


\section{3}

tus. No foramina below, except supratympanic; above, a supraglenoid and one or two postglenoids.

Phascolarctos; subsquamosal and postzygomatic only: the latter communicating with an empty chamber.

Macropus and Hypsiprymnus; postglenoid, postzygomatic, supratympanic and postsquamosal ; the second communicating with a cliamber filled witli cancelli.

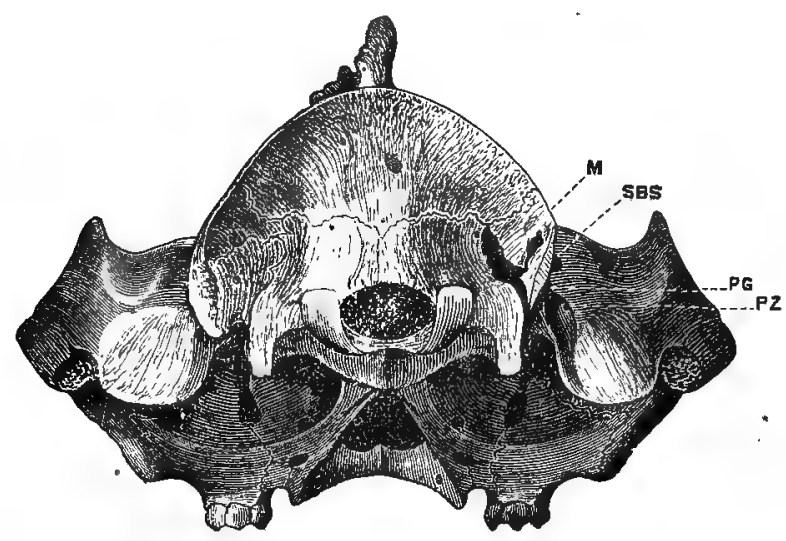

FIG. 1.-Skull of opossum (/helphys vwriniuna) latural size, posterior view, parts of the right mistoid and squitmosal bones removed. M, mastoid fora-men; SBS, subsquamosal ; PG, poslglenoid; PZ, postzygomatic foremen.

Didelphys; postglenoid, postzygomatic, sulusquamosal and mastoid ; postzygomatic small.

Dasyurus; postglenoid, subsquamosal and probably mastoid. I cannot fincl a postzygomatic:

Phalangista; postsquamosal and postparictal only; no posțygomatic nor supratympanic.

\section{Edentata.}

Tamandua; $F . f$. diploëtica anterior and posterior, and postsquamosal only.

Dasypus (6-cinctus); postwlenoid (large), postsquamosal, mastoid, sevcral postparietals, and a small subsquamosal.

Chlamydophorus ; a postiglenoid only.

Manis ; postzygomatic only.

Megalonyx; postsquamosal and supratympanic ; a closed fissure at position of postglenoid. A large foramen below the ustal position of mastoid.

Bradypus and Cholcepus; no fornmina. 


\section{RODENTIA.}

In this order, so far as yet observed, the supraglenoid and postparietal foramina are never present, while the mastoid is rarely, and the subsquamosal is generally, represented. The ridge connecting the zygoma with the inion being weak, the difference between this foramen and the postsquamosal is less marked in this order than in the Marsupialia. It is, however, always on the infelior border of the squamosal bone.

Lepus and Lagomys; no formina.

Lagidium; no foramina.

Cercolabes; no foramina.

Lagostomus, Geomys and Erithizon; an enormous postglenoid without internal canal.

Capromys, Cologenys, Sciurus, Haplodontice, Hesperomys, Mus ; postglenoid and postsquamosal only.

Hystrix, Hydrochærus, Neotome and Arvicola; postglenoid and postsquamosal foramina confluent; no others.

Castor, Cynomys and Spermophilus; postglenoid, postsquemosal and mastoid.

\section{INSECTIVORA.}

The foramina are very much as in the Rodentia in the smaller forms, and as in the Carnivora in the larger.

Blarina, Condylura and Scalops; postsquamosal only.

Erinaceus; postglenoid and postsquamosal only. Mystomys the same, according to Allnan's figures.

Centetes ; postglenoid, postparietal and mastoid.

Solenodon (from Peters' figures); postglenoid and postparietal.

\section{Chiropteria.}

In some members of this order the foramina are, as in inany Carnivora, limited to the postglenoid and postparietal.

Scotophilus (fuscus); postglenoid, postparietal and mastoid.

Pteropus; postglenoid, subsquamosal and postsquamosal.

\section{Calrivitira.}

In this order the foramina are few in number, and are very well defined. None of them possess more than three, while the specialized forms, both terrestrial and aquatic, do not possess them.

Trichecus and Arctocephalus; no foramina.

Phoca; a rudimental postglenoid.

Ursus, Arctotherium and Hycenodon; postglenoid, wastoid and postparietal. 
En'ydrocyon and Temnocyon; postglenoid and postparietal only.

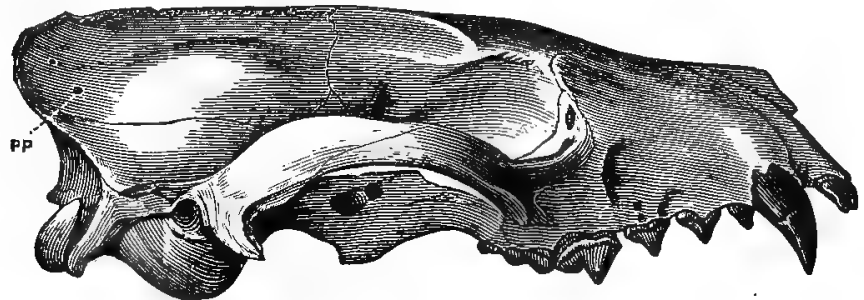

FIG. 2.-Temnocyon corvphaus Cope, Lower Miocene of Oregon; one-half natural size. $P P$, postparietal foramen.

Archablurus, Dinictis, Pogonodox, Hoplophoneus and Machcerodus (cereBratis); postglenoid and postparictal only.

Procyon, Nasua and Eassaris; postglenoid only.

Canis, Vulpes and Vrocyon; postglenoid only.

Viverra, Mustela, Putorius and Mephitis; postglenoid only.

Felis (domestica); sometimes a minute postglenoid only; sometimes none.

Hyæna, Encia, Cyncelurus ; no foramina.

\section{Prosimias.}

I.emur, Chirogaleus and Tursius; a postglenoid only.

Quadrumana.

Hapale; postglenoid and postsquamosal.

Cebus; postglenoid and postparietal. The latter is on the suture of the parietal and squamosal bones; in Hapale penicillata it is entirely within the squamosal bones.

Ateles, Callithrix, Mycetes, Semnopithecus and Cynocephalus; no foramina.

Macacus; a small postglenoid.

Troglodytes niger, gorilla; a closed fissure, but no foramen postglenoideuin.

Homo; no foramina in sixteen Nortl American Indians examined of the Klamath, Bannock, Crow, Sioux and Cheyenne tribes. One postglenoid on one side in a South Australian. One or two mastoids are more usual, being found in a good many specimens of all races. They are rarest in Hottentot negroes.

\section{Cetacea.}

Balcona, Beluga and Monodon; no formina.

Sirenia.

Halicore and Manatus; a huge mastoid only.

Hyrax; no foramina.

\section{Hyracoidea.}

Elephas; no foramina. 


\section{Peitissodactyla.}

In this order the number of the foramina ranges from very few to many.

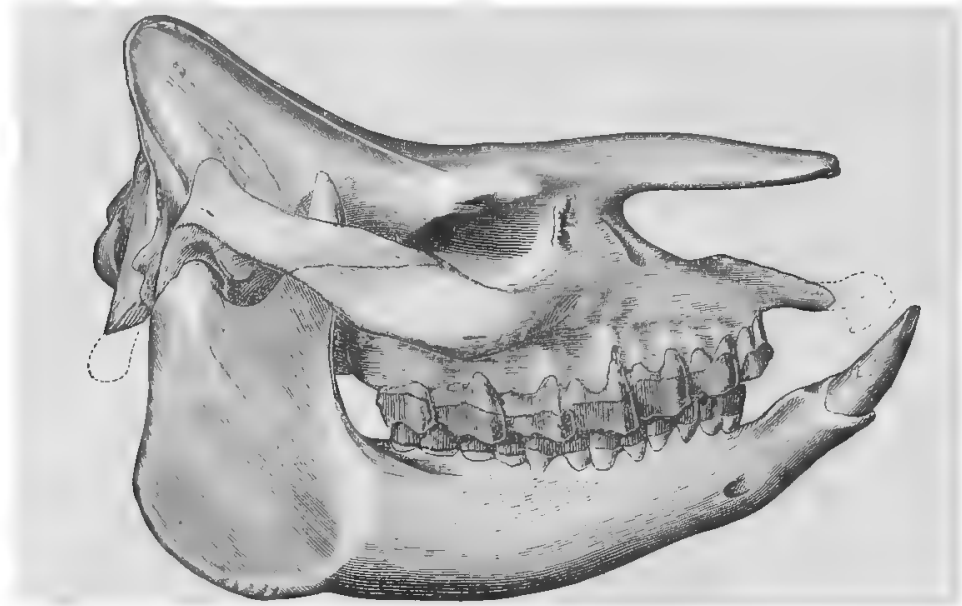

FrG. 3.-Aphelops megalodus Cope, Loup Fork of Colnrado; one-sixth natural si\%e; showing postparietal foramen.

Rhinocerus, Aphelops; postparietal only.

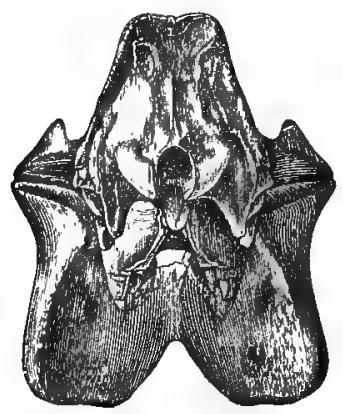

Fig.4.

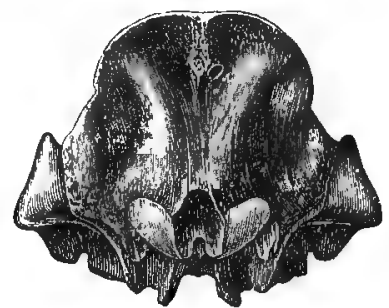

FIG. 5 .

Skkulls of Aphelops megalodus (Fig. 4) and A. fossiger (Fig. 5) from behind; onesixth natural size; showing absence of mastoid formen.

Tapirus; postparietal and a huge mastoid.

Anchitherium, Hippotherium, Protohippus and Equus; postparietal, postsquamosal, postglenoid and supraglenoid. In the last three genera the vessel issuing from the postsquamosal, grooves the petrous bone, leaving it at a point near that usually occupied by the mastoid foramen. In the second and last genera, and probably in the third, the sinous canal is protected by a bony crest in front, througliout its entire length. 


\section{7}

\section{ARTIODACTYia.}

Great diversities are found in this order, especially between the suilline and ruminant divisions. In the former, with the exception of the Hippopotamida, there are no foramina; in the Ruminantia they are more numerous than in any other vider of the class. The Ruminantia are, like the equine Perissodactyla, characterized by the presence of the supraglenoid foramen; to this the Comelide and some others add the mastoid. The Tragulina must be excepted from this rule, for they have nothing but the postglenoid.

\section{Omnivora.}

Sus, Dicotyles and Phacocharus; no foramina.

Hippopotamus and Chceropsis; postgleooid, postsquamosal, mastoid and a rudimental supraglenoid.

\section{Rumirantia.}

Tragulus; postglenoid only.

Oreodon; postparietal and mastoid. In one specimen of 0 . culbertsonit from Colorado, I find a minute supraglenoid on ench side; in other specimens it is wanting.

Poëbrotherium; postparietal, postgienoid; mastoid ; a small supraglenoid.

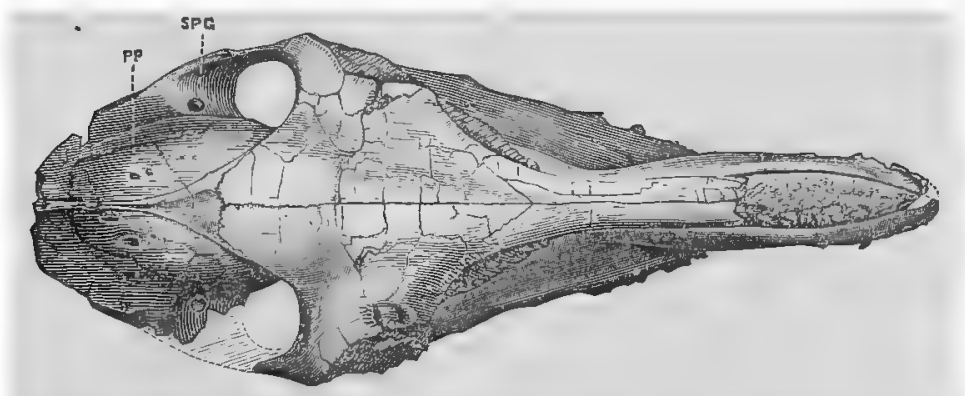

F'IG, 6.-Skull of Procamelus occidentalis reidy, Loup Fork of New Mexico; nne-fourth natural size; showing supraglenoid foramen, SPG.

Procamelus, Camelus, Auchenin ; postglenoid, supraglenoid and mastoid. Bos; postglenoid and supraglenoid only.

Antilocapra; postparietal, postglenoid, mastoid, and a large supraglenoid.

Giraffa; pos:glenoid, supraglendid, postsquamosal and mastoid.

Oreas, Ovis, Cervus: postglenoid, supraglenoid, postsquamosal, postparietal and mastoid.

From the preceding the following conclusions may be derived :

(1) The sinous formina furnish valuable dingnostic characters, and may, with proper limitation, be used in systematic definition.

(2) The primitive condition of the various mamınalian orclers appears to have been the possession of a limited number of these forminat. 
(3) The monotreme-marsupial line have developed a number of coramina in their own special way.

(4) The Rodentia have chicfly developed those of the inferior part of the squamosal bone, if any.

(5) The Curnivora commenced with but few foramina, and have obliterated these on attaining their highest development.

(6) The history of the Quadrumana is identical with that of the Carnivora.

(7) The Perissodactyla present very few foramina in the lowest forms, and did not increase them in the line of the Rhinocerida. In the line of the horses an increase in their number appeared early in geologic time, and is fully maintained in the existing species.

(8) In the Omnivornus division of the Artiodactyla, time las obliterated all the sinous formina. In the Camels an increased uumber was apparent at the same geologic period as in the history of the horses (White River or Lowest Miocene), and has been maintained ever since; while the existing Pecora present a larger number of the foramina than any of the class of Mummalia.

The only relation between these structures and the habits of the species concerned that can now be traced is, that the largest number of the foramina is found in the specialized vegetable feeders, while the smallest number is found in omnivorous forms.

I now give a synopsis of the distribution of the sinous foramina according to the foramina themselves. The $f . f$. diploëtica, postzygomatica and supratympanicum are not included, as their existence is restricted to the few types alrearly mentioned.

I. No foramina.

Homo, Troglodytes, Cynocephalus, Semnopithecus, Mycetes, Callithrix, Ateles.

Uncia, Hyona, Arctocephalus, Trichecus.

Elephas, Hyrax;

Sus, Phacochorus, Dicotyles.

Lepus, Lagidium, Cercolabes.

Cholcepus, Bradypus.

II. Postglenoid only.

c. Rudimental.

Felis; Phoca.

a.. Developed.

Chlamydophorus.

Lemur, Chirogaleus, Tarsius;

Macacus.

Mustela, Putorius, Mephitis; Vanis. Vulpes, Uiocyon; Viverra.

Procyon, Nasua, Bassaris.

Tragulus.

raa. Enormous.

Lagostomus and Geomys. 
III. Subsquamosal only.

Phascoluretos.

IV. Postsquamosal only.

Ornithorhynous, Tamandua, Blırina, Condylura, Scalops.

V. Postparietal only.

Rhinocerus, Aphelops.

VI. Mastoid only.

Halicore, Manatus.

TII. Postglenoicl and subsquamosal only.

Hystrix, Hydrochorus, Capromys, Cozlogenys, Scinurus, Haptodontice, Neotoma, Hesperomys, Mus, Arvicola.

VIII. Postglenoid and postsquamosal only.

Erineceus.

Macropus, Hypsiprymnus.

IIapale.

IX. Postglenoid and postparietal.

Chimoptera sp.

Temeryon, Enhydrocyon;

Archolurus, Dinirtis, Pogonodon, Hoplophoneus, Machcerodus. Cebus.

X. Mastoid ancl postparietal.

1.. Mastoid small.

Oreodon.

w. Mastoid enormous.

Trupirus.

XI. Mastoid, postglenoid and postsquamosal.

Castor, Cynomys, Spermophitus.

XIT. Mastoid, postglenoid and subsquamosal.

Dasyurus, Didelphys.

XIII. Mastoid, postglenoid and postparietal.

Scotophitus (fuscus).

Centetes.

Hycenodon. Ursus, Arctotherium;

XIV. Supraglenoid and postsquamosal only.

Ploascolomys.

$\mathrm{XV}$. Supraglenoid and postglenoid only.

Bos.

XVI. Supraglenoid, postglenoid and mastoid.

Procamelus, Camelus, Auchenta.

X.VII. Supraglenoid, postglenoid, mastoid, postparietal. c

o. Supraglenoid small.

Pö̈brotherizm.

r\%. Supraglenoid large.

Antilocapra.

XVIII. Supraglenoid, postglenoid, mastoid and postsquamosal.

\%. Supraglenoid small.

Hippopotamus, Ohceropsis. 


\section{- 10}

ar. Supraglenoid large.

Giraffa.

XIX. Supraglenoid, pustglenoid, postparietal and postsquamosal.

«. Supraglenoid small; mastoid not grooved.

Anchitherium.

3. Supraglenoid large, mastoid grooved.

Hippotherium, Protohippnts, Equus.

XX. Supraglenoid, postglenoid, postparietal, postsquamosal and mastoid.

Oervus, Oreas, Ovis.

Pubtished March 6, 1880. 




\section{(From the American Naturalist, December, 1880.)}

The Northern Wasatch Fauna.-The following species have been received from ${ }^{-} \mathrm{Mr}$. Wortman from the beds of the Wind River group, subsequent to the publication of my last notice of his - discoveries:1 (I) Esthonyx spatularius, sp. nov. Represented by five molar and premolar, and two incisor or canine teeth, apparently belonging to one individual. These are about the size of those of E. bisulcatus, but present several differences of detail. Thus the basin of the heel of the last inferior molar is not obliquely cut off by a crest which extends forwards from the heel, but is surrounded by an elevated border, which rises into a cusp on the external side. The incisor-canine teeth are more robust than those of E. bisulcatus, one of them especially haviny a spoon-shaped crown, with the concave side divided by a longitudinal rib, on which the enamel is very thin. The enamel descends much further down on the external than the internal side of these teeth. The rodentlike tooth does not accompany the specimen. Length of base of last inferior molar, .009; width anteriorly, .005; length of crown of canine-incisor No. I, .009; width of do. at base, .005; length of crown of second canine-incisor at base, .0I2; width of do., .006. (2) Didymictis leptomylus; represented by the posterior three inferior molars. These indicate a species of smaller size than the $D$. protenus, with the tubercular molar relatively narrower, and perhaps longer. The anterior part of the latter has the three cusps well defined and close together, and behind them is an oblique longitudinal cutting edge. The middle of the posterior margin rises into a tubercle. The anterior cusps of the tubercular sectorial are elevated; the heel has a strong external cutting edge and internal ledge. Length of tubercular sectorial, .009; width of do., .005; length of tubercular, .007; width of do. in front, .0035 . (3) Hyopsodus speirianus, sp. nov. Founded on a portion of a mandibular ramus supporting the last three molars in perfect preservation. It is distinguished by its very small size, since it is considerably less than the H. vicarius (H.? minusculus), and by the equality in size of the molars. The heel of the third molar is very small, and the two cones of the inner side of the crowns of all the molars are acute. The external crescents are very well defined; the anterior sending a horn round the anterior extremity of the crown. The posterior is connected with the corresponding internal tubercle by a median conic posterior tubercle. Length of true molar series, .008; length of second molar, .0025; width of do., .0022; length of last true molar,.0025; width of do., .00I6. Depth of ramus at second molar, .0043. Dedicated to my friend, Mr. Francis Speir, of Princeton, N. J., who, in connection with

1 Naturalist, Oct. (Sept.), I880, p. 745. 
Messrs. Scott and Osborne, has made important additions to our knowledge of the Eocene Vertibrata.-E. D. Cope.

Geological News.-Mr. Hébert has recently published in the Comptes Rendus an account of the geology of the British Channel. - The last number of the Palæontographica contains two important memoirs: Roëmer on a Carbonaceous chalk formation of the West Coast of Sumatra; and Branco on the development. of the extinct Cephalopoda.—M. Filhol having finished his work on the extinct Vertebrata of San Gerand le Puy, is about to publish one on those discovered at Ronzon.-The Powell Survey has just published Capt. Dutton's report on the Centrai Plateaus of the Colorado drainage.

Published December 9, 1880. 

(From the American Naturalist, February, 1881.)

Catalogue of Vertebrata of the Permian Formation of the United STÁtes.

\section{PISCES.}

\section{CROSSOPTERYGIA.}

Ectosteorhachis Cope; Pal, Bull., No. 32, i880, p. 19.

I. E. nitidus Cope; l. c. Texas.

Ctenodus Agass.

\section{DIPNOI.}

2. C. fossatus Cope; Proc. Amer. Phil. Soc. 1877, p, 54. Eastern Illinois.

3. C. gurleianus Cope; 1. c., p. 55. Eastern Illinois.

4. C. periprion Cope; Proc. Aner. Phil. Soc. 1878, p. 527. Texas.

5. C. porrectus Cope; l. c. Texas.

6. C. dialophus Cope; 1. c. p. 528 . Texas.

7. C. pusillus Cope; Proc. Amer. Phil. Soc., 1877, p. 19r. Eastern Illinois. Ptyonodus Cope; Proceed. Amer. Philos. Soc. 1877, p. 192.

8. P. vinslovii Cope; Proc. Acad. Philada. 1876, p. 410. Eastern Illinois.

9. P. paucicristatus Cope; Proc. Amer. Phil. Soc. 1877, p. 54. Eastern Illinois 
JanAsSA Münst.

\section{SELACHII,}

10. F. gurleiana Cope; Proc. Amer. Phil. Soc. 1877, p. 191. Eastern Illinois.

11. F. strigritina Cope; $S$. linguaformis Cope; 1. c. p. 53 , not of older authors. Eastern Illinois.

12. F. ordiana Cope; Texas.

Diplodus Agass.

13. D. ? compressus Newb. Eastern Illinois.

I4. D. sp. Texas.

ORTHACANTHUS Agass.

15. O. gracilis Newberry. Eastern Illinois.

16. O. quadriseriatus Cope; 1, c. p. 192. Eastern Illinois.

\section{BATRACHIA.}

\section{STEGOCEPHALI.}

Ganocephala Owen, Cope (emend.) Amer. Natur. i88o, p: 60.

Eryops Cope ; Proc. Amer. Phil. Soc. 1877, p. 188.

17. E. megacephalus Cope; l. c. Texas.

Trimeror hachis Cope; Proc. Amer. Phil. Soc. 1878, p. 524.

18. T. insignis Cope; 1. c. Texas.

ZATRACHYS Cope ; 1. c. p. 523.

19. Z. serratus Cope; 1. c. Texas.

PARToxys Cope; 1. c. p. 52 I.

20. P. ferricolus Cope; l. c. Texas.

Pantyi.us Cope; Bull. U. S. Geol. Surv. Terr. I88I (80). 21. P. cordatus Cope; 1. c. Texas.

Embolomera Cope, American Naturalist, 188o, p. 5 ro.

CRIcotus Cope; Proceed. Acad. Phila. 1876, p. 405.

22. C. gibsoni Cope; Proc. Amer. Phil. Soc. 1877 , p. 185 . Eastern Illinois.

23. C. heteroclitus Cope; Proc. Acad. Philada. 1876, p. 405. Eastern Illinois; Texas.

\section{REPTILIA.}

THEROMORPHA Cope; American Naturalist, 1878, p. 829.

Pelycosauria Cope; 1 . c.

\section{Diplocaulida.}

Diplocaulus Cope; Proc. Amer. Phil. Soc. I877, p. 187. 24. D. salamandroides Cope; l. c. Eastern Illinois.

Clepsydropida.

Pariotichus Cope; Proc. Amer. Phil. Soc. 1878, p. 508. 25. P. brachyops Cope; 1. c. Texas.

EcTOCYNODON Cope; 1 . c. 26. E. ordinatus Cope; 1. c. Texas.

ARCH ÆOBELUS Cope; Proc. Amer. Phil. Soc. 1877, p. 192.

27. A. vellicatus Cope; 1. c. Eastern Illinois.

L EPSYDROPS Cope; Proc. Acad. Philada. 1876, p. 404.

28. C. collettii Cope; 1. c. p. 407. Eastern Illinois.

29. C. vinslovii Cope; Proc. Amer. Phil. Soc. 1877, p. 62. Eastern Illinois.

30. C. pedunculatus Cope; 1. c. p. 63. Eastern Illinois.

31. C. natalis Cope; Proc. Amer. Phil. Soc. 1878, p. 509. Texas.

Dimetrodon Cope; Proc. Amer. Phil. Soc. I878, p. 512.

32. D. incisizus Cope; l. c. Texas.

33. D. rectiformis Cope; 1. c. p. 514. Texas.

34. D. biradicatus Cope; Bull. U. S. Geol. Surv. Terrs. 1880 (8I).

35. D. gigas Cope; 1. c. p. 515 . Texas.

36. D. cruciger Cope; Amer. Natur. 1878 , p. 830 . Texas.

Theropleura Cope; Proc. Amer. Phil. Soc. 1878, p. 5 rg.

37. T. retroversa Cope; 1. c. Texas.

38. T. uniformis Cope; 1. c. Texas. 
39. T. triangulata Cope; 1. c. p. 520. Texas.

40. T. obtusidens Cope; Pal. Bull. No. 32, I88o, p. 4. Texas.

Metrarmosajrus Cope; Proc. Amer. Phil. Soc. I878, p. 5 I6.

4I. M. fossatus Cope; 1. c. Texas.

EMBolophorus Cope; 1. c. p. 5 I8.

42. E. fritillus Cope; 1. c. Texas.

Lysorophus Cope; Proc. Amer. Phil. Soc. 1877, p. 187.

43. L. tricarinatus Cope; 1. c. Eastern Illinois.

\section{Bolosauride.}

Bolosaurus Cope; Proc. Amer. Phil. Soc. 1878, p. 506.

44. B. striatus Cope; 1. c. Texas.

Diadectidee Cope; Pal. Bull. No. 32, 1880, p. 8.

Dradectes Cope ; Proc. Amer. Fhil. Soc. 1878, p. 505.

45. D. sideropelicus Cope; 1. c. Texas.

46. D. phaseolinus Cope; Pal. Bull. No. 32, 1880, p. 9. Texas.

Empedocles Cope; Proc. Amer. Phil. Soc. 1878, p. 516.

47. E. alatus Cope; 1. c. Texas.

48. E. latibuccatus Cope; 1. c. Texas.

49. E. molaris Cope; Pal. Bull. No. 32, 1880, p. Io. Texas.

Helodectes Cope; Pal. Bull. II, No. 32, p. II.

5o. $H$. paridens Cope ; 1. c. Texas.

51. H. isaaci Cope; l. c. p. I2. Texas.

\section{SyNopsis.}

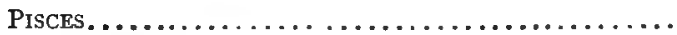

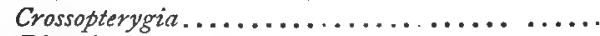

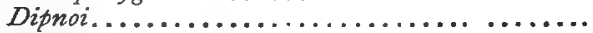

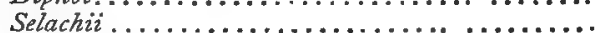

BatrachIA..........................

Stegocephali......................

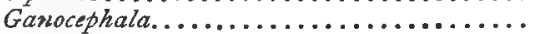

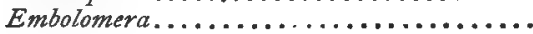

RePtilia..........................

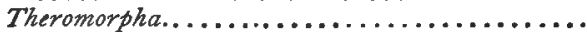

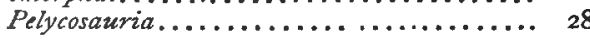

Total number of species.

Published February I, I88I. 
T H E

\section{Systematie Arrangement}

OF THE

\section{ORDER PERISSODACTYLA,}

WITH A NOTE ON THE

. STRUCTURE OF THE FOOT OF TOXODON. BY E. D. COPE.

(Read before the American Philosophical Society, April 15, 1881.) 

1881.]

[Cope.

The Systematic Arrangement of the Order Perissodactyla. By E. D. Cope.

(Read before the American Philosophical Society, Apric 15, 1881.)

\section{PERISSODACTYLA.}

This, the second great order of the ungulate Mammalia, naturally occupies a position between the Amblypoda and the Artiodactyla. Its lower forms are more specialized in the structure of the feet than the Amblypoda, while its highest types do not reach the perfection of structure seen in the Artiodactyla. This is particularly indicated by the form of the astragalus, which has but one, the tibial trochlea, and never displays the distal one characteristic of the cloven-footed families. The Perissodactyla occupy, as regards their dentition, a position parallel with the Artiodactyla. They are always superior in dental complication to the Proboscidia and the suilline Artiodactyla, but only one series, that of the horses, reaches the com- 
plexity of molars general in the Ruminantia. The dentition of the mass of the Perissodactyla might be described as intermediate between that of the Proboscidia and the lowest selenodont Artiodactyla.

The families of this order form a closely connected series, and the division of them into three divisions, the "Pachydermata," "Solipeda" and Perissodactyba, has no warrant in nature. Especially unnatural is the conjunction of the genera included under the first name, with the Proboscidia and certain suilline Artiodactyla, in a single order, as was proposed by Cuvier. The modifications of dentition from the simple type seen in Menodus, to the most complex, as in Equus, are close and consecutive. So, also, the gradual diminution in the number of digits from 5-4 to 1-1 can be traced through all the intervening stages.

The following definitions of families are applicable in the present stage of knowledge. Those of all but three were published in the Bulletin of the U. S. Geological Survey of the Territories, 1879 , p. 228. A modification in the diagnoses of the families Chalicotheriidas and Palcentheriida is now introduced:

I. Anterior exterior crescent of superior molars shortened, not distinguished from the posterior by external ridge; inferior molars with cross-crests ; premolars different from molars.

1. Toes $4-3 \ldots \ldots \ldots \ldots \ldots \ldots \ldots \ldots \ldots \ldots \ldots . \ldots \ldots$ Lophiodontido.

2. Toes $3-3 . \ldots \ldots \ldots \ldots \ldots \ldots \ldots \ldots \ldots \ldots \ldots \ldots \ldots \ldots \ldots \ldots$ Triplopodida.

II. Exterior crescents of superior molars as in I; inferior molars with cross-crests ; superior molars and premolars alike, with cross-crests.

8. Mastoid bone forming part of the external wall of the skull ......... Hyracodontida.

4. Mastoid bone excluded from the walls of the skull by the contact of the

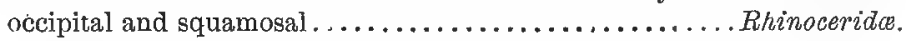

III. Exterior crescentoid crests of superior molars subequal, distinct; inferior molars with cross-crests.

5. Superior molars and premolars alike and with cross-crests ; toes $4-3 .$.

Tapirida.

IV. The external crescentoid crests of the superior molars subequal, separated by an external ridge; inferior molars with crescents.

A. Superior premolars different from molars; with only one internal cusp.

6. Toes 4-3; a vertebrarterial canal.............. Chalicotheriidas.

7. Toes 3-3; no vertebrarterial canal............. Macraucheniido. AA. Premolars like molars, with two internal lobes above.

8. Toes with digits, $4-3 \ldots \ldots \ldots \ldots \ldots \ldots \ldots \ldots \ldots \ldots \ldots \ldots \ldots \ldots$ Menodontides.

9. Toes with digits, $3-3 \ldots \ldots \ldots \ldots \ldots \ldots \ldots \ldots \ldots$ Palcootheriidco.

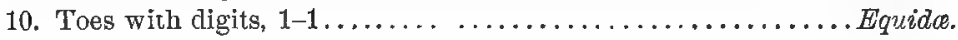


The genera included in these fumilies are the following. The table shows their geological distribution :

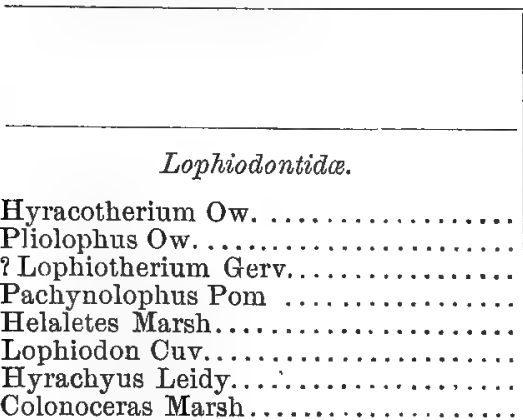

\section{Triplopide.}

Triplopus Cope

\section{Hyracodontida.}

Hyracodon Leidy.

\section{Rhinocerontida}

Aceratherium Kaup.

Conopus Cope

Diceratherium Marsh

Zis Cope

Aphelops Cope.

Ceratorhinus Gray...

Rhinocerus Linn.

Peraceras Cope....................

Attlodus Pom.....................

Colodonta Bronn.

Tapirida.

Listriodon Gerv.

\section{Tapirus Linn.}

Elasmognathus Gill.

\section{Chaticotheriidas.}

Rhagatherium Pict

Leurocephalus S. S. and $0 \ldots \ldots \ldots \ldots$

Palæosyops Leidy..................

Limnohyus Leidy.

Lambdotherium Cope...............

Propalæotherium Gerv.............

Chalicotherium Kaup.

Nestoritherium Kaup................

Meniscotherium Cope

\section{Macraucheniidos.}

Macrauchenia Ow.

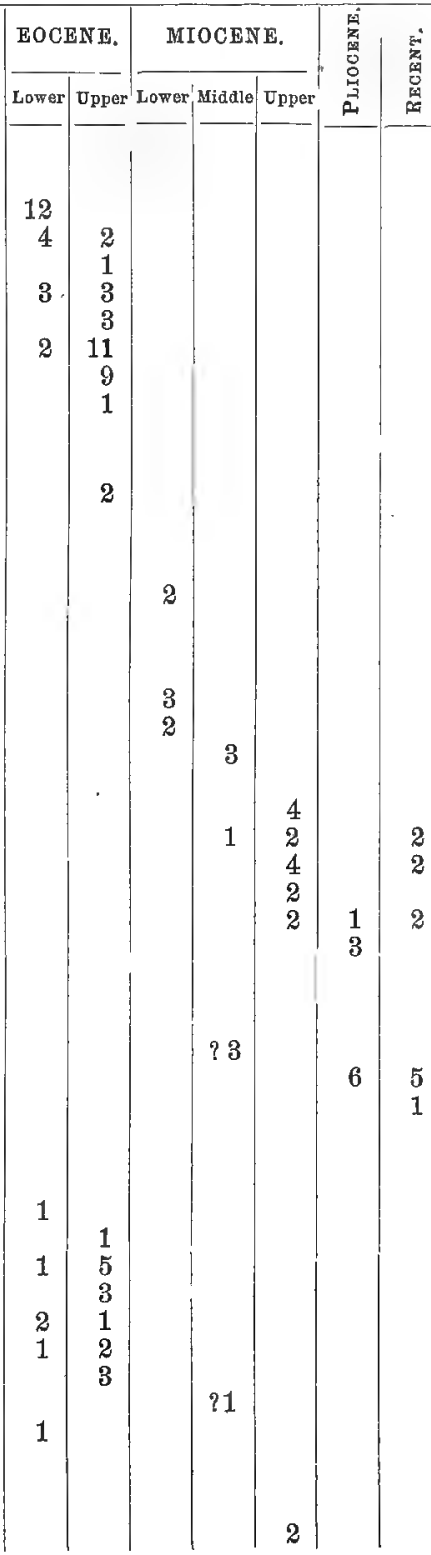

PROC. AMER. PHILOS. SOC. XIX. 108. 2v. PRINTED MAY 14, 1881. 


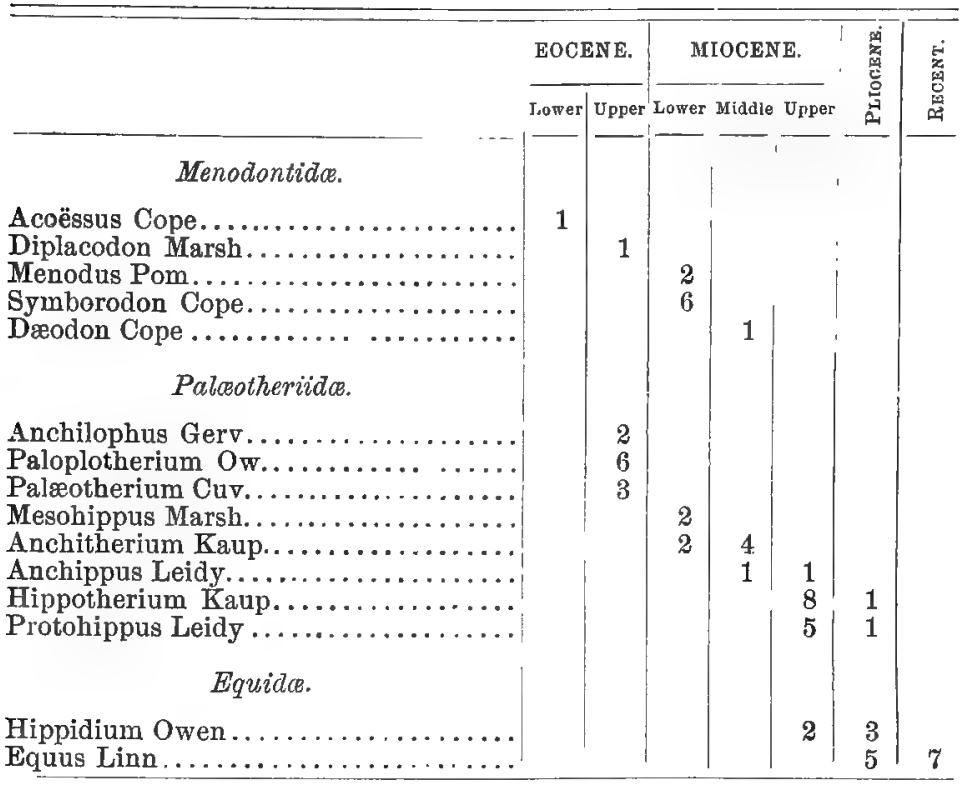

Total number of well determined species, one hundred and eighty-nine.

From the preceding table it can be readily seen that this order was abundantly represented during the Eocene period, and that the recent species are comparatively few. It may also be observed that certain families predominated during certain periods. Thus the prevalent Perissodactyla of the Eocene are Lophiodontidee and Chaticotherizdas; those of the Miocene are Rhinocerontidce and Paloeotheriidcs. The Tapiridas and Equidce characterize the latest tertiary epochs. A genealogical tree of the order may be constructed as follows :

Equidæ.

Rhinoceridæ. Palæotheriidæ.

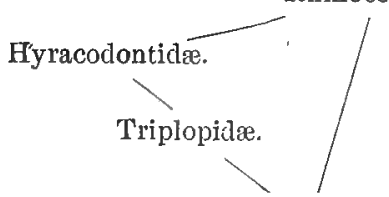

Lophiodontidæ.

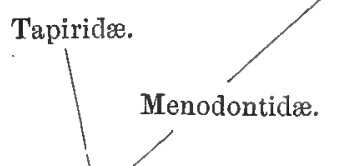

Chalicotheriidæ.

Hyracotheriinæ.

The types of the Lophiodontidoe and Chalicotheriida differ only in the two 
points of the separation, or non-separation, of the exterior crescents of the superior molars, as already pointed out. That no great modification of known forms (as Lambdotherium in the Chaticotheriida, and Hyracotherium in the Lophiodontidce) would be necessary to obliterate this difference, is quite clear. The parent types of the order, which present the most generalized dentition, Hyracotherium, Rhagatherium, and Acoëssus, were cotemporaries of the Lower Eocene epoch.

\section{LOPHIODONTID正.}

This family embraces a larger number of known species than any of the others of the order. With one exception, all the species belong to the Eocene period. They range from the size of a rabbit to that of an ox. They resembled most, among living animals, the tapirs.

The genera are characterized as follows :-

I. External lobes of superior molars well separated and little flattened; lobes of inferior molars scarcely united (Hyracotheriincs).

A. No diastema behind first premolar.

a. Third and fourth inferior premolar like the first true molar.

Last inferior molar with five lobes.................. Lophiotherium.

$A A$. A diastema behind the first premolar in both jaws.

a. Last inferior premolar different from first true molar ;

Last inferior molar with heel ; cross-crests of superior molars interrupted; Hyracotherium.

a.. Last inferior premolar like first true molar ;

True molars as in Hyracotherium.................... Pliolophus.

II. External lobes of superior molars flat, not well distinguished. (Lophiodontince.)

"A. No diastema in lower jaw.

Last inferior molar with third lobe ................... Helaletes."

$A A$. Lower jaw with diastema.

* No diastema behind first premolar.

a. No inferior premolars like the true molars.

Superior molars 7.

Last inferior molar with heel .................... Pachynolophus.

Superior molars 6 ;

Last inferior molar with heel...................... Lophiodon.

Last lower molar without heels, no horns .............. Hyrachyus.

Last lower molar?; "an attachment for a dermal horn on each nasal

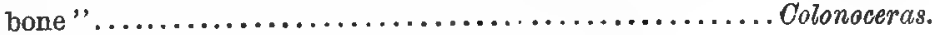

The geographical range of these genera is as follows :-

North America only....................Helaletes, Colonoceras. 
North America and Europe; Pachynolophus, Hyrachyus, Hyracotherium, Pliolophus.
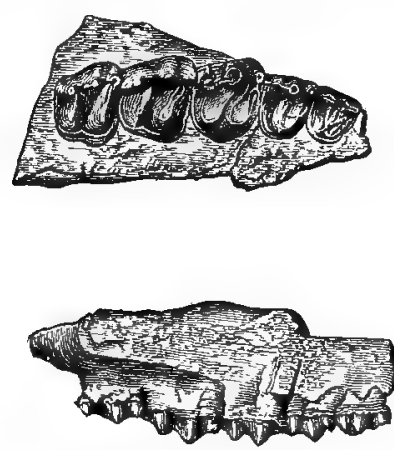

Fig. 1. Part of right maxillary bone of Pachynolophus singularis Cope; from the Wasuteh beds of New Mexico, from Capt. Wheeler's report iv ii pl. Ixvi.
Europe only ; Lophivdon, Lophiotherium.

Four of the genera ascribed to North America have come under my observation.

\section{TRIPLOPID $\mathbb{A}$}

Cope, American Naturalist, 1881, April (March 25th), p. 340.

But one genus of this family is known at present, but the number will probably be increased when the structure of the feet of various imperfectly known species is ascertained.

\section{TRIPLOPUS Cope.}

American Naturalist, 1880, p. 383 (April 27th).

Dental formula, I. ?; C. $\frac{1}{1} ;$ P-m. ; 釆; M. $\frac{3}{3} ;$ a considerable diastema anterior to the first premolar. Molars with only two vertical exterual ridges, the anterior cingular and the approximated median of the anterior crescent. Transverse crests two, uninterrupted and rather oblique; a ? third and short crest, on the posterior base of the first true molar. Premolars different from molars, the third and fourth with two transverse crests. Inferior molars with two transverse crests, as in Lophiodon, the last without heel.

An ossified inferior wall of the meatus auditorius externus. Posttympanic and paroccipital processes distinct form each other. No postorbital arch. Postparietal and mastoid foramina preserved; the latter large. Cervical vertebræ rather long; axis with subcylindric odontoid process. Scapula with small coronoid process. Great tuberosity of humerus long; curved. No trochlear crest on condyles of humerus; epicondyles rudimental. Ulna and radius distinct throughout their length ; ulnar articulation with carpus, small. Trapezoid bone of carpus with a facet for the trapezium. Unciform with two inferior facets. Metacarpals three principal ones, and one, the ifth, rudimental ; the distal extremities of the second and fifth opposite; the third a little longer.

The dentition of this genus is nearly that of Hyrachyus. The only exception is the possible third transverse crest of the first true molars*. The other portions of the skeleton known, are also much like those of Hyrachyus, with the exception of the number of digits of the anterior foot. The entirely rudimental character of the fifth metacarpal, which with its

* This point is further considered in the description of the species. 
digit, is so well developed in Hyrachyus, places Triplopus in another family, and in another line of descent. I think that it must be regarded as one of the forms of the series connecting the tapirs with the rhinoceroses. The fourth digit (the fifth) was retained by the earliest type of rhinoceros in Europe, the genus Aceratherium, but in America it appears to have been lost earlier. None of the American rhinoceroses of the Lower Miocene of the genus Canopus Cope present it, and in the present genus we have an ancestral type of the Eocene period, in which the last digit is already lost. The premolars of different structure from the true molars, exclude this genus from the Rhinocerontida, and with the character of the feet place it between that family and the Lophiodontides.

As yet, but one species of Triplopus is certainly known, but a second is placed in it provisionally.

\section{Triplopus cubitalis Cope.}

American Naturalist, 1880 , p. 383.

This species is represented by a nearly entire skull with lower jaw ; most of the cervical vertebræ; a left anterior limb nearly complete; a part of the left scapula, and a part of the right anterior limb ; all belonging to one animal. The specimen was not quite adult, as the last superior molar is just protruding its crown through the maxillary wall, and the last two superior milk premolars still remain in place, much worn and closely pressed by the overlying successional teeth.

The cranium is peculiar in its wide orbital region, and short compressed muzzle; the latter is damaged in the specimen so that the form of the nasal bones cannot be determined, except at their proximal portions. The interorbital space is plane in buth directions, and rises very gently posteriorly. The sagittal crest is narrow and low, until above the meatus auditorius, where it rises. Above the posttympanic process it bifurcates, and each rounded lateral lobe extends posteriorly to a point above the occipital condyles. Viewed from above the head is wide between the zygomatic fossæ, and at the posterior premaxillary teeth. The top of the muzzle narrows rapidly above the latter, but does not contract below until the first premolar is reached. The zygomatic arch is not convex along its middle, and encloses a narrow fossa. The superciliary border is prominent, and nearly straight, and is bounded by a notch behind. The squamosooccipital ridge is well marked. The posttympanic process is shorter than the paroccipital, and is separated from it by an open shallow groove, which is probably bottomed by the mastoid bone. The paroccipital process is much narrowed below and is turned a little outwards. There are two closely adjacent tubercles on the anterior border of the orbit, probably on the lachrymal bone.

Foramina. Only a few of these are well preserved; among the lost is the $f$. infraorbitale. There are two postparietal foramina on one side, and one on the other, above the point of origin of the zygomatic process of the squamosa' bone; and one in the usual posterior position. The postsquamosal has the same anterior position as the anterior postparietals, 
being immediately below them; I cannot discover whether there is a posterior one or not owing to injuries to the specimen. There is apparently a fissure-like one on the parieto-squamosal suture posteriorly. The mastoid is quite large, expanding downwards and outwards ; it is not so large as in a tupir, but much exceeds that in Hyrachyus eximius. The meatus auditorius externus is large, and occupies only the posterior part of the space between the postglenoid and posttympanic processes. It is enclosed anteriorly and below by the border of a wide element which may be tympanic. It encloses the petrous bone below in a bulla; as however the inner portion of the best preserved one is broken away, I cannot speak of its relations to the basioccipital bone. The foramen lacerum posterius is reduced to a jugular and perhaps another connected foramen by the close apposition of the petrous bone to the basioccipital for a considerable distance. The region of the $f . l$. medius is injured. Posterior to the $f . l$. posterius is a foramen opposite the base of the paroccipital process, anterior to the usual position of the $f$. condylordeum.

Mandible. The angle of the lower jaw is produced posteriorly, as in some species of Hyrachyus: cfr. figs. Vol. IV, U. S. Geol. Surv. Terrs. The coronoid process is long and is curved backwards to above the posterior border of the condyle. There is no tuberosity behind the condyle. The symphysis is quite contracted and is short. The mental foramen is below the middle of the inferior diastema. The ramus is compressed and at the same time strong.

Dentition. As the deciduous third and fourth premolar teeth, in a worn condition, remained in the maxillary bone, I removed them from one side, thus displaying the crowns of the corresponding permanent teeth. The first premolar may belong to the permanent dentition; the second is the deciduous. The former has two roots. The crown is cutting for a short distance anteriorly, but posteriorly it expands into a heel, much less developed than the internal lobe of the succeeding teeth. The crowns of the third and fourth premolars differ externally, as well as in their crests, from those of the true molars. The median-anterior and cingular vertical ridges are not so prominent as in the latter. The external crest is not divided into two by the notch in its grinding face. The anterior cross-crest, at its inner or distal extremity, is turned shortly backwards and then inwards, giving a "pot-hook" outline to its triturating surface. The fourth deciduous premolar presents a peculiar character already ascribed to the first true molar. This consists of a crest running parallel with the posterior transverse crest and close to it, along its posterior side. It forms the border of the tooth for a short distance, but as its direction is slightly obliquely forwards as well as outwards, the posterior cingulum appears for a very short distance.

The first true molar is subquadrate in outline. The anterior transverse crest commences at the middle-anterior ridge, and is first transverse, then directed a little obliquely backwards. The second crest commences at the apex of the posterior external crescent, leaving a wide posterior marginal 
fossa. Its internal extremity is broken off. Posterior to, and in contact with it, the posterior cingulum rises in a crest, which occupies the internal half only of the border. Its inner border is imperfect. It appears to me to be probable that the normal posterior crest is turned posteriorly on itself so as to give the "pot hook" shape seen in the anterior crest of the fourth permunent premolar. The corresponding accessory crest in the fourth temporary premolar appears to have been distinct at its internal extremity. The second true molar has a more oblique posterior external crest, and the posterior internal is oblique and simple. It has narrow anterior and posterior basa] cingula. There is no tubercle between the inner bases of the transverse crests of this or the last true molar. The latter is characterized by the rudimental character of the posterior external crescent crest, which is shortened like that of Byrachyus. The transverse crests are curved backwards; the posterior is short and simple.

The canines are small, and are directed forwards. The extremity of the muzzle being broken, the relation of the incisors cannot be stated, but there was not probably any precanine diastema. An incisor preserved has the crown transversely expanded, and rather oblique.

The third and fourth inferior premolars are the deciduous ones, and are both three-lobed, but differ in the forms of the anterior lobe. In the third, it is narrow and incurved, as in the corresponding permanent teeth of some Artiodactyla. The transverse crests of the true molars are rather oblique, running forwards as well as outwards.

Their external extremities are bent at right angles, and there results a short descending crest running forwards and inwards; the anterior one turns inwards, again forming a transverse anterior ledge. No cingula on internal or external bases of crown; a rudimental posterior one.

Measurements of Cranium.

Length from front of canine tooth to end of occipital

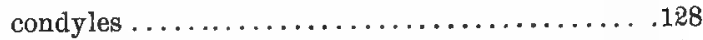

Length from same to postglenoid process.......... 096

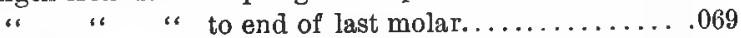

" " " $"$ " to first premolar.....................

" " " to line of front of orbit...............

Width between superciliary borders............. 046

" of zygomata at orbits................. .064

" of brain-case at glenoid surface............ .048

" of occipital condyles.................. .023

" of basioccipital bone between ossa petrosa...... .006

Distance between postglenoid and posttympanic pro-

cesses................................ .014

Depth of occiput behind......................... .

" of mandible from condyle................. .040

"s of mandibular ramus at third premolar......... .014

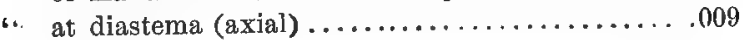

Least width of symphysis...................... 011 


\section{Measuroments of Cranium.}

M.

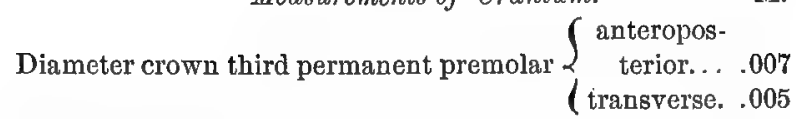

Anteroposterior diameter crown first premolar....... .0045

Diameters crown first true molar $\left\{\begin{array}{l}\text { anteroposterior..... .010 } \\ \text { transverse .........012 }\end{array}\right.$

Diameters crown second inferior true molar $\left\{\begin{array}{cc}\text { anteropos- } \\ \text { terior } & .011 \\ \text { transverse. } & .0075\end{array}\right.$

Diameter of root of inferior canine near crown........ .0035

Vertebro. The atlas is about as long relatively as that of the horse. Its transverse processes have more anteroposterior than transverse extent. The summit of the neural arch has a median ridge separating two grooves. The infelior surface of the centrum has a nearly median, obtuse hypa. pophysis. The axial facets are well separated below. The vertebrarterial canal pierces the base of the transverse process behind and below, and notches it deeply anteriorly. Above this notch the usual perforation of the arch is present. The axis is not relatively quite so long as that of the horse; it is a little longer than in Hyrachyus eximius; but rather shorter than in Hyracodon arcidens (Pl. CII, Fig. 17). The atlantal facets are spread well apart, and the articulating surface of the odontoid does not connect with them. The latter is rather long, is obtuse, and slightly recurved; it has no raised borders. Between the atlantal faces the inferior surface is plane. Posterior to this the middle line bears a prominent keel. The diapophyses are long, narrow and recurved, and each is pierced at the base by the vertebrarterial canal. The posterior articular face is but little concave, and a little oblique, and is a little wider than long.

The succeeding cervicals regularly diminish in length, and become more strongly opisthocelous, the seventh having quite a ball in front. The sixth has a slender diapophysis directed posteriorly, and quite distinct from the wide and long parapophysis which is directed downwards and outwards. The posterior angle of the latter extends as far back as the centrum. The seventh has only a flat transverse diapophysis. The first dorsal has a very stout diapophysis excavated below for the rib tubercle. The diapophyses of the third and fourth dorsals are not so stout. The capitular fossæ are large. The centra of the anterior dorsals are flattened below; they are concealed in part by the matrix in this specimen. The neural spine of the sixth cervical is narrow, and is directed forwards. That of the seventh is vertical, and narrows rapidly from a base which is rather wide anteroposteriorly. The spines of the dorsals are wider, and are directed gently posteriorly; they are probably long, judging from the size of their bases.

Measurements of Vertebrce.

Length centrum of atlas on side................027

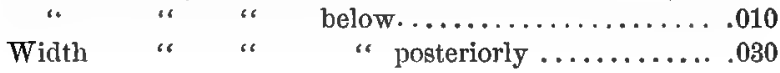




\section{Moasurements of Vertebroc.}

Width transverse process of atlas................ 010

Vertical diameter neural and odontoid canal.......... .015

Length axis to odontoid process.................. 033

$" \quad$ odontoid process........................ .007

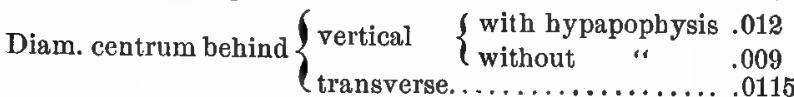

Length of centrum of fifth cervical. ...............030

" " seventh..................... 017

" " $"$ second dorsal............... 014

Anteroposterior diameter of base of neural spine of

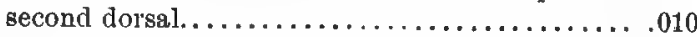

Expanse of head and tubercle of first rib..........,012

Fore Limb. - The greater part of the blade of the scapula is lost. The neck is stout, and the coracoid is a short aliform process. The humerus is moderately robust, most so proximally. The greater tuberosity is a strongly incurved crest, with truncate summit, which is a little elevated above the plane of the head, from which it rises rather abruptly. The bicipital ridges are not strong nor prominent. The olecranar fossa is deeper than the coronoid fossa, and they communicate by perforation. The inner part of the condyle is the largest, and forms an acute angle with the interior epicondylar surface. The exterior part of the condyle is divided by an oblique angle of the surface separating an external bevelled band of the same, which narrows to extinction on the posterior side. As compared with the humerus of Hyrachyus eximius, that of Triplopus cubitalis is very similar, differing mainly in two points at the distal extremity. The olecranar fossa is smaller and is less excavated, and its lateral bounding ridges are of unequal elevation; in $T$. cubitalis they are equal.

The ulna and radius are more than one-fourth longer than those of $H$. eximius. Although they are entirely distinct throughout, the ulna is quite slender anterior to the proximal third. The shaft is much more slender than that of Hyrachyus eximins. The olecranon is compressed, deep, and truncate behind. The distal epiphysis is remarkable for its length, being twice as long as that of the radius. The head of the radius is subequally divided by fossæ, the external being the shallower. The inferior or ulnar facet is regularly and gently convex downwards, and is bounded behind by a roughened ridge, which, near the external border turns backwards to the humeral border. The shaft of the radius is robust and flattened. The carpal facet of the radius is contracted, and has three times the superficial area of that of the ulna. The scapholunar dividing ridge is present, but is very low. The scaphoid face is the more excavated, and then rolls backwards, forming a very narrow posterior facet, which is narrower than that found in the species of Anchitherium. There is no distinct fossa on its inner or posterior border, as in many ungulates. The trapezium and scaphoid are the only bones of the carpus which are wanting. The latter

PROC. AMER. PHILOS. SOc. XIX. 108. 2W. PRINTED MAY 16, 1881. 
is probably wider than long or deep, while both the lunar and cuneiform are longer than wide. The cuneiform has not its external border excavated; its proximal surface is oblique and continuous, the ulnar and pisiform facets being in line. The pisiform is large, and is enlarged distally; its proximal facets are equal. The exposed face of the trapezoides is rather larger than that of the magnum, and is nearly as large as its own face of contact with the latter. The magnum has the usual great anteroposterior extension, with elevated posterior convexity applied to the fossa of the lunar. Its posterior process is long, nearly equal to the rest of the bone, and is depressed and flattened distally. The metacarpal facet is very concave. The unciform's anterior or exposed face is a little longer than wide. Its two proximal facets are about equal. It is about as deep as wide, and extends half its length distad to the magnum. Its posterior process is rather narrow; it is narrow and abruptly decurved. Distally, the facet for the fifth metacarpal is well marked, and has about half the area of that for the fourth metacarpal. The functional metacarpals are of moderate length as compared with the elongation of the ulnoradius. The third is largely in contact proximally with the uncifurm as well as with the magnum. The condyles are stout, and each is laterally impressed by a fossa. The second and fourth have chiefly lateral presentation, but are not much narrower in the shaft than the median metucarpal. The first phalange of the lateral digit is a little shorter than that of the median, while the seconds are of equal length. The extremity of the second digit reaches the proximal third of the length of the median ungual phalange. The fissure of the ungual phalange reaches the middle of its length. The fifth metatarsal is proximally rather stout; but it soon contracts to a thin rounded extremity, at ouly one-fifth the length of the fourth.

Measurements of Fore Limb. M.

Antero-posterior diameter of cotyloid cavity of scapulu. . ,015

Diameter of head of humerus $\{$ transverse................ 020

anteroposterior ..........019

" with greater tuberosity................. 030

Length of humerus on outer side..............110

Diameter humerus at epicondyles $\left\{\begin{array}{c}\text { transverse......... } \\ \text { anteroposterior ex- } \\ \text { ternally........... }\end{array}\right.$

Length of ulna ..............................165

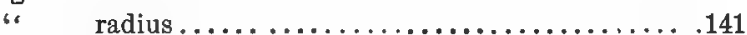

Depth of olecranon distally ................... 015

Width of ulna at coronoid ...................... .015

" " carpal facet (greatest).............. .007

" radius at head....................... 016

" " carpal facets....................014

، " " widest point distally............016

Length of carpus at magnum................. 015

" " unciform....................... 
Length of lunar............................ 010

Depth " $\ldots \ldots \ldots \ldots \ldots \ldots \ldots \ldots \ldots \ldots \ldots \ldots . . \ldots 11$

Length of magnum...................... 005

Depth " $\quad \ldots \ldots \ldots \ldots \ldots \ldots \ldots \ldots \ldots \ldots \ldots . . \ldots 17$

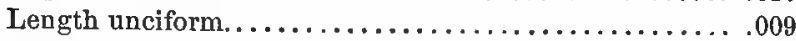

Width " $\quad \ldots \ldots \ldots \ldots \ldots \ldots \ldots \ldots \ldots \ldots \ldots \ldots . . \ldots 09$

Depth " (total) ...................... 014

" " of inferior facets................ 007

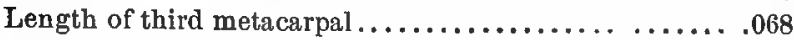

Proximal diameter third metacarpal $\left\{\begin{array}{l}\text { anteroposterior... } 008 \\ \text { transverse }\end{array}\right.$

Length of fifth metacarpal................... 012

" median series of phalanges............. .027

" first median phalange.................. .010

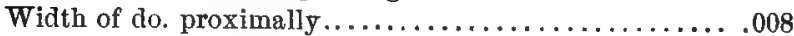

Length of second phalange.................. 006

Widths of median ungual phalange $\left\{\begin{array}{l}\text { proximally } \ldots \ldots \ldots .0070 \\ \text { medially ............ } \\ \text { greatest........... } 0075\end{array}\right.$

The bndy of this animal was about the size of that of a red fox. The legs were more slender or elevated, and the head of course was shorter and thick.

The unique specimen on which our knowledge of this species rests was cut from a block of calcareous sandstone of the bed of the Washakie basin of the Bridger Eposh, near South Bitter creek, Wyoming Territory. The bones are generally in the relation of the position in which the animal died. The neck is depressed and the left fore leg raised so as to be in contact with it, and the head is raised so as to clear the left wrist.

\section{Triplopus amarorum Cope.}

The characters of the fore-foot of this species being unknown, it is not possible to determine its generic position. It has, however, one of the well-marked characteristics of the genus Triplopus, in the osseous enclosure of the meatus auditorius externus, through the ossification of the external prolongation of the otic bulla, and tympanic cartilage. I cannot therefore refer it to Hyrachyus.

It is represented by a skull from which a large part of both maxillary bones and the mandible have been lost, and which is accompanied by parts of the ulna and radius, parts of the ilium, a femur, and tibia, and nearly all of the posterior foot of the right side. The posterior parts of both maxillary bones remain, and they support each, the last superior molar tooth from which the external wall has been broken away. The portions of molars remaining exhibit characters which lead me to suspect that the 
species does not belong to Hyrachyus. The anterior cross-crest of the molar preserved, is lobate, resembling the same ridge in the species of $A n$ chitherium. The posterior cross-crest is uninterrupted. If this species possesses affinity with Anchitherium, it will perhaps possess three digits of the manus, in which case it will be reterred to the Triplopida, in harmony with the indication furnished by the ear structure.

The Triplopus amarorum is much larger than the $T$. cubitalis, equalling the Hyracodon nebrascensis. It differs from the $T$. oubitalis in the stronger temporal ridges, and more elevated sagittal crest; also, in the shorter posttympanic process. The internal lobes of the last superior molar are connected by a basal ledge, not found in the $T$. cubitalis.

The interorbital space is wide and flat, and is most expanded at the postorbital angles.

From this point the face contracts rapidly forwards. From the same angle it contracts abruptly posteriorly to the rather narrow brain-case. The anterior temporal ridges are nearly transverse near the postorbital processes, and then converge more gradually, uniting opposite the posterior inferior border of the zygomatic tossa. The elevated sagittal crest diverges into two lateral supraoccipital crests, which contract as they descend, and continue to the extremities of the posttympanic processes. Although the postorbital angles are prominent, they cannot be called processes. The paroccipital processes are large, and are directed vertically downwards. They are separated by the usual concavity from the occipital condyles. The posttympanics are very short, forming only an angle projecting downwards at the anterior base of the paroccipitals, from which they are only separated by a notch. The inferior side of the tympanic bone is flat near the meatus, but opposite the stylomastoid fossa its posterior border is turned forwards, and is produced into a well marked process. It encloses a groove in front of it, which is continuous with the pterygoid fossa. The petrous bone is not inflated, and its inferior surface is divided into two longitudinal ridges. The inner is the less prominent, and is in close contact with the basioccipital. The postglenoid processes are robust and obtuse. The basioccipital is excavated in front of each of the condyles. The inferior surface is nearly flat, with a slight median keel. The pterygoid fossa is well defined, and is long and narrow. The posterior nareal trough is elongate, the descending pterygoid processes of the sphenoid originating as far back as the apex of the os petrosum. This species is especially characterized by the presence of an acute keel-like ridge, which extends horizontally above the foramina sphenoörbitale and opticum, and turns upwards anterior to the latter, terminating a half inch below the inferior base of the postorbital process. All the foramina are below it, but there is a fossa above it, opposite the interspace between the $f$. optioum and f. sphenoörbitale.

A supraorbital foramen pierces the frontal bone, a quarter of an inch within the superciliary border. There are five or six postparietal foramina, two of which are nearly on the squamosal suture. There is a postsqua- 
mosal foramen, and also a not very small supraglenoid foramen. There is a small foramen anterior to the optic, and in line with the posterior part of the postfrontal angle. The foramen opticum is large, and is $10 \mathrm{~mm}$. in front of the $f$. sphenoörbitale. The latter is separated by a lamina from the large and vertically oval $f$. rotundum. The latter is joined by the large alisphenoid canal, whose posterior orifice is as large as the furamen ovale. The latter is large, and is well separated from the $f$. lacerum anterius. The $f$. $f$. lacera are well closed up, the posterius being reduced to what is probably the jugular foramen. The $f$. condyloideum is large, and is an anteroposteriorly placed oval. Its anterior extremity is opposite to and well separated from the $f$. jugulare.

The nasal bones are spread out posteriorly, and their posterior extremities are truncate. The coronal suture passes downwards at the narrowest part of the cranium behind the postfrontal angles. The squamosal bone does not reach the frontal. The parietal does not extend so far posteriorly as the lateral occipital crests, except near the squamosal.

The characters of the last superior molars have already been mentioned. The posterior transverse crest is uninterrupted, but the anterior consists of closely united internal and median lobes. The division is marked on the posterior side, and on the edge of the crest; the anterior face is plane. The longitudinal external crest sends a strong protuberance into the head of the valley, which is grooved on its surface. There is a strong anterior basal cingulum which rises to an anterior cusp. On numerous surfaces the enamel is slightly rugose. The inferior canine teeth are in continuous series with the incisors, and are slightly larger than they.

Measurements of Skull.

M.

Length from line connecting anterior borders of orbits

to occipital crest.................... 0.132

Length from line connecting posterior borders of

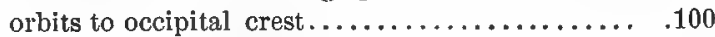

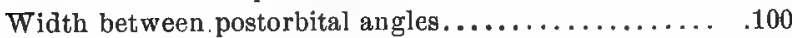

“ " anterior borders of orbits............ 076

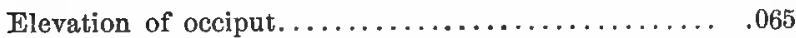

Width between mastoid ridges................ 065

" " ossa petrosa at middle............ .018

Diameters third superior true molar $\begin{cases}\text { anteroposterior... } & .0200 \\ \text { transverse...... } & .0205\end{cases}$

Diam. second superior true molar (base) $\left\{\begin{array}{cc}\text { anteroposte- } \\ \text { rior........ } & .0200 \\ \text { transverse... } & .0150\end{array}\right.$

The portion of ilium remaining exhibits a rather narrow neck and a concave external face. A fragment of the femur shows a prominent third trochanter, with an obtusely rounded apex. The distal part of the fibula is not coössified with the tibia. Its shaft is exceedingly slender. The angles bounding the trochlear grooves and ridges of the tibia are of sub-equal 
lengths. The median ridge is rather wide; the inner malleolus is narrow, has no distal facets and no distinct tendinous grooves externally.

The posterior foot is both relatively and absolutely smaller than that of Hyrachyus eximius. The trochlea of the astragalus is narrower and more deeply grooved. The crests are obtuse, and not so narrowed as in Mesohippus bairdi, nor are the malleolar facets of the astragalus so sharply defined as in the latter species. The external ligamentous fossa is, however, deep, and is bounded anteriorly by a low trihedral tuberosity not found in the $M$. bairdi. The head of the astragalus is not sessile as in $M$. bairdi, and has rather the proportions of $H$. eximius. The cuboid facet is a bevel of the external side of the distal extremity, as in H. eximius, and is not on a produced ledge, as in $M$. bair di. The internal tuberosity of the head is not as much developed as in either of the species named. The navicular face of the astragalus is horizontally divided by a shallow ligamentous fossa. The calcaneum is much like that of Hyrachyus eximius. The cuboid face is less oblique than in that species, in the anteroposterior direction, and is less crescentic in outline than in $M$. bairdi. The sustentaculum is rather more extended transversely than in $H$. eximius, but resembles that species more than the $M$. bairdi, in wanting the deep groove at its base on the inferior side, which cuts it off from the rest of the calcaneum. The remainder of the inferior surface is llat, and not grooved for a tendon as in $H$. eximius.

The remainder of the tarsus includes the usual five bones, the three cuneiforms being present. They are in general a good deal like the corresponding bone of Hyrachyus eximius. The navicular differs in having a low transverse ridge on its proximal face, which fits the groove of the astragalus already mentioned. The hook of the cuboid is large. The external (anterior) face of the mesocuneiform has one-third the superficial area of the anterior face of the ectocuneiform. The entocuneiform is rather large, and is flat and subsemicircular. Its position is externo-posterior. The ectocuneiform presents facets to both the second and fourth metatarsals, that with the latter the largest. The distal haives of the metatarsals are lost. At their proximal portions they are of subequal width, as in Hyrachyus eximius, but the lateral ones are rather narrower at the middles of the shafts.

Measurements. M.

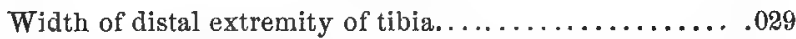

. astragalar face " $\ldots \ldots \ldots \ldots \ldots \ldots \ldots . . . \ldots 19$

Length of inner malleolus....................007

" astragalus on inner side ............... 030

Depth of trochlea " "

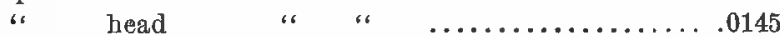

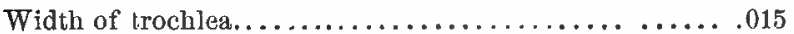

" navicular facet...................... 0195

Length of head from inner crest of trochlea......... 005

" calcaneum..................... .058 
Measurements.
Length of free part of calcaneum....................

Distal depth of the calcaneum...................

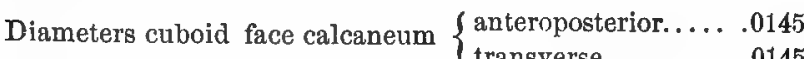

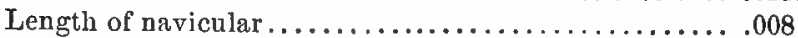

" cuboid ........................ 0145

Transverse proximal width of three metatarsals ...... .027

Diameters of secoud metatarsal $\{$ anteroposterior....... .014

$\{$ transverse ............007

Antero-posterior diameter of third metatarsal.......... .0145

Diameters of fourth metatarsal $\left\{\begin{array}{l}\text { anteroposterior........ } 014 \\ \text { transverse.......... }\end{array}\right.$

This species was obtained in 1873 from the bad lands of South Bitter creek, Wyoming, from the Washakie basin of the Bridger formation. The locality is the same as that which furnished the Triplopus cubitalis, the Achonodon insolens, etc.

\section{HYRACODONTID}

This family, which I characterized in 1879, includes, so far as yet known, the single genus Hyracodon, which is found in the Oligocene White river formation of North America. According to Marsh, the digits of this genus number three on both anterior and posterior limbs. It has a full series of incisor teeth in both jaws.

\section{RHINOCERID Æ.}

This extensive fumily has left representatives in all parts of the Northern Hemisphere, and species still exist in the Old World. From the following table the range of variation of its genera can be readily seen :

I. Four anterior digits.

Incisors $\frac{2}{1}$; canine $\frac{0}{1}$; no horn ; posttympanic bone distinct. Aceratherium. II. Three anterior digits.

a. Posttympanic process not coössified with postglenoid.

Incisors $\frac{2}{1}$; canines $\frac{0}{1}$; no dermal horn ................. Conopus.

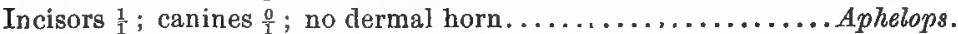
Incisors $\frac{0}{1}$; canines $\frac{0}{1}$; no dermal horn........................... Incisors $\frac{1}{1}$; canines $\frac{0}{1}$; a tuberosity for a dermal horn on each nasal bone.

Diceratherium.

Incisors $\frac{1}{1}$; canines $\frac{0}{1}$; a median dermal nasal horn ......... Ueratorhinus.

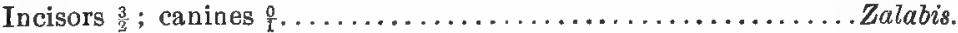
Incisors $\frac{0}{0}$; canines $\frac{0}{0}$; dermal horn median ; no osseous nasal septum....

aa. Posttympanie process coösified with postglenoid ;

Atelodus.

Incisors $\frac{1}{1}$; canine $\frac{0}{1}$; dermal horn median; nasal septum not ossified....

Rhinocerus.

Incisors $\frac{0}{0}$; canine $\frac{0}{6}$; dermal horn median; nasal septum ossifed....... 
It can readily be seen that the genera above defined form a graduated series, the steps of which are measured principally by successive modifications of four different parts of the skeleton. These are, first, the reduction of the number of the toes of the auterior foot; second, the reduction in the number and development of the canine and incisor teeth; third, the degree of closure of the meatus auditorius externus below ; and, fourth, in the de- velopment of the dermal horns of the nose and its supports. While these characters have that tangible and measurable quantity which renders them available for generic diagnosis, there are others which possess a similar significance, and which I have noticed in an article published in the bulletin of the U. S. Geological Survey of the Territories for September 1879.

This series may be represented in genealogical relation, as follows :*

\section{Colodonta.}

Rhinocerus.

Atelodus.

Ceratorhinus. Peraceras.

Zalabis.

Cœropus.

Diceratherium.

The early type, which corresponds most nearly with Conopus, and which preceded both it and the Aceratheria in time, is the genus Triplopus Cope, which has left a species in the Upper Bridger of Wyoming. Here the incisors are probably $\frac{3}{3}$ and the canines $\frac{1}{1}$. This formula is that of the Eocene tapirs, where the normal numbers $\frac{3}{3} \frac{1}{1}$ prevail. Triplopus further differs in the primitive condition of the premolars above, which, as in the Lophiodontida, differ from the molars in their greater simplicity. Thus it is probable that tapirolds, probably Lophiodontidoe, gave origin to the Rhinocernde, as Marsh las suggested. And it is further altogether probable that the general type of deutition presented by the Rhinocerida, Lophiodontido, etc., which I have named the palæotheriodont, took its origin from the type which is intermediate between it and the bunodont, viz, the symborodont, as I have pointed out in an essay on this subject.

The first appearance of dermal horns was apparently in a pair placed transversely on the nasal bones, in species of Eocene Lophiodontida of the genus Colonocercrs. The same character has been observed by Marsh in species of the Lower Miocene, which probably belong to the true Rhinocerida, and which he has called Diceratherium. This genus appears to have terminated the line exhibiting this structure, and the family in North America remained without horn. As we have seen, the types possessing the median horn arose in Europe, in the Ceratorhinus schleiermacheri of the Middle Miocene, and still survives.

* See American Naturalist, 1880, p, 611. 
1881.]

[Cope.

It may be observed in conclusion that a successive increase of size in the species of this line has taken place in North America with the advance of geologic time. Thus, their probable ancestors of the genus Triplopus were the least of all. The Ocenopoda of the White River formation were larger ; the oldest $C$. mite, being the smallest. The Aphelopes of the Loup River or Upper Miocene formation were all larger, and were nearly equal to the large existing species.

\section{TAPIRID $\approx$.}

The genera of this family are not numerous as yet. The oldest, Listriodon, appears in the Middle Miocene (Gers, France), and Tapirus is first found in the Upper Miocene (Epplesheim). The recent species of the family belong to Tapirus L., and Elasmognathus (Gill). A small species, the Tapirulus hyracinus Gerv., is from a bed at Perreal, France, which Pictet has identified with the gypsum of Paris (Oligocene). It is sometimes referred to this family, but is not sufficiently well known to determine its position. In America, Listriodon, or a genus which has not yet been distinguished from it, is found in the Miocenes.

The three genera are distinguished as follows:

Three anterior premolars different from fourth premolar and true molars; last inferior molar with heel........

Listriodon.

One superior premolar different from true molars; no heel of third inferior molar; nasal septum cartilaginous....

Tapirus. Like Tapirus, but nasal septum osseous.............Elasmognathus.

\section{CHALICOTHERIID无.}

Gill ; Cope, American Naturalist, 1881, p. 340.

This family had numerous representatives during Eocene time, and a few species of Chaticotherium extended into Miocene time. The boundaries which separate the family from the Lophiodontidcs on the one hand and the Menodontidas on the other, are not always easy to determine. From the former the symmetrically developed external Vs of the superior molars, and the double Vs of the inferior molars distinguish it. Yet in $R h a g a-$ therium the external $\mathrm{Vs}$ are not so well distinguished as in other Chalicotheriidas; and in Propalcotherium, the anterior cingular cusp produces a part of the assymmetry found in the Lophiodontides. The character of the double inner cusps of the superior premolars, which distinguish the Menodontide, is only applicable to the last premolar in Diplacodon of the latter, while a trace of the additional cusp of this tooth is found in the Chalicotheroid Nestoritherium.

In using the following table it must be borne in mind that the number of the toes has been determined in a very few of the genera. Should any of them prove to have but three digits on the anterior foot, such genera must be referred to a new family intermediate between this one and the Palasotheriidos.

Proc. AMer. Philos, soc. XIX. 108. 2X. PRINTed May 16, 1881. 
I. Internal cones of superior molars separate from external lobes.

$A$. Cusps of inferior molars not completely united;

$\alpha$. External lobes of superior molars more or less conic.

Inferior premolars III and IV compressed, three lobed; a diastema both

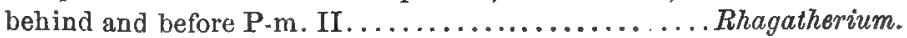

$A A$. Cusps of inferior molars united into two Vs.

a. Incisors present.

ק. No diastema in front of second inferior premolar.

Second premolar without inner lobe; last molar with one inner cone.....

Leurocephalus.

Second premolar with inner cone; last superior molar with an inner cone................................ Palososyops.

Second premolar with inner cone; last superior molar with two inner

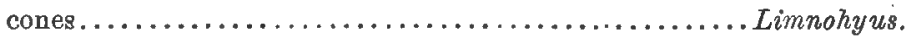

$\beta \beta$. A diastema in front of second inferior premolar.

Two inner cones of last superior molar............. Lambdotherium. ac. Incisors absent from both jaws.

Last superior molar with one internal cone........... Nestoritherium.

II. One or both internal cusps of superior molars united with the external lobes by cross-crests.

a. External cusps of superior molars more or less conic ;

An anteroexternal cingular cusp................. Propabootherium. $\alpha \alpha$. External lobes of superior molars, inflected Vs.

$\beta$. No crescentic inner lobes.

No intermediate lobes Ohalicotherium.

$\beta \beta$. One or more lobes of each molar crescentic.

Intermediate lobes, and one internal cone of superior molars...........

Meniscotherium.

The following regions have thus far furnished species of the above-mentioned genera :

Europe-Rhagatherium, Propalaotherium, Chalicotherium.

N. America-Leurocephalus, Palcosyops, Limnohyus, Lambdotherium, Meniscotherium.

Asia-Nestoritherium.

Of the American genera, Leurocephalus S. S. \& O. has been found by the Princeton exploring experition of 1877 in the Bridger formation, but I have not met with it myself. Meniscotherium Cops, is known from a single species found by myself in the Wasatch formation of New Mexico, and described in my report to Capt. G. M. Wheeler (1877). 


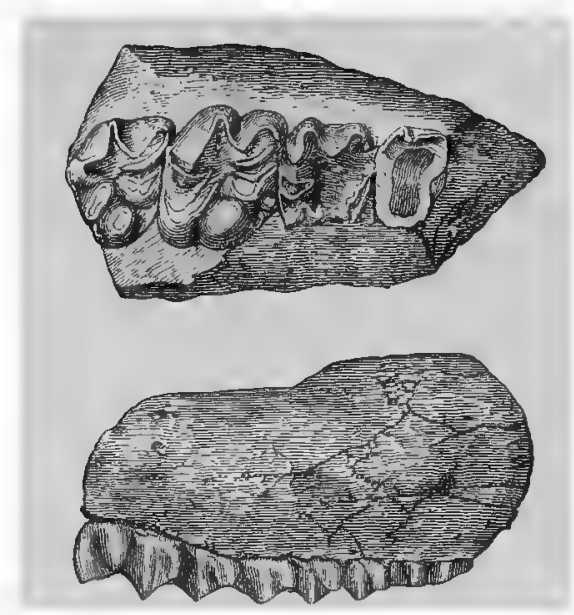

FIG. 2. Part of right maxillary bone of Meniscotherium chamense Cope, from the Wasatch bed of New Mexico. From Report Capt. G. M. Wheeler, IV, ii, Pl. LXVI.

\section{MENODONTID正.}

The known genera of this family are not numerous. They are defined as follows:

I. Vs of inferior molars probably incomplete; superior molars with intermediate tubercles.

Internal cusps of superior molars well separated............... Acoëssus.

II. Inferior molars with the crowns thrown into two Vs; superior molars without intermediate tubercles.

a. Last superior premolar only with two inner tubercles.

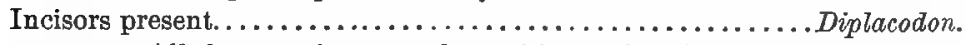
aa. All the superior premolars with two interior cusps.

Six inferior incisors, canines very large................. Doodon. Six inferior incisors; canines very small ................... Menodus. No inferior, and four small superior incisors ; canine very small.........

Symborodon.

The first appearance of this family was in the Early Eocene in the genus Acoëssus Cope, which was a cotemporary of Hyracotherium, and which it resembles in some respects. Its typical species was called Hyracotherium siderolithicum by Pictet, its describer, but Kowalewsky has already expressed the opinion that the species does not belong to that genus. It is from the Lower Eocene of Mauremont, Switzerland. The remaining genera are, as yet, American, excepting one, which is represented by all Austrian species, not yet well known. Diplacodon, in its simpler premolars, approaches the Chalicotheriida, and is the oldest of the American genera. It is from the Uinta or Upper Eocene. Menodus and Symborodon, which include some species of gigantic size, belong in the White river or Oligocene, while Dasodon has so far unly been obtained from the Truckee or Upper Oligncene. 


\section{MACRAUCHENIID Æ.}

But one genus of this family is known at the present time. The following are the dental characters of Macrauchenia. Formula: I. $\frac{3}{3} ;$ C. $\frac{1}{1}$; P.m. $\frac{4}{4} ;$ M. $\frac{3}{3}$, forming an uninterrupted series. The superior molars present two external Vs, and two oblique transverse crests, somewhat as in Palcotherium. The spinous foramina pierce the neural arch of the dorsal vertebræ (Gervais). There is no intertrochlear crest of the humerus, but the carpal facets of the radius are well distinguished. The internal malleolis is small, but the fibular malleolus is coosssified with the tibia at an early age, and articulates with the calcaneum. The trochlea of the astralagus is well developed. The lateral digits are large, and the distal keels of the metapodials are continued on the anterior face of the condyle.

The position indicated by the above characters is a remarkable one. The uninterrupted dental series and the absence of intertrochlear humeral crest, are primitive features among ungulate Mammalia. The radiocarpal articulation is facetted as in higher ungulates, but lacks the inferior condyloid face of those types. The completeness of the metapodial distal keels is a feature of high specialization, only seen in the Equide of this order. The coössification of the external malleolus is also a character peculiar to the Equida among the Perissodactyla. There are two other characters which are not elsewhere found in this order, viz: the articulation of the fibula with the calcaneum, and the absence of the vertebrarterial canal. The former belongs to the Artiodactyla generally, and to the Proboscidæ, and the latter to the ruminant family of the Camblidos. Thus the Macruucheniidas stand out as one of the most distinct of the families of the Perisso. dactyla, and one to which we may anticipate considerable accessions in future.

But two species of Macrauchenia are known, a larger, $M$. patachonica, and a smaller, M. baliviensis, both from the Pliocene formation of South America.

\section{PALAOTHERIID平.}

This family has been already defined on page 378. In its complex premolar teeth, which in the upper jaw resemble the molar's in composition, it shows an advance over the Chalicotheroid and other genera of the Lower Eocene. In fact, it has not been found in the Lower Eocene, but commences in the Upper Eocene in the genera Palaotherium and Paloplotherium. Thence it extends to the very summit of the Miocene, and may even occur in the European Pliocene (Protohippus). Its members exhibit considerable range of variation in the details of the teeth and feet, but no striking break of family importance occurs. The most noteworthy interruption is that which is found between the Palcotherincs and Hippotheriino, where there is a change in the form of the proximal extremity of the humerus from a tapiroid to a horse-like form, and a modification of similar significance in the molar teeth, by the addition of a deposit of cementum. 
The characters of the genera are as follows :

I. Palcotheriina. Bicipital groove of humerus simple; teeth without cementum.

a. One or more internal tubercles of superior molars distinct.

External Vs of superior molars not well distinguished externally.........

Anchilophus.

External Vs separated by a vertical rib; intermediate tubercles not con-

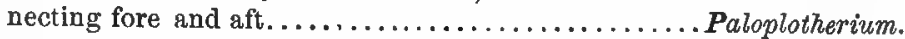

External Vs separated; intermediate tubercles extended fore and aft.....

Anchippus.

$a \alpha$. Internal tubercles of superior true molars continuous with the transverse ridges.

Inferior molars with two Vs only; lateral toes large.........Palceotherium.

Inferior molars with distinct internal tubercles; lateral toes small ; a short

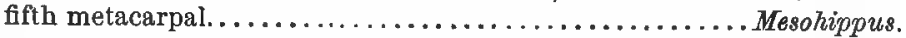

Inferior molars with cusps at the inner extremities of the $\mathrm{Vs}_{\mathrm{s}}$; lateral toes small; no fifth metacarpal.................... Anchitherium,

II. Hippotheriinas. Bicipital grooove of humerus double; molars with cement in the valleys. (Intermediate tubercles connected fore and aft.)

a. One or more internal tubercles of superior molars distinct.

Inner lobes of inferior molars enlarged............... Hippotherium. $a \alpha$. Internal tubercles of molars not distinct,

Inner lobes of inferior molars enlarged .............. Protohippus.

The genera of this family are generally of less antiquity than those of the Chalicotheridide, and they range from the Middle Eocene to the Pliocene. Paloplotherium is found in the Middle Eocene, and is, as might have been anticipated, more nearly allied to the Chalicotheriidoe than any other genus of this family. Propalcotherium is not far removed from it. $A n$ chilophus is upper Eocene, and is allied to the genus just named, and also to Puchynolophus among the Lophiodontida. These early genera constitute by their similarity, the bond of connection between the three farnilies which in their later and specialized forms are very different from each other. Palosotherium is chiefly found in the Upper Eocene, and Mesohip. pus is only known from the White river or Oligocene, an age between Eocene and Miocene. Anchitherium commences in the Middle Miocene and has Anchippus for a cotemporary. Hippotherium existed only in the latter part of the Miocene Epoch, consistently with the greally specialized structure of its limbs and teeth, and the nearly allied Protohippus lived with it; while in Europe a species with the same type of molar teeth is found in the Pliocene epoch (Forsyth-Major). These forms were cotemporary with the Equidos, which outlived then. They have many points of resemblance to that family, but nevertheless remain at a considerable interval from them in the structure of the feet. 
The geographical distribution of these genera, so far as present knowledge shows, is as follows:

North America alone-Mesohippus, Anchippus.

North America and Europe-Anchitherium, Hippotherium, Protohippus. Europe only-Anchilophus, Paloplotherium, Palaotherium.

\section{EQUID画.}

The two genera of this family are distinguished as follows :

Internal lobes of superior molars subequal.............. Hippidium. Anterior internal lobes of superior molars much larger than the pos-

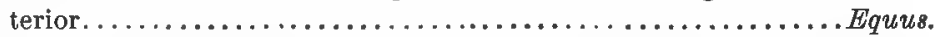

The genus Hippidium is extinct, and its species have been thus far found only in North and South America, in beds of Pliocene age. Equus made its appearance during the same period, and is represented by several existing species.

Besides the reduction in the number of digits, which is carried farther here than in any other family of Mammatia, there are several other characteristics of specialization. Thus in the dentition, the spaces between the tubercles are filled with cementum. These valleys are generally deep, owing to the prismatic forms of the molars. The cups of the incisors are completely developed, and also filled with cementum. There are two bicipital grooves of the humerus. The preceding characters are also found in the Hippotheriince of the Palcootheriida.

The Equida adds another evidence of greater specialization than the latter group in the structure of its feet, $i$. e., the distal metapodial keels are completed forwards, as in most ruminants.

The similarity of the modifications which have supervened on the Artiodactyle and Perissodactyle lines in attaining their most specialized extreme has often been noticed. I repeat them here in tabular form in three columns. These show (Table I) the modifications in which the Equidos and Bonidas are identical or nearly so, which place them at the heads of their respective orders; Table II, those in which the Equidos are the more specialized of the two ; and Table III, those in which the Bovido displays the highest differentiation. 
1881.]

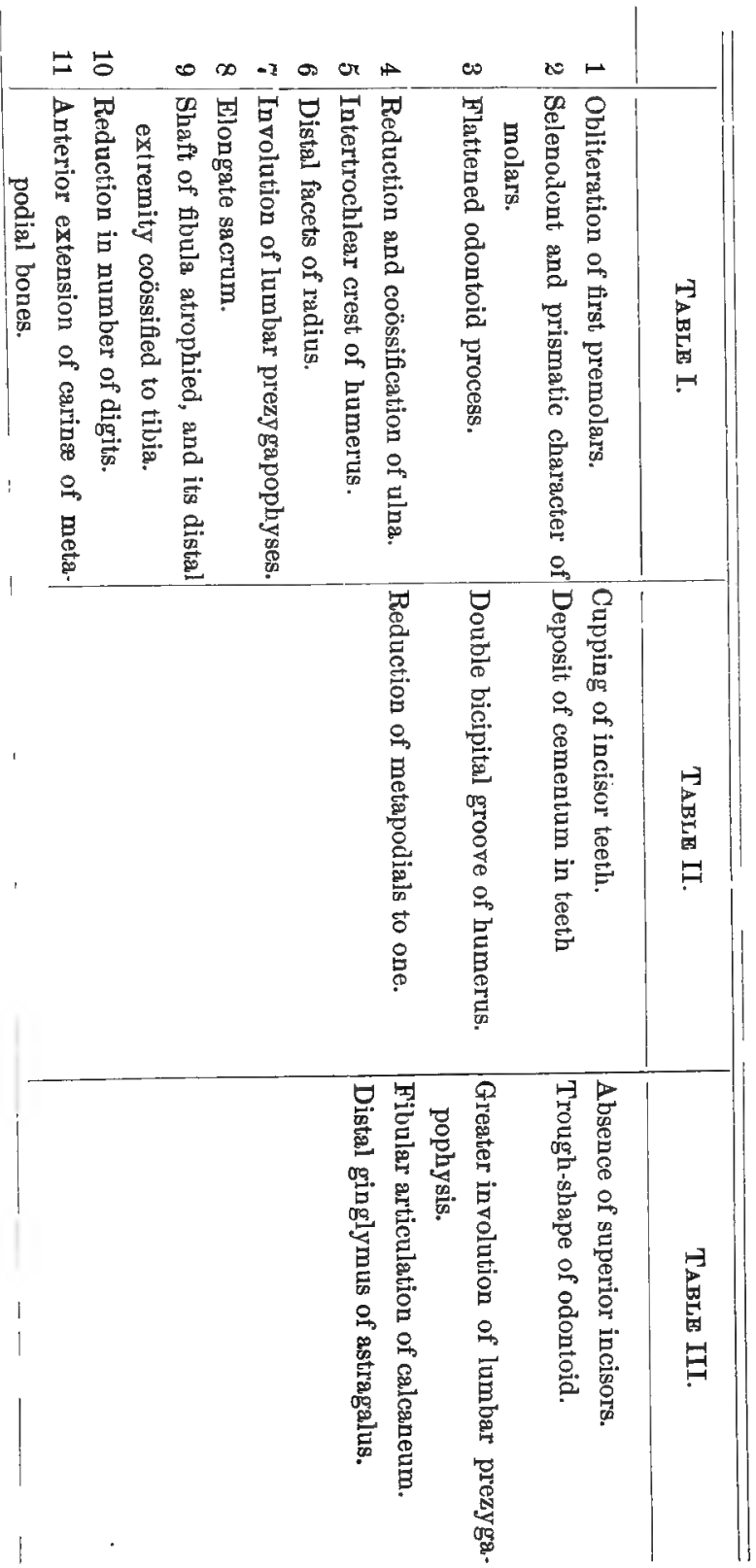


Note on the Structure of the Posterior Foot of Toxodon. By E. D. Oope.

The position of the genus Toxodon in the system of Mammalia, is a question upon which few authorities have expressed positive opinions, and which is generaily regarded as still an open question. In the lack of certainty on the subject, a separate order, the "Toxodontia," has been proposed for its reception. It is known that the genus is ungulate, but the opinions of authors are much divided as to its relations to the three principal orders included under that head. Resemblances to the Probosciden have been detected, but Professor Gervais (Comptes Rendus, 1878), asserts that there is a close resemblance to the genus Hippopotamus in the structure of the posterior foot.

Having come into possession of remains of Toxodon, which include the greater part of the skeleton, I make a few observations on the aftinities suggested by the posterior foot, the only portion just now accessible in my collection. The calcaneum and astragalus have been more or less imperfectly figured by De Blainville and Burmeister, but no one has, to my knowledge, represented the entire foot. The calcaneum is rather short and stout, and its external convex tuberosity is of unusual size. Its articular surface is divided into two subequal parts, the internal of which supports the astragalus, the external the fibula. Thus the fibular articulation is of unusual size. The cuboid facet is on the inferior face of the extremity of the calcaneum, thus looking directly downwards when the bone is prone. In order to articulate with the remainder of the foot, the calcaneum must have been inclined upwards and forwards at an angle of $45^{\circ}$, and the cuboid inclined downwards and forwards at a similar angle. That the axis of the astragalus had the latter inclination is proven by the fact that the superior plane of the sustentaculum lies at that angle to the axis of the remainder of the calcaneum. The great convexity of the external tuberosity for the astragalus will also permit of such a position for the astralagus. The navicular facet of the astragalus is plane and truncates the bone somewhat inferiorly as well as distally, so as to present in the same way as the cuboid. There is probably no cuboid facet. I have not seen the cuneiform bones. The metatarsals and phalanges are robust and rather short. The distal keels of the former are posterior and rudimental. Their proximal extremities have a small lateral tarsal facet as well as the principal one. The median digits are of unequal length, and the lateral ones are much shorter, but robust. Whether there are four or five digits I cannot definitely ascertain.

The above characteristics are very significant. They at once refute any supposition of affinity to the Artiodactyla, whether suilline or ruminant. The form of the astragalus and wide fibular condyle of the calcaneum, opposes the reference of the genus to the Perissodactyla. On the other hand, all the characters of the feet thus far adduced, are found in the Proboscidea. They are not only those of that order, but they are carried to a degree of exaggeration, as though Toxodon represented a high grade of 
specialization of that order. The posterior feet were more truly plantigrade for the extremity of the calcaneum reached the ground, while the instep was elevated above it, being supported, no doubt, by a more or less elastic pad. This arched or angulate plantigrade type of foot, has a remote parallel in that of man. It is quite unique among ungulate Mammalia.

What difficulties the other parts of the skeleton may present, I do not yet know, but I perceive nothing in the dentition which forbids the reference of Toxodon to the Proboscidia. The dentition is scarcely more different from that of Mastodon or Dinotherium, than that of Bos is from Dicotyles or Hippopotamus. The former genera may be the extremities of a series whose intermediate members are as yet undiscovered. In the latter case, the intermediate forms are mostly known.

Printed Mat 17th, 1881. 

(From the American Naturalist, Fone, r88r.)

Miocene Dogs.-In the Bulletin of the Hayden Survey, Vol. vI, p. I77 (Feb., r $88 \mathrm{I}$ ), I gave a synopsis of the genera and species of this family found in the Lower Miocene formation of the Western Territories. These numbered seven and nineteen respectively. The recovery and discovery of some material since that date, enables me to make the following corrections and additions: (I) The proper dental formula of Hycenocyon is I. $\frac{?}{3}$; C. $\frac{1}{1}$; Pm. $\frac{3}{3} ;$ M. $\frac{1}{1}$. Its reference to the Canidx is not certain. (2) It seems that the species I named Icticyon crassivultus cannot be placed in Icticyon on account of an important difference in the dental formula. It must be considered typical of a new genus which I will call Oligobunis, and compare its characters with those of Icticyon as follows: Oligobunis, I. $\frac{3}{3}$; C. $\frac{1}{1} ; \mathrm{Pm}^{4}{ }^{4}$; M. $\frac{1}{2}$; an internal tubercle of the inferior sectorial, which has a basin-shaped heel; Itticyon, I. $\frac{3}{3}$; C. $\frac{1}{1}$; Pm. $\frac{4}{4} ;$ M. $\frac{2}{2}$; no internal tubercle of the inferior sectorial, which has a trenchant heel-E. D. Cope.

Geological News.-Dr. Alpheus Hyatt has published his researches on the forms of Planorbis found in the Tertiary beds of Steinheim. The variations are extraordinary, and furnish important evidence for the evolutionist.-Neumayr and Uhlig publish an extensive and well illustrated paper on the Ammonites of the "Hilsbildungen" of North Germany, in the last number of the Palaontographica.-Professor H. A. Nicholson, of Edinburgh, publishes a handsomely illustrated volume on the possibly polypoid group of the Monticuliporida.-Mr. S. A. Miller has recently described some additional species of the interesting genus Myelodactylus Hall.—Professor Cope has published in the Proceedings of the American Philosophical Society, the cuts illustrating the Permian vertebrata described in his Paleontological Bulletin, No. 32. The genera illustrated are Eryops, Cricotus, Empedias (= Empedocles nom. praeocc.) and Dimetrodon.

Published May 28, $158 \mathrm{r}$. 


THE principal specializations in the structure of the feet of the 1 Mammalia may be summarized as follows:

I. The reduction of the number of the toes to one in the Perissodactyla (horses, etc.), and two in the Artiodactyla (cloven feet). II. The second hinge-joint in the tarsus of the Artiodactyla.

1 Read before the National Academy of Sciences, April, 188r. Abstract. Some of the points of this paper have already been discussed in the NaTuralist (April), but the present abstract contains additional matter. 
III. The trochlear ridges and keels at the various movable articulations of the limbs. These are as follows:

I. Looking downwards-

$a$. Intertrochlear crests of the humerus.

$\beta$. On the carpal end of the radius.

$\gamma$. Metacarpals, distal ends.

$\delta$. Tibia distally.

$\varepsilon$. Metatarsals distally.

2. Looking upwards-

$\alpha$. Radius distally.

B. Astragalus, edges.

r. Astragalus distally (Artiodactyla).

$\delta$. Phalanges (very weak).

The following observations may be made respecting the structures included under division III : The trochlear keels which look downwards are much the most prominent and important. Those enumerated as looking upwards are weak and insignificant, or of a different character from the down-looking ones. The latter are all projections from the middles of the ends of the respective elements. The up-looking are generally projections of the edges of bones. Such are the lateral crests of the astragalus,

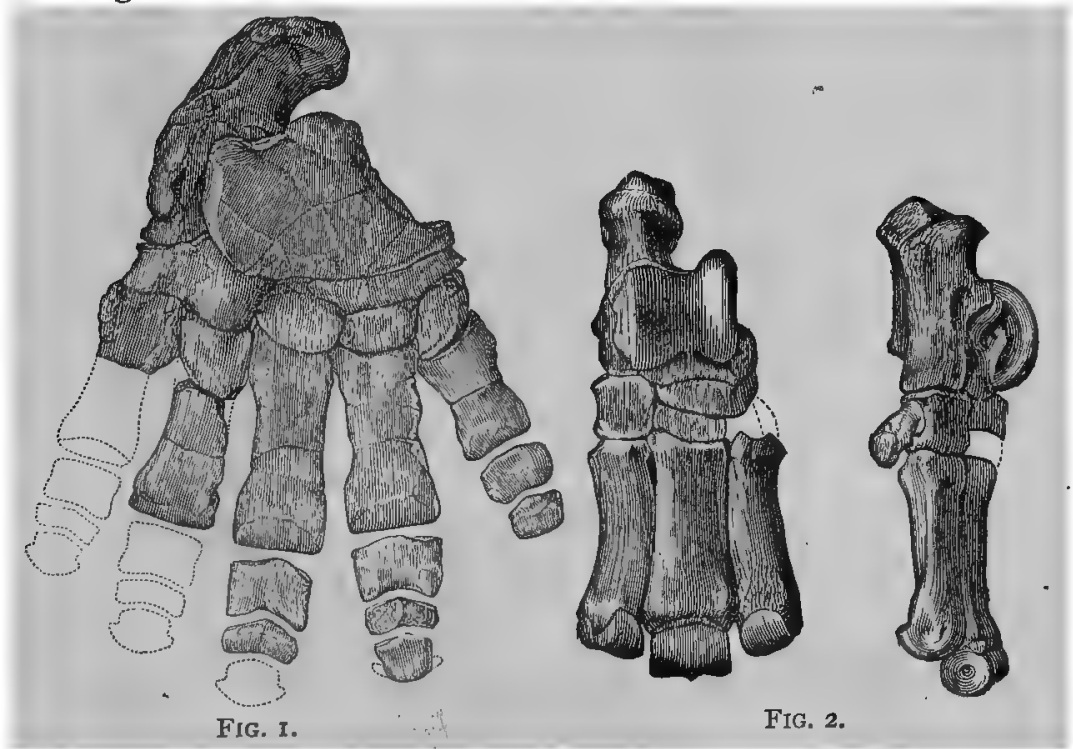

Fig, I.-Right posterior foot of a species of Coryphodon from New Mexico, onehalf nat. size. From Report Expl. W. of rooth Mer., G. M. Wheeler, IV, Pl. LIX.

FIG. 2.-Right posterior foot of Aphelops megalodies Cope, from Colorado, onehalt natural size. From Report U. S. Geol. Surv. Terrs., F. V. Hayden, IV, Pl. Cxxx.

and the adjacent edges of the cuboid and navicular bones which 
cause the distal emargination of the astragalus in the Artiodactyla. The proximal ridges of the phalanges are very weak, and the concavities in the extremity of the radius cannot be called trochlear, as they are adaptations to the carpal bones.

I. The reduction in the number of toes is supposed to be due to the elongation of those which. slightly exceeded the others in length, in consequence of the greater number of strains and impacts received by them in rapid progression, and the complementary loss of material available for the growth of the smaller ones. This is rendered probable from the fact that the types with reduced digits are dwellers on dry land in both orders, and those that have more numerous digits are inhabitants of swamps and mud. In geological history it is supposed that the Perissodactyles

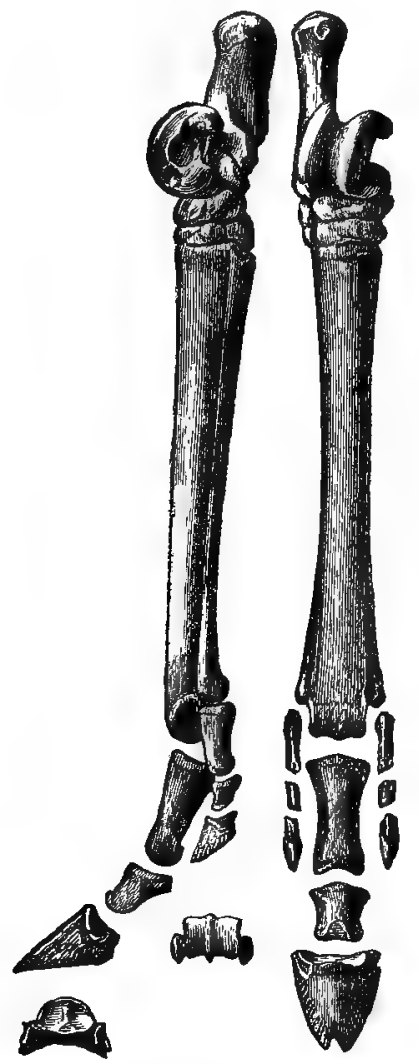

FIG. 3 .

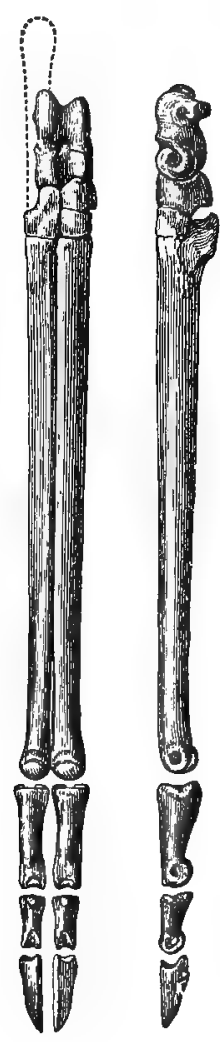

FIG, 4.

FIG. 3.-Right posterior foot of Protohippus sejunctus Cope from Colorado, about one-half nattral size. From Report U. S. Geol. Surv. Terrs., F. V. Hayden, Iv.

Frg. 4.- Right posterior-fnot of Poëbrotherium labiatum Cope, from Colorado three-fifths nat. size. From Hayclen's Report, Iv, Pl. cxv. 
(figures 2-3) originated from the Amblypoda, or primitive Ungztlata (figure I), which first assumed terrestrial habits, while the Artiodactyla (figures 4 and 9-I ), originating from the same order, long continued as mud dwellers; as witness the hippopotami and hogs of to-day. The mechanical effect of walking in the mud is to spread the toes equally on opposite sides of the middle line. This would encourage the equal development of the digits on each side of the middle line, as in the cloven-footed types. In progression on hard ground, the longest toe (the third) will receive the greatest amount of shock from contact with the earth. There is every reason to believe that shocks, if not excessive, encourage growth in the direction of the force applied. This is strongly suggested by the relations between the length of the legs and the rate of speed of animals; and the lengths of the teeth and their long-continued use. Certain it is that the lengths of the bones of the feet of the Ungulate orders have a direct relation to the dryness of the ground they inhabit, and the possibility of speed which their habitat permits them, or necessarily imposes on them.

II. The hinge between the first and second series of tarsal. bones in the Artiodactyla, may be accounted for by reference to the habits which are supposed to have caused the cloven-footed character. Observation on an animal of this order walking in mud, shows that there is a great strain anteroposteriorly transverse to the long axis of the foot, which would readily cause a gradual loosening of an articulation like that connecting the two series of tarsals in the extinct Amblypoda. Any one who has examined this part of Coryphodon will see that a little additional mobility at this point would soon resemble the second tarsal joint of the hogs. In the case of animals which progress on hard ground, no such cross-strain would be experienced, and the effect would be to consolidate by flattening the fixed articulation.

III. The trochlex. These prominences, which form the tongues of the tongue and groove articulations, exhibit various degrees of development in the different Mammalia. Those of different parts of the skeleton coincide in their condition in any one type of ambulatory Mammalia, and so may be all considered together. This fact suggests strongly that they are all due to a common cause.

They are all imperfect in the Rodentia and Carnivora (figures 5-6) (except the J-eforida, which are especially characterized by 
their great speed). Among ungulates they are very imperfect in the Proboscided. The orders mentioned all have elastic pads on the under sides of their feet or toes. The same is true of the lowest types of both the $A r$ tiodactyla and Perissodactyla, the hippopotami and rhinoceroses. In the Ruminantia the trochlea are well developed. (figure IO) with one ex-

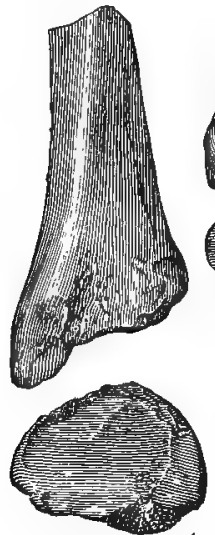

FIG. 5 .

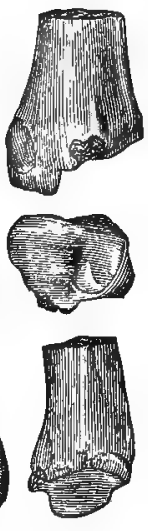

FIG. 6.

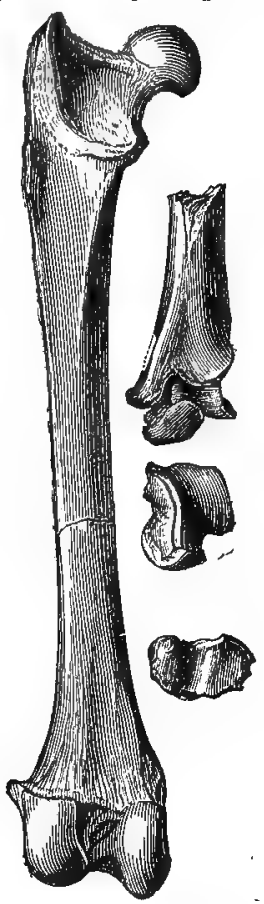

FIG. 8. FIG. 7 .

FIG. 5.-Distal extremity of tibia of Amblyctonus sinosus Ccpe. FIG. 6.-Distal extremity of tibia of Oxyana morsitans Cope. Both flesh-eaters and two-thirds natural size. From Report Expl, and Surv. W. of 1ooth Mer., G. M. Wheeler, IV, Pt. II.

Frg. 7.- End of tibia and astragalus of Archalurus debilis. Fig. 8.-Femur of Nimravus gomphodus. Carnivora, one-third natural size. Mus. Cope.

. ception, and that is the distal metacarpal and metatarsal keels of the Camelida (figure 9). These animals confirm the probability of the keels being the effect of long-continued shocks, for they ate the only Ruminants which have elastic pads on the inferior sides of their digits.

That these processes may be displacements due to shocks long: continued, is rendered probable by the structure of the bones themselves. (1) They project, mostly in the direction of gravity. Constant jarring on the lower extremity of a hollow cylinder with soft (medullary) contents, and flexible end walls would tend to a decurvature of both inferior and superior adjacent end walls. If the side walls are wide and resistant, the projection will be median, and will be prolonged in the direction of the 
flexure of the joint. (2) They fit entering grooves of the proximal ends of corresponding bones. These will be the result of the same application of force and displacement, as the protrusion of the inferior, commencing with a concavity (Elephas); becoming

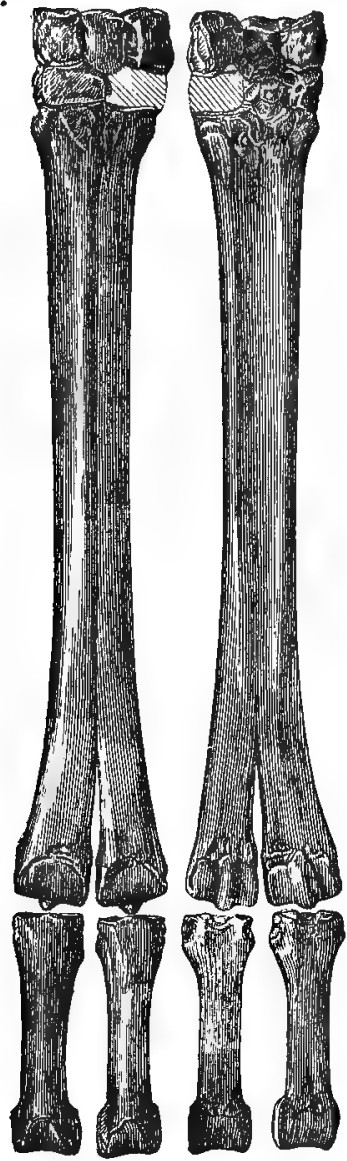

FIG. 9.

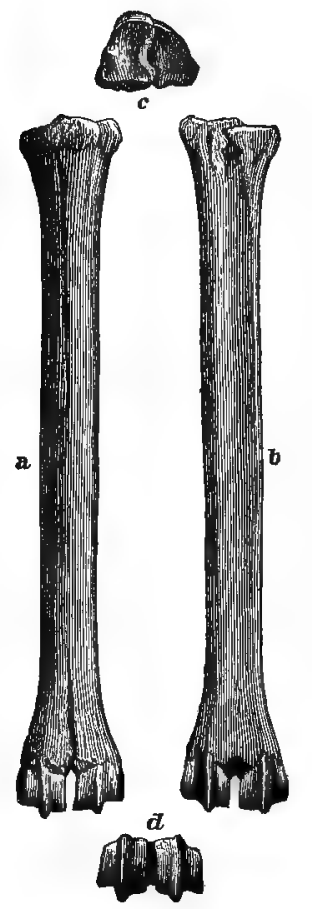

FIG. IO.

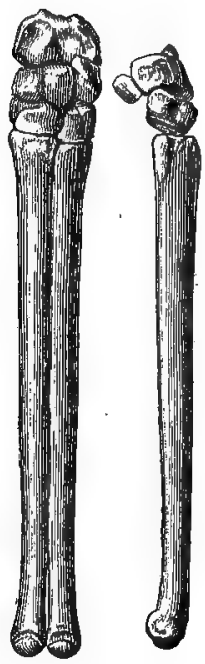

FIG. 9.-Part of anterior foot of Procamelus occidentalis from New Mexico. From Report of Capt. G. M. Wheeler, Vol. IV, Pt. II.

FIG. 10.-Metacarpals of Cosory $x$ furcatus from Nebraska, two-thirds natural size; $a$, anterior face; $b$, posterior; $c$, proximal end ; $d$, distal end.

FIG. I1.-Left forefoot with part of radius of Pö̈brotherium vilsoni Leidy, from Colorado, three-fifths natural size. From Hayden's Report, IV.

more concave (Fig. 7), and becoming finally a groove. (3) When the dense edge of a bone, as in the case of the lateral walls of the astragalus, is presented upwards, a groove is produced in the 
down-looking bone; e.g., the lateral grooves of the distal end of the tibia. (4) When the inferior bones are the denser, the superior articular face yields; $e . g$., the distal end of the radius to the first row of carpals (Fig. I I).

(5) The metapodial keels commence in the lower types on the. posterior side of the distal extremity of the bone. This is partly due to the presence there of a pair of sesamoid bones, which with the tendons in which they are developed, sustain and press on the lateral parts of the extremities, and leave the middle line without support.

Published June 27, I88r. 


\section{$n \div / 29$}

PALFONTOLOGICAL BULLETiN, No. 33. ON SOME MAMMAEIA

OF THE LOWEST EOCENE BEDS OP NEW MEXICO BY ᄅ. D. COPE.

(Extr. Am. Phil. Soc.)

(Read before the Amer. Philosophical Society, Sept. 17, 1881.)

FOR SALE BY A. E. FOOTE,

1123: BELMONT AVENUE, 


On some Mammatia of the Loroest Eocene beds of Nero Mexico. By E. D. Cope.

\section{(Read before the American Philosophical Society, Sept. 17, 1881.)}

Mesonxx navajovius, sp. nov. Smaller than the two known species, and with the crowns of the molars more compressed and the blades of the heels of the inferior series more acute. Molars seven, the first one-rooted. Last molar with a cutting heel like the others, and with the penultimate, with a rudimental anterior inner cusp. All the molars with an anterior basal tubercle except the first, second and third. No basal cingula. Principal cusp elevated and compressed, as in the premolars of Oxyana. Enamel minutely rugose. Mandibular rumi and inferior canine teeth compressed, the angle of the latter not inflected. Length of inferior molar series M. .078; do. of premolar series .046; fourth premolar, length of base .010 ; elevation of cusp .008 ; second true molar, length .012 , elevation .010 ; width of heel .005 ; depth of ramus at .020 ; diameter of base of crown of canine, vertical .009 .

Periptrohus carinidens, gen. et. sp. nov. Creodontium. Char. Gen. No distinct sectorial teeth, the first and second true inferior molars similar. They support a principal median cusp, a broad heel and a prominent anterior cingulum. The heel is more or less divided into tubercles; the anterior cingulum is on the inner side, and represents the anterior cusp of a sectorial tooth. On the inner side of the principal cusp a cingulum rises, forming a flat internal tubercle. Last molar not smaller than the others; premolars unknown.

This genus belongs to the Amblyctonide with Amblyctonus and Palceonyctis. It differs from both in the rudimental character of the anterior cusp, and from the former, in the presence of the internal tubercle. In Mesonyx the heel has a median cutting edge. Char. Specif. Parts of both mandibular rami and the shaft of a humerus represent this species. They indicate an animal of the size of the red fox, but much more robust. The manclibular ramus is rather shallow and thick, and the molars are not large. The heel of the penultinate supports three tubercles, of which the external is the largest. The anterior cingulum supports a small cusp, and then rises to the internal tubercle, which is compressed. The sides of all the cusps are marked with distinct, well separated, vertical ridges. Each extremity of the internal cusp is connected with the principal cusp by a ridge. The first true molar has fewer cusps. Those of the heel are scarcely distinct, and form a border which rises prominently into the flat internal tubercle, which forms a narrow longitudinal blade. The anterior cingulum has no cusp and does not rise into the inner tubercle. The principal cusp has a strong entering groove next the inner tubercle. Length of crown first molar.0115; width of do. .006; elevation of do. .006 . Length of second molar .011; width of do. $.00 \%$; elevation of do. .0065 . Depth of ramus at do. .020. The species is a good deal smaller than the Amblyctonus sinosus. 
Trirsodon qutvirensis, gen. et sp. nov, Char. gen. Derived from the lower jaw. Probably only three premolars. True molars alike, consisting of three anterior cusps and a heel. The cusps are relatively small and the heel large. Of the former the internal is much smaller than the external, and the anterior is rudimental, being merely a projection of the cingulum. The cutting edges of the large external cusp are obtuse. The heel is basin-shaped, and its posterior border is divided into tubercles, of which the external is a large cusp. The fourth premolar has no anterior inner tubercle, so that the anterior part of the crown consists of a compressed cutting cusp. The heel has two well-developed posterior cusps. The third premolar has a similar principal trenchant cusp, but a smaller heel. Canines large.

This genus differs from Herpetotherium and Ictops in the simplicity of its fourth inferior premolar, and from Stypolophus and Deltatherium in the rudimental character of the accessory anterior cusps of the true molars, as well as in the three premolars. The rudimental anterior cusp of the true molars, with the three similar true molars, separates it from Palconyctis, and the presence of a conic inner cusp of the same indicates it as different from Amblyctonus and Periptychus. It is not possible to state whether Trizsodon must be placed in the Amblyctonida or not, on account of the absence of the superior molar teeth.

This specimen of the type species of this genus is instructive as showing the succession of premolar teeth. Both the third and fourth premolars have temporary predecessors. The predecessor of the fourth premolar differs much from it in form, and is essentially identical in all respects with the true permanent molars. The crown of the predecessor of the third premolar is wanting, the roots only remaining in the jaw.

The permanent third premolar was protruded before the permanent fourth. Which temporary tooth of Trizsodon is homologous with the single one of the Marsupialia pointed out by Professor Flower?* As the additional permanent teeth of the placental Mammalia must have appeared later in time than the one already found in the implacentals, they must be those later protruded; hence the fourth tooth in the jaw of Trizsodon must be regarded as homologous with the fourth premolar of a placental, which is the last of that series to appear. If this be true, the tooth which follows the shed tooth of the Marsupials is not the fourth premolar, as supposed by Professor Flower, but the third premolar. This view is confirmed by the fact that the milk tooth displaced by the fourth tooth in Trizsodon resembles in all respects the true molars, just as the permanent tooth occupying the same position does in Didelphys and some extinct eocene genera. This goes to show that this tooth, permanent in marsupials, is temporary in placentals, and that, in spite of its form in the former group, it is the fourth premolar, and not the first true molar, as supposed by Professor Flower. Thus the posterior milk-molar of diphyodonts is a permanent tooth in the Marsupialic.

* Transactions of the Royal Society, 1867, p. 631. 
This observation confirms my conclusion that the Credonta form a group intermediate between the Marsupialia and Carnivora. I may add that in Trizisodon the inferior border of the lower jaw is not inflected posteriorly.

Char. specif.-Size about that of the wolf. Inferior canine directed upwards, its section nèarly elliptic; a faint posterior, no anterior cutting elge. Fourth premolar rather large, with an anterior basal cingulum which is angulate upwards, and is not continued on the inner side of the crown. Cusps of the heel each sending a ridge forwards, the internal lower, obtuse and descending to base of inner side of large cusp ; the external larger, with an acute anterior cutting edge continuous with the cutting edge of the large cusp. True molars with an external, but no internal basal cingulum. Border of heel with one large and three smaller tubercles, the former with, the latter without, anterior cutting edge. Enamel of all the teeth nearly smooth. All the cusps are rather obtuse. Measurements.-Length of inferior molar series: M. .080; long diameter of base of canine .013; length of true molar series .044; length of base of Prem. IV. .016; elevation of crown of do. .014; length of base of M. II. .016 ; width of do, in front .011 ; elevation of do., .014. The measurements of the jaw are not given, as the animal is not adult, the last molar not being yet protruded.

From the lowest Eocene beds of New Mexico.

Deltatherrum fundamints, gen. et sp. nov. Char. Gen. Fam. Leptictide, agreeing with Ictops and Mesodectes in possessing an internal tubercle of the third superior premolar, but differing from both in having but one external cusp of the fourth superior premolar. Char. Specif. Represented by the dentition of both maxillary bones minus the canines. The second premolar is convex on the inner face. The base of the third is a nearly equilatera] triangle. The bases of the true molars are triangles, with the bases external. The internal angle supports an acute cusp, and has a posterior basal cingulum, which is very strong in the last three molars. The two external cusps of the first and second molars are situated well within the base, which is folded into a strong cingulum. This cingulum develops strong anterior and posterior angles. This is the largest species of the family yet discovered. Extent of series of last six molars, M. .045; of true molars .026 ; diameters of fourth premolar, anteroposterior .0074 ; transverse .0076 ; do. of second true molar, anteroposterior .0087 ; transverse .0100. This species was a fourth larger than the common opossum, and very much resembles it in dental characters.

Conoryctes comma, gen. et sp. nov. Char. Gen. Allied to Mesonyx. Inferior canines not rodent-like, with conic crowns. Molars $3-3$, the first one-rooted, the second two-rooted, the third with an anterior conic cusp and a posterior grinding heel. True molars consisting of two lobes, of subcylindric section, separated by deep vertical grooves. Enamel developed on internal and external faces of crowns. Char. Specif. Founded on a mandibular ramus which lacks the last molar, and has the crowns of the others worn. The external faces of the molars are much more $\mathrm{ex}$ - 
posed than the internal, and are somewhat contracted inwards. In the unworn crown there is a distinct anterior inner cusp, which is soon confounded on attrition. The heel of the last premolar has a crescentic section, the internal horn the narrower. The anterior lobe is a robust cone. The base of the second and third premolar is oblique to the axis of the ramus outwards and forwards. It is possible that there is a minute first premolar filling the short space between the second and the canine. No cingula ; enanel obscurely plicate, ramus robust. Length of molars minus the last .0465; length of base of first true molar .010; width of do. .009 ; elevation of crown do. .0055 ; length of base of fourth premolar .011 ; width of do. .008; elevation of crown of do. .0065. Anteroposterior diameter of base of crown of canine .010. Depth of ranus at first true molar .023; width of do. at do. .013. This genus differs from Estho$n y x$ in the form of the fourth premolar. In the latter the anterior lobe is compressed and trenchant. The species is larger than any of that genus, and nearly equal to the Eitoganus gliriformis.

Catathl zus rhabdodon, gen. et sp. nov. Char. Gen. With this genus I commence descriptions of several genera with bunodont dentition, which has some resemblance to that of some of the hogs. The one above named, with Mioclcenus, remind one of Tetraconodon Falc. and Lydd., in the enlarged proportions of their premolar teeth. I compare the genera as follows, introducing a probably perissodactyle form (Protogonia) for comparison :

I. Third and fourth superior premolars one or two lobed externally, and with internal lobes.

a. Superior premolars with two external lobes; inferior fourth with two median cusps.

Intermediate tubercles; premolars not enlarged........... Phenacodus. $\alpha \alpha$. Superior premolars enlarged, generally with one external cusp.

$\beta$. A posterior internal cusp of superior molars ;

Intermediate tubercles present; last inferior premolar with inner cusp;

Catathloous.

Intermediate tubercles wanting, replaced by branches of an internal $\mathrm{V}$; no cusp on inner side of last inferior premolar.........Anisonchus.

Intermediate tubercle present, connected with anterior inner by ridges; inferior molars with Vs...................... Protogonia.

$\beta \beta$. No posterier inner cusp of superior molars.

Intermediate tubercles present; no inner lobe of last inferior premolar

Mioclconus.

II. Superior premolars 1, 2 and 3 without inner lobe; third with three external lobes (Pictet).

Premolars compressed.......................... Dichobune.

In the genus Catathloeus the development of the premolars is remarkable while the true molars are relatively small. The last three superior premolars have an elevated internal crescentic cingulum homologous with 
the inner lobe of the fourth superior premolar of the ruminants. The general character of the true molars is that of Phenacodus. Parts of two or three individuals of this species have come into my possession, one of which includes nearly all of the molar dentition of both jaws. The external cusp of the superior premolars is compressed conic, and the internal cinguium extends to its anterior base in the second, third, and fourth. The crown of the last true molar is about as long as wide, while that of the first is wider than long. Each supports seven cusps; two subconic external, and one large median internal, which is connected by ridges with a small anterior and posterior median. Then there are a small anterior and posterior internal, making three internal. The internal crest is distinct from the principal cusp in the inferior premolars III and IV, but unites with it in the II ; it supports on the IV an anterior, a median and a posterior cusp, the latter forming part of the rather narrow heel. The true molars I and II have seven tubercles, the four principal ones, and three smaller, one anterior, one posterior, and one median. On the third the posterior forms a large hecl. All of the molars, but especially the premolars, have the enamel thrown into sharp vertical parallel folds, in a manner I have not seen in any other mammal. Length of six superior molars .067; length of three true molars .029; length of base of third premolar.012; width of do. .012; width of base of first true molar .010; do. of third true molar .009; length of do. .010. Length base fourth inferior premolar .012; width do. .010; length of third true molar.0115; width of do. .009 . The teeth indicate an animal of the size of the peccary.

Anisonchus sectorius, gen. et sp. nov. Char Gen. This is derived from the superior P-m. IV and M. I and II, and from all the inferior molars of three individuals. The superior teeth are accompanied by a ramus mandibuli, which contains alveoli of all the inferior molars, and the crowns of the P-m. IV and M. II. The leading characters have been given above. The inner posterior lobe is more prominent in this genus than in any of the others, and has a V-shaped apex. It projects further inwards than the anterior inner lobe. It is represented by a mere tubercle of the cingulum in Mioclconus. In the lower jaw the last premolar is quite simple, consisting of a principal cusp, and a non-cutting heel. The second true molar has intermediate anterior and posterior cusps. The genus differs from Pantolestes in the more numerous tubercles of the molars, and in the fact that the anterior inner tubercle of the true molars is not double. It may, however, be allied to that genus.

Char. Specif. The fourth superior premolar covers a larger base than either of the true molars. The external cusp has a base extended anteroposteriorly, but the apex is conical, and there are no basal tubercles. The inner cusp has a crescentic base as in Catathlceus, but the apex is narrowel and compressed conic. The external tubercles of the true molars are subconic, and do not develop any external ridges. They are connected by the erescentic slightly angular crest, whose apex forms the inner ante- 
rior boundary of the crown. This crest is not divided into parts homologous with the intermediate tubercles. The crowns of the M. I and II are surrounded by a basal cingulum, which in the M. I develops a tubercle at the anterior external angle. No internal or external cingulum on P-m. IV. Enamel nearly smooth.

The ramus of the mandible is rather slender anteriorly. The P-m. IV is robust, and the cusp is behind the middle of the base of the crown. The heel is short and narrow, and has a raised border, connected with the base of the main cusp. The cusps of the second true molar are elevated and conic, the anterior external the highest, the others subequal. The base of the posterior pair is a little narrower than that of the anterior pair. There is no central tubercle as in Catathlaus rhabdodon, and no basal cingulum on either tooth.

$$
\text { Mecusurements. } \quad \text { M. }
$$

Length of three superior molars............... 0160

Diameters superior P-m. IV $\{$ anteroposterior.......... 0055

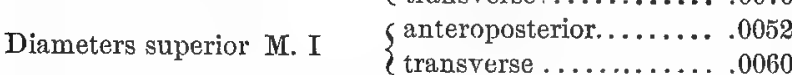

Length of inferior molar series................ 0610

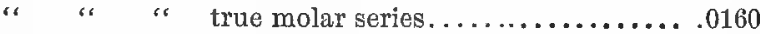

Diameters inferior P-m. IV $\left\{\begin{array}{l}\text { anteroposterior ......... . . . . . . . . . . .0040 } \\ \text { transverse.... }\end{array}\right.$

Diameters inferior M. II $\{$ anteroposterior ......... 0050

Depth ramus at M. II. ........................ 0090

A number of minor points will distinguish this species from those included among the Mesodonta, and especially those of Pantolestes, which it most resembles. The molar teeth are narrower behind, and the fourth premolar is larger. It is Mioclonus sectorius, American Naturalist, October, 1881, p. 831.

Mrocl 2 Nus turgidus, gen, et sp. nov. This genus differs from Catathlaeus in the structure of the inferior premolars, which are without internal crest or cusp. The inner lobe of the superior premolars is less developed than that genus. In the present species the characters of Mioclconus are best seen in the subconical tubercles of the premolars, particularly that of the heel of the fourth inferior premolar. In the other three species this heel is more of a crest and is connected with the principal cusp by a low ridge. The four species may be characterized as follows :

a. Cusps of last premolars conical in both jaws.

Size medium. Last lower molar disproportionately small; cusps low; two anterior inner distinct; true molars, $.018 \ldots . . . . . M$. turgidus. ac. Fourth superior premolar with flattened external and conic internal cusp ; inferior unknown. 
Size medium; fourth upper premolor equilateral; all cusps acute; true

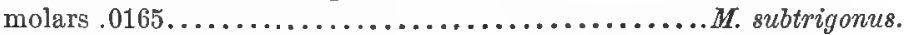
$\alpha \alpha \alpha$. Cusps of last premolars compressed in lower jaw.

Least. Second and third lower true molars subequal; cusps, especially the internal, elevated; anterior inner confluent into an edge; true

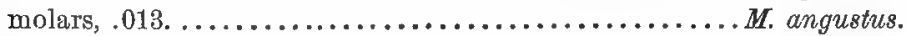

Largest; cusps of inferior molars obtuse; P-m. III .008, its heel short

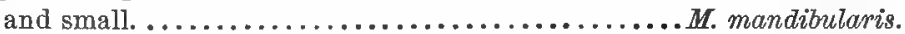

Medium ; last inferior molar larger than penultimate ; true molars, .014;

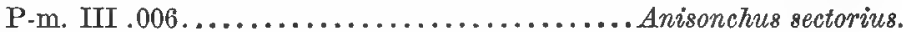

Of $M$. turgidus there are two specimens; and of $\boldsymbol{M}$. subtrigonus, $\boldsymbol{M}$. angustus and $M$. mandibularis one each.

In the $M$. turgidus there are no cingula on the fourth premolar. It is wider than long, and the external face is a little flattened. The tubercles are conic; the external has a small one at the anterior base, and a rudiment at the posterior base, and there is a low one on the posterior side at the middle. The second true molar is wider than the first. The tubercles are all round in section. Besides those already mentioned, there is a rudiment of a posterior inner on the first, which is represented by a cingulum on the second. The latter has basal cingula all around except on the inner side; the same are visible on the first true molar in a rudimental condition. Enamel nearly smooth.

The inferior molars are of robust proportions. Their sizes are, commencing with the largest: P-m. IV; M. II ; M. I; M. III. The last molar is only half as large as the penultimate. It has two anterior and an external lateral tubercles, and a heel. On the penultimate molar, there are two anterior tubercles with a trace of anterior inner ; also a broad flat heel, with a low tubercle on the external side. The constitution of the first true molar is identical. The fourth premolar has a rudimental heel consisting of a low tubercle only. The principal cusp is conic and is over the middle of the transverse diameter, and a little behind the middle of the anteroposterior diameter. No cingula. Enamel nearly smooth.

Measurements.

M.

Maxillary bone.

Length of base of P-m. IV, M. I and M. II.......... 0175

Diameters base P.m. IV $\{$ anteroposterior.......... 0055

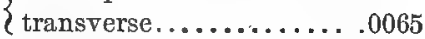

Diameters base M. I

S anteroposterior......... 0060

$\{$ transverse.............0070

Diameters base M. II

S anteroposterior ..........0060

¿ transverse...............0095

Mandible.

Length of bases of last four molars.................. 0250

Diameters P-m. IV

S anteroposterior ......... .0070

\{transverse..............0055 
Measurements.

Diameters M. I

Santeroposterior .........0060

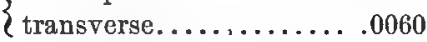

Diameters M. III

s anteroposterior ...........0055

$\{$ transverse..............0043

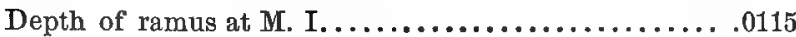

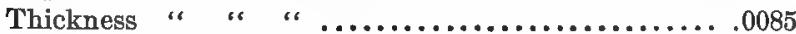

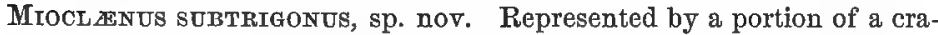
nium anterior to the orbits and lacking the extremity of the muzzle, distorted by pressure. It exhibits nearly all of the molar teeth. The species differs from $M$. turgidus in the greater actiteness of all its cusps, and in the equilateral form of the fourth premolar. It is too large to belong to the $\boldsymbol{M}$. angustus, which is represented by a mandible only ; and too small to be the $\boldsymbol{M}$. mandibularis, whose maxillary dentition is unknown.

The inner borders of the molar teeth are shorter than the outer, especially in the last two molars. The last true molar is smaller than either of the others. The cusps are all subconical, but the internal is connected with the intermediate by ridges, which give it a triangular section. The latter form a V, homologous with that in Anisonchus, but not so distinct, and the intermediate tubercles are not lost in its branches as in that genus. The posterior inner lobe of that and other genera, is represented by a thickening of the cingulum. This cingulum extends entirely round the P-m. IV and M. I, and M. II ; the M. III is injured. The sides of the base of the P-m. IV are slightly concave. The enamel of all the molars is wrinkled.

Measurements. $\mathrm{M}$.

Length of bases of last five molars . ............... 0285

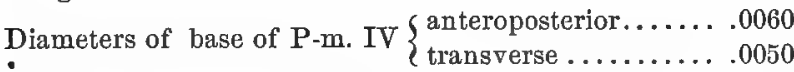

Diameters of base of M. I $\quad\left\{\begin{array}{l}\text { anteroposterior.................. } 0060 \\ \text { transverse......... }\end{array}\right.$

Diameters base of M. II $\quad\left\{\begin{array}{l}\text { anteroposterior................. } \\ \text { transverse ..... }\end{array}\right.$

anteroposterior....... 0040

Diameters base of M. III

$\{$ transverse..............0060

Mrocl 7 mus angustus Cope, American Naturalist, 1881, October (September 22d), p. 831. The least species of the genus, with the teeth about the size of Hyopsodus partus Leidy, but with more robust jaw. The molar teeth diminish in size regularly posteriorly from the $P-m$. IV. They all have three subequal posterior cusps which are less elevated than the anterior ones. The median is enlarged into a heel on the last tooth. The anterior are opposite, and the external is larger than the internal. There is no anterior internal. The external wears into an anteroposterior narrow grinding surface, which looks like a combination with an anterior median. The latter is, however, not separate on the least worn molars. The 
anterior outer cusp increases in size anteriorly, and is the large cusp of the P-m. IV. It sends a branch backwards on the inner side of the crown which forms the edge of the narrow concave heel. There are no cingula except a short one on the anterior corners of the base of the crown of the P-m. IV. Enamel obscurely w rinkled.

Measurements.

M.

Length of posterior four molars................. 0180

Diameters of P-m. IV

$\{$ anteroposterior $\ldots \ldots \cdot .0050$

\{transverse.............0035

Diameters of M. I

Santeroposterior .......0050

\{transverse...........0035

Diameters of M. II

Santeroposterior ........0040

$\{$ transverse...........0032

Diameters of M. III

Santeroposterior........0045

$\{$ transverse............0030

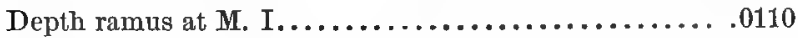

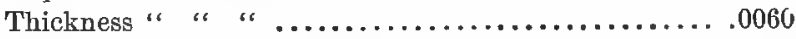

Phenacodus Puercensts, sp. nov. Three individuals. Last superior molar smallest; first and second true molars with six tubercles, two external, two median and two internal. A strong basal cingulum except on inner side. Inferior true molars besides the usual five tubercles, furnished with an anterior ledge with a tubercle at its interior extremity. A weak exteraal basal cingulum. A little larger than the $P$. vortmani. Length of superior true molars M. .021; length of base of crown of M. III .006 ; do. of M. I .008; width of do. .008; length of base of crown of inferior M. III .0085; width of do. in front.006; depth of ramus at M. I .019.

Phenacodus zuniensis, sp. nov. The least species of the genus, represented by the mandibles of two individuals. The first and second true molars are narrowed in front, and there is no distinct anterior ledge, only a minute anterior inner tubercle. The external cingulum is more distinct and the enamel is wrinkled. The fourth premolar has a short base and the inner cusp is much smaller than the principal one; it has a wide heel and an anterior basal tubercle. Length of true molars, M. .018; of last true molar .006; of base of first true molar .006; width of do. .004; depth of ramus at do. .011.

Protogonia subquadrata, gen. et sp. nov. Fourth superior premolar with one external and one internal lobe. True molars with two external, two internal, und two intermediate lobes, both the latter connected with the anterior internal by a ridge. Supposed inferior true molars with two Vs with weak anterior branches; last true molar with heel.

This genus will enter the Chalicotheriidas of my system of Perissodactyla, if the feet are found to possess the requisite characters. It is allied, apparently, also to Hyracotherium, but differs in the Vs of the infe-

* See Proceedings Amer. Philosoph. Society, 1881, p. 377-8. 
rior molars, if they are properly identified; and in the superior molars. The anterior transverse crest of that genus is represented in Protogonia, but not the posterior. This is replaced by a low ridge running across the course it pursues in Hyracotherium. The posterior median tubercle is also not found in the latter genus. Protogonia differs from Limnohyus in the subconic character of the external lobes of the superior molars. If the tubercles, excepting the posterior inner, should be converted into crescents, the genus Meniscotherium would be produced.

Char. Specif. Probably two specimens; one supporting three superior molars ; the other including damaged superior molars and the last two inferior molars. The animal was about the size of the red fox. The external cusp of the fourth superior premolar is flattened externally, and has a small lobe on its posterior edge. The inner tubercle is conic and is separated by a tubercle from the anterior base of the external. True molars without external ridges. The external cusps of the true molars are lenticular in section. The posterior inner cusp is in nearly the same anteroposterior line with the anterior, its section about equaling that of the intermediate cusps. The first and second molars have an external, an anterior and posterior, but no internal, basal cingula. The enamel is somewhat wrinkled where not worn.

The heel of the last inferior true molar is elevated, and its worn surface forms the extended posterior branch of the posterior $V$. The posterior edge of the penultimate molar is elevated and curved forwards on the in ner side of the crown. The anterior cusp forming the angle of the $\mathrm{V}$ of this tooth, is higher than the posterior angular cusp, but the anterior limb descends rapidly as in Ooryphodon. A weak antero-external, and posteroexternal cingula. Enamel wrinkled where not worn.

$$
\begin{aligned}
& \text { Measurements. } \\
& \text { No. } 1 .
\end{aligned}
$$

Length of bases of three superior molars...........025

Diameters of superior P-m. IV $\left\{\begin{array}{l}\text { anteroposterior........ } 0066 \\ \text { transverse . . . . . . . } 0086\end{array}\right.$

Diameters of superior M. I $\left\{\begin{array}{l}\text { anteroposterior........ } 0085 \\ \text { transverse .......... } 011\end{array}\right.$

Diameters superior M. II

Santeroposterior........009

transverse ...........011

No. 2.

Length of bases of last two inferior molars......... .0225

Diameters of last inferior molar $\left\{\begin{array}{l}\text { anteroposterior........ } 0114 \\ \text { transverse. ......... } 0066\end{array}\right.$

Diameters of inferior M. II

\{ anteroposterior.........0112

$\{$ transverse ..........0080

Depth of ramus at M. II.................... .0240

Thickness " " " .........................

Meniscotherium terrardBr, sp. nov. My specimens of this species embrace the dentition of several individuals. 
The dimensions of the superior molars increase to the penultimate, while the external and posterior sides of the last molar are contracted, reducing its size. The external faces of the external $\mathrm{Vs}$ of the true molars are considerably impressed; those of the premolars are nearly flat.

The second premolar is two-rooted, and has a compressed crown, without either heel or cingulum, except a thickening of the posterior base. The base of the crown is triangular. The external plate of the third premolar is simple, and is connected with the internal cusp by a cingulum on the posterior base of the crown. The crown is transverse, and the inner tubercle rather small. The fourth premolar is much larger than the third. Its external plate is divided into two apices, which are not impressed. Their external faces are separated by a faint ridge, and are clivided medially by a faint ridge. The anterior external angle is rather prominent. The anterior and a posterior cingulum extend to and round the inner base of the interior tubercle. Within the anterior external apex, is a well developed intermediate crest parallel to it; and there is a corresponding crest within the posterior external apex. This one turns inwards at its posterior extremity, which is on the posterior cingulum.

The anterior angle or horn of each external crescent of the true molars is very prominent. They are sections of short vertical ridges, which unite near the base of the crown, giving abruptness to the impression of the external surface of the anterior lobe. The middle of each face has a faint median ridge. The two molars have an anterior basal cingulum, but no posterior or internal, excepting a trace between the bases of the internal lobes. The anterior intermediate crescent is quite parallel with the external; the anterior internal tubercle has a slightly V-shaped section. The posterior inner tubercle is quite confluent with an oblique intermediate crest, as in $M$. chamense. In the last true molar, as there is only one internal tubercle, this crest is short, terminating at the posterior borter. The last true molar is like the last premolar, except in its two impressed external crescents.

A fragment of the right branch of the lower jaw supports two molars, and the alveoli of two others, all of which have two roots. These teeth are the four premolars, although the last one has the form of the first true molar. Should my surmise be correct, then the third premolar has nearly the same form and structure as the fourth. The anterior horn of its anterior $\mathrm{V}$ is not produced quite so far inwards as in the fourth tooth. At the point of junction of the acljacent horns of the Vs there is a slight anteroposterior extension, forming a median buttress of the inner side of the crown as in Anchitherium. The posterior horn of the posterior $\mathrm{V}$ is also incurved, as in that genus. The angles of the Vs of the inferior molars are rounded.

The surfaces of the enamel of the teeth of both jaws is smooth.

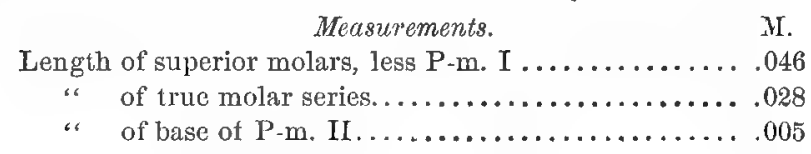


Measurements. M.

Diameters of base P-m. III $\left\{\begin{array}{l}\text { anteroposterior..........006 } \\ \text { transverse............ } 007\end{array}\right.$

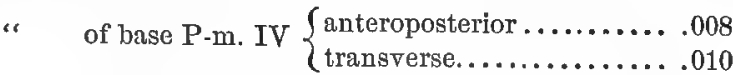

“ of base of M. II $\left\{\begin{array}{l}\text { anteroposterior ........... } 011 \\ \text { transverse.............. } 013\end{array}\right.$

" inferior P-m. III (or IV) $\left\{\begin{array}{l}\text { vertical.......... .005 } \\ \text { anteroposterior ... .007 } \\ \text { transverse........ .005 }\end{array}\right.$

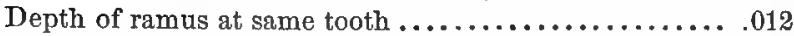

Thickness ramus at succeeding tooth.................. 009

The Meniscotherium terrembro differs from the $M$. chamense in two features. The first is its superior size. The second is the flattened form of the external faces of the true molars and the absence of the convexity of the external bases of the crown.

My specimen of this species is from the red Eocene bed in Northwestern New Mexico, from the true Wasatch horizon, or higher than that which produced the other species here described. It was found by my assistant, D. Baldwin.

\section{REMarks.}

As stated in my report to Lieut. Wheeler in $187 \%$, no vertebrate remains had been found in the Puerco beds, which underlie the Wasatch in New Mexico, up to that time. It was therefore uncertain whether they form the top of the Cretaceous or the bottom of the Tertiary series. I have recently obtained evidence of the existence of Champsosaurus in them, so that their position might be supposed to be in the Postcretaceous system.

It is however quite possible that the species of Mammalia described in this paper were derived from the Puerco Formation. Their horizon is below the Wasatch, and they represent a different fauna from that of those beds.

Attention has already been directed to this fauna in the pages of the American Naturalist.* I have recorded the presence of the Creodont genera, Periptychus, Trizsodon and Dettatherium, and of the saurian Chompsoscurus. I have now added the genera Hyracotherium and Meniscotherium, and a number of new forms of considerable interest. These are the Creodont Mesonyx, a new genus allied to Esthonyx, and a series of genera and species with a suilline type of dentition, but whose affinities are by no means certain. This point cannot be determined until the characters of the feet are known.

The facies of this fauna differs in several points from that of the Wasatch. Coryphodon has not yet been discovered in it, and the flesheaters are very primitive. The suilloid genera are characteristic.

* April, August and October, 1881.

Printed Septemier 30, 1881. 







\section{GEOLOGY AND PALAONTOLOGY.}

Mammalia of THe Lowest EOCENE; -Attention has already been directed, in these pages, ${ }^{1}$ to the fauna of an early Tertiary period, probably the Puerco formation, which lies below the Wasatch, in New Mexico. I have recorded the presence of the Creodont genera Periptychus, Triisodon and Deltatherium, and probably the Saurian Champsosaurus. I now add the genera Hyracotherium, Meniscotherizm and Mesonyx, and a number of new forms of considerable interest. These are a new genus allied to Esthonyx, and a series of genera and species with a suilline type of dentition, but whose affinities are by no means certain. This point cannot be determined until the characters of the feet are known.

Conoryctes comma, gen. et sp. nov. Char. gen.-Allied to Esthonyx. Inferior canines not rodent-like, with conic crowns. Molars $3-3$, the first one-rooted, the second two-rooted, the third with an anterior conic cusp and a posterior grinding heel. True molars consisting of two lobes, of subcylindric section, separated by deep vertical grooves. Enamel developed on internal and external faces of crowns. Char. specif.--Founded on a mandibular ramus which lacks the last molar, and has the crowns of the others worn. The external faces of the molars are much more exposed than the internal, and are somewhat cuntracted inwards. In the unworn crown there is a distinct anterior inner cusp, which is soon confounded on attrition. The heel of the last premolar has a crescentic section, the internal horn the narrower. The anterior lobe is a robust cone. The base of the second (third) premolar is oblique to the axis of the ramus outwards and forwards. It is possible that there is a minute first premolar filling the short space between the second and the canine. No cingula; enamel obscurely plicate; ramus robust. Length of molars minus the last, .0465; length of base of first true molar, .oro; width of do., .009; elevation of crown do., .0055; length of base of fourth premolar, .OII ; width of do., .008; elevation of crown of do., .0065. Anteroposterior diameter of base of crown of canine, .0IQ. Depth of ramus at first true molar, .023; width of do. at do., .or 3. This genus differs from Esthonyx in the form of the fourth premolar. In the latter the anterior lobe is compressed and trenchant. The species is longer than any of that genus, and nearly equal to the Ectoganus gliriformis.

Catathlaus rhabdodon, gen. et sp. nov. Char gen.-With this genus I commence descriptions of some genera with bunodont dentition, which has some resemblance to that of some of the hogs. The òne above named, with Mioclenus, remind one of

1 April and August, 1881. 
Tetraconodon Falc. and Lydd., in the enlarged proportions of their premolar teeth. I compare the genera as follows:

I. Third and fourth superior premolars one or two-lobed externally, and with internal lobes.

a. Superior premolars with two external lobes; inferior fourth with two median cusps.

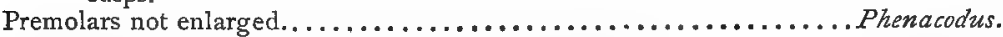

$\alpha \alpha$. Superior premolars with one external cusp, enlarged.

Inferior fourth premolar with internal crest and cusp............. Catathlous.

Inferior fourth premolar without internal crest or cusp............. Mioclenus.

II. Superior premolars I, 2 and 3 without inner lobe; third with three external lobes (Pictet).

Premolars compressed..............................Dichobune.

In the genus Catathleeus the development of the premolars is remarkable, while the true molars are relatively small. The last three superior premolars have an elevated internal crescentic cingulum, homologous with the inner lobe of the fourth superior premolar of the ruminants. The general character of the true molars is that of Phenacodus. Parts of two or three individuals of this species have come into my possession, one of which includes nearly all of the molar dentition of both jaws. The external cusp of the superior premolars is compressed conic, and the internal cingulum extends to its anterior base in the second, third, and fourth. The crown of the last true molar is about as long as wide, while that of the first is wider than long. Each supports seven cusps; two subconic external ; one large median internal, which is connected by ridges with a small anterior and posterior median. Then there are a small anterior and posterior internal, making three internal. The internal crest is distinct from the principal cusp in the inferior premolars III and IV, but unites with it in the II ; it supports on the IV, an anterior, a median and a posterior cusp, the latter forming part of the rather narrow heel. The true molars I and II have seven tubercles, the four principal ones, and three smaller, one anterior, one posterior, and one median. On the third the posterior forms a large heel. All of the molars, but especially the premolars, have the enamel thrown into sharp parallel folds, in a manner I have not seen in any other mammal. Length of six superior molars, .067; length of three true molars, .029; length of base of third premolar, .012; width of do., .012; width of base of first true molar, .OIO; do. of third true molor, .009; length of do., .010. Length of base of fourth inferior premolar, .OI 2 ; width do., .OI 2 ; of third true molar, oI I 5 ; width of do., .009. The teeth indicate an animal of the size of the peccary.

Mioclcenus turgidus, gen. et sp. nov. This genus differs from Catathleeus in the greater simplicity of the structure of the inferior premolars, which are without internal crest or cusp. The inner lobe of the superior premolars is less developed than that genus: In the M. turgidus the characters of Mioclanus are 
best seen in the subconical tubercles of the premolars, particularly that of the heel of the fourth inferior premolar. In the other three species this heel is more of a crest, and is connected with the principal cusp by a low ridge. The four species may be characterized as follows:

a. Cusps of last premolars conical in both jaws.

Size medium. Last lower molar disproportionately small ; cusps low, two anterior inner distinct; true molars, .or $8 . . . . . . . . . . . . . . . . . . M$. turgidus.

a.. Cusps of last premolars compressed in both jaws.

Least. Second and third lower true molars subequal; cusps, especially the internal, elevated; anterior inner confluent into an edge; true molars, .or 3

M. angustus.

Medium. Last inferior molar larger than penultimate; true molars, oI4; p. m. III

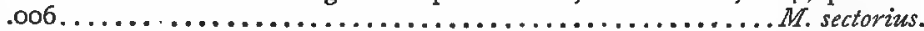

Largest. Cusps of inferior molars obtuse; $\mathrm{p} . \mathrm{m}$. $\mathrm{xII}$.008, its heel short and small

M. mandibularis.

Of $M$. turgidus there are two specimens; of $M$. sectorius three, and of $M$. angustus and $M$. mandibularis one each.

Geology of the . Lake Valley Mining District.-This district lies in the Eastern foothills of the Mimbres mountains, New Mexico, at the western border of a plain which extends from the Rio Grande. Several cuttings of the Atchison, Topeka and Santa Fé R. R. disclose the formation of the surface of the plain, while the shafts at the mines, and various monoclinal hills exhibit the general structure of the country.

The more elevated hills are dikes of trachyte-porphyry, and the directions of their axes are various. It partly decomposes into a reddish soil, and partly breaks down into gravel-like fragments. The lowest sedimentary rock I have seen in place is a quartzite, frequently not very hard, and often perforated by irregular cavities. This material forms low hills, and is overlaid by one or two hundred feet of a fine carbonaceous shale from which most of the valleys are eroded. I was unable to determine the age of either this bed or the quartzite. Overlying the shale are from I5O to 200 feet of more or less siliceous limestone, the upper part of which is very fossiliferous. Professor White finds the fossils to demonstrate the age of this formation to be the Middle Carboniferous; see July, i $88 \mathrm{r}$, Naturalist.

The only formation found covering the limestone is drift. In the foothills this is composed of worn fragments of limestone and trachyte; on the plain it mostly consists of fragments of basalt, with some trachyte, which are more or less coated with lime.

The rich silver deposit which is now attracting attention to this district, is found in the limestone, which forms low monoclinal hills between the higher trachyte ridges and the still lower hills of quarzite. At the Lake Valley, mines the dip of the strata is S.S.W. from $12^{\circ}$ to $30^{\circ}$. The silver-bearing rock form numerous veins which traverse the limestone from N.W. by W. to S.E. by $\mathrm{S}$, or at right angles to the dips. The veins are of various 
widths, from a few inches to a hundred and more feet, and they are nearly uninterrupted for a length of 4000 feet along the sloping surface of the hill. They are probably outflows from an ore body which is bedded with the limestone. At a depth of thirty or forty feet, in some of the shafts, the veins change direction so as to be conformable to the limestone, and many of the veins have been already shown to be connected below the surface. The gangue of the veins is iron oxide and carbonate, with much manganese in pyrolusite, psilomelane, etc., which are mixed with crystalline limestone, chert, etc. Galena and lead carbonate are abundant, and the silver appears as ceratargyrite, embolite and sulphuret. These are either visible in amorphous or crystalline bodies, or are disseminated in an invisible form, but in large quantity, through the gangue substances. The average of the assays is high, especially in some of the ores where the silver is not recognizable by the eye. The green embolite is easily seen in specimens from all parts of this outcrop, and in some larger bodies of gangue it colors the entire rock.-E. D. Cope.

Published September 22, I88I. 
(From the American Naturalist, Notember, 1881 .)

GEOLOGY AND PAL丑ONTOLOGY.

Eocene Plagiaulacide.-This remarkable family of Marsupialia belongs, as is well known, to the Jurassic period, and genera have been found in both Europe and North America. Falconer traced resemblances to the existing Hypsiprymnus of Australia, and there might be some remote affinity between the families. But in the formations which represent the long period between the Jurassic and present ages, no trace of intervening genera has been found. It is therefore of interest that I am able to announce the discovery of such a one from the Lowest Eocene (perhaps Puerco) beds of New Mexico. The specimen was found with the jaw of the Trïsodon quivirensis (Naturalist, for August, 1881), and consists of a single tooth of the lower jaw. It is the characteristic obliquely ridged cutting tooth well known in Plagiaulax. It presents the following differences from those of Plagiaulax and Ctenacodon, which I regard for the present as generic.

Char. gen. Cutting edge convex and continuous with the anterior edge of the crown, and serrate from the union of ridges which ascend on each side. Ridges curved backwards, all reaching the edge excepting above the posterior root of the tooth, where they are discontinued, leaving a smooth edge. In Plagiaulax the ridges are continued to the posterior edge of the crown, and in Ctenacodon the ridges do not extend on the sides of the crown. In Hypsimromnns the ridges are vertical.

Cluar. specif. The tooth is much larger than that of any of the 
Plagiaulacida yet known, exceeding the corresponding one of the kangaroo-rat of Australia. There are twelve ridges on the side of the crown, extending from the base. They are crowded anteriorly and become more widely spaced posteriorly. The anterior margin is acute from near the base; the latter projects a little beyond the root. The most elevated point of the crown is between the roots. Ridges fine, enamel smooth. Length of base of sculptured part of crown, .00ó2; elevation of do., .0047; thickness of do. at base, .0025. The genus and species may be called Ftilodus medicevus.-E. D. Cope.

Belodon in New Mexico.-Some years ago I I identified certain fossils discovered in North Carolina by Emmons as Belodons; and later," referred a species found by Wheatley in Pennsylvania, to the same genus. I am now in a position to prove that the genus ranged over the Rocky mountains, and that there, as in other parts of the world, it haunted the shores of the Triassic seas and lakes. In the same region a related form, the Typothorax coccinarmm, existed at the sane period. ${ }^{3}$ There are two species of Belodon in my New Mexican collections, one as large as the gavial of India, the other smaller. In the former the inuzzle is keeled above, and rises into a crest in front of the nares. In the other species the muzzle is subcylindric, and does not rise anterior to the septum of the nostrils. The larger species I call Belc don buceros; the smaller one $B$. scolopax, and define them as follows :

Belodon buceros.-Size of the gavial. Muzzle slender, compressed, with a narrow median superior ridge, rising at the middle of the length into a compressed crest, whose summit is in the plane of the frontal region. Nostrils a little further anterior to the orbits than the diameter of the latter, longer than wide, and separated by a thin septum. Orbits round, looking a little upwards, the interorbital region a little narrower than each orbit. Preorbital region compressed; preorbital foramen large, inferior. The quadrate bones are directed forwards, and their articular faces are in the transverse line of the two rather narrow notches of the posterior outline of the parietal bone. The auricular meatus is bounded by a descending hook-like process; and the squamosal bone is continued still further posteriorly into a short triangular acute horn. The superior surface of this bone with the parietal and frontal, are roughened with tubercles. The palate has a strong ridge on each side, so as to be grooved. The posterior teeth have compressed denticulate crowns. Tip of muzzle lost. Total length preserved, M. .700; length of muzzle to posterior edge of nares, .420 ; do. from latter to lines of anterior edge of orbits, .060; do. from do. to posterior parietal notch, . I60. Width at posterior bor-

1 Proceedings Academy of Natural Sciences, Philadelphia, 1866.

2 Transactions Amer. Philos. Sos., xIv, 1869.

3 Cope, Report G. M. Wheeler, U. S. Surv. W. of rooth Mer., IV., 1877. 
der of quadrate condyles, .240; interorbital do., .048; do. at slender part of muzzle, .045. Depth of slender part of muzzle, .050; do. of elevated part, .I 20 ; do. at parietal region, .I4O.

This species is of the size of the $B$. kapf $f$ Mever, and is, in the form of the muzzle, intermediate between that species and the $B$. plieningeri.

Belodon scolopax. This species is represented by a snout, which includes the anterior border of the nares; it is broken into five pieces, which should be counected with intermediate fragments, which are lost. This muzzle is a little shorter than that of $B$. plieningeri, but is a good deal more slender, the distal part having only half the diameter of the latter. Besides this character, it differs from that of $B$. plieningeri in three others. The extremity of the muzzle is not so much decurved. All the alveolæe have a more lateral exposure, and the lateral ridges of the palate are thus more distinctly seen from the side. The two teeth on the extremity of the muzzle are closely crowded together, and their large alveolæ are scarcely distinct.

The surface of the muzzle is distantly and weakly grooved and punctate. The anterior alveolæ are round, the posterior ones oval. Diameters an inch anterior to nares; transverse, .0230; vertical, .0235. Diameters three inches from extremity; transverse, .oI9; vertical, .oI 45.

GEOLOGICAL NoTES.- The third part of the Contributions to the Palæontology of Austro-Hungary, by Mojsisovics and Neumayr, contains two articles. These are, the Jura formation of the neighborhood of Brünn, by V. Uhlig; and the fossils of the Nizniow Limestone, by Von Alth.-The Palcontographica, for June, I $88 \mathrm{I}$, consists of a memoir on the extinct Elephants of Japan. The species mentioned are Stegodon clifti, S. insignis, Elephas nomadicus and E. primigenius. The August number contains the first part of a memoir on the fauna of the Kelheim Diceras limestone.-Mr. Hulke, in the Quarterly Journal of the Geological Society of London, for 1879 and 1880 , has described two new Dinosauria of the Iguanodontzde, under the names of Vectisaurus valdensis, and Iguanodon prestreichii._- The Revue Scientifique, of Paris, gives a review of the last year's progress in vertebrate palæontology. It covers five pages and a half, of which one page is given to South American and four pages to North American works on the subject.—Prof. Cope's Palæontological Bulletin, No. 33, contains descriptions of fourteen new species of Mammalia from the Lowest Eocene beds of New Mexico. Eight new genera are characterized. - In the Bulletin of the Geological Society of France, M. Fischer describes a new Eocene Creodont under the name Apterodon gaudryi._-Dr. H. G. Seeley has recently reexamined the vertebrate fossils found at Neue Welt, near Vienna, and has made a number of important rectifications in the determinations.

Published November 12, I 881 . 

BY E. D. COPE AND A. S. PACKARD, JR.

THIS cave is situated near that point of the southern boundary 1 of Tennesse where it is joined by the line which separates the States of Georgia and Alabama. In dimensions it ranges with the Mammoth and Wyandotte caves of Kentucky and Indiana, whose faunæ have already been described in earlier volumes of the Naturalist. Many miles of galleries have been explored, and no end has yet been reached. The entrance is in the northern side of a hill, not far from the road that passes on the south side of the bottom of the Tennessee river. It is of much more imposing proportions than that of either of the caves already mentioned. The visitor climbs the hill from the road, following 
a path which leads along the high bank of a considerable creek. The entrance has a wide floor which is cut by a gorge at one side, through which the stream just mentioned, issues. The roof is flat and is overhung by vegetation. The following pages record the results of two collecting expeditions made there by Professor Cope.

Near the mouth of the cave a salamander of the genus Plethodon was found, which is very peculiar. Instead of the black color with or without pale bluish dots, of the P. glutinosus, the sides and back are thickly spotted with large irregular yellowishgreen blotches of irregular form, producing an effect something like the coloration of the Mexican Spelerpes leprosus. The dorsal spots are much larger than the lateral, and are often confluent. On the head they almost exclude the ground color. In addition to this color peculiarity, the feet differ from those of the $P$. glutinosus, in the rudimental character of the inner digit, both anteriorly and posteriorly. It is represented by metapodial bones only, having no phalanges. There are thirteen costal foids, one less than in $P$. glutinosus, and the vomerine teeth do not extend beyond, or even to, the internal nares. The tail is round and rather slender. Length to axilla, .020; to groin, .05I ; to end of tail, m. .r22. This species is about the size of the $P$. glutinosus, and as it is distinct from it, we propose that it be called Plethodon aneus Cope.

In company with it was found the smaller $P$. cinereus. Then there was a small scorpion; a Polydesmus, and some other centipedes, and a beetle like Scarites, but larger than the common northern species. Snails, as in other limestone regions, are abundant.

On entering the mouth of the cave abundant traces of former human habitation are found. These consist principally of charcoal and remains of shells-as Ios and Unios from the Tennessee river, brought there by the Indians as food. The creek was formerly dammed at this point and supplied water to a mill at the mouth of the cave. This was grinding the grain of the neighborhood at the time of the first visit, but had disappeared by the second. Fishing was attempted from this point far into the depths of the cave. The results were chiefly Crustacea, which are described below. No blind fishes were seen or taken, but some fishes of the outer world were caught at a point where 
a very little light from the mouth was distinguishable. These were the common blob, Potamocottus moridionalis, and sucker, Catostomus toris.

At a distance of a mile from the mouth, the blind crawfish, Orconectes hamulatus, began to be abundant; their snowy white forms being readily distinguished by candle light in the clear water.

On the land the Spirostrephon cavernarum proved to be common in some places, especially near to bat excrement, where were also found a number of Pselaphid beetles.

On examination of the aquatic cave life, it appears that of the five kinds of animals found living in the waters of the cave, all but one differ decidedly from those of the caves of Kentucky, Indiana or Virginia. This is a matter of considerable interest from an evolutional point of view, as it shows that these cave forms are the descendants of different out-of-door species from those of the caves to the northward. The Nickajack cave may be in a different faunal region from the Mammoth or Wyandotte caves, and thus the blind crawfish has perhaps originated from a different species of Cambarus than that which gave origin to Orconectes pellucidus. Thus while the conditions, such as dryness and temperature, of cave life are much the same throughout the United States, the ancestors of the different cave animals were, in most cases, distinct, since they belonged to somewhat different zoö-geographical areas.

The first animal to notice, and one not uncommon in the waters of the cave, is a little Isopod Crustacean which is evidently a modified Asellus, or water wood-louse, of tha same genus as that so abundant in the caves, subterranean streams and wells of Indiana and Kentucky. We originally described the Mammoth cave form as Cecidotea stygia Packard; our new species may be called Cecidotea nickajackensis Packard. ${ }^{1}$

${ }^{1}$ It is eyeless, and the boly is longer, narrower and slenderer than in C. stygia. The first antenne are very long and reach to the end of the third joint of the second antennæ; they are nearly twice as long as in C. sty, ri.., and are purplish white, while the flagellum is provided with long hatr. The second antenna are as long as the head and extend backwards as far as the base of the abdomen. The legs are much longer and slenderer than in C. stygin. The abdomen is long and narrow, and the caudal appendages are moderately long in one specimen and short in another; in one individual the outer branch is much shotter and smaller than in the others, and in most it is as long as the basal joint. On the whole the caudal appendages are no longer than the telson or terminal segment of the abdumen, while in $C$. stygia they are hall as long as the entire body. Length $6 \mathrm{~mm}$. 
This species forms, in the antennxe and slightly purplish color and the proportions of the leg-joints, perhaps a nearer approach to the genus Asellus than that of Mammoth and Wyandotte caves; on the other hand C. stygia approaches Asellus more in its shorter, broader body, with the shorter, broader abdomen. It seems quite evident that the two species must have descended from different species of Asellus. Thus far we know of but one species of Asellus, A. communis of Say, from the Middle and Northern States; whether there is an additional species in the Gulf States from which the present species may have been derived, remains to be seen.

The genus Cecidotae differs from Asellus in the larger and much longer head, the longer claw of the first pair of feet, the much longer telson, and in the rami of the caudal appendages being of nearly equal size, while in Asellus one is minute; it is also eyeless. The Asellus borelii of the Swiss lakes belongs to Cecidotar.

The second crustacean discovered swimming about in the subterranean stream, was a species of Amphipod belonging to the genus Crangonyx, and which may be called Crangonyx antennatus Packard. It is a large purplish species with very long antennæ, and distinct, well developed black eyes. This genus occurs in caves and subterranean wells in Europe and this country.

The form of most decided interest, however, is the blind craw-

${ }^{1}$ It is a larger and purplish species; the first antennæ very long; the flagellum with 20-24 joints; the entire antenna being over one-half, and nearly two thirds as long as the body; the last joint of the peduncle being slightly more than half as long as the penultimate joint. Compared with C. gracilis Smith, from Lake Superior, it differs in the form of the eyes, the longer and stouter first antenna, the flagellum having a greater number of joints, and in the different proportions of the joints of the peduncle; the second joint of the latter being much longer than in $C$. gracilis, while the first joint of the scape is much longer, and the second and thirl joints onethird longer in proportion than in C. gracilis. The fourth pair of epimera are unusually large and nearly square. The telson, together with the citudal stylets is much as in $C$. gracilis, but the rami are slightly stouter and more polished, and the spinules a little stouter. It probably is a little Iarger species than $C$. gracilis, the specimens being $6-7 . \mathrm{mm}$. in length; the eyes are not so distinct and are only one-fourth as large as in C.gracilis. It is very different from C. vilveus Cope, of Mammoth cave, and from C. packardii Snith, differing in its distinct eyes, and larger, more numerously jointed antennæ. 
PLATE VII.

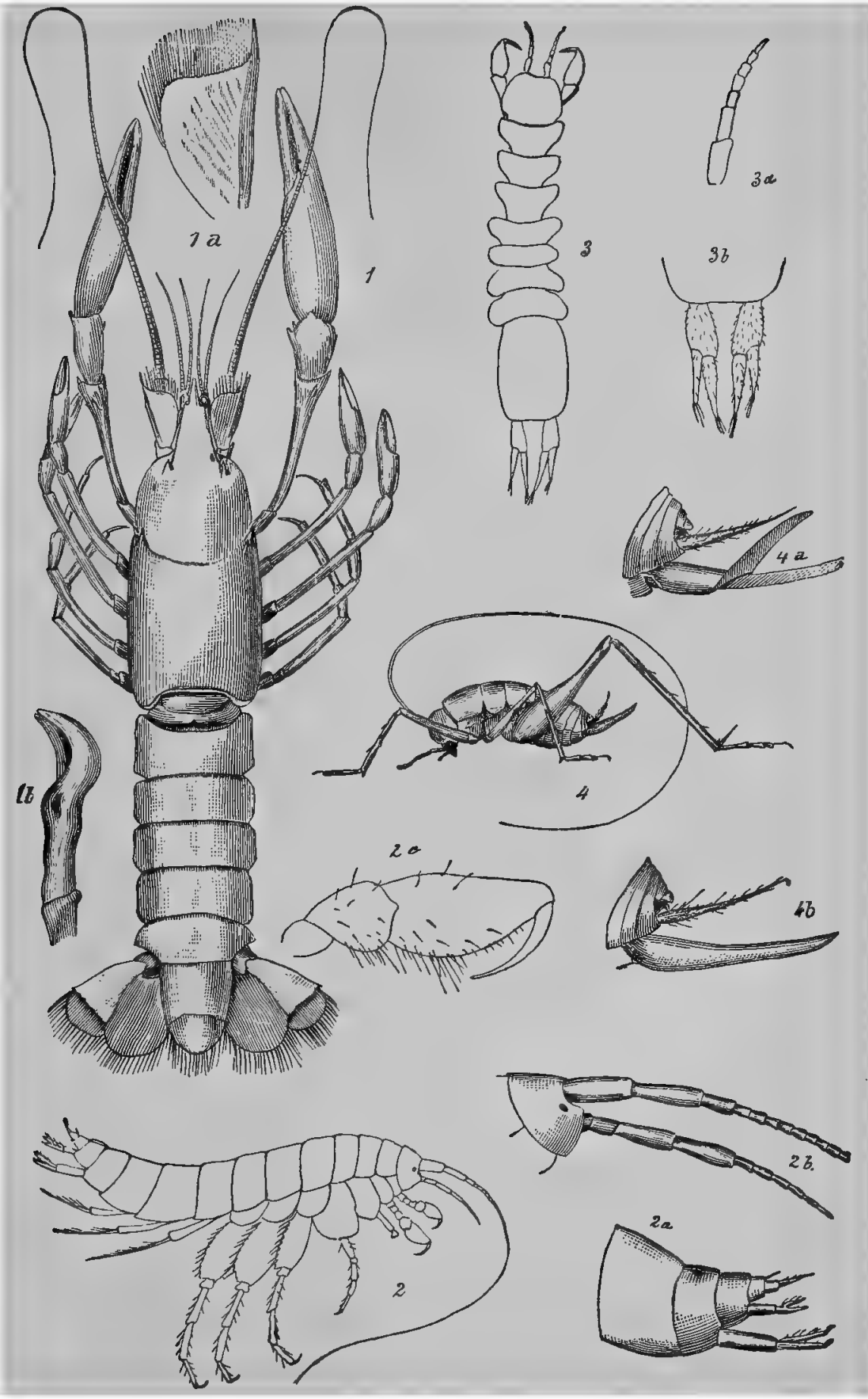

Tun Fatrat of Nickajack CAye 

fish (Orconectes hamulatus $\operatorname{Cope}^{1}$ ). It is quite different from $O$. pellucidus of Mammoth and $W_{y}$ andotte caves, in the rostrum, the slender hands, the much broader antennal scale, and in the form of the gonopods, while the whole creature is slightly slenderer than $O$. pellucidus, though the rudimentary eyes are of the same proportion to the neighboring parts as in the other species.

It is obvious that the form from which $O$. hamulatus has been derived, is quite different from that which has given origin to the blind crawfish of the Kentucky and Indiana caves. The most common species in Nortlern Georgia is Cambarus latimanus, it having been found at Athens and Milledgeville, Georgia, and probably being abundant in the northern' limestone region of Alabama. At any rate it is perhaps to Cambarus latimanus that

In this species the teeth of the mandibles are usually much sharper than in the other blind species, there being three well marked sharp posterior teeth in 0 . hamulatus, which in $O$. pellucidus are represe'sted by low, obtuse, nearly obsolete teeth; though in different specimens the obtuseness of the teeth vary. The epistoma is much as that of $C$. bartonii, but shorter and broader; while the median terminal topth is less marked than in C. latimanus, and the sides fall away rapidly from the front margin. It is entirely different in shape from that of 0 .pellucidus. The antennal lamina is shorter, broader and much more rounded on the inner edge than in O. pellucidus, and in this respect differs from C. Intimanus. The rostrum is narrower than in $O$. pellucidus, while the first pair of (large) claws are nuch slenderer, and the telson narrower than in 0 .pellucidus. The most obvious difference is seen in the nodified first and second pairs of abdominal feet of the male, to which we may apply the term gonopod, for it is not properly an intromittent organ. The first and secnnd pair of gonopods differ decidedly from those of 0 . pellucidus, and closely resemble those of Furm II of Cambarus latimanus (from Athens, Georgia, figured by Hagen), those of the first pair being shorter, thicker and the last juint being much bent, hock or sickle-shaped, whence the specific name hamulatus. The first gonopods differ in the proportion of parts from those of C. latimanus, but the joint is much more acute than in C. latimanus.

The first pair of gonopods, compared with the latimanus form of obesus from Maryland, given me by $\mathrm{Mr}$. Uhler, are much like it in general form, but the sinuous branch is longer and straighter, while the hook is much slenderer. In the second pair of accessory gonopods the knoh is proportionately smaller. In other more important characters $O$. hamulatus is quite unlike the latimanus form of $C$. obesus, the scale of the second antennx being very different and the chelæ one-hall as wide, and the antennie much longer, while the rostrum is much longer and more pointed. Length of the largest male, 5 centimeters.

Note on the function of the Gonopods. - As stated by Milne Edwards and others, the gonopods of the crawfish are not intromittent, but simply rucle gutters for the passage of the fertilizing fluid to the eggs. It is obvious that in the 1:sbster the gonopods form simply a rutle tube or gutter to conduct the seminal fluid to the eggs as they pass backward from the oviducts to the swimming feet of the female. During the process of fertilization of the eggs, the male, without doubt, as in the crawtish, holds the female by the claws, she resting on ber back. The term gronopod is aplied for conventence in descriptive carcinology to the external reproductive organs of the crustacea, since they are only modified limbs.-(A. S. PACKard, JR.) 
we are to look for the ancestors of Orconectes hamulatus. On the other hand, in the form of the body, of the scale and rostrum, as well as of the upper lip and the chelre (though not of the gonopods), Orconectes hamulatus approaches Cambarus affinis. Now of all our North American crawfishes, it would appear, as Mr. Uhler has told the writer, and as seems evident to us upon an examination of several types and the excellent figures of Dr. Hagen, that C. affinis is the more generalized form, and this is tantamount to saying that it is the ancestral form of our North American crawfishes. So while our Nickajack blind crawfish may have been an immediate derivative of C. latimanus of the Gulf States, it probably ultimately originated from $C$. affinis, a more wide-spread species.

It is also of interest to note that $O$. hamulatus presents the same generic characters as $O$. pellucidus, the eyes being rudimentary, functionless, the body long and the appendages slender; we thus feel justified in separating the genus from Cambarus.

Of the two crickets found in Nickajack cave, there were three small specimens of Hadenoecus subterraneus Scudder, which only differed from Mammoth cave individuals in having rather shorter, thicker maxillary palpi; but this is not even a varietal difference, as the antennæ and legs have the same proportions. The other cricket is a new species of Ceuthophilus, and may be called Ceuthophilus ensifer Packard. ${ }^{1}$ It is very nearly allied to $C$. stygius of Mammoth cave, but may be distinguished by the characters given below.

\section{EXPLANATION OF PLATE VII.}

Frg. I.-Orconectes hamulatus Cope, twice nat. size. I $a$, antennal scale, enlarged; I $b$, first gonopod.

FIG, 2.-Crangony $x$ antennaizs Packard, $2 a$, end of abdomen and appendages; $2 b$, head with base of upper, and entire lower antenna and eyes; $2 c$, claws; all enlarged.

FIG. 3.-Cecidotea nickajackensis Packard (only one pair of antennæ drawn). $3 a$, upper or smaller antennæ; $3 b$, end of telson with the caudal appendages; all enlarged.

Fig. 4--Ceuthophilus ensifer Packard, nat. size. $4 a$, end of abdomen, with the outer rhabdite or blade of the ovipositor bent up to show the shape of the toothed ovipositor, the six teeth are not well shown by the artist; $4 b$, the end of the body with the ovipositor. J.S. Kingsiley, del.

\footnotetext{
${ }^{1}$ This species differs 1rom C. stygius Scudder, of Mamnuth cave, by the much more pointed sabre-shaped ovipositor, its tip being long, slender and acutely curved, with six smaller teeth, there being but five in large individuals of $C$. stygius, in which the ovipositor is blunt, and the ip obliquely truncate, while the hind femora are a litule lunger: The eyes are as well developed as in C. siygius. The color and marking are nuch the same in the two species, both being thickly spotted with blackbrown; $C$. ensifer has darker colors and more distinct spots than $C$. stygizs, though the latter grows to a larger size. Length of whole body, not including the ovipositor, $22 \mathrm{~mm}$.; length of ovip.ssitor, $8 \mathrm{~mm}$; of hind femur, $20 \mathrm{~mm}$.; of hind tibia, $20 \mathrm{~mm}$. It differs from $C$. liveus Seudder and $C$. sloanii Packard in the longer legs, and can only be confounded with $C$. sitygizs.
}

Published November 5, 1881 . 


(From the American Naturalist, December, 188r.)

\section{GEOLOGY AND PAL}

A New TYPe of Perissodactyla.-In a paper on the "homologies and origin of the molar teeth of the Mammalia Educabilia, published in March, I 874, ${ }^{1}$ I ventured the generalization that the primitive types of the Ungulata would be discovered to be characterized by the possession of five-toed plantigrade feet, and tubercular teeth. No Perissodactyle or Artiodactyle mammal was known at that time to possess such feet, nor was any Perissodactyle known to possess tubercular teeth. Shortly after advancing the above hypothesis, I discovered the foot structure of Coryphodon, which is five-toed and plantigrade, but the teeth are not of the tubercular type. For this and allied genera, I defined a new order, the Amblypoda, and I have published the confident anticipation that genera would be discovered which should possess tubercular (bunodont) teeth. This prediction has not yet been realized. I now, however, record a discovery, which goes far towards satisfying the generalization first mentioned, and indicates that the realization of the prophecy respecting the Amblypoda, is only a question of time.

In $1873,{ }^{2}$ I described from teeth alone, a genus under the name of Phenacodus, and although a good many specimens of the dentition have come into my possession since that date, I have never been able to assign the genus its true position in the mammalian class. The teeth resemble those of suilline Ungulates, but I have never had sufficient evidence to permit its reference to thit group. Allied genera recently discovered by me, have been stated to have a hog-like dentition, but that their position could not be determined until the structure of the feet shall have been ascertained.

In his recent explorations in the Wasatch Eocene of Wyoming, Mr. J. L. Wortman was fortunate enough to discover a nearly entire skeleton of a Phenacodus very near the typical $P$. primavus, which presents all the characters essential to a full determination of its place in the system. The unexpected result is, that this genus must be referred to the order Perissodactyla, and that, with its allies, it must form a special division of that order corresponding in the tubercular characters of its teeth with the bunodont or suilline division of the Artiodactyla. In this character, however, there is a closer gradation than in the case of the Artiodactyla,

1 Journal of the Academy of Natural Sciences Pbiladelphia.

${ }^{2}$ Palæontological Bulletin No. 17, Oct., 1873, p. 3; also, Report G. M. Wheeler, U. S. Engineers Expl. W. Ioo Mer., iv, p. 174-1877. 
and it would scarcely be necessary to create such a group on that character alone. But the genus differs further from the Perissodactyla and approaches the Proboscidia, in the fact that the astragalus articulates with the navicular only, and by a universally convex surface, as in the Carnivora.

The astragalus resembles that of the latter order very closely, and differs from that of Hyracotherium and the nearest forms among the Perissodactyla. Phenacodus has moreover five well developed toes on all the feet, and was probably not entirely plantigrade. The cast of the brain case shows that the celebral hemispheres were quite small and nearly smooth, and that the very large cerebellum and olfactory lobes were entirely uncovered by them. The bones of the two carpal rows alternate with each other, and there is a large third trochanter of the femur. The cervical vertebræ are opisthocoelous. The systematic position of the genus may be schematically represented as follows :

Order Perissodactyla; ungulate; digits of unequal lengths; carpal bones alternating; a postglenoid process. Astragalus with proximal trochlea, and without distal double ginglymus.

Suborder Diplarthra; astragalus distally plane or concave in one direction, and uniting with both navicular and cuboid bones; a third trochanter of the femur. The known families belong here.

Suborder Condylarthra; astragalus convex in all directions distally, only uniting with navicular bone; a third trochanter of femur.

Family Phenacodontide. Molar teeth tubercular; the premolar teeth different from the molars; five digits on all the feet.

Genera; Phenacodus Cope, and very probably Catathlaus, ${ }^{1}$ Mioclenus, and Protogonia ${ }^{2}$ Cope, and perhaus also Anisonchas Cope. These genera include fifteen species, all from the lower Eocene beds. The Condylarthra are then the ancestral type of the known Perissodactyla, that is of the horses, tapirs and rhinoceroses, and of the numerous extinct forms. $-E$. D. Cope.

New genus of Perissodactyla diplarthra.-Good specimens of the Hyracotherium tapirinum Cope, show that the superior dentition is uninterrupted from the canine inclusive. It thus differs from Hyracotherium which has one or two diastemata. The fourth inferior premolar is like the third premolar. The $H$. tapirinim may then be referred to a new genus under the name Systemodon.-E. D. Cope.

Notes on Creodonta.-A fine series of specimens of Mesonyx demonstrates the following points: (I) Pachyæna was founded on a superior molar of Mesonyx, and must be suppressed. (2) Apterodon Fischer, is the same as Mesonyx. (3) Mesonyx

1 American Naturalist, October, 1880.

2 Procecdirigs Amer. Philosoph. Soc., September, 188r. 
navajovius Cope $^{1}$ must be separated as a distinct genus, since the apices of the crowns of the last two molars have two cusps. This genus may be called Dissacus. (4) It results that there are four species of Mesonyx: M. ossifragus Cope, $M$. lanius Cope, $M$. obtusidens Cope, and M. gaudryi Fisch. M. ossifragus was the largest Creodont of the Eocene, equaling the largest grizzly bear in the size of its skull.

The number of possible combinations of tubercular and tubercular-sectorial molar teeth is considerable, and many of them are represented in the genera of the Creodonta. A new one must now be added, in a genus which has, in the lower jaw, two tubercular sectorials, and one tubercular posterior to them. The genus thus stands between Stypolophus and Didymictis, but is nearer the former than the latter, since it has three true molars. It differs further from both in having but three premolars and a wide diastema. The canine is well developed. I call the genus Lipodectes, and describe two species, both from the Lowest Eocene, probably Puerco, of New Mexico.

Lipodectes penetrans, sp. nov., represented by a left mandibular ramus with three of the molars preserved. The last has a long heel; the first and second true molars are alike, and resemble those of Trizsodon, but the appendicular cusps are better developed. The anterior inner cusp is, however, smaller than the others and is nearly median in position. The heel is elevated on its external border into a strong triangular cusp. The posterior border rises into an acute cusp, which is internal to the middle line. The internal border of the heel is not elevated, and the surface is the oblique inner face of the external cusp. The anterior cusps are only moderately elevated and the cusps are acute. The enamel is smooth, and there is a low cingulum on the external base. The first (second) premolar is two-rooted, and has a large base. The second (third) consists principally of an elevated cusp with a subtriangular section. The heel is very small and acute, and there is no anterior basal tubercle. The internal face is strongly grooved in front. Canines directed upwards, with robust base. Symphysis short. Length of moliar series, .043; of premolars, .o19; of diastema, .or 2 ; length of base of last molar, .oro; do of canine, .007; depth of ramus at last molar, oI 8; of diastema, .oI5. As large as, but more robust, than the red fox.

Lipodectes pelvidens. This species is about the size of $L$. penetrans, and differs from it in the less carnassial character of the inferior molars. The anterior cusps are relatively smaller in every way, and are more distinctly separated by deeper emarginations. The heel is wider, and has a less elongated external marginal cusp. The inner margin of the heel is elevated, enclosing a basin-like fossa, and rises into a flat cusp posteriorly. There is

${ }^{1}$ Palæontological Bulletin, No. 33, p. 454. 
a small median posterior marginal rubercle, which runs into a posterior cingulum, and is wanting from the L. penetrans. The tubercular has the three anterior cusps distinct as in Didymictis sp., while the heel is longer than in the known species of that genus. Its external border rises into a prominent cusp with triangular base. The fourth premolar has a small heel on the inner posterior side, and an acute anterior basal cusp. The principal cusp is robust and the basal portion is widely. grooved posteriorly (apex lost). True molars with an external cingulum. Enamel obsoletely wrinkled. Length of true molar series, .024; of fourth. premolar, .0075; length of last molar, .008; width of heel of second true molar, .005; length of crown of do., .007.-E. D. Cope.

The Permian Formation of New Mexico.-This formation is richly fossiliferous in New Mexico, and the vertebrates include several of the types already known from Texas and Illinois. Such are, among reptiles, the genera Diadectes, Dimetrodon and probably Clepsydrops. Of batrachians there are two genera, Eryops, and what is probably Zatrachys. Diplodus represents the fishes. All the individuals, and hence, probably, the species, are of smaller size than those of the Texan Permian, resembling in this respect those found in Illinois. Two species of batrachians of the genera above mentioned, are new, and may be described as follows:

Eryops reticulatus.- The most prominent peculiarity of this species is seen in the neural spines, which are not expanded at the summit as in E. megacephalus, but have rather contracted apices. Another character is the sharply reticulate sculpture of the maxillary bones. The species is much smaller than the $E$. megacephalus, or even than the Trimerorhachis insignis, and the extent of ossification of the vertebral elements is intermediate between the two species. The inferior surfaces of the intercentra are smooth, and the diapophyses are compressed. The occipital condyles are depressed and not very well distinguished inferiorly. The humeri have expanded extremities with enlarged epicondyles and well developed condyles, and no epitrochlear foramen. Width of occipital condyles, m. .oI6; elevation of dorsal vertebra, .024; width of intercentrum, orr; lengtin of intercentrum (below), .007 ; five maxillary teeth in .or 5 .

Zatrachys apicalis.-Represented by vertebræ and dermal bones. The summits of the neural spines are expanded, and the superior faces of the expansions are tubercular and have a median prominence. The expansions are sometimes large, resembling the dermal bones of crocodiles, and in that case the medran prominence is a keel. On the smaller expansions the latter is a mere apex. There are narrow flat bones which I suppose to be neural spines, which are ornamented with inosculating ridges. A capitular head of a diapophysis is compressed. Intercentra well ossified, those preserved without lateral notch. Inferior surface with 
crowded small fossæ, giving a delicate reticulate relief. Length of an intercentrum, .OI3; width of do., .014; width of the summit of a neural spine, .020; length of do., .or4; width of a second do, .025; length of do., OI5; width of a third (two unite), .034; length of do., .039. The reference of this species is provisional only. It is much larger than the $Z$. serratus.-E. $D$. Cope.

Published November 29, I881 








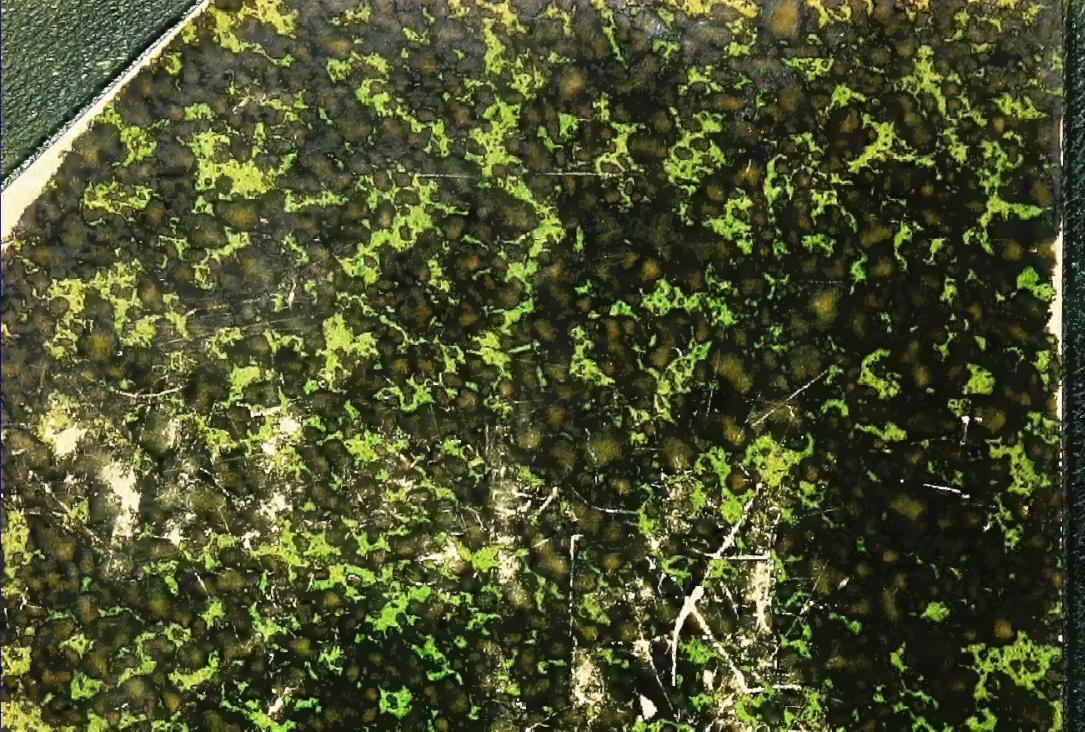

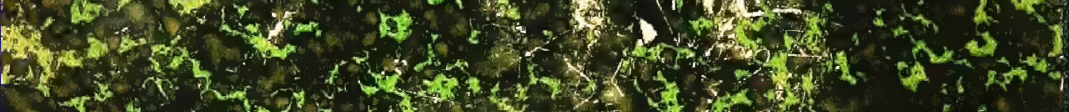

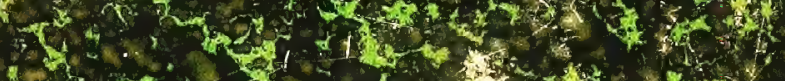

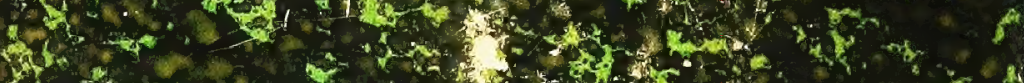

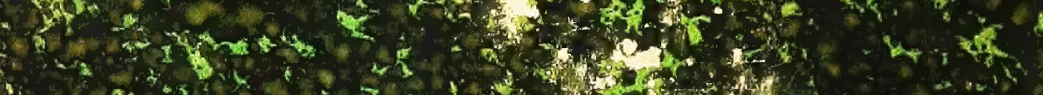

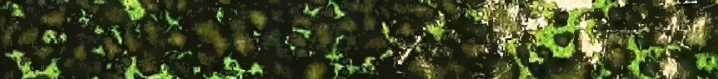

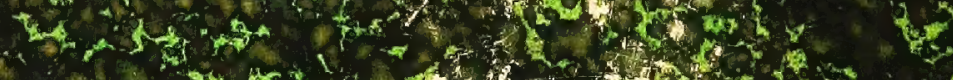

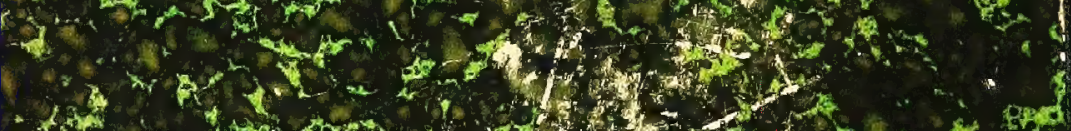
20.

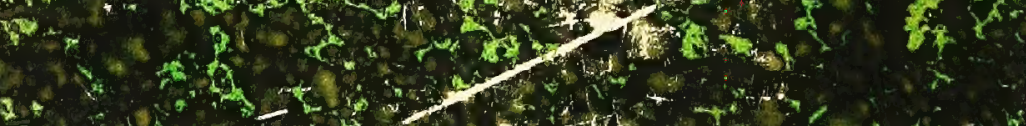

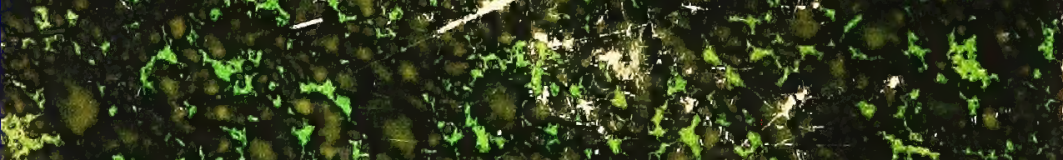

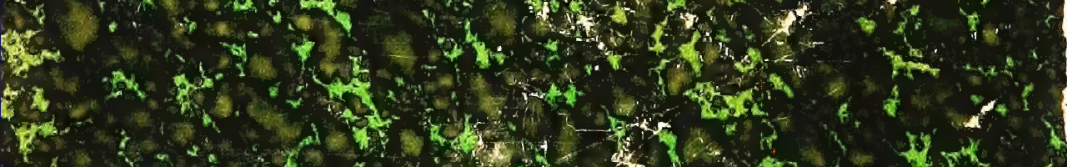

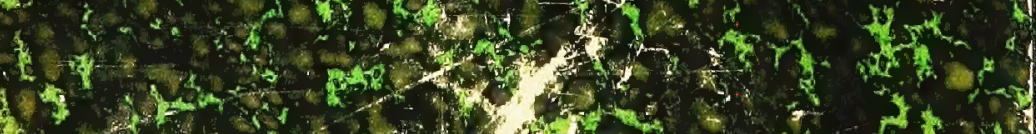

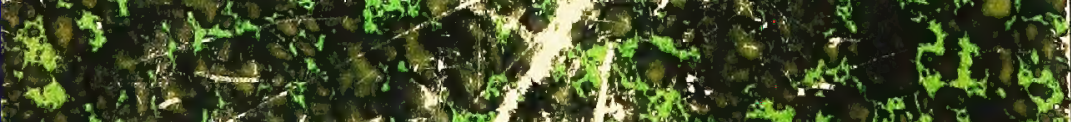

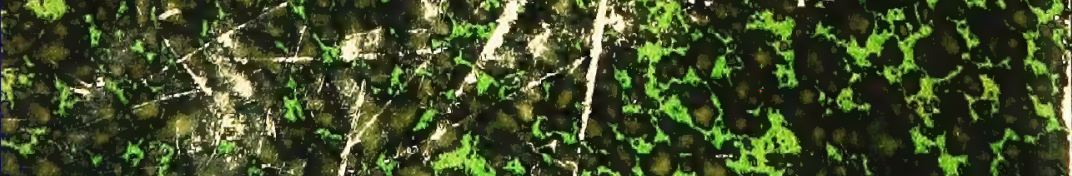

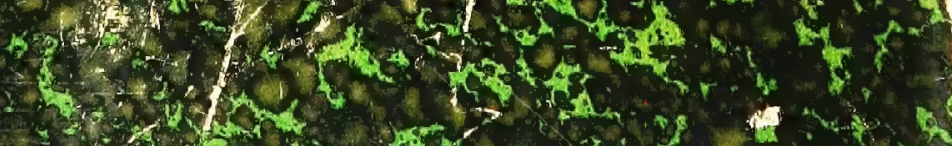

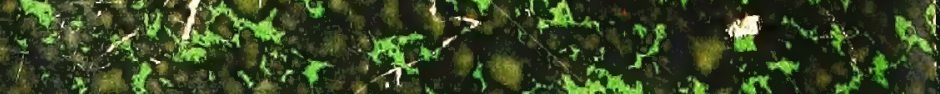

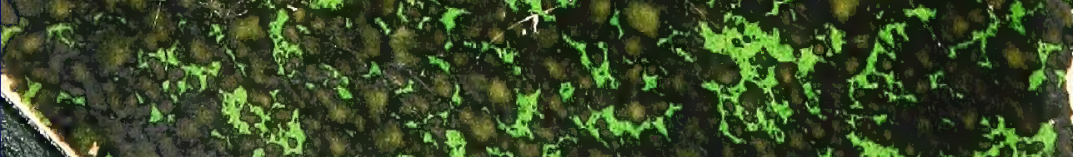

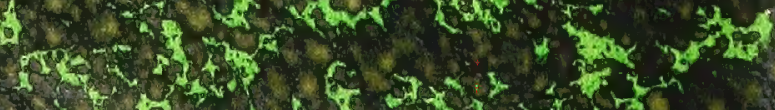

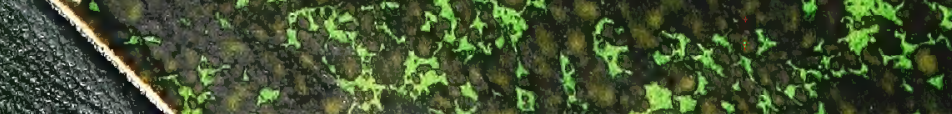

